VLADMIR OLIVEIRA DA SILVEIRA

\title{
EVISTA DE
}

\section{DIREITO BRASILEIRA}

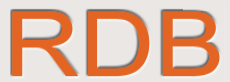

BRAZILIAN JOURNAL OF LAW

ANO 4 • Vol.9 • EDIÇÃO ESPECIAL • 2014

ISSN 2237-583X

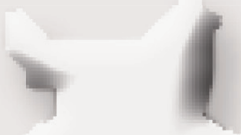




\section{Revista DE}

\section{DIREITO}

\section{BRASILEIRA}

BRAZILIAN JOURNAL OF LAW

Ano 4 • vol.9 • edição especial 2014 Quadrimestral - Florianópolis/SC www.rdb.org.br 



\section{REVISTA DE \\ DIREITO \\ BRASILEIRA}

BRAZILIAN JOURNAL OF LAW

Ano $4 \cdot$ vol.9 $\cdot$ edição especial $\cdot 2014$

Quadrimestral - Florianópolis/SC

www.rdb.org.br

\section{Coordenação e Editor/Coordination and Publisher}

Vladmir Oliveira da Silveira - UNINOVE; PUC-SP/BRASIL

\section{Coordenadores-adjuntos/Assistant coordinators}

Adriana Silva Maillart - UNINOVE/SP/BRASIL

Samantha Ribeiro Meyer-Pflug - UNINOVE/SP/BRASIL

\section{Comitê de Política Editorial/Editorial Policy Committee}

Raymundo Juliano Feitosa - CONPEDI

José Alcebiades de Oliveira Junior - CONPEDI

João Marcelo de Lima Assafim - CONPEDI

Julia Maurmann Ximenes - CONPEDI

Felipe Chiarello de Souza Pinto - CONPEDI

Gilmar Ferreira Mendes- (IDP, Brasilia/DF- BRASIL)

Paulo Gustavo Gonet Branco - (IDP, Brasilia/DF- BRASIL)

Aires José Rover - (UFSC- Florianopolis/SC- BRASIL)

Orides Mezzaroba - (UFSC- Florianopolis/SC- BRASIL)

Lilia Malia Morais Sales - (UNIFOR- Fortaleza/CE- BRASIL)

Gina Vidal Marcílio Pompeu - (UNIFOR- Fortaleza/CE- BRASIL)

Conselho Científico/Scientific Council

Alcindo Fernandes Gonçalves - UNISANTOS

Alexandre Coutinho Pagliarini - UNIT

Alexandre de Moraes - USP

Alexandre Walmott Borges - UFU

Ana Candida da Cunha Ferraz - UNIFIEO

André Luis Callegari - Unisinos

Ángel Oquendo - University of Connecticut

Antônio Carlos Diniz Murta - FUMEC 
Antonio Carlos Wolkmer - UFSC

Antônio de Moura Borges - UCB

Angelo Schillaci - Università di Roma

Argemiro Cardoso Martins - UNB

Carlos Alberto Alvaro de Oliveira - UFRGS

Carlos Alberto Rohrmann - FDMC

Carlos Ayres Brito - UFS

Caroline Proner - UNIBRASIL

Celso Antonio Pacheco Fiorillo - FMU

Celso Hiroshi Iocohama - UNIPAR

Claudio José Langroiva Pereira - PUC/SP

Daury Cesar Fabriz - FDV

Eduardo Henrique Lopes Figueiredo - FDSM

Eduardo Vera Cruz - Universidade Clássica de Lisboa

Enoque Feitosa Sobreira Filho - UFPB

Fernando Borges Araujo - Universidade de Lisboa

Francisco de Queiroz Bezerra Cavalcanti - UFPE

Francisco Fernandez Segado - Universidad Complutense de Madrid

Francisco Rezek - UNICEUB

George Sarmento - UFAL

Giordano Bruno Soares Roberto - UFMG

Giselda Maria Fernandes Novaes Hironaka - FADISP

Hector Fix-Zamudio - Universidade do México

Ingo Wolfgang Sarlet - PUC/RS

Ives Gandra da Silva Martins - UPM

Jacinto Nelson de Miranda Coutinho - UFPR

Javier Chinchón Álvarez - Universidad Complutense de Madrid

João Grandino Rodas - USP

João Luis Nogueira Matias - UFC

João Marcelo De Lima Assafim - UCAM

João Maurício Adeodato - UFPE

João Paulo Fernandes Allain Teixeira - UNICAP

Jorge Bacelar Gouveia - Universidade Clássica de Lisboa

Jorge Carlos Fonseca - Instituto Superior de Ciências Jurídicas e Sociais de Cabo

Verde

Jorge Douglas Price - Universidade de Comahue

Jorge Miranda - Universidade Clássica de Lisboa

Jorge Renato dos Reis - UNISC 
José Afonso da Silva - USP

José Antônio Peres Gediel - UFPR

José Eduardo Cardoso - PUC/SP

José Francisco Siqueira Neto - MACKENZI

José Manoel Arruda Alvim Neto - PUC/SP

José Sebastião de Oliveira-CESUMAR

Julia Ximenes - IDP

Jussara Maria Moreno Jacintho - FUFSE

Kafft Kosta - Faculdade de Direito de Bissau

Lafayette Pozzoli - FEESR e PUC/SP

Leandro Martins Zanitelli - UNIRITTER

Lenio Luiz Streck - UNISINOS

Leonardo Macedo Poli - PUC/MG

Lívia Gaigher Bósio Campello - UFMS

Luana Pedrosa de Figueiredo Cruz - UIT/MG

Luis Edson Fachin - UFPR/PR

Luis Gustavo Grandinetti Castanho de Carvalho - UNESA

Luís Roberto Barroso - UFRJ

Luiz Alberto David Araujo - PUC/SP

Luiz Fux - UFRJ

Manoel Gonçalves Ferreira Filho - USP

Marcio Tomaz Bastos - USP

Marcelo Cottoni - UFMG

Marcelo Dias Varella - UNICEUB

Marcelo Galupo - PUC/MG e UFMG

Marcelo Neves - UNB

Marcia Carla Pereira Ribeiro - PUC/PR

Marco Aurelio de Mello - UNB

Margareth Leister - UNIFIEO

Margarida Lacombe Camargo - UFRJ

Maria Cristina Vidotte Blanco Tárrega - UFG

Maria de Fátima Ribeiro - UNIMAR

María Méndez Rocasolano - Unviversidade Católica de Murcia (UCAM)

Maria dos Remédios Fontes Silva - UFRN

Maria Stella Faria de Amorim - UGF

Maria do Rosario Barbato - UFMG

Markus Kotzur - Universidade de Leipzig

Marlene Kempfer Basoli - UEL 
Menelick de Carvalho Neto - UNB

Michel Temer - PUC/SP

Mirta Gladys Lerena Manzo de Misailidis - UNIMEP

Monica Herman Salem Caggiano - USP e UPM

Mônica Neves Aguiar da Silva - UFBA

Nelson Jobim - UFSM

Nuno Manuel Morgadinho dos Santos Coelho - UNIPAC

Pablo Lucas Verdu (in memorian) - Universidade Complutense de Madrid (UCM)

Paulo de Barros Carvalho - PUC/SP e USP

Paulo Bonavides - UFC

Paulo César Corrêa Borges - UNESP

Paulo Ferreira da Cunha - Universidade do Porto

Paulo Márcio Cruz - UNIVALI

Paulo Roberto Lyrio Pimenta - UFBA

Peter Häberle - Universidade de Bayreuth

Raffaele De Giorgi - Universidade de Lecce

Ricardo Hasson Sayeg - PUC/SP

Robert Alexy - Universidade de Kiel

Rogério Dultra dos Santos - UFF

Ronald Dworkin - University College London (in memorian)

Ruth Maria Chittó Gauer - PUC/RS

Sérgio Augustin - UCS

Serguei Aily Franco de Camargo - UEA

Thomas Buergenthal - George Washington Law School (Washington); American

University (Washington)

Valerio de Oliveira Mazzuoli - UFMT

Valesca Raizer Borges Moschen - UFES

Vicente de Paulo Barretto - UNESA

Virgilio Afonso da Silva - USP

Viviane Séllos - Unicuritiba - UNICURITIBA

Willis Santiago Guerra Filho - UNIRIO e PUC/SP

Zeno Veloso - UFPA 


\section{Membros natos do ConPedi}

Vladmir Oliveira da Silveira (2009-2013)

Marcelo Campos Galuppo (2007-2009)

Raimundo Juliano Feitosa (2003-2007)

Leonardo Grecco (2000-2003)

Jose Ribas Vieira (1997-2000)

José Alfredo Baracho (1992-1997) (in memorian)

Membros da diRetoria (GESTÃo 2013/2015)

\section{Presidente}

Prof. Dr. Raymundo Juliano Feitosa - UFRN

\section{Vice-presidente Sul}

Prof. Dr. José Alcebiades de Oliveira Junior - UFRGS

\section{Vice-presidente Sudoeste}

Prof. Dr. João Marcelo de Lima Assafim - UCAM

Vice-presidente Nordeste

Profa. Dra. Gina Marcílio Vidal Pompeu - UNIFOR

\section{Vice-presidente Norte/Centro}

Profa. Dra. Julia Maurmann Ximenes - IDP

\section{Diretor de Relações Internacionais}

Prof. Dr. Antônio Carlos Diniz Murta - FUMEC

\section{$1^{\circ}$ Diretora de Eventos}

Profa. Dra. Viviane Coêlho de Séllos-Knoerr - UNICURITIBA

\section{$2^{\circ}$ Diretora De Eventos}

Profa. Dra.Valesca Raizer Borges Moschen - UFES

\section{Diretor de Relações com a Graduação}

Prof. Dr. Alexandre Walmott Borges - UFU

\section{Secretário Executivo}

Prof. Dr. Orides Mezzaroba - UFSC 


\section{Secretário Adjunto}

Prof. Dr. Felipe Chiarello de Souza Pinto - UPM

\section{Conselho Fiscal}

Prof. Dr. José Querino Tavares Neto - UFG; PUC/PR

Prof. Dr. Roberto Correia da Silva Gomes Caldas - PUC/SP

Profa. Dra. Samyra Haydêe Dal Farra Naspolini Sanches - UNINOVE

Prof. Dr. Lucas Gonçalves da Silva - UFS (suplente)

Prof. Dr. Paulo Roberto Lyrio Pimenta - UFBA (suplente)

\section{Representante Discente}

Mestre Caio Augusto Souza Lara - UFMG (titular)

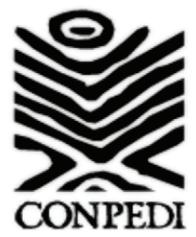

Conselho Nacional de Pesquisa e Pós-Graduação em Direito www.conpedi.org.br

Rua Desembargador Vitor Lima, 260, sala 508 - CEP 88040-400

Bairro Trindade - Florianópolis/SC

Telefone/Fax (48) 3334-3077

CNPJ:05.855.238/0001-12 


\section{REVISTA DE \\ DIREITO}

\section{BRASILEIRA}

BRAZILIAN JOURNAL OF LAW

Ano $4 \cdot$ vol.9 • edição especial 2014

Quadrimestral - Florianópolis/SC

www.rdb.org.br

Coordenação e Editor/Coordination and Publisher

Vladmir Oliveira da Silveira - UNINOVE; PUC-SP

Coordenadores-adjuntos/Assistant coordinators

Adriana Silva Maillart - UNINOVE

Samantha Ribeiro Meyer-Pflug - UNINOVE

\section{ApoIo}

INSTITUTO BRASILIENSE DE DIREITO PÚBLICO - IDP

UNIVERSIDADE DE FORTALEZA - UNIFOR

UNIVERSIDADE FEDERAL DE SANTA CATARIANA - UFSC

UNIVERSIDADE NOVE DE JULHO - UNINOVE

\section{Publicação oficial do}

Conselho Nacional de Pesquisa e Pós-Graduação em Direito - CONPEDI

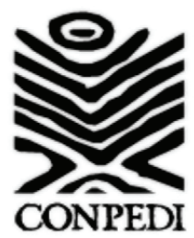


ISSN 2237-583X

\section{REVISTA DE \\ DIREITO \\ BRASILEIRA}

BRAZILIAN JOURNAL OF LAW

Ano $4 \cdot$ vol.9 • edição especial $\bullet 2014$

Quadrimestral - Florianópolis

www.rdb.org.br

\section{Coordenação e Editor/Coordination and Publisher}

Vladmir Oliveira da Silveira - UNINOVE; PUC-SP

Os colaboradores desta Revista gozam da mais ampla liberdade de opinião e de crítica, cabendo-lhes a responsabilidade das ideias e conceitos emitidos em seus trabalhos.

(C) edição e distribuição do CONPEDI 


\section{LINHA EDITORIAL}

Missão: A Revista de Direito Brasileira - Brazilian Journal of Law tem como missão precípua fomentar o estudo das questões mais relevantes que envolvem a jurisdição constitucional tanto em âmbito nacional quanto internacional.

Foco: A Revista de Direito Brasileira - Brazilian Journal of Law tem interesse na publicação de artigos científicos, jurisprudência comentada, resenhas de obras jurídicas, legislação nacional, estrangeira ou internacional comentada e pareceres. São aceitas colaborações do Brasil e do Exterior, no campo da jurisdição constitucional. São incentivadas a pluralidade de abordagens e perspectivas. Em virtude da amplitude do tema da jurisdição constitucional, a Revista abarca um espectro amplo de subdomínios de conhecimento, perspectivas e questões.

Submissão: Os trabalhos devem ser encaminhados à Redação pela internet pelo site www.rdb.org.br. . Os artigos deverão estar em duas línguas: inglês/espanhol ou inglês/português. Os artigos obedecerão às regras da ABNT e deverão possuir os seguintes requisitos: (a) ser inédito; (b) conter resumo na língua portuguesa ou espanhola e inglesa com no mínimo 100 palavras e no máximo 250 palavras; (c) conter no mínimo 03 palavras-chave e no máximo 5 na língua portuguesa ou espanhola e inglesa (separada por ponto); (d) desenvolvimento e referências; (e) possuir de 15 a 30 laudas no formato Word (A4, posição vertical; Fonte: Times New Roman; Corpo: 12; Alinhamento: Justificado, sem separação de sílabas; Entre linhas: Espaçamento um e meio; Espaçamento simples entre as linhas do resumo em português ou espanhol e inglês; Parágrafo: $1,5 \mathrm{~cm}$; Margem: superior e esquerda $-3 \mathrm{~cm}$; Inferior e direito - 2 cm); (f) as citações devem obedecer às regras da ABNT (NBR10520/2002); (g) as referências devem ser conforme a ABNT (NBR 6023/2002); (h) o sistema de chamada das referencias das citações diretas ou/e indiretas pode ser autor-data ou numérico (NBR 10520/2002). As notas de rodapé, se necessárias, devem ser somente explicativas (NBR 6022/2003) e (i) conforme a NBR 6024/2003, os títulos, subtítulos e sub-subtítulos devem ser alinhados à esquerda e conter um texto relacionado com eles;(f) o arquivo contendo o artigo deve ser enviado em formato word..

InEDITISMo E EXCLuSIVIDADE: Os artigos submetidos à publicação na Revista de Direito Brasileira/Brazilian Journal of Law devem ser inéditos e não devem estar sendo considerados por outro periódico. Para garantir o ineditismo das publicações todos artigos aprovados serão registrados no sistema Digital Object Idetifier - DOI. 
Avaliação: O processo de avaliação de artigos submetidos à Publicação na Revista de Direito Brasileira/ Brazilian Journal of Law consiste em duas etapas: uma avaliação preliminar, que examina a adequação do trabalho à linha editorial da Revista e seu potencial para publicação, e uma avaliação duplo-cega. No sistema Double Blind Peer Review o artigo é avaliado por doutores em Direito que desconhecem os autores, assim como estes desconhecem os seus avaliadores. A avaliação ocorre, necessariamente, por no mínimo dois pareceristas ad hoc (avaliadores). Todavia caso haja discrepância superior a 3 (três) pontos (avaliação de zero a dez) ocorrerá uma terceira avaliação. Importante destacar, que os avaliadores da $R D B$ são professores de programas de mestrado e doutorado em Direito e foram (e continuarão sendo) indicados pelos 7 coordenadores dos programas de pós-graduação em direito de todo o Brasil. A avaliação dos trabalhos implica na realização de comentários e no oferecimento de sugestões, bem como reavaliações contínuas, no intuito de reunir esforços para com vistas ao aprimoramento dos artigos. O Comitê de Política Editorial pode acrescentar às sugestões dos revisores um aconselhamento editorial, cujo objetivo é adequar o artigo aos padrões da revista.

Preparação para Publicação: Após a aprovação do artigo ele é submetido à edição final e à revisão técnica, ortográfica e gramatical.

Direitos AUtorais: Os direitos patrimoniais dos artigos aceitos para publicação, inclusive de tradução passam a ser de propriedade do Conselho Nacional de Pesquisa e Pós Graduação em Direito - CONPEDI. É permitida a citação parcial de artigos publicados, sem autorização prévia, desde que seja identificada a fonte. A reprodução total de artigos é proibida. Em caso de dúvidas, solicitamos consultar o Comitê de Política Editorial (revistardb@gmail.com). 
A redação da Revista de Direito Brasileira/Brazilian Journal of Law agradece a todos os avaliadores que gentilmente colocaram sua experiência e seus conhecimentos a serviço da busca da melhoria dos trabalhos acadêmicos publicados.

Aguinaldo Alemar (UFU, Uberlândia/MG - Brasil)

Alberto Jorge Correia (UFAL, Maceio/AL - Brasil)

Adrualdo de Lima Catão (UFAL, Maceio/AL - Brasil)

Aldacy Rachid Coutinho (UFPR, Curitiba/PR - Brasil)

Adegmar José Ferreira (UFG, Goiânia/GO - Brasil)

Alessandra Marchioni (UFAL, Maceio/AL - Brasil)

Alexandre Belmonte (UNIPAC, Juiz de Fora/MG - Brasil)

Alexandre Morais da Rosa (UNIVALI, Vale do Itajaí/SC - Brasil)

Alexandre Travessoni (UNIPAC, Juiz de Fora/MG - Brasil)

Alexandre Walmot Borges (UFU, Uberlândia/MG - Brasil)

Aloízio Gonzada Andrade Araújo (UNIPAC, Juiz de Fora/MG - Brasil)

Altamirando Pereira Da Rocha (UFU, Uberlândia/MG - Brasil)

Alvaro Felipe da Rocha (PUC-RS, Porto Alegre/RS - Brasil)

Álvaro Borges de Oliveira (UNIVALI, Vale do Itajaí/SC - Brasil)

Álvaro Gonçalves Antunes Andreucci (UNINOVE/SP- Brasil)

Ana Candida da Cunha Ferraz (UNIFIEO, Osasco/SP - Brasil)

Ana Elizabeth Lapa Wanderley Cavalcanti (FMU, São Paulo/SP- Brasil)

Ana Paula Ávila (UNIRITTER, Porto Alegre/RS - Brasil)

Anderson Rosa Vaz (UFU, Uberlândia/MG - Brasil)

André Cordeiro Leal (FUMEC, Belo Horizonte/MG - Brasil)

Andre Lipp Pinto Basto Lupi (UNIVALI, Vale do Itajaí/SC - Brasil)

Andrea Borghi Moreira Jacinto (UEA, Manaus/AM - Brasil)

André Leonardo Copetti Santos (URI, Erechim/RS - Brasil)

Andreas Krell (UFAL, Maceio/AL - Brasil)

Antônio Alberto Machado (UNESP, Franca/SP - Brasil)

Antônio Gaio (UNIPAC, Juiz de Fora/MG - Brasil)

Antônio Carlos Diniz Murta (FUMEC, Belo Horizonte/MG - Brasil)

Antonio Celso Alves Pereira (UGF, Rio de Janeiro/RJ - Brasil)

António José Avelãs Nunes (UFPR, Curitiba/PR - Brasil) 
Arnaldo Bastos Santos Neto (UFG, Goiânia/GO - Brasil)

Arno Wehling (UGF, Rio de Janeiro/RJ - Brasil)

Aury Celso de Lima Lopes (PUC-RS, Porto Alegre/RS - Brasil)

Belinda Cunha (UFPB, João Pessoa/PB - Brasil)

Bethânia de Albuquerque Assy (PUC-RJ, Rio de Janeiro/RJ - Brasil)

Caitlin Sampaio Mulholland (PUC-RJ, Rio de Janeiro/RJ - Brasil)

Camila Barreto (PUC-SP, São Paulo/SP- Brasil)

Carlos Eduardo de Abreu Boucault (UNESP, Franca/SP - Brasil)

Carlos Eduardo Japiassú (UNESA, Rio de Janeiro/RJ - Brasil)

Carlos José Cordeiro (UFU, Uberlândia/MG - Brasil)

Carlos Molinaro (PUC-RS, Porto Alegre/RS - Brasil)

Caroline Proner (UNIBRASIL, Curitiba/PR - Brasil)

Carmen Beatriz de Lemos Tibúrcio Rodrigues (UGF, Rio de Janeiro/RJ - Brasil)

Célia Rosenthal Zisman (UNIP, São Paulo/SP- Brasil)

César Augusto Fiúza, (FUMEC, Belo Horizonte/MG - Brasil)

Christian Edward Cyrill Lynch (UGF, Rio de Janeiro/RJ - Brasil)

Claudia Maria Barbosa (PUC-PR, Curitiba/PR - Brasil)

Claudio Pereira de Souza Neto (UGF, Rio de Janeiro/RJ - Brasil)

Cleyson Mello (UNIPAC, Juiz de Fora/MG - Brasil)

Cristiano Gomes De Brito (UFU, Uberlândia/MG - Brasil)

Cristina Zainaghi (UNINOVE/SP - Brasil)

Danielle Andrade Moreira (PUC-RJ, Rio de Janeiro/RJ - Brasil)

Danielle Anne Pamplona (PUC-PR, Curitiba/PR - Brasil)

Débora Gozzo (UNIFEO, Osasco/SP - Brasil)

Denise Fincato (PUC-RS, Porto Alegre/RS - Brasil)

Edihermes Marques Coelho (UFU, Uberlândia/MG - Brasil)

Edinilson Donisete Machado (UNIVEM, Marília/SP - Brasil)

Edson Ricardo Saleme (UNISANTOS, Santos/SP - Brasil)

Edson Damas da Silveira (UEA, Manaus/AM - Brasil)

Eduardo Goulart Pimenta (PUC-MG, Belo Horizonte/MG - Brasil)

Eduardo Biacchi Gomes (UNIBRASIL, Curitiba/PR - Brasil)

Egon Bockman Moreira (UFPR, Curitiba/PR - Brasil)

Eid Badr (UEA, Manaus/AM - Brasil)

Elaine Macedo (PUC-RS, Porto Alegre/RS - Brasil)

Elena de Carvalho Gomes (UNIPAC, Juiz de Fora/MG - Brasil)

Eliane Maria Octaviano Martins (UNISANTOS, Santos/SP - Brasil) 
Elisabete Maniglia (UNESP, Franca/SP - Brasil)

Enoque Feitosa (UFPB, João Pessoa/PB - Brasil)

Estefânia Maria De Queiroz Barboza (UNIBRASIL, Curitiba/PR - Brasil)

Eriberto Francisco Bevilaqua Marin (UFG, Goiânia/GO - Brasil)

Erivaldo Cavalcanti e Silva Filho (UEA, Manaus/AM - Brasil)

Ernesto Pimentel Filho (UFPB, João Pessoa/PB - Brasil)

Eroulths Cortiano Junior (UFPR, Curitiba/PR - Brasil)

EveraldoTadeu Quilici Gonzalez (UNIMEP, Piracicaba/SP - Brasil)

Fabio Corrêa Souza de Oliveira (UNESA, Rio de Janeiro/RJ - Brasil)

Fábio Carvalho Leite (PUC-RJ, Rio de Janeiro/RJ - Brasil)

Fabio Roberto D'Avila (PUC-RS, Porto Alegre/RS - Brasil)

Fabricio Macedo Motta (UFG, Goiânia/GO - Brasil)

Fernando Antonio Vasconcelos (UFPB, João Pessoa/PB - Brasil)

Fernando Fernandes da Silva (UNISANTOS, Santos/SP - Brasil)

Francisco de Guimaraens (PUC-RJ, Rio de Janeiro/RJ - Brasil)

Flávia Piva Almeida Leite (FMU-SP, São Paulo/SP- Brasil)

Francisco José Rodrigues de Oliveira Neto (UNIVALI, Vale do Itajaí/SC - Brasil)

Frederico Wildson Dantas (UFAL, Maceio/AL - Brasil)

Frederico da Costa Carvalho Neto (UNINOVE/SP- Brasil)

Frederico De Andrade Gabrich (FUMEC, Belo Horizonte/MG - Brasil)

Gabriel Ivo (UFAL, Maceio/AL - Brasil)

George Sarmento (UFAL, Maceio/AL - Brasil)

Gilberto Marcos Antonio Rodrigues (UNISANTOS, Santos/SP - Brasil)

Gilberto Passos de Freitas (UNISANTOS, Santos/SP - Brasil)

Gilberto Sturmer (PUC-RS, Porto Alegre/RS - Brasil)

Giovani Agostini Saavedra (PUC-RS, Porto Alegre/RS - Brasil)

Girolamo Domenico Treccani (UFPA, Belem do Para/PA - Brasil)

Gisele Guimarães Cittadino (PUC-RJ, Rio de Janeiro/RJ - Brasil)

Guilherme Calmon Nogueira da Gama (UGF, Rio de Janeiro/RJ - Brasil)

Gustavo Rabay Guerra (UFPB, João Pessoa/PB - Brasil)

Gustavo Sampaio Teles Ferreira (UGF, Rio de Janeiro/RJ - Brasil)

Henrique Macedo Hinz (UNIMEP Piracicaba/SP - Brasil)

Hilário De Oliveira (UFU, Uberlândia/MG - Brasil)

Irene Patrícia Nohara (UNINOVE/SP- Brasil)

Jacinto Nelson de Miranda Coutinho (UFPR, Curitiba/PR - Brasil)

Jairo José Gênova (UNIVEM, Marília/SP - Brasil) 
Jete Jane Fiorati (UNESP, Franca/SP - Brasil)

João Baptista Villela (UNIPAC, Juiz de Fora/MG - Brasil)

João da Cruz Gonçalves Neto (UFG, Goiânia/GO - Brasil)

João Miguel da Luz Rivero (UNIMEP, Piracicaba/SP - Brasil)

João Ricardo Wanderley Dornelles (PUC-RJ, Rio de Janeiro/RJ - Brasil)

Jorge Luis Mialhe (UNIMEP Piracicaba/SP - Brasil)

José Antônio Peres Gediel (UFPR, Curitiba/PR - Brasil)

José Augusto Fontoura Costa (UNISANTOS, Santos/SP - Brasil)

José Carlos Moreira (PUC-RS, Porto Alegre/RS - Brasil)

José Ernesto Pimentel Filho (UFPB, João Pessoa/PB - Brasil)

José Eustáquio Romão (UNINOVE/SP- Brasil)

José Fernando Vidal de Souza (UNIMEP, Piracicaba/SP - Brasil)

José Heder Benatti (UFPA, Belem do Para/PA - Brasil)

Josemar Sidinei Soares (UNIVALI, Vale do Itajaí/SC - Brasil)

José Maria RosaTesheiner (PUC-RS, Porto Alegre/RS - Brasil)

José Renato Martins (UNIMEP, Piracicaba/SP - Brasil)

Juarez Estevam Xavier Tavares (UGF, Rio de Janeiro/RJ - Brasil)

Lafayette Pozzoli (UNIVEM, Marília/SP - Brasil)

Larissa Liz Odreski Ramina (UNIBRASIL, Curitiba/PR - Brasil)

Larissa Pinha de Oliveira (UNESA, Rio de Janeiro/RJ - Brasil)

Lenio Luiz Streck (UNESA, Rio de Janeiro/RJ - Brasil)

Leandro Marins Zanitelli (UNIRITTER, Porto Alegre/RS - Brasil)

Leandro Reinaldo da Cunha ( UNINOVE, São Paulo/SP- Brasil)

Leonardo Isaac Yarochewsky (PUC-MG, Belo Horizonte/MG - Brasil)

Leonardo Nemer Caldeira Brant (PUC-MG, Belo Horizonte/MG - Brasil)

Letícia de Campos Velho Martel (PUC-RJ, Rio de Janeiro/RJ - Brasil)

Liton Lanes Pilau Sobrinho (UNIVALI, Vale do Itajaí/SC - Brasil)

Lorena de Melo Freitas (UFPB, João Pessoa/PB - Brasil)

Luciene Dal'Ri (UNIVALI, Vale do Itajaí/SC - Brasil)

Luciano Feldens (PUC-RS, Porto Alegre/RS - Brasil)

Lúcio Antônio Chamon Jr. (UNIPAC, Juiz de Fora/MG - Brasil)

Luis Henrique Barbante Franze (UNIVEM, Marília/SP - Brasil)

Luís Rodolfo de Souza Dantas (UNIFIEO, Osasco/SP - Brasil)

Luiz Alberto Blanche (PUC-PR, Curitiba/PR - Brasil)

Luiz Antônio Soares Hentz (UNESP Franca/SP - Brasil)

Luis Carlos Balbino Gambogi (FUMEC, Belo Horizonte/MG - Brasil) 
Luiz Carlos Figueira De Melo (UFU, Uberlândia/MG - Brasil)

Luiz Carlos Falconi (UFG, Goiânia/GO - Brasil)

Luiz Magno Pinto Bastos Junior (UNIVALI, Vale do Itajaí/SC - Brasil)

Manoel Cavalcante (UFAL, Maceio/AL - Brasil)

Manoel Alexandre Belo (UFPB, João Pessoa/PB - Brasil)

Maitê Cecília Fabbri Moro (UNINOVE/SP- Brasil)

Marcelo Lamy (UNISANTOS, Santos/SP - Brasil)

Marcelo Maciel Ramos (UNIPAC, Juiz de Fora/MG - Brasil)

Marcelo Benacchio (UNINOVE/SP- Brasil)

Márcia Nina Bernardes (PUC-RJ, Rio de Janeiro/RJ - Brasil)

Marcia Carla Pereira Ribeiro (PUC-PR, Curitiba/PR - Brasil)

Marciano Seabra de Godoi (PUC-MG, Belo Horizonte/MG - Brasil)

Márcio Alexandre Da Silva Pinto (UFU, Uberlândia/MG - Brasil)

Marcio Antonio Teixeira (UNIVEM, Marília/SP - Brasil)

Marco Aurélio Nogueira (UFU, Uberlândia/MG - Brasil)

Marcos Augusto Maliska (UNIBRASIL, Curitiba/PR - Brasil)

Marcos Bernardes de Mello (UFAL, Maceio/AL - Brasil)

Marcos Leite Garcia (UNIVALI, Vale do Itajaí/SC - Brasil)

Marcos Simão Figueiras (UNESP, Franca/SP - Brasil)

Maria Áurea Baroni Cecato (UFPB, João Pessoa/PB - Brasil)

Maria Amália de Figueiredo Alvarenga (UNESP, Franca/SP - Brasil)

Maria Cecília Máximo Teodoro (PUC-MG, Belo Horizonte/MG - Brasil)

Maria Cristina Carmignani (UNIFIEO, Osasco/SP - Brasil)

Maria Cristina Vidotte Blanco Tarrega (UFG, Goiânia/GO - Brasil)

Maria Luiza Machado Granziera (UNISANTOS, Santos/SP - Brasil)

Maria Nazareth da Penha Vasques Mota (UEA, Manaus/AM - Brasil)

Maria Tereza Dias (FUMEC, Belo Horizonte/MG - Brasil)

Mario Furlaneto Neto (UNIVEM, Marília/SP - Brasil)

Marisa Rossinholi (UNIVEM, Marília/SP - Brasil)

Maurício de Albuquerque Rocha (PUC-RJ, Rio de Janeiro/RJ - Brasil)

Mauricio Mota (UNESA, Rio de Janeiro/RJ - Brasil)

Mirta Gladys Lerena Misailidis (UNIMEP, Piracicaba/SP - Brasil)

Mônica Bonetti Couto (UNINOVE/SP- Brasil)

Nádia de Araújo (PUC-RJ, Rio de Janeiro/RJ - Brasil)

Nelson Finotti Silva (UNIVEM, Marília/SP - Brasil)

Nereu José Giacomolli (PUC-RS, Porto Alegre/RS - Brasil) 
Ney Fayet de Souza (PUC-RS, Porto Alegre/RS - Brasil)

Nilton Cesar Flores (UNESA, Rio de Janeiro/RJ - Brasil)

Noel Struchiner (PUC-RJ, Rio de Janeiro/RJ - Brasil)

Norma Sueli Padilha (UNISANTOS, Santos/SP - Brasil)

Nuno Manuel Morgadinho dos Santos Coelho (UNIPAC, Juiz de Fora/MG - Brasil)

Octavio Campos Fischer (UNIBRASIL, Curitiba/PR - Brasil)

Oswaldo Giacoia Junior (UNIVEM Marília/SP - Brasil)

Ozorio Jose de Menezes Fonseca (UEA, Manaus/AM - Brasil)

Paulo César Corrêa Borges (UNESP, Franca/SP - Brasil)

Paulo Fernando de Britto Feitoza (UEA, Manaus/AM - Brasil)

Paulo Ricardo Schier (UNIBRASIL, Curitiba/PR - Brasil)

Paulo Vinicius S. de Souza (PUC-RS, Porto Alegre/RS - Brasil)

Pedro Henrique Nogueira (UFAL, Maceio/AL - Brasil)

Pedro Sergio dos Santos (UFG, Goiânia/GO - Brasil)

Rabah Belaidi (UFG, Goiânia/GO - Brasil)

Rafael Iorio (UNESA, Rio de Janeiro/RJ - Brasil)

Rafhael Frattari Bonito (FUMEC, Belo Horizonte/MG - Brasil)

Raquel Cristina Ferraroni Sanches (UNIVEM Marília/SP - Brasil)

Renata Ribeiro Rolim (UFPB, João Pessoa/PB - Brasil)

Regina Ruaro (PUC-RS, Porto Alegre/RS - Brasil)

Ricardo Aronne (PUC-RS, Porto Alegre/RS - Brasil)

Ricardo Lobo Torres (UGF, Rio de Janeiro/RJ - Brasil)

Ricardo Stanziola Vieira (UNIVALI, Vale do Itajaí/SC - Brasil)

Renato Bernardi (UNIVEM, Marília/SP - Brasil)

Ricardo Waldman (UNIRITTER, Porto Alegre/RS - Brasil)

Richard Paulro Paes Kim (UNIMEP, Piracicaba/SP - Brasil)

Roberto Brocanelli Corona (UNESP, Franca/SP - Brasil)

Roberto Kant de Lima (UGF, Rio de Janeiro/RJ - Brasil)

Rodrigo Almeida Magalhães (PUC-MG, Belo Horizonte/MG - Brasil)

Rodrigo Sanchez Rios (PUC-PR, Curitiba/PR - Brasil)

Rodrigo Xavier Leonardo (UFPR, Curitiba/PR - Brasil)

Rodolfo Viana Pereira (FUMEC, Belo Horizonte/MG - Brasil)

Rômulo Palitot Braga (UFPB, João Pessoa/PB - Brasil)

Ronaldo Brêtas de C. Dias (PUC-MG, Belo Horizonte/MG - Brasil)

Rosalice Fidalgo Pinheiro (UNIBRASIL, Curitiba/PR - Brasil)

Rosemiro Pereira Lea (PUC-MG, Belo Horizonte/MG - Brasil) 
Rubens Valtecides Alves (UFU, Uberlândia/MG - Brasil)

Rúbia Carneiro Neves (UFMG, Belo Horizonte/MG - Brasil)

Rui Décio Martins (UNIMEP, Piracicaba/SP - Brasil)

Ruy Cardozo de Mello Tucunduva Sobrinho (UNINOVE/SP- Brasil)

Sandro Nahmias Melo (UEA, Manaus/AM - Brasil)

Samyra Haydée Dal Farra Naspolini Sanches (UNINOVE/SP- Brasil)

Sergio G. Porto (PUC-RS, Porto Alegre/RS - Brasil)

Sérgio Mendes Botrel Coutinho (FUMEC, Belo Horizonte/MG - Brasil)

Shirlei Silmara De Freitas Mello (UFU, Uberlândia/MG - Brasil)

Simone Silva Prudêncio (UFU, Uberlândia/MG - Brasil)

Terezinha de Oliveira Domingos (UNINOVE, São Paulo/SP - Brasil)

Thadeu Weber (PUC-RS, Porto Alegre/RS - Brasil)

Thereza Christina Nahas (UNIVEM, Marília/SP - Brasil)

Valentina Jungmann Cintra (UFG, Goiânia/GO - Brasil)

Valmir César Pozzetti (UEA, Manaus/AM - Brasil)

Vanice Lirio do Valle (UNESA, Rio de Janeiro/RJ - Brasil)

Vladimir Garcia Magalhães (UNISANTOS, Santos/SP - Brasil)

Vicente de Paulo Barretto (UNESA, Rio de Janeiro/RJ - Brasil)

Vinicius Scarpi (UNESA, Rio de Janeiro/RJ - Brasil)

Victor Hugo Tejerina Velazquez (UNIMEP, Piracicaba/SP - Brasil)

Wagner Luiz Menezes Lino (USP/SP- Brasil)

Yvete Flávio da Costa (UNESP, Franca/SP - Brasil) 


\section{EDITORIAL}

A Revista de Direito Brasileira (Brazilian Journal Of Law) - RDB é uma publicação quadrimestral e oficial do CONPEDI, que visa fomentar o estudo das questões mais relevantes que envolvem a jurisdição constitucional tanto em âmbito nacional quanto estrangeiro. Neste sentido, procura-se estudar os principais temas do Direito Contemporâneo de modo reflexivo e dialético. Objetiva-se criar um campo vasto de discussão e aproximação do Direito interno e internacional, propiciando um intercâmbio de informações e soluções sobre as mais diversas questões jurídicas situadas no âmbito da jurisdição constitucional. Tem como finalidade oferecer aos estudiosos do Direito uma visão atualizada dos principais temas das Cortes Constitucionais, buscando aproximar a teoria da prática.

Para tanto, o periódico traz artigos doutrinários inéditos, nacionais e estrangeiros, sendo $20 \%$ dos artigos enviados, a cada edição, por autores convidados de significativo conhecimento do tema, tanto de âmbito nacional quanto internacional. Já os artigos restantes passam necessariamente pelo sistema Double Blind Peer Review, em que o artigo é avaliado por Doutores em Direito que desconhecem os autores, assim como estes desconhecem os seus avaliadores. A avaliação ocorre, necessariamente, por no mínimo dois pareceristas ad hoc (avaliadores). Todavia, caso haja discrepância superior a três pontos (avaliação de zero a dez), ocorrerá uma terceira avaliação. Importante destacar, que os avaliadores da $R D B$ são professores de programas de Mestrado e Doutorado em Direito e foram (e continuarão sendo) indicados pelos coordenadores dos programas de Pós-graduação em Direito stricto sensu de todo o Brasil, reconhecidos pela CAPES/MEC.

Para se evitar o plágio, assim como artigos não inéditos entre outros problemas, mas, principalmente, para garantir a longevidade das publicações e facilitar a sua identificação no meio eletrônico, todos os artigos aprovados serão registrados no sistema Digital Object Idetifier - DOI.

A $R D B$ terá sempre uma versão impressa e outra eletrônica, sendo que na versão on-line os artigos estão em duas línguas: inglês/espanhol ou inglês/português. Os artigos obedecerão às regras da $\mathrm{ABNT}$ e deverão possuir os seguintes requisitos: (a) ser inédito; (b) conter resumo na língua portuguesa ou espanhola e inglesa com no mínimo 100 palavras e no máximo 250 palavras; (c) conter no mínimo três palavras-chave e no máximo cinco na língua portuguesa ou espanhola e inglesa (separadas por ponto); (d) desenvolvimento e referências; (e) possuir de 15 a 30 laudas no formato Word (A4, posição vertical; fonte: Times New Roman; corpo: 12; alinhamento: justificado, sem separação de sílabas; entre linhas: espaçamento um e meio; espaçamento simples entre as linhas do resumo em português ou espanhol e inglês; parágrafo: $1,5 \mathrm{~cm}$; margem: superior e esquerda $-3 \mathrm{~cm}$; inferior e direito $-2 \mathrm{~cm})$; (f) as citações devem obedecer às regras da ABNT (NBR10520/2002); (g) as referências devem ser conforme a ABNT (NBR 6023/2002); (h) o sistema de chamada das referências das citações diretas ou/e indiretas pode ser autor-data ou numérico (NBR 10520/2002). As notas de rodapé, se necessárias, devem ser somente explicativas 
(NBR 6022/2003) (i) conforme a NBR 6024/2003, os títulos, subtítulos e sub-subtítulos devem ser alinhados à esquerda e conter um texto relacionado com eles; e j) o arquivo deve ser enviado em formato word.

Há que se destacar ainda que em cada edição poderão ser criteriosamente selecionados acórdãos, de inteiro teor, pelos editores e membros do comitê de política editorial, com o máximo de seis meses de publicação e acompanhados de uma resenha do julgado. Poderão constar também de cada edição, resenhas de obras jurídicas, legislação nacional, estrangeira ou internacional comentada e pareceres.

Importante destacar que após intenso trabalho nas primeiras três edições a RDB foi classificada como B1 pela Qualis/CAPES/MEC.

A RDB decidiu fazer uma edição especial em virtude da realização do primeiro encontro de internacionalização do CONPEDI, que ocorreu na Universidade de Barcelona, na Espanha nos dias 8, 9 e 10 de outubro de 2014. O tema do encontro foi "Atores do desenvolvimento econômico, político e social diante do Direito do século XXI" que revelou a dimensão do desafio que as diferentes linhas de investigação nos Programas de Pós-Graduação em Direito no Brasil têm buscado enfrentar ao acolherem abordagens que possibilitem analisar de forma consistente a crescente complexidade do processo de globalização.

Os artigos apresentados nos diversos grupos de trabalho propiciaram um intenso debate sobre o tema tanto sob a perspectiva do direito brasileiro, como do direito espanhol. Em razão da qualidade e da atualidade dos textos apresentados pelos professores espanhóis publicamos essa edição especial da RDB.

Por fim, gostaríamos de agradecer a todos os autores que colaboraram nesta edição especial, bem como aos pareceristas que levaram a efeito a criteriosa avaliação dos artigos.

A todos desejamos uma excelente leitura!

Vladmir Oliveira da Silveira

Coordenador 



\section{SUMARIO}

EDITORIAL

1. La llamada "Garantía JUVENIL" (WARRanty For young) en Europa y SU

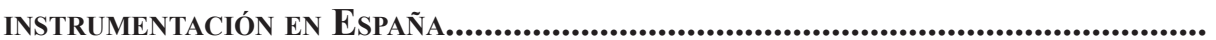

\section{Belén del Mar López Insua}

Profesora Doctora del Departamento de Derecho del Trabajo y de la Seguridad Social. Universidad de Granada.

E-mail: blinsua@ugr.es

2. LA DESLEALTAD EN LAS COMUNICACIONES COMERCIALES.......................................

\section{Eva Cordobés Millán}

Doctora en Derecho con Mención Europea en el título de Doctora por la Universidad de Barcelona y abogada en ejercicio en el despacho Iusta Causa, S.L. E-mail: evaalcanar@hotmail.com

3. Algunas Reflecyiones, deSde la PERSPeCtiva del ORdenAmiento JuRídico INTERNACIONAL, SOBRE LOS RETOS A LOS QUE SE ENFRENTAN LAS ORGANIZACIONES INTERNACIONALES EN LA SOCIEDAD INTERNACIONAL CONTEMPORANEA......................8 8 Anna M. Badia Martí

Catedrática de Derecho Internacional, directora del Máster en Estudios Internacionales de la Universitat de Barcelona.

E-mail: abadia@ub.edu

4. LA PROTECCIÓN de LOS SOCIOS MINORITARIOS EN LA NUEVA LEY DE GOBIERNO

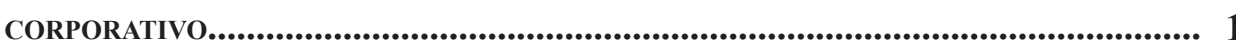

\section{Daniel Vázquez Albert}

Profesor da Universidad de Barcelona.

Email: dvazquez@ub.edu

\section{Pedro Pablo Pérez Carbó}

Investigador en formación del Instituto de Investigaciones Jurídicas de la Universidad de Barcelona. 
5. EL NUEVO RÉGIMEN JURÍdICO DE LOS CONTRATOS A DISTANCIA............................

\section{Manuel Pino Abad}

Profesore de la Universidad de Córdoba.

E-mail: ad1piabm@uco.es

\section{José Manuel Serrano Cañas}

Profesore de la Universidad de Córdoba.

E-mail: jose24mayo@yahoo.es

6. De la grossdisparity a la UNFAIREXPloitation: MOdElos PARA UNA FUTURA REGULACIÓN EN SUPUESTOS DE DESEQUILIBRIO ECONÓMICO CONTRAC-

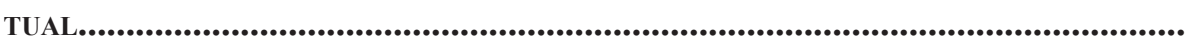

\section{Rosa Barceló Compte}

Investigadora predoctoral. Universidad de Barcelona.

E-mail: rbarcelo@ub.edu

\section{Gemma Rubio Gimeno}

Profesora Agregada de Derecho Civil. Universidad de Barcelona.

E-mail: grubio@ub.edu

7. La REPUESTA ESPAÑola a LA PROLIFERACión de CARTAS dE INTENCIONES EN LA CONTRATACIÓN PRIVADA

\section{Aurelio Barrio Gallardo}

Profesor Contratado Doctor de Derecho Civil. Universidad de Zaragoza. E-mail: abarrio@unizar.es

8. El DESISTIMIENTO UNILATERAL EN LOS CONTRATOS DE TRACTO SUCESIVO: CIVIL VS COMMON LAW EN LOS CONTRATOS DE DISTRIBUCIÓN

\section{Maria Cruz Lascorz Collada}

Profesora de Derecho Civil de la Universidad de Zaragoza.

E-mail: mlascorz@unizar.es

9. Deben las leyes esPañolas Regular El Contrato de alojamiento?

\section{Paula Castaños Castro}

Profesora. Derecho Civil I da Universidad de Malaga.

E-mail paulace@uma.es 


\section{Luisa Moreno-Torres Herrera}

Profesora. Derecho Civil I da Universidad de Malaga.

E-mail: mImt@uma.es

10. El fenómeno de la subcontratación en Brasil y España. Principales DIFERENCIAS Y CUESTIONES CONTROVERTIDAS DE AMBOS PAÍSES

\section{Pepa Burriel Rodríguez-Diosdado}

Doutora em Direito pela Universidade Federal de Pernambuco (UFPE); Coordenadora e Professora do Programa de Pós-Graduação Stricto Sensu de Mestrado e Doutorado em Direito Constitucional da Universidade de Fortaleza (UNIFOR).

E-mail: ginapompeu@unifor.br

11. El DERECHO DE INFORMACIÓN EN LAS SOCIEDADES DE CAPITAL Y LAS CONSECUENCIAS DE SU VULNERACIÓN

\section{Silvia Gómez Trinidad}

Facultat de Dret.

E-mail: sgomezt@ub.edu

\section{Judith Morales Barceló}

Universitat de Barcelona.

E-mail: jmorales@ub.edu

12. INSTRUMENTOS JURÍDICOS PARA LA AUTODETERMINACIÓN PERSONAL: RELACIONES DE CONSUMO, COMUNICACIONES COMERCIALES, PRIVACIDAD Y SMART SOCIETY..

\section{María Rosa Llácer Matacás}

Catedrática de Derecho civil. Universidad de Barcelona.

E-mail: mrllacer@)ub.edu

13. LA REGULACIÓN DE LA INCAPACIDAD TEMPORAL COMO FACTOR DINAMIZADOR DE LAS RELACIONES LABORALES: LA EXPERIENCIA ESPAÑOLA

\section{Juan Carlos García Quiñones}

Profesor Contratado Doctor (Acreditado a Profesor Titular) de Derecho del Trabajo y de la Seguridad Social. Facultad de Derecho. Universidad Complutense de Madrid.

E-mail: juancarlosgarciaquinones@der.ucm.es 


\section{Francisca Moreno Romero}

Profesora Asociada de Derecho del Trabajo y de la Seguridad Social. Facultad de Derecho. Universidad Complutense de Madrid.

E-mail: francamoro2@gmail.com

14. Datos abiertos, transparencia y filosofía del derecho open data, TRANSPARENCE AND PHILOSOPHY OF LAW

\section{Fernando Galindo}

Doctor en Derecho por la Universidad de Zaragoza. Catedrático de Filosofía del Derecho del Departamento de Derecho Penal, Filosofía del Derecho e Historia del Derecho de la Universidad de Zaragoza. Zaragoza, Aragón, España.

E-mail: cfa@unizar.es e-mail; cfa@unizar.es

15. Los Retos de La SEguridad SOCial ESPAÑola EN El SIGLO XXI: De LAS PENSIONES A LA INCAPACIDAD TEMPORAL

\section{José Luis Tortuero Plaza}

Catedrático de Derecho del Trabajo y de la Seguridad Social y Director del Titulo de Experto en Seguridad Social de la Universidad Complutense de Madrid. E-mail: jltortuero@gmail.com

16. LA ORDENACIÓN DE LA CARTERA DE SERVICIOS DEL SISTEMA NACIONAL DE SALUD Y EL DERECHO A LA PRESTACIÓN POR INCAPACIDAD TEMPORAL

\section{Olimpia Del Águila Cazorla}

Profesora Titular Interina de Derecho del Trabajo y de la Seguridad Social de la Universidad Complutense de Madrid.

E-mail: olimpiadelaguila@der.ucm.es

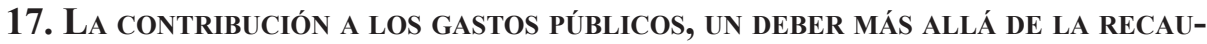
DACIÓN.

\section{Miguel Ángel Sánchez Huete}

Profesor de Derecho Financiero y Tributario de la Universitat Autónoma de Barcelona, con anterioridad y durante más de quince años se ha de dedicado al ejercicio profesional de la abogacía. Es Licenciado en Derecho por la Universitat de Barcelona y Doctor por la Universitat Internacional de Catalunya. Dentro de sus líneas principales de investigación y publicación destacan: las infracciones y sanciones tributarias, el uso de sociedades como instrumento de elusión y el análisis de la responsabilidad social desde la perspectiva tributaria. E-mail: miguelangel.sanchez@uab.es 
ConTENTS

1. The warranty for young in Europe and its implementation in SPa IN

Belén del Mar López Insua

2. The FAITHLESSNESS IN THE COMMERCIAL COMMUNICATIONS.

Eva Cordobés Millán

3. SOME THOUGHTS FROM THE PERSPECTIVE OF INTERNATIONAL LAW, ON THE CHALLENGES TO WHICHFACING INTERNATIONAL ORGANIZATIONS IN CONTEMPORARY INTERNATIONAL SOCIETY

Anna M. Badia Martí

4. THE PROTECTION OF MINORITY SHAREHOLDERS IN THE NEW LAW ON CORPORATE GOVERNANCE.

Daniel Vázquez Albert and Pedro Pablo Pérez Carbó

5. The NEW LEgal Regime OF Distance CONTRACTS

Manuel Pino Abad and José Manuel Serrano Cañas

6. GRosSdisparity OF THE UNFAIREXPLOITATION: MODELS FOR FUTURE REgUlATION IN CASES OF CONTRACTUAL ECONOMIC IMBALANCE.

Rosa Barceló Compte and Gemma Rubio Gimeno

7. THE SPANISH RESPONSE TO THE PROLIFERATION OF LETTERS OF INTENT IN PRIVATE CONTRACTING.

Aurelio Barrio Gallardo

8. UNILATERAL WITHDRAWAL ON SUCCESSIVE CONTRACTS: CIVIL VS COMMON LAW ON DISTRIBUTION CONTRACTS

Maria Cruz Lascorz Collada

9. The SPANISH LAW SHOULD REgULATE THE CONTRACT OF ACCOMMODATION?....... Paula Castaños Castro and M. Luisa Moreno-Torres Herrera

10. The phenomenon of outsourcing in Brazil and Spain. Main differences AND CONTROVERSIAL ISSUES IN BOTH COUNTRIES Pepa Burriel Rodríguez-Diosdado 
11. ThE RIGHT TO INFORMATION ON LIMITED LIABILITY COMPANIES AND THE CONSEQUENCES OF THEIR VIOLATION

Silvia Gómez Trinidad and Judith Morales Barceló

12. LEGAL INSTRUMENTS FOR SELF-DETERMINATION PERSONAL: CONSUMER RELATIONS, ADVERTISING, PRIVACY AND SMART SOCIET.

María Rosa Llácer Matacás

13. The REgUlation OF TEMPORARY DISABILITY AS A DYNAMIC FACTOR OF LABOR RELATIONS: THE SPANISH EXPERIENCE

Juan Carlos García Quiñones and Francisca Moreno Romero

14. OPEN DATA, TRANSPARENCE AND PHILOSOPHY OF LAW.

Fernando Galindo

15. The Challenges of the SPanish Social Security in the XXI Century: PENSIONS FOR TEMPORARY DISABILITY

José Luis Tortuero Plaza

16. Portfolio management Service national health SyStem and the Right TO TEMPORARY DISABILITY BENEFIT.

Olimpia Del Águila Cazorla

17. CONTRIBUTION TO PUBLIC EXPENDITURE: BEYOND DUTY TO CONTRIBUTE 


\title{
LA LLAMADA "GARANTÍA JUVENIL" (WARRANTY FOR YOUNG) EN EUROPA Y SU INSTRUMENTACIÓN EN ESPAÑa
}

The warranty for young in Europe and its implementation in Spain

\author{
Belén del Mar López InSua
}

Profesora Doctora del Departamento de Derecho del Trabajo y de la Seguridad Social. Universidad de Granada. E-mail: blinsua@ugr.es.

\section{RESUMEN}

La grave situación de crisis económica y financiera mundial ha golpeado a todos los estractos de la sociedad, siendo el colectivo de los jóvenes el más perjudicado por esta lacra. Las terribles consecuencias que ha causado este fenómeno se han visto reflejadas en un mercado de trabajo debilitado en donde ahora reinan los principios de precariedad, desprotección, desorientación y desmotivación laboral. La alarmante cifra de desempleo juvenil ha preocupado enormemente a la Unión Europea, es por ello que todos sus esfuerzos se hayan centrado en la consolidación de una Europa económicamente más fortalecida y comprometida con el futuro laboral de sus jóvenes. Tras diversas iniciativas y conatos legislativos, finalmente, se ha aprobado la "Garantía Juvenil".

Palabras Clave: Garantía Juvenil. Desempleo. Emprendimiento.

\begin{abstract}
The critical situation suffered worldwide because of the current economical and financial crisis has struck all the social layers, from which it has especially impaired the group composed by the young. This fact has prompted awful consequences in a weakened labour market, where precariousness, confusion and lack of legal protection and motivation freely rule. The high rates of youthful unemployment have strongly concerned the European Union for the last years and so, it has focused all its efforts to economically consolidate an Europe much more committed to provide a reliable labour future for its young people. After several legal trials it has finally approven the named "Garantía Juvenil" ("Warranty for young").
\end{abstract}




\section{KEYWORDS: WARRANTY FOR YOUNG. UNEMPLOYMENT. BUSINESS VENTURE.}

SumARIO: Introducción. 1. Respuestas e iniciativas comunitarias frente al desempleo juvenil: la denominada "garantía juvenil". 2. El establecimiento de un marco jurídico-político para el crecimiento del empleo juvenil en españa: la ley de emprendedores. 2.1. Plan de medidas de políticas de empleo en españa. 2.2. Las leyes de medida y apoyo al emprendimiento. Conclusiones. Bibliografía.

"El Estado democrático del trabajo se basa en la idea fundamental de que la conservación y evolución de la existencia individual, la propagación de la especie y, finalmente, la tutela de la vida, de la integridad física y de la salud, que son para los individuos las finalidades más importantes, deben también considerarse como la razón y misión primera de toda actividad del Estado"(MENGER, 2004)1.

\section{INTRODUCCIÓN}

Desde que la crisis llamó a nuestra puerta a principios del año 2008, todos hemos sido testigos de los efectos devastadores que este fenómeno económico ha originado y aún continúa causando tanto a nivel nacional, como a escala mundial. Constantemente vemos como son más y más las personas que ven extinguidos sus contratos de trabajo o, incluso, el cese de su actividad por el cierre de la empresa en la que trabajaban, y como ahora se encuentran en las largas listas del paro. Esta crispada situación se ha traducido en un crecimiento exponencial y de larga duración de los niveles de desempleo, debido todo ello a la caída de la actividad productiva.

La crisis económica ha golpeado en todas las capas de sociedad, pero sin duda, ha sido el colectivo de los jóvenes uno de los más afectados. La situación ha sido particularmente aguda en ciertas regiones y Estados miembros en donde las tasas de desempleo juvenil se han visto incrementadas significativamente ${ }^{2}$, habiéndose

${ }^{1}$ Menger, A.: El Estado democrático del trabajo, edición y estudio preliminar, "Derechos sociales y Estado democrático en Anton Menger", a cargo de J. L. Monereo Pérez, Granada, Ed. Comares, 2004, pag. 177.

${ }^{2}$ Según publica el Eurostat: en abril de 2013 la tasa de desempleo juvenil alcanzó el 23,5\% en el conjunto de los 27 Estados miembros. Más aún, entre los distintos Estados miembros e incluso entre las regiones de un mismo Estado las diferencias son significativas, así pues: mientras que en algunos Estados miembros la tasa de desempleo juvenil ronda el 50\% y supera el $70 \%$ en algunas regiones, en otras, la tasa se sitúa muy por debajo del $5 \%$. Mucho más importante aún, actualmente más de 7,5 millones de jóvenes de menos de 25 años no se 
con todo ello experimentado una lamentable pérdida de inmensos costes humanos y sociales $^{3}$. Lo cual ha supuesto una seria amenaza para la cohesión social, así como un incremento de la inestabilidad política ${ }^{4}$.

El predominio de la precariedad laboral, la desorientación, la falta de formación y la desmotivación ${ }^{5}$, son problemas que están latentes a día de hoy en el grupo de jóvenes que forma parte de la Unión Europea. De ahí que a la hora de adentrarnos en la identificación del desempleo juvenil, tengamos que hablar de dos subgrupos de jóvenes con importantes riesgos de exclusión social: de un lado, aquellos que ni estudian, ni trabajan, ni tienen, ni buscan un empleo (los "ni-ni") ${ }^{6}$; y de otro lado, los trabajadores pobres, cuyas condiciones salariales son extremadamente precarias y cuyos contratos de trabajo tienen un carácter de temporalidad limitada (MONEREO PÉREZ, 2009, p.111 y HERNÁNDEZ BERAJANO, 2013, p. 281 Y 282).

\section{RESPUESTAS E INICIATIVAS COMUNITARIAS FRENTE AL DESEMPLEO JUVENIL: LA DENO- MiNADA "GaRANTÍA JuVENIL"}

La economía comunitaria se encuentra atravesando un momento muy delicado debido al alto nivel de endeudamiento y al deterioro de sus fundamentos, lo que se refleja en una elevada tasa de desempleo. La clave para eliminar esa segmentación de los mercados laborales sólo será posible cuando Europa se haya sobrepuesto a la crisis económica. Para lo cual resultará imprescindible la puesta en marcha de cuatro elementos "claves" que frenen dicha caída, a saber: 1) mantener una estabilidad financiera; 2) construir un sistema económico más fuerte a través del saneamiento de las finanzas públicas y mejora de la competitividad; 3) reforzar la unión económica y monetaria, y en particular, la unión bancaria; y 4) luchar contra el desempleo y

encuentran desempeñando un empleo, una educación o una formación (Neither in employment, education or training -NEET-).

3 Véase las conclusiones del Consejo de Europa de 27 y 28 de junio del 2013 (EUCO 104/2/13 REV 2).

${ }^{4}$ En palabras del presidente del Concilio Europeo, Herman Van Rompuy, en la Cumbre europea de 27 y 28 de junio de 2013 (press.office@consilium.europea.eu http://www.consilium. europa.eu).

${ }^{5}$ Se observa en el mercado de trabajo una marcada polarización. Así pues, jóvenes con una escasa cualificación abandonan pronto sus estudios, mientras que otros altamente cualificados, están subempleados.

${ }^{6}$ Según la Encuesta de Población Activa (EPA) elaborada por el Instituto Nacional de Estadística a fecha de 24 de octubre de 2013, en España hay 445.700 jóvenes de entre 16 y 29 años que ni estudian, ni trabajan, ni buscan empleo (ello supone un 5,7\% de la población en esta franja de edad). Tres puntos más que la media europea, lo cual sitúa a España entre los tres países (junto con Bulgaria, Italia e Irlanda) con más desempleo juvenil. 
apoyar el crecimiento a corto plazo ${ }^{7}$.

Actualmente, la problemática del empleo juvenil constituye uno de los temas que más preocupan al colectivo comunitario (SURÁREZ CORUJO, 2014, p. 85). Es por ello que ocupe un lugar prioritario dentro del propio plan de trabajo de la Comisión Europea ${ }^{8}$, habiéndose así diseñado una serie de estrategias que buscan actuar a modo de plan de choque contra el desempleo, tratando además de favorecer la creación de empresas y la inserción de jóvenes en el mercado de trabajo (SEMPERE NAVARRO, 2013, p. 1).

Procurando hacer justicia a ese ambicioso objetivo, en 2010 se aprueba en la Unión Europea (UE) la "Europa 2020, una estrategia para un crecimiento inteligente, sostenible e integrador" (ISI) ${ }^{9}$. En este relevante documento, la Comisión propone a la UE una serie de pautas a largo plazo (a realizar durante el periodo 2014-2020) para hacer guiar los procesos y objetivos a conseguir por cada uno de los estados miembros ${ }^{10}$, entre los cuales se encuentra: el empleo, la educación y la lucha contra la pobreza ${ }^{11}$. Se trata, por tanto, de un ideal perfectamente alcanzable, pero que si bien requiere de la participación de todos los estados miembros, agentes

${ }^{7}$ Véase la Carta del Presidente Herman Van Rompuy a los miembros del Consejo Europeo sobre el Empleo Juvenil, publicada en Bruselas a fecha de 24 de mayo del 2013 (http://www. european-council.europa.eu/the-president). Y European Council -27/28 june 2013 -Factsheet on youth employment (http://www.consilium.europea.eu).

${ }^{8}$ Ver Carta del Presidente Herman Van Rompuy a los miembros del Consejo Europeo sobre el Empleo Juvenil.

${ }_{9}^{9}$ Publicado en Bruselas a 3 de marzo del 2010, COM (2010) 2020 final.

${ }^{10}$ Los objetivos que marca el ISI son representativos de las tres prioridades de crecimiento inteligente, sostenible e integrador, pero no son exhaustivos, pues precisan de una amplia gama de acciones a nivel nacional, comunitario e internacional para sustentarlos. Véase páginas 5 y 6 del texto publicado por la Comisión Europea (http://eur-lex.europa.eu/LexUriServ/ LexUriServ.do?uri=COM:2010:2020:FIN:ES:PDF).Entre las siete iniciativas que propone la Comisión destacan en materia de empleo juvenil las siguientes: 1) "Unión por la innovación"; 2) "Juventud en movimiento"; 3) "Agenda de nuevas cualificaciones y empleos" y 4) "La plataforma europea contra la pobreza". Para poder hacer llegar esta información, en la UE se adoptarán directrices y se harán recomendaciones específicas a los Estados miembros, pudiendo la Comisión hacer propuestas para orientar la acción y promover las iniciativas comunitarias.

${ }^{11}$ En esta Estrategia ISI la UE define el lugar que quiere ocupar en 2020, para ello se fija como reto a conseguir para entonces: 1) un incremento del $75 \%$ del empleo entre la población de entre 20 a 64 años, mediante, entre otras cosas, una mayor participación de las mujeres y los trabajadores más mayores, y una integración de los inmigrantes en la población activa; 2) el porcentaje de abandono escolar debe ser inferior al $10 \%$; y 3 ) se pretende que al menos el $40 \%$ de la generación más joven haya cubierto su nivel de estudios universitarios o de Formación Profesional (FP). Véase en este sentido "la Agenda de nuevas cualificaciones y empleos" de 23 de noviembre de 2010. 
sociales e instituciones europeas para obtener ese triunfo.

La alarmante e inaceptable cifra de jóvenes (O'HIGGINS, 2001, p. 11) $)^{12}$ desempleados debe paliarse gracias al establecimiento tanto a escala nacional, como regional de la UE de un catálogo de iniciativas comunitarias, entre las que destacan: 1) "Juventud en movimiento"13 (de 15 de septiembre de 2010); 2) "Unión por la innovación" ${ }^{14}$ (publicado el 6 de octubre de 2010); 3) "Agenda de nuevas cualificaciones y empleos"15 (23 de noviembre de 2010); y 4) "Oportunidades para la juventud" ${ }^{16}$ (20 de diciembre de 2011).

${ }^{12}$ Según la definición que ofrecen las Naciones Unidas de “juventud”, ésta comprende desde los 15 a los 24 años de edad. Sin embargo en la práctica, la definición operativa de gente joven varía ampliamente de un país a otro, dependiendo de factores culturales, institucionales y políticos.

${ }^{13}$ En líneas generales se busca aquí: 1) mejorar los programas de movilidad, universidad e investigación (como Erasmus, Erasmus Mundus, Tempus y Marie Curie) y ligarlos a los programas y recursos nacionales; 2) modernizar la educación superior, incluyendo la evaluación comparativa de los resultados de las universidades y de los sistemas educativos en un contexto general; 3) explorar nuevas formas de promover el espíritu emprendedor mediante programas de movilidad para jóvenes profesionales; 4) promover el reconocimiento del aprendizaje no formal e informal; y 5) lanzar un Marco de Empleo de los Jóvenes que subraye las políticas destinadas a reducir la tasa de desempleo de los jóvenes. Véase la Comunicación de la Comisión al Parlamento Europeo, a la Comisión, al Comité Económica y Social Europeo, y al Comités de las Regiones de 15 de septiembre de 2010 -Juventud en movimiento- Una iniciativa destinada a impulsar el potencial de los jóvenes para lograr un crecimiento inteligente, sostenibles e integrador en la UE, COM (2010) 477 final.

${ }^{14}$ Entre sus objetivos llama muy especialmente la atención: a) la racionalización de los mecanismos administrativos para facilitar el acceso a la financiación por parte de las PYMES, mejorando el entorno empresarial mediante contrataciones públicas que incentiven la innovación; b) la promoción de la cooperación de conocimientos y reforzar los vínculos entre educación, empresa, investigación e innovación; y c) del espíritu emprendedor por medio del apoyo a jóvenes empresas innovadoras. Ver el documento: Una "Unión por la innovación": convertir las ideas en empleo, crecimiento ecológico y progreso social, publicado en Bruselas, IP/10/1288.

${ }^{15}$ Se desea aquí modernizar los mercados laborales y potenciar la autonomía de las personas mediante el desarrollo de capacidades a lo largo de su vida con el fin de aumentar la participación laboral y adecuar mejor la oferta y demanda de trabajos, en particular mediante la movilidad laboral. Véase la Comunicación de la Comisión al Parlamento Europeo, a la Comisión, al Comité Económica y Social Europeo, y al Comités de las Regiones -Agenda de nuevas cualificaciones y empleos: una contribución europea hacia el pleno empleo- publicada en Estrasburgo, COM (2010) 682 final.

${ }^{16}$ Básicamente persigue: 1) facilitar el desarrollo de capacidades y apoyar la transición de la educación al trabajo; b) apoyar la movilidad en el mercado laboral, y 3) reforzar la aplicación de políticas en el marco. Ver Comunicación de la Comisión al Parlamento Europeo, a la Comisión, al Comité Económica y Social Europeo, y al Comités de las Regiones sobre 
Todas estas declaraciones de buenas intenciones deberán estar plenamente interconectadas para garantizar que los jóvenes adquieran la formación necesaria que demanda el mercado, facilitando además su inserción laboral. Siendo, a tal fin, imprescindible que los Estados amplíen la inversión pública destinada a educación y formación, dirigiéndose de forma adecuada para lograr la máxima rentabilidad (HERNÁNDEZ BERAJANO, 2013, p. 283 Y 284). No obstante, para que puedan ponerse en marcha estos programas la Comisión reclama que el Consejo de Europa apoye este inicial plan marco. Se espera pues que éste último concrete, a la mayor brevedad posible, los detalles de la Estrategia incluyendo las directrices integradas y los objetivos nacionales.

La respuesta del Consejo de Europa se hace esperar, llegando finalmente a ver la luz en la cumbre de 27 y 28 de junio de 2013. Efectivamente, tal y como reconoce abiertamente el Consejo, la lucha contra el desempleo juvenil debe ocupar un papel prioritario en el programa a desarrollar por la UE. Se trata de un problema que afecta con especial intensidad a millones de jóvenes en la Eurozona y que está causando gravísimas repercusiones en el desarrollo de estas generaciones (MONEREO PÉREZ, 2009, p. 116) $)^{17}$, por no hablar de las consecuencias que a largo plazo va tener en el campo de la Seguridad Social (empobrecimiento y debilitamiento de las prestaciones, alargamiento de la edad de jubilación, disminución de los niveles de cotización a causa de la rotación en el empleo a tiempo parcial y/o temporal y el disfrute del subsidio por desempleo...etcétera).

Principalmente, el enfoque global de choque contra el desempleo juvenil se sustenta en las siguientes medidas: 1) aceleración de la Iniciativa sobre Empleo Juvenil (hasta un total de 6.000 millones de euros) y concentración del esfuerzo al comienzo del periodo $2014^{18}$; 2) aceleración en la ejecución de la Garantía Juvenil; 3) aumento de la movilidad juvenil ${ }^{19}$; y 4) participación de los interlocutores sociales.

la "Iniciativa de oportunidades para la juventud", publicado en Bruselas a fecha de 20 de diciembre de 2011, $\operatorname{COM}(2011) 933$ final.

${ }^{17}$ Cuanta más tarde es la incorporación al mercado de trabajo, más se retrasa la proyección de un futuro plan de vida familiar, debiendo los jóvenes convivir con sus progenitores hasta que consigan un empleo estable que les permita vivir dignamente $\mathrm{y}$ de forma independiente.

${ }^{18}$ Este plan de estar preparado para su puesta en funcionamiento en enero de 2014, debiendo ejecutarse entre 2014 y 2015, en lugar de distribuirlo entre el periodo 2014 a 2020 tal y como preveía la Estrategia Europa 2020 (ISI).

${ }^{19}$ Se está trabajando para impulsar la movilidad de los jóvenes solicitantes de empleo, por medio del refuerzo del programa "tu primer trabajo EURES" (your first EURES job). Para lo cual los Estados miembros podrán hacer uso de parte de las asignaciones que destine el Fondo Social Europeo (FSE) para el apoyo de los regímenes de movilidad transfronteriza. En este sentido, y de igual modo, el programa 
Con vistas a lograr los mejores resultados, la UE pone a disposición de aquellos Estados con una tasa de desempleo juvenil superior al 25\% (entre los que se encuentra España, Portugal, Grecia, Italia, Francia y Eslovenia) los fondos comunitarios (especialmente los del FSE y otros instrumentos de cohesión provenientes de la reprogramación de fondos estructurales sin gastar) destinados a la creación de empleo, formación profesional y prevención del abandono escolar, reforzando así la nueva iniciativa sobre el Empleo juvenil (2014-2020) ${ }^{20}$. Los Estados miembros que sean beneficiarios de la Iniciativa sobre Empleo Juvenil deberán adoptar un plan para abordar el paro de los jóvenes, en particular, mediante la aplicación de la "Garantía Juvenil". De este modo, se evitará que ningún joven de hasta 25 años se quede más de cuatro meses sin trabajo, formación o periodo de prácticas (SUÁREZ CORUJO, 2014, p. 87 ${ }^{21}$. Asimismo, el Banco Europeo de Inversiones (BEI) contribuirá también en la lucha contra el desempleo a través de su iniciativa "Trabajo para jóvenes" y su programa "Inversión en la Capacitación".

Finalmente, destaca la puesta en marcha de un nuevo "Plan de Inversiones" para fomentar el crecimiento y el empleo gracias al apoyo financiero de las PYME. Y es que, resulta fundamental potenciar el emprendimiento y el trabajo por cuenta propia ${ }^{22}$, como se verá a continuación en el siguiente apartado.

\section{El establecimiento de UN MARCo JURÍdico-POLÍtico PARA EL CRECIMIEN- TO DEL EMPLEO JUVENIL EN ESPAÑA: LA LEY DE EMPRENDEDORES}

\subsection{Plan de medidas de políticas de empleo en España}

De conformidad con el marco jurídico que establece la actual Ley 56/2003, de 16 de diciembre, de Empleo (BOE núm. 301 de 17 de diciembre de 2003): "La política de empleo (en España) se desarrollará, dentro de las orientaciones gene-

"Erasmus+", deberá estar plenamente operativo a partir de enero del 2014.

${ }^{20}$ De los 6.000 millones de euros que la UE destina para la lucha contra el desempleo juvenil, España recibirá: a) 918 millones de euros, procedentes de la partida presupuestaria específica para Empleo juvenil y b) 932 millones de euros, procedentes del FSE.

${ }^{21}$ En aras de acceder a estos fondos de financiación, el Gobierno español ha enviado a la Comisión Europea, en diciembre de 2013, el "Plan Nacional de Implantación de la Garantía Juvenil en España". En este documento se recogen, entre otros, los mecanismos de instrumentación de la "Garantía Juvenil" en nuestro país a través de las medidas de mejora de la intermediación, la empleabilidad, el emprendimiento y la contratación.

${ }^{22}$ Véase las conclusiones del Consejo de Europa de 27 y 28 de junio del 2013 (EUCO 104/2/13 REV 2), páginas: 3 a 5. 
rales de la politica económica, en el ámbito de la estrategia coordinada para el empleo regulada por el Tratado Constitutivo de la Comunidad Europea" (artículo 1.1). Por lo que, desde un primer momento, se deja claro que la política de empleo nacional queda condicionada a lo dispuesto por la política de integración europea (MONEREO PÉREZ, 2009, p. 6-49).

Haciendo gala del ejercicio de competencias que se atribuyen por el art. 3.1 de la Ley del Empleo, se publica en 2011 la Estrategia Española de Empleo 2012$2014^{23}$. Normativa que ha constituido desde entonces el nuevo paradigma estratégico de las políticas de empleo que se han de fijar en nuestro territorio (con carácter general) a través del Sistema Nacional de Empleo, señalando para ello, una serie de metas (tanto de carácter económico, como político) y acciones a alcanzar a corto plazo ${ }^{24}$.

El fin último que se pretende no es otro que el de: "fomentar el empleo de la población activa y aumentar la participación de hombres y mujeres en el mercado de trabajo, mejorando la productividad y la calidad en el empleo en un mercado de trabajo sostenible, basado en la igualdad de oportunidades, la cohesión social y territorial"25. O dicho en otras palabras, de lo que se trata es de hacer justicia al tenor literal del art. 35.1 de la Constitución Española (CE), esto es, al "derecho al trabajo" (MONEREO PÉREZ, 2009, p. 9-12) ${ }^{26}$, en armonía con lo previsto por el art. 40.1 del mismo cuerpo legal: "los poderes públicos promoverán las condiciones favorables para el progreso social y económico y para una distribución de la renta regional y personal más equitativa, en el marco de una política de estabilidad económica. De manera especial realizarán una política

\footnotetext{
${ }^{23}$ Aprobada como Real Decreto 1542/2011, de 31 de octubre por el que se aprueba la Estrategia Española de Empleo 2012-2014 (BOE núm. 279, de 19 de noviembre de 2011). Normativa que se inserta dentro del Plan Nacional de Reformas.

${ }^{24}$ En particular, se determinan seis objetivos de política de empleo: 1) elevación de la tasa de empleo al 74\% para la población de entre 30-64 años en el horizonte de 2020, con un sub-objetivo de tasa de empleo femenino para el mismo grupo de edad del $68,5 \%$; 2 ) reducir la temporalidad y la segmentación del mercado de trabajo; 3 ) reforzar el trabajo a tiempo parcial y la flexibilidad interna de las empresas; 4) mejorar y adecuar las competencias profesionales a las necesidades del mercado; 5) promover una rápida y adecuada reinserción de las personas en el mercado laboral; y 6) promover la igualdad de género en el mercado.

${ }^{25}$ Véase apartado 3.1 "La estrategia española de empleo 2012-2014 y la estrategia Europa 2020", página: 22 del texto legal.

${ }^{26}$ Como bien señala el profesor J.L Monereo Pérez, de lo que se trata es de garantizar “.... la protección de la persona del trabajador en el empleo y en el mercado de trabajo..., pero también fuera o al margen del mercado de trabajo a través de las políticas de protección de Seguridad Social por desempleo".
} 
orientada al pleno empleo"; y lo dispuesto por el artículo 14 de la $\mathrm{CE}^{27}$. Ahora bien, no será posible la consecución de dicha meta, si antes no se han asentado las bases para la confección de los instrumentos jurídicos que van a servir de orientación a las políticas públicas hacia la obtención de un empleo estable, de calidad y que asegure plenas garantías laborales a todos los trabajadores ${ }^{28}$.

Para la Estrategia Española, la cualificación e inserción laboral de los jóvenes se alza en un plano preferente. No obstante, teniendo en cuenta la heterogeneidad de edades, se han previsto distintas acciones dependiendo de la etapa y el nivel de formación en la que este colectivo se encuentre ${ }^{29}$. Asimismo, se impulsa el empleo del contrato para la formación y el aprendizaje como doble vía para la inserción laboral y la formación ${ }^{30}$.

${ }^{27}$ En esta línea, no debemos olvidar la previsión recogida en los arts. 21 y 23 de la Carta de los Derechos Fundamentales de la UE. Así pues, mientras que el primero de ellos versa sobre el principio de no discriminación por razón de sexo, el segundo, evoca el principio de igualdad entre mujeres y hombres. Para un análisis más exhaustivo en esta materia, véase los estudios que realiza la profesora C. Monereo Atienza a dichos preceptos en VV.AA, Monereo Atienza, C y Monereo Pérez, J.L: La Europa de los Derechos. Estudio sistemático de la Carta de los Derechos Fundamentales de la Unión Europea, Granada, Comares, 2012, páginas: 463-480 y 503-529.De igual modo, debe tenerse presente lo dispuesto por la Directiva 2000/78/CE del Consejo, de 27 de noviembre del 2000, relativa al establecimiento de un marco general para la igualdad de trato en el empleo y la ocupación (EUR-32000L0078) $\mathrm{y}$ en concreto, sus artículos 2 (en donde se propugna el principio de igualdad de trato entre mujeres y hombres) y 25 ("La prohibición de discriminación por razones de edad constituye un elemento fundamental para alcanzar los objetivos establecidos por las directrices sobre el empleo y para fomentar la diversidad en el mismo"). Téngase en cuenta también la sentencia del Tribunal de Justicia de la Unión Europea, de 21 de julio de 2011 (TJCE/2011/277), en donde se realiza una interpretación de las circunstancias que pueden dar lugar a llevar a cabo diferencias de trato por motivos de edad.

${ }^{28}$ Punto en el que también insiste la Comisión Europea al hablar de la necesidad de elaborar un marco de calidad para evitar que se utilice a los jóvenes como mano de obra barata y gratuita, fomentando así una espiral viciosa de empleo precario. A este respecto, hacen saltar las alarmas de la UE acerca de las condiciones en las que trabajan muchos jóvenes en Europa, los hechos ocurridos a fecha de 20 de agosto de 2013 en la ciudad de Londres, lugar en donde muere un becario del Bank of América de 21 años tras estar 72 horas seguidas trabajando (http://www.thetimes.co.uk/tto/news/uk/article3848066.ece).

${ }^{29}$ Para los jóvenes menores de 20 años no titulados, las medidas se focalizan hacia la reincorporación al sistema educativo, de la misma manera que para aquellos con edades comprendidas entre 20 y 25 años.

${ }^{30}$ Véase también el Real Decreto 1529/2012, de 8 de noviembre, por el que se desarrolla el contrato para la formación y el aprendizaje y se establecen las bases de la formación profesional dual (BOE núm. 270 de 9 de noviembre de 2012). 
Tanto los poderes públicos, como los agentes sociales están preocupados por la situación económica y política del empleo juvenil. Así pues, como se refleja en el siguiente gráfico, la tasa de desempleo juvenil en España ha aumentado considerablemente en los últimos años hasta situarse en un 53,1\% en los menores de 25 años:

España: Paro menores de 25 años 2014

\begin{tabular}{|r|r|r|r|}
\hline \multicolumn{1}{|c|}{ Periodo } & $\begin{array}{r}\text { Paro menores de 25 } \\
\text { años (ambos sexos) }\end{array}$ & $\begin{array}{r}\text { Paro hombres me- } \\
\text { nores de 25 }\end{array}$ & $\begin{array}{c}\text { Paro mujeres } \\
\text { menores de 25 }\end{array}$ \\
\hline Junio 2014 & $53,1 \%$ & $53,8 \%$ & $52,4 \%$ \\
Marzo & $55,5 \%$ & $56,0 \%$ & $54,9 \%$ \\
2014 & $54,9 \%$ & & \\
Diciembre & $54,1 \%$ & $55,6 \%$ & $54,1 \%$ \\
2013 & & $54,0 \%$ & $54,4 \%$ \\
Septiembre & 5 & & \\
2013 & & & \\
\hline
\end{tabular}

Gráfica 1. Elaborada por el INE tras un estudio trimestral de la situación del mercado de trabajo en los jóvenes menores de 25 años.

A la vista de estos resultados, el Gobierno Español ha elaborado un elenco de medidas para favorecer la participación laboral de este grupo, evitando así un incremento del desempleo juvenil y potenciando además el crecimiento de la actividad económica que permita crear empleo. Son muestra de todo ello, por matizar en algunas de estas iniciativas: 1) la Resolución de 30 de enero de 2012, de la Dirección General de Empleo, por la que se registra y publica el II Acuerdo para el Empleo y la Negociación Colectiva 2012, 2013 y 2014 ${ }^{31}$; 2) el Acuerdo para el progreso económico y social de Andalucía ${ }^{32}$; 3) la Resolución de 28 de agosto de 2013, de la Secretaría de Estado de Empleo, por la que se publica el Acuerdo del Consejo de Ministros de 2 de agosto de 2013, por el que se aprueba el Plan Anual de Política de Empleo para $2013^{33}$. Para esta última se han contemplado un listado de acciones y/o medidas a ejecutar, entre las que se encuentra la de "mejora de la empleabilidad de los jóvenes

\footnotetext{
${ }^{31}$ BOE núm. 31 de 6 de febrero de 2012. Acuerdo subscrito a fecha de 25 de enero del 2012, de una parte, por la Confederación Española de Organizaciones Empresariales (CEOE) y la Confederación Española de la Pequeña y Mediana Empresa (CEPYME) y, de otra parte, por las Confederaciones Sindicales de CCOO y UGT.

${ }^{32}$ Firmado a fecha de 20 de marzo del 2013 por UGT, CCOO y la Confederación de Empresarios de Andalucía (CEA). Tienen como destinatarios preferentes, entre otros, a las personas jóvenes menores de 35 años.
}

${ }^{33}$ BOE núm. 217 de 10 de septiembre de 2013. 
y el apoyo al emprendimiento"34. Regla, que si bien, se encuentran en la misma línea que las de aquellas otras que recoge la Ley 3/2012, de 6 de agosto de medidas urgentes para la reforma del mercado laboral: 1) como fomento de la empleabilidad; 2) garantía del empleo y de la contratación indefinida; y 3) facilitación del autoempleo. Concretamente, sobre estas últimas se enmarcan las actuales estrategias de fomento y apoyo al emprendimiento.

\subsection{LAS LEYES DE MEDIDA Y APOYO AL EMPRENDIMIENTO}

Para recuperar la senda del crecimiento económico y de creación empleo en nuestra nación resultará necesario que el Gobierno continúe con el esfuerzo reformista, pero en el sentido autentico de una reforma propia de un Estado social y democrático de derecho. Para ello las estrategias de empleo juvenil habrán de estar orientadas a la consecución del pleno empleo, es decir, a la obtención de un trabajo decente, digno y de calidad en el marco de un modelo de política de competitividad por innovación y conocimiento, que rechace frontalmente el modelo neoliberal de política de competitividad por reducción de costes y precarización del trabajo. A tal fin todas las miradas se centran en aumentar la calidad y estabilidad de los jóvenes en el empleo a través de los sistemas de inserción laboral que se proponen en la ley de emprendedores.

Recientemente, a nivel nacional se han publicado dos importantes normas en esta materia (las cuales podrán ser aplicables tanto para el ámbito de la empresa privada, como para el caso de que la contratación se realice en el sector público), de un lado la Ley 11/2013, de 26 de julio de medidas de apoyo al emprendedor y de estímulo del crecimiento y de la creación de empleo ${ }^{35}$; y de otro lado la Ley 14/2013, de 27 de septiembre, de apoyo a los emprendedores y a su internalización ${ }^{36}$. A ni-

34 Junto a esta se encuentran también: a) la mejora de la empleabilidad de otros colectivos especialmente afectados por el desempleo; b) la mejora de la calidad de la formación profesional en el empleo y; 3 ) la mejora de la vinculación de las políticas activas y pasivas de empleo. Véase apartado 5 "Estructura y objetivos" de esta resolución.

${ }^{35}$ BOE núm. 179, de 27 de julio del 2013. Previamente a esta, sale a la luz el Real Decreto, de 22 de febrero, de medidas de apoyo al emprendedor y de estímulo del crecimiento y de la creación de empleo (BOE núm. 47, de 23 de febrero de 2013). Normativa que trata de dar respuesta y se inserta entre las medidas que el Ministerio de Empleo y Seguridad Social están llevando a cabo, dentro de la llamada "Estrategia de Emprendimiento y Empleo Joven 2013-2016".

36 BOE núm. 233, de 28 de septiembre de 2013. Esta última normativa ha sido objeto de aclaración por la Junta Consultiva de Contratación Administrativa Estatal a la vista de las dudas interpretativas que le han surgido a una pluralidad de órganos de contratación del Sector Público desde su entrada en vigor. Recordemos que esta Ley 14/2013, de 27 de septiembre, modifica algunos preceptos de la Ley de Contratos del Sector Público (Real Decreto Legislativo 3/2011, de 14 de noviembre, por el que se aprueba el Texto Refundido de la Ley 
vel andaluz, con motivo del reparto de competencias entre Estado y Comunidades Autónomas (CCAA), nace el Decreto-Ley de 8/2013 de 28 de mayo, de Medidas de Creación de Empleo y Fomento del Emprendimiento ${ }^{37}$, convalidado a fecha de 28 de junio del 2013 por Resolución de la Presidencia del Parlamento de Andalucía ${ }^{38}$. De igual modo, en el resto de CCAA se han creado y publicado también leyes de emprendedores como respuesta a esa iniciativa nacional para el fomento del empleo juvenil ${ }^{39}$.

de Contratos del Sector Público -BOE núm. 276 de 16 de noviembre de 2011-), entre los que cabe destacar el art. 146. Para un conocimiento más exhaustivo en esta materia véase la Recomendación de 26 de noviembre de 2013 (JUR/2013/356789).

${ }^{37}$ BOJA núm. 105, de 31 de mayo del 2013.

${ }^{38}$ BOJA núm. 133, de 10 de julio de 2013.

${ }^{39}$ A saber: Ley núm. 2/2012, de 4 de abril de apoyo a los emprendedores y las emprendedoras y a la micro, pequeña y mediana empresa en la Comunidad Autónoma de las Islas Baleares (BOE no 105 de 2 de mayo de 2012); La ley núm. 16/2012, de 28 de junio de Apoyo a las Personas Emprendedoras y a la Pequeña Empresa del País Vasco (Boletín Oficial del País Vasco $\mathrm{n}^{\circ} 132$ de 6 de julio de 2012); Decreto núm. 97/2012, de 19 de julio, por el que se establece en el marco del emprendimiento, las bases reguladoras de subvenciones relativas al Plan de fomento al emprendedor autónomo y Pyme destinadas a la iniciativa de autoempleo en Castilla-La Mancha (LCLM 2012/167); Orden núm. 2680/2012, de 26 de diciembre, de la Consejería de Empleo, Turismo y Cultura, por la que se establecen las bases reguladoras para la compensación de cuotas a la Seguridad Social a aquellos emprendedores que creen empleo o prorroguen la duración de los contratos ya existentes, y se convocan subvenciones para el año 2012 (BOCM de 13 de noviembre de 2012); Ley Foral núm. 12/2013, de 12 de marzo, de apoyo a los emprendedores y al trabajo autónomo en Navarra (BOE n ${ }^{\circ} 83$ de 6 de abril de 2013); Ley núm. 5/2013, de 19 de junio, de Estímulo a la Creación de Empresas en Castilla y León (BOE n ${ }^{\circ} 168$ de 15 de julio de 2013); Ley núm. 5/2013, de 8 de julio, de apoyo a los emprendedores y a la competitividad e internacionalización de las pequeñas y medianas empresas (PYMES) de la Región de Murcia (Boletín Oficial de la Región de Murcia n ${ }^{\circ} 158$ de 10 de julio de 2013); Ley núm. 10/2013, de 21 de octubre, de apoyo a emprendedores, autónomos y Pymes en La Rioja (BOE n⿳ 268 de 8 de noviembre de 2013); Ley núm. 6/2013, de 6 de noviembre, de Cooperativas de Cantabria (BOE n 284 de 27 de noviembre de 2013); Decreto núm. 245/2013, de 30 de diciembre, por el que se modifica el Decreto213/2012, de 19 de octubre, por el que se establecen las bases reguladoras del programa de ayudas para el fomento de la investigación, el desarrollo tecnológico y la innovación en la actividad emprendedora y empresarial de las pequeñas, medianas y grandes empresas en el ámbito de la Comunidad Autónoma de Extremadura (DOE n 5 de 9 de enero de 2014); Decreto núm. 36/2014, de 14 de marzo, de Gobierno de Aragón por el que se modifica el Decreto 111/2012, de 24 de abril por el que se aprueba el Programa de Emprendedores y se establecen las bases reguladoras para la concesión de las subvenciones contempladas en el mismo para la promoción del empleo de aquellos emprendedores que se establezcan como trabajadores autónomos o constituyan microempresas en la Comunidad Autónoma de Aragón (Boletín Oficial de Aragón n ${ }^{\circ} 155$ de 19 de marzo de 2014); Orden núm. EMO/114/2014, de 4 de abril, por la 
Sin embargo, antes de entrar en el análisis de cada una de las leyes de emprendedores, cabe aludir al "contrato indefinido de apoyo a emprendedores" que recoge el art. 4 de la Ley 3/2012, de 6 de agosto de medidas urgentes para la reforma del mercado laboral. Gracias a esta normativa nace en nuestro sistema iuslaboralista un nuevo contrato que, deroga al antiguo "contrato de fomento del empleo estable", pero que, al igual que hacía su precedente, se dirige, entre otros, a jóvenes entre 16 y 30 años ${ }^{40}$. Entre los estímulos que este contrato ofrece para facilitar el empleo estable aparece, de un lado, una serie de deducciones fiscales -art. 43 del Texto Refundido de la Ley de Impuesto sobre Sociedades, aprobado por Real Decreto Legislativo

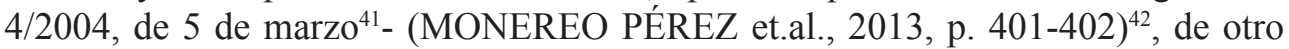
lado, bonificaciones a cargo del Servicio Público de Empleo Estatal y, finalmente, reducciones de las cuotas sociales durante un periodo de tres años, siendo su cuantía variable dependiendo del colectivo laboral al que se dirija ${ }^{43}$. Las empresas de menos

que se aprueban las bases reguladoras de la línea de ayudas en forma de garantía para la financiación empresarial de proyectos de autónomos, micro, pequeñas y medianas empresas, y se hace pública la correspondiente convocatoria para la Línea de emprendedores, autónomos y comercios para el año 2014 en Cataluña (DOGC núm. 6604 de 15 de Abril de 2014); Orden de 30 de mayo de 2014, por la que se establecen las bases reguladoras del Programa de las iniciativas emprendedoras y de empleo $(\mathrm{I}+\mathrm{E}+\mathrm{E})$, cofinanciado por el Fondo Social Europeo, y se procede a su convocatoria para el año 2014 (DOG n 110 de 11 de junio de 2014); Ley núm. 5/2014, de 25 de julio, de Fomento y Consolidación del Emprendimiento, el Trabajo Autónomo y las Pymes en la Comunidad Autónoma de Canarias (Boletín Oficial de Canarias $\mathrm{n}^{\mathrm{o}} 152$ de 7 de agosto de 2014).

${ }^{40} \mathrm{Y}$ a mayores de 45 años.

${ }^{41}$ BOE núm. 61 de 11 de Marzo de 2004.

${ }^{42}$ Estas deducciones serán de 3000 Euros para la contratación del primer trabajador de la empresa cuando sea menor de 30 años, de una parte, y del 50\% de una de las cantidades variables atendiendo a la cuantía de prestación que le reste por percibir si se contrata a perceptores de prestaciones por desempleo del nivel contributivo. En este caso, se podrá compatibilizar la prestación por desempleo y el salario hasta un máximo del $25 \%$ de aquélla.

${ }^{43}$ Véase el art. 4.5 de la Ley 3/2012: ... a) Jóvenes entre 16 y 30 años, ambos inclusive, la empresa tendrá derecho a una bonificación en la cuota empresarial a la Seguridad Social durante tres años, cuya cuantía será de 83,33 euros/mes (1.000 euros/año) en el primer año; de 91,67 euros/mes (1.100 euros/año) en el segundo año, y de 100 euros/mes (1.200 euros/ año) en el tercer año.Cuando estos contratos se concierten con mujeres en ocupaciones en las que este colectivo esté menos representado las cuantías anteriores se incrementarán en 8,33 euros/mes (100 euros/año).b) Mayores de 45 años, la empresa tendrá derecho a una bonificación en la cuota empresarial a la Seguridad Social, cuya cuantía será de 108,33 euros/ mes (1.300 euros/año) durante tres años. Cuando estos contratos se concierten con mujeres en ocupaciones en las que este colectivo esté menos representado, las bonificaciones indicadas serán de 125 euros/mes (1.500 euros/año).Estas bonificaciones serán compatibles con otras ayudas públicas previstas con la misma finalidad, sin que en ningún caso la suma de 
de 50 trabajadores podrán recurrir a esta modalidad de contrato mientras la tasa de desempleo sea superior al 15\%, no perdiendo los incentivos indicados siempre que el trabajador se mantenga en su puesto de trabajo al menos durante tres años (tras la superación del periodo de prueba de 1 año).

Actualmente, el "contrato indefinido de apoyo a emprendedores" constituye una de las figuras más criticadas tanto por la doctrina, como por la jurisprudencia. Y ello es porque por ley se ha fijado, como condición sine qua non, un período de prueba de 365 días para que el trabajador pueda acceder a la contratación indefinida $\mathrm{y}$, por consiguiente, pueda la empresa disfrutar de todo ese conjunto de beneficios fiscales y de Seguridad Social (hasta un periodo máximo de tres años, contados a partir de la superación del periodo de prueba) $)^{44}$. Ciertamente, en momentos de crisis económica se deben adoptar medidas coyunturales para potenciar el empleo estable, ahora bien, entiendo que ello no debe conllevar la disminución de derechos en los trabajadores. La praxis ordinaria está demostrando como por obra de ese periodo de prueba tan dilatado en el tiempo ( 1 año) se ha abierto la puerta a que los empresarios desistan de los contratos celebrados, antes de la terminación del periodo de prueba, creando así un círculo vicioso en donde los trabajadores (previamente contratados) son despedidos y sustituidos por segundos trabajadores, de cuyos contratos nuevamente desistirá el empresario y así sucesivamente ${ }^{45}$. Los temas centrales en los que se centra este intenso debate se sitúa en torno a estas tres cuestiones: 1) la naturaleza jurídica del periodo de prueba y si en caso de desistimiento constituiría éste un despido ad nutum $^{46}$; 2) la necesidad o no de alegar una causa para proceder al desisti-

las bonificaciones aplicables pueda superar el $100 \%$ de la cuota empresarial a la Seguridad Social.En el supuesto de que el contrato se celebre a tiempo parcial, las bonificaciones se disfrutarán de modo proporcional a la jornada de trabajo pactada en el contrato.

${ }^{44}$ Para un conocimiento más completo véase, MONEREO PÉREZ, J.L: "Nuevos contenidos de la Negociación Colectiva y límites legales de los mismos, con particular atención a la jubilación obligatoria y al periodo de prueba", Temas Laborales, monográficos sobre los efectos de la reforma laboral en la negociación colectiva, $\mathrm{n}^{\circ} 120,2013$, páginas 439 y siguiente, en particular, páginas 473 y 477.

${ }^{45}$ Véase, a este respecto, la STC de 17 de julio de 2014, en donde tan sólo el voto particular que formula el Magistrado don Fernando Valdés Dal-Ré a esta sentencia con recurso inconstitucionalidad núm. 5603-2012 (y al que se adhiere la Magistrada Doña Adela Asua Batarrita y el Magistrado Don Luis Ignacio Ortega Álvarez) camina en esta misma línea (Apartado III, punto 5 del voto particular)).

${ }^{46}$ Argumenta la opinión mayoritaria del TC en su sentencia de 17 de julio de 2014 que: “... el desistimiento durante el periodo de prueba no constituye un despido, sino la plasmación, a través de una declaración de voluntad, de una condición resolutiva, positiva y potestativa, expresamente asumida por las partes en el momento de suscripción del contrato. Es cierto que la posibilidad legal de introducir en el contrato tal condición resolutiva (...) constituye un mecanismo que habilita la extinción contractual ad nutum a iniciativa empresarial. Desde esta perspectiva, por tanto, el periodo de prueba admitido y regulado por el legislador puede 
miento del trabajador ${ }^{47}$ y el derecho a una indemnización ${ }^{48}$ y 3) la razonabilidad o

actuar como una limitación del derecho a la estabilidad en el empleo (...) y que, por tal razón, entra en conexión con el art. 35.1 Constitución Española...”.

${ }^{47}$ En este punto argumenta la tesis mayoritaria del Constitucional que: “... el legislador ha optado, como regla general, por admitir en las relaciones laborales la posibilidad de pactar un periodo de prueba, durante cuyo transcurso, cualquiera de las partes -incluido el empresariopuede proceder a la resolución contractual. De este modo la admisión normativa de dicha estipulación se configura como una excepción al carácter causal que el ordenamiento legal, también como regla general, exige a las extinciones contractuales a iniciativa empresarial; sin perjuicio, claro está, de que, como este Tribunal ha reiterado, la motivación de la decisión extintiva se encuentre limitada por el necesario respecto a los derechos fundamentales y el principio de no discriminación" (Véase el Fundamento Jurídico $\mathrm{n}^{\circ} 3$ en su apartado c). Por el contrario, el voto particular a esta sentencia de 17 de julio de 2014 sostiene que "... las resoluciones impugnadas... aparece reforzadas por el hecho de que tanto exigencias constitucionales, como compromisos internacionales, hacen que rijan entre nosotros el principio general de la limitación legal del despido, así como su sujeción para su licitud a condición de fondo y forma. (...) No debe olvidarse... que, en su vertiente individual, el derecho al trabajo (art. 35.1 CE) se concreta en el derecho a la continuidad o estabilidad en el empleo, es decir, en el derecho a no ser despedido sin justa causa. (...) la desregulación de las dos grandes modalidades de despido (por incumplimiento del trabajador de los deberes contractuales y por razones relacionadas con el funcionamiento de la empresa) resultaría de todo punto incompatibles con el art. 35.1 CE, de modo que queda proscrito, por mandato constitucional, el establecimiento de extinciones ad nutum... pues la medida afectaría al contenido esencial del derecho al trabajo (Ver apartado III, punto 2 de este voto particular). En el ámbito comunitario, el reconocimiento expreso del derecho "de todo trabajador a una protección en caso de despido injustificado" se encuentra expresamente reconocido en el art. 30 de la Carta de Derechos Fundamentales de la Unión Europea del año 2009 (Carta de Niza), incorporada al Tratado de la Unión... Esta incorporación ha tenido el efecto de reforzar notablemente el carácter causal del despido y la necesidad de adoptar sistemas de "reacción adecuados" contra los ceses empresariales, a fin de evitar el debilitamiento del derecho del trabajo y, a su través, el vaciamiento de su función tuitiva, que ha de entenderse integrada en su código genético (Apartado III, punto 2, letra a) de este voto particular)".

48 Sobre este tema la STC de 17 de julio de 2014 declara la pérdida del derecho a una indemnización cuando el trabajador es despedido sin causa durante el periodo de prueba, lo que priva al trabajador de sus derechos laborales (tal y como sostiene el voto particular que formula el Magistrado Fernando Valdés Dal-Ré). En la misma línea del voto particular a la anterior STC (y, por consiguiente, en contra de lo que sostiene la opinión mayoritaria), la Sentencia del Juzgado de lo Social de Barcelona de 19 de noviembre de 2013 (AS 2013/2802) entiende que el hecho de que la Ley 3/2012 se publique en un momento de crisis económica no puede conllevar dejar desprotegido a los derechos de los trabajadores. De ahí que declare el desistimiento durante el periodo de prueba de un trabajador contratado bajo la fórmula del "contrato indefinido de apoyo a emprendedores" como un despido improcedente. Debiendo el empleador optar por la readmisión del trabajador o el derecho a un indemnización calculada a razón de 45 días de salario por año de servicio (Ver el Fundamento de Derecho Quinto 
no de la duración del periodo de prueba ${ }^{49}$ y los límites que a la negociación colectiva impone la Ley $3 / 2012^{50}$.

de esta sentencia).

49 Defiende el TC, posición mayoritaria, en su Sentencia de 17 de julio de 2014 que: “... la introducción del contrato de trabajo por tiempo indefinido de apoyo a los emprendedores y del régimen jurídico que lo acompaña no constituye sino una nueva actuación del legislador sobre la duración de la contratación laboral y de la estabilidad en el puesto de trabajo. Pretende ofrecer una respuesta que entiende adecuada ante una situación de grave crisis del empleo como la que refleja el preámbulo de la Ley 3/2012, donde se deja constancia de una cifra de paro de 5.273.600 personas. Respecto a la determinación de la duración razonable, la OIT ha afirmado que se trata de un aspecto que corresponde resolver a cada Estado. El límite de duración de tal período lo ha fijado en que no sea "excesivamente largo"(...) Atendido el contexto de grave crisis económica y alto desempleo... hemos de afirmar que la fijación en esta modalidad contractual de un periodo de prueba superior al generalmente previsto para las demás relaciones laborales encuentra justificación; no sólo en la finalidad típica de todo período de prueba sino, sobre todo, en la específica y legítima finalidad de potenciar la iniciativa empresarial como instrumento para contribuir, junto con otras medidas de su régimen jurídico, a promover la creación de empleo establece, de conformidad con el mandato que el art 40.1 CE dirige a los poderes públicos para llevar a cabo una política orientada al pleno empleo (Apartado 3, letra e) de los Fundamentos Jurídicos".Por el contrario, el Magistrado Valdés Dal-Ré considera que: “... un período tan excesivo no es "razonable”, como exige el convenio de la OIT, pues priva al trabajador de lo esencial de sus derechos en materia de despido, colocándolo en una situación comparable a la existente en un momento anterior a la Ley 13 de julio de 1973 en la cual la carga de la prueba del abuso de la ruptura recaía en el trabajador. Y concluyo su razonamiento estimando que esa regresión es contraria a los principios fundamentales del derecho del trabajo, desarrollados por la jurisprudencia y reconocidos por la ley, privando a los trabajadores de las garantías de ejercicio de su derecho al trabajo. (...) Como se desprende de la regulación transcrita, el límite temporal es decisivo para el logro de una adecuada configuración legal del periodo de prueba que garantice el constitucionalmente exigible equilibrio entre los intereses de los empresarios y de los trabajadores. Al formar parte el principio de causalidad del contenido esencial del derecho del trabajo ex art. 35.1 CE, la limitación temporal del periodo de prueba confiere a la suspensión de dicho principio un carácter transitorio, asegurando su activación una vez transcurrido ese plazo. En tal sentido, no estará de más recordar que el Convenio 158 de la OIT autoriza a los Estados a “exceptuar" el régimen causal durante el período de prueba "siempre que la duración se haya fijado de antemano y sea razonable" (art. 2.2 b). El Convenio se constituye así en un canon interpretativo insoslayable" (Apartado III, punto 5)).

${ }^{50}$ Tanto la opinión mayoritaria, como el voto particular a la STC de 17 de julio de 2014 afirman que la previsión que contiene el art. 4.3 de la Ley 3/2012, impone un límite a la negociación colectiva al no permitir que ésta pueda fijar un periodo de duración menor para ese período de prueba. Ahora bien, mientras que la tesis mayoritaria entiende que esta medida resulta razonable dada la situación económica de nuestro país, por el contrario, el voto particular defiende que se está produciendo una intromisión en el derecho a la negociación colectiva, el cual es reconocido en nuestra Carta Magna (Véase STC de 17 de julio de 2014). 
Pasando ya al análisis de las distintas leyes de emprendedores aparece, en primer lugar, la Ley 11/2013 de 26 de julio, la cual se caracteriza, principalmente, por contener una regulación muy heterogénea en la que confluyen todo un elenco de disposiciones de carácter laboral, de Seguridad Social, fiscal, de sector (hidrocarburos, ferroviario...), de lucha contra la morosidad...etc, que modifican diversos preceptos del actual Real Decreto Legislativo 1/1994, de 20 de junio, por el que se aprueba el Texto Refundido de la Ley General de la Seguridad Social (LGSS). En lo referente al ámbito profesional, la normativa busca impulsar un conjunto de medidas orientadas a una doble dirección: a) el autoempleo y emprendimiento, y b) la inserción laboral por cuenta ajena. Haciendo además, partícipes de estas disposiciones tanto a instituciones públicas y privadas, como empresas y organizaciones que deseen colaborar ${ }^{51}$.

Para incentivar el autoempleo de los más jóvenes $\left(1^{\circ}\right.$ bloque de medidas $)$ deberá, previamente, incentivarse a todos los niveles de nuestra sociedad un espíritu emprendedor. Encontrándose a este fin la clave de éxito en la reforma del sistema educativo ${ }^{52}$. En esta línea de pensamiento se presenta, en segundo lugar, la Ley 14/2013, de 27 de septiembre que incorpora ahora en todas las etapas de la Educación Básica (Primaria y Secundaria), Formación Profesional (FP) y Bachillerato; un revolucionario mecanismo que persigue, sin ambages, reforzar las competencias y habilidades necesarias para despertar en los jóvenes ese espíritu emprendedor. Para lo cual el personal docente habrá de adquirir las competencias y habilidades necesarias, a través de la formación inicial y permanente, cumpliendo así de forma eficaz con dicho objetivo. De igual modo las Universidades no pueden quedar exentas, siendo necesarias en ellas la ejecución de tareas de información y asesoramiento para que los estudiantes se inicien en el emprendimiento ${ }^{53}$.

Al margen de estas medidas de las que muchos jóvenes no han podido actualmente beneficiarse, llaman poderosamente la atención, primeramente, un conjunto de reducciones y bonificaciones a la Seguridad Social ${ }^{54}$ que mediante Ley 11/

${ }^{51}$ Véase Preámbulo de la Ley 11/2013, de 26 de julio.

52 En esta línea, VV.AA: Empleo Juvenil en España, Madrid, Ministerio de Trabajo y Asuntos Sociales, 2007, páginas: 55 a 81 .

${ }^{53}$ Véase Título I. "Apoyo a la iniciativa emprendedora”, concretamente en su capítulo I. "Educación en emprendimiento" (artículos 4, 5 y 6). Como consecuencia de ello, el legislador ha encomendado a las administraciones educativas la revisión y adecuación de los currículos de las enseñanzas regladas a estos nuevos fines. Ya en la Universidad de Granada se ha iniciado esta tarea gracias a la apertura de un curso para el fomento de la capacidad emprendedora a través del Centro de Promoción de Empleo y Prácticas (CPEP). A este respecto, puede consultarse el anuncio que realiza el periódico Ideal de Granada a fecha de 29 de octubre de 2013 en su página 12.

${ }^{54}$ Sobre este punto, la Asociación Española de Salud y Seguridad Social (AESSS) ha emitido un comunicado, con fecha de julio de 2014, en donde lamenta y denuncia que el legislador 
2013 se han previsto que puedan ser de aplicación a los menores de 30 o de 35 años (en el caso de las mujeres) que deseen iniciar su actividad profesional por cuenta propia (SEMPERE NAVARRO, 2013, p. 1) ${ }^{55}$ y no empleen a trabajadores por cuenta ajena ${ }^{56}$. Entre las primeras se encuentran las que enumera el artículo 1 de esta ley y que pretenden incentivar a los jóvenes con la atribución de una reducción (durante 15 meses) de las cuotas a la Seguridad Social por contingencias comunes correspondientes, en función de la base de cotización elegida y el tipo aplicable. Reducción que será equivalente al $30 \%$ de la cuota que resulte de aplicar sobre la base mínima de cotización aplicable al tipo mínimo de cotización vigente en cada momento

haya tenido que recurrir a estas medidas incentivadoras para fomentar la contratación de parados, menguando así, por consiguiente, los ingresos de una precaria tesorería con el pretexto de impulsar una contratación laboral exhaustiva por las medidas de flexibilidad. Exponen así: "Con independencia de que tales incentivo provocan en realidad un efecto sustitutivo, es decir, no crean empleo neto sino que determinan el empleo de los integrantes de un colectivo en lugar de los de otros, y de que según la teoría económica el impacto de tales incentivos se halla muy desacreditado, pues se considera como una "lluvia de mayo" que refuerza una decisión ya tomada, pero en muy pocos casos mueve por sí misma a emplear, estas atractivas reducciones suponen otras tantas vías de agua para un barco que atraviesa momentos difíciles en varios de sus parámetros de gasto, como el de las prestaciones por desempleo o las pensiones, por lo que deberían suprimirse en todas sus fórmulas". Ver Archivo: "AESS. Comunicado. Tarifa plana y tarifa joven de la Seguridad Social (estudio; Lápiz Rosa).

${ }^{55}$ En opinión del profesor A. Sempere Navarro: "Contrasta la voluntad legislativa de la reforma laboral de 2012 que pretendía racionalizar a través de la supresión de las bonificaciones a la Seguridad Social la creación dispersa de estos incentivos con la creciente promulgación de normativa diversa que vuelve a fomentarlos y que crea una confusión en los empresarios ante el cúmulo de normas en materia de bonificaciones y reducciones a la Seguridad Social". 56 "Las bonificaciones y reducciones de cuotas previstas en la presente ley se financiarán con cargo a la correspondiente partida presupuestaria del Servicio Público de Empleo Estatal (SPEE) y se soportará por el presupuesto de ingresos de la Seguridad Social, respectivamente" (Disposición adicional primera, apartado 1 de la Ley 11/2013). "Las bonificaciones y reducciones de cuotas de la Seguridad Social se aplicarán por los emprendedores con carácter automático, sin perjuicio de su control y revisión por la Inspección de Trabajo y Seguridad Social, por la Tesorería General de la Seguridad Social y por el SPEE, en sus respectivos ámbito de competencia" (Disp. adicional $1^{\circ}$, apartado 2 de la Ley 11/2013). Para un estudio más completo ver, RODRÍGUEZ-PIÑERO Y BRAVO-FERRER, M y CASAS BAAMONDE, M.E: "El uso del Decreto Ley como instrumento de las reformas laborales. La garantía juvenil y la tarifa plana para el fomento del empleo y la contratación indefinida", Relaciones Laborales, $\mathrm{n}^{\circ}$ 4, 2014, página 6 de la edición digital. AARAGÓN GÓMEZ, C: "Una aproximación al cuadro actual de incentivo al empleo, haciendo especial referencia a la tarifa plana en la cotización a la Seguridad Social", en VV.AA, GARCÍA-PERROTE ESCARTÍN, I y MERCADER UGUINA, J.R: Las reformas laborales y de Seguridad Social de la Ley 11/2013 de 26 de julio al Real Decreto-Ley 3/2014, de 28 de febrero, Pamplona, Lex Nova- Thomsin Reuters, 2014, páginas: 196 y siguientes. 
(incluida la incapacidad temporal) $^{57}$. Asimismo, durante los 15 meses siguientes al término del periodo de reducción se podrán obtener una bonificación por el mismo importe que la antedicha reducción.

En el caso de los menores de 30 años que causen alta inicial en el Régimen Especial de Trabajadores Autónomos (RETA) o que no hubiesen estado en situación de alta en los cinco años inmediatamente anteriores, se podrán aplicar ciertas reducciones y bonificaciones sobre la cuota por causas comunes hasta un periodo máximo de 30 meses, siguiendo esta escala ${ }^{58}$ : (i) la reducción será equivalente al $80 \%$ de la cuota durante los 6 meses siguientes a la fecha del alta; (ii) al 50\% de la cuota en los posteriores 6 meses; (iii) al 30\% en los siguientes 3 meses; y (iv) se bonificará con el 30\% de la cuota en los 15 meses siguiente al término del periodo de reducción ${ }^{59}$.

Seguidamente, cabe destacar un conjunto de medidas que posibilitan para compatibilizar la prestación por desempleo con el trabajo por cuenta propia cuando así lo establezcan los programas de empleo destinados a colectivos con mayores dificultades de inserción laboral. Así pues, en tanto el programa de fomento al empleo lo permita, podrán los menores de 30 años que no tengan trabajadores a su cargo beneficiarse de esta posibilidad durante un máximo de 270 días y siempre que lo soliciten antes del plazo de 15 días desde el inicio de la actividad por cuenta propia (art. 2 y 3 de la Ley 11/2013).

En tercer lugar, aparecen en esta ley de 26 de julio del 2013 una ampliación de las posibilidades de aplicación de la capitalización de la prestación por desempleo. A este respecto, el artículo 4 permite que los menores de 30 años (o 35 años en el caso de mujeres) puedan percibir de una sola vez el 100\% del importe de la prestación por desempleo para su aportación al capital social de una mercantil de nueva constitución o constituida en un plazo máximo de 12 meses anteriores a su aportación $^{60}$. Ahora bien, será requisito indispensable que éstos desarrollen en la mercantil su actividad laboral con carácter indefinido ${ }^{61}$.

\footnotetext{
${ }^{57}$ Para las personas con un grado de discapacidad igual o superior al 33\% que se establezcan como trabajadores autónomos, la reducción y bonificación será del 50\% (en las mismas condiciones).
}

58 Cabe señalar que ambas bonificaciones y reducciones son perfectamente compatibles, siempre que no superen el plazo máximo de 30 meses.

59 Escala que se ha visto progresivamente ampliada en el caso de los trabajadores por cuenta propia con un grado de discapacidad igual o superior al 33\% que tengan menos de 35 años y que causen alta inicial o no hubiesen estado en situación de alta en los cinco meses inmediatamente anteriores. A saber: (i) la reducción será equivalente al 80\% durante los 12 meses y (ii) al 50\% durante los cuatro años siguientes.

${ }^{60}$ Se modifica así el apartado 1 de la disposición transitoria cuarta de la Ley 45/2002, de 12 de diciembre, de medidas urgentes para la reforma del sistema de protección por desempleo y mejora de la ocupabilidad (BOE núm. 298 de 13 de Diciembre de 2002).

${ }^{61}$ A este respecto, resulta interesante destacar que en por medio de la Ley 14/2013, de 27 de 
En cuarto lugar, se podrá suspender o reanudar el cobro de la prestación por desempleo cuando el trabajador autónomo haya realizado un trabajo por cuenta propia inferior a 24 meses o en el caso de los menores de 30 años, inferior a 60 meses (artículo 5 de la Ley 11/2013).

En quinto lugar, el legislador ha permitido que los menores de 30 años puedan voluntariamente decidir si cotizar o no por contingencias profesionales, incluida la cobertura por cese de la actividad (art. 6 de la Ley 11/2013).

En sexto lugar, para no penalizar excesivamente a los trabajadores pluriempleados, se reducen las cuotas de la Seguridad Social para aquellos que coticen en el Régimen General y en otro Régimen a tiempo completo cuando realicen una actividad económica alternativa. Se pretende de este modo de estimular nuevas altas en el RETA (arts. 28 y 29 -Título II- de la Ley 14/2013, de 27 de septiembre).

Adicionalmente, las leyes 11/2013 y 14/2013 disponen de otra serie de medidas, al margen de las de naturaleza social, que igualmente procuran impulsar y apoyar la actividad de los jóvenes emprendedores, a saber: 1) al objeto de frenar el excesivo número de gastos que supone el inicio en el desempeño del trabajo por cuenta propia, se han previsto diversas medidas de apoyo fiscal (por ejemplo: deducciones en el Impuesto de Valor añadido, Impuesto sobre Sociedades e Impuesto sobre la Renta de las Personas Físicas ${ }^{62}$; 2) se han introducido medidas para agilizar a través de los sistemas telemáticos todos y cada uno de los trámites para el arranque, ejercicio y cese de la actividad emprendedora (arts. 13 a 20 de la Ley 14/2013); 3) para apoyar la financiación del emprendimiento (arts. 31 a 35 de la Ley de 27 de septiembre de 2013); 4) de fomento del crecimiento y desarrollo de los proyectos empresariales (entre otros, se han creado medidas de simplificación de cargas administrativas -arts. 36 a 41-, para impulsar la contratación pública con emprendedores -arts. 42 a 47-, de simplificación de los requisitos de información económica financiera -arts. 48 y 49-); y por último, 5) con vistas no sólo a atraer inversión y talento a España, sino también a diseñar una estrategia de impulso de la internacionalización de la economía española, la ley 14/2013 ha impuesto el establecimiento de dos tipos de disposiciones, de un lado, aquellas que se destinan al fomento de la internalización (arts. 50 a 60) y, de otro lado, otras que inciden en la facilitación e incentivación de la movilidad internacional (arts. 61 a 76).

Un $2^{\circ}$ bloque de medidas lo conforman aquellos estímulos que se destinan hacia la inserción laboral de jóvenes por cuenta ajena y de creación de empleo (Título I, Capítulo III). Constituyen todos ellos mecanismos complementarios al ante-

septiembre, se han creado dos nuevas figuras mercantiles: de un lado, "el emprendedor de Responsabilidad limitada" (Capítulo II, artículos 7 a 11); y de otro lado, "la Sociedad Limitada de Formación Sucesiva" (Capítulo III, en su arts. 12).

${ }^{62}$ Arts. 7 y 8 de la Ley 11/2013 y arts. 23 a 27 de la Ley 14/2013. Además, téngase en cuenta la disposición final octava de la Ley 14/2013 por la que se modifica el art. 7 de la Ley $11 / 2013$. 
rior grupo, puesto que en la medida en que quede garantizado el crecimiento de los mercados (es decir, cuanto la tasa de desempleo en España se sitúe por debajo del $15 \%)$ se podrá entonces incentivar la contratación por cuenta ajena de trabajadores noveles. No obstante permiten también que, actualmente, empresas ya constituidas puedan contratar a jóvenes en desempleo al tiempo que adquieren una formación o una primera experiencia profesional.

En primer lugar, como mecanismo de estímulo hacia el empleo de carácter coyuntural se inserta la figura del contrato a tiempo parcial (art. 9 de la Ley 11/2013). Aunque la nueva ley no modifica en absoluto el régimen jurídico previsto para esta tipo de contratación por el art. 12 del Estatuto de los Trabajadores (ET) ${ }^{63}$, sí pretende aparentar, bajo la atribución de una serie de variantes a cumplir por la empresa y por el trabajador ${ }^{64}$ para la obtención de beneficios, que el fin último no es otro que el de fomento del empleo de los más jóvenes a través de la formación (LLEÓ CASANOVA, 2013, p. 15-18; SEMPERE NAVARRO, 2013, p. 3 y SIERRA BENÍTEZ, 2013, p. 224 Y 225.).

En lo que respecta a la empresa, incluidos trabajadores autónomos, que contraten a trabajadores menores de 30 años bajo esta forma jurídica: 1) tendrán derecho a disfrutar durante un máximo de 12 meses de una reducción de la cuota empresarial a la Seguridad Social por contingencias comunes del (a) 100\% cuando la plantilla de la empresa conste de menos de 250 trabajadores o (b) del $75 \%$ en empresas que ocupen 250 o más trabajadores ${ }^{65}$; 2) deberán no haber adoptado, en los seis meses anteriores a la celebración del contrato, decisiones extintivas improcedentes $\left.\left(1^{\circ} \text { límite }\right)^{66} ; 3\right)$ deberán mantener el nivel de empleo alcanzado con el contrato a

${ }^{63}$ Pudiendo éste ser por tiempo indefinido o por duración determinada, no debiendo la jornada ser superior al $50 \%$ de la correspondiente a un trabajador a tiempo completo comparable (art. 9.4 de la Ley 11/2013).

${ }^{64}$ A este respecto, se ha añadido un nuevo requisito a cumplir por el trabajador y es que deberá éste ser beneficiario del Sistema Nacional de Garantía Juvenil en España (Art. 9.2 en su letra e)). Véase, en este sentido, el número 2 del artículo 9 redactado por el artículo 4 del R.D.-ley 16/2013, de 20 de diciembre, de medidas para favorecer la contratación estable y mejorar la empleabilidad de los trabajadores («B.O.E.» 21 diciembre) y la letra e) del número 2 del artículo 9 introducida por el apartado uno del artículo 108 del R.D.-ley 8/2014, de 4 de julio, de aprobación de medidas urgentes para el crecimiento, la competitividad y la eficiencia («B.O.E.» 5 julio).

${ }^{65}$ Ahora bien, cuando el trabajador esté cursando formación o lo haya cursado en los seis últimos meses, podrá el disfrute de ese beneficio ser prorrogado por otros 12 meses (art. 9. 1 apartado segundo).

${ }^{66}$ Límite que afectará "únicamente a las extinciones producidas a partir del 24 de febrero de 2013, y para la cobertura de aquellos puesto de trabajo del mismo grupo profesional que los afectados por la extinción y para el mismo centro centros de trabajo" (art. 9.5 de la Ley 11/2013). 
tiempo parcial con vinculación formativa, al menos, por un periodo equivalente a la duración de dicha figura con un máximo de 12 meses desde su celebración ${ }^{67}$. En caso contrario se procederá al reintegro de los incentivos $\left(2^{\circ} \text { límite }\right)^{68}$.

Por su parte, los trabajadores deberán encontrarse en alguno de los siguientes supuestos: a) no tener experiencia laboral o que ésta sea superior a 3 meses; b) proceder de otro sector de actividad (SEMPERE NAVARRO, 2013, p. 3) ${ }^{69}$; c) ser desempleado y estar inscritos en la oficina de empleo durante los últimos 18 meses de manera ininterrumpida; d) carecer de título oficial de enseñanza obligatoria, de título de formación profesional o de certificado de profesional.

Se combinan en este modelo formación con empleo $^{70}$, no obstante, claramente la preferencia es a favor del segundo frente al primero. Efectivamente, la formación podrá no estar vinculada a la actividad a desarrollar ${ }^{71} \mathrm{y}$, de igual modo, no necesitará atribuírsela al trabajador durante el desempeño de la relación laboral ${ }^{72}$.

En segundo lugar, se presenta el contrato indefinido para microempresas y empresarios autónomos (art. 10 de la Ley 11/2013), el cual queda orientado hacia la contratación de menores de 30 años sin experiencia laboral en empresas de 9 o menos trabajadores. Por lo que a efectos de motivar dicha contratación, las empresas podrán beneficiarse de una reducción del $100 \%$ de la cuota empresarial a la Seguri-

${ }^{67}$ Ambos límites están presentes también en el contrato indefinido de un joven por microempresas y empresarios autónomos (art. 10 de la Ley 11/2013), y el primer empleo joven (art. 12 de la Ley 11/2013).

68 Se explicitan a continuación los supuestos en los que no se considerará incumplida la obligación de mantenimiento del empleo: 1) cuando se extinga por causas objetivas; 2) por despido disciplinario cuando uno u otro sea declarado o reconocido como procedente; 3 ) por extinciones causadas por dimisión, muerte, jubilación o incapacidad permanente total, absoluta o gran invalidez de los trabajadores; 4) expiración del tiempo convenido o realización de la obra o servicio objeto del contrato, o por resolución durante el periodo de prueba (art. 9.6 de la Ley 11/2013).

${ }^{69}$ A este respecto, considera el profesor A. Sempere Navarro, que la finalidad de esta regla no es otra que la de ofrecer una forma de recualificación para los trabajadores de los sectores más afectados por la crisis.

70 "Los trabajadores deberán compatibilizar el empleo con la formación..." (Art. 9.3 apartado primero de la Ley 11/2013).

71 "La formación, no teniendo que estar vinculada específicamente al puesto de trabajo objeto del contrato, podrá ser: a) Formación acreditable oficial o promovida por los servicios públicos de empleo; b) Formación en idiomas o tecnologías de la información y la comunicación de una duración mínima de 90 horas en cómputo anual" (Art. 9.3 apartado segundo de la Ley 11/2013). Téngase en cuenta también el RD 34/2008, de 18 de enero, por el que se regulan los certificados de profesionalidad (BOE núm. 27 de 31 de diciembre de 2008).

72 "... o justificar haberla cursado en los seis meses previos a la celebración del contrato" (Art. 9.3 apartado primero de la Ley 11/2013). 
dad Social por contingencias comunes durante el primer año ${ }^{73}$.

En tercer lugar, aparecen los incentivos a proyectos de emprendimiento joven (art. 11, Ley 11/2013). Destinados, básicamente, a aquellos emprendedores menores de treinta años y sin trabajadores asalariados que a fecha de 24 de febrero de 2013 contraten por primera vez y de forma indefinida (ya sea a tiempo completo o parcial) a personas desempleadas mayores de 45 años. A estos efectos, para concertar esta modalidad contractual, el trabajador deberá además cumplir alguno de los siguientes requisitos: (i) haber estado inscrito durante 12 meses en un plazo superior de 18 meses en la oficina de empleo; (ii) haber agotado su prestación por desempleo o; (iii) resultar beneficiario del programa de recualificación profesional (PREPARA $)^{74}$, lo que dará lugar a la concesión de una reducción del 100\% de todas las cuotas empresariales de Seguridad Social durante un periodo de 12 meses.

Con el título de "primer empleo joven" se enuncia, en cuarto lugar, uno de los instrumentos contractuales más criticados por la doctrina (LLEÓ CASANOVA, 2013, p. 1-12 y SEMPERE NAVARRO, 2013, p. 3) a causa de la temporalidad en el empleo contractual (art. 12, Ley 11/2013) ${ }^{75}$. En efecto, el legislador al introducir como causa justificativa para la contratación temporal la obtención de una primera experiencia profesional, en realidad lo que pretende es establecer la figura del contrato temporal no como mecanismo para responder a las necesidades temporales de trabajo en las empresas, sino como vía o trampolín de acceso al mercado de trabajo para los jóvenes menores de 30 años que carezcan de nula experiencia laboral o cuando sea ésta inferior a tres meses ${ }^{76}$.

No obstante y pese a lo expuesto, a simple vista choca bastante que pueda dirigirse este nuevo mecanismo a jóvenes que ya hayan trabajado anteriormente por

${ }^{73}$ Este contrato es incompatible con el "contrato indefinido de apoyo a emprendedores" que regula el art. 4 de la Ley 3/2012 (art. 10.2 letra a) de la Ley 11/2013).

${ }^{74}$ Véase la Resolución de 1 de agosto de 2013, del Servicio Público de Empleo Estatal, por la que se determina la forma y plazos de presentación de solicitudes y de tramitación de las ayudas económicas de acompañamiento incluidas en el programa de recualificación profesional de las personas que agoten su protección por desempleo prorrogado por el Real Decreto-ley 1/2013, de 25 de enero (BOE núm. 196, de 16 de agosto de 2013).

${ }^{75} \mathrm{Se}$ supone que uno de los aspectos que más se han criticado a nivel europeo es el excesivo recurso a la temporalidad en el empleo de los más jóvenes. Y es que con frecuencia se emplea esta vía de forma abusiva, gracias al concierto de condiciones laborales precarias.

${ }^{76}$ Recordemos que los contratos coyunturales no responden a una necesidad organizativa o productiva de la empresa, sino que su finalidad es el fomento del empleo. Hasta hoy día, los únicos contratos temporales coyunturales que encontrábamos en nuestro ordenamiento jurídico son los previstos por el art. 15 de la Ley 44/2007, de 13 de diciembre, para la regulación del régimen de las empresas de inserción (BOE núm. 299 de 14 de diciembre de 2007), modificado por la Ley 27/2009, de 30 de diciembre, de medidas urgentes para el mantenimiento y el fomento del empleo y la protección de las personas desempleadas (BOE núm. 315 de 31 de diciembre de 2009). 
un máximo de tres meses cuando, por el contrario, el rótulo de este precepto específicamente indica que la finalidad es la obtención de un "primer empleo". Ello plantea el interrogante de si en vez de hablar de "experiencia laboral" tenía el legislador de 2013 que haber seguido el mismo sentido que expresa el RD 1543/2011 de 31 de octubre, al regular las prácticas no laborales a jóvenes ${ }^{77}$ y diferenciar así entre los conceptos de "experiencia laboral" y "experiencia profesional" (LLEÓ CASANOVA, 2013, p. 3-4).

Se trata por tanto, de un contrato temporal propio con las excepciones establecidas por el art. 15.1 b) ET y que consta de una duración mínima de tres meses y una máxima de seis meses, ampliable a 12 meses cuando así se establezca por convenio colectivo sectorial -art. 12.2 de la Ley 11/2013- (LLEÓ CASANOVA, 2013, p. $10)^{78}$. Ahora bien este contrato podrá transformarse en indefinido al término del periodo mínimo de tres meses (SEMPERE NAVARRO, 2013, p. 3) ${ }^{79}$, lo que otorgará a la empresa ciertas bonificaciones en las cuotas empresariales a la Seguridad Social ${ }^{80}$.

Ciertamente, para alcanzar el objetivo que se pretende de "mejora de la empleabilidad en los jóvenes" no basta, en mi opinión, con esa breve duración de tiempo, sino que sería preciso que esa primera toma de contacto se ajustara al objetivo último de obtención de una formación profesional acreditable en los términos del RD 1224/2009 de 17 de julio, de reconocimiento de las competencias profesionales adquiridas por experiencia laboral (BOE núm. 205, de 25 de agosto de 2009) en desarrollo de la LO 5/2000 de 19 de julio, de las Cualificaciones y de la Formación Profesional (LLEÓ CASANOVA, 2013, p. 8-11). De igual modo, no pienso que pueda fomentarse la creación de empleo estable y de calidad para los jóvenes copiando las mismas fórmulas contractuales temporales existentes a día de hoy por el ET. Resul-

${ }^{77}$ Véase RD 1542/2011, de 31 de octubre por el que se regulan las prácticas no laborales en empresa (BOE núm. 278, de 18 de noviembre de 2011). Art. 1: "El presente real decreto regula las prácticas no laborales en empresas o grupos empresariales... dirigidas a personas jóvenes que, debido a su falta de experiencia laboral, tengan problemas de empleabilidad". Art. 3.1: "Las prácticas no laborales irán dirigidas a personas jóvenes desempleadas inscritas en la oficina de empleo, con edades comprendidas entre 18 y 25 años inclusive, que... no deberán haber tenido una relación laboral u otro tipo de experiencia profesional superior a tres meses en la misma actividad...".

${ }^{78}$ Para esta autora resulta incomprensible cómo mientras que en las prácticas no laborales en empresa la duración máxima es de nueve meses, en el tipo contractual establecido por el art. 12.2 la duración del contrato es inferior, a pesar de que la finalidad en ambas es la misma, esto es, la adquisición de una primera experiencia profesional en donde no se tiene en cuenta el nivel de cualificación del joven.

79 "El contrato es ciertamente un periodo de prueba ampliado...".

${ }^{80}$ Véase art. 12. 4 de la Ley 11/2013: "Las empresas..., que, una vez transcurrido un plazo mínimo de tres meses desde su celebración, transformen en indefinido los contratos a que se refiere este artículo tendrán derecho a una bonificación en las cuotas empresariales a la Seguridad Social... durante tres años". 
tará, por consiguiente, necesario que el legislador frene los actuales abusos a los que se encuentran sometidos los jóvenes mediante la imposición de medidas correctoras y limitadoras. De lo contrario, las cifras de trabajo precario se mantendrán y alzarán de manera estrepitosa en nuestro país.

En quinto lugar y como novedad, el art. 13 de la Ley 11/2013 ha modificado el régimen previsto para los contractos en práctica por el art. 11.1 del ET. Así pues, de un lado se ha elimina el límite temporal (de 5 años de manera general o de 7 en caso de discapacitados) para la obtención del título o certificado de profesionalidad habilitante para el desempeño del contrato en prácticas por menores de 30 años y de otro lado se ha concedido a los empresarios una bonificación del 50\% de la cuota empresarial por contingencias comunes durante la vigencia del contrato de trabajo. Ahora bien cuando se trate de trabajadores que al tiempo de dicha contratación estuviesen realizando prácticas no laborales en la empresa, la reducción será del 75\% (art. 13.2, Ley 11/2013) ${ }^{81}$. En el caso de que el contrato se formalice con personas beneficiarias del Sistema Nacional de Garantía Juvenil, se aplicará de forma adicional una bonificación del $50 \%$ cuando se contraten en prácticas a jóvenes menores de 30 años, aplicándose una reducción del 25 en la cuota empresarial a la Seguridad Social por contingencias comunes correspondiente al trabajador contratado durante toda la vigencia del contrato (medida que resultará aplicable a todas aquellas contrataciones que se efectúen hasta el 30 de junio de 2016) ${ }^{82}$.

En sexto lugar, se incorporan una serie de incentivos a la contratación de jóvenes en entidades de economía social (art. 14). Constituyen éstas bonificaciones a las cuotas empresariales de la Seguridad Social aplicables: a) a las cooperativas o sociedades laborales que incorporen trabajadores desempleados menores de 30 años como socios trabajadores o de trabajo y; b) a las empresas de inserción cuando dichos contratos sean subscritos por personas menores de 30 años en situación de exclusión social incluidas en el art. 2 de la Ley 44/2007, de 13 de diciembre, para la regulación del régimen de las empresas de inserción, en caso de contratación indefinida. Bonificaciones que no serán compatibles con las previstas en el art. 16.3 a) de la Ley 44/2007, de 13 de diciembre.

En lo que se refiere a los contratos para la formación y aprendizaje, la Ley 11/2013 ha modificado la prohibición que se establecía por el art. 10.2 de la Ley 14/1994 de 1 de junio ${ }^{83}$, al permitir ahora que las Empresas de Trabajo Temporal (ETTs) puedan celebrar estas fórmulas de contratación a las que antes no tenían ac-

${ }^{81}$ Téngase en cuenta también la Disposición final segunda de esta Ley 11/2013, por la que se modifica el art. $11.1 \mathrm{c}$ ) del ET para el contrato en prácticas.

${ }^{82}$ Nuevo apartado añadido por el Párrafo final del número 2 del artículo 13 introducido por el apartado tres del artículo 108 del R.D.-ley 8/2014, de 4 de julio, de aprobación de medidas urgentes para el crecimiento, la competitividad y la eficiencia («B.O.E.» 5 julio).

${ }^{83}$ Ley por la que se regulan las Empresas de Trabajo Temporal (BOE núm. 131, de 2 de junio de 1994). 
ceso. De este modo las ETTs podrán poner a disposición de una empresa usuaria a trabajadores contratados para la formación y aprendizaje conforme a lo previsto en el art. 11.2 del ET (Disposición adicional tercera y cuarta) ${ }^{84}$, pudiendo además beneficiarse de las bonificaciones y reducciones previstas para el primer empleo joven en el art. 12 de esta ley (Disposición adicional quinta). Por lo que la empresa usuaria actuará como si fuese la empleadora desde el inicio (SEMPERE NAVARRO, 2013, p. 4).

También se han previsto por la Ley 11/2013 una serie de medidas para la mejora de la intermediación laboral ${ }^{85}$ y seguimiento y evaluación de la Estrategia de Emprendimiento y Empleo Joven a través de la creación de una Comisión Interministerial ${ }^{86}$.

Finalmente, en el ámbito de la Comunidad Autónoma de Andalucía ${ }^{87}$ y con motivo del reparto de competencias entre Estado y CCAA (arts. 149.1.7 y 149.1.13 ${ }^{\mathrm{a}}$ Constitución Española), el Gobierno Andaluz junto a los Agentes Económicos y Sociales más representativos han consensuado el establecimiento de un listado de medidas para hacer frente al notable crecimiento de la inseguridad laboral y del desempleo juvenil ${ }^{88}$. Todo ello, por supuesto, en el marco del Acuerdo para el Progreso Económico y Social de Andalucía. Lo que finalmente ha motivado, como ya se ha dicho, la publicación del Decreto-Ley 8/2013, de 28 de mayo, de Medidas de Creación de Empleo y Fomento del Emprendimiento, convalidado por Resolución de 28 de junio del 2013. Normativa que viene a constituir fiel reflejo de las leyes 11/2013 y 14/2013 adoptadas a nivel estatal.

En esta normativa, principalmente, se pueden encontrar tres bloques de medidas: 1) aquellas que tienen por finalidad contribuir al empleo; 2) las que favore-

${ }^{84}$ Y también, por supuesto, en el RD 1529/2012, de 8 de noviembre, antes citado.

${ }^{85}$ Véase el Título I, Capítulo IV. Las medidas consisten, básicamente, en: a) la subscripción de acuerdos marco entre los servicios públicos de empleo y las entidades empresariales para la contratación de servicios que faciliten la intermediación laboral y b) la creación de un portal único de empleo, como garantía de transparencia y unidad de mercado.

86 Ver la Disposición Adicional segunda de la Ley 11/2013.

87 Véase el artículo 9 y $10.3 .1^{\circ}$ del Estatuto de Autonomía para Andalucía (Ley Orgánica 2/2007 de 19 de marzo).

${ }^{88}$ A este respecto, en su sesión de 12 de febrero de 2013 la Junta de Andalucía ha aprobado una serie de programas específicos que actuarán como plan de choque: 1) El Plan de Oportunidades Laborales de Andalucía (OLA); 2) Generación de empleo verde; 3) Plan de Fomento del Empleo Agrario 2013; 4) Plan extraordinario de Acción Social; 5) Programa de Promoción del Empleo Autónomo; 6) Programa de incentivos para el Fomento de la Innovación y el Desarrollo empresarial de Andalucía; y 7) Programa de Suelo Productivo. En lo que se refiere específicamente a la actividad emprendedora, el Instituto Andaluz de la Juventud ha creado los siguientes programas: a) el formativo en empleabilidad; b) la Escuela de Emprendedores; y 3) el Portal de Emancipación. 
cen la inversión productiva generadora de empleo y; 3 ) aquellas que tienen por objetivo el reforzamiento de las políticas activas de empleo y la mejora de los servicios de las oficinas de empleo del Servicios Andaluz de Empleo. De entre las líneas de actuación destinadas a incentivar el empleo juvenil destacan: a) el Programa Bono de Empleo Joven (Título II); b) el Programa de Apoyo y Fomento del Trabajo Autónomo (Título III); c) el programa de Apoyo a la Economía Social (Título IV), entre las que se encuentra, las Acciones de Fomento para las personas Emprendedoras menores de 35 años (línea 2) ${ }^{89}$ y; d) el Programa de Becas de Internalización para titulados superiores de formación profesional (Título V).

\section{Conclusiones}

A finales de la primera década de este siglo se produjo una grave crisis económica y financiera a nivel mundial. Obviando las causas y las pertinentes responsabilidades, son los efectos de la misma los que suponen el presente de la política social e internacional. El término más temido, pero a la vez más remarcable es el desempleo. Toda la UE ha sido azotada con esta lacra, lo que ha puesto en peligro la estabilidad política de la eurozona y su cohesión social. Como en toda crisis, los estamentos más débiles han sido los más perjudicados, especialmente la porción poblacional que incluye a los jóvenes. Aunque hay que reseñar, que si bien es cierto que todos los estados miembros han visto peligrosamente aumentado el paro juvenil, no todos han sufrido esta situación con la misma magnitud, lo que a la postre ha abierto comprometedoras grietas entre países que han corrido diferente suerte en este asunto.

La universalidad del problema ha suscitado una enorme preocupación a nivel comunitario, que ha tenido su respuesta en la adopción de diversas estrategias coordinadas entre los países miembros. Los máximos responsables europeos han llegado a una conclusión inevitable; una Europa cada vez más envejecida no puede darse el lujo de perder una generación completa de jóvenes formados, puesto que el porvenir de nuestras naciones ha de escribirse con sangre nueva. En este sentido la UE ha decidido poner en práctica una serie de medidas de choque contra el desempleo juvenil y su precariedad laboral. A la enorme masa de jóvenes desemplea-

${ }^{89}$ Busca sobre todo solventar las perentorias dificultades que encuentran los jóvenes empresarios para acceder al crédito de las entidades financieras dada la escasez o indisponibilidad crediticia, con el objetivo de fomentar la creación y mantenimiento del empleo. Algunas de las ayudas más destacadas que se han creado por la Junta de Andalucía son estas: 1) Fondo reembolsable para los trabajadores autónomos (FORAN-Empleo Autónomo); 2) Apoyo a la primera contratación del autónomo/autónoma; 3) Incentivos para trabajadores por cuenta propia; 4) Actuaciones dirigidas a emprendedores y empresarias; 5) incentivos para el autoempleo y créditos blandos; 6) Programas de Apoyo a la Economía Social: Fomento del Emprendimiento Social; 7) Programa de apoyo y fomento del trabajador autónomo; 8) Apoyo a la iniciativa empresarial joven en Andalucía...etc. 
dos hay que añadir a aquellos otros que conforman el colectivo "ni-ni”. Este último grupo se compone de personas que han perdido el rumbo en el panorama laboral y que con excesiva frecuencia incluye a jóvenes que han abandonado los estudios por varios motivos, pero entre los que se debe subrayar una fuerte desmotivación. Sin embargo, el más lamentable de los casos es el representado por los trabajadores precarios. Deplorable es el término que mejor define la realidad de este último colectivo, pues los términos y contratos de prácticas y aprendizaje, generalmente conocidos como temporales, con los que se inserta a los jóvenes al mercado laboral son sinónimo de abuso.

Concretamente la UE, aparte de las iniciativas generales ya comentadas, ha desarrollado la Estrategia para la Garantía del Empleo Juvenil, de aplicación obligatoria para aquellos estados miembros con una tasa de desempleo juvenil superior al 25\%. Por triste que pueda ser, España está incluida entre los estados que cumplen este dudoso mérito. Con este fin se ha puesto a disposición de estos países los fondos comunitarios, destinados a la creación de empleo de los más jóvenes, formación profesional y prevención de abandono escolar.

Siguiendo estas directrices se ha publicado en España la "Estrategia de Empleo 2012-2014", que pretende implantar un plan de medidas que garanticen la estabilidad en el empleo, el progreso económico y social y la igualdad de oportunidades. A pesar de que se han aprobado numerosos instrumentos normativos a nivel estatal, los más destacados son sin duda, la Ley 11/2013 de apoyo al emprendedor y de estímulo de crecimiento y de la creación de empleo y la Ley 14/2013 de apoyo a los emprendedores y su internacionalización. Y siguiendo su estela la Junta de Andalucía ha dictado el Decreto-Ley 8/2013 y ha acordado con las fuerzas sociales la adopción de una serie de medidas de creación de empleo y fomento del emprendimiento. Todas ellas son normativas muy heterogéneas, en las que se recogen entre otras una serie de incentivos de carácter fiscal y laboral, que van dirigidos a facilitar la creación de empresas por parte de los menores de 30 años o a fomentar su contratación por empresas ya constituidas.

Toda medida y actuación político-legislativa que busque una salida a la situación que se vive debe darse por bienvenida y ya habrá tiempo de corregir y adaptarse a la realidad. Es por ello que la enseñanza que contempla la normativa del emprendimiento deba resultar de inmediata implantación a todos los niveles educativos (Primaria, Secundaria, FP, Bachillerato) a fin de que cumpla sus objetivos y evite la cruda realidad que azota el mercado laboral. Y es que el desalentador exilio al que muchos jóvenes (incluidos los más preparados y capaces) se ven obligados a someterse al tener que emigrar a otros países en busca de oportunidades constituye, hoy día, un hecho cada vez más frecuente.

Pese a las buenas intenciones de las disposiciones de autoempleo, éstas adolecen de los mismo males que acucian al régimen jurídico del RETA. ¿Por qué? Porque para redactar la Ley de emprendedores el legislador se ha limitado a copiar 
de manera descarada, eso sí incorporando incentivos que actúen como incitadores, los mismos esquemas previstos actualmente para los trabajadores por cuenta propia. No se puede esperar nada mejor de lo que ya estamos presenciando diariamente en nuestro anquilosado mercado laboral. La aparición de "falsos autónomos" será un problema tan común con esta normativa como lo ha sido y sigue siendo en el RETA. No transcurrirá mucho tiempo para que surjan fraudes tan elementales como el representado por trabajadores asalariados que sean obligados por despóticos empresarios a darse de alta como trabajadores autónomos para eludir el pago de las cotizaciones a la Seguridad Social. Por otro lado, los casos de abusos a trabajadores autónomos económicamente dependientes, que en realidad no sean tales, sino simples trabajadores por cuenta ajena anegarán con suma facilidad el panorama laboral español. En este sentido, cabe preguntarse: ¿no estaremos asistiendo a un cambio sutil y soterrado del modelo de sistema de la Seguridad Social en el que predomine el régimen especial del RETA en detrimento del Régimen General de la Seguridad Social, con las consecuencias que ello conlleva?

En lo que respecta a las medidas de estímulo de empleo en las empresas se observa cómo se han incrementado los contratos temporales, en lugar de la contratación indefinida, lo cual es contrario a la razón de existencia misma de la Garantía Juvenil de la UE y a la exposición de motivos de la las leyes de emprendedores. Efectivamente, si el fin que persigue la UE es incentivar la el mantenimiento del empleo de los jóvenes, claramente se puede afirmar que este objetivo no se ha conseguido, pues todo ese conjunto de bonificaciones temporales no logrado todavía modificar la cultura empresarial española. Los contratos temporales más notables son el contrato a tiempo parcial, el contrato de primer empleo joven, el contrato en prácticas y el contrato para la formación y aprendizaje:

- El contrato a tiempo parcial ofrece las mismas condiciones previstas por el ET, con el consecuente predominio del empleo sobre la formación. Así tomará el papel de mero elemento de inserción ocupacional de jóvenes al ámbito laboral, favoreciendo el abuso sobre los mismos, tal y como sucede en la práctica hoy día.

- El contrato de primer empleo joven no es más que una mascarada, que oculta la realidad de su naturaleza. Bajo este término de contrato de primer empleo joven se esconde lo que normalmente se conoce como periodo de prueba, con lo que se favorece que las empresas produzcan la rotación en un mismo puesto de trabajo, deshaciéndose de cada "contratado" al término de este contrato temporal.

- El contrato en prácticas es igual al recogido en el ET, pero sin imponer límites que eviten el encadenamiento entre contratos temporales, concretamente entre el de formación y aprendizaje y el de prácticas, ya que el certificado de profesionalidad que se adquiere con el primero permite el 
acceso al segundo. En este caso los jóvenes profesionales se convierten en marionetas de la empresa o empresas correspondientes, entrando en una enloquecedora y funesta espiral en la que su vida laboral será, en el mejor de los casos, un rico compendio de contratos temporales.

- El contrato para la formación y aprendizaje está sujeto a las mismas condiciones del ET, sólo que en este caso se permite que las ETTs puedan concertar esta fórmula contractual, mecanismo al que no tenían acceso previamente. Además se concretan algunos aspectos de distribución de obligaciones de formación derivadas del marco de relaciones triangulares puestas en funcionamiento en virtud del contrato de puesta a disposición.

En definitiva, las leyes de emprendedores producidas a nivel estatal y autonómico en España como consecuencia de la Estrategia de Garantía Juvenil elaborada por la UE son elementos jurídicos interesantes que pretenden alcanzar objetivos loables, pero que cuentan con las mismas lagunas características de la normativa laboral vigente en España. Muy a nuestro pesar no parece que vayan a tener repercusiones positivas, sino que va a incrementar la precariedad laboral juvenil y la temporalidad en el empleo de uno de los sectores más indefensos y vulnerables de nuestra población activa. El futuro de nuestra sociedad será tan bueno como el trato que demos a las generaciones llamadas a sostener nuestra realidad social.

\section{Bibliografía}

AARAGÓN GÓMEZ, C (2014). Una aproximación al cuadro actual de incentivo al empleo, haciendo especial referencia a la tarifa plana en la cotización a la Seguridad Social. En García-Perrote Escartín, I y Mercader Uguina, J.R. Las reformas laborales y de Seguridad Social de la Ley 11/2013 de 26 de julio al Real Decreto-Ley 3/2014, de 28 de febrero. Pamplona: Lex Nova- Thomson Reuters.

HERNÁNDEZ BEJARANO, M (2013). La inserción de los jóvenes en el mercado laboral: un difícil reto para las políticas activas de empleo. En Cabeza Pereiro, J y Fernánez Prol, F (Coordinadores). Políticas de Empleo. Navarra: Thomson Reuters Aranzadi, Universidad de Vigo y Xunta de Galicia.

LLEÓ CASANOVA, B (2013). Novedades en materia de contratación laboral introducidas por el RD-Ley 4/2013, de 22 de febrero, de medidas de apoyo al emprendedor y de estímulo del crecimiento y de la creación de empleo. Revista General de Derecho del Trabajo y de la Seguridad Social, n 34, 2013.

MENGER, A (2004). El Estado democrático del trabajo, edición y estudio preliminar, "Derechos sociales y Estado democrático en Anton Menger", a cargo de J. L. Monereo Pérez. Granada: Ed. Comares.

MONEREO PÉREZ, J.L (2013). Nuevos contenidos de la Negociación Colectiva y 
límites legales de los mismos, con particular atención a la jubilación obligatoria y al periodo de prueba. Temas Laborales, monográficos sobre los efectos de la reforma laboral en la negociación colectiva, $\mathrm{n}^{\mathrm{o}} 120$.

MONEREO PÉREZ, J.L (2009). La política de empleo como instrumento para la lucha contra la precariedad laboral. Albacete: Bomarzo.

MONEREO PÉREZ, J.L; MOLINA NAVARRETE, C y MORENO VIDA, M ${ }^{\mathrm{a}} \mathrm{N}$ (2013). Manual de Derecho del Trabajo. Granada: Comares.

O'HIGGINS, N (2001). Desempleo juvenil y políticas de empleo. Una perspectiva global. Madrid: Colección Informes OIT núm. 54.

RODRÍGUEZ-PIÑERO Y BRAVO-FERRER, M y CASAS BAAMONDE, M.E (2014). El uso del Decreto Ley como instrumento de las reformas laborales. La garantía juvenil y la tarifa plana para el fomento del empleo y la contratación indefinida. Relaciones Laborales, $\mathrm{n}^{\circ} 4$.

SEMPERE NAVARRO, A (2013). Novedades Legislativas: Ley 11/2013, de 26 de julio, de medidas de apoyo al emprendedor y de estímulo del crecimiento y de la creación de empleo. Noticias Breves: Julio de 2013.

SIERRA BENÍTEZ, E.M (2013). Las medidas urgentes para la reforma del mercado laboral: aspectos laborales tras la promulgación de la Ley 3/2012. En VV.AA. Economía Española y Protección Social. Madrid: Asociación de Actuarios, Estadísticos y Economistas de la Seguridad Social.

SUÁREZ CORUJO, B (2014). Modalidades contractuales para jóvenes desde el paradigma de la precariedad. En García-Perrote Escartín, I y Mercader Uguina, J.R (Directs). Las reformas laborales y de Seguridad Social de la Ley 11/2013, de 26 de julio al Real Decreto-ley 3/2014, de 28 de febrero. Pamplona: Lex Nova- Thomson Reuters.

MONEREO ATIENZA, C y MONEREO PÉREZ, J.L (2012): La Europa de los Derechos. Estudio sistemático de la Carta de los Derechos Fundamentales de la Unión Europea. Granada: Comares.

VV.AA (2007). Empleo Juvenil en España. Madrid: Ministerio de Trabajo y Asuntos Sociales. 



\title{
2
}

LA DESLEALTAD EN LAS COMUNICACIONES COMERCIALES

\author{
The faithlessness in the commercial communications
}

\section{Eva Cordobés Millán}

Doctora en Derecho con Mención Europea en el título de Doctora por la Universidad de Barcelona y abogada en ejercicio en el despacho Iusta Causa, S.L. E-mail: evaalcanar@hotmail.com

\section{RESUMEN}

La definición del concepto de "prácticas comerciales con los consumidores y usuarios" se encuentra en el inciso segundo del art. 19.2 TRLGDCU y se identifica con todo acto, omisión, conducta, manifestación o comunicación comercial, incluida la publicidad y la comercialización. De ahí la relevancia de delimitar qué debemos entender por comunicación comercial. Para poder analizar las comunicaciones comerciales desde su deslealtad hacia el consumidor y usuario resulta imprescindible delimitar el término mediante el examen de la normativa reguladora de las comunicaciones comerciales europea (Libro Verde sobre las comunicaciones comerciales en el Mercado Interior y Directiva sobre el comercio electrónico) y nacional (LODC y LSSICE, entre otras). Asimismo, resulta necesario diferenciar los dos grandes tipos de comunicaciones comerciales existentes en la praxis: las comunicaciones comerciales electrónicas y las no electrónicas. Tras un estudio legislativo, complementado con estudios doctrinales y jurisprudenciales, de ambas tipologías de comunicaciones nos centramos en la deslealtad de las comunicaciones comerciales electrónicas. Se destaca, dedicando gran parte expositiva del presente estudio, la práctica comercial desleal regulada en el art. 29 LCD. Ello es así porque el mencionado precepto regula las prácticas comerciales agresivas por acoso efectuadas por medios a distancia, supuesto de hecho idéntico al previsto por la LSSICE. Por este motivo, emerge un especial interés en observar las conexiones y, especialmente, la autonomía funcional y aplicativa de ambas normativas. Finalmente, mediante la STJUE de 12 de mayo de 2011 (asunto C-122/10) analizamos las comunicaciones comerciales electrónicas engañosas, en este caso, por omisión de información.

Palabras clave: Práctica comercial desleal. Comunicación comercial. Tutela DEL CONSUMIDOR. 


\section{Abstract}

The definition of the concept of "commercial practices with consumers and users" can be found in the second record of the article 19.2 TRLGDCU and is defined as every commercial act, omission, behavior, manifestation or communication, including advertising and merchandising. Hence the importance of delimiting what has to be meant by commercial communication. To be able to analyze the commercial communications by the point of view of their untrustworthiness towards the consumer and the user it is essential delimiting the meaning of the word by means of the examination of both the European regulation of the commercial (the Green Book on the commercial communications in the internal market and the Directive on electronic commerce) and the national one (LODC and LSSICE among others). In the meanwhile, it is necessary to differentiate the two great kinds of commercial communications actually used: the electronic commercial communications and the non-electronic ones. After having conducted a legislative analysis, supported by several doctrinarian and jurisprudential studies, we will focus on the untrustworthiness of the electronic commercial communications. We will particularly highlight, devoting to it the greatest part of this study, the commercial unfair practice that is regulated by the article $29 \mathrm{LCD}$. This is so because the aforementioned article regulates the aggressive commercial practices in the case of harassment brought about through electronic media, a situation identical to the one regulated by the LSSICE. For this reason it emerges a special interest in the observation of the connections and, especially, of the functional and ruling autonomy of the two precepts. Finally, through the STJUE of 2011, May the 12 (record C-122/10) we analyze the untrustworthy electronic commercial communications whose untrustworthiness in caused, this time, by an omission of information.

KeYWords: COMMERCIAL UNFAIR PRACTICES. COMMERCIAL COMMUNICATIONS. CONSUMER PROTECTION.

SUMARIO: Introducción. 1. El concepto "amplio" de comunicación comercial. 1.1. Comunicaciones comerciales no electrónicas. 1.2. Comunicaciones comerciales electrónicas. 1.2.1. Régimen jurídico de las comunicaciones comerciales electrónicas: LSSICE. 2. Comunicaciones comerciales desleales agresivas per se: artículo 29 de la Ley de Competencia Desleal. 3. Sentencia del Tribunal de Justicia de la Unión Europea sobre comunicaciones comerciales y prácticas desleales engañosas. 3.1. Cuestiones prejudiciales planteadas 4. Conclusiones. Bibliografía. 


\section{INTRODUCCIÓN}

La incorporación al Ordenamiento español de la Directiva de 11 de mayo de 2005, relativa a las prácticas comerciales desleales de las empresas en sus relaciones con consumidores (DPCD) modificó, entre otros textos legales, la Ley 3/1991, de 10 de enero, de Competencia Desleal (LCD). En relación con los cambios incorporados en esta última, cabe destacar como principal novedad la regulación de ciertas prácticas desleales que tienen como únicos destinatarios a consumidores y usuarios. Estas prácticas pueden clasificarse en dos categorías: prácticas abusivas y prácticas engañosas.

Dentro de las prácticas abusivas, nos limitaremos al análisis de las que se denominan "prácticas agresivas por acoso", concretamente, las que se refieren a la realización reiterada de propuestas comerciales no deseadas por medios telefónicos, electrónicos y cualquier otro medio de comunicación a distancia (art. 29.2 LCD). En la última década, debido al perfeccionamiento de nuevos medios tecnológicos, en especial, la utilización de Internet ha supuesto un nuevo marco económico donde desarrollar las técnicas de publicidad. Las empresas consideran esencial darse a conocer a través de las nuevas tecnologías. Para ello, no sólo crean páginas web, sino que recurren a otros medios interactivos como el banner, los links, microsites y las comunicaciones comerciales electrónicas. En este trabajo, nos centramos a éstas últimas debido a su mayor complejidad y la generalización del uso del correo electrónico. La práctica agresiva por acoso recogida en el art. 29.2 LCD "se entenderá sin perjuicio de lo establecido en la normativa vigente sobre servicios de la sociedad de la información" (art. 29.2.4 LCD), que se aplicará cuando el acceso dependa del tratamiento de información personal. Es decir, mientras la LSSICE tutela la esfera personal del consumidor, la LCD prohíbe el acceso reiterado del profesional de comunicaciones comerciales. La diversidad del objeto perseguido por ambas normas es la razón en la que descansan los distintos presupuestos de ilicitud.

Las prácticas comerciales engañosas, se analizarán a partir del estudio de la STJUE de 12 de mayo de 2011 (asunto C-122/10). Concretamente, se estudian varias cuestiones prejudiciales planteadas al TJUE en materia de comunicaciones comerciales electrónicas. Concretamente, se destaca el estudio del término "invitación a comprar" y de la "información sustancial" que debe facilitar el empresario a los consumidores en los casos en que existe una invitación a comprar.

\section{EL CONCEPTO “AMPLIO" DE COMUNICACIÓN COMERCIAL}

Las comunicaciones comerciales se definen como práctica comercial de las empresas en relación con los consumidores (cfr. art. 19.2 TRLGDCU).

A nivel comunitario, la Comisión define en su Libro Verde sobre las comunicaciones comerciales en el Mercado Interior, de 23 de mayo de 1996, la comunicación comercial como "todo tipo de publicidad, marketing directo, patrocinio, promoción de ventas y relaciones públicas destinadas a promocionar los productos 
o servicios". Asimismo, el art. 2.f) de la Directiva 2000/31/CE del Parlamento Europeo y del Consejo, de 8 de junio, relativa a determinados aspectos jurídicos de los servicios de la sociedad de la información, en particular el comercio electrónico en el mercado interior (Directiva sobre el comercio electrónico), define a las comunicaciones comerciales como "todas las formas de comunicación destinadas a proporcionar ${ }^{90}$ directa o indirectamente bienes, servicios o la imagen de una empresa, organización o persona con una actividad comercial, industrial, artesanal o de profesiones reguladas".

La utilización del término "comunicación" en vez del clásico "publicidad" no es casual, sino que responde a la voluntad de ensanchar el concepto de referencia, propiciando así la regulación y el control de nuevos fenómenos promocionales. La definición ofrecida destaca como la finalidad de promoción que persiguen las comunicaciones puede ser no solo directa sino también indirecta evitando, de este modo, que sea posible interpretar la locución de manera restrictiva. En relación, se habla de promocionar, ya no el producto o servicio a comercializar sino la propia imagen de la empresa permitiendo que se incluyan diversas técnicas de marketing moderno, por ejemplo la edición de una memoria de responsabilidad social corporativa ${ }^{91}$ en la que se ponga de manifiesto un extraordinario comportamiento en materia de sostenibilidad. De hecho, la propia EM de la Directiva 2005/29/CE, del Parlamento Europeo y del Consejo de 11 de mayo de 2005, relativa a las prácticas comerciales desleales de las empresas en sus relaciones con los consumidores en el mercado interior (en adelante, DPCD) evidencia como la intención del legislador es englobar bajo la denominación genérica de prácticas todas aquellas "actuaciones" que, respondan o no al clásico concepto de comunicación o al más estricto de publicidad, tengan relación con la promoción del producto y, en definitiva, puedan afectar al comportamiento económico del consumidor medio ${ }^{92}$.

${ }^{90}$ La versión española de la Directiva tradujo erróneamente el término inglés promote por el de proporcionar, la noción correcta hubiera sido promocionar.

91 Álvarez (2008, p. 125) expone una gran variedad de ejemplos en los que las grandes empresas no se limitan a anunciar sus políticas de responsabilidad social corporativa en abstracto sino que concretan el alcance especifico de sus actuaciones. El autor nos presenta los siguientes anuncios: el anuncio de la fundación Telefónica en el diario El País, de 3 de noviembre de 2007, suplemento Babelia, p. 40, en el que explicita el número de beneficiarios directos e indirectos de su programa "Proniño", el número de países afectados o el número de voluntarios movilizados; el anuncio de Iberdrola Renovables publicado en el diario El País, de 17 de noviembre de 2007, p. 27, en el que se considera primera eólica del mundo en potencia instalada, con implantación en 19 países y capacidad de generar energía para más de 10 millones de personas y el anuncio del Grupo Liberty Seguros, diario El País, de 25 de noviembre de 2007, p. 27, en el que, como prueba del compromiso con el desarrollo sostenible, se afirma que es la primera empresa española que compensa el 100\% de las emisiones de $\mathrm{CO} 2$, que tiene un compromiso de reducir tales emisiones en un $6 \%$ anual.

${ }^{92}$ Piénsese, por ejemplo, en la inclusión de aquellas "informaciones" que puedan contribuir a que el consumidor tome una decisión sobre la transacción que no hubiera tomado de otra 


\subsection{COMUNiCACIONES COMERCIALES NO ELECTRÓNICAS}

En nuestro Derecho, las comunicaciones comerciales no electrónicas (envíos por correo ordinario, por ejemplo) deberán ser conformes a la Ley Orgánica 15/1999, de 13 de diciembre, de Protección de Datos de Carácter Personal (LOPD). $\mathrm{El}$ art. 30 de la Ley establece los requisitos necesarios para poder realizar tratamientos de datos personales con fines de publicidad y prospección comercial. Las dos únicas posibilidades de procedencia de los datos a utilizar con estos fines son: que los datos sean facilitados por los propios interesados o sean obtenidos con su consentimiento o que los datos figuren en fuentes accesibles al público (censo promocional; repertorios telefónicos; listas de personas pertenecientes a grupos de profesionales; Diarios y Boletines oficiales; medios de comunicación; cfr. art. 3.j) LOPD). En relación a lo expuesto, el art. 96 del Real Decreto Legislativo 1/2007, de 16 de noviembre, por el que se aprueba el texto refundido de la Ley General para la Defensa de los Consumidores y Usuarios y otras leyes complementarias (TRLGDCU), referente a las comunicaciones comerciales, especifica que cuando se utilicen datos procedentes de fuentes accesibles al público se proporcionará al destinatario la información que señala la LOPD (origen de los datos; la identidad del responsable del tratamiento así como de los derechos que le asisten, cfr. art. 5.5 LOPD) y, asimismo, se deberá ofrecer la posibilidad de poder oponerse a la recepción de las mismas.

En la legislación española, los propios arts. 4.7 LOPD y 8.1 RLOPD prohíben recoger y tratar datos por medios fraudulentos o desleales, estos últimos se identifican con conductas que disminuyen la percepción de la recogida y del tratamiento distorsionando (o siendo aptas para distorsionar) la decisión de autorización del tratamiento del consumidor o usuario. La prohibición de recoger y de tratar datos por medios fraudulentos o desleales se corresponde con el mandato de buena fe y de honradez en los tratos que se predica de las relaciones jurídicas privadas en general (cfr. art. 111-7 CCCat). Es decir, las conductas que se ajusten a la ley pero puedan interpretarse objetivamente como contrarias a la buena fe recibirán el mismo trato de ilicitud. En este sentido, sería desleal solicitar el consentimiento para tratar datos personales con fines ajenos al contrato cada vez que se usa el servicio contratado, si existen los medios para ello (LLÁCER, 2011).

\subsection{COMUNICACIONES COMERCIALES ELECTRÓNICAS}

Por su parte, las comunicaciones comerciales por vía electrónica se definen como un servicio de la sociedad de la información ${ }^{93}$. Los servicios de la sociedad

forma. Cfr. art. 6.1 DPCD: "Se considerará engañosa toda práctica comercial que contenga información falsa..." y el art. 7.1 DPCD: "Se considerará engañosa toda práctica comercial que (...) omita información sustancial...".

${ }^{93}$ Letra a) del anexo de la LSSICE: “(...) Son servicios de la sociedad de la información, 
de la información se conceptúan como aquellos servicios prestados normalmente a título oneroso, a distancia, por vía electrónica y a petición individual del destinatario. Con ello se entiende que existen cuatro aspectos importantes a considerar: los servicios de la sociedad de la información pueden ser onerosos o gratuitos; son servicios a distancia realizados a través de un medio electrónico; se requiere del almacenamiento de datos en un equipo electrónico como condición necesaria y por último, los sujetos que intervienen son como mínimo un "prestador de servicios" y un "destinatario de un servicio", según terminología acuñada por la mencionada Directiva 2000/31/ CE, de Comercio Electrónico (MORENO, 2002).

En relación, el legislador español define las comunicaciones comerciales en el Anexo f) de la Ley 34/2002, de 11 de julio, de servicios de la sociedad de la información y de comercio electrónico (LSSICE). Específicamente, establece que la comunicación comercial consiste en "toda forma de comunicación dirigida a la promoción directa o indirecta de la imagen o de los bienes o servicios de una empresa, organización o persona que realice una actividad comercial, industrial, artesanal o profesional" ${ }^{\prime 94}$. Por tanto, partimos de la premisa de que las comunicaciones comerciales son una forma más de realizar publicidad, de servicios o productos, y una forma de realizar prospección comercial. Como todo medio de publicidad tiene sus limitaciones, en cuanto a su contenido, el Anexo f) delimita su concepto excluyendo del mismo a: "los datos que permitan acceder directamente a la actividad de una persona, empresa u organización, tales como el nombre de dominio o la dirección de correo electrónico, ni las comunicaciones relativas a los bienes, los servicios o la imagen que se ofrezca cuando sean elaborados por un tercero y sin contraprestación económica".

Debe enfatizarse que la definición ofrecida destaca la finalidad promocional pero no incide en el destino individual o general de la comunicación. De este modo, no solo podemos encontrar comunicaciones comerciales dirigidas al público de los consumidores en abstracto sino, también, comunicaciones destinadas a un consumidor concreto ${ }^{95}$.

entre otros y siempre que representen una actividad económica, los siguientes: 4 . El envío de comunicaciones comerciales".

${ }^{94}$ Art. 111-2.s) de la Ley 22/2010, de 20 de julio, del Código de Consumo de Cataluña (C. Cons.Cat.) que describe las comunicaciones comerciales como "cualquier forma de comunicación dirigida a la promoción, directa o indirecta, de la imagen o de los bienes o servicios de una empresa, un establecimiento, una organización o una persona que realice una actividad económica con la finalidad de establecer relaciones de consumo".

${ }^{95}$ LLácer, 2011, pp. 62-92, estudia el régimen de las comunicaciones comerciales relacionado con su carácter personalizado, presente en leyes de consumo o sectoriales. La autora analiza el envío de la comunicación cuando presupone la selección de un individuo y la utilización de sus datos de contacto. Cfr. con el Grupo de Trabajo del artículo 29 en su Dictamen 2/2010, sobre publicidad comportamental en línea, adoptado el 22 de junio de 2010 (00909/10/ES, 


\subsubsection{Régimen jurídico de las comunicaciones comerciales electrónicas: LSSICE}

El régimen jurídico de las comunicaciones comerciales por correo electrónico u otros medios de comunicación electrónica equivalentes ${ }^{96}$ se regirá por su normativa específica. En el derecho español, encuentran su regulación en la LSSICE, tal y como se desprende del propio art. 1.1 $\mathrm{LSSICE}^{97}$ que dispone cómo las comunicaciones comerciales electrónicas entran dentro de su objeto de regulación que es el régimen jurídico de los servicios de la sociedad de la información y de la contratación por vía electrónica.

Concretamente, la LSSICE dedica a las comunicaciones comerciales por vía electrónica su Título III que bajo la rúbrica "Comunicaciones comerciales por vía electrónica" se desarrolla en los arts. 19 a $22 \mathrm{LSSICE}^{98}$. La aplicación preferente de la LSSICE se fundamenta en el art. 94.2 TRLGDCU: "Cuando lo dispuesto en este título entre en contradicción con el contenido de la normativa especifica sobre servicios de la sociedad de la información y comercio electrónico, ésta será de aplicación preferente, salvo lo previsto en el artículo 97.7, párrafo segundo".

GT 171), que clasifica la publicidad personalizada en comportamental, contextual y seleccionada. Todas ellas representan una selección del mensaje publicitario en función de características conocidas de un individuo.

${ }^{96} \mathrm{El}$ art. 111-2.t) C.Cons.Cat. define las comunicaciones comerciales electrónicas como toda "comunicación comercial transmitida por medio de equipamientos electrónicos de tratamiento y almacenamiento de datos conectados a una red de telecomunicaciones". El hecho de utilizar el correo electrónico para realizar comunicaciones publicitarias implica que toda comunicación publicitaria por correo electrónico es comunicación comercial pero no toda comunicación comercial, entendida en sentido amplio, tiene que ser necesariamente realizada por vía de correo electrónico. Así lo expresaba De La Cuesta, 1981, p. 893.

${ }^{97}$ Art. 1.1 LSSICE: "Es objeto de la presente Ley la regulación del régimen jurídico de los servicios de la sociedad de la información y de la contratación por vía electrónica, en lo referente a las obligaciones de los prestadores de servicios incluidos los que actúan como intermediarios en la transmisión de contenidos por las redes de telecomunicaciones, las comunicaciones comerciales por vía electrónica, la información previa y posterior a la celebración de contratos electrónicos, las condiciones relativas a su validez y eficacia y el régimen sancionador aplicable a los prestadores de servicios de la sociedad de la información". ${ }^{98} \mathrm{Si}$ el comercio electrónico es el término genérico para describir la manera en que las organizaciones negocian electrónicamente, Internet es sin duda la herramienta tecnológica de comunicación electrónica más conocida y de mayor potencialidad, si bien no la única, pues también existen Intranets, intercambio electrónico de datos (EDI) y tarjetas inteligentes, entre otros. Puede consultarse respecto a la extraordinaria expansión de las redes de telecomunicaciones y, en especial de Internet como vehículo de transmisión e intercambio de todo tipo de información, una ya abundante bibliografía española, entre la que cabe mencionar: Botana, 2001; Burgos y De León, 2001; Calvo y Carrascosa, 2001; Méndez y Vilalta, 2003 y Barral, 2003. 
Aunque, la LSSICE sea de aplicación preferente, el propio art. 19.1 LSSICE especifica que: "Las comunicaciones comerciales y las ofertas promocionales se regirán, además de por la presente Ley, por su normativa propia y la vigente en materia comercial y de publicidad". Por ello, la LSSICE no será la única normativa aplicable y deberá complementarse con otras, tales como la LOPD, y su normativa en cuanto a la obtención de datos personales, información de los interesados y la creación y mantenimiento de los ficheros de datos personales (cfr. art. 19.2 LSSICE). Asimismo, cuando estemos ante un contrato suscrito por vía electrónica ${ }^{99}$ (cfr. Título IV LSSICE) dado que son contratos a distancia ${ }^{100}$, las prescripciones de la LSSICE han de completarse con las contenidas en el Título III del TRLGDCU en materia de contratos celebrados a distancia. Además, deberá tenerse en cuenta la normativa sectorial aplicable a los contratos a distancia con consumidores, por ejemplo, la Ley 22/2007, de 11 de julio, sobre comercialización a distancia de servicios financieros destinados a los consumidores (cfr. art. 14 LCDSFC).

Las comunicaciones comerciales realizadas por correo electrónico, deberán cumplir, tres requisitos de forma: deberán identificarse como comunicaciones comerciales; deberán identificar a la persona física o jurídica que las realiza o en nombre de la que se realizan las mismas y deberán incluir la palabra "publicidad" (cfr. art. 20 LSSICE).

Se prohíbe, como regla general, el envío de comunicaciones comerciales publicitarias o promocionales por correo electrónico o por otro medio de comunicación electrónica equivalente cuando previamente no hayan sido solicitadas o expresamente autorizadas por los destinatarios de las mismas (cfr. art. 21.1 LSSICE). Excepcionalmente, se considerarán legítimas las comunicaciones realizadas a personas con las que el prestador de servicios de la sociedad de la información haya tenido una relación contractual previa, en la que haya procedido a recoger los datos lícitamente (conforme a la LOPD ${ }^{101}$ ) y utilice la comunicación comercial para publicitar o

${ }^{99}$ La LSSICE no define directamente el concepto de contratación electrónica, sin embargo, el Anexo h) señala que se entiende por "contrato celebrado por vía electrónica" o "contrato electrónico" a "todo contrato en el que la oferta y la aceptación se transmiten por medio de equipos electrónicos de tratamiento y almacenamiento de datos, conectados a una red de telecomunicaciones". La contratación por vía electrónica se regula en el Título IV de la LSSICE (arts. 23 a 29 LSSICE).

${ }^{100}$ El contrato a distancia es definido en el art. 2 de la Directiva 97/7/CE del Parlamento Europeo y del Consejo de 20 de mayo de 1997, relativa a la protección de los consumidores en materia de contratos a distancia, como "todo contrato entre un proveedor y un consumidor sobre bienes o servicios celebrado en el marco de un sistema de ventas o de prestación de servicios a distancia organizado por el proveedor que, para dicho contrato, utiliza exclusivamente una o más técnicas de comunicación a distancia hasta la celebración del contrato, incluida la celebración del propio contrato".

${ }^{101}$ Destacamos la importancia que en la LOPD adquieren los requisitos de consentimiento libre, inequívoco, específico e informado y de seguridad de los datos incluidos en nuestros 
promocionar productos o servicios de su propia empresa que sean similares a los que inicialmente fueron objeto de contratación con el cliente ${ }^{102}$. Ahora bien, tal y como prosigue el precepto, tanto en el momento de recogida de los datos como en cada una de las comunicaciones comerciales que le dirija, se deberá ofrecer al destinatario la posibilidad de oponerse al tratamiento de sus datos con fines promocionales mediante un procedimiento sencillo y gratuito (cfr. art. 21.2 LSSICE).

La regulación de las comunicaciones comerciales termina con el art. 22 LSSICE en el que se recoge el derecho de revocación del consentimiento prestado por el destinatario para el envío de comunicaciones comerciales. Este derecho de revocación exige la adopción por los prestadores de servicios de la sociedad de la información de procedimientos sencillos para que se pueda ejercitar la revocación. Procedimientos que deberán ser accesibles a los usuarios por medios electrónicos y gratuitos.

La solución judicial de los conflictos que se presenten en la configuración de servicios de la sociedad de la información y de comercio electrónico se halla en el Capítulo I del Título V de la LSSICE. Particularmente, el art. 30 LSSICE regula la posibilidad de ejercer la acción de cesación. Al respecto se indica que podrá interponerse ésta contra las conductas contrarias a esta Ley que lesionen intereses colectivos o difusos de los consumidores. Dicha acción se dirige a obtener una sentencia que condene al demandado a cesar en la conducta contraria a esta Ley y a prohibir su reiteración futura. También podrá ejercitarse para prohibir la realización de una conducta si ésta finalizó al tiempo de ejercitar la acción, si existen indicios suficientes que hagan temer su reiteración de manera inminente. Esta acción se ejercerá conforme al art. 452 de la LEC. La solución extrajudicial de los conflictos se encuentra reglamentada en el Capítulo II del mismo Título, concretamente el art. 32 LSSICE indica que el prestador y el destinatario de servicios de la sociedad de la información podrán someter sus conflictos a los arbitrajes previstos en la legislación de arbitraje y de defensa de los consumidores y usuarios, y a los procedimientos de resolución extrajudicial de conflictos que se instauren por medio de códigos de conducta u otros instrumentos de autorregulación (al respecto, cfr. disposición adicional tercera LSSICE relativa al Sistema Arbitral de Consumo).

ficheros de datos personales (cfr. art. 3.h) LOPD). En consecuencia, el consentimiento, además de previo, específico e inequívoco, deberá ser informado. Y esta información deberá ser plena y exacta acerca del tipo de tratamiento y su finalidad, con advertencia sobre el derecho a denegar o retirar el consentimiento.

${ }^{102}$ El destinatario deberá haber sido debidamente informado de la posibilidad de utilizar sus datos con la finalidad de enviarle comunicaciones comerciales por correo electrónico o por otro medio de comunicación equivalente referentes a productos o servicios similares a los que hayan sido objeto del contrato. 


\section{Comunicación COMERCial desleal agresiva Per SE: ARTículo 29 de la Ley de Competencia Desleal}

Un claro ejemplo de práctica comercial entendida como comunicación comercial lo encontramos en el artículo 29 de la Ley 3/1991, de 10 de enero, de Competencia Desleal (en adelante, LCD) concerniente a las prácticas agresivas por acoso efectuadas por medios a distancia.

El segundo apartado del artículo 29 establece que "se reputa desleal realizar propuestas no deseadas y reiteradas por teléfono, fax, correo electrónico ${ }^{103} u$ otros medios de comunicación a distancia, salvo en las circunstancias y en la medida en que esté justificado legalmente para hacer cumplir una obligación contractual". Los medios que enuncia el precepto son el "teléfono, fax, correo electrónico u otros medios a distancia". La enunciación de los supuestos de marketing directo es puramente indicativa pues debemos acogernos a un criterio abierto tal y como sucede en otras normas relativas a las comunicaciones a distancia (cfr. art. 92 TRLGDCU).

A pesar de que la LCD regula un supuesto de hecho idéntico al regulado por la LSSICE, la LCD formula la deslealtad partiendo de un presupuesto distinto. Mientras que, como se ha visto, la LSSICE exige en todo caso el consentimiento del destinatario de la publicidad por medios electrónicos de comunicación a distancia (sistema opt in), la LCD solo reputará desleal la publicidad enviada a quien se haya opuesto a su recepción y la remisión de la comunicación comercial sea persistente (sistema opt out). La diversidad del objeto perseguido por ambas normas es la razón en la que descansan los distintos presupuestos de licitud. En este sentido, el precepto de la LCD prevé tutelar los intereses de los consumidores, ya sea directa o indirectamente, rechazando el envío persistente de publicidad no deseada el cual puede derivar en una situación de acoso que altere su comportamiento económico. El art. 29 LCD exige que éstos sean persistentes como presupuesto para su declaración de deslealtad, de ahí que una llamada telefónica aislada, o el envío de un único mensaje publicitario por fax o correo electrónico no puedan ser calificados como desleales. Tal conclusión solo se comprende si se parte de la premisa de que dichas llamadas o mensajes aislados, objetivamente considerados, revisten escasa entidad y difícilmente pueden ser aptos para implicar un cambio en el rumbo del comportamiento económico del consumidor (Tato; Fernández; Herrera, 2010). La Ley sobre servicios de la sociedad de la información y del comercio electrónico persigue, sin embargo, proteger la privacidad de aquéllos. Por tanto, enviar spam, aunque sea una sola vez,

${ }^{103}$ La Directiva 2002/58/CE del Parlamento europeo y del Consejo de 12 de julio de 2002 relativa al tratamiento de los datos personales y a la protección de la intimidad en el sector de las comunicaciones electrónicas (Directiva sobre la privacidad y las comunicaciones electrónicas) define, en su art. 2.h), correo electrónico como "todo mensaje de texto, voz, sonido o imagen enviado a través de una red de comunicaciones pública que pueda almacenarse en la red o en el equipo terminal del receptor hasta que éste acceda al mismo". 
podría constituir una infracción conforme a la LSSICE, pero no conforme la LCD. Esta reflexión es la que se extrae del art. 29 in fine LCD al señalar que la deslealtad de la publicidad difundida a través de medios de comunicación a distancia no impide que la normativa vigente sobre los servicios de la sociedad de la información, incluida la contratación a distancia de los servicios financieros, sancionen esta conducta. El juicio de deslealtad es independiente de la ilicitud de la publicidad a través de medios de comunicación a distancia en otros sectores del ordenamiento (Tato; Fernández; Herrera, 2010).

El empresario o profesional que quiera utilizar estas técnicas de marketing directo, sin incurrir en supuestos de prácticas comerciales desleales, deberá utilizar sistemas que permitan al consumidor dejar constancia de su oposición a seguir recibiendo propuestas comerciales de dicho empresario o profesional (art. 29.2.2 LCD) $\mathrm{y}$, en el caso de las llamadas telefónicas, para que el consumidor o usuario pueda ejercer su derecho a manifestar su oposición a recibir propuestas comerciales no deseadas, las llamadas deberán realizarse desde un número de teléfono identificable (art. 29.2.3 LCD).

Ante este tipo de prácticas tendrá legitimación activa para iniciar las acciones legales previstas cualquier persona física o jurídica que participe en el mercado y cuyos intereses económicos resulten perjudicados o amenazados por la conducta desleal, lo cual incluye a los empresarios y profesionales que concurran en el mercado. Dentro de estas acciones, puede destacarse la de resarcimiento de los daños y perjuicios ocasionados así como la de cesación o prohibición de la conducta desleal (cfr. art. 32 LCD).

\section{Sentencia del Tribunal de Justicia de la Unión Europea sobre comu- NICACIONES COMERCIALES Y PRÁCTICAS DESLEALES ENGAÑOSAS}

El Tribunal de Justicia de la UE en su Sentencia de 12 de mayo de 2011 (asunto C-122/10) resolvió varias cuestiones prejudiciales relacionadas con la posible deslealtad de una comunicación comercial (SIGNES DE MESA, 2011).

En el supuesto de hecho en cuestión, el defensor del consumidor sueco (konsumentombudsmannen) consideró que la comunicación comercial publicada por una agencia de viajes (Ving Sverige $A B$ ) era desleal por infringir el art. 12 de la Ley 2008:486 sueca $^{104}$.

${ }^{104}$ El art. 12 de la Ley 2008:486 establece que: "Una práctica comercial será engañosa cuando el comerciante, en una comunicación comercial, invite al consumidor a comprar un producto concreto indicando un precio, pero sin que dicha comunicación contenga los siguientes datos esenciales: 1) las características principales del producto, en la medida adecuada al medio utilizado y al producto, 2) el precio y el precio por unidad de medida, indicados conforme a los artículos 7 a 10 de la Ley 2004:347 de información sobre los precios, 3) la identidad y dirección geográfica del comerciante, 4) los procedimientos de pago, entrega y funcionamiento, y el sistema de tratamiento de las reclamaciones, si se apartan de 
El mencionado anuncio se publicó el 13 de agosto de 2008 en un diario sueco y en él figuraba la siguiente información: en grandes caracteres "Nueva York a partir de 7.8202coronas" y debajo de dicho texto y en letra más pequeña "Vuelos desde Arlanda con British Airways y dos noches en el hotel Bedford. Precio por persona en habitación doble, incluidas las tasas de aeropuerto. Noche adicional a partir de 1.320 coronas. Condiciones válidas para viajes en septiembre-diciembre. Número limitado de plazas" y, en la parte inferior izquierda del anuncio "Vingflex.se Tél. 0771-995995".

El 27 de febrero de 2009, el defensor del consumidor interpuso un recurso contra la agencia ante el órgano jurisdiccional remitente debido a que, a su juicio, dicha comunicación comercial era una invitación a comprar que incluía una omisión engañosa, en la medida en que los datos sobre las características principales del viaje, en particular su precio, eran insuficientes o no se incluían. El konsumentombudsmannen solicitó que se obligara a Ving a indicar un precio fijo en su anuncio y que se le prohibiera indicar un precio de partida. Además, requirió que se obligara a dicha agencia de viajes a precisar si las características principales del viaje, como, por ejemplo, las fechas, las opciones ofrecidas al consumidor o las características análogas, afectaban al precio de partida indicado en la comunicación comercial, y, en su caso, de qué modo.

Por su parte, Ving negó que la comunicación comercial en cuestión constituyera una invitación a comprar. Con carácter subsidiario, alegó que las características principales del producto se indicaban de manera apropiada teniendo en cuenta el medio de comunicación utilizado y el producto de que se trataba, y que el precio se mencionaba conforme a la Ley 2004:347, de información sobre los precios. Además, la agencia refutó que dicha comunicación comercial constituyera una práctica desleal por omisión. A su juicio, la omisión de la información controvertida no podía alterar la aptitud del destinatario para tomar una decisión sobre una transacción comercial con conocimiento de causa.

El defensor del consumidor consideró que la resolución del litigio dependía de la interpretación de varios conceptos recogidos en la DPCD. Por ello, planteó al TJUE cuestiones relacionadas con el art. 2.i) DPCD que define el término "invitación a comprar" como "comunicación comercial que indica las características del producto y su precio de una manera adecuada al medio de la comunicación comercial utilizado, y permite así al consumidor realizar una compra" y con el art. 7.4 DPCD delimitador del concepto "información sustancial" en los casos en que

las prácticas habituales del sector o relativas al producto de que se trate, 5) la información sobre el derecho de revocación o cancelación, que debe facilitarse al consumidor conforme a la ley. Una práctica comercial será asimismo engañosa cuando el comerciante, en una comunicación comercial, invite al consumidor a comprar varios productos concretos indicando un precio global, sin que la invitación contenga los datos esenciales previstos en los números 1 a 5 del párrafo primero". 
existe una invitación a comprar. En otras palabras, el TJUE debía aclarar con precisión qué se entiende por "invitación a comprar" y delimitar los datos esenciales que el consumidor necesita conocer para poder tomar una decisión sobre una transacción con el debido conocimiento de causa y cuya omisión derivaría en la calificación de la comunicación como engañosa y, por lo tanto, desleal.

\subsection{Cuestiones prejudiciales planteadas:}

1) ¿Debe interpretarse el requisito "permite así al consumidor realizar una compra”, establecido en el artículo 2, letra i), de la Directiva 2005/29 [...] en el sentido de que existe una invitación a comprar cuando la información sobre el producto anunciado y su precio es suficiente para que el consumidor pueda tomar una decisión de compra, o es necesario que la comunicación comercial también ofrezca la posibilidad real de comprar el producto (por ejemplo, cupón para un pedido) o que dicha comunicación aparezca en conexión con tal posibilidad (por ejemplo, publicidad delante de una tienda)?

La primera cuestión pretendía clarificar si la expresión "permite así al consumidor realizar una compra", recogida en el art. 2. i) DPCD, debe interpretarse en el sentido de que supedita la calificación de invitación a comprar a la existencia de un medio concreto de adquisición del producto comercializado, o en el sentido de que existe una invitación a comprar desde el momento en que la información relativa al producto de que se trate y a su precio es suficiente para que el consumidor pueda tomar una decisión sobre una transacción.

$\mathrm{Al}$ respecto, $\mathrm{y}$ antes de analizar la cuestión, debemos tener presente que una interpretación no restrictiva del concepto "invitación a comprar" es la única conforme con los objetivos de la norma comunitaria que consiste en alcanzar un elevado nivel de protección de los consumidores (cfr. art. 1 DPCD). Asimismo, y en virtud del art. 7.4 DPCD, la invitación a comprar es una forma específica de publicidad que conlleva una obligación de mayor información.

Dicho esto, el TJUE fue contundente en afirmar que la expresión "permite así al consumidor realizar una compra" no debe analizarse de modo que suponga un requisito suplementario necesario para la calificación de invitación a comprar. Existe invitación a comprar desde el momento en que la información relativa al producto comercializado y a su precio es suficiente para que el consumidor pueda tomar una decisión sobre una transacción. A fin de que una comunicación comercial pueda calificarse de invitación a comprar tampoco es necesario que incluya un medio concreto de compra o que aparezca en conexión con tal medio o con ocasión de él. 
2) Si la respuesta a la [primera] cuestión [...] es que es necesario que exista una posibilidad real de comprar el producto, ¿puede considerarse que existe esta posibilidad cuando la comunicación comercial remite a un número de teléfono o a una página web en la que se puede encargar el producto?

En relación a la segunda cuestión, y teniendo en cuenta lo indicado en la respuesta precedente, se concluyó que no es necesario que exista una posibilidad real de comprar el producto en cuestión.

3) ¿Debe interpretarse el artículo 2, letra i), de la Directiva [2005/29] en el sentido de que se cumple el requisito relativo al precio cuando la comunicación comercial contiene un "precio de partida", es decir, el precio más bajo al que puede adquirirse el producto o la categoría de productos anunciados, al mismo tiempo que el producto o la categoría de productos anunciados existen en otras variantes o con otro contenido a precios que no se indican?

El art. 2.i) DPCD prevé que una invitación a comprar ha de indicar el precio del producto de una manera adecuada al medio de la comunicación comercial utilizado. Dicho esto, es concebible que, en virtud del medio utilizado, sea difícil mostrar el precio del producto correspondiente a cada una de sus variantes. Además, el art. 7.4.c) de la DPCD admite, en materia de omisiones engañosas que teniendo en cuenta de la naturaleza del producto un profesional puede razonablemente no estar en condiciones de comunicar el precio final de antemano. Por otro lado, si debiera considerarse que la mención de un precio de partida no cumple el requisito relativo a la indicación del precio mencionado en el art.2.i) DPCD sería fácil para los profesionales indicar únicamente un precio de partida para que la comunicación comercial en cuestión eludiese la calificación de invitación a comprar, y, por lo tanto, el respeto de lo establecido en el artículo 7.4 de dicha Directiva. Tal interpretación iría en contra de la finalidad de la norma comunitaria.

En resumen, el precio de partida puede cumplir el requisito relativo a la mención del precio del producto, en el sentido del art. 2.i) de la DPCD, cuando, en función de la naturaleza y de las características del producto, así como del soporte de la comunicación comercial utilizado, esta mención permita al consumidor tomar una decisión sobre una transacción. Corresponde al órgano jurisdiccional comprobar si la mención de un precio de partida permite al consumidor tomar una decisión sobre una transacción.

4) ¿Debe interpretarse el artículo 2, letra i), de la Directiva [2005/29] en el sentido de que se cumple el requisito relativo a las características del producto cuando existe una presentación escrita o visual del producto [...], es decir, de modo que se identifica el producto pero no se describe con más detalle? 5) En caso de respuesta 
afirmativa a la [cuarta] pregunta [...], ¿también puede aplicarse ese criterio cuando el producto anunciado se ofrece con algunas variantes, pero la comunicación comercial sólo se refiere a ellas con una denominación común?

Mediante sus cuestiones cuarta y quinta, que procede examinar conjuntamente, se plantea si el art. 2.i) DPCD debe interpretarse en el sentido de que una presentación escrita o visual del producto permite cumplir el requisito relativo a la indicación de las características del producto, incluso en el supuesto de que se utilice una misma presentación escrita o visual del producto para designar un producto ofrecido en varias variantes. En la medida en que el precepto exige que se indiquen las características del producto de una manera adecuada al medio de la comunicación comercial utilizado, el soporte de la comunicación comercial debe tenerse en cuenta a tal fin, exigiéndose diversos grados de precisión en la descripción del producto. Una presentación puede permitir al consumidor forjarse una opinión sobre la naturaleza y las características del producto para tomar una decisión sobre una transacción, incluso si se designa un producto ofrecido en varias variantes. Incumbe al órgano jurisdiccional determinar caso por caso, tomando en consideración la naturaleza y las características del producto, así como el soporte de comunicación utilizado, si el consumidor dispone de datos suficientes para identificar y distinguir el producto a fin de tomar una decisión sobre una transacción.

6) Ante una invitación a comprar, ¿debe interpretarse el artículo 7, apartado 4, letra a), [de la Directiva 2005/29] en el sentido de que basta con que sólo se indiquen determinadas características principales del producto y que el comerciante, por lo demás, se remita a su página web, siempre que en ésta aparezca información esencial sobre las características principales del producto, el precio y los demás requisitos establecidos en el artículo 7, apartado 4 [de dicha Directiva]?

Mediante su sexta cuestión, debemos plantearnos si basta con que se indiquen sólo determinadas características principales del producto y que el comerciante, por lo demás, se remita a su sitio en Internet, siempre que en éste aparezca información esencial sobre las características principales del producto, el precio y los demás requisitos establecidos en el art. 7.4 DPCD.

En relación, el Tribunal recuerda que las prácticas comerciales incluidas en el art. 7.4 de la Directiva requieren una apreciación casuística. El precepto en su letra a) se refiere a las características principales del producto, sin definir no obstante este concepto o proporcionar una lista exhaustiva de ellas. Sin embargo, precisa que debe tenerse en cuenta, por un lado, el medio de comunicación utilizado, y por otro, el producto de que se trata. Esta disposición relacionada con su apartado primero, según el cual la práctica comercial ha de apreciarse teniendo en cuenta, en particular, todas sus características y circunstancias y las limitaciones del medio de 
comunicación utilizado y tercero, que prevé expresamente que se tomarán en consideración, para determinar si se ha omitido información, las limitaciones de espacio y de tiempo del medio de comunicación empleado y todas las medidas adoptadas por el comerciante para poner la información a disposición del consumidor por otros medios, se deduce que el alcance de los datos relativos a las características principales de un producto que tiene que comunicar un comerciante en el marco de una invitación a comprar ha de apreciarse en función del contexto de dicha invitación, de la naturaleza y características del producto y del soporte de comunicación utilizado. De lo anterior se desprende que el art. 7.4.a) DPCD no se opone a que en una invitación a comprar se mencionen únicamente determinadas características principales del producto, si el comerciante remite, por lo demás, a su sitio en Internet, siempre que dicho sitio contenga las informaciones esenciales relativas a las características principales del producto, al precio y los demás requisitos, establecidos en el artículo 7 de dicha Directiva.

Sin embargo, es necesario recordar que según el apartado 5 del art. 7 DPCD, se considerarán sustanciales los requisitos establecidos por el Derecho de la Unión en materia de información relacionados con las comunicaciones comerciales, de los que el anexo II de dicha Directiva contiene una lista no exhaustiva. Entre los textos mencionados en este anexo figura el artículo 3 de la Directiva 90/314/CEE del Consejo, de 13 de junio de 1990, relativa a los viajes combinados, las vacaciones combinadas y los circuitos combinados, cuyo apartado 2 enuncia un cierto número de datos que debe contener un folleto relativo a este tipo de viajes, vacaciones y circuitos. Incumbe al órgano jurisdiccional examinar caso por caso, tomando en consideración el contexto de la invitación a comprar y el medio de comunicación utilizado, así como la naturaleza y las características del producto, si la mera mención de determinadas características principales del producto permite al consumidor tomar una decisión sobre una transacción con conocimiento de causa.

7) ¿Debe interpretarse el artículo 7, apartado 4, letra c), [de la Directiva 2005/29] en el sentido de que basta con indicar un "precio de partida" para que se cumpla el requisito relativo al precio?

Mediante su séptima cuestión, se analiza si es suficiente indicar un precio de partida para que se cumpla el requisito relativo al precio. A diferencia de la tercera cuestión que analiza el art. 2.i) DPCD cuyo objeto consiste en determinar la calificación de la invitación a comprar, el art. 7.4. c) de dicha Directiva define las informaciones que deben considerarse sustanciales en una invitación a comprar. Pues bien, aunque es cierto que el art. 7.4 DPCD considera que las informaciones relativas al precio son, en principio, sustanciales, no lo es menos que la letra c) de dicha disposición establece que, en caso de que el precio no pueda calcularse razonablemente de antemano por la naturaleza del producto, las informaciones deben incluir 
la forma en que se determina el precio, así como, cuando proceda, todos los gastos adicionales de transporte, entrega o postales o, cuando tales gastos no puedan ser calculados razonablemente de antemano, el hecho de que pueden existir dichos gastos adicionales. Por consiguiente, la mera indicación de un precio de partida puede estar justificada en los supuestos en los que el precio no pueda calcularse razonablemente de antemano, teniendo en cuenta, en particular, la naturaleza y las características del producto. Para determinar el precio final de un viaje, puede tenerse en cuenta un número determinado de factores variables, concretamente el momento de la reserva y el atractivo del destino en función de la existencia de eventos religiosos, artísticos o deportivos, de las particularidades de las condiciones estacionales y de las fechas y las horas del viaje. Sin embargo, cuando únicamente figura el precio de partida en la invitación a comprar, sin que se indiquen las modalidades de cálculo del precio final, $\mathrm{y}$, en su caso, los costes suplementarios o la mención de que dichos gastos corren a cargo del consumidor, cabe preguntarse si esta información basta a fin de permitir al consumidor tomar una decisión sobre una transacción con conocimiento de causa, o si no debe concluirse que existen omisiones engañosas. El artículo 7.3 de la Directiva precisa que, cuando el medio utilizado para comunicar la práctica comercial imponga limitaciones de espacio o de tiempo, a la hora de decidir si se ha omitido información deberán tenerse en cuenta esas limitaciones y todas las medidas adoptadas por el comerciante para poner la información a disposición del consumidor por otros medios. Las indicaciones aportadas por dicha disposición, que se refieren a los elementos que es necesario tener en cuenta para determinar si la práctica debe calificarse de omisión engañosa, se aplican a las invitaciones a comprar a que se refiere el art. 7.4 DPCD. El alcance de la información relativa al precio se determinará en función de la naturaleza y de las características del producto, pero también en función del medio de comunicación utilizado para la invitación a comprar, y habida cuenta de los complementos de información que en su caso proporcione el comerciante. En consecuencia, la mera indicación de un precio de partida en una invitación a comprar no puede considerarse per se constitutiva de una omisión engañosa. El órgano jurisdiccional deberá comprobar, en particular, si la omisión de las modalidades de cálculo del precio final no impide al consumidor tomar una decisión sobre una transacción con conocimiento de causa y, en consecuencia, no le incita a tomar una decisión sobre una transacción que, de otro modo, no habría tomado. También le incumbe tomar en consideración los límites inherentes al soporte de comunicación utilizado, la naturaleza y las características del producto y el resto de medidas que el comerciante ha adoptado realmente para que dichas informaciones estén a disposición del consumidor. 


\section{Conclusiones}

I.- Las comunicaciones comerciales se definen en el art. 19.2 TRLGDCU como práctica comercial de las empresas en relación con los consumidores y se definen en el art. 2.f) de la Directiva sobre el comercio electrónico como "todas las formas de comunicación destinadas a proporcionar directa o indirectamente bienes, servicios o la imagen de una empresa, organización o persona con una actividad comercial, industrial, artesanal o de profesiones reguladas". Esta definición extensa de comunicación comercial coincide con el término genérico de práctica comercial permitiendo englobar en estas categorías nuevos fenómenos promocionales que afecten o puedan afectar al comportamiento económico del consumidor medio.

II.- Las comunicaciones comerciales pueden ser de dos tipologías: no electrónicas y electrónicas. Las primeras deberán ser conformes a la LOPD mientras que las comunicaciones comerciales por correo electrónico u otros medios de comunicación electrónica equivalentes, al considerarse un servicio de la sociedad de la información, se regularán por la LSSICE. Concretamente, la LSSICE dedica a las comunicaciones comerciales por vía electrónica su Título III que bajo la rúbrica "Comunicaciones comerciales por vía electrónica" se desarrolla en los arts. 19 a 22 LSSICE. Sin embargo, esta aplicación preferente no impide su complementación con otras normas tales como la LOPD, TRLGDCU, LCDSFC o la LCD.

III.- Las prácticas agresivas por acoso efectuadas por medios a distancia reguladas en el art. 29 LCD son un ejemplo de práctica comercial entendida como comunicación comercial desleal. La LCD formula la deslealtad partiendo de un presupuesto distinto al de la LSSICE. En primer lugar, la LCD solo reputará desleal la publicidad enviada a quien se haya opuesto a su recepción y la remisión de la comunicación comercial sea persistente (sistema opt out). En segundo lugar, el objeto perseguido por la LCD consiste en tutelar los intereses de los consumidores, ya sea directa o indirectamente, rechazando el envío persistente de publicidad no deseada el cual puede derivar en una situación de acoso que altere su comportamiento económico.

IV.- Es criticable la falta de sistemática de la regulación en materia de comunicaciones comerciales no deseadas y agresivas por acoso. Debería valorarse que el tratamiento de las vulneraciones de los empresarios en las comunicaciones comerciales se equiparara a prácticas comerciales desleales. A nuestro juicio, sería conveniente trasladar los recursos colectivos previstos para la deslealtad, como la acción de cesación (cfr. art. 32.1.2 LCD), a infracciones sobre el tratamiento de datos personales. Remedios pensados para tutelar el comportamiento económico de un consumidor se aplicarían para velar derechos de la personalidad afectados por de- 
sequilibrios decisionales sustanciales constituyendo un sistema jurídico más seguro y previsible.

V.- Otro ejemplo de comunicación comercial desleal, en este caso por engaño, son las invitaciones a comprar que omiten la información sustancial exigida por el art. 7.4 DPCD. La jurisprudencia del TJUE ha permitido aclarar algunos de los conceptos y nociones de la DPCD; concretamente, sus Sentencias han demostrado ser útiles para aclarar cuestiones generales referentes a la relación entre la DPCD y la legislación nacional, así como otras cuestiones más específicas relativas a la interpretación de algunas de sus disposiciones sustantivas. La STJUE de 12 de mayo de 2011 (Asunto C-122/10), aclaró el concepto de "invitación a comprar", definido en el artículo 2.i) de la DPCD: “(...) una invitación a comprar se da en cuanto hay una presentación visual del producto y su precio, sin que exista un mecanismo real de compra inmediatamente disponible" y qué debemos entender por "información sustancial” en las invitaciones a comprar (art. 7.4 DPCD).

\section{Bibliografía}

ÁLVAREZ RUBIO, J. "Hacia un nuevo concepto de comunicación comercial". En: Tomillo Urbina, J. (dir.) y Álvarez Rubio, J. (coord.). El futuro de la protección jurídica de los consumidores. Navarra: Aranzadi, 2008.

BARRAL VIÑALS, I. (coord.). La regul@ción del comercio electrónico. Madrid: Dykinson, 2003.

BOTANA GARCÍA, G. "Noción de comercio electrónico". En: Botana García, G. (coord.). Comercio electrónico y protección de los consumidores. Madrid: La Ley, 2001, cap. I.

BURGOS SOLANS, D. y De León Fernández, L. Comercio electrónico, publicidad y marketing en Internet. Madrid: McGraw Hill, 2001.

CALVO CARAVACA, A.L. y Carrascosa González, J. Conflictos de leyes y conflictos de jurisdicción en Internet. Madrid: Colex, 2001.

DE LA CUESTA RUTE, J.M. "Tratamiento jurídico en España de la comunicación publicitaria ilícita", La Ley: Revista jurídica española de doctrina, jurisprudencia y bibliografía, 1981, núm. 4. pp. 893-917.

LLÁCER MATACÁS, M.R. "La autodeterminación informativa en la sociedad de la información y la vigilancia”. En: LLácer Matacás, M.R. (coord.). Protección de datos personales en la sociedad de la información y la vigilancia. Madrid: La Ley. Grupo Wolters Kluwer, 2011.

MÉNDEZ TOMÁS, R.M. y Vilalta Nicuesa, A.E. Comunicaciones comerciales y 
contratación por vía Electrónica. Barcelona: Bosch, 2003.

MORENO NAVARRETE, M.Á. DERECHO-e Derecho del Comercio Electrónico. Madrid: Marcial Pons, 2002.

SIGNES DE MESA, J.I., "Sentencia del Tribunal de Justicia de la Unión Europea sobre comunicaciones comerciales y prácticas desleales", Revista de derecho bancario y bursátil, núm. 123, 2011, pp. 301 y 302.

TATO PLAZA, A.; Fernández Carballo-Calero, P. y Herrera Petrus, CH. La reforma de la Ley de Competencia Desleal. Madrid: La Ley, 2010. 


\section{3}

Algunas reflecxiones, Desde la Perspectiva del ordenamiento JURÍDICO INTERNACIONAL, SOBRE LOS RETOS A LOS QUE SE ENFRENTAN LAS ORGANIZACIONES INTERNACIONALES EN LA SOCIEDAD INTERNACIONAL CONTEMPORANEA

Some thoughts from the perspective of international law, on the challenges to whichfacing international organizations in contemporary international society

Anna M. Badia Martí

Catedrática de Derecho Internacional, directora del Máster en Estudios Internacionales de la Universitat de Barcelona. E-mail: abadia@ub.edu

\section{RESUMEN}

El trabajo parte de establecer que tipo de Organizaciones internacionales merecen el calificativo de sujeto de derecho internacional. A partir de aquí, y acudiendo a la práctica internacional se analizan los hechos que inciden en la propia existencia de las Organizaciones Internacionales y a las relaciones que se desencadenan entre ellas. Tres son las cuestiones de la práctica internacional que se analizan 1.Decadencia del modelo institucionalizado .2. Gestión transversal de los temas de interés global. 3. Proceso de institucionalización en ámbitos sectoriales. La práctica seguida permite identificar los cambios que se producen en las actividades de las Organizaciones Internacionales y en la forma de afrontar los retos a los que se enfrenta. Punto central del desarrollo del trabajo es la "transversalidad" de los temas de dimensión internacional.

Palabras clave: Organizaciones Internacionales. Sujetos de Derecho. TransverSALIDAD DE LOS TEMAS.

\section{RESUMO}

O trabalho tem por objetivo esclarecer quais organizações internacionais merecem ser classificadas como sujeito de direito internacional. A partir daqui e socorrendo-se da prática internacional, analisam-se os fatos que incidem na própria existência de organizações internacionais e nas relações que se desencadeiam entre 
elas. Três são os temas referentes à prática internacional que se analisam: 1. Decadência do modelo institucionalizado. 2. Gestão transversal dos temas de interesse global. 3. Processo de institucionalização em âmbitos setoriais.

Palavras-chave: Organizações internacionais. Sujeito de direito internacional. GESTÃo TRANSVERSAL DOS TEMAS DE INTERESSE GLOBAL

SumARIO: Planteamiento. I. Noción de Organización Internacional como sujeto de derecho internacional. II. Retos a los que se enfrentan las Organizaciones Internacionales. 1. Decadencia del modelo institucionalizado. 2 Gestión transversal de los temas de interés global. 3. Proceso de institucionalización en ámbitos sectoriales. Consideraciones finales. Bibliografía.

\section{Planteamiento}

El tema de esta contribución se ha elegido tomando en cuenta el título del congreso: "actores del desarrollo económico, político y social", así como la disciplina de mi especialidad, el Ordenamiento jurídico internacional (OJI). Ambas referencias, me sitúan a delimitar el objeto de mi reflexión en torno al papel que desempeñan las Organizaciones internacionales (OOII) en la gestión de los intereses económicos, políticos y sociales, tomando como marco de referencia la Sociedad Internacional actual; y plantearnos cuáles son los problemas en que se ven envueltas y el tratamiento que se da para resolverlos.

El punto de partida en el que se sustenta mi reflexión, es considerar que la participación de las OOII en la Sociedad Internacional está consolidada en la actualidad, y además se han convertido en un actor imprescindible a partir del Orden internacional establecido después de la II guerra mundial, y reflejado en la Carta de las Naciones Unidas. Situación que no es ajena a los cambios que operan en las relaciones internacionales y a la permeabilidad que muestra el OJI en su adaptación a estos cambios.

En el contexto indicado, la primera cuestión que se plantea es la necesidad de determinar, que tipo de Organizaciones internacionales merecen el calificativo de sujeto de derecho internacional, a la luz del conjunto de organizaciones internacionales que operan en el mundo contemporáneo. A partir de aquí y acudiendo a la práctica internacional se identifican las particularidades a que se enfrentan en el momento actual y se analizan los hechos que inciden en aspectos diferentes de la propia existencia de OOII y a las relaciones que se desencadenan entre ellas. Tres son los puntos que, a mi juicio, agrupan los retos a los que se enfrentan las OOII y el papel que desempeñan en el conjunto de la sociedad internacional. 
1. La importante actividad de los denominados G. 20, así como las coaliciones internacionales dirigidas a actuar en territorios de terceros Estados, --estoy pensado en la reciente actuación de septiembre de 2014 en el denominado "Estado Islámico"--, permite plantear si se está ante una cierta decadencia del modelo institucionalizado de ordenación de las relaciones internacionales. Se buscan modelos que intentan soslayar las asociaciones de Estados como sujetos de derecho internacional. La hipótesis que nos planteamos es si en determinados ámbitos se ha superado la participación y actividades de las OOII en un sentido técnico jurídico.

2. El Segundo punto a tratar, se deriva de la interrelación que se produce entre los diferentes temas de interés en una Sociedad que debe gestionar "intereses comunes", ello produce que temas en concreto tiene una dimensión trasversal, es decir que afectan a diferentes ámbitos al mismo tiempo. Sirva de ejemplo el denominado "empoderamiento" de la mujer, los temas relacionados con la bioética o bien la gestión de Internet. Si estudiamos cada uno de ellos y su ámbito de incidencia, nos damos cuenta que afectan a la esfera competencial de diferentes OOII, la cuestión que nos planteamos es como se relacionan entre si las diferentes organizaciones afectadas, y qué medidas se toman al respecto.

3. Por último, asistimos a un proceso de institucionalización de signo contrario al planteado en primer lugar. Acciones de los Estados que se desarrollan y gestionan sin aparato institucional permanente, paulatinamente van estableciendo un organigrama de carácter administrativo. Permite constatar este hecho, la instauración una Secretaria en el Régimen Antártico, o bien una Secretaria de apoyo a las Cumbres Iberoamericanas, o incluso la Secretaria de la Unión por el Mediterráneo. La cuestión que nos plateamos en este caso es, en qué medida se trata de OOII las denominadas "secretarias" como sujeto de derecho internacional, cuando se instituyen como entes de gestión.

\section{I- Noción de Organización Internacional como sujeto de derecho internacional.}

El punto de partida del estudio es determinar que entendemos por OOII como sujeto de derecho internacional. Desde el pronunciamiento de la CIJ de 1949, en el conocido asunto del Conde Bernadotte (ICJ Reports 1949), no se presentan dudas sobre la consideración de las OOII como sujetos de derecho, además que se trata de un sujeto de carácter "objetivo", es decir que a pesar de que un Estado no sea Miembro de una OOII su existencia le es oponible.

Vamos pues a plantear brevemente en estas páginas los elementos que configuran esta realidad como sujeto de derecho internacional, pero además la cuestión 
que no interesa a los efectos del objeto de estudio en este trabajo es, como se articula la coexistencia de organizaciones internacionales y si existen principios que orienten su coexistencia, ahora en el s. XXI.

Asimismo, también debe de tenerse en cuenta que, no todos los entes que operan en la Sociedad Internacional denominados Organizaciones Internacionales, son sujetos de derecho internacional, e incluso puede pensarse, para supuestos concretos, que quiere soslayarse esta categoría jurídica.

Para considerarse una OOII sujeto de derecho internacional, debe gozar de los atributos que se desprenden de la Personalidad jurídica internacional. En definitiva que su existencia, funcionamiento, actividad y en su caso su responsabilidad activa o pasiva, se rige por el ordenamiento jurídico internacional, y están sometidas a las normas generales de dicho ordenamiento. Entendiendo que el contenido exacto de esta personalidad jurídica depende en cada caso de su tratado constitutivo, como se ha puesto repetidamente de manifiesto por diferentes opiniones consultivas de la CIJ ((ICJ Reports 1949, ICJ Reports 1980, ICJ Reports 1996).

Aun siendo muy conscientes de la diversidad de OOII existentes, es útil el criterio descriptivo con frecuencia utilizado para conceptuarlas, con la idea de enumerar los rasgos esenciales, y englobar al mayor número posible de las mismas que pueden considerarse sujetos de derecho internacional.

Así, el profesor. Diez de Velasco, en su Manual de referencia en la materia define, en base al criterio descriptivo, a las OOII como: Asociaciones voluntarias de Estados establecidas por acuerdo internacional, dotadas de órganos permanentes, propios e independientes encargados de gestionar, unos intereses colectivos y capaces de expresar una voluntad jurídicamente distinta de la de sus miembros (DIEZ DE VELASCO p. 43).

El proceso de codificación y desarrollo progresivo sobre la responsabilidad internacional de las OOII, llevado a cabo en el seno de las Naciones Unidas (NNUU), ha puesto de manifiesto una vez más, las dificultades que comporta la definición de OOII (CORTÉS MARTÍN, 2008). La noción aprobada por la CDI y con posterioridad, en 2011, por la Asamblea General (A/Res 66/100), queda en los siguientes términos:

"Es una organización instituida por un tratado u otro instrumento regido por el derecho internacional y dotado de personalidad jurídica propia. Además de los Estados las organizaciones internacionales pueden contar entre sus miembros con otras entidades".

La definición transcrita, matiza la noción de Diez de Velasco en un doble sentido: 1. no sólo son Miembros los Estados, sino que caben otros entes (como otras OOII) y que pueden crearse por otras vías que no sean los Tratados internacionales (cómo podría ser una acto de una OOII).

Cómo pone de manifiesto el profesor Gutiérrez Espada (2010, p 28), “... la 
Comisión ha evitado el frecuente calificativo de intergubernamental para referirse a estos sujetos funcionales: dos razones expone para ello: de una parte, hay organizaciones internacionales que han sido creadas por órganos de los Estados miembros distintos del gobierno o en las que los Estados que la forman no están representados siempre por sus gobiernos; de otra un número cada vez mayor de organizaciones cuentan entre sus Miembros tanto a Estados como a otro tipo de entidades distintas, caso en el que la expresión "organización intergubernamental" parece excluirlas".

Vista la existencia de la personalidad jurídica internacional de las organizaciones internacionales, cuando éstas reúnen los elementos necesarios para ser consideradas como tales; el siguiente paso es establecer como se califica a este sujeto de derecho internacional.

En primer lugar son sujetos de carácter "funcional", -- es decir ostentan los atributos de la personalidad jurídica, para ejercer las competencias, asignadas en el acto jurídico constitutivo, necesarias para alcanzar sus objetivos ${ }^{105}-\mathrm{y}$ en segundo lugar, rige el principio de especialización, principio que expresa el ámbito en que se concreta su actividad.

Estos sujetos, se han articulado perfectamente en las relaciones internacionales y forman parte de la vida internacional, tanto las OOII en sí, cómo sus actos. Además la práctica indica que se ha consolidado su existencia a nivel global, coexistiendo a nivel universal y regional, a pesar de que su creación no responde a parámetros preestablecidos, cabe entender que responde a los intereses determinados de un grupo, más o menos extenso, de Estados que tienen interés en su establecimiento.

Si su existencia responde a los intereses del momento exclusivamente, cabe preguntarse cómo se articula su coexistencia y si responde a algún otro criterio distinto al señalado. La apariencia es que se está ante una realidad anárquica, que puede conducir a la duplicidad de actuaciones, o en su caso, a la ausencia de actividad institucionalizada o bien a la rivalidad entre OOII.

$\mathrm{Si}$ acudimos al intento de institucionalización de las relaciones internacionales establecido en el Sistema de NNUU, entendido como el marco que va a permitir el desarrollo de un Orden internacional en el que participarán las OOII ${ }^{106}$, podemos encontrar algún principio rector, que pueden servir de guía a la coexistencia de OOII.

${ }^{105}$ La Corte en la opinión consultiva de 1996, afirmando la subjetividad de las OOII pero de carácter diferente de la subjetividad de los Estados, afirma: " La Corte cree apenas necesario recordar que las organizaciones internacionales son sujeto de derecho internacional que no goza, a diferencia de los Estados, de competencias generales" ( ICJ, Reports 1996, p, 78párrf 25).

${ }^{106}$ Formalmente se refleja en los art. 1-4 de la Carta y en el art. 103, y corroborada en la A/ Res 55/2 "Declaración del Milenio" de 8 de septiembre de 2000. 
En síntesis el "sistema" se concibe con una OOII central: las Naciones Unidas, y alrededor de la misma pivotan un conjunto de "Organismos especializados" creados en base al principio de especialización y que están vinculadas a la Organización general mediante acuerdos de vinculación ${ }^{107}$. Además dentro del sistema se cuenta con la participación de Organizaciones regionales (Capitulo VIII) que desarrollaran las actividades con carácter de proximidad. Aunque esté previsto para el mantenimiento de la paz y la seguridad internacional responde a las aspiraciones del "regionalismo", para darle entrada, en un paraguas de vocación universal e intentar armonizar el universalismo y el regionalismo de forma positiva, a modo de dos posiciones que forzosamente deben coexistir. Coexistencia que como pone de manifiesto BOISSON DE CHAZOUNERS (2010, p.400) puede calificarse de diferente forma: "Les relations entre organisations universelles et organisationes regionales sont de nature variée. Selon les organisations concernées, divers labels permettent de caractériser ces relations. Des relations de complémentarieté, d'autonomie, de proimote décisionnelle, de coopération operationnelle et d'emulation entre organisations universelles et organisartions régionelles ont pu être évoquées".

La práctica muestra la complejidad y riqueza de la convivencia entre la disparidad de organizaciones internacionales ${ }^{108}$. Considero que tres son las bases en que se sustenta el sistema de OOII en la actualidad: 1. Especialización, tomando como fundamento las funciones atribuidas en los tratados constitutivos, y derivado del carácter de su subjetividad 2. Coordinación, como principio que debería presidir el ejercicio de competencias de cada una de ellas, y 3. Coexistencia, con diferentes articulaciones entre organizaciones universales y regionales, tal como se ha dicho, y buscando plasmar el principio de subsidiariedad, siempre que fuese posible.

\section{Retos a los que se enfrentan las OOII.}

Como se ha indicado en la introducción tres son los aspectos que se han seleccionado para mostrar los retos a los que se enfrentan las OOII: 1.Decadencia del modelo institucionalizado .2. Gestión transversal de los temas de interés global. 3. Proceso de institucionalización en ámbitos sectoriales. Los tres nos ofrecen elementos de reflexión e inciden en el tema apuntado en el apartado anterior de buscar la articulación jurídica de la coexistencia de las diferentes organizaciones internacionales.

${ }^{107}$ Vid artículos 57, 63 y 64de la Carta de las NNUU. Para un estudio de los problemas de coordinación vid FOMERAND J. DIJKZEUL (2007, pp. 561-581)

108 Algún autor lo ha plasmado aludiendo a la existencia de un Principio de Interorganizacional de buena vecindad entre Organizaciones internacionales y de equilibrio entre instituciones, tal como recoge PONS RAFOLS, X. (2010, p. 123). 


\section{Decadencia del modelo institucionalizado}

En dos materias centrales de las relaciones internacionales, como son la economía y el mantenimiento de la paz y la seguridad internacional, se ha producido, y quizás acrecentado en los últimos tiempos, un desplazamiento del modelo institucionalizado en la toma de decisiones y acciones conjuntas, hacia fórmulas al margen de las OOII.

Para el modelo económico nos referiremos a la falta de liderazgo de las instituciones de Bretton Woods en la gestión de la crisis financiera de 2007, y para el tema de mantenimiento de la paz y la seguridad internacional, el tema central es el papel del Consejo de Seguridad de las NNUU en la materia.

\section{Materia económica}

En lo que se refiere a la dimensión económica, la piedra angular la constituye el liderazgo del denominado G20 (www.g20.org). Su vocación es de gestión de los intereses económicos de los Estados que tienen mayor incidencia en él (países más desarrollados y ampliado con las denominadas economías emergentes (BRICS)).

Los rasgos que definen desde el Ordenamiento jurídico internacional, al G 20 son: Constitución por cooptación, ausencia de acto jurídico constitutivo y ausencia de entramado institucional, indeterminación jurídica de los documentos finales de sus reuniones y dudas razonables sobre su legitimación (MARTIN Y PEREZ DE NANCLARES, J. E, 2010 p.44). Rasgos que casan mal con la noción de OOII, y probablemente se instituyeron estas reuniones periódicas, para soslayar el significado jurídico que va implícito a una OOII, y en definitiva obviar actuar dentro de un nuevo sujeto de derecho internacional.

Su existencia sin embargo corre en paralelo a las actividades del FMI, y de las organizaciones de carácter financiero internacional, y sin suplantarlas si les han rebajado su protagonismo. Pero también debe tenerse en cuenta el momento de cambio de las circunstancias; surge el modelo escasamente institucionalizado para gestionar el tema económico ante el proceso de globalización, pero en el momento en que el modelo económico entra en recesión y crisis las instituciones de gestión de las cuestiones económicas también son sensibles a ello. La situación en que nos encontramos no permite afirmar que exista un liderazgo real de una OOII en concreto, pero tampoco una gestión liderada exclusivamente por el modelo no institucionalizado del G20.

Materia de mantenimiento de la paz y seguridad internacional.

El elemento angular de reflexión es el papel del Consejo de Seguridad 
(CdeS) como órgano que tiene encomendado por la comunidad internacional en su conjunto, la responsabilidad de mantenerla, lo que queda reflejando en sus competencias en torno al conocido como "sistema de seguridad colectiva"109.

Ha sido ampliamente estudiado por la doctrina(CARRILLO SALCEDO J.A, 2009) y por la práctica de la Organización ${ }^{110}$ como enfocar la reforma del Consejo tanto en lo que se refiere a la composición, como a la forma de ejercer sus competencias, que conduce tanto a su parálisis, como a tomar decisiones poco ajustadas a su marco competencial.

Lo cierto es, que se constata una falta de liderazgo del CdeS, y cada vez que se toman decisiones al margen de este liderazgo, se pone en tela de juicio la institución y corroe su razón de ser.

Sirva de ejemplo, la reciente coalición contra el Estado Islámico, liderada por Estados Unidos ${ }^{111}$, y lanzada en la Conferencia internacional sobre la paz y la seguridad en Irak, celebrada el 15 de septiembre de $2014^{112}$. La Coalición, sin embargo, basa su existencia en la Resolución 2170(2014) de 15 de agosto, que nos remite a su vez a la Resolución 1373(2001) base de la actual acción en la lucha contra el terrorismo.

\section{GeStión TRANSVERSAL DE LOS TEMAS DE INTERÉS GLOBAL}

Bajo este enunciado, se quiere poner de manifiesto la capacidad que muestran determinados temas de dimensión internacional de afectar a diferentes ambitos de distinta naturaleza, de forma simultanea. Dependerá de la perspectiva por la que se opte en su tratamiento las medidas que se adopten para gestionarlo, sirva de

${ }^{109}$ Que engloba los tres capítulos de la Carta de las NNUU (Cap. VI, VII, VIII) aunque el núcleo del sistema se encuentra en el Cap. VII.

${ }^{110} \mathrm{La}$ Carta prevé dos procedimientos uno de reforma y otro de modificación. El primero se ha utilizado en tres ocasiones para adecuar la composición de los órganos al incremento del número de Miembros de la Organización. Por lo que se refiere a la modificación, se prevé la convocatoria de una conferencia a los 10 años de vida de la Organización (art. 109 de la Carta). Conferencia que no se ha producido por no exitir el consenso necesario para su convocatoria. Ahora bien, el Comité Especial de la Carta de las NNUU y del fortalecimiento del papel de la Organización ha sido el que ha canalizado los esfuerzos para encauzar el debate a nivel intergubernamental. El proceso de modificación se ha liderado a través de informes realizados o encargados por el Secretario General.No se ha logrado la revisión de la Carta, quizás el intento más serio ha sido con ocasión de los 60 años de las NNUU y gira en torno al informe del Secretario General "Un concepto más amplio de Libertad".

${ }^{111}$ Coalición que tiene el apoyo de 40 países. Significativamente ninguno Latinoamericano

112 Asistieron a la Conferencia, los Miembros del CdeS, 10 países vecinos (Arabia Saudita, Bahréin, Egipto, Emiratos Árabes, Líbano, Jordania, Kuwait, Omán Qatar, Turquía. Por lo que se refiere a OOII estuvieron representadas: ONU, la Unión Europea y la Liga de Estados Árabes. El gran ausente fue Irán. 
ejemplo la "Trata de personas". La aproximación al tema y los resultados que se pretenden, variaran si ponemos el acento en la dimensión de "seguridad" o en centrarnos en la rehabilitación de las víctimas de la trata; en el primero tendremos una dimensión policial y en el segundo de derechos humanos, la cuestión es si puede tratarse de forma estanca y pueden mantenerse su enfoque de forma separada o, por el contrario, los esfuerzos deben ir dirigidos a tratarse las cuestiones de tal manera que se contemplen conjuntamente los aspectos esenciales, lo que denominamos de "forma transversal".

Si se opta por una forma u otra, abordar una sola dimensión, o dar un enfoque mas transversal, incide, naturalmente, en la actuación de las OOII, que es lo que nos interesa en este momento.

Así, si se decide afrontar un enfoque transversal, a veces imprescindible, podemos fácilmente encontrarnos con que un tema puede afectar al campo competencial de diferentes OOII, o bien a diferentes órganos de una misma organización.

El resultado es que afecta al principio de "especialización y coordinación" que, se han identificado como principios rectores de la cohabitación de las diferentes organizaciones internacionales, la cuestión que nos planteamos es como se soluciona.

Planteada la cuestión, y acudiendo a la práctica nos encontramos que no hay una solución única, dependerá de cada materia, y por el momento no podemos apuntar pautas de carácter general, sólo cuestionarnos si, los principios indicados (especialización y coordinación) están o no erosionándose o no existen en realidad y únicamente pueden enunciarse a nivel formal.

Para ilustrar la cuestión planteada, tal como se ha indicado en el planteamiento de esta presentación, se han seleccionado tres temas con carácter ilustrativo: El "empoderamiento" de la mujer, la bioética y la gestión de Internet; cada uno se gestiona de forma diferente.

a) El "empoderamiento" de la mujer.

Buscar la igualdad entre los géneros, es una cuestión que se ha tratado desde el inicio de la vida de la organización de las Naciones Unidas (RODRIGUEZ MANZANO, 2008). Será la Conferencia de Beijing sobre la Mujer de 1995, que aporta un nuevo enfoque a la cuestión del género y se retomado con intensidad renovada y con connotaciones algo distintas, se incorpora del término "mainstreaming de género" $" 113$.

${ }^{113}$ Para conocer el alcance de su significado es ilustrativo en los términos que aparece en la pág. Web del Instituto de la Mujer del Gobierno de España en relación al termino. (http:// www.inmujer.gob.es/areasTematicas/mainstreaming/home.htm). En la página se establece textualmente: Una de las áreas en las que el Instituto de la Mujer desarrolla su labor es en la promoción de la transversalidad del principio de igualdad entre mujeres y hombres en 
El término alude al carácter "transversal" con el que debe afrontarse la cuestión de género, entendiendo por tal: "El principio de igualdad de trato y oportunidades entre mujeres y hombres informará, con carácter transversal, la actuación de todos los Poderes Públicos. Las administraciones públicas lo integrarán, de forma activa, en la adopción y ejecución de sus disposiciones normativas, en la definición y presupuestación de políticas públicas en todos los ámbitos y en el desarrollo del conjunto de todas sus actividades". Noción extraída del artículo 15 de la Ley Orgánica 3/2007 para la igualdad entre hombre y mujeres, y que nos permite entender el concepto "mainstreaming", en términos de la ley española, como "Tranversalidad de las políticas de género".

La acción de NNUU emprendida en aplicación de esta política se concreta en el establecimiento "ONU mujeres" tal como se establece en el párrf 49 de la A/ Res 64/289 de 21 de julio de 2010, en el que la Asamblea General, decide establecer:

“.... la Entidad de las Naciones unidas para la Igualdad entre los generos y el Empoderamiento de la Mujer, y que se conocerá como ONU -Mujeres, mediante la consolidación y la transferencia a la Entidad de los mandatos y funciones de la Oficina del Asesor Especial en Cuestiones de Género y Adelanto de la Mujer y la División para el Adelanto de la Mujer de la Secretaría , así como los fondos de Desarrollo de las Naciones Unidas para la Mujer y el Instituto Internacional de Investigaciones y Capacitación para la Promoción de la Mujer, para que funcione como secretaria y también desempeñe actividades operacionales en los países".

La Entidad consta de una Junta Ejecutiva con una estructura transversal

todos los niveles de la administración pública. En este sentido, y dando cumplimiento a la Ley de Igualdad, el Instituto ejecuta el "Programa de mainstreaming de género" que tiene como objetivo principal incorporar la transversalidad de género en los diferentes ámbitos de intervención de las políticas públicas, en particular, a través del asesoramiento a los centros directivos de la Administración General del Estado, la Autoridad de Gestión del Fondo Social Europeo, y a otro tipo de organismos, como por ejemplo redes transnacionales y Comunidades Autónomas. Este programa está cofinanciado por el Fondo Social Europeo.Según el Consejo de Europa de 1998 la transversalidad de género, también conocida por su denominación en inglés "mainstreaming de género" es: "la (re)organización, mejora, desarrollo y evaluación de los procesos políticos para incorporar, por parte de los actores involucrados normalmente en dichos procesos, una perspectiva de igualdad de género en todos los niveles y fases de todas las políticas". La transversalidad de género es una estrategia eficaz para el avance en la consecución de la igualdad entre mujeres y hombres en las políticas públicas y supone contribuir a eliminar desigualdades de género, corregir procedimientos y métodos de trabajo e impulsar tendencias de cambio social. No se trata de una aplicación esporádica de medidas puntuales sino de la aplicación de políticas transversales de género que supongan un cambio estructural y social. 
(A/Res/64/289 párrf. 57 a 68) en la que participan 49 Miembros --bajo el criterio de distribución geográfica equitativa--, estará regido por unos Principios generales, dispondrá de apoyo de la Secretaria y participara tanto en los procesos normativos de la Organización como en actividades operacionales. ONU-mujeres informará tanto a la Asamblea General como al Consejo Económico y Social (http://www.unwomen.org/ es). Por último, recordar que su creación, a través de la A/Res. 64/289 "Coherencia del sistema", de 21 de julio de 2010, es resultado de los trabajos de la Cumbre Mundial de 2005, e intenta racionalizar las actividades operacionales de la Organización dirigidas a la cooperación para el desarrollo.

El ente "ONU- Mujeres" incorpora el carácter transversal de la cuestión de género focalizado en a la esfera de la cooperación, pero la noción va más allá ya que también opera en materia de mantenimiento de la paz y la seguridad internacional. El Consejo de Seguridad adoptó la Resolución 1325 de 31 de octubre de 2000; en ella se incorpora el concepto de la "Transversalidad" en un doble sentido; por un lado la situación de vulnerabilidad que supone para las mujeres el estar viviendo un conflicto armado, tal como ya se refleja en el derecho internacional humanitario, y por otro lado se contempla la participación de las mujeres como miembro de las operaciones de mantenimiento de la paz y en su dirección y organización.

\section{b) Bioética}

La conveniencia de formular postulados "éticos" en el campo de la ciencia de la vida, desemboca en la aproximación bioética de la investigación científica y la medicina. Sus postulados en un mundo global, han tomado una dimensión internacional muy marcada a partir de los avances realizados en la identificación del genoma humano y su aplicación en la clonación.

En el momento que entra plenamente en la esfera internacional, se incorpora en las actividades de las Organizaciones internacionales, en la medida que inciden en su área de competencias. Interesa ver como se soluciona la confluencia de OOII y órganos de las mismas OOII, que están implicados en el tratamiento del tema con incidencia en el amplio espectro que supone la aproximación bioética.

El carácter transversal de las cuestiones bioéticas ha conducido a que en 2003 se estableciese un "Comité Interinstitucional de las Naciones Unidas sobre bioética" ${ }^{114}$ para gestionar la concurrencia de entes con potencialidad de coincidir en sus actividades en el cumplimiento de sus objetivos ${ }^{115}$.

El Comité tiene como objetivo la acción coordinada de los diferentes entes,

\footnotetext{
${ }^{114}$ Establecido por iniciativa del Director General de la UNESCO Sr. Matsuura. La denominación más frecuente es en lengua inglesa: United Nations Inter - Agency Committee on Bioethics (UNIACB)

115 Como organizaciones y órgano implicado cabe señalar: FAO, OIT, UNESCO, OMPI, OMS, alto Comisionado de las Naciones Unidas para los derechos humanos.
} 
acción que como pone de manifiesto H. BOUSSARD (2008 p. 376), puede calificarse de carácter positivo y/o negativo . La idea es interesante y refleja una constante en las relaciones entre OOII.

Se considera una coordinación negativa aquella que consigue que únicamente un órgano desarrolle la actividad y los demás entes dejan de ocuparse del tema, con ella se evita la duplicidad de textos y se fundamenta en la aplicación estricta del "principio de especialidad". Por el contrario, la coordinación positiva será aquella que es capaz de sumar esfuerzos recogiendo de cada organismos especializado su aportación, y esta se integra en un único texto resultante, que será la suma de todas las aportaciones.

De acuerdo con el estudio citado de H. BOUSSARD (2008, p.378), el Comité interinstitucional sobre bioética, constituye una "solución dinámica" que pretende evitar no solamente la duplicación sino también la contradicción de las normas.

A pesar de algunos problemas para el estudio de los trabajos del Comité de coordinación, como es por ejemplo la publicación de sus actividades directamente ${ }^{116}$, o incluso algunos problemas de coordinación con las entidades no gubernamentales, me estoy refiriendo a las asociaciones de científicos reconocidos en la materia, que llevan una coordinación paralela y no participan en el Comité. Su actividad se califica, siguiendo el razonamiento de H. BOUSSARD, de coordinación positiva y de cooperación entre las instituciones que la componen.

El trabajo del Comité está encaminados a potenciar la coherencia del sistema internacional, buscando la conciliación entre los aspectos del comercio y de la ética, la armonización de posiciones, y el reforzamiento normativo de los textos que se adoptan, plasmándose en la formalización jurídica de las normas bioéticas en la esfera internacional, plasmadas en las Declaraciones de la UNESCO: la Declaración Universal sobre el Genoma Humano y los derechos humanos de 11 de noviembre 1997, la Declaración Internacional sobre los Datos Genéticos Humanos, de 16 de octubre de 2003 y la Declaración universal sobre Bioética y Derechos Humanos de 19 de octubre 2005.

\section{c) Gestión de Internet}

Las implicaciones de Internet, en la esfera internacional, inciden directamente ya en la propia concepción de lo que es de dimensión internacional, ya que su forma de operar es al margen de la división del mundo en estructuras de poder de base territorial. Puede considerarse una de las herramientas de la denominada globalización; las nuevas tecnologías de la información y las comunicaciones (TIC's) son tanto un medio de desarrollo en la esfera de comercio, y educación (por poner dos ejemplos) como un fin en si mismo que debe gestionarse, como ilustra el término

${ }^{116}$ El Comité, sesiona a puerta cerrada, y desde su creación tiene una secretaría que corre a cargo de la UNESCO 


\section{"gobernanza".}

El tema de "gobernanza" ${ }^{117}$, entiendo que debe afronta el hecho de que la tecnología de Internet se inició y gestó en los Estados Unidos ${ }^{118}$, por tanto un liderazgo de este Estado. Pero al mismo tiempo su uso por naturaleza es global, de carácter planetario y cuya gestión opera al margen de las fronteras político/geográficas y que está forzada a convivir con la gestión de intereses particulares, lo cual evidencia la tensión entre ambas percepciones; la noción de gobernanza debe dar salida a esta tensión. Esta realidad fáctica ha conducido a calificar el fenómeno de naturaleza ajurisdiccional (GIBBONS, 1997), o bien contemplar que jurídicamente se califique de "patrimonio común de la humanidad", como se hizo en su momento con los fondos marinos y de determinados bienes culturales de acuerdo con el Convenio de la UNESCO, y de algunos convenios ambientales por el tipo de obligaciones que asumen los Estados parte; vía, que tal como pone de manifiesto la investigación de SEGURA SERRANO (2006, p.254 y ss), daría salida a las propuesta de gobernanza de la Cumbre Mundial de la Sociedad de la Información.

El marco del proceso de negociación de la "gobernanza" es la Cumbre Mundial sobre la Sociedad de la Información, organizada a través de conferencias y diferentes grupos de trabajo. En este contexto se aprobó el texto de referencia en

${ }^{117}$ En el marco del Grupo de trabajo sobre gobernanza de Internet se llego a la siguiente noción en 2007: "la gobernanza de Internet es el desarrollo y la aplicación por los Gobiernos, el sector privado y la sociedad civil, en las funciones que les competen respectivamente, de principios, normas, reglas, procedimientos de adopción de decisiones y programas comunes que configuran la evolución y la utilización de Internet"

118 "A finales de la década de 1960, el gobierno de los Estados Unidos patrocinó el desarrollo de la Agencia de Proyectos de Investigación Avanzada para la Defensa (DARPANet por sus siglas en inglés), un servicio de comunicación flexible diseñado para sobrevivir en caso de un ataque nuclear.Para la década de 1980, una comunidad internacional más amplia estaba ya utilizando las facilidades de esta red, la cual para este momento ya era conocida como Internet. En 1986 se estableció la Fuerza de Tareas de Ingeniería para Internet (IETF por sus siglas en ingles). La IETF administró el sucesivo desarrollo de Internet por medio de un proceso de toma de decisiones cooperativas y consensuales que involucraba a una amplia variedad de individuos. No existía ni gobierno ni planificación central y no contaba con un diseño maestro.(...) Sin embargo en 1994, la Fundación Nacional de las Ciencias de los Estados Unidos (NSF por sus siglas en inglés) decidió involucrar al sector privado subcontratando la administración de Nombres de Dominio (DNS por sus siglas en inglés) a la empresa Network Solutions Inc (NSI). Este paso no fue bien recibido por la comunidad internacional y dio inicio a la "guerra del DNS".Esta "Guerra del DNS" involucró a las partes interesadas: el sector comercial, las organizaciones internacionales y los gobiernos de otras naciones. Esta guerra finalizó en 1998 con el establecimiento de una nueva organización, la Corporación de Internet para la Asignación de Nombres y Números (ICANN).Desde 1998 y desde la incorporación de ICANN, el debate sobre la gobernanza de Internet se ha caracterizado por una participación más intensa de los gobiernos de diferentes naciones." (KURBALIJA, J., GELBSTEIN,E., 2005 p.9). 
dos fases, en la reunión de Ginebra de 2003 y la de Túnez de 2005, en las que se adoptó: la declaración de Principios y el plan de acción de Ginebra y la agenda de la Sociedad de la Información (http://www.itu.int/wisis), dirigida a la búsqueda de la gobernanza.

$\mathrm{Su}$ organización, junto con los grupos de trabajo también tiene una organización territorial por países. El órgano de seguimiento en NNUU es la Comisión de Ciencia y tecnología para el desarrollo (CCTD) que asiste al Consejo Económico y Social como centro de coordinación en el sistema de seguimiento de la Cumbre Mundial.

\section{Proceso de institucionalización en Ámbitos Sectoriales}

El tercer punto y último a comentar, es poner de manifiesto el hecho de que surgen "secretarias" que se ocupan de temas específicos y que tienen una relevancia determinada sin llegar a poder considerarse, todos los casos, de OOII en los términos concretos de ser sujetos de derecho internacional.

Secretarias, que responden a un proceso de institucionalización de las relaciones entre Estados, y se han articulado en torno a procesos político-diplomáticos o de carácter técnico, tienen en común en ambos casos que operan en un área geográfica determinada.

Ejemplos de las que denominamos, en estas páginas, proceso de carácter político-diplomático, responde las Secretarias de las Cumbre Iberoamericanas (DIAZ-BARRADO, 2007) y la Secretaria de la Unión por el Mediterráneo (BADIA, 2011). Tienen en común su origen en reuniones periódicas de representantes de los Estados, mediante la fórmula de conferencias en las que participan representantes de Estados de un área geográfica determinada, y como evolución de los acuerdos tomados en su seno se adoptan las secretarias, ambas con personalidad jurídica internacional.

Con origen compartido de reuniones de representantes de los Estados, pero de carácter distinto, que se ha denominado en estas páginas de carácter técnico, no encontramos con la Secretaria del Tratado Antártico. En este caso se trata de la gestión internacional de un espacio geográfico, el continente Antártico a través de un Régimen Internacional para la protección de intereses generales de la Comunidad Internacional, relativo al espacio geográfico del continente Antártico, sus recursos y, la protección del medio ambiente.

Desde que se instauró el Sistema del Tratado Antártico en 1959, con el Tratado de Washington, la administración del sistema correspondía cada año por turno a uno de las Estados Antárticos, con estatus consultivo, es decir aquellos Estados que además de ser parte del Tratado de Washington, realizan investigación científica en la Antártida. 
El aumento del número de Estados ${ }^{119}$ en el sistema y el incremento de actividades derivadas de la potencialidad de la investigación realizada, ha facilitado adoptar la decisión, en la reunión de las Partes Consultivas de 2001, no sin antes haberse discutido ampliamente ${ }^{120}$ la conveniencia de su establecimiento (CONSIGLI).

La Secretaria (http://www.ats.aq/index.htm) se estableció en 2003 en Buenos Aires, tal como se acordó en la Medida 1(2003), como órgano de la Reunión Consultiva del Tratado Antártico y subordinado al mismo y a la que dará apoyo así como a la Comisión para el Medio Ambiente, establecida en el Protocolo de 1991 sobre la protección del medio ambiente.

En el artículo V, de la Medida citada de 2003, se refiere a la "Capacidad jurídica y privilegios e inmunidades" de que disfrutara la Secretaria, y nos remite a la celebración de un Acuerdo de Sede a negociar entre el gobierno de Argentina y la presidencia de la Reuniones consultivas.

El Acuerdo de Sede se firmó el 10 de mayo de 2010, justifica su establecimiento en el cumplimiento de los objetivos del Tratado Antártico, y nos recuerda al carácter funcional del "órgano", al que le reconoce capacidad jurídica en el ordenamiento Argentino "...compatible con el derecho internacional” (art, 4 párrf. 1 del Acuerdo de Sede). Su contenido es muy parecido a los acuerdos de Sede de las Organizaciones Internacionales, aunque en este caso no se le reconoce expresamente personalidad jurídica internacional (HUBER, J).

La Secretaría del Tratado, tienen la particularidad de la expresa mención a que no tiene personalidad jurídica internacional y es relevante ante el ordenamiento interno argentino. Además, Anexo a la Decisión 3 (2003) se incluye un "Reglamento del personal de la Secretaría del Tratado Antártico", que se refieren al personal que trabajara para la Secretaria, estableciéndose su Estatuto y tal como puede leerse en el Preámbulo “... establece los principios fundamentales de empleo, regula las relaciones laborales y establece los derechos y deberes de los empleados de la Secretaria del Tratado Antártico ..... y comprende a los Miembros del personal que prestan sus servicios y reciben remuneración de la Secretaría del Tratado Antártico". El estatuto del personal de la secretaria es muy particular, ya que por un lado este esta formalizado en un texto de naturaleza internacional, pero que trabajan en un ente que tiene reconocida personalidad jurídica en el ordenamiento interno argentino, no en el conjunto de ordenamientos internos de los Estados que han acordado su creación.

11926 partes consultivas y 11 no consultivas.

${ }^{120}$ Parece que la primera Reunión consultiva que trato el tema fue en 1983, en Camberra. 
Asentada la personalidad jurídica internacional de las Organizaciones Internacionales y, su versatilidad en el momento de delimitar su condición de sujeto, la práctica muestra que en ocasiones se prescinde de esta condición jurídica.

La opción de acudir a otros modelos de actuación, erosiona el liderazgo de la organización en el tema en que es competente, la cuestión es de mayor enjundia si se trata de órganos de Organizaciones internacionales con competencias específicas y poco frecuentes.

En concreto, a mi juicio no puede valorarse de la misma forma, que se actué al margen del Consejo de Seguridad en una actuación directamente cubierta por la noción de "seguridad colectiva", frente a que se articulen medidas económicas, en paralelo, a las organizaciones internacionales universales y regionales con competecias en la materia. La razón estriba en que en el primer caso hay una sustitución de la actividad, no se decide en el seno del Consejo de Seguridad, y se actúa bajo el liderazgo unilateral, aunque el órgano competente sigue tratando el tema vinculado al mantenimiento de la paz y la seguridad internacional, pero no toma "medidas".

Por lo que se refiere a la cuestión económica no creo que pueda decirse que se actúa en "sustitución" de las Organizaciones económicas. También señalar que no hay un equivalente al "sistema de seguridad colectiva" en materia económica. El papel del poder público en este ámbito es distinta, las imbricaciones del elemento económico se gestiona a través de otros entes en los que juegan un papel determinante las empresas transnacionales, y las Organizaciones de Integración, cuando estas funcionan, no pueden equiparase a las de cooperación.

Las actuaciones al margen, o en paralelo, del modelo institucionalizado, entiendo que no ponen en tela de juicio su función en la gestión de los intereses de la Sociedad internacional. Cabe valorarlo, como una búsqueda de modelos de relación distintos y que va en consonancia con los vaivenes que se producen en la Sociedad Internacional. La línea que permite distinguir entre cooperación internacional institucionalizada de la que no lo es, es variable, así de acuerdo con los términos utilizados podría calificarse de una línea que no es estática. Desde mi punto de vista el elemento central es, su apreciación desde la perspectiva jurídica internacional; aproximación que subsiste junto con otras que tienen su base en diferentes áreas de conocimiento: ciencias políticas, relaciones internacionales, economía, historia; pero es el ordenamiento jurídico internacional el que las provee de subjetividad.

Una hipótesis que se nos planteaba al principio de la exposición, era considerar si en determinados ámbitos se ha superado la participación y actividades de las OOII en un sentido técnico jurídico, es decir desde la perspectiva formal. Entiendo que su consideración jurídica se mantiene en los mismos términos desde su conceptuación en 1949 por la Corte Internacional de Justicia, y siempre permeable a formalizar relaciones de diferente naturaleza protagonizadas por diferentes sujetos.

El punto nuclear, entorno al que gira las reflexiones de este trabajo es plantear como conviven el conjunto de Organizaciones Internacionales, y si en esta coexistencia entre los sujetos, podemos seguir hablando de los principios de "especialización y coordinación ", al menos como principios informadores para armonizar 
su coexistencia.

Si nos atenemos los temas seleccionados de: "Transversalidad del género", bioética y gobernanza de Internet, los tres tienen en común que buscan como incidir en la actuación de los "entes" implicados en el tema, buscando una cierta racionalización; además también muestra que existe una redefinición de los términos en que se enuncian los objetivos de cada Organización, así como una reinterpretación de sus competencias.

Esta realidad muestra, que efectivamente hay una preocupación en como ordenamos la cohabitación de las diferentes OOII, y que no existe principio jurídico alguno que nos ayude a solucionarlo, al menos de momento. También es cierto que se trata de un tema abierto, las actuaciones emprendidas para armonizar son diferentes pero muestran su potencialidad como vía abierta.

La "transversalidad del género" se gestiona a través de un "Ente" -ONUmujeres-, término que indica que no estamos ante una nueva Organización internacional, pero sí que actúa dentro de NNUU y tiene un marcado carácter operacional, ya que está destinado a la cooperación para el desarrollo y tiene el mismo carácter cuando nos referimos al mantenimiento de la paz y la seguridad internacional.

El tema de la Bioética, se gestiona a través de un órganos, cuya particularidad reside en sus componentes que son designados para participar por diferentes órganos a su vez de diferentes Organizaciones Internacionales. Su operatividad es cuestionada, y entiendo que se debe a una pugna por el liderazgo en la materia.

La "gobernanza" de Internet, bajo el paraguas de la Conferencia sobre nuevas tecnologías, no creo que signifique ninguna novedad, ya que en si mismo es convocar a todos los que tienen algo que decir e interés en el tema. Por el contrario, la gobernanza de Internet, si que constituye un reto en sí mismo, al que entiendo caben diferentes opciones: Tratar y gestionar punto por punto en los que incide, con lo cual prácticamente entra en el ámbito competencial de todas las OOII. Otra posibilidad, compatible con la anterior, es la gestión internacional de la técnica que permite internet, es decir el sistema de las comunicaciones. Para ello caben dos posibilidades., o bien se incorpora plenamente a la UIT (Unión Internacional de las Comunicaciones), que por materia le correspondería, o bien se crea una Organización nueva, cuya composición se adecue a los intereses en presencia. Actualmente continúa siendo una cuestión abierta y con el marco de negociación en conferencias internacionales.

La aportación que suponen las "secretarias", es interesante pero es un mecanismo errático, en el sentido que es acomodaticio, y se muestra con una cierta discrecionalidad en el momento de establecer bajo que rama del derecho se instituye. $\mathrm{Su}$ aportación, reside en mostrar el carácter instrumental que tiene el proceso de institucionalización de las relaciones internacionales, y que este depende del interés mostrado por sus Miembros, tanto desde la perspectiva unilateral -como reflejo de las pretensiones individuales — como por el tema en sí del que se ocupa la Secretaria. 


\section{Bibliografía Citada}

\section{JURISPRUDENCIA}

Reparation for Injuries Suffered in the Service of the United Nations, Advisory Opinion, ICJ Reports 1949

Interpretation of Agreement of 25 March 1951 between the WHO and Egipt, Advisory Opinion, ICJ Reports 1980

Legality of the threat or use of nuclear weapons, Advisory Opinion, ICJ Reports 1996.

\section{Bibliografía}

BADIA MARTI, A.M. "Modelos de cooperación institucionalizada entre los Estados: Puntos de conexión con la Unión por el Mediterráneo" en La Unión por el Mediterráneo: retos de la cooperación institucionalizada en la región L. HUICI (Coord), Colección Tribuna Internacional, nº 11 Edit. Marcial Pons, 2011 pp 31-52

BOISSON DE CHAZOURNES, L. "Les relations entre organisations régionales et universelles", R.C.A.D.I, 2010, tomo 347.

BOUSSARD, H. "La coordination des organisations internacionales: 1'exemple du comité interinstitutions des Nations Unies sur la bioéthique" en Revue Francaise d'Administration Publique, vol 126, 2008 pp. 373-385.

CARRILLO SALCEDO, J.A."Reforma de las Naciones Unidas o aplicación del espíritu y la letra de la Carta" en El Derecho Internacional ante los retos de nuestro tiempo, Homenaje a la Profesora Victoria Abellán, Marcial Pons 2009 pp. 115-130.

CONSIGLI J.A. "The Antartic treaty secretariat: the first three years' experience" in The Antartic Legal pp. 143-152

CORTÉS MARTÍN J.M: Las Organizaciones internacionales: Codificación y Desarrollo Progresivo de su Responsabilidad Internacional, Instituto Andaluz de Administración Pública, 2008.

DIAZ BARRADO, C.,"Tres propuestas para el fortalecimiento y la articulación de la Comunidad Iberoamericana de Naciones" en ALDECOA LUZARRAGA F. y SOBRINO HEREDIA J.M. (coords) Migraciones y Desarrollo, Marcial Pons, Madrid 2007, pp. 195-212

DIEZ DE VELASCO, M. Las Organizaciones Internacionales, Décimo sexta edición coordinada por J.M Sobrino Heredia, Tecnos, 2010

FOMERAND J. DIJKZEUL D., "Coordinating econòmic and social affairs", en WEISS T.G DAWS S. The Oxford handbook on the United Nation, Oxford Univer- 
sity Press, 2007.

GIBBONS, L.J. "No regulation, Goverment Regulation or Self-regulatión: Social Enforcement or Social Contracting Governance in Cyberspace", Cornell Journal of law \& Public Policy, 6 (1997) pp. 175 y ss

GUTIERREZ ESPADA, C La responsabilidad internacional de Estados y organizaciones (balance provisional de coincidencias y matices), Edit. Diego Marín, Librero Editor. 2010 p. 27-28.

HUBER, J. "The Antarctic Treaty: Toward a New Partnership" en Science Diplomacy: Antarctica, science, and the governance of International spaces, Washington DC: Smithsonian Institution scholarly Pres, pp. 89-95

KURBALIJA, J., GELBSTEIN, E. Gobernanza de Internet asuntos, actores y brechas, DiploFoundation, 2005.

MARTIN Y PEREZ DE NANCLARES, J. E, "El Derecho Internacional Público ante los interrogantes de una Sociedad internacional en cambio permanente: ¿Hacia una cierta relativización de su caràcter jurídico, internacional y público?" en Estados y organizaciones internacionales ante las nuevas crisis globales, Edit Iustel 2010,

PONS RAFOLS X "Estados soberanos y cooperación multilateral: el papel de las organizaciones internacionales " en Estados y organizaciones internacionales ante las nuevas crisis globales, Edit. Iustel 2010, p.123

RODRIGUEZ MANZANO,I., Mujeres y Naciones Unidas, igualdad, desarrolllo y paz, , Edit. Los libros de La Catarata, 2008.

SEGURA-SERRANO, A. "Internet Regulation and the Role of International Law", Max Planck UNYB 10 (2006). 

LA PROTECCIÓN DE LOS SOCIOS MINORITARIOS EN LA NUEVA LEY DE GOBIERNO CORPORATIVO

The protection of minority shareholders in the new law on corporate governance

\author{
Daniel Vázquez Albert
}

Profesor da Universidad de Barcelona.Email: dvazquez@ub.edu

\title{
Pedro Pablo Pérez Carbó
}

Investigador en formación del Instituto de Investigaciones Jurídicas de la Universidad de Barcelona

\section{RESUMEN}

La protección de los socios minoritarios en la nueva ley de gobierno corporativo, analiza la actualidad normativa que afecta los derechos de esta minoría en las sociedades de capital no cotizadas -regulados en el Proyecto de Ley de 30 de mayo de 2014,por el que se modifica la Ley de Sociedades de Capital para la mejora del gobierno corporativo-. Es una temática abordada con interés por la Comisión Europea a través de los planes de modernización del Derecho de Sociedades, que ha sido asumida por España; para implicar de manera más activa a los socios minoritarios en la supervisión de las sociedades de capital. Este trabajo analiza, describe y evalúa, si el alcance de los nuevos preceptos legales responde a los objetivos del legislador y a los principios de buen gobierno corporativo aplicables a las sociedades no cotizadas. La relevancia del tema radica, en primer lugar, en que aborda la regulación de los derechos de socios minoritarios sometidos a prácticas abusivas frecuentes por parte de los mayoritarios -una temática no resuelta por el legislado español-. En segundo lugar, en que más del ochenta por ciento del tejido económico español está conformado por sociedades no cotizadas afectadas por las consecuencias negativas de prácticas abusivas -que perjudican el buen gobierno corporativo y la eficiencia empresarial-y; en tercer lugar, por ser una cuestión hasta ahora poco abordada desde esta perspectiva. Para cumplir los objetivos propuestos sigue una estructura de tres apartados; el primero analiza los derechos y facultades de los socios minoritarios en sede de junta general; el segundo el derecho de estos a impugnar los acuerdos sociales y; el tercero el derecho a conocer la identidad de todos los socios de la mercantil en cuestión. 
Palabras clave: Gobierno corporativo. Socios minoritarios. Abuso de derecho. Códigos DE BUEn GOBIERNO. DeRECHOS DE MINORÍAS.

\section{Abstract}

The protection of minority in the new law of corporate governance partners, analyzes current legislation that affects the rights of this minority in capital companies unlisted-regulated in the Draft Law of 30 May 2014 laying modifies the Corporations Act for the improvement of corporate governance. It is a topic addressed forward by the European Commission through the modernization of company law, which has been assumed by Spain, to engage more actively to the minority shareholders in monitoring capital companies way. This paper analyzes, describes and evaluates whether the scope of the new legal provisions to meet the objectives of the legislator and the principles of good corporate governance applicable to unlisted companies. The relevance of the issue lies, first, in addressing the regulation of the rights of minority shareholders under common unfair practices by the majority-a topic not settled by the Spanish legislated. Second, when more than eighty percent of the Spanish economic fabric consists of unlisted companies affected by the negative consequences of abusive practices -that hurt good corporate governance and business efficiency- and; thirdly, as a matter hitherto little studied from this perspective. To meet the objectives follows a structure of three sections; The first analyzes the rights and powers of minority shareholders in general meeting headquarters; the second their right to challenge corporate resolutions and; the third party the right to know the identity of all members of the corporation in question.

key words Corporate governance, minority shareholders, abuse of rights, good governance codes, minority rights.

Keywords: Corporate governance. Minority shareholders. Abuse of rights. GOOD GOVERNANCE CODES. MiNORITY RIGHTS

SUMARIO: Introducción. 1. Derechos y facultades de los socios minoritarios ante la Junta General. 2. Impugnación de los acuerdos sociales. 3. Derecho a conocer la identidad de todos los sócios. Conclusiones. Bibliografía 


\section{INTRODUCCIÓN}

Los derechos de los accionistas en general y, en especial, la influencia real y efectiva de los socios minoritarios en la junta general, sigue siendo una cuestión de creciente interés y amplio debate internacional. Nuestra apuesta decidida a contribuir a las múltiples discusiones sobre el tema, nos obliga a traer a colación la reciente y significativa modificación que en el estatus de las minorías societarias, introduce el Proyecto de Ley, de 30 de mayo de 2014, por el que se modifica la Ley de Sociedades de Capital para la mejora del gobierno corporativo ${ }^{121}$.

En España los códigos de buen gobierno o soft law junto con el principio de cumplir o explicar, constituyen una vía acertada para alcanzar gran parte de los objetivos de buen gobierno corporativo. Así mismo representan una guía del comportamiento ético a seguir en el tema que nos ocupa, una tendencia sostenida en los principales países de la Unión Europea y en los más desarrollados de otras áreas geográficas. La OCDE sostiene que, a diferencia de la regulación prudencial, estos siguen siendo una alternativa a la regulación.

La crisis económica y financiera actual ha demostrado la relevancia de los mencionados códigos en el ámbito de las sociedades cotizadas. Ese mismo contexto ha confirmado también que, aspectos hasta hace poco no exigibles a todas las sociedades de capital, deberían aplicarse al resto del tejido societario no cotizado, que por cierto, constituye la mayor parte en España, lo cual es otro elemento que muestra la dimensión e impacto de esta temática.

La experiencia societaria actual reafirma que, no obstante sus fortalezas, estos principios de actuación no son suficientes, por lo que recomendamos combinarlos con un sistema de normas de obligado cumplimiento. Es esta una justificación adicional por abordar las modificaciones que introduce la LGC en la Ley de Sociedades de Capital ${ }^{122}$, como otro intento de complementar y actualizar las demandas de las minorías societarias.

El objetivo fundamental del presente trabajo, es analizar las modificaciones legislativas que en materia de derecho de sociedades no cotizadas, afectan los intereses de las minorías societarias en la LGC de 2014. La misma fue encargada por el Consejo de Ministros en 2013, a un grupo de expertos en la materia. La pretensión de modificar la Ley de Sociedades de Capital para la mejora del gobierno corporativo, formaba parte desde entonces, del Plan Nacional de Reformas.

La necesidad de amparo de las legítimas expectativas de los socios minoritarios, fue uno de los particulares temas encargados a la mencionada comisión, puesto que particularmente la protección de los socios minoritarios es una exigencia derivada de la necesaria salvaguarda de la propiedad privada ${ }^{123}$. Ello evidencia la

${ }^{121}$ En lo sucesivo LGC -Ley de Gobierno Corporativo de 2014-.

${ }^{122}$ En lo sucesivo LSC.

${ }^{123}$ Vázquez Lepinette, T. La protección de las minoríassocietariasfrente a la opresión (145 
prioridad de este asunto dentro de los objetivos nacionales de alcanzar, el más alto nivel de cumplimiento de los criterios y principios internacionales de buen gobierno. Prioridad reforzada por un sinnúmero de iniciativas, cuya aplicación se ha acelerado desde el inicio de la crisis financiera. En sintonía con nuestra comprensión de la magnitud de su impacto en las sociedades no cotizadas, el legislador las ha incluido en la LGC.

Entre las más recientes iniciativas para la promoción de buenas prácticas de gobierno corporativo, vale destacar: el Código Unificado de Buen Gobierno de las sociedades cotizadas, de 2006; el Texto Refundido de la Ley de Auditoría de Cuentas, de 2010; la Ley 2/2011 de Economía Sostenible; la Ley 25/2011 de reforma parcial de la Ley de Sociedades de Capital y de incorporación de la Directiva 2007/36/CE del Parlamento Europeo y del Consejo, sobre el ejercicio de determinados derechos de los accionistas de las sociedades cotizadas. A las anteriores podríamos agregar las Propuestas de Código Mercantil de 2013 y 2014, que con sus diferencias, aportan al análisis de los derroteros a seguir en esta temática.

La solución y límite de gran parte de las prácticas opresivas contra el socio minoritario, pasa actualmente por las decisiones judiciales. La nueva Ley introduce modificaciones en la regulación de las expectativas de las minorías en las sociedades de capital cotizadas y no cotizadas para contribuir a rebajar la conflictividad societaria y la carga de los órganos de justicia.

Así hemos desarrollado un trabajo de carácter documental teniendo como base la importancia de las sociedades no cotizadas en el tejido empresarial español. Describiendo, analizando y evaluando, con sentido crítico, el alcance de los preceptos legales introducidos, en todo cuanto concierne a la eficacia de su cometido respecto a la salvaguarda de los derechos del socio minoritario.

La intención de aportar nuestra posición a la discusión y mejora de la protección de las minorías societarias, nos ha planteado estructurar el análisis en tres apartados que han respetado -en su desarrollo lógico- la técnica jurídica utilizada por el legislador en la creación de la norma. En consecuencia: por una parte analizamos los derechos de las minorías relacionados directamente con la actividad de la junta general, por otra, la capacidad de estos para impugnar las decisiones que les afecten y, por último, el derecho a conocer la identidad de la totalidad de socios de la mercantil en cuestión, constituyendo un mecanismo adicional de organización para el ejercicio de los derechos de las minorías, ante los acuerdos de la Junta General.

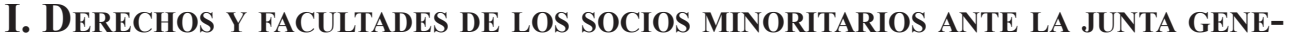 RAL}

La junta general constituye uno de los más importantes espacios de realiza-

p.). Editorial Aranzadi, SA. Cizur Menor (Navarra). 2007. (p. 70). 
ción de los derechos del socio minoritario ${ }^{124}$. Las decisiones que en ella se adoptan, afectan la organización empresarial y el ejercicio de los derechos del socio. Aunque existen competencias aplicables a la junta general de los diferentes tipos societarios capitalistas, debe tenerse en cuenta las especificidades de cada una, realizables a través de una autonomíalimitadaque alcanza también a lafacultad de redacción de los estatutos sociales.

Las modificaciones relativas a la junta general han pretendido reforzar su papel en la actividad social y fomentar la participación de los socios. Unas reformas nutridas esencialmente de los Planes de acción -que en los últimos años ha emprendido la Comisión Europea, enfocándose en las sociedades cotizadas- en los que para conseguirla modernización del Derecho de sociedades, prioriza los derechos del socio.

Los derechos políticos o administrativos del socio minoritario ante la junta generalson de diversa naturaleza. Siguiendo los pasos del legislador, hemos considerado conveniente analizar: (i) el derecho de convocatoria de la junta general extraordinaria; (ii) el derecho de asistencia i voto; (iii) el derecho de adopción de acuerdos y; (iv) el derecho de información del socio.

\section{Convocatoria de la junta general extraordinaria}

La solicitud de convocatoria ${ }^{125}$ de junta general es una de las materias que -según el propio legislador- se encuentra mejor adaptada a la normativa europea, al destacarse respecto de las legislaciones de sistemas jurídicos comparables. Ello condicionó que solamente considerase procedente ajustar algunos elementos capaces de elevar el nivel de transparencia, cuestión que coadyuva a la disposición de información fidedigna que necesita el socio medio para formarse un criterio y ejercitar sus derechos.

En el régimen actual de la junta general, la facultad de convocarlaes de los

${ }^{124}$ El socio minoritario es, según el consenso doctrinal, el que dispone individual o colectivamente de una participación del cinco por ciento en las sociedades no cotizadas y del uno por ciento en las sociedades cotizadas. A partir de este criterio cuantitativo se establecen los derechos de minoría en las sociedades de capital.

${ }^{125}$ En la vigente Ley de sociedades de Capital, la convocatoria de junta general ordinaria y extraordinaria constituye, por imperativo legal, facultad de los administradores (artículo 166 LSC). En el supuesto que la administración se confiera a varios administradores solidarios, cualquiera de ellos estará facultado para convocar la junta general, si es a varios administradores mancomunados y alguno de ellos es cesado en el cargo, cualquiera de los otros podría convocarla. (SAP Tarragona 10.7.1997 y SAP Jaén 22.5.2001. en Moralejo, Ignacio. en Rojo Fernández-Río, Ángel (Dir) [y otros]. Comentario de La Ley de Sociedades de Capital.Cizur Menor, Navarra : Civitas Thomson Reuters, (p. 1229). 2011.). 
administradores, pero la iniciativase extiende a los socios ${ }^{126}$ que ostenten, individual o colectivamente, el cinco por ciento del capital social ${ }^{127}$ (artículo 168 LSC). De esta manera si los administradores no cumplieran con su deber de convocatoria dentro de los dos meses siguientes contados desde la fecha de presentación del requerimiento, los socios titulares del cinco por ciento, podrán presentar el requerimiento ${ }^{128}$ notarial alegando incumplimiento del mandato legal impuesto al órgano de administración.

El impulsode la convocatoria ejercitado por los socios minoritarios, debe dirigirse al órgano de administración de la sociedad y contener el orden del día de los asuntos que son de interés a tratar, teniendo en cuenta que dada la naturaleza de la pretensión, deberán incluirse asuntos propios de las juntas generales extraordinarias.

A partir de ello los administradores están obligados, por imperativo legal, a incluirlos en la convocatoria que deberán realizar mediante un anuncio en el BOR$\mathrm{ME}^{129} \mathrm{y}$ en el portal web de la sociedad o, para las que no dispongan, pueden utilizar el diario de mayor circulación de la provincia del domicilio de la sociedad.

Las sociedades de responsabilidad limitada -si lo han previsto estatutariamente-podrán utilizar otros medios, entre los que cabe destacar: un diario de circulación del término municipal del domicilio social u otros medios de comunicación individuales y escritos que permitan la recepción de la convocatoria.

Tengamos presente que en el supuesto que no consten en la solicitud los temas a abordar o, aunque incluidos constituyan objeto de las juntas generales ordinarias, estaremos ante una posible causa de exoneración del deber de convocatoria del órgano de administración, con lo cual decaería la iniciativa de los minoritarios.

La recepción de la solicitud de convocatoria de la junta general extraordinaria puede generar, en principio, dos posibles reacciones de los administradores: acceder positivamente a la solicitud convocando la junta general o negarles ese derecho. En el supuesto de negativa, cualquier socio, incluidos los socios en minoría, podrán solicitar al juez de lo mercantil del domicilio social de la mercantil, que realice la convocatoria judicial de la junta general previa audiencia de los administradores (artículo 169 LSC).

${ }^{126} \mathrm{La}$ LSC reconoce a los socios que representen un cinco por ciento del capital el ejercicio de determinados derechos ante conductas sociales que le afecten, estos son denominados por la doctrina como derechos de minorías.

${ }^{127}$ En las sociedades cotizadas, el legislador mantiene un porcentaje fijo del capital para el ejercicio de los derechos de las minorías, respetando la tradición del derecho español, exceptuando la legitimación para impugnar los acuerdos sociales, cuestión a la que nos referiremos más adelante.

128 Para hacer efectivo el requerimiento, los socios deben acreditar su condición de tal. En el caso de las acciones al portador la presentación del título o el certificado del depósito en una entidad autorizada (artículo 122 LSC) y cuando son nominativas la acreditación como inscritas en el libro-registro de acciones nominativas (artículo 116.2 LSC).

${ }^{129}$ Boletín Oficial del Registro Mercantil. 
La LSC respecto a la información previa a la junta general establece que desde la publicación del anuncio de convocatoria y hasta la celebración de la junta general, la sociedad debe publicar ininterrumpidamente en su página web, entre otros, los textos completos de las propuestas de acuerdos o, en caso de no existir, un informe de los órganos competentes, comentando cada uno de los puntos del orden del día. A medida que se reciban, se incluirán también las propuestas de acuerdos presentadas por los accionistas (artículo 518 LSC).

La LGC con la intención de resolver el problema interpretativo de la expresión -propuestas de acuerdo- incorpora cambios en el régimen de la información previa a la junta general al establecer que desde la publicación del anuncio de convocatoria y hasta la celebración de la junta general, la sociedad deberá publicar ininterrumpidamente en su página web los -textos completos- de las propuestas de acuerdo sobre todos y cada uno de los del orden del día o, en relación con aquellos puntos de carácter puramente informativo, un informe de los órganos competentes en el que se computen cada uno de dichos puntos. A medida que se reciban, se incluirán también las propuestas de acuerdo presentadas por los accionistas (artículo 518 PGC).

Es justo celebrar el acierto del legislador en este punto, pues independientemente que la expresión -propuestas de acuerdos- parece referirse básicamente a elementos informativos con escasa repercusión en el fondo de los acuerdos a adoptar, en la práctica ha sido ocasionalmente utilizado para justificar que no se formulen propuestas en relación con todos los puntos del orden del día o que su publicación se haya realizado con posterioridad a la convocatoria ${ }^{130}$.

La legitimación subsidiaria de la minoría (artículo 239 LSC) es sustituida por lalegitimación de la minoría (artículo 239 LGC), cuando precisan la convocatoria de junta general para que se decida sobre la acción de responsabilidad. La norma actual exige que sea la junta general la que decide sobre la pertinencia de ejercitar o no, la acción de responsabilidad.

Con esta diferente calificación la LGC permite que, aquellos socios representantesdel cinco por ciento del capital social, puedan ejercitar por sí mismos la acción de responsabilidad en defensa del interés social en los supuestos en que los administradores no convoquen la junta general solicitada; cuando la sociedad no la presentase en el plazo de un mes contado desde la fecha de adopción del acuerdo; o cuando este hubiera sido contrario a la exigencia de responsabilidad.

El legislador va más allá en la legitimación de la minoría cuando la LGC permite a los socios minoritarios, por una parte, ejercitar la acción social de responsabilidad directamente cuando se fundamente en el incumplimiento del deber de lealtad, ello sin necesidad de contar con la autorización de la junta general y, por la otra, cuando reconoce expresamente el derecho de reembolso de los gastos incurri-

${ }^{130}$ España. Informe de la Comisión de Expertos en materia de Gobierno Corporativo. Creada por Acuerdo del Consejo de Ministros, de 10 de mayo de 2013, publicado por Orden ECC/895/2013, de 21 de mayo. Madrid, 14 de octubre. (96 p.). 2013. (p. 17). 
dos, a los socios que actúen como parte actora, en caso de estimación parcial o total de la demanda(artículo 239 LGC).

Es criticable ${ }^{131}$ la exigencia del cinco por ciento de participación en el capital social para instar la celebración de la junta general extraordinaria, pues si bien es cierto que algún socio podría utilizar la condición que ostenta para alterar el normal funcionamiento de la sociedad ${ }^{132}$, este porcentaje podría ser inferior, con lo cual habría mayor equilibrio entre la limitación del derecho político del socio y la defensa del interés de la sociedad.

Elevar el cinco por ciento requerido para el ejercicio de este derecho es improcedente por tratarse de un derecho reconocido a las minorías. Es aceptada, en cualquier caso, la exigencia de un porcentaje inferior, sobre todo en el caso de grandes compañías (RDGRN 13.1.1994 ${ }^{133}$ ), cuestión positiva para mejorar la participación del socio.

Una vez abordado el derecho a convocar la junta general como un fundamental aspecto que afecta los derechos y facultades de los socios minoritarios ante el principal órgano de gobierno de la sociedad, conviene acercarnos al derecho que les corresponde a asistir a la junta general extraordinaria que han impulsado (artículo 93 inciso c LSC), un derecho de asistencia que no ha de estar relacionado directamente con el derecho de voto, con lo cual estamos ante la posibilidad de que los socios puedan participar de las discusiones sobre los temas del orden del día y no manifestar $\mathrm{s}$ voluntad a través del voto.

${ }^{131}$ La LGC mantiene intacto el cinco por ciento de participación en el capital social regulado en la LSC para las sociedades no cotizadas fundamentándolo en que: (i) esta materia está adaptada a la normativa comunitaria (artículo 6.2 Directiva 2007/36/CE), pues, el análisis del derecho de convocatoria de junta general en otros ordenamientos comparables, muestra la exigencia de porcentajes más altos para que los socios minoritarios puedan solicitarla; la Comisión de Expertos lo justificó en el cinco por ciento exigido en Francia, Alemania, Austria y Portugal y el diez por ciento en países como el Reino Unido, Holanda o Italia. (ii) La omisión de un porcentaje mínimo exigible en la actual normativa comunitaria respecto al derecho de convocar la junta general de accionista permite que el ordenamiento español, al no excederse del cinco por ciento como máximo establecido en los estándares comunitarios (artículo 6.2 Directiva 2007/36/CE), disponga de una calificación positiva.

${ }^{132}$ En cuanto a las sociedades cotizadas, celebramos la novedad que el Proyecto de Ley introduce en cuanto a la posibilidad de convocatoria de junta general. Teniendo en cuenta la dispersión de la propiedad de su capital y los distintos intereses a proteger, fija el tres por ciento para el ejercicio de ciertos derechos de los accionistas dejando atrás al cinco por ciento (nuevo artículo 495.3 LGC), entre ellos afecta el de completar el orden del día de la junta general y el de presentar nuevas propuestas de acuerdos (artículo 519 LGC). De esta manera y de acuerdo con el estudio de la Comisión de Expertos, nuestro ordenamiento ha establecido el porcentaje más bajo, para la convocatoria de junta general en los países estudiados.

${ }^{133}$ Resolución de la Dirección General de Registros y Notarías. 


\section{Derecho de asistencia y voto}

Estos derechos políticos del socio a participar y votar en la junta general, tienen diferente tratamiento según el tipo de sociedad de que se trate. Teniendo en cuenta la distinción que el propio legislador ha realizado en su regulación,abordamos primero la sociedad de responsabilidad limitada y, después, la anónima.

La actual regulación de la asistencia a la junta general en la sociedad de responsabilidad limitada abarca a todos los socios, sin distinguir si se trata de una junta ordinaria o extraordinaria. De esta manera se prohíbe que los estatutos sociales prevean un número mínimo de participaciones sociales para poder ejercitarla (artículo 179.1 LSC). En cualquier caso si será necesario, como ya hemos apuntado, la acreditación de la condición de socio.

En la sociedad anónima para participar en la junta los estatutos podrán exigir en el sistema actual -respecto de todas las acciones, cualquiera que sea su clase o serie- la posesión de un número mínimo sin que, en ningún caso, supere el uno por mil ${ }^{134}$ del capital social (artículo 179.1 LSC).

De ello resulta que los estatutos deben prever una limitación que por un lado, incluya a todas las clases de acciones y, por el otro, restrinja al número mínimo de acciones con acceso a la celebración de la junta general. Los socios minoritarios pueden, pese a esta restricción, ejercitar su derecho de participación agrupando sus acciones (artículo 189.1 LSC) a través de un representante que actúe ante este órgano de gobierno.

Con relación al derecho de voto, cabe señalar que en la sociedad de responsabilidad limitada, salvo disposición contraria de los estatutos sociales, cada participación concede a su titular el derecho a emitir un voto (artículo 188.1 LSC). En la sociedad anónima el requisito limitativo no debe constituir un impedimento infranqueablepara ejercitar el derecho de voto, pues en este tipo de sociedad no es necesario un mínimo de participación en el capital social para poder ejercitarlo. Entonces permite que el propio representante de los títulos agrupados puede emitir los votos correspondientes a cada uno de sus representados (artículo 188.2 LSC).

En materia de votaciones existendos temas fundamentales que aborda la reforma de la LSC: primer lugar el referido a la votación separada de las propuestas de acuerdo y; en segundo lugar, el conflicto de intereses.

En cuanto a la votación separada de las propuestas de acuerdo, el legislador ha reconocido la importancia de que los socios puedan pronunciarse, por separado,

${ }^{134}$ El legislador consideró que el uno por mil exigido para poder participar en las juntas generales de las sociedades no cotizadas, es excesivo para las cotizadas. El análisis de las dificultades de orden práctico que plantea la junta general en las sociedades cotizadas con un gran número de socios y la previsión de eliminar la mayor cantidad de obstáculos para el ejercicio del derecho de asistencia, provocó la fijación de un umbral máximo de mil acciones en la LGC. 
en cada uno de los asuntos que se ponen a su consideración. Ello es adecuado para evitar la distorsión que en las votaciones puede generar la acumulación de asuntos en un mismo acto de manifestación de la voluntad.

Las dos materias de especial relevancia para la práctica societaria en las que frecuentemente se agrupan las propuestas aunque su contenido es sustancialmente independiente: (i) el nombramiento, la reelección o separación de cada administrador (artículo 201 bis inciso a) PGC) y; (ii) las modificaciones estatutarias la de cada artículo o conjunto de artículos que no sean interdependientes (artículo 201 bis inciso b) PGC).

Se entiende de especial relevancia que, en estas cuestiones, se dé a los accionistas la oportunidad de expresar su voto de forma diferenciada, tal y como señala la recomendación quinta del Código Unificado, cuya incorporación a una norma legal se propone con carácter general para todas las sociedades de capital, mediante un nuevo artículo 201 bis en una nueva subsección tercera dentro de la sección tercera de la $\operatorname{LSC}^{135}$.

Por lo que se refiere al conflicto de interés, es cierto queel sistema legal actual plantea problemas técnicos en las decisiones de la junta general. La solución puede ir ex ante con el establecimiento de una cláusula general de prohibición de voto, hasta la alternativa ex post obviando su existencia y, saliendo a la luz, a través de la impugnación de la votación en la que existía conflicto de interés.

El legislador plantea una alternativa intermedia con tres partes complementarias del sistema de regulación de los conflictos con aplicaciónpara todas las sociedades de capital. De ahí que establece como primero, una cláusula específica de prohibición de derecho de voto en los casos más controvertidos de conflicto de interés, como son las votaciones que tienen por objeto: autorizarle a trasmitir acciones o participaciones sujetas a restricción legal o estatutaria; excluirle de la sociedad; liberarle de una obligación o concederle un derecho; facilitarle cualquier asistencia financiera, incluida la prestación de garantía a su favor o; dispensarles de las obligaciones derivadas del deber de lealtad acordada (artículo 230 de la LSC).

En las sociedades anónimas, la reforma establece que, los dos primeros supuestos serán eficaces cuando hayan estado expresamente previstos estatutariamente en cuanto a la libre trasmisión o la exclusión (artículo 190.1 LGC).

La segunda parte de la solución sistémica, pasa por el establecimiento de una presunción de infracción del interés social, en los casos en que el voto del socio incurso en el conflicto de interés haya sido determinante para la adopción del acuerdo corresponderá, en caso de impugnación, a la sociedad y en su caso a los socios la carga de la prueba de la conformidad del acuerdo con el interés social. A los socios impugnantes les bastará acreditar la existencia del conflicto de interés, excluyéndose

${ }^{135}$ España. Informe de la Comisión de Expertos en materia de Gobierno Corporativo. Creada por Acuerdo del Consejo de Ministros, de 10 de mayo de 2013, publicado por Orden ECC/895/2013, de 21 de mayo. Madrid, 14 de octubre. (96 p.). 2013. (p. 20). 
los conflictos de interés que no tengan naturaleza transaccional, sino que sean de mera posición (artículo 190.3 LGC).

La tercera parte se refiere a las votaciones separadas-de diferentes grupos de socios- en las modificaciones estatutarias que -afectándolos asimétricamente- dan lugar a un trato discriminatorio sustancial. Por ello cuando la modificación afecte sólo a una parte de las acciones pertenecientes a la misma y, en su caso única clase y suponga un trato discriminatorio entre ellas, se debe considerar como clases independientes las acciones afectadas y no afectadas por la modificación, lo que condiciona el acuerdo separado de cada una de ellas. A estos efectos se considerará discriminatorio cualquier modificación que en el plano sustancial tenga impacto asimétrico, en lo económico o político, sobre unas u otras acciones de sus titulares (artículo 293.2 LGC).

La normativa actual establece que una vez que el socio ha podido participar en la junta y decidir si vota las propuestas debatidas, el acuerdo será efectivo si se ha adoptado por la mayoría ordinaria (artículos 198 y 201 LSC).

La práctica plantea la necesidad de conocer con certeza, el criterio de cómputo de la mayoría necesaria para la validación del acuerdo, pues el pequeño cambio introducido por la LSC refiriéndose a la mayoría ordinaria, no solucionó las dudas interpretativas generadas respecto a si el precepto establece una mayoría relativa -entendida como mayor número de votos a favor que votos en contra- o; absoluta-entendida como más de la mitad de los votos presentes o representados en la junta- y a partir de esto, cuál es la relevancia de los votos nulos, en blanco y las abstenciones; cuestión que hasta ahora no ha estado resuelta en las normas precedentes a la LGC, de ahí la importancia de analizar el posicionamiento de esta nueva norma al respecto.

\section{Adopción de acuerdos en la junta general}

El actual sistema de adopción de acuerdos sociales -tanto en la sociedad anónima como el la de responsabilidad limitada- se adopta por mayoría ordinaria de los socios presentes o representados.

La novedad de la LGC radica en que adopta el criterio de la mayoría relativa. En la sociedad anónima, los acuerdos sociales se adoptarán por mayoría relativa de los votos de los accionistas presentes o representados, de tal forma que un acuerdo se entenderá adoptado cuando haya más votos a favor que en contra del capital presente o representado (artículo 201 LGC).

Actualmente la adopción de los acuerdos referidos casos especiales (artículo 194 LSC) como pueden ser el aumento o reducción del capital y cualquier otra modificación de los estatutos sociales, por sólo citar algunos, requerirá el voto favorable de los dos tercios del capital presente o representado en la junta cuando en la segunda convocatoria concurran accionistas que representen el veinticinco por ciento o más del capital suscrito con derecho de voto sin alcanzar el cincuenta por 
ciento, bastando que sea aprobado por mayoría absoluta, si el capital presente o representado supera el cincuenta por ciento. A través de la vía estatutaria se deja abierta la posibilidad de elevar las mayorías previstas.

Este sistema de asunción de las mayorías asumido por la LGC, intenta destacar que la participación del socio que se persona a la junta y vota en blanco o se abstiene, ha ejercido su derecho de asistencia estando presente en la reunión y participando en el debate que precede a la votación, pero ha decidido legítimamente no ejercer su derecho de voto. En este caso el legislador lo equipara con el socio que no ha asistido a la junta, pero que a la vez no ha nombrado representante.

Entonces el cómputo de la mayoría para la adopción de acuerdos en la junta general debe efectuarse teniendo en cuenta únicamente los votos a favor frente a los adversos, lo que, además de facilitar la formación de la mayoría, permite respetar plenamente la voluntad de los accionistas que, aun asistiendo a la junta, deciden no participar en la adopción de la decisión. ${ }^{136}$

Este criterio, recogido en diversas jurisdicciones comparadas es, además, el propuesto en defecto de regulación específica para la sociedad anónima europea por el Reglamento (CE) n. ${ }^{\circ} 2157 / 2001$ del Consejo, de 8 de octubre de 2001, que en sus artículos 57 y 58 establece que los acuerdos de la junta general se tomarán por mayoría de votos válidos emitidos, y que entre los votos emitidos no se contarán los correspondientes a las acciones cuyos poseedores no hayan participado en la votación o se hayan abstenido, hayan votado en blanco o hayan emitido voto nulo. ${ }^{137}$

El acceso a la información de la sociedad es fundamental para emitir el voto con todos los elementos de juicio del asunto en cuestión. Por ello constituye el complemento obligado del ejercicio del derecho de voto el poder satisfacer la necesidad de información, antes y durante la celebración de la junta. Aunque la regulación actual del derecho de información del sociocomparte los estándares de la comunitaria yla comparable, ha sido conveniente perfeccionar los fines y consecuencias de las distintas modalidades de su ejercicio.

\section{Derecho de información del socio}

El ejercicio del derecho de información del socio antes de la realización de la junta general, está vinculado a su interés de complementar la información para formarse un criterio de voto. La legislación actual establece la posibilidad de que el socio de la sociedad anónima pueda solicitar-al órgano de administración- las informaciones o aclaraciones respecto de las cuestiones incluidas en el orden del día hasta el séptimo díaanterior a la celebración de la junta. El órgano de administración debe

\footnotetext{
${ }^{136}$ España. Informe de la Comisión de Expertos en materia de Gobierno Corporativo. Creada por Acuerdo del Consejo de Ministros, de 10 de mayo de 2013, publicado por Orden ECC/895/2013, de 21 de mayo. Madrid, 14 de octubre. (96 p.). 2013. (p. 24).

${ }^{137}$ Ibidem, (p. 24).
} 
entregarla por escrito hasta el día de la realización de la junta. Similar derecho tiene el socio a solicitar información durante la celebración de la junta y en el caso que no sea posible responderlas durante la sesión, este órgano cuenta con siete días de plazo para satisfacer la solicitud, salvo que decidan denegarla ante el posible perjuicio al interés social (artículo 197.1 LSC).

El socio de la sociedad de responsabilidad limitada podrá solicitarlo en cualquier momento antes y durante la reunión (artículo 196.1 LSC). El órgano de administración está obligado a proporcionarla de forma verbal o por escrito, salvo que la información suministrada pueda afectar el interés social, no obstante, si el socio representa individual o colectivamente el veinticinco por ciento del capital social, se le ha de aportar toda la información solicitada (artículo 196.2.3 LSC).

Se recomienda establecer procedimientos periódicos de información entre la empresa y los socios y se aconseja que el órgano de administración se asegure de que existe una comunicación fluida con los socios más desvinculados de la realidad diaria de la empresa, a los efectos de que conozcan los planes, los logros y objetivos de la sociedad. Con carácter general, debe informarse oportuna y periódicamente a todos los accionistas y no solo con ocasión de la celebración de la junta general ${ }^{138}$.

La LGC propone que el ejercicio del derecho de información del accionista sea ejercitable hasta el quinto día anterior a la celebración de la junta general (artículo 520.1 PGC) para las sociedades cotizadas, con lo cual se reduce el plazo de contestación para la sociedad. Escriticable que la extensión del plazo que beneficia al socio, no sea de aplicación también para las sociedades no cotizadas.

La activación del derecho de información del socio durante la celebración de la junta general, se utiliza con frecuencia para originar un motivo de impugnación. Para lograr un relativoequilibrio entre las diferentes posiciones presentes sin que suponga una limitación expresa del ejercicio del derecho de información, el legislador establece dos elementos novedosos:

El primero, que durante la celebración de la junta general -los administradores estarán obligados a proporcionar la información solicitada- salvo que sea innecesaria para la tutela de los intereses del socio, existan razones fundadas para considerar que podría utilizarse para fines extra sociales o su publicidad perjudique a la sociedad o a las sociedades vinculadas (artículo 197.3 LGC).

El segundo, que en caso de vulneración del derecho de información, sólo facultará al accionista para exigir el cumplimiento de la obligación de información y los daños y perjuicios que se le hayan podido ocasionar. Es motivo de crítica el blindaje que se impone sobre la posibilidad de que esta limitación constituya una causal de impugnación de la actuación de la junta general (artículo 197.5.6), con el argumento de que, en legislaciones como la británica, el derecho a intervenir durante la junta no se considera una forma de ejercicio del derecho de información, sino un

${ }^{138}$ Hierro Anibarro, S. (Dir), [y otros]. Gobierno corporativo en sociedades no cotizadas (p. 518). Madrid: Marcial Pons. 2014. (p.56) 
derecho autónomo de aquel, del que gozan los accionistas con la finalidad de exponer opiniones o intercambiar puntos de vista sobre la evolución de la sociedad ${ }^{139}$.

El hecho que la utilización abusiva o perjudicial de la información solicitada por el socio, sea causal de responsabilidad respecto de los daños y perjuicios ocasionados (artículo 197.6 LGC), es una cuestión que parece lógica;pero es criticable que, respecto del órgano de administración, no se establezca responsabilidad alguna para el administrador que ha incumplido la obligación de aportar la información al socio que la haya solicitado sin serleaplicable el (artículo 197.3).

Celebramos que con carácter imperativo los administradores deban facilitar, por escrito hasta el día de la celebración de la junta, la información solicitada (artículo 197.1 LGC). Esto es complementario a la publicación de las informaciones, aclaraciones o preguntas realizadas por escrito y sus respuestas, que deberán incluirse en la página web de la sociedad (artículo 520.3 LGC). Ambos elementoscontribuyen a la transparencia corporativa yconstituyen medios eficaces de realización del derecho del socio a la información.

Si la regulación del régimen de derechos y facultades del socio ante la junta general constituye un elemento fundamental para la adecuada configuración del buen gobierno de las sociedades de capital, similar relevancia tiene el sistema de normasreguladoras de la impugnación de acuerdos sociales. La afectación que estas normas tiene sobre los derechos de las minorías, resulta un elemento de obligado análisis.

\section{IMPUGNACIÓN DE LOS ACUERDOS SOCIALES}

La impugnación de los acuerdos adoptados en la junta general y en el consejo de administración son fundamentales, complementarios y posibilitadores, por un lado, de la realización material de los derechos del socio y garante del interés de la sociedad y, por el otro, asegura el tráfico jurídico y posibilita mejores niveles de eficiencia empresarial.

La norma vigente establece que son impugnables los acuerdos contrarios a la ley, los estatutos o sean lesivos al interés social en beneficio de uno o varios socios. Este sistema distingue entre los acuerdos nulos - contrarios a la ley- y anulables -el resto de los supuestos- y considera improcedente la impugnación del acuerdo que se haya dejado sin efecto o se haya sustituido por otro (artículo 204 LSC).

En cuanto a la caducidad de la acción de impugnación la normativa actual establece el plazo de un año, con la excepción de los que resultaren contrarios al orden público. En el caso de los acuerdos anulables caducará la acción a los cuarenta días. Estos plazos se computan desde la fecha de adopción del acuerdo y en el caso

${ }^{139}$ España. Informe de la Comisión de Expertos en materia de Gobierno Corporativo. Creada por Acuerdo del Consejo de Ministros, de 10 de mayo de 2013, publicado por Orden ECC/895/2013, de 21 de mayo. Madrid, 14 de octubre. (96 p.). 2013. (p. 27). 
de los inscribibles desde su publicación en el BORME (artículo 205 LSC).

El sistema actual de impugnación de los acuerdos sociales nulos, permite que cualquier socio, administrador y tercero con interés legítimo acreditado pueda ejercitarlo. En el caso de los acuerdos anulables están legitimados los socios asistentes a la reunión que hicieron constar en acta su inconformidad con el acuerdo, los ausentes, los privados del voto y los administradores. En cualquier caso las acciones de impugnación se dirigen contra la sociedad (artículo 206 LSC).

La LGC establece que son impugnables, entre otros, los acuerdos que se opongan a los estatutos o al reglamento de la junta general de la sociedad (artículo 204.1 LGC) y del consejo de administración (artículo 251.1 LGC). Estos dos elementos novedosos intentandotar de relevancia a las normas internas de la sociedad, velando el comportamiento éticoque va más allá de los estatutos. Pero no perdamos de vista las limitaciones que, la propia configuración de la norma, genera en la realización del verdadero control del socio minoritario a los órganos societarios, al condicionarlo a representar el uno por ciento del capital social.

La lesión del interés social se produce también cuando el acuerdo, aun no causando daño al patrimonio social, se impone de manera abusiva por la mayoría -entendiendo su carácter abusivo cuando se impone sin responder a una necesidad razonable de la sociedad y se adopta por la mayoría para obtener un beneficio propio en detrimento injustificado de los demás socios-(artículo 204.1 LGC).

La validez de la interposición de una demandadespués de haberse cambiado el acuerdo que la provocó, es un elemento que merece ser cuestionado. El socio minoritario como sujeto activo de la acción de impugnación, después que el socio mayoritario -como parte de una estrategia de presión ${ }^{140}$ - modifica el acuerdo que constituyó la causa de impugnación, es limitado en el ejercicio de este derecho.

Esta práctica el legislador intenta solucionarla estableciendo expresamente que no será procedente la impugnación de un acuerdo social cuando haya sido dejado sin efecto o sustituido válidamente por otro adoptado antes o después de interpuesta la demanda de impugnación (artículo 204.2 LGC). Una solución que si bien puede frenar las sucesivas demandas oportunistas contra la sociedad, no parece ser el tratamiento adecuado para evitar la situación de abuso sobre el socio minoritario que fundadamente impugnó el acuerdo posteriormente modificado por la junta.

Otra peculiar manera que el legislador tiene de reforzar la defensa de los derechos de los socios minoritarios -como uno de los objetivos de la reforma-, es a

${ }^{140}$ Entre las más frecuentes estrategias que utiliza el socio mayoritario -como manifestación del abuso de derecho (artículo 7.2 Código Civil (cc)) contra el minoritario- cabe destacar: en primer lugar, el aumentos de capital no necesario para el desarrollo de la empresa -planificado única y exclusivamente con la finalidad de diluir a la minoría- y; en segundo lugar, dos prácticas que persiguen asfixiar económicamente al socio minoritario: (i) la práctica recurrente de no distribuir dividendos y, (ii) el cese del socio minoritario en el cargo de administrador o empleado. 
través de la reducción expresa de las causas de impugnación. En consecuencia establece que tampoco procederá la impugnación de los acuerdos sociales que se basen en la mera infracción de los requisitos procedimentales establecidos por la ley, los estatutos o los reglamentos de la junta general y del consejo de administración, para la convocatoria o la constitución del órgano o para la adopción del acuerdo, salvo que se trate de una infracción relativa a la forma y plazo previo de la convocatoria, a las reglas esenciales de constitución del órgano o a las mayorías necesarias para la adopción de los acuerdos, así como cualquier otra que tenga carácter relevante (artículo 2014.3 LGC). Respecto al uso de(relevante), parece ser más apropiado el término (irrelevante).

Otros motivos irrelevantes pasan, además, por la incorrección o insuficiencia de la información facilitada por la sociedad en respuesta al ejercicio del derecho de información, salvo que la información incorrecta o no facilitada, hubiera sido esencial para el ejerciciorazonable por parte del accionista o socio medio, del derecho de voto o de cualquiera de los demás derechos de participación -entonces quién deberá determinar el carácter esencial de la información solicitada por el socio-; la participación en la reunión de personas no legitimadas, salvo que esa participación hubiera sido determinante para la válida constitución del órgano y; la invalidez de uno o varios votos o el cómputo erróneo de los emitidos, salvo que el voto inválido o el error de cómputo hubieran sido determinantes para la consecución de la mayoría exigible (artículo 204.3 incisos b, c y d LGC).

La eliminación de la diferenciación artificial entre los acuerdos nulos y anulables se extiende a todo lo que hace referencia a la caducidad del plazo de impugnación. De esta manera también se incluye en el cómputo del plazo de caducidad, la fecha de adopción del acuerdo, si hubiera sido adoptado en el consejo de administración (artículo 205 LGC).

Es criticable que para impugnar el acuerdo social esté legitimado el socio de la sociedad no cotizada que, individual o colectivamente, represente al menos el uno por ciento del capital social (artículo 206.1 LGC). El legislador justifica este elemento nuevo como una forma de evitar el abuso de derecho de la minoría -lo cual escontradictorio y poco consistente-. Resulta llamativo que, el abuso de derecho de la mayoría sobre la minoría -que es la práctica más habitual- no esté aun resuelto y se configure una norma para evitar el abuso que ejerce el socio en minoría ${ }^{141}$.

Los estatutos podrán reducir el uno por ciento de capital exigible, en principio la respuesta es sí (artículo 206.1 LGC). Cosa distinta es la realidad de unos estatutos, resultantes de unapráctica frecuente delos notarios, que mantienenel por-

${ }^{141}$ La acción de impugnación en la sociedad cotizada, pasa a estar condicionada a la representación del 0,1 por ciento del capital social, o lo que es lo mismo, representar individual o colectivamente el uno por mil del capital social. El socio cuya representación esté por debajo de este umbral, tiene derecho a reclamar la indemnización de los daños y perjuicios que le haya ocasionado el acuerdo impugnado (artículo 495.4 LGC). 
centaje establecido legalmente yque tiende a ser asumido por las mercantiles.

Los socios que no alcancen el uno por ciento, tendrán derecho al resarcimiento del daño que les haya ocasionado el acuerdo impugnable (artículo 206.1 LGC), debiendo dirigirla acción de impugnación contra la sociedad (artículo 206.3 LGC).

El plazo de caducidad de la acción de impugnación de los acuerdos socialeses de un año ${ }^{142}$ para las sociedades de capital no cotizadas, salvo que por sus circunstancias, causa o contenido resulten contrarios al orden público, en cuyo caso la acción no caducará ni prescribirá. El plazo de caducidad se computa desde la fecha de adopción del acuerdo si ha sido adoptado en junta general o en el consejo de administración; desde la fecha de recepción de la copia del acta si el acuerdo hubiera sido adoptado por escrito y; si se hubiera inscrito, se computa desde la fecha en que es oponible la inscripción (artículo 205 LGC).

Teniendo en cuenta el porcentaje de participación que el socio minoritario debe tener en el capital social para ejercitar derechos con relación a la junta general y la impugnación de los acuerdos sociales, resulta oportuno abordar el derecho a conocer la identidad del resto de los socios que -aunque regulado exclusivamente para las sociedades cotizadas en la LSC y ahora en la LGC- constituyeuna herramienta importante para la promoción del ejercicio colectivo de sus derechos y, con ello, se materializa una acertada aplicación de los principios de buen gobierno corporativo en las sociedades de capital no cotizadas.

\section{DERECHO A CONOCER LA IDENTIDAD DE TODOS LOS SOCIOS}

El actual ordenamiento societario español establece -con relación al derecho a conocer la identidad de los accionistas- que las entidades que deban llevar los registros de los valores representados por medio de anotaciones en cuenta, están obligadas a comunicar a la sociedad emisora los datos que resulten indispensables para la identificación de los socios y los medios para contactarlos (artículo 497 LSC).

El derecho a conocer la identidad del socio, tanto por la propia sociedad como por el resto de socios, ha sido incluido por el legislador español teniendo en cuenta su relevancia para el desarrollo del buen gobierno corporativo. No obstante, le parece excesivo que la informaciónsobre la identidad del socio gestionada por las emisoras, deba estar a disposición de cualquiera de ellos ${ }^{143}$. La alternativa que

\footnotetext{
${ }^{142}$ El plazo de caducidad de la acción en las sociedades cotizadas es de 3 meses, lo cual se ha justificado en su mayor necesidad de lograr estabilidad en los acuerdos sociales adoptados (artículo 495.5 LGC).En la vigente LSC, el plazo de caducidad para impugnar los acuerdos sociales, es de cuarenta días.

${ }^{143}$ La Ley 2/2011 de 4 de marzo, de Economía Sostenible, cambió la letra del artículo 497 de la LSC con la ampliación de los derechos de las sociedades cotizadas para conocer en cualquier momento la identidad de sus accionistas. El antecedente de esta ley está en el artículo
} 
le ha parecido más adecuada, es la de concederle ese derecho alsocio que,gracias a su participación en el capital social, está legitimado para promover actuaciones con relación a la junta general.

En la nueva propuesta normativa, la sociedad emisora tiene derecho a obtener en cualquier momento de las entidades -que lleven los registros de los valores de datos correspondientes a los accionistas- las direcciones y medios de contacto de que disponga (artículo 497.1 LGC). El mismo derecho tendrán las asociaciones de accionistas que se hubieran constituido en la sociedad emisora, así como los accionistas que tengan individual o conjuntamente una participación de, al menos, el tres por ciento del capital social, exclusivamente a efectos de facilitar su comunicación con los accionistas para el ejercicio de sus derechos y la mejor defensa de sus intereses comunes (artículo 497.2 LGC).

Es criticable la supeditación del ejercicio de este derecho a una participación determinada en el capital social. La posición del legislador es desacertada una vez más pues, al pretender evitar que el ejercicio de este derecho pueda utilizarse con fines ilegítimos, ha condicionado la posibilidad de actuación de mala fe, solo del socio cuyo capital sea superior al tres por ciento, o es que el actuar de mala fe en los que cuentan con el tres por ciento o más de participación en el capital social no es posible -el límite al socio o asociación que podría utilizar la información de forma abusiva o perjudicial, está en la posibilidad de exigir responsabilidad por los daños y perjuicios ocasionados-. Aunque el contenido y redacción de la norma en sí misma es técnicamente superior a su predecesora de la LSC, constituye otra limitación al ejercicio efectivo de los derechos del socio minoritario.

\section{Conclusiones}

La novedad más destacable en el Proyecto de Ley -de 30 de mayo de 2014, por el que se modifica la Ley de Sociedades de Capital para la mejora del gobierno corporativo- es la regulación de los derechos que afectan la situación del socio minoritario respecto a la junta general y la impugnación de los acuerdos sociales adoptados por esta, siendo destacables las medidas para mejorar la transparencia.

Debe reconocerse el progreso que representa en la legitimación y protección de las minorías: el poder ejercitar directamente la acción social de responsabilidad sin tener que contar con la autorización de la junta general y el derecho de reembolso en caso de estimación parcial o total de la demanda; el progres que representa la votación separada de la propuestas de acuerdos sociales; la adopción de los acuerdos por el criterio de mayoría relativa; el ejercicio del derecho de información hasta el quinto día anterior a la celebración de la junta; que sean impugnables los acuerdos que se opongan a los estatutos o al reglamento de la junta general o del consejo y; que el plazo de caducidad de la acción de impugnación para la sociedades

22.3 del Real Decreto 116/1992, de 14 de febrero. 
no cotizadas sea de un año.

Es criticable con relación al objetivo de mejora de la participación del socio y del cumplimiento de los principios de buen gobierno: el derecho a incluir asuntos en el orden del día y a presentar propuestas supeditándolo a la titularidad de una participación mínima en el capital social, el cinco por ciento para las no cotizadas y el 3 por ciento para las cotizadas; el blindaje impuesto a la vulneración del derecho de información como una causal de impugnación; la exigencia del uno por ciento de participación en el capital social que legitime la impugnación de un acuerdo que se oponga a los estatutos o al reglamento de la junta general o del consejo; la reducción expresa de las causas de impugnación por mera infracción de requisitos procedimentales salvo que tengan carácter relevante y; que el derecho a obtener información del resto de socios que integran la sociedad sea regulado exclusivamente a favor de las sociedades cotizadas y que, además, su ejercicio se supedite a una participación del tres por ciento de participación en el capital social.

Sorprende que, no obstante, la intención de la LGC de ofrecerle mayor participación al socio minoritario, está lejos de lograrlo, pues plantea una serie de construcciones técnicas que más que beneficiarlo, contribuyen a limitar el ejercicio de sus derechos. Ello debe ser punto de partida para superar los obstáculos y lograr la noble intención que -respecto al socio minoritario y su papel en el perfeccionamiento del gobierno corporativo- animó la elaboración del proyecto.

\section{Bibliografía}

HIERRO ANIBARRO, S.(Dir), [y otros]. Gobierno corporativo en sociedades no cotizadas (p. 518). Madrid: Marcial Pons. 2014.

JORDÁ GARCÍA, R. "Reformas en curso para las sociedades no cotizadas por mejora del gobierno corporativo". Diario La Ley. La Ley-Actualidad.(p. 1-10). 2014.

ROJO FERNÁNDEZ-RÍO, Ángel [y otros]. Comentario de La Ley de Sociedades de Capital.(3419 p). Cizur Menor, Navarra :Civitas Thomson Reuters, 2011.

VÁZQUEZ LEPINETTE, T.La protección de las minoríassocietariasfrente a la opresión (145 p.). Editorial Aranzadi, SA.Cizur Menor (Navarra). 2007.

\section{Otros MATERIALES}

España. Proyecto de Ley por el que se modifica la Ley de Sociedades de Capital para la mejora del gobierno corporativo. Boletín Oficial de las Cortes Generales.Congreso de los Diputados. 30 de mayo. Madrid.(30 p.)2014. 
España. Informe de la Comisión de Expertos en materia de Gobierno Corporativo. Creada por Acuerdo del Consejo de Ministros, de 10 de mayo de 2013, publicado por Orden ECC/895/2013, de 21 de mayo. Madrid, 14 de octubre.(96 p.). 2013.

Propuesta de Directiva del Parlamento Europeo y del Consejo por la que se modifica la Directiva 2007/36/CE en lo que respecta al fomento de la implicación a largo plazo de los accionistas y la Directiva 2013/34/UE en lo que respecta a determinadoselementos de la declaración sobre gobernanza empresarial. Comisión Europea. Bruselas. 2014.

Propuesta de Directiva del Parlamento Europeo y del Consejo relativa a las sociedadesunipersonalesprivadas deresponsabilidad limitada. Bruselas: Comisión Europea. 2014.

Instituto de Consejeros-Administradores. Principios de Buen Gobierno Corporativo Para Empresas No Cotizadas. Código de BuenasPrácticas Para Los Administradores, Consejeros y El Consejo.Madrid (España). (36 p.). 2005-2006.

España. Real Decreto Legislativo 1/2010, de 2 de julio. "Ley de Sociedades de Capital.” Boletín Oficial del Estado de 30 de agosto de 2010; núm. 210. 2010.

OECD. "CorporateGovernance of Non-ListedCompanies in Emerging Markets". París. (267 p.). 2006. [en línea]. Disponible en: http://www.ifc.org/wps/wcm/connect/582f0a804af4b8b8a5cfb5b94e6f4d75/oecd_nonlist.pdf?MOD=AJPERES 


\title{
EL NUEVO RÉGIMEN JURÍDICO DE LOS CONTRATOS A DISTANCIA ${ }^{144}$
}

\author{
The new legal regime of distance contracts
}

\section{Manuel Pino Abad}

Profesore de la Universidad de Córdoba. E-mail: ad1piabm@uco.es

\section{José Manuel Serrano Cañas}

Profesore de la Universidad de Córdoba. E-mail: jose24mayo@yahoo.es

\section{RESUMEN}

El presente trabajo tiene como finalidad principal exposición pormenorizada del nuevo régimen jurídico de los contratos celebrados a distancia. Como consecuencia de la promulgación de la Ley 3/2014, de 27 de marzo, por la que se modifica el texto refundido de la Ley General para la Defensa de los Consumidores y Usuarios y otras leyes complementarias, se ha dado una nueva redacción al Título III del Libro II del TRLGDCU (artículos 92 a 112). El contenido de estos artículos se adapta fielmente al texto de la Directiva 2011/83/UE.

Palabras clave: Consumidor. Contratos a distancia. Deberes de información. Derecho de DEsistimiento.

\section{Abstract}

This paper work has as main purpose to detailed exposition of the new legal regime of distance contracts. As a consequence of the publication of the Law $3 / 2014,27$ th March, that approved the text of the Law for the Defence of Consumers and Users and other complementary laws, has given a new wording to the Title III of Book II of TRLGDCU (articles 92 to 112). These articles faithfully adapts the text of Directive 2011/83/EU.

\footnotetext{
${ }^{144}$ Este trabajo se enmarca dentro del Proyecto de Investigación de Excelencia "Contratación mercantil y Competencia empresarial: nuevas tendencias reguladoras y propuestas de conexiones normativas" (referencia DER2013-43674-P), financiado por el Ministerio de Economía y Competitividad y del que son Investigadores Principales los Profesores Miranda Serrano y Pagador López.
} 
Keywords: Consumers. Distance contracts. Duty of disclosure. Disclosure DUTIES. RIGHT OF WITHDRAWAL.

SUMARIO: I. Introducción a los contratos a distancia 1. La represión de las prácticas agresivas como fundamento de la tutela legal. 2. Causas justificativas del tratamiento normativo de los contratos a distancia. II.La regulación legal de los contratos a distancia: la transposición de la directiva 2011/83/UE. III. Delimitación del ámbito subjetivo y objetivo de los contratos a distancia. 1 . Delimitación subjetiva del ámbito de aplicación de los contratos a distancia. 2. Delimitación objetiva del ámbito de aplicación de los contratos a distancia. 2.1. Sistema organizado de contratación a distancia. 2.2.- Empleo de técnicas de comunicación a distancia. 3. Contratos excluidos del ámbito de aplicación de los contratos a distancia. IV. Nuevo régimen jurídico de los contratos celebrados a distancia. 1. Los deberes de información precontractual y de confirmación del contrato. 1.1. Requisitos formales de las obligaciones de información precontractual y de confirmación del contrato.1.2. Contenido de la información precontractual.1.3. Consecuencias del incumplimiento de los deberes de información precontractual y de confirmación del contrato. 2. La facultad de desistimiento del consumidor. 2.1. Fundamentación y naturaleza jurídica del derecho de desistimiento en los contratos celebrados a distancia. 2.2. Duración y cómputo del plazo de desistimiento. 2.3. Forma de desistimiento. 2.4. Prueba del desistimiento. 2.5. Consecuencias derivadas del ejercicio de la facultad de desistimiento. 2.6. Consecuencias derivadas del ejercicio de la facultad de desistimiento sobre los contratos complementarios. 2.7.-Excepciones al derecho de desistimiento. 3. Ejecución de los contratos celebrados a distancia. Bibliografía.

\section{INTRODUCCIÓN A LOS CONTRATOS A DISTANCIA}

\section{LA REPRESIÓN DE LAS PRÁCTICAS AGRESIVAS COMO FUNDAMENTO DE LA TUTE- LA LEGAL}

Desde sus orígenes, el Derecho de los consumidores ha tenido como principal finalidad la salvaguarda de la libre formación de la autonomía decisional del consumidor en el momento de prestar su consentimiento contractual. Este principio tuitivo se hace presente en muchas de las normas que integran este sector del ordenamiento jurídico ${ }^{145}$. Con tal fin, este entramado normativo intenta reprimir

${ }^{145}$ Sirva a modo de ejemplo, sin ánimo de exhaustividad, la individualización de prácticas 
aquellas prácticas comerciales agresivas que de forma directa causan una merma (cuando no un verdadero vicio) del consentimiento negocial, atentando contra la libertad contractual, o bien, más sibilinamente, aprovechan situaciones de grave debilidad negocial o de insuficiente (o deficiente) formación de la voluntad para incrementar el volumen de facturación.

Como siempre, los nuevos hechos, reclaman un nuevo derecho. Y la aparición y auge de las comunicaciones comerciales a distancia (reforzada ahora por la consolidación del empleo de Internet como herramienta usual en nuestras relaciones comerciales) suponen un nuevo hecho que necesita un nuevo derecho. El auge de prácticas de captación agresiva (por no decir coactiva) de la voluntad decisoria de los consumidores ha provocado, como efecto reflejo, la necesidad de una conveniente respuesta por el legislador. Téngase presente que estas prácticas, además de rozar el ilícito contractual (por vicios del consentimiento), suponen, a su vez, una alteración ilegítima de las reglas de la competencia y del funcionamiento del mercado. La ausencia de que estas prácticas agresivas quedasen impunes a toda sanción jurídica conllevaría que la "mano invisible" no sólo no eliminaría a aquellas empresas cuya actuación sea más que cuestionable, sino que, por el contrario, las premiaría. Por lo tanto, la represión de estas prácticas comerciales agresivas no obedece simple y llanamente a la defensa y protección del consumidor (contratante y contraparte negocial débil), sino que en ella también están en juego los intereses de los restantes competidores así como el interés público al mantenimiento de un libre y leal funcionamiento del mercado.

\section{Causas justificativas del tratamiento normativo de los Contratos a DISTANCIA}

De entre las prácticas/ventas agresivas merecedoras de algún reproche legal, tradicionalmente se han incluido una modalidad específica de contratación: los contratos a distancia. Desde la primera iniciativa legislativa prevista para regular los contratos a distancia (arts. 38 a 48 de la Ley de Comercio Minorista; Directiva 97/7 sobre contratos a distancia), el legislador toma como punto de partida una concepción previa (presupuesto o, sin más, prejuicio) de esta modalidad promotora de la contratación: en estos contratos, el cliente consumidor se encuentra en una situación de especial vulnerabilidad negocial, de indefensión negocial alejado

desleales con consumidores llevada a cabo por la Ley de Competencia Desleal, o de los actos de publicidad ilícita por la Ley General de Publicidad, o la imposición de deberes informativos a los empresarios con carácter previo a la celebración de los contratos con consumidores que se regulan el Texto Refundido de la Ley General de Defensa de los Consumidores y Usuarios, o en el Real Decreto del Derecho de aprovechamiento por turnos de bienes inmuebles, o en el Real Decreto Carta de Derechos de los usuarios de telecomunicaciones electrónicas, o en la Ley del Contrato de Seguro, etc. 
del estándar normal y razonablemente aceptable, fuente, por tanto, de abusos por parte del otro sujeto contratante. A partir de entonces, la doctrina ha tenido ocasión de determinar cuáles son las principales razones por las que se entiende que el consumidor se encuentra en una especial situación de vulnerabilidad negocial. A saber:

En primer lugar, en estos contratos concurre una circunstancia que ha dado en denominarse riesgo de incumplimiento o decepción, esto es, el riesgo de que el cliente reciba un bien o servicio defectuoso o no coincidente con el solicitado ${ }^{146}$. Téngase presente que a diferencia de la contratación presencial o tradicional, en la contratación a distancia, por su propia naturaleza, el consumidor contrata "a ciegas", sin tener la posibilidad real de manipular el producto, cotejarlo, tenerlo entre manos. El consumidor sólo puede conocer las características del producto o servicio contratado a través de las indicaciones y de la presentación comercial elaborada por el empresario. Se da, pues, un serio déficit de información a la hora de perfeccionar el contrato ${ }^{147}$.

En segundo lugar, en esta modalidad suele darse un déficit de reflexión. Al igual que sucede con los contratos fuera de los establecimientos mercantiles, esta modalidad de contratación favorece la celebración de negocios irreflexivos, no suficientemente meditados y faltos de plena consciencia negocial. Pese a que tradicionalmente se entendía que un mismo contrato no puede reunir la doble condición de ser a distancia y, al mismo tiempo, celebrado fuera del establecimiento mercantil del empresario, la Directiva 2011/83/UE rompe esta concepción y aboga por la unificación del régimen jurídico de ambas modalidades contractuales.

\section{LA REGULACIÓN LEGAL DE LOS CONTRATOS A DISTANCIA: LA TRANSPOSICIÓN DE LA DIRECTIVA 2011/83/UE}

El tratamiento legislativo de los contratos a distancia ha sufrido un proceso de evolución en nuestro ordenamiento jurídico. La finalidad perseguida por el legislador (comunitario y patrio) es doble. Por una parte, la tutela de la libre decisión negocial del cliente que contrata a distancia, esto es, de su libertad de saber y de querer a la hora de celebrar contratos. Por otra, la protección de la seguridad, honestidad y lealtad en el tráfico mercantil negociado a distancia. En efecto, el auge de Internet y su uso masivo fuerzan al legislador a establecer los medios necesarios para hacer

\footnotetext{
${ }^{146}$ MIRANDA SERRANO, L. M., «La contratación a distancia de consumo: TRDCU y Directiva 2001/83/UE», en AA.VV., Derecho (privado) de los consumidores, coord. MIRANDA SERRANO, PAGADOR LÓPEZ, Marcial Pons, Madrid, Barcelona, Buenos Aires, 2012, p. 146.

${ }^{147}$ De hecho, el Considerando 37 de la Directiva 2011/83/UE, fija como fundamento del derecho del desistimiento le hecho de que "en las ventas a distancia el consumidor no puede ver los bienes antes de celebrar el contrato".
} 
posible que los sujetos participantes en este nuevo sistema de contratación muestren un grado de confianza equivalente a la confiada en la contratación presencial. La confianza se erige en un valor de primer orden que interesa estatuir en interés tanto de los empresarios y profesionales como en interés de los consumidores ${ }^{148}$.

La Ley 26/1984, General para la Defensa de los Consumidores y Usuarios no introdujo ninguna medida específica de protección para la contratación a través de técnicas de comunicación a distancia. Tuvo que ser Ley 7/1996, de 15 de enero, de Ordenación del Comercio Minorista la que llevara a cabo la primera regulación de los contratos a distancia a nivel estatal (arts. 38 a 48 del capítulo II, del Título III). No obstante, con la promulgación de la Directiva 97/7/CE, en materia de contratos a distancia, el legislador español se vio obligado a modificar el contenido de la primigenia regulación; lo que tuvo lugar mediante la Ley 47/2002, de 19 de diciembre, de reforma de la Ley 7/1996, de 15 de enero, de Ordenación del Comercio Minorista, para la transposición al Ordenamiento jurídico español de la Directiva 97/7/CE en materia de contratos a distancia y para la adaptación de la Ley a diversas Directivas comunitarias.

Esta regulación fue modificada en noviembre de 2007 como consecuencia de la aprobación del Texto refundido de la Ley General para la Defensa de los Consumidores y Usuarios (Real Decreto Legislativo 1/2007). La regulación sobre los contratos a distancia contenida en la LOCM queda vigente aún para la regulación de las relaciones empresariales. Por la disposición derogatoria única del TRDCU se derogan el art. 48 de la LOCM (que establecía el carácter imperativo de las normas de la LOCM reguladoras de los contratos a distancia para los supuestos en que los clientes actuaran en condición consumidora -contratos de consumo-), y la disposición adicional primera de la LOCM que extendía la aplicación de los arts. 38 a 48 LOCM a los contratos de consumo a distancia referentes a la prestación de servicios.

El 11 de noviembre de 2011 se publicó en el Diario Oficial de la Unión Europea, el texto final de la Directiva 2011/83/UE del Parlamento Europeo y del Consejo, de 25 de octubre de 2011, sobre los derechos de los consumidores. Esta nueva Directiva ha modificado la Directiva 93/13/CEE del Consejo y la Directiva 1999/44/CE del Parlamento Europeo y del Consejo sobre cláusulas abusivas y garantías en las ventas de bienes de consumo, y ha derogado las Directivas 85/577/ CEE del Consejo y 97/7/CE del Parlamento Europeo y del Consejo sobre contratos celebrados fuera de los establecimientos mercantiles y a distancia ${ }^{149}$.

La Directiva 2011/83/UE es el resultado de un largo proceso de revisión de las normas de consumo iniciado por la Comisión Europea en 2001, con la publicación del Libro Verde sobre la protección de los consumidores en la UE, cuyo principal objetivo consistía en poner en marcha una amplia consulta pública acerca del rumbo que habría de tomar en el futuro la política comunitaria de defensa de

\footnotetext{
${ }^{148}$ MIRANDA SERRANO, L. M., op. cit., p. 148.

149 http://revista.uclm.es/index.php/cesco/article/view/10/12
} 
los consumidores ${ }^{150}$. Con motivo de la aprobación de la Directiva sobre prácticas comerciales desleales se puso de manifiesto la necesidad de reformar las Directivas de protección de los consumidores existentes, con la finalidad de garantizar la coherencia general del sistema. En el seno de este proceso armonizador, se promulga la Directiva 2011/83/UE, que nace con pretensiones de alcanzar un nivel de armonización máxima o plena en aquellas materias que han sido expresamente contempladas y reguladas $^{151}$. El legislador europeo ha optado por uniformar la regulación de los distintos Estados miembros en el ámbito de los contratos celebrados a distancia y fuera de los establecimientos mercantiles. Por tanto, los diferentes Estados miembros únicamente cuentan con la posibilidad de transponer e incorporar la Directiva, sin que estén facultados para insertar en el acto de transposición niveles de protección distintos de los establecidos por ella. Como consecuencia de esta Directiva, el legislador español ha promulgado la Ley 3/2014, de 27 de marzo, por la que se modifica el texto refundido de la Ley General para la Defensa de los Consumidores y Usuarios y otras leyes complementarias, aprobado por el R.D. Legislativo 1/2007, de 16 de noviembre. Esta Ley ha dado una nueva redacción al Título III del Libro II del TRLGDCU (arts. 92 a 112), cuyo contenido se adapta fielmente, como no podía ser de otra manera, al texto de la Directiva 2011/83/UE.

Ahora bien, la regulación de la LOCM en materia de contratos a distancia continúa vigente. Así pues, los arts. 92 a 112 resultan aplicables a los contratos a distancia de entrega de bienes o de prestación de servicios que merezcan categorizarse como de consumo, esto es, celebrados entre empresarios y consumidores. Al mismo tiempo, los arts. 38 a 48 LOCM rige para las ventas minoristas a distancia que no puedan caracterizarse como de consumo ${ }^{152}$.

${ }^{150}$ COM -2001-, 531 final, p. 2.

${ }^{151}$ En efecto, su art. 4 establece que "los Estados miembros no mantendrán o introducirán, en su legislación nacional, disposiciones contrarias a las fijadas en la presente Directiva, en particular disposiciones más o menos estrictas para garantizar un diferente nivel de protección de los consumidores, salvo disposición en contrario de la presente Directiva".

${ }^{152}$ Además, la contratación a distancia viene completada con dos normas: el RD 1906/99, de 17 de diciembre, por el que se regula la contratación electrónica y telefónica con condiciones generales en desarrollo del art. 5.3 LCGC, aplicable a los contratos a distancia telefónicos y electrónicos celebrados mediante condiciones generales y la Ley de Servicios de la Sociedad de la Información y del Comercio Electrónico. En este sentido, el nuevo art. 94 TRDCU establece que en las comunicaciones comerciales por correo electrónico o cualquier otro medio de comunicación electrónica y en la contratación a distancia de bienes o servicios por medios electrónicos, se aplicará tanto el TRDCU como la normativa específica sobre servicios de la sociedad de la información y comercio electrónico. En caso de contradicción entre ambos cuerpos normativos, el párrafo $2^{\circ}$ del art. 94 acoge el criterio lex specialis derogat lex generalis, y así establece que será preferente la normativa específica sobre servicios de al sociedad de la información y comercio electrónico, con una excepción: contenido y modo de cumplimiento del deber de información precontractual impuesto al empresario en esta 


\section{DELIMITACIÓN DEL ÁMBITO SUBJETIVO Y OBJETIVO DE LOS CONTRATOS A DISTANCIA}

El régimen de los contratos a distancia viene delimitado mediante el empleo de dos criterios delimitadores. A saber: un criterio personal o subjetivo, por una parte, y un criterio material u objetivo, por otra. El estudio de la aplicación del régimen jurídico de los contratos a distancia no sólo tiene interés por meras razones del conocimiento del derecho aplicable (esto es, por razones de seguridad jurídica), sino porque los criterios delimitadores sirven para caracterizar y conceptualizar el sistema de contratación a cuyo modelo responden los contratos a distancia.

\section{Delimitación subjetiva del Ámbito de aplicación de los contratos a DISTANCIA}

Los nuevos artículos 92 y ss. sólo encuentran aplicación cuando estemos ante contratos de consumo (esto es, contratos celebrados entre empresarios y consumidores, art. 92.2 TRDCU). Se sigue así la tradicional empleado por la Directiva 85/577 y continuado por el ya derogado art. 92.1 TRDCU. Tanto el legislador comunitario como el patrio emplean la expresión "contratos celebrados con consumidores y usuarios". Los contratos de consumo se definen como aquellos "realizados entre un consumidor o un usuario y un empresario" (art. 59.1 TRDCU). Los conceptos legales de consumidor y usuario, por un lado, y, por otro, de empresario están positivizados en los artículos 3 y 4 TRDCU. En efecto, según el primero de los artículos citados, "son consumidores o usuarios las personas físicas que actúen con un propósito ajeno a su actividad comercial, empresarial, oficio o profesión" 153 . Mientras que, por mor del art. 4 TRDCU, empresario es "toda persona física o jurídica, ya sea privada o pública, que actúe directamente o a través de otra persona en su nombre o siguiendo sus instrucciones, con un propósito relacionado con su actividad comercial, empresarial, oficio o profesión"154.

\section{Delimitación obJetiva del Ámbito de aplicación de los Contratos a DISTANCIA}

El régimen jurídico de los contratos a distancia se contiene ahora en

modalidad promotora de la contratación.

${ }^{153}$ La Ley 3/2014 también ha incidido en el concepto de consumidor en el sentido de considerar también como tales a "las personas jurídicas y las entidades sin personalidad jurídica que actúen sin ánimo de lucro en un ámbito ajeno a una actividad comercial o empresarial” (párrafo $2^{\circ}$ del art. 3 TRDCU).

${ }^{154}$ La redacción del artículo 4 también se debe al apartado dos del artículo único de la Ley $3 / 2014$. 
la nueva redacción dada a los arts. 92 y ss. TRDCU (cuyo germen normativo se encuentra en la Directiva 2011/83/UE) ${ }^{155}$. La definición de contrato a distancia la encontramos en el art. 2.7) de la Directiva y en el nuevo art. 92.1 TRDCU. Por contratos a distancia se debe entender ahora aquellos celebrados "en el marco de un sistema organizado de venta o prestación de servicios a distancia, sin la presencia física simultánea del empresario y del consumidor y usuario, y en el que se hayan utilizado exclusivamente una o más técnicas de comunicación a distancia hasta el momento de la celebración del contrato y en la propia celebración del mismo".

De una primera lectura de estos dos preceptos, se puede llegar a una primera conclusión. La Directiva 2011/83/UE caracteriza desde un punto de vista material la contratación a distancia como un sistema de contratación consistente en celebrar contratos sin existencia de contacto presencial entre oferentes y aceptantes, esto es, sin presencia física simultánea de las partes contratantes. La emisión de la aceptación, pues, las partes se deben valer en todo momento de técnicas de comunicación a distancia de cualquier naturaleza.

Por tanto todo contrato, cualquiera que sea su modalidad (compraventa, suministro, arrendamiento, etc.) y su objeto (productos -esto es, bienes muebles o inmuebles- o servicios), puede categorizarse como celebrado a distancia. Ahora bien, para que así ocurra deben concurrir los siguientes elementos caracterizadores legalmente establecidos.

\subsection{Sistema ORgANiZADO DE CONTRATACión A DisTANCIA}

La contratación a distancia se configura legalmente como un sistema de contratación alternativo al tradicional (esto es, alternativo al celebrado dentro del establecimiento mercantil, en el que se encuentran presentes física y simultáneamente las partes contratantes). Pero sólo queda incluido dentro de este régimen especial aquel negocio que forme parte de un sistema organizado de contratación. Por sistema organizado de contratación debe entenderse la creación por parte del empresario de una verdadera organización establecida al objeto de la distribución comercial de bienes o servicios en el mercado a través de técnicas de comunicación a distancia de

${ }^{155}$ Es necesario realizar dos interesantes precisiones: La primera es que la normativa de la Directiva y del texto refundido se aplica tanto a los contratos como a las ofertas de contrato realizadas por los consumidores en las mismas circunstancias, letra b). En segundo lugar, han de incluirse las situaciones en las que el comerciante tiene con el consumidor un contacto personal e individual fuera de su establecimiento mercantil, aunque el contrato se celebre posteriormente dentro de él o a través de un medio de comunicación a distancia, letra c), así como las compras realizadas en el curso de una excursión organizada por el comerciante durante la cual éste proporciona y vende los productos a los consumidores, letra d). MIRANDA SERRANO, L., «La Directiva 2011/83/UE sobre derechos de los consumidores: una nueva regulación para Europa de los contratos celebrados a distancia y extramuros de los establecimientos mercantiles», $R c D$, núm. 11, 2012, pp. 90 ss. 
cualquier naturaleza. Este concepto debe incluir los sistemas ofrecidos por un tercero distinto del comerciante pero utilizado por éste, como una plataforma en línea. No obstante, no debe cubrir los casos en que las páginas web ofrecen información solamente sobre el comerciante, sus bienes o servicios y sus datos de contacto (considerando 20 Directiva 2011/83/UE). Así el nuevo art. 95 TRDCU impone a los operadores de las técnicas de comunicación a distancia (esto es, las personas físicas o jurídicas, públicas o privadas, que sean titulares de las técnicas de comunicación a distancia utilizadas por los empresarios) la obligación de procurar que se respeten por parte de los empresarios el nuevo régimen legal de los contratos a distancia

En cualquier caso, no tendrán la consideración de contratos a distancia todos aquellos negocios que, pese a celebrarse a través de medios de comunicación a distancia (esto es, sin contacto presencial entre los sujetos contratantes) revisten carácter meramente ocasional y aislado. Nos referimos a los supuestos de ventas ocasionales celebradas por teléfono, fax o, incluso, correo electrónicos, entre un consumidor y un operador económico pero que carezca de un sistema organizado de contratación a distancia que le permita ofertar sus bienes a distancia y contratar también a distancia con todos sus potenciales clientes, sino que su sistema habitual de contratación sea el presencial o tradicional.

\subsection{EMPLEO de TÉCNICAS dE COMUNICACIÓN A disTANCIA}

La contratación a distancia se presenta como un sistema de contratación conforme al cual los contratos se concluyen a través de técnicas de comunicación a distancia y, por tanto, sin la presencia física simultánea de los sujetos contratantes. Así lo dispone la ley y lo viene sosteniendo tanto la jurisprudencia como la doctrina. Se trata de una contratación entre distantes, esto es, entre sujetos físicamente distanciados que para contratar se valen de técnicas de comunicación a distancia de cualquier naturaleza.

Distinto de los contratos a distancia son los contratos entre distantes o ausentes. En efecto, tradicionalmente el Derecho privado ha conceptualizado un tipo de contratos, caracterizados por una doble confluencia de eventos: un factor físico o geográfico (por el cual, no deben encontrarse físicamente presentes las partes contratantes) y un factor temporal (intervallo temporis) entre el momento en que se emite la aceptación y el instante en que es conocida por el oferente. De tal forma que no se consideran contratos entre distantes o ausentes los realizados a través del teléfono puesto que en esos casos, la oferta y la aceptación negocial tiene lugar de modo instantáneo.

La contratación a distancia sólo tiene lugar exclusivamente cuando se dé el requisito geográfico, esto es, cuando no exista contacto presencial de los sujetos contratantes. Eso sí, esa ausencia de la presencia física inter partes ha de darse tanto en el momento precontractual (fase previa de la celebración del contrato), 
como en el momento mismo de la celebración del contrato. Por tal razón, quedan excluidos del régimen de los contratos a distancia (pero incluido en el régimen de los contratos celebrados fuera de los establecimientos mercantiles) aquellos celebrados mediante un medio de comunicación a distancia pero "inmediatamente después de que haya existido contacto personal e individual con el consumidor y usuario en un lugar que no sea el establecimiento mercantil del empresario, con la presencia física simultánea del empresario y el consumidor y usuario" [nuevo apartado c) art. 92.2 TRDCU]. Como tampoco quedan incluidos en este régimen aquellos cuya contratación haya comenzado utilizando un medio de comunicación a distancia pero que termina celebrándose en el establecimiento mercantil del empresario (considerando 20 Directiva 2011/83/UE).

La fase de ejecución contractual queda, sin embargo, al margen de esta exigencia legal. Así, el hecho de que la ejecución de un contrato no sea a distancia no excluye al contrato en cuestión de la normativa propia de los contratos a distancia, siempre, claro está, que el contrato fuera negociado y concluido a través de técnicas de comunicación a distancia.

Por técnicas de comunicación a distancia, el legislador comunitario y patrio acoge un criterio de permisibilidad muy amplio. Así, el mismo art. 92.1 TRDCU entiende que "entre otras, tienen la consideración de técnicas de comunicación a distancia: el correo postal, Internet, el teléfono o el fax". Lo determinante es que la técnica de comunicación permita transmitir las declaraciones negociales de quienes contratas, siendo, además, indiferente la identidad o coincidencia entre la técnica empleada por el operador económico o profesional y la usada por el consumidor.

En cualquier caso, en la utilización de una técnica de comunicación a distancia, el empresario o profesional deberá cumplir con los deberes establecidos por el nuevo art. 96 TRDCU. A saber:

En primer lugar, debe constar inequívocamente el carácter comercial de la comunicación comercial remitida por el empresario o profesional al consumidor.

En segundo lugar, el empresario deberá precisar explícita y claramente, al inicio de cualquier conversación con el consumidor y usuario, su identidad, o si procede, la identidad de la persona por cuenta de la cual efectúa la llamada, así como indicar la finalidad comercial de la misma. Además, se prohibe realizar llamadas telefónicas comerciales antes de las 9 horas ni más tarde de las 21 horas, ni durante los dias festivos o los fines de semana.

En tercer lugar, se necesitará el consentimiento expreso previo del consumidor y usuario para la utilización por parte del empresario de técnicas de comunicación que consistan en un sistema automatizado de llamadas sin intervención humana o el telefax. En este sentido, se impone a todo empresario o profesional la prohibición de entablar cualquier tipo de comunicación comercial con aquellos consumidores que no figuren en guías de comunicaciones electrónicas disponibles al público, o hubieren ejercido el derecho a que los datos que aparecen en ellas 
no sean utilizados con fines de publicidad o prospección comercial, o solicitado la incorporación a los ficheros comunes de exclusión de envio de comunicaciones comerciales regulados en la normativa de protección de datos personales (siempre, claro está, que no medie consentimiento del interesado). Esta prohibición se completa con el reconocimiento a favor de todo consumidor o usuario del derecho de oponerse a la recepción de ofertas comerciales no deseadas, por teléfono, fax u otros medios de comunicación equivalente, incluso en el marco de una relación preexistente. Para tal fin, se impone al empresario o profesional el deber de informar en cada una de las comunicaciones comerciales de los medios para oponerse a recibirlas. Estos medios deberán ser "sencillos y gratuitos".

En quinto lugar, aquellos casos en que una oferta comercial no deseada se realice por teléfono, las llamadas deberán llevarse a cabo desde un número de teléfono identificable. Cuando el usuario reciba la primera oferta comercial del emisor, deberá ser informado tanto de su derecho a manifestar su oposición a recibir nuevas ofertas como a obtener el número de referencia de dicha oposición. A solicitud del consumidor y usuario, el empresario estará obligado a facilitarle un justificante de haber manifestado su oposición que deberá remitirle en el plazo más breve posible y en todo caso en el plazo máximo de un mes.

El emisor estará obligado a conservar durante al menos un año los datos relativos a los usuarios que hayan ejercido su derecho a oponerse a recibir ofertas comerciales, junto con el número de referencia otorgado a cada uno de ellos, y deberá ponerlos a disposición de las autoridades competentes.

Por último, el empresario deberá cumplir las disposiciones vigentes sobre protección de los menores y respeto a la intimidad. Cuando para la realización de comunicaciones comerciales se utilicen datos personales sin contar con el consentimiento del interesado, se proporcionará al destinatario la información que señala el artículo 30.2 de la Ley Orgánica 15/1999, de 13 de diciembre, de Protección de Datos de Carácter Personal, y se ofrecerá al destinatario la oportunidad de oponerse a la recepción de las mismas.

\section{Contratos ExCluidos del ÁMbito de APLiCACión DE LOS CONTRATOS A Dis- TANCIA}

Al igual que en la antigua regulación de los contratos a distancia y de los contratos fuera de los establecimientos mercantiles, la Directiva 2011/83/UE y el nuevo art. 93 excluyen de la especial protección algunos contratos que no reúnen los elementos que caracterizan a la contratación celebrada fuera de los establecimientos mercantiles. El legislador comunitario, a tal fin, se ha servido de varios criterios.

En primer lugar, se excluyen por un criterio material u objetivo (esto es, por razón de la naturaleza del objeto sobre el que verse el contrato) los siguientes contratos: 
- Los contratos de servicios sociales, incluidos la vivienda social, el cuidado de los niños y el apoyo a familias y personas necesitadas, temporal o permanentemente, incluida la atención a largo plazo [art. 93 a)]. A juicio de la Exposición de Motivos de la Directiva 2011/83/UE, estos contratos poseen "unas características bien diferenciadas que se reflejan en la legislación específica del sector, de la cual, una parte se decide a nivel de la Unión y otra, a nivel nacional" (Considerando 29).

- Los contratos de servicios relacionados con la salud, prestados por un profesional sanitario a pacientes para evaluar, mantener o restablecer su estado de salud, incluidos la receta, dispensación y provisión de medicamentos y productos sanitarios, con independencia de que estos servicios se presten en instalaciones sanitarias [art. 93 b)]. Estos contratos son excluidos puesto que para la Directiva 2011/83/UE demandan una regulación especial "debido a su complejidad técnica, su importancia como servicio de interés general y su importante financiación pública" (Considerando 30).

- Los contratos de servicios financieros [art. 93 d)], viajes combinados, las vacaciones combinadas y los circuitos combinados regulados en esta ley [art. $93 \mathrm{~g}$ )], así como aquellos determinados aspectos de los contratos de aprovechamiento por turno de bienes de uso turístico, de adquisición de productos vacacionales de larga duración, de reventa y de intercambio regulados en la Ley 4/2012, de 6 de julio, de contratos de aprovechamiento por turno de bienes de uso turístico, de adquisición de productos vacacionales de larga duración, de reventa y de intercambio y normas tributarias [art. 93 h)]. La razón de su exclusión resulta obvia. Estos contratos cuentan con su regulación específica. Rige, por tanto, el principio general del Derecho por el cual la norma del sector específico prevalece sobre el régimen del Testo refundido (normal general).

- Los contratos de creación, adquisición o transferencia de bienes inmuebles o de derechos sobre los mismos [art. 93 e)], así como los contratos para la construcción de edificios nuevos, la transformación sustancial de edificios existentes y el alquiler de alojamientos para su uso como vivienda [art. $93 \mathrm{f}$ )].

- Los contratos de servicios de transporte de pasajeros, sin perjuicio de la aplicación del artículo 98.2 [art. $93 \mathrm{k}$ )].

En segundo lugar, se excluyen en atención a un criterio circunstancial, esto es, por razón de las concretas circunstancias concurrentes en su celebración, los contratos siguientes:

- Los contratos que, con arreglo a la legislación vigente, deban celebrarse ante un fedatario público, obligado por ley a ser independiente e imparcial y a garantizar, mediante el suministro de una información jurídica comprensible, que el consumidor y usuario celebra el contrato únicamente previa reflexión suficiente y con pleno conocimiento de su alcance jurídico [art. 93 i)].

- Los contratos celebrados mediante distribuidores automáticos o 
instalaciones comerciales automatizadas [art. 93 1)].

- Los contratos celebrados con operadores de telecomunicaciones a través de teléfonos públicos para la utilización de esos teléfonos, o celebrados para el establecimiento de una única conexión de teléfono, Internet o fax por parte de un consumidor y usuario [art. $93 \mathrm{~m}$ )].

La exclusión de la normativa específica viene justificada por cuanto que, en ellos, queda eliminado tanto el elemento sorpresivo como la presión psiconegocial del empresario. En efecto, ya desde la primera Ley reguladora de los contratos a distancia (la Ley 26/1991, de 21 de noviembre), se excluían el primer tipo de contratos (los contratos documentados notarialmente) por entender que la información preventiva que el notario ofrece al consumidor diluye los riesgos inherentes a los contratos a distancia. En cambio, el origen las dos exclusiones siguientes ya lo encontramos en la Directiva 97/7/CE, en cuyo art. 3 se excluía de su ámbito de aplicación los negocios celebrados mediante distribuidores automáticos o locales comerciales automatizados (como, por ejemplo, los contratos concluidos en máquinas expendedoras de bebidas, alimentos, juguetes o periódicos) y los concluidos con los operadores de telecomunicaciones debido a la utilización de los teléfonos públicos.

En tercer lugar, la Directiva emplea un criterio mixto (en parte objetivo y en parte circunstancial) para excluir algunos negocios de su ámbito de aplicación. Nos encontramos, en efecto, con una serie de supuestos específicos de exclusión cuya causa estriba en la combinación de un criterio objetivo y uno circunstancial. Así, concretamente, quedan excluidos los contratos para el suministro de productos alimenticios, bebidas u otros bienes de consumo corriente en el hogar (criterio objetivo), suministrados físicamente por un empresario mediante entregas frecuentes y regulares en el hogar o lugar de residencia o de trabajo del consumidor y usuario (criterio circunstancial) [art. 93 j)]. El origen de esta exclusión se encuentra en la Directiva $85 / 577 / \mathrm{CE}$, por cuyo art. 3.2 b) se descartaba a "los contratos relativos a la entrega de productos alimenticios, de bebidas o de otros bienes del hogar de consumo corriente suministrador por distribuidores que realicen viajes frecuentes $y$ regulares". La exigencia de que tales bienes sean suministrados de forma regular excluye el elemento de la sorpresa propio de este sistema de contratación. Al mismo tiempo, quedan excluidos los contratos de actividades de juego por dinero (criterio objetivo) que impliquen apuestas de valor monetario en juegos de azar (criterio circunstancial), incluidas las loterías, los juegos de casino y las apuestas [art. $93 \mathrm{c}$ )]. Para la Directiva (Considerando 31), estos contratos deben contar con una específica regulación de protección de los consumidores, de carácter más estricto.

Porúltimo, se hace necesario destacar la desaparición del criterio cuantitativo como elemento de exclusión del régimen legal de los contratos a distancia. En efecto, el ya derogado art. 108 b) TRDCU excluía la protección de los contratos a distancia a aquellos contratos en los que la cuantía de la prestación total a cargo del consumidor 
fuera inferior a 40,08 euros. En este punto, la Directiva 2011/83/UE facultaba a los Estados miembros a no aplicar sus normas o disposiciones nacionales equivalentes a los contratos a distancia en los que el pago que debe efectuar el consumidor no fuera superior a 50 euros (art. 3.4). Es más, habilitaba a los Estados miembros a definir un valor inferior en sus legislaciones nacionales. No obstante, nuestro legislador español no ha hecho uso de esta facultad y no aparece ningún criterio cuantitativo como excluyente de la aplicación de los arts. 92 y ss. TRDCU. Se elimina así la picaresca consistente en la práctica de ofrecer al consumidor en una misma relación un conjunto de productos o servicios cuyo importe total sea superior a los $50 €$, pero cuyos precios individuales, esto es, fijados por separado, sean inferiores a dicha cifra. Por tal razón, el ya derogado art. 108 b) TRDCU establecía que, a los efectos de computar el importe de los 40,08 € determinantes de la exclusión del contrato, "se considerará como prestación total la suma de todas las correspondientes a cada uno de los contratos celebrados por el consumidor y usuario con ocasión de uno de los actos o en algunas de las circunstancias a que se refiere el artículo anterior". Por tanto, el nuevo régimen legal de los contratos a distancia se aplica a todos los negocios, independientemente de la cuantía que el consumidor tenga que satisfacer en concepto de precio.

En cambio, sí se prevé una presunción legal de inclusión. Así, por mor del art. 92.4 TRDCU, todos los contratos y ofertas celebrados fuera del establecimiento mercantil se presumen sometidos al régimen tuitivo de los contratos a distancia. Se trata de una presunción iuris tantum, que admite prueba en contrario. En este caso, corresponde al empresario probar la no aplicación de las normas reguladoras de la contratación celebrada fuera de los establecimientos mercantiles, por estar incurso en algunas de las excepciones contempladas por el nuevo art. 93 TRDCU.

\section{NUEVO RÉGIMEN JURÍDICO DE LOS CONTRATOS CELEBRADOS A DISTANCIA.}

\section{LOS DEBERES DE INFORMACIÓN PRECONTRACTUAL Y DE CONFIRMACIÓN DEL CONTRATO}

\subsection{REQUisitos FORMALES DE LAS OBLIGACIONES DE INFORMACIÓN PRECON- TRACTUAL Y DE CONFIRMACIÓN DEL CONTRATO}

La libertad de elección del consumidor a la hora de celebrar un contrato depende directamente de que esté debidamente informado acerca de la naturaleza y características de la prestación objeto del contrato y de las condiciones jurídicas y económicas del mismo. Esta es, fundamentalmente, la razón que justifica la imposición, por parte del TRDCU, a los empresarios de la necesidad de cumplir determinados requisitos formales a la hora de contratar con consumidores y usuarios. 
A tenor de lo dispuesto en los arts. 97,1 y 98 TRDCU, el empresario, antes de que el consumidor o usuario quede vinculado por cualquier contrato celebrado a distancia o por cualquier oferta, deberá facilitar a éste de forma clara y comprensible la información precontractual prevista en el art. 97,1.

Dicha información, deberá ser proporcionada, o bien puesta a disposición del consumidor, por parte del empresario, al menos en castellano así como en la lengua utilizada en la propuesta de contratación o, en su caso, en la lengua elegida para la contratación, de forma acorde con las técnicas de comunicación a distancia utilizadas, en términos claros y comprensibles y siempre respetando, en particular, el principio de buena fe en las transacciones comerciales, así como los principios de protección de quienes sean incapaces de contratar. Así pues, no se configura ningún soporte como medio preferente para facilitar la información precontractual legalmente exigida, sino que, por contra, la elección de un determinado medio o soporte dependerá de su adecuación a las técnicas de comunicación a distancia empleadas, si bien siempre que se emplee un soporte duradero para proporcionar dicha información, éste habrá de ser legible (art.98,1 TRDCU).

Por soporte duradero, a los efectos aquí analizados, habrá que entender, según se infiere de la Directiva 2011/83/UE, todo instrumento que permita al consumidor o al comerciante almacenar información que se le transmita personalmente de forma que en el futuro pueda recuperarla fácilmente durante un periodo de tiempo acorde con los fines de dicha información y que permita la reproducción de la información almacenada sin cambios. Así pues, podemos considerar que cumplen los requisitos exigidos la información suministrada en papel, memoria USB, CD-ROM, DVD, tarjetas de memoria, discos duros de ordenador, email, entre otros soportes.

No obstante, como ya hemos afirmado, el TRDCU no exige que en todo caso la información precontractual se proporcione al consumidor mediante el empleo de algún soporte duradero. Así, cuando el contrato se celebre a través de alguna página Web, la información precontractual podrá facilitarse al consumidor en línea sin necesidad de emplear soporte duradero alguno siempre que se le permita archivar las condiciones generales aplicables a la contratación (art. 27,4 Ley 34/2002, de 11 de julio, de Servicios de la Sociedad de la Información). Igualmente, si el contrato se celebra por vía telefónica, se podrá proporcionar la información principal por teléfono y remitir al consumidor a otro medio complementario (página Web, email, correo postal, etc) a fin de que pueda ampliar la información recibida.

Por el contrario, a diferencia de lo que acontece con la información precontractual legalmente exigida, el art.98,7 del TRDCU sí exige, en todo caso, que el empresario facilite al consumidor la confirmación del contrato celebrado en un soporte duradero dentro de un plazo razonable tras la celebración del mismo y, a lo sumo, en el momento de la entrega de los bienes, o bien, del inicio de la ejecución del servicio objeto del contrato a distancia celebrado. Tal confirmación incluirá toda la información que figura en el artículo 97.1, salvo en el supuesto de que el empresario 
ya la hubiese facilitado al consumidor en un soporte duradero antes de la celebración del contrato a distancia, y, además, en su caso, la confirmación del previo consentimiento expreso del consumidor y del conocimiento por su parte de la pérdida del derecho de desistimiento de conformidad con el art.103.m) del TRDCU.

En el supuesto de que se trate de contratos celebrados por medios electrónicos que impliquen obligaciones de pago para el consumidor, se imponen al empresario especiales exigencias respecto al contenido, al momento y a la forma de la información precontractual que debe proporcionar al consumidor. Concretamente, el art.98,2 TRDCU obliga al empresario a que, en estos casos, ponga en conocimiento del consumidor, de manera clara y destacada y justo antes de que efectúe su pedido, al menos la información principal establecida en los apartados a), e), p) y q) del art.97,1 y que se refieren a las características y precio de los bienes y servicios ofertados, así como a la duración del contrato y de las obligaciones del consumidor. Por tanto, en estos supuestos no bastará con que el empresario ponga a disposición del consumidor, de forma acorde con las técnicas de comunicación a distancia empleadas, la información requerida por el art.97,1 TRDCU, es decir, no será suficiente con la indicación de un enlace que el consumidor pueda visitar para informarse sobre las condiciones del contrato, sino que, en estos casos, el empresario estará obligado a poner en conocimiento del consumidor, y con anterioridad a la realización del pedido, al menos la información principal del contrato antes citada.

Además, el mismo art. 98,2 exige que, con la finalidad de que el consumidor sea consciente de la obligación de pago que asume, confirme expresamente, en el momento de efectuar su pedido, que es consciente de que el pedido realizado implica una obligación de pago. Por esta razón, si la realización del pedido se hace activando un botón o una función similar, éstos deberán etiquetarse, de manera que sea fácilmente legible, con la expresión "pedido con obligación de pago» o una formulación análoga no ambigua que indique que la realización del pedido implica la obligación de pagar al empresario. En caso contrario, el consumidor y usuario no quedará obligado por el contrato o pedido.

Con la misma finalidad de incrementar al alza las exigencias informativas en los contratos electrónicos, las web de comercio electrónico "deberán indicar" (no sólo facilitar información remitiendo a otros enlaces informativos), de modo claro y legible (tamaño de letra adecuado, información fija y no en formato flash), "a más tardar al inicio del procedimiento de compra" si se aplican algunas restricciones de entrega (ej. en función de la distancia o de los gastos de transporte y entrega) y cuáles son los medios de pago aceptados y su eventual coste.

En los supuestos en los que el contrato se celebre a través de una técnica de comunicación a distancia en la que el espacio o el tiempo para facilitar la información sean limitados (p.ej. vía telefónica, SMS, restricción del número de caracteres por pantalla reducida, anuncio de televisión o radio, etc), el empresario deberá facilitar, con anterioridad a la celebración del contrato y en ese soporte 
especifico, como mínimo la información precontractual sobre las características principales de los bienes o servicios, la identidad del empresario, el precio total, el derecho de desistimiento, la duración del contrato y, en el caso de contratos de duración indefinida, las condiciones de resolución, tal como se refiere en el artículo 97.1. a), b), e), i) y p). El resto de la información prevista en el art.97,1 del TRDCU deberá ser facilitada al consumidor de una manera apropiada a la técnica de comunicación empleada (p.ej. remisión a una web con la información completa sobre el servicio y a solicitud del interesado, número telefónico o envío en soporte papel $\mathrm{u}$ otro soporte duradero de todas las condiciones aplicables al contrato) (art.98,4 TRDCU).

Sin perjuicio de lo dispuesto en el comentado art.98,4 en relación con los deberes informativos del empresario cuando el contrato se celebre a través de una técnica de comunicación a distancia en la que el espacio o el tiempo para facilitar la información sean limitados, si el contrato se celebrara por vía telefónica, el empresario deberá revelar, al inicio de la conversación, su identidad o, en su caso, la identidad de la persona por cuenta de la cual efectúa la llamada e indicar el objeto comercial de la misma. Así mismo, deberá confirmar la oferta al consumidor por escrito, o salvo oposición del mismo, en cualquier soporte de naturaleza duradera, no resultado vinculado el consumidor hasta que haya aceptado la oferta mediante su firma o mediante el envio de su acuerdo por escrito (email, fax o SMS) (art.98, 5 y 6 TRDCU).

Por último, según dispone el art.98,9 TRDCU, corresponderá al empresario probar el cumplimiento los deberes de información previstos en el citado precepto, así como, adoptar las medidas adecuadas que permitan identificar inequívocamente al consumidor con el que celebre el contrato.

\subsection{CONTENIDO DE LA INFORMACIÓN PRECONTRACTUAL}

De conformidad con el art.97,1 TRDCU, antes de que el consumidor y usuario quede vinculado por cualquier contrato celebrado a distancia o cualquier oferta correspondiente, el empresario le facilitará de forma clara y comprensible la siguiente prolija información, la cual, además, deberá ser legible y estar redactada al menos en castellano (art.99,1 TRDCU):

a) Las características principales de los bienes o servicios, en la medida adecuada al soporte utilizado y a los bienes o servicios; b) La identidad del empresario, incluido su nombre comercial; c) La dirección completa del establecimiento del empresario y el número de teléfono, número de fax y dirección de correo electrónico del mismo, cuando proceda, con objeto de que el consumidor y usuario pueda ponerse en contacto y comunicarse con él de forma rápida y eficaz, así como, cuando proceda, la dirección completa y la identidad del empresario por cuya cuenta actúa; d) Si es diferente de la dirección facilitada de conformidad con la letra c), la dirección 
completa de la sede del empresario y, cuando proceda, la del empresario por cuya cuenta actúa, a la que el consumidor y usuario puede dirigir sus reclamaciones; e) El precio total de los bienes o servicios, incluidos los impuestos y tasas, o, si el precio no puede calcularse razonablemente de antemano por la naturaleza de los bienes o de los servicios, la forma en que se determina el precio, así como, cuando proceda, todos los gastos adicionales de transporte, entrega o postales y cualquier otro gasto $\mathrm{o}$, si dichos gastos no pueden ser calculados razonablemente de antemano, el hecho de que puede ser necesario abonar dichos gastos adicionales. En el caso de un contrato de duración indeterminada o de un contrato que incluya una suscripción, el precio incluirá el total de los costes por período de facturación. Cuando dichos contratos se cobren con arreglo a una tarifa fija, el precio total también significará el total de los costes mensuales. Cuando no sea posible calcular razonablemente de antemano el coste total, se indicará la forma en que se determina el precio; f) El coste de la utilización de la técnica de comunicación a distancia para la celebración del contrato, en caso de que dicho coste se calcule sobre una base diferente de la tarifa básica; g) Los procedimientos de pago, entrega y ejecución, la fecha en que el empresario se compromete a entregar los bienes o a ejecutar la prestación de los servicios, así como, cuando proceda, el sistema de tratamiento de las reclamaciones del empresario; $h$ ) La lengua o lenguas en las que podrá formalizarse el contrato, cuando ésta no sea la lengua en la que se le ha ofrecido la información previa a la contratación; i) Cuando exista un derecho de desistimiento, las condiciones, el plazo y los procedimientos para ejercer ese derecho, así como el modelo de formulario de desistimiento; j) Cuando proceda, la indicación de que el consumidor y usuario tendrá que asumir el coste de la devolución de los bienes en caso de desistimiento y, para los contratos a distancia, cuando los bienes, por su naturaleza, no puedan devolverse normalmente por correo, el coste de la devolución de los mismos; k) En caso de que el consumidor y usuario ejercite el derecho de desistimiento tras la presentación de una solicitud con arreglo al artículo 98.8 o al artículo 99.3, la información de que en tal caso el consumidor y usuario deberá abonar al empresario unos gastos razonables de conformidad con el artículo 108.3 ; 1) Cuando con arreglo al artículo 103 no proceda el derecho de desistimiento, la indicación de que al consumidor y usuario no le asiste, o las circunstancias en las que lo perderá cuando le corresponda; m) Un recordatorio de la existencia de una garantía legal de conformidad para los bienes; n) Cuando proceda, la existencia de asistencia posventa al consumidor y usuario, servicios posventa y garantías comerciales, así como sus condiciones; o) La existencia de códigos de conducta pertinentes y la forma de conseguir ejemplares de los mismos, en su caso. A tal efecto, se entiende por código de conducta el acuerdo o conjunto de normas no impuestas por disposiciones legales, reglamentarias o administrativas, en el que se define el comportamiento de aquellos empresarios que se comprometen a cumplir el código en relación con una o más prácticas comerciales o sectores económicos; $p$ ) La duración del contrato, cuando proceda, $\mathrm{o}$, si el contrato es de duración indeterminada 
o se prolonga de forma automática, las condiciones de resolución; q) Cuando proceda, la duración mínima de las obligaciones del consumidor y usuario derivadas del contrato; r) Cuando proceda, la existencia y las condiciones de los depósitos u otras garantías financieras que el consumidor y usuario tenga que pagar o aportar a solicitud del empresario; s) Cuando proceda, la funcionalidad de los contenidos digitales, incluidas las medidas técnicas de protección aplicables; t) Cuando proceda, toda interoperabilidad relevante del contenido digital con los aparatos y programas conocidos por el empresario o que quepa esperar razonablemente que éste pueda conocer; u) Cuando proceda, la posibilidad de recurrir a un mecanismo extrajudicial de reclamación y resarcimiento al que esté sujeto el empresario y los métodos para tener acceso al mismo.

\subsection{CONSECUENCIAS DEL INCUMPLimiento DE LOS DEBERES DE INFORMACIÓN PRECONTRACTUAL Y DE CONFIRMACIÓN DEL CONTRATO}

Si el empresario no cumple los requisitos de información sobre gastos adicionales $u$ otros costes contemplados en el apartado 1. e), o sobre los costes de devolución de los bienes contemplados en el apartado 1. j), del art.97 TRDCU, el consumidor no deberá abonar dichos gastos o costes (art.97,6 TRDCU)

Además, si el contrato se hubiese celebrado sin que se hubiese facilitado al consumidor la copia del mismo o su confirmación, de acuerdo con el art.98, 7, podría ser anulado a instancia del consumidor por vía de acción o excepción. Sin embargo, en ningún caso podría ser invocada la causa de nulidad por el empresario, salvo que el incumplimiento fuese exclusivo del consumidor y usuario (art.100 TRDCU).

En todo caso, corresponderá al empresario probar el cumplimiento de las obligaciones formales referidas anteriormente (arts.97,8, 98,9 y 100 TRDCU).

Así pues, el TRDCU impone al empresario la obligación de probar el cumplimiento de sus obligaciones formales con el fin de reforzar la posición jurídicotuitiva del consumidor que participe en estos negocios. En consecuencia, si el consumidor solicitara la anulación del contrato por incumplimiento de los requisitos formales legalmente exigidos ex art.98,7 TRDCU, sería el empresario el encargado de demostrar el cumplimiento de los mismos. Si, por el contrario, fuese el empresario quien solicitara el cumplimiento del contrato, correspondería, en su caso, al consumidor oponer la invalidez del mismo por incumplimiento de los citados requisitos formales. 


\section{LA FACULTAD DE DESISTIMIENTO DEL CONSUMIDOR}

\subsection{FUNDAMENTACIÓN Y NATURALEZA JURÍDICA DEL DERECHO DE DESISTIMIENTO EN LOS CONTRATOS CELEBRADOS A DISTANCIA}

Como es bien sabido, en nuestro Ordenamiento jurídico los contratos, en cuanto fruto del acuerdo entre dos o más voluntades, se perfeccionan, como regla general, por el mero consentimiento y desde entonces obligan no sólo al cumplimiento de lo expresamente pactado sino también a todas las consecuencias que según su naturaleza sean conformes a la buena fe, al uso y a la Ley (art.1.258 C.C). De este modo, las obligaciones que nacen de los contratos adquieren fuerza de Ley entre las partes contratantes (art.1.091 C.C), sin que ninguna de éstas pueda unilateralmente y a su libre albedrío decidir acerca del cumplimiento y la validez de los contratos por ellas celebrados (art.1.256 C.C).

Para nuestro legislador decimonónico el contrato se concibe, pues, como el producto de la actuación libre y espontánea de las partes contratantes que, de este modo, manifiestan su consentimiento contractual de forma seria, espontánea, libre, y desde un plano de igualdad que impide que una de las partes quede sujeta al convenio $y$, entre tanto, la otra reste libre de él. De esta forma, el contrato habrá de considerarse válido y eficaz salvo que, ante la ausencia de alguna de las circunstancias antes aludidas en el consentimiento contractual, se decrete la invalidez del negocio por vicios del consentimiento, o bien las partes decidan por mutuo acuerdo desistir del contrato celebrado entre ambas.

En consecuencia, es posible afirmar que la facultad de desistimiento conferida unilateralmente al consumidor en el TRDCU se presenta, al menos en línea de principio, como una excepción a las reglas generales, antes referidas, de validez y eficacia de los contratos, en cuanto que se concede al consumidor el derecho a separarse de forma unilateral y discrecional del contrato celebrado, pese a no mediar ni un vicio del consentimiento prestado por el mismo, ni un previo acuerdo de resolución contractual con el empresario. En este sentido, este derecho de desistimiento reconocido en favor del consumidor se puede considerar como una verdadera novedad justificada, a nuestro juicio, a tenor del proceso evolutivo de transformación experimentado por el viejo Derecho privado obligado a adaptarse a la siempre cambiante realidad socioeconómica circundante en la que debe aplicarse.

Dado que en los contratos celebrados a distancia el consumidor celebra el contrato sin haber tenido la posibilidad real de ver el producto o de conocer las características del servicio y/o, además, puede verse compelido a contratar afectado por una posible presión psicológica o por un elemento de sorpresa independientemente de que haya solicitado o no el contacto con el empresario, el TRDCU, en sus arts. 102 y s.s., le confiere un derecho de desistimiento que le va a permitir, durante el plazo legalmente previsto, poner fin a la relación contractual previamente nacida 
de forma totalmente discrecional y sin necesidad de que medie justa causa alguna.

De este modo, la facultad de desistimiento del consumidor se configura legalmente como una declaración de voluntad unilateral, recepticia, discrecional y de libre ejercicio. Es unilateral en cuanto que emana de una sola parte y no requiere para producir sus efectos ser aceptada por la otra, -esto es, por el empresario-; se ha de considerar recepticia dado que su eficacia depende de que sea conocida por parte del empresario, con independencia de que ello suceda con posterioridad al plazo de reflexión durante el cual el consumidor tiene la posibilidad de desistir del contrato, puesto que lo realmente importante es que el derecho de desistimiento se ejerza dentro del período de reflexión; se trata, finalmente, de una declaración de voluntad discrecional y de libre ejercicio, en cuanto que permite al consumidor desligarse del contrato válido y perfecto dentro del plazo legal de reflexión si así lo estima oportuno y sin necesidad de que concurra justa causa alguna en la que sustentar su decisión.

En segundo lugar, el derecho de desistimiento se configura como una facultad de carácter imperativo e irrenunciable por parte del consumidor. Por esta razón, su existencia o reconocimiento no resulta negociable por las partes contratantes sino que es consustancial al mismo contrato celebrado fuera del establecimiento mercantil (art.97,5 TRDCU) cualquiera que sea el bien o servicio objeto del mismo (salvo las excepciones previstas en el art.103 TRDCU) y, además, de obligatoria inclusión en el documento contractual, de forma que, la infracción de esta obligación, esto es, la no inclusión en el contrato de la citada cláusula de desistimiento, a parte de no impedir que el comprador posea este derecho, podrá ser sancionada por el Juez competente en la forma prevista en el art.105 TRDCU tal y como después analizaremos.

Por último, este derecho de desistimiento se caracteriza por tener un cierto carácter retroactivo en cuanto que pone fin a un contrato perfectamente válido y carente de vicios, de modo que, obliga a las partes a restaurar la situación anterior a la celebración del contrato y, por consiguiente, a restituirse, recíprocamente entre sí, las prestaciones que previamente se hubiesen intercambiado, desapareciendo los efectos que el contrato hubiera comenzado a producir como si tal contrato nunca hubiese existido (arts.106, 107 y 108 TRDCU)..

\subsection{Duración y Cómputo del Plazo de Desistimiento}

El TRDCU establece en sus arts.102,1, 104 y 105 un plazo de catorce días naturales dentro del cual el consumidor podrá ejercer su derecho de desistimiento del contrato previamente celebrado a distancia. El momento a partir del cual comenzará a computarse el citado plazo será diferente según se trate de contratos que tengan por objeto la prestación de servicios, o bien tengan por objeto la entrega de bienes. Así, mientras que en el primer caso, el art.104 TRDCU establece que el cómputo del plazo comenzará a partir del día de la celebración del contrato, en el segundo, dispone que el plazo de desistimiento comenzará el día en el que el consumidor o un tercero por 
él indicado, distinto del transportista, adquiera la posesión material de los bienes solicitados, o bien: $\mathbf{1 .}^{\mathbf{0}}$ en caso de entrega de múltiples bienes encargados por el consumidor en el mismo pedido y entregados por separado, el día que éste o un tercero por él indicado, distinto del transportista, adquiera la posesión material del último de los bienes; $\mathbf{2 .}^{\circ}$ en caso de entrega de un bien compuesto por múltiples componentes o piezas, el día que el consumidor o un tercero por él indicado, distinto del transportista, adquiera la posesión material del último componente o pieza; y 3. ${ }^{\circ}$ en caso de contratos para la entrega periódica de bienes durante un plazo determinado, el día que el consumidor o un tercero por él indicado, distinto del transportista, adquiera la posesión material del primero de esos bienes.

Sin embargo, excepcionalmente, este plazo general de desistimiento resulta ampliado por el art.105 TRDCU en los supuestos en los que el empresario no facilite al consumidor, en la forma legalmente exigida en el art.97.1.i), la información sobre su derecho a desistir del contrato. En tal supuesto, el periodo de desistimiento finalizaría doce meses después de la fecha de expiración del periodo de desistimiento inicial, determinada de conformidad con el artículo 104. No obstante, si el empresario facilitara al consumidor la citada información en el plazo de doce meses a partir de la fecha contemplada en el artículo 104, el plazo de desistimiento expirará a los 14 días naturales de la fecha en que el consumidor recibiera dicha información.

Sin lugar a duda, consideramos muy acertada la solución de ampliar el plazo para desistir en los supuestos en los que el empresario incumpla en la forma legalmente prevista sus deberes formales de información, por cuanto que ello redundará en una sensible mejora de la confianza de los consumidores en el tráfico mercantil sobre todo si tenemos en cuenta la importancia que tiene la citada información para que el consumidor ejerza su derecho a desistir del contrato. Pese a todo, hubiésemos considerado más acertada la norma si el incumplimiento por parte del empresario de su deber de informar al consumidor acerca de su derecho a desistir del contrato hubiese supuesto no sólo la ampliación del plazo de desistimiento, sino, más bien, la posibilidad de que el consumidor pudiese desistir del contrato entre tanto el empresario cumpliese con su deber de información. Así, lo entendemos pese a que la Directiva 2011/83/UE considerara en su Exposición de Motivos que conviene introducir un plazo de prescripción de doce meses para garantizar la seguridad jurídica, y ello, porque la solución que propugnamos es, en nuestra opinión, la que en mayor grado contribuye a compeler a los empresarios a cumplir con sus deberes de información, al tiempo que es la que mejor ampara los intereses económicos de los consumidores y la tan necesitada confianza en el tráfico mercantil

Por último, debemos tener presente que, según establece el art.106,2 TRD$\mathrm{CU}$, el consumidor habrá ejercido su derecho de desistimiento dentro de los plazos contemplados en los artículos 104 y 105, cuando haya enviado la comunicación relativa al ejercicio del derecho de desistimiento antes de que finalicen dichos plazos. 
Por tanto, para determinar la observancia del plazo para desistir se tendrá en cuenta la fecha de expedición de la declaración de desistimiento, independientemente de cuál sea la fecha concreta en la que la ésta llegue a ser recibida y conocida por el empresario, dado que su eficacia depende de que sea conocida por el empresario, con independencia de que ello suceda con posterioridad al plazo de reflexión durante el cual el consumidor tiene la posibilidad de desistir del contrato, puesto que lo realmente importante es que el derecho de desistimiento se ejerza dentro del período de reflexión.

\subsection{ForMA DE DESISTIMIENTO}

Parece claro que el TRDCU acoge en esta materia el principio espiritualista de libertad de forma, por cuanto que, el consumidor, según establece literalmente el art.106,1 del TRDCU, comunicará al empresario, antes de que venza el plazo de desistimiento, su decisión de desistir del contrato, pudiendo para ello utilizar el modelo de formulario de desistimiento que figura en el anexo B del TRDCU, o bien realizar otro tipo de declaración inequívoca en la que señale su decisión de desistir del contrato (como p. ej. carta, llamada telefónica, fax o, incluso, mediante la devolución de las mercancías recibidas como forma tácita de ejercer el derecho de desistimiento al constituir un hecho concluyente e inequívoco de que el consumidor desea poner fin a la relación contractual con el empresario). Incluso, el párrafo tercero del citado art.106 permite al empresario ofrecer al consumidor la posibilidad de cumplimentar y enviar electrónicamente el modelo de formulario de desistimiento que figura en el anexo $B, o$ cualquier otra declaración inequivoca a través del sitio web del empresario. En tales casos, el empresario comunicará sin demora al consumidor en un soporte duradero el acuse de recibo de dicho desistimiento.

Así pues, lo realmente importante para que el desistimiento del consumidor alcance eficacia jurídica no es la forma empleada por el consumidor para comunicar al empresario su deseo de desistir del contrato con éste celebrado, sino que esa comunicación se haya producido dentro del plazo legalmente previsto y que el consumidor esté en condiciones de acreditar que asi ha acontecido.

Finalmente, consideramos que, a tenor de la libertad de forma impuesta por el legislador en esta materia, cualquier cláusula contractual por la que se le exigiera al consumidor por parte del empresario el cumplimiento de cualquier requisito formal respecto al ejercicio de su facultad de desistimiento, debería reputarse nula y como no puesta.

\subsection{Prueba del desistimiento}

Según establece el art.106,4 TRDCU, la carga de la prueba del ejercicio del derecho de desistimiento recaerá sobre el consumidor, quién deberá probar no sólo el hecho de haber comunicado al empresario su deseo de desistir del contrato 
sino, también, que esa comunicación se ha producido dentro del plazo legalmente previsto.

\subsection{Consecuencias derivadas del EJercicio de la FaCUltad de Desisti- MIENTO}

La principal consecuencia que el ejercicio de la facultad de desistimiento conlleva consiste en que se extinguirán las obligaciones de las partes de ejecutar el contrato celebrado fuera del establecimiento mercantil o, en su caso, de celebrar el mismo, cuando el consumidor haya realizado una oferta (art.106,5 TRDCU). Esto es, según distingue el citado precepto, cuando la declaración de voluntad emitida por el consumidor hubiese tenido por finalidad la aceptación de la oferta realizada por el empresario y, en consecuencia, la perfección del contrato celebrado con éste, el ejercicio de la facultad de desistimiento por parte del consumidor provocará la extinción del contrato y, por ende, de las obligaciones contractuales recíprocamente asumidas por las partes. Sin embargo, cuando el consumidor hubiese hecho al empresario una simple oferta de contrato, el ejercicio de la facultad de desistimiento no provocaría la extinción del contrato puesto que éste nunca habría llegado a perfeccionarse, sino que, tan sólo provocaría la extinción del compromiso asumido por las partes de celebrar el contrato.

La extinción del contrato como consecuencia del ejercicio de la facultad de desistimiento acarreará que las partes se vean compelidas a restituirse recíprocamente las prestaciones ya realizadas como consecuencia de la ejecución del contrato extinto. Así, según se infiere del art.107,1 TRDCU, el empresario deberá reembolsar al consumidor todo pago recibido de éste, incluidos, en su caso, los costes de entrega, sin demoras indebidas y, en cualquier caso, antes de que hayan transcurrido 14 días naturales desde la fecha en que hubiese sido informado de la decisión de desistimiento del contrato por parte del consumidor de conformidad con el art. 106 del TRDCU.

Además, en el supuesto de que el empresario se retrase injustificadamente en la devolución de las sumas abonadas, el consumidor podrá reclamar que se le pague el doble del importe adeudado, sin perjuicio de su derecho a ser indemnizado por los daños y perjuicios sufridos en los que excedan de dicha cantidad.

No obstante, en los contratos de venta con previa entrega de bienes, el empresario podrá retener el reembolso aludido hasta haber recibido los bienes entregados al consumidor, o hasta que éste haya presentado una prueba de la devolución de los mismos, salvo en el caso de que el empresario se haya ofrecido a recoger él mismo los bienes (art.107,3 TRDCU).

Por su parte, tras ejercer su facultad de desistimiento y producirse la extinción del contrato vigente, el consumidor vendrá obligado a devolver al empresario, o a la persona por éste autorizada, los bienes recibidos objeto del contrato celebrado, 
salvo que el propio empresario se ofrezca a recogerlos. Dicha devolución deberá producirse sin ninguna demora indebida y, en cualquier caso, a más tardar en el plazo de 14 días naturales a partir de la fecha en que comunique su decisión de desistimiento del contrato al empresario, de conformidad con el artículo 106 del TRDCU (art.108,1 TRDCU).

No obstante, si los bienes se hubiesen entregado en el domicilio del consumidor en el momento de la celebración del contrato y debido a la naturaleza de los mismos, éstos no pudiesen devolverse por correo, deberá el empresario recogerlos a su propio cargo.

Además, a pesar de la rotundidad con la que se pronuncia el art.73 TRDCU cuando establece que en los contratos celebrados con consumidores "el ejercicio del derecho de desistimiento no implicará gasto alguno para el consumidor y usuario", el consumidor deberá soportar los costes directos de la devolución de los bienes, salvo cuando el empresario hubiese aceptado asumirlos o no hubiese cumplido con su deber de información precontractual al no informar al consumidor de que le correspondería asumir esos costes en caso de ejercer su facultad de desistimiento (art.108,1 TRDCU).

El consumidor también será responsable de la disminución del valor de los bienes derivada de una manipulación distinta a la necesaria para establecer la naturaleza, las características o el funcionamiento de los mismos, salvo en el supuesto de que el empresario no le hubiese informado de su derecho de desistimiento con arreglo al artículo 97.1.i) del TRDCU (art.108,2 TRDCU).

Cuando un consumidor ejerza su derecho de desistimiento tras haber realizado una solicitud expresa de que la prestación de un servicio o el suministro de agua, gas, electricidad o calefacción dé comienzo durante el plazo para desistir, resultará obligado a abonar al empresario un importe proporcional a la parte ya prestada del servicio en el momento en que haya informado al empresario del ejercicio del derecho de desistimiento. El importe proporcional que habrá de abonar al empresario se calculará sobre la base del precio total acordado en el contrato, salvo que dicho precio sea excesivo, en cuyo caso, el importe proporcional se calculará sobre la base del valor de mercado de la parte ya prestada del servicio. Sin embargo, el consumidor no asumirá coste alguno por la prestación de los servicios o el suministro de agua, gas, electricidad o de calefacción durante el período de desistimiento, cuando el empresario no le hubiera facilitado información con arreglo al artículo 97.1.i) o k), o bien, cuando el consumidor no hubiera solicitado expresamente que la prestación del servicio se iniciara durante el plazo de desistimiento con arreglo al art. 98.8 del TRDCU (art.108,3 y 4 TRDCU).

Tampoco asumirá el consumidor gasto alguno por el suministro, en su totalidad o en parte, de contenido digital que no se preste en un soporte material, cuando no hubiese dado expresamente su consentimiento previo a la ejecución antes de la finalización del periodo de 14 días naturales contemplado en el artículo 102, o 
no fuese consciente de que renuncia a su derecho de desistimiento al dar dicho consentimiento; o bien, según los casos, cuando el empresario no hubiese facilitado la confirmación con arreglo al art.98,7 TRDCU (art.108,4 TRDCU).

Por último, si el consumidor hubiese optado expresamente por una modalidad de entrega diferente a la modalidad menos costosa de entrega ordinaria estará obligado a soportar los costes adicionales que de ello se deriven (arts. 107,2 y 108,5 TRDCU).

\subsection{CONSECUENCIAS DERIVADAS DEL EJERCICIO DE LA FACULTAD DE DESISTIMIEN- TO SOBRE LOS CONTRATOS COMPLEMENTARIOS}

Según se infiere del tenor literal del art.76 bis TRDCU, el ejercicio, por parte del consumidor de su derecho de desistimiento conforme a lo previsto en el TRDCU, tendrá por efecto la extinción automática y sin coste alguno para él de todo contrato complementario, excepto en aquellos casos en los que, sin perjuicio de su extinción automática, el consumidor debiera asumir los costes previstos en los artículos 107,2 y 108 del TRDCU.

En este sentido, la Directiva 2011/83/UE nos ofrece, en su art.2,15, un concepto bastante amplio de lo que debemos considerar como contrato complementario pues define a tal contrato como aquel "por el cual el consumidor adquiere bienes $o$ servicios relacionados con un contrato a distancia ... y dichos bienes o servicios son proporcionados por el comerciante o por un tercero sobre la base de un acuerdo entre dicho tercero y el comerciante". Así pues, podemos encuadrar dentro de la categoría de contrato complementario no sólo a los contratos de crédito o financiación celebrados por el consumidor a fin de financiar la adquisición de bienes o servicios mediante la celebración de contratos celebrados a distancia, sino, también, a cualquier otro contrato que permita al consumidor obtener bienes o servicios del propio empresario, o de un tercero con el que aquél haya llegado a un acuerdo previo, que se puedan considerar accesorios de la prestación principal obtenida por el consumidor en virtud del contrato principal celebrado a distancia. Así, por ejemplo, se podría considerar como contrato complementario o accesorio el contrato de prestación de un servicio de mantenimiento, por parte del propio empresario o de un tercero sobre la base un acuerdo previo con aquél, del vehículo que el consumidor hubiese adquirido por medio de un contrato celebrado a distancia. En consecuencia, el desistimiento por parte del consumidor del contrato principal de compraventa del vehículo conllevaría la automática resolución del contrato accesorio o complementario de mantenimiento del mismo.

De conformidad con lo dispuesto en el ya citado art.76, bis TRDCU, ejercido el derecho de desistimiento sobre el contrato principal, las partes deberán restituirse reciprocamente las prestaciones recibidas en virtud del contrato complementario, sin ninguna demora indebida y, en cualquier caso, antes de que hayan 
transcurrido 14 días naturales desde la fecha en que el consumidor hubiese informado al empresario de su decisión de desistir del contrato principal.

En el supuesto de que el empresario no reintegrara todas las cantidades abonadas por el consumidor en virtud del contrato complementario en el plazo señalado o bien no lograra probar tal circunstancia, el consumidor podría reclamar que se le pagara el doble de la suma adeudada, sin perjuicio a su derecho de ser indemnizado por los daños y perjuicios sufridos en lo que excedan de dicha cantidad.

Igualmente, además del reintegro de las cantidades abonadas, el consumidor tendrá derecho al reembolso de los gastos necesarios y útiles que hubiera realizado en el bien.

Por el contrario, en el supuesto de que al consumidor le fuera imposible devolver la prestación objeto del contrato complementario por pérdida, destrucción u otra causa que le sea imputable, deberá responder del valor de mercado que hubiera tenido la prestación en el momento del ejercicio del derecho de desistimiento, salvo que dicho valor fuera superior al precio de adquisición, en cuyo caso responderá de éste.

No obstante, cuando el empresario hubiera incumplido el deber de información y documentación sobre el derecho de desistimiento del contrato principal, la imposibilidad de devolución sólo será imputable al consumidor y usuario cuando éste hubiera omitido la diligencia que le es exigible en sus propios asuntos.

\subsection{EXCEPCIONES AL DERECHO DE DESISTIMIENTO}

Excepcionalmente, según establece el art.103 TRDCU, el consumidor no dispondrá de la facultad de desistir del contrato celebrado a distancia cuanto el mismo tenga por objeto:

a) La prestación de servicios, una vez que el servicio haya sido completamente ejecutado, cuando la ejecución haya comenzado, con previo consentimiento expreso del consumidor y con el reconocimiento por su parte de que es consciente de que, una vez que el contrato haya sido completamente ejecutado por el empresario, habrá perdido su derecho de desistimiento; b) El suministro de bienes o la prestación de servicios cuyo precio dependa de fluctuaciones del mercado financiero que el empresario no pueda controlar y que puedan producirse durante el periodo de desistimiento; c) El suministro de bienes confeccionados conforme a las especificaciones del consumidor y usuario o claramente personalizados; d) El suministro de bienes que puedan deteriorarse o caducar con rapidez.; e) El suministro de bienes precintados que no sean aptos para ser devueltos por razones de protección de la salud o de higiene y que hayan sido desprecintados tras la entrega; f) El suministro de bienes que después de su entrega y teniendo en cuenta su naturaleza se hayan mezclado de forma indisociable con otros bienes; g) El suministro de bebidas alcohólicas cuyo precio haya sido acordado en el momento 
de celebrar el contrato de venta y que no puedan ser entregadas antes de 30 días, y cuyo valor real dependa de fluctuaciones del mercado que el empresario no pueda controlar; h) Los contratos en los que el consumidor haya solicitado específicamente al empresario que le visite para efectuar operaciones de reparación o mantenimiento urgente. No obstante, si, en esa visita, el empresario presta servicios adicionales a los solicitados específicamente por el consumidor o suministra bienes distintos de las piezas de recambio utilizadas necesariamente para efectuar las operaciones de mantenimiento o reparación, el derecho de desistimiento debe aplicarse a dichos servicios o bienes adicionales; i) El suministro de grabaciones sonoras o de vídeo precintadas o de programas informáticos precintados que hayan sido desprecintados por el consumidor y usuario después de la entrega; j) El suministro de prensa diaria, publicaciones periódicas o revistas, con la excepción de los contratos de suscripción para el suministro de tales publicaciones; k) Los contratos celebrados mediante subastas públicas; 1) El suministro de servicios de alojamiento para fines distintos del de servir de vivienda, transporte de bienes, alquiler de vehículos, comida o servicios relacionados con actividades de esparcimiento, si los contratos prevén una fecha o un periodo de ejecución específicos; $\mathrm{m}$ ) El suministro de contenido digital que no se preste en un soporte material cuando la ejecución haya comenzado con el previo consentimiento expreso del consumidor y usuario con el conocimiento por su parte de que en consecuencia pierde su derecho de desistimiento.

\section{EJECUCIÓN DE LOS CONTRATOS CELEBRADOS A DISTANCIA}

Salvo que las partes hayan acordado otra cosa, el empresario deberá ejecutar el pedido sin ninguna demora indebida y a más tardar en el plazo de 30 días naturales a partir de la celebración del contrato (art.109 TRDCU).

En el supuesto de que no se ejecute el contrato por parte del empresario debido a que no se encuentre disponible el bien o servicio contratado, el consumidor deberá ser informado de esta falta de disponibilidad y podrá recuperar sin ninguna demora indebida las sumas que haya abonado en virtud del mismo. Si el empresario se retrasara injustificadamente en la devolución de dichas cantidades adeudadas, el consumidor podrá reclamar que se le pague el doble del importe adeudado, sin perjuicio de su derecho a ser indemnizado por los daños y perjuicios sufridos en lo que excedan de dicha cantidad (art.110 TRDCU).

No obstante, en el supuesto de que el consumidor hubiese sido informado expresamente, podrá el empresario, ante la falta de disponibilidad de bien o servicio contratado, sustituir el mismo por otro bien o servicio de características similares al contratado, que tenga la misma o superior calidad y sin que ello suponga un aumento del precio que deba abonar el consumidor (art.111 TRDCU).

Finalmente, si el consumidor abona el importe de la compra realizada mediante el empleo de una tarjeta de crédito, deberá indemnizar al empresario por los daños y perjuicios que le ocasione la anulación de dicha compra, a no ser que la 
misma fuese consecuencia del ejercicio por el consumidor de su facultad de desistir del contrato celebrado a distancia.

Sin embargo, cuando el importe de una compra o de un servicio hubiese sido cargado fraudulenta o indebidamente utilizando el número de la tarjeta de crédito del consumidor, éste podrá exigir la inmediata anulación del cargo, debiéndose realizar, a la mayor brevedad posible, las correspondientes anotaciones de adeudo y reabono en las cuentas del empresario y del consumidor titular de la tarjeta (art.112 TRDCU).

\section{Bibliografía}

AA.VV., Derecho (privado) de los consumidores, coord. MIRANDA SERRANO, PAGADOR LÓPEZ, Marcial Pons, Madrid, Barcelona, Buenos Aires, 2012;

BERCOVITZ, A., «Modalidades especiales de venta y protección del consumidor», EC, núm. 4, 1985, p. 57 ss.;

LETEACHIRICA, J., «La propuesta de Directiva sobre derechos de los consumidores: ¿nihil novum sub sole?», en AA.VV., Estudios jurídicos en memoria del profesor José Manuel Lete del Río, coord. García Rubio, Civitas, Madrid, 2009, pp. 493 a 512 ;

MIRANDA SERRANO, L. M., "Contratos celebrados a distancia», en AA.VV., La defensa de los consumidores y usuarios. Comentario sistemático del TRDCU, dir. REBOLLO PUIG/IZQUIERDO CARRASCO, Iustel, Madrid, 2011, pp. 1443 a 1562 ;

MIRANDA SERRANO, L., M., «La contratación a distancia de consumo: TRDCU y Directiva 2001/83/UE», en AA.VV., Derecho (privado) de los consumidores, coord. MIRANDA SERRANO, PAGADOR LÓPEZ, Marcial Pons, Madrid, Barcelona, Buenos Aires, 2012, p. 145 a 181;

MIRANDA SERRANO, L., «La Directiva 2011/83/UE sobre derechos de los consumidores: una nueva regulación para Europa de los contratos celebrados a distancia y extramuros de los establecimientos mercantiles», RcD, núm. 11, 2012, pp. 77 a 133;

MIRANDA SERRANO, L./PANIAGUA ZURERA, M., «La protección de los consumidores y usuarios en la fase previa a la contratación: la tutela de la libertad negocial», en AA.VV., Derecho (privado) de los consumidores, coord. MIRANDA SERRANO, PAGADOR LÓPEZ, Marcial Pons, Madrid, Barcelona, Buenos Aires, 2012, pp. 63 a 98 ;

TOBÍO RIVAS, A. M., «Contratos celebrados fuera de los establecimientos mercantiles y contratos a distancia», en AA.VV., Contratos mercantiles especiales, Cuadernos de Derecho Judicial, Madrid, 1997, pp. 37 ss. 



\section{6}

DE LA GROSSDISPARITY A LA UNFAIREXPLOITATION: MODELOS PARA UNA FUTURA REGULACIÓN EN SUPUESTOS DE DESEQUILIBRIO ECONÓMICO CONTRACTUAL ${ }^{156}$

Grossdisparity of the unfairexploitation: models for future regulation in cases of contractual economic imbalance

Rosa Barceló Compte

Investigadora predoctoral. Universidad de Barcelona. E-mail: rbarcelo@ub.edu

\section{Gemma Rubio Gimeno}

Profesora Agregada de Derecho Civil. Universidad de Barcelona. E-mail: grubio@ub.edu

\section{RESUMEN}

El derecho contractual europeo ha regulado unas nuevas figuras jurídicas que permiten la anulación contractual en los casos en que haya un desequilibrio en el poder de negociación de las partes. Así, hablamos de grossdisparity (excesiva desproporción), unfairadvantage (beneficio excesivo) o unfairexploitation (explotación injusta) como instrumentos que consideran relevante la ventaja excesiva que obtiene una de las partes que celebra un contrato, aprovechándose de la situación de debilidad de la otra, y que permiten la anulación de este tipo de negocios jurídicos. La mayor parte de Códigos civiles europeos permiten anular el contrato en caso de excesiva desproporción o ventaja injusta, fijándose algunos más en la situación de la parte débil o en la pura lesión económica, otros. La Propuesta de Modernización del Código Civil se aparta del derecho español vigente en la cuestión relativa a la ventaja excesiva, aproximándose así a las propuestas contractuales europeas.

Palabras Clave: Grossdisparity. Unfairexploitation. Desequilibrio Económico Contractual.

\footnotetext{
${ }^{156}$ Este Trabajo se enmarca en las actividades del "Grup de Recerca en Dret Privat, Consum i Noves Tecnologies" (GREDINT, 2014 SGR 688) y en la ejecución del Proyecto: "La nueva contratacion privada: diseño y codificación de instrumentos reequilibradores en contextos de asimetría negocial" (DER2012-32667) otorgado por el Ministerio de Economía y Competitividad, cuya investigadora principal es la Dra. Maria Rosa Llácer Matacás.
} 


\begin{abstract}
European Contractual Law has come up with some new legal concepts of avoiding contracts that involve a great disparity between the obligations. New remedies are called gross disparity, unfair advantage or unfair exploitation, and they refuse to uphold contracts that appear to be the result of some bargaining weakness on one side and conscious advantage-taking on the other, and they allow avoiding this kind of legal acts. The majority of the European civil codes give the possibility of avoiding a contract as a consequence of an unfair exploitation or gross disparity. Some Codes put more emphasis on the personal situation of the weakness party and others on the damages arising from the unduly onerous or unfair contracts. The new Proposal of Modernization of the Spanish Civil Code on the contractual fields, by regulating the unfair advantage concept, has followed the new European contractual Law, sidelining the current Spanish Law.
\end{abstract}

Keywords: Grossdisparity. UnFAIREXPLOITATION. CONTRACTUAL ECONOMIC IMBALANCE.

SUMARIO: Objetivo y metodología. 1. Introducción: la nueva regulación del derecho europeo en materia contractual. 2. Principios contractuales europeos que persiguen modelos de equilibrio contractual. 2.1. Principios unidroit y la gross disparity (excesiva desproporción, excessivadesproporção). 2.1.1. Determinación del concepto de ventaja excesiva. 2.1.2. Elementos subjetivos que aparecen incorporados en la regulación del artículo 3.10 de los principios unidroit. 2.2. Los principios lando y la unfair advantage (ventaja excesiva, vantagemexcessiva) . 2.2.1. Requisitos que permiten anular un contracto según el art. 4:109 de los principios lando. 2.3. La explotación injusta o unfairexploitation del marco común de referencia(exploração injusta). 2.3.1 requisitos para anular un contrato por unfairexploitation. 2.3.1.1. La debilidad de la víctima. 2.3.1.2. El conocimiento de dicha situación de debilidad por la otra parte contratante. 2.3.1.3. La obtención de un beneficio excesivo. 2.3.1.4. La obtención de una ventaja manifiestamente injusta. 2.4. La articulación de la explotación injusta en algunos códigos civiles europeos. 3. Planteamiento del código civil en relación a la explotación injusta. 3.1. El estado de necesidad como vicio del consentimiento y la violencia económica. 3.2. Concepto de violencia a la luz del código civil que permitiría anular los contratos celebrados en estado de necesidad. 3.3. La propuesta de modernización del código civil en relación a la explotación injusta. Conclusiones. Bibliografía 


\section{ObJetivo y Metodología}

El objetivo del presente estudio es el análisis de uno de los mecanismos de reequilibrio contractual previstos en el nuevo Derecho contractual europeo, cual es la llamada unfairexploitation, relacionada con el remedio tradicional de la rescisión por lesión.

El principio de libertad contractual, regla fundamental del derecho de los contratos, se basa en la idea de igualdad entre las partes contratantes. Sin embargo, esta pretendida igualdad -en muchos casos- es solamente teórica. Por ello el Derecho debe reaccionar contra este desequilibrio estableciendo unos mecanismos destinados a proteger a la parte (a priori) más débil.

Este estudio tiene la voluntad de seguir construyéndose para conformar una tesis doctoral que permita el estudio de los instrumentos reequilibradores en contextos de asimetrías negociales. Así, se quiere contribuir al proceso de modernización del derecho contractual. Es conveniente trasladar los instrumentos de reequilibrio de asimetrías negociales al proceso de renovación del derecho de contratos español: de esta forma, se podría obtener un marco común resultante de la sistematización de los instrumentos de reequilibrio de asimetrías negociales. Para ello será preciso definir hasta dónde llegan los estándares de reequilibrio comunes y dónde empiezan los remedios más protectores vinculados exclusivamente al derecho de consumo.

La metodología empleada ha sido el estudio y la investigación de los textos legales de Derecho contractual europeo (principios UNIDROIT, principios LANDO y el Marco Común de Referencia), del Código civil español y de la bibliografía más adelante citada.

\section{Introducción: La nueva Regulación del Derecho europeo en Materia CONTRACTUAL}

Los inicios de la creación del Derecho contractual europeo se deben al profesor Ole LANDO, quién el año 1976 propuso la redacción de un UniformCommercialCode a Europa o Restatement de derecho contractual europeo ${ }^{157}$. Durante el año 1982 empezó a trabajar en la Comisión de Derecho Contractual Europeo (también conocida como "Comisión Lando") con una finalidad: redactar un conjunto de Principios de Derecho contractual para los países de la Comunidad Económica Europea.

El Parlamento Europea dio luz verde, en sus resoluciones de 1989 y 1994, a una maratón que inició el camino hacia un derecho privado más coherente y mejor articulado. ${ }^{158}$

${ }^{157}$ QUIÑONES ESCÁMEZ, A.M., "Hacia un derecho contractual europeo", Indret, Barcelona: 2008, pág. 1 y sig.

${ }^{158}$ El Parlamento Europeo en su Resolución de 26 de mayo de 1989 "sobre un esfuerzo para armonizar el derecho privado de los Estados Miembros" y destacó que la cobertura jurídica 
En fecha de 16 de marzo de 2000, el Parlamento reclama a la Comisión que confeccione un estudio sobre la conveniencia de armonizar el Derecho civil ${ }^{159}$ y resultado de este encargo es la Comunicación de la Comisión al Consejo y al Parlamento Europeo, de 11 de julio de 2001, sobre derecho contractual europeo ${ }^{160}$. La Comunicación se centra exclusivamente en la situación del derecho contractual (por tanto, no todo el derecho privado ${ }^{161}$ ) porque "constituye la principal normativa de regulación de las transacciones internacionales y ya existen diversos actos legislativos comunitarios para reglamentar el Derecho contractual" (párr. $\left.12^{\circ}\right)^{162}$.

Por otro lado, la Comunicación de la Comisión al Parlamento, de 12 de febrero de 2003, "Un derecho contractual más coherente: plan de acción", significó un impulsos más importantes acometido por las instituciones europeas. Esta comunicación -conocida como Action Plan- fue la reacción de la Comisión a varios requerimientos del Parlamento y del Consejo Europeo, que vertieron en sus respuestas a la Comunicación del año $2001^{163}$.

de temas concretos no resultaba suficiente para las necesidades y aspiraciones de un mercado único y sin fronteras, por lo que acabó sugiriendo que se iniciaran los trabajos preparatorios para la elaboración de "Código europeo común de derecho privado". DOCE C/158, de 26 de junio de 1989.En la Resolución de 1994, el Parlamento reafirmó su voluntad y mostró su apoyo a la Comisión de Derecho Contractual Europeo. Se solicitó expresamente que se diera comienzo a los trabajos preparatorios para la elaboración de un "Código europeo común de derecho privado" (Resolución del Parlamento Europeo para la armonización de determinadas brancas del Derecho privado de los Estados miembros), DOCE, C205, de 25 de julio de 1994, págs. 518 y 519.

${ }^{159}$ DOCE C 377, de 29 de diciembre de 2000, pág. 323.

${ }^{160}$ COM (2001) 398 final

${ }^{161}$ Por ejemplo, la Directiva 86/653, del Consejo, de 18 de diciembre, relativa a la coordinación de los derechos de los Estados miembros en lo referente a los agentes comerciales independientes; Directiva 2001/31, del Parlamento Europeo y del Consejo, de 8 de junio, relativa a determinados aspectos jurídicos de los servicios de la sociedad de la información, en particular el comercio electrónico en el mercado interior.

${ }^{162}$ No obstante, se reconoce que "(...) teniendo en cuenta el contexto económico, también podrían estar concernidas las normas en materia de garantías de crédito relativas a bienes mobiliarios y la normativa de enriquecimiento indebido. Por último, también se deberían tener en cuenta los aspectos de la normativa de responsabilidad civil vinculados a los contratos y a sus restantes características pertinentes para el mercado interior, en la medida en que y a formen parte de la normativa comunitaria existente" (pár.13 in fine). Por el conntrario, "En algunos ámbitos del Derecho privado los contratos no constituyen más que uno de los instrumentos de reglamentación, ya que las relaciones existentes entre las partes son de una gran complejidad. Estos ámbitos, como el derecho laboral o el derecho de família, plantean problemas pariculares que no están contemplados en esta Comunicación" (pár. 14).

${ }^{163}$ Comunicación de la Comisión al Parlamento Europeo y al Consejo "Un derecho contractual europeo más coherente", Plan de Acción, DOCE, C 63, de 15 de marzo de 2003 
El proceso de elaboración del conjunto de normas, principios y reglas relativas al derecho privado europeo (lo que a posteriori se llamará Marco Común de Referencia) tiene aquí su partida de nacimiento (Action Plan). Con la voluntad de superar las contradicciones del acquiscommunitaire, la Comunicación del año 2003 menciona un proyecto y apunta uno de nuevo: el marco común de referencia relativo a los principios comunes del derecho contractual europeo, así como una terminología general y compartida y un instrumento facultativo (optionalinstrument) ${ }^{164}$.

Esta apuesta por la unificación del derecho privado se ve aumentada gracias a una posterior comunicación de la Comisión al Parlamento Europeo y al Consejo, de 11 de octubre de 2004, "sobre derecho contractual europeo y revisión del acervo: perspectivas para el futuro" 165 . Se insiste en la necesidad de consolidar un marco común de referencia que mejore la calidad y la coherencia del acervo comunitario y se abre un nuevo plan de futuro: el desarrollo del CommonFrame of Reference (Marco Común de Referencia), definido como una herramienta para la relectura y revisión del derecho contractual relevante.

En 2010, la vicepresidenta de la Comisión Europea, VivianeReding, promovió una nueva estrategia en el ámbito del Derecho de contratos: en primer lugar, la publicación del Libro Verde de la Comisión sobre opciones para avanzar hacia un Derecho contractual europeo para consumidores y empresas; y, en segundo lugar, la constitución de un grupo de expertos para un MCF (marco común de referencia) en el ámbito del Derecho contractual europeo; y, finalmente, en tercer lugar, la presentación a la Comisión Europea por dicho grupo de expertos de un estudio de viabilidad para un futuro instrumento de Derecho contractual europeo (Feasibilitystudyfor a futureinstrument in EuropeanContractLaw) ${ }^{166}$.

Más recientemente, el proceso de europeización del derecho de obligaciones y contratos ha sido marcado por dos hitos que sucedieron a finales del año 2011: la promulgación de la Directiva 2011 \83\UE sobre derechos de los consumidores y la publicación del proyecto de Reglamento sobre un derecho común de la compraventa (más conocido como Instrumento opcional o CESL) ${ }^{167}$, que tomaron como base el proyecto de Marco Común de Referencia (DCFR).

${ }^{164}$ INFANTE RUIZ, F.J., "Entre lo político y lo académico: un Common Frame of Reference de derecho privado europeo", Indret, 2008, pág. 2 y sig.

165 Comunicación de la Comisión al Parlamento Europeo y al Consejo, de 11 de octubre de 2004 "sobre derecho contractual europeo y revisión del acervo: perspectivas para el futuro COM (2004) 651 final (DOCE 2005, 14/6)

${ }^{166}$ GÓMEZ POMAR, F., GILI SALDAÑA, M., "El futuro instrumento opcional del Derecho contractual europeo: una breve introducción a las cuestiones de formación, interpretación, contenidos y efectos", Indret: Barcelona, 2012, págs. 5 y 6.

${ }^{167}$ VAQUER ALOY, A, BOSCH CAPDEVILA, E, SÁNCHEZ GONZÁLEZ, M.P. (Coords): Derecho europeo de Contratos. Libros II y IV del Marco Común de Referencia. Tomo I. Atelier: Barcelona, 2012. Págs. 71 y sig. 
De todos los trabajos que han ido armonizando el derecho contractual europeo destacan los elaborados por la Comisión Lando (Comisión de Derecho Europeo de los Contratos) que dio lugar a la publicación, entre 1997 y 2002, de las tres partes de los Principios de Derecho contractual europeo (PECL). Además, paralelamente a los trabajos de la Comisión Lando, dentro del Instituto para la Unificación del Derecho Privado (UNIDROIT) se creó un grupo con la misión de preparar los principios sobre los contratos mercantiles internacionales: el resultado de ello fue la publicación de los principios UNIDROIT, en 1994, sobre los Contratos Comerciales Internacionales.

El 26 de abril de 2010, la Comisión Europea nombró un grupo de veinte expertos muy cualificados en el ámbito del Derecho civil y, en particular, del Derecho de contratos para que elaborara - a partir del DCFR, otros trabajos de investigación realizados en este ámbito y el acervo de la Unión- una propuesta de MCR que se pudiera implementar como instrumento opcional. Más específicamente, el grupo de expertos debía ayudar a la Comisión Europea a seleccionar aquellas porciones del DCFR que estuvieran relacionadas, directa o indirectamente, con el Derecho contractual, así como a reestructurar, revisar y completar los contenidos seleccionados.

El trabajo del grupo de expertos concluyó en mayo de 2011 con la presentación a la Comisión de un texto de 189 artículos (Feasibilitystudyfor a futureinstrument in EuropeanContractLaw) que recogía las normas de Derecho de contratos de mayor relevancia práctica en las relaciones contractuales transfronterizas ${ }^{168}$.

Todos estos principios que configuran el derecho contractual europeo (principios de derecho contractual europeo, DCFR e incluso los principios UNIDROIT), aunque se configuran como un instrumento académico o una especie de softlaw (porque no cubren todas las materias del derecho patrimonial) al que también se le ha denominado toolbox (caja de herramientas) o blue bottom (instrumento facultativo al que pueden acudir las partes para regir su contrato) se han visto reflejados en alguna jurisprudencia reciente del Tribunal Supremo ${ }^{169}$.

\section{Principios contractuales europeos Que Persiguen modelos de equili- BRIO CONTRACTUAL}

El auge de la codificación del derecho privado a nivel europeo ha ido configurando nuevos instrumentos jurídicos en aras a incorporar reglas que permitan anular un contrato por excesiva onerosidad de una de las partes. Veamos cuáles son estos nuevos remedios jurídicos.

${ }^{168}$ GÓMEZ POMAR, F., GILI SALDAÑA, M., "El futuro instrumento opcional del Derecho contractual europeo: una breve introducción a las cuestiones de formación, interpretación, contenidos y efectos"... Op. Cit, Pág. 7

169 A título de ejemplo, véase STS, Sección 1a, núm. 1180/2008, de 17 de diciembre (RJ $\backslash 2009 \backslash 675)$ 


\subsection{PRINCIPIOS UNIDROIT Y LA GROSSDISPARITY (EXCESIVA DESPRO- PORCIÓN, EXCESSIVA DESPROPORÇÃO)}

Durante los años 80, encabezado por MICHAEL J. BONELL, se creó un grupo especial dentro del Instituto Internacional para la Unificación del Derecho Privado (UNIDROIT) que tenía como encargo preparar los principios sobre los contratos mercantiles internacionales: ello dio como resultado la publicación, en el año 1994, de los Principios UNIDROIT sobre los Contratos Comerciales Internaciona$\operatorname{les}^{170}$.

La grossdisparity viene regulada en el artículo 3.10, que establece que:

(1) Cualquiera de las partes puede dar por anulado un contrato o cualquiera de sus disposiciones si en el momento de su celebración, éste o alguna de sus cláusulas otorgan a la otra parte una ventaja excesiva. A tal efecto, se deben tener en cuenta, entre otros, los siguientes factores:

a. Que la otra parte se haya aprovechado injustificadamente de la dependencia, aflicción económica o necesidades apremiantes de la impugnante, o de su falta de previsión, ignorancia, inexperiencia o falta de habilidad en la negociación; y

b. La naturaleza y finalidad del contrato.

(2) A petición de la parte legitimada para dar por anulado el contrato, el tribunal podrá adaptar el contrato o la cláusula en cuestión, a fin de ajustarlo a criterios comerciales razonables de lealtad negocial.

(3) El tribunal también podrá adaptar el contrato o la cláusula en cuestión, a petición de la parte que recibió una comunicación de darlo por anulado, siempre y cuando dicha parte le haga saber su decisión a la otra inmediatamente, y, en todo caso, antes de que ésta obre de conformidad con su voluntad de dar por anulado el contrato. Se aplicarán, por consiguiente, las previsiones del Artículo 3.13.

Esta disposición permite a una de las partes anular el contrato en los casos de excesiva desproporción de las prestaciones que resulta en una ventaja injustificada y excesiva para la otra.

\subsubsection{Determinación del concepto de ventaja excesiva}

La ventaja excesiva debe producirse en el momento de conclusión del contrato, y no sobrevenidamente. La expresión ventaja excesiva denota que, para

${ }^{170}$ Véase PERALES VISCASILLAS, P., "Los principios de UNIDROIT sobre los contratos comerciales internacionales" en BOSCH CAPDEVILA, E., Derecho contractual europeo, Barcelona: 2009, págs. 183 y sig. 
permitir la anulación o adaptación del contrato se requiere un desequilibrio de tal magnitud que resulte escandaloso para una persona razonable ("so great as to shock theconscience of a reasonableperson" ${ }^{171}$.

Aquí se observa la diferencia de la grossdisparity con otra figura jurídica que también es regulada por los principios UNIDROIT: la hardship o alteración sobrevenida de las circunstancias (art. 6.2 de los principios UNIDROIT), que se configura como un remedio extraordinario que tiene por objeto reconducir la relación económica entre prestaciones al equilibrio originario que hubieran previsto ${ }^{172}$. Así, vemos que en la hardship la excesiva onerosidad es sobrevenida y no originaria (como sí sucede en lagrossdisparity).

La Propuesta de Modernización del Código Civil del año 2009 hace referencia también a la figura jurídica de la alteración o cambio de las circunstancias sobrevenidas en su artículo 1213 y exige que el cambio de circunstancias haya hecho la ejecución del contrato "excesivamente onerosa para una de las partes" o bien "se haya frustrado la ejecución del contrato"173.

\subsubsection{Elementos subjetivos que aparecen incorporados en la regulación del artículo 3.10 de los principios UNIDROIT}

Los elementos subjetivos que aparecen en la regulación del artículo 3.10 de los principios UNIDROIT afectan a la formación de la voluntad; por el contrario, si habláramos de elementos objetivos, deberíamos hacer referencia a la falta de equivalencia o a la naturaleza o finalidad del contrato.

Así, no parece suficiente que la ventaja sea excesiva sino que también debe ser injustificada (para valorar esto, es necesario hacer referencia a todas las circunstancias que rodean al caso en concreto). Vemos que el precepto en cuestión señala como ejemplos: situaciones de dependencia, aflicción económica o de necesidad apremiante y de situaciones de debilidad inherentes al perjudicado (falta de previsión, ignorancia, inexperiencia o falta de habilidad negociadora $)^{174}$.

Aunque no aparezca como requisito en el apartado 1, podemos deducir que cuando este precepto considera que la parte más fuerte se haya aprovechado ("has

\footnotetext{
${ }^{171} \mathrm{http}$ //www.unidroit.org/spanish/principles/contracts/principles2004/integralversionprinciples2004-s.pdf, pág. 112

${ }^{172}$ MARTÍN CASALS, M., "Perspectives de futur de la rescissió per lesió ultra dimidium en el futur del dret patrimonial de Catalunya", en Materials de les Desenes Jornades de Dret català a Tossa, Valencia: Tirant lo Blanch, 2000, pág. 494

${ }^{173}$ SALVADOR CORDECH, P., "Alteración de circunstancias en el art. 1213 de la Propuesta de Modernización del Código Civil en materia de Obligaciones y Contratos", Indret, Barcelona: Octubre, 2009, pág. 25

${ }^{174} \mathrm{http}$ //www.unidroit.org/spanish/principles/contracts/principles2004/integralveresionprinciples2004-s.pdf, pág. 113
} 
takenunfairadvantage") de la debilidad de la otra parte, se intuye que la parte que obtiene la ventaja ha conocido las deficiencias subjetivas de la otra (o al menos tenía el deber de conocerlas).

\subsection{LOS PRINCIPIOS LANDO Y LA UNFAIR ADVANTAGE (VENTAJA EXCE- SIVA, VANTAGEM EXCESSIVA)}

El artículo 4:109 de los Principios de Derecho Contractual Europeo (Principios LANDO o PECL) permite anular el contrato en caso que una de las partes haya obtenido un beneficio excesivo o una unfairadvantage. El precepto tiene el tenor literal siguiente:

(1) Una parte puede anular el contrato si, en el momento de su conclusión:

a. Dependía de la otra parte, tenía una relación de confianza con ella, se encontraba con dificultades económicas o tenía otras necesidades urgentes, no tenía capacidad de previsión o era ignorante, inexperimentado o carente de capacidad negociadora, y

b. La otra parte conocía o debería haber conocido dicha situación y, atendidas las circunstancias y el objeto del contrato, se aprovechó de ello de manera claramente injusta y obtuvo asi un beneficio excesivo.

(2) A petición de la parte interesada, y si resulta oportuno, el juez o tribunal puede adaptar el contrato y ajustarlo a lo que podría haberse acordado respetando el principio de buena fe contractual.

(3) La parte a quien se comunica el ejercicio de la acción de anulabilidad del contrato por beneficio excesivo o ventaja injusta, puede igualmente solicitar del juez una adaptación del contrato, siempre que esta parte informe de ello sin dilación a la parte que le comunicó el ejercicio de su acción $y$ antes de que dicha parte actúe en función de ella".

Vemos que se toma en consideración situaciones en las que existe una situación de debilidad de una de las partes en el momento de la celebración del contrato que, en su globalidad o en alguna de sus cláusulas, permite que la otra obtenga una ventaja excesiva e injustificada.Observamos la mezcla de elementos objetivos o de justicia material de las condiciones pactadas (substantive unfairness) con requisitos de tipo subjetivo, referidos a las partes (procedural unfairness) ${ }^{175}$.

${ }^{175}$ MARTÍN CASALS, M., "Perspectives de futur de la rescissió per lesió ultra dimidium en el futur del dret patrimonial de Catalunya"... Op. Cit. pág. 253 
2.2.1. Requisitos que permiten anular un contracto según el art. 4:109 de los principios $L A N D O$

Los requisitos que aparecen en el texto legal para poder anular el contrato son los siguientes ${ }^{176}$ :

a) La situación de debilidad de una de las partes, que bien puede producirse por las condiciones subjetivas de esta persona (por su ignorancia o falta de habilidad negociadora) o por su relación con la otra (situación de dependencia) o por su situación de necesidad (asfixia económica). Vemos, pues, situaciones muy variadas, desde un defecto de capacidad a una falta de libertad. Lo esencial en ello es que una de las partes no es totalmente libre cuando presta su consentimiento, sino que su decisión se ve condicionada por alguna circunstancia.

b) La mala fe de la otra parte: esta debe conocer o conoce la situación de debilidad.

c) Que la parte fuerte se hubiera aprovechado de tal situación de debilidad para obtener, así, un beneficio excesivo; si no existiera tal beneficio excesivo no se podría anular el contrato.

Así, se requiere una circunstancia subjetiva (la debilidad de una de las partes y la mala fe de la otra) y un elemento objetivo (la lesión o excesiva desproporción entre las prestaciones de las partes).

\subsection{La explotación injusta o unfairexploitation del Marco Común de REFERENCIA (EXPLORAÇÃO INJUSTA)} manera $^{177}$ :

El artículo II.-7:207 (explotación injusta) está redactado de la siguiente

${ }^{176}$ MARTÍN CASALS, M., "Perspectives de futur de la rescissió per lesió ultra dimidium en el futur del dret patrimonial de Catalunya"... Op. Cit. págs. 257-258

${ }^{177}$ En su versión original:A party may avoid a contract if, at the time of the conclusion of the contract:The party was dependent on or had a relationship of trust with the other party, was in economic distress or had urgent needs, was improvident, ignorant, inexperienced or lacking in bargaining skill; andThe other party knew or could reasonably be expected to have known this and, given the circumstances and puropose of the contract, exploited the first party's situations by taking an exccessive benefit or grossly unfair advantage.Upon the request of the party entitled to avoidance, a court may if it is appropiate, adapt the contract in order to bring it into accordance with what might have been agreed had the requirement of the good faith and fair dealing been observed.A court may similarly adapt the contract upon the request of a party receiving notice of avoidance for unfair exploitation, provided that this party informs the party who gave the notice without undue delay after receiving it and before that party has 
(1) Una parte puede anular el contrato si, en el momento de su conclusión:

a. Tenía una relación de dependencia o de confianza con la otra, o se encontraba en dificultades económicas o tenía necesidades urgentes, era imprevisora, ignorante, inexperimentada o carente de habilidad en la negociación; y

b. Esta otra parte sabía o es razonable suponer que sabía dicha situación del otro contratante $y$, atendidas las circunstancias y la finalidad del contrato, se aprovechó de ello para conseguir un beneficio excesivo o una ventaja manifiestamente injusta.

(2) A petición de la parte legitimada para anular el contrato, el juez puede, si lo considera oportuno, adaptar el contrato con el fin de ajustarlo a lo que hubiera acordado si se hubiesen respetado las exigencias de la buena fe y la honradez en los tratos.

(3) El juez también puede adaptar el contrato a petición de la parte que haya recibido la notificación de su anulación por explotación injusta, siempre que ésta informe sin demora excesiva a la que solicitó su anulación y antes de que dicha parte actúe en consecuencia.

El artículo II.-7:207 adopta el principio que un contrato que otorga a una de las partes una ventaja excesiva y que lleva implícita una explotación injusta puede ser anulado o modificado a instancia de la parte que ha sido perjudicada.

Uno de los principios tradicionales del derecho de contratos es la regla pacta suntservanda, según la cual los contratos deben cumplirse conforme a lo pactado. Ahora bien, este principio nace de la idea que las partes acuerdan libremente el contenido del contrato a cumplir. No obstante, a veces el consentimiento no es tan libre como aparenta porque uno de los contratantes ha concluido el contrato engañado por las circunstancias ${ }^{178}$. Aquí es donde la propuesta del MCR otorga la posibilidad de anular el contrato por la parte perjudicada, pero sujeto a una serie de requisitos.

\subsubsection{Requisitos para anular un contrato por unfairexploitation}

Para que la parte perjudicada por el contrato pueda anularlo por unfairexploitation se requieren unos requisitos (de carácter subjetivo y objetivo):

acted in reliance on it.

${ }^{178}$ BOSCH CAPDEVILA, E., Derecho europeo de los contratos. Libros II y IV del Marco Común de Referencia Tomo I, Atelier, Barcelona, 2012, pág. 493 


\subsubsection{La debilidad de la víctima}

La víctima tenía una relación de dependencia con la otra parte o se encontraba en dificultades económicas o bien tenía necesidades urgentes. También puede que fuera carente de habilidad negociadora o no del todo consciente del perjuicio que le podía suponer el contrato en cuestión: cuando tenía una relación de confianza con la otra y piensa que esta no se aprovechará de esta confianza, o bien era imprevisora, ignorante o inexperimentada.

Todos estos conceptos aluden a una situación de debilidad pero también a una falta de diligencia de la víctima (si se tratara de un contrato de cierta trascendencia, el "inexperto" hubiese debido recabar el asesoramiento de un experto).

\subsubsection{El conocimiento de dicha situación de debilidad por la otra parte contra- tante}

Esta parte sabía o podía razonablemente esperarse que supiese dicha situación, y se aprovecha de ello.

Existe una presión sobre el sujeto para que celebre el contrato que lo celebra porque se encuentra en un estado de necesidad (no configurado como vicio autónomo del consentimiento en nuestro Código civil). La parte que obtiene la ventaja es consciente de ello (aunque no produzca él mismo la violencia-económica- sí es consciente de que se aprovecha de la situación de debilidad de la otra parte). Según la regulación actual del Código Civil, en el caso que una parte, conociendo la situación angustiosa de la otra, obtenga provecho de tal situación al celebrar el contrato en unas condiciones muy ventajosas para ella, $y$, a pesar que el consentimiento de la parte perjudicada se halle viciado por la falta de libertad ocasionada por su angustiosa situación, el contrato no podría anularse. Porque el estado de necesidad no es contemplado como un vicio autónomo del consentimiento, a diferencia de la violencia o la intimidación que sí lo son (ex art. $1268 \mathrm{CCE}$ ). Aquí surge la cuestión que el derecho contractual europeo resuelve: por qué esta diferencia de trato entre el consentimiento prestado a consecuencia de las amenazas causados por un tercero, y el prestado en un estado de necesidad. Configurando el estado de necesidad como un vicio autónomo del consentimiento que permita anular los contratos celebrados bajo el ámbito de este ${ }^{179}$ se resolvería la cuestión.

${ }^{179}$ BOSCH CAPDEVILA, E., "Estado de necesidad y consentimiento contractual: ¿una reinterpretación de los conceptos de violencia e intimidación como vicios del consentimiento a la luz del derecho contractual europeo y comparado" Revista crítica de derecho inmobiliario, Año 85, nº711, 2009, pág. 71 


\subsubsection{La obtención de un beneficio excesivo}

El artículo II.-7:207 resultará de aplicación cuando el beneficio que obtiene una de las partes es excesivo si se compara con el "precio normal".

La cuantía del perjuicio es indeterminada ya que se habla de ventaja o beneficio excesivo o de considerable desproporción entre las prestaciones de las partes en función de las concretas circunstancias concurrentes en el supuesto enjuiciado.

\subsubsection{La obtención de una ventaja manifiestamente injusta}

El artículo también se aplicaría aun cuando no habiendo un beneficio excesivo en términos monetarios, se produce una ventaja manifiestamente injusta.

Las consecuencias que se derivan de ello serán o bien la anulación o la adaptación del contrato por parte del juez.

A la parte perjudicada se le da la posibilidad de pedir al juez la anulación del contrato o la adaptación a criterios estándares de corrección comercial (cfr. 3.10 Principios UNIDROIT) o lo que se hubiera acordado si se hubieran seguido criterios de buena fe y negociación justa (art. 4:109 PECL). En el DCFR las consecuencias son las mismas y la adaptación del contrato la puede solicitar cualquiera de las partes (también la beneficiada por el contrato). ${ }^{180}$ Ello resulta más razonable porque se hace a instancias de la parte que por la anulación resultará perjudicada con respecto a las condiciones inicialmente pactadas.

\subsection{LA ARTICULACiÓN DE LA EXPLOTACIÓN INJUSTA EN ALGUNOS CÓDIGOS CIVI- LES EUROPEOS}

La mayoría de los sistemas jurídicos europeos permiten la anulación del contrato que se ha celebrado por explotación injusta, aunque algunos sólo contemplan la anulación sólo porque el contenido del contrato es injusto ${ }^{181}$.Algunos sistemas se fijan más en qué haya una parte débil en el contrato pero otros no se fijan en la vulnerabilidad de una de las partes sino simplemente se basan en la lesión económica.

Por ejemplo, muchos sistemas otorgan un remedio a la parte desventajada cuando la otra ha sacado alguna ventaja por las circunstancias de la otra parte para

${ }^{180}$ BOSCH CAPDEVILA, E., Derecho Europeo de los contratos. Libros II y IV del Marco Común de Referencia, Op. Cit. Pág. 494

181 STUDY GROUP ON A EUROPEAN CIVIL CODE AND THE RESEARCH GROUP ON EC PRIVATE LAW (Acquis Group), Based in part on revised of the Principles of European Contract Law., Principles, Definitions and Model Rules of European Private Law, Draft Commonf Frame of Reference (DCFR), Full Edition, Sellier. European Law Publishers: Munich, 2009, pág. 510 
obtener un contrato injusto. Así, la jurisprudencia francesa habla de abuso sobre la necesidad económica de la otra parte como una forma de violencia (violencia doméstica). La doctrina belga da solución sólo en los casos de abuso de derecho, cuando éste da lugar a un contrato desproporcionado, bajo la doctrina de la lesión cualificada (si no hay abuso de derecho, es difícil conceder un remedio a la lesión). El Código civil portugués considera la coaç̧ao moral como un vicio de la voluntad que hace anulable el negocio (arts. 255 y 256), mientras que no produce ningún efecto la declaración en que el declarante fue coagido pela força física e emiti-la (art. 264).

En cambio, hay otros sistemas que dan más importancia a la ventaja excesiva y no tanto a las circunstancias de la parte perjudicada: el Código civil austríaco, el BGB alemán y el Código civil griego, por ejemplo, combaten la excesiva desproporción de los contratos (como algo contrario a la buena fe y, por ende, anulable), aunque se concentran más en la desproporción de las obligaciones que en las parte perjudicada.

En el CommonLaw, el derecho inglés (por ejemplo), tiene dos remedios similares a la unfairexploitation: la undueinfluence, que se produce cuando una parte ejerce o está en posición de ejercer una influencia en la otra parte y, en segundo lugar, la unconscionablebargaing (negocios inconscientes) que considera que si una parte se aprovecha de la pobreza o ignorancia de la otra para comprar propiedades por un precio que no es el de mercado, la perjudicada puede prescindir el contrato. El poder judicial del CommonLaw inglés considera que la doctrina de la undueinfluence se asemeja a la unfairadvantage-taking, es decir, a la unfairexploitation ${ }^{182}$.

Cabe mencionar que el Código civil de Brasil hace una distinción entre la coaçao (art. 151) y el estado do perigo (art. 156).

\section{Planteamiento del Código Civil en relación a la explotación injusta}

El planteamiento que acoge el Código Civil es el de no conceder ningún remedio frente a la explotación injusta. Sin embargo, a través de una reinterpretación del concepto de "violencia" del art. 1267 CC, podría facilitarse la anulación de los contratos celebrados en estado de necesidad ${ }^{183}$.

\subsection{El ESTADO DE NECESIDAD COMO VICIO DEL CONSENTIMIENTO Y LA VIOLENCIA ECONÓMICA}

El Código Civil no contempla el estado de necesidad como vicio del consentimiento: el aprovecharse de una situación de superioridad o prevalencia social o ${ }^{182}$ BIGWOOD R., "Contracts by Unfair Advantage: From Exploitation to Transactional Neglect”, Oxford Journal of Legal Studies, Vol, 25, Nº1. 2005, pág. 69

${ }_{183}$ BOSCH CAPDEVILA, E en Derecho europeo de los contratos. Libros II y IV del Marco Común de Referencia, VAQUER ALOY, A, BOSCH CAPDEVILA, E., SÁNCHEZ GONZÁLEZ, M.P (Coords). Barcelona: Atelier, Tomo I, 2012, págs.494-495 
económica no configura ningún vicio de consentimiento autónomo en nuestro Código. Se discute la eficacia anulatoria del aprovechamiento por una de las partes de la situación de necesidad, apremio, inexperiencia o circunstancias angustiosas padecidas por la otra parte; o, desde otra perspectiva, el aprovecharse de su superioridad o prevalencia social o económica.

El artículo 1265 del Código Civil enumera como vicios del consentimiento -que determinan la anulabilidad del contrato- el error, el dolo, la violencia y la intimidación.

La violencia es definida como una fuerza irresistible (hay violencia cuando para arrancar el consentimiento se emplea una fuerza irresistible, ex art. 1267 $\mathrm{CCE}$ ). Hay declaración obtenida mediante violencia física, vis absoluta, vis phisica o vis corporiillata, cuando el acto en que aquella consiste se arranca materialmente por la fuerza al violentado ${ }^{184}$.

Cuando el Código regula la violencia -y la intimidación- presupone que la fuerza o amenaza proviene de la otra parte contratante, o de un tercero (vid. Art 1268 $\mathrm{CCE}$ ). No obstante, la libertad también puede faltar cuando la declaración de voluntad se emite como consecuencia de una presión externa (ya sea porque el contratante se encuentra en una situación de dependencia, estado de necesidad o de peligro) ${ }^{185}$.

\subsection{Concepto de violencia a la luz del Código Civil que permitiría anu- LAR LOS CONTRATOS CELEBRADOS EN ESTADO DE NECESIDAD}

Podríamos apuntar que la anulación de un contrato en el que la amenaza constituya una fuerza irresistible - aunque dicha amenaza no haya sido provocada por la otra parte o por un tercero sino por el estado de necesidad- podría configurar este estado de necesidad como un vicio autónomo del consentimiento.

El Código civil, cuando regula la violencia y la intimidación, presupone que la fuerza o la amenaza provienen de la otra persona contratante, o de un tercero (ex art. 1268 CCE). Pero la libertad también puede faltar cuando la declaración es emitida como consecuencia de una presión externa (porque el contratante se halla en una situación de necesidad, peligro o de urgencia).

Lo esencial y lo que caracteriza la violencia es la fuerza irresistible, con independencia de quién amenaza o sufre el mal con el que se amenaza.

La jurisprudencia francesa ha ido consolidando la denominada "violencia económica", la que no deriva de un acto de un tercero sino de un acontecimiento o de una situación que son subsumibles dentro del concepto de violencia propuestos por los artículos 1111 y siguientes del Code Civil francés ${ }^{186}$. Además, el Anteproyecto

\footnotetext{
${ }^{184}$ ALBALADEJO GARCÍA, M., Derecho civil I. Introducción y parte general. Edisofer SL, Madrid, 2006, pág. 656

${ }^{185}$ BOSCH CAPDEVILA, E., "Estado de necesidad y consentimiento contractual: ¿una reinterpretación de los conceptos de violencia e intimidación como vicios del consentimiento a la luz del derecho contractual europeo y comparado"... Op. Cit. pág. 59

186 BOSCH CAPDEVILA, E., “Estado de necesidad y consentimiento contractual: ¿Una reinterpretación de los conceptos de violencia e intimidación como vicios del consentimiento a la luz del derecho contractual europeo y comparado?’... Op. Cit., pág. 81
} 
de Reforma del Derecho de Obligaciones francés ha establecido en su artículo 1114 que hay violencia cuando una parte se compromete bajo la presión de una amenaza que le produce el temor de ver expuesta su persona, su fortuna o la de sus allegados a un mal considerable.

Ahora bien, la posibilidad de anular un contrato celebrado bajo estado de necesidad, bajo la protección del Código civil, que no constituya una situación de fuerza irresistible ya sería dar un paso más, siguiendo más fielmente las propuestas del derecho europeo y comparado ${ }^{187}$.

Ante la necesidad de hallar un mecanismo que sirva de protección para el contratante que, ante una situación de necesidad, celebra un contrato en condiciones claramente desventajosas para sus intereses, el Derecho europeo -así como el comparado- han regulado algunas respuestas que dan la posibilidad a la parte perjudicada de anular ese contrato (si dicha situación de necesidad da lugar a una excesiva desproporción entre las partes contratantes). Lo que el Derecho europeo exige para anular el contrato es que la falta de libertad venga originada por una situación de necesidad (hablamos de lesión, desproporción, lucro excesivo, ventaja patrimonial desproporcionada, excessivebenefit, unfairadvantage y grossdisparity). Para anular el contrato, no es suficiente que se haya celebrado este en un contexto de necesidad ni tampoco es suficiente la simple lesión económica. Por tanto, vemos que se mezclan elementos objetivos y subjetivos: la desproporción o lesión económica y el estado de necesidad o de urgencia que determinará la falta de libertad final.

También cabría apuntar otra línea de interpretación renovadora de la jurisprudencia a través del dolo incidental: el artículo 1270 CCE reza, al final, "el dolo incidental sólo obliga al que lo empleó a indemnizar los daños y perjuicios". Así, los supuestos de contratación en que una de las partes abuse de la ligereza o inexperiencia de la otra parte también podrían estructurarse como manifestaciones del dolo incidental a base de una ponderada delimitación de este vicio de la voluntad (tal y como hace el art.1448 del Código civil italiano que acoge la lesión con eficacia rescisoria para todos los contratos conmutativos, siempre que exceda la mitad del precio justo y la desproporción obedezca a la explotación de la necesidad de una de las partes por la otra, y sin que exista riesgo contractual de cargo de la parte lesionada ${ }^{188}$.

${ }^{187}$ Las propuestas armonizadoras del Derecho contractual euroepo permiten anular el contrato celebrado mediante amenazas (irresistibles o no), como el celebrado en situacón de necesidad (siempre que exista una desproporción entre las partes, y la parte beneficiada se haya aprovechado de la situación. La falta de liebrtad que se ocasiona sno se incluye dentro del concepto de violencia considerado en un sentido amplio, sino dentro de lo que se denomina gross disparity, excessive benefit o unfair advantage. BOSCH CAPDEVILA, E.: "Estado de necesidad y consentimiento contractual: ¿Una reinterpretación de los conceptos de violencia e intimidación como vicios del consentimiento a la luz del derecho contractual europeo y comparado?", en Revista Crítica de Derecho Inmobiliario, Año 85, n711, 2009, pág. 90.

${ }^{188}$ DÍEZ PICAZO, L., "Notas sobre la indemnización del daño causado por el dolo incidental", Anuario de Derecho Civil, Vol. 62, n³, Año 2009. Pág. 1043 
En el dolo incidental el contratante movido por el dolo, que no puede decir que no haya tenido voluntad contractual, puede alegar que, si no hubiera surgido el dolo (incidental) hubiera celebrado el contrato pero lo hubiera hecho en unas condiciones distintas.

\subsection{La Propuesta de Modernización del Código Civil en relación a la EXPLOTACIÓN INJUSTA}

La Propuesta de Modernización del Código Civil en materia de obligaciones y contratos (PMCC) fue presentada por la Comisión General de la Codificación el año 2009. Esta propuesta regula, en su artículo 1301, una figura afín a la unfairexploitation del art. II.-7:207 del MCR ${ }^{189}$.

Desde un punto de vista subjetivo, la PMCC exige la situación de debilidad del perjudicado de una forma más estricta que las propuestas contractuales europeas: las dificultades económicas se califican de "extraordinarias" y se ha excluido la relación de confianza y la falta de habilidad en la negociación. Además, en relación a las circunstancias subjetivas del beneficiado, no se exige el conocimiento de la situación de debilidad de la víctima: se excluye, por tanto, cualquier valoración de la buena o mala fe del beneficiado.

El factor determinante que permite anular el contrato es, junto a la situación de debilidad de la víctima, la ventaja excesiva que logra el beneficiado (dicha aventaja no aparece cuantificada).

Además, en la PMCC sólo la parte perjudicada puede solicitar al juez la adaptación del contrato -y no la parte beneficiada, como sí ocurre en el DCFR en que el beneficio de solicitar la adaptación del contrato se contempla para las dos partes-.

189 "Una de las partes puede anular el contrato que, en el momento de su celebración, otorga a la otra parte una ventaja excesiva si, teniendo en cuenta la naturaleza y fin de aquél, resulta que se ha aprovechado injustamente de una situación de dependencia, de extraordinarias dificultades económicas o de necesidad apremiante, o de su ignorancia, de su inexperiencia o falta de previsión. A petición de la parte perjudicada, puede el Juez introducir en el contrato aquellas modificaciones que sean necesarias para adaptarlo a las exigencias de la buena fe y lo que sea usual en el tráfico jurídico". Vid. Comisión General de Codificación. Propuesta de Modernización del Código Civil en materia de obligaciones y contratos. $<$ Ministerio de Justicia. Gobierno de España. Año LXIII. Enero 2009 > -documento online-: http://www. mjustiica.gob.es/cs/Satellite/1292338914438?blobheader 


\section{Conclusiones}

\section{Primera.La protección de la parte débil del contrato como mecanismo de reequilibrio contractual}

Es necesaria la regulación de instrumentos de reequilibrio que tengan aplicación en aquellos contratos que puedan conducir una situación de ventaja excesiva para una de las partesy dicha regulación debe plantearse en sede de parte general del contrato.

\section{Segunda. Cambio de paradigma en las propuestas codificadoras de derecho contractual español \\ La Propuesta de Modernización del Código Civil se aparta del derecho es- pañol vigente para seguir las líneas del derecho contractual europeo que posibilitan la anulación contractual de aquellos casos en que haya una obtención de una ventaja excesiva para una de las partes, generando un remedio que se relaciona con la exacta formación de la voluntad contractual.}

Tercera. Unfairexploitation y principio de la buena fe contractual

La unfairexploitationconstituye una manifestación del principio de la buena fe contractual como corrector de una situación de asimetría económica basada en el abuso económico ejercido por una parte sobre la otra.

Cuarta. Estado de necesidad y violencia económica como presupuestos del nuevo remedio reequilibrador del contrato

La configuración de la violencia económica como vicio autónomo del consentimiento permitiría la anulación de aquellos contratos celebrados bajo estado de necesidad.

\section{Bibliografía}

ALBALADEJO GARCÍA, M., Derecho civil I. Introducción y parte general, Edisofer SL, Madrid, 2006

BOSCH CAPDEVILA, E., en Derecho europeo de los contratos. Libros II y IV del Marco Común de Referencia, VAQUER ALOY A, BOSCH CAPDEVILA E, SÁNCHEZ GONZÁLEZ M.P (Coords). Atelier: Barcelona, Tomo I, 2012

- $\quad$ "Estado de necesidad y consentimiento contractual: ¿una reinterpretación de los conceptos de violencia e intimidación como vicios del consentimiento a la luz del derecho contractual europeo y comparado" Revista crítica de derecho inmobiliario, Año 85, nº711, 2009

BIGWOOD R., "Contracts by Unfair Advantage: From Exploitation to Transactional Neglect", Oxford Journal of Legal Studies, Vol. 25, Nº1,2005

COMISIÓN GENERAL DE CODIFICACIÓN. Propuesta de Modernización del 
Código Civil en materia de obligaciones y contratos. Ministerio de Justicia. Gobierno de España, Año LXIII, Enero 2009

DÍEZ PICAZO, L., "Notas sobre la indemnización del daño causado por el dolo incidental", Anuario de Derecho Civil, Vol. 62, n³, Año 2009

GÓMEZ POMAR, F., GILI SALDAÑA, M., "El futuro instrumento opcional del Derecho contractual europeo: una breve introducción a las cuestiones de formación, interpretación, contenidos y efectos", Indret: Barcelona, 2012

INFANTE RUIZ, F.J., "Entre lo político y lo académico: un Common Frame of Reference de derecho privado europeo", Indret, 2008

MARTÍN CASALS, M., "Perspectives de futur de la rescissió per lesióultra dimidium en el futur del dret patrimonial de Catalunya", en Materials de les Desenes Jornades de DretCatalà a Tossa, Tirant lo Blanch: Valencia, 2000

PERALES VISCASILLAS, P., "Los principios de UNIDROIT sobre los contratos comerciales internacionales" en BOSCH CAPDEVILA, E., Derecho contractual europeo, Barcelona, 2009

QUIÑONES ESCÁMEZ, A. M. "Hacia un derecho contractual europeo", Indret, 2008

SALVADOR CORDECH, P., "Alteración de circunstancias en el art. 1213 de la Propuesta de Modernizaación del Código Civil en materia de Obligaciones y Contratos, Indret, Barcelona: Octubre, 2009

STUDY GROUP ON A EUROPEAN CIVIL CODE AND THE RESEARCH GROUP ON EC PRIVATE LAW (Acquis Group), Based in part on revised of the Principles of European Contract Law., Principles, Definitions and Model Rules of European Private Law, Draft Commonf Frame of Reference (DCFR), Full Edition,Sellier. EuropeanLawPublishers: Munich, 2009

VAQUER ALOY, A, BOSCH CAPDEVILA, E, SÁNCHEZ GONZÁLEZ, M.P. (Coords): Derecho europeo de Contratos. Libros II y IV del Marco Común de Referencia, Tomo I, Atelier, Barcelona, 2012 



\title{
La Respuesta Española A La Proliferación Decartas De Intenciones En La Contratación Privada
}

The spanish response to the proliferation of letters of intent in private contracting

\section{Aurelio Barrio Gallardo}

Acr. Profesor Contratado Doctor de Derecho Civil.

\section{Resumen}

El empleo de instrumentos precontractuales importados del comercio internacional, como la letter of intent o el memorandum of understanding, comienza a ser cada vez más frecuente en la contratación privada interna. Tampoco son escasas las ocasiones en que estos documentos sirven de apoyo a una acción interpuesta ante los Tribunales españoles (vid. p. ej. la reciente SAP Barcelona 15 marzo 2013) donde se reclama la perfección y ejecución del contrato, una vez superada la negociación preliminar y, en consecuencia, la indemnización del interés positivo, que comprende no sólo el daño emergente, propio de la responsabilidad precontractual, sino también el lucro cesante. Es preciso, por tanto, analizar qué respuesta están dando la jurisprudencia y la comunidad científica a la incorporación masiva de estas instituciones jurídicas foráneas en nuestro país, intentar extraer unas pautas generales de actuación y dilucidar si pueden tener cabida concediéndoles carta de naturaleza en nuestro Derecho o, si por el contrario, deben ser reconducidas a las categorías jurídicas tradicionales vinculadas a la formación del contrato: tratos preliminares, precontrato y contrato.

Palabras Clave: Negociación del contrato. Fase precontractual. Cartas de intenciones. Respuesta nacional legal y jurisprudencial.

\begin{abstract}
The use of pre-contractual instrumentsimportedfrominternationaltrade, such as letters of intent (LOIs) or memoranda of understanding (MoUs), isbe-
\end{abstract}


comingincreasinglycommon in domesticcommercialrelations. Not are fewoccasions in whichthesedocumentssupportanactionbroughtbeforetheSpanishcourts (vid. recent SAP Barcelona March 15, 2013) and theplaintiffclaimsfordamagesdue to a breach of contract; he orsherequeststheconclusion and perfomance of contract, once thepreliminarynegotiations are alreadyfinished, consequently, thecompensation of positive interest, whichincludesnotonlydamages (costsincurred), typical of pre-contractual liability, butalsolostprofitsisgranted. Itisnecessary, therefore, to considerwhat response isgivingbylaw and scholars to themassiveincorporation of theseforeign legal institutions in our country, try to infersome general guidelines to reactproperly to thisphenomenon and determine whetherthey can be givenanofficialseal of approvalor, onthecontrary, theymust be led back to thetraditional legal categoriesrelated to contractformation: preliminarynegotiation, pre-contractorcontract

Keywords: Contract negotiation. Precontractual stage. Letters of intent. NaCional legal and case-law response.

Sumario: A. Introducción. 1. La regulación nacional. 2. La realidad de la práctica comercial. B. Objetivos y metodología. 1. Breve estudio jurisprudencial. 2. Análisis de la doctrina científica. C. Conclusiones. Bibliografía.

\section{a. Introducción}

\section{La regulación nacional}

El legislador español no regula con el detalle deseable la fase preparatoria del negocio jurídico ${ }^{190}$ y sigue aferrado al antiguo dogma decimonónico ${ }^{191}$ de que el conjunto de actos y operaciones que llevan a cabo los interesados o sus auxiliares con el fin de elaborar, discutir y concertar el contrato $^{192}$ carecen de toda relevancia jurídica, como si aquello que antecede al cierre de una operación comercial no tuviera ninguna importancia (all or nothing) ${ }^{193}$. Parece que la única preocupación

\footnotetext{
${ }^{190}$ Vid. sobre las diversas fases del iter contractual, García Cantero, 1992: 700-701; Díez-Picazo, 2007: 309; Martínez de Aguirre, 2011: 387.

${ }^{191}$ Vicent, 2006: 819.

${ }^{192}$ Díez-Picazo, Fundamentos, 1993: 267, 270; Llodrà, 2003: 15; cf., además, Moreno Quesada, 1963: 17; Cabanillas Sánchez, 1995: 747; entre las resoluciones, vid. STS 2 diciembre 1991 [RJ 1991, 1718].

${ }^{193}$ Cf. Pasquau Liaño, 2009: 2312.
} 
de los codificadores nacionales ${ }^{194}$ comienza con la perfección contractual ${ }^{195}$, siendo irrelevantes las negociaciones preliminares al cruce de voluntades ${ }^{196}$. Sin embargo, es en esta antesala del contrato donde se gesta el consentimiento; etapa, por tanto, de vital importancia, pues en ella se sucederán todos los hechos y circunstancias que a la postre pueden redundar en la nulidad e ineficacia del negocio (capacidad, vicios volitivos, insuficiencia de poder...) sin menospreciar la trascendencia que para la interpretación ${ }^{197}$ e integración del contrato a través de la buena fe ${ }^{198}$ pueden tener estos tanteos previos.

\section{La Realidad De La Práctica Comercial}

El marco normativo contrasta con la praxis de los actores económicos; la realidad es mucho más sofisticada ${ }^{199}$ y conoce novedosos instrumentos como la battle of forms, letter of intent, merger clauses propios de una contratación por etapas ${ }^{200}$ importados del tráfico internacional, donde las empresas norteamericanas imponen su particular modo de hacer negocios. La regulación del Cc español responde así a una contratación de perfección instantánea (S. XIX), en la que oferta y aceptación concurren simultáneamente ${ }^{201}$, y no a una contratación progresiva o por etapas ${ }^{202}$ caracterizada por mediar un lapso sustancial entre el intercambio de consentimientos $^{203}$; dicha temporización ${ }^{204}$ es propia de una economía globalizada (S. XXI ${ }^{205}$. Estos proyectos de gran envergadura, p. ej. merges \& adquisitions ${ }^{206}$, joint ventures,ciertas compraventas de acciones ${ }^{207}$ así como otras operaciones típicas del crédito

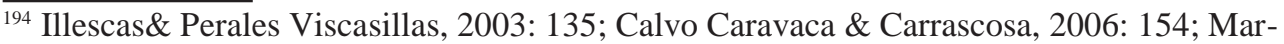
tínez de Aguirre, 2011: 387-388; BernadMainar, 2014: 359.

${ }^{195}$ Cfr. art. 1262 Cc español.

196 Vid. Pasquau 2009: 2312; Viguri, 1994: 135.

197 Oviedo, 2012: 76; BernadMainar, 2014: 359.

198 Alonso, 1971: 859

199 Valpuesta: 633; Vicent, 2006: 819; Gaspar, 2010: 127.

${ }^{200}$ Cf. Vicent, 2006: 820; BernadMainar, 2014: 356.

201 Menéndez Mato, 1998: 98-99; Valpuesta: 663.

${ }^{202}$ Aznar Giner, 2010: 53; Vicent, 2006: 820; STS 3 de junio de 1998 [RJ 1998, 3715].

${ }^{203}$ Moreno, 1956: 115

204 García Granero, 2002: 328.

205 Así, Calvo Caravaca \& Carrascosa, Curso, 2006: 154.

${ }^{206}$ Lutter, 1982: 11, 149; Wolf, 1995: 15; Miquel, 1998; Gaspar, 2010: 127; Serrano Acitores: 6; Echarri, 2002: 27, 260.

207 Vicent, 2006: 231.
} 
bancario internacional ${ }^{208}$, son tan complejas técnicamente que su negociación puede prolongarse durante meses ${ }^{209}$.

Intervienen en ellas expertos que asesoran sobre la repercusión financiera del negocio ${ }^{210} \mathrm{y}$ se incurre en gastos exorbitantes que en caso de fracaso resultan inasumibles, conduciendo a la inmediata quiebra de uno de los intervinientes (es paradigmático p. ej. el caso Texaco, Inc. v. Penzzoil, Inc. en EEUU) ${ }^{211}$. La parte que pecha con ellos no quiere dejar la recuperación de esa cuantiosa inversión inicial a la libre operatividad del régimen de los tratos preliminares, cuyo resarcimiento del interés negativo ${ }^{212}$ (reliance damages) resulta muy excepcional ${ }^{213}$, sino disipar toda incertidumbre al prever anticipadamente cómo se distribuirá el coste económico de una operación fallida.

El vacío legal de los textos nacionales se suple mediante la autorregulación de la etapa precontractual al amparo del principio general de la autonomía de la voluntad. Se aprecia así entre los sujetos empresariales una tendencia a contractualizar la fase negociadora ${ }^{214}$. Los agentes conciertan un contrato rector de la negociación, es decir, un contrato sobre cómo hacer otro contrato (contract to make a contract) ${ }^{215}$, un acuerdo sobre cómo negociar la operación final ${ }^{216}$ imponiéndose mutuamente deberes de confidencialidad (confidentiality agreement) y exclusividad (no-shop clau$s e)^{217}$, repartiendo convencional y equitativamente las expensas realizadas en atención al futuro contrato para el caso de que no se llegue a celebrar ${ }^{218}$ o cuantificando el valor del desistimiento a través del pago de una penalización (walk-away fee) (19 $^{219}$

${ }^{208}$ Carrasco \& Álvarez Arjona, 2004: 89; Egusquiza, 1998: 209.

${ }^{209}$ Díez Picazo, 2007: 310; Fernández Rozas, 2013: 264; BernadMainar, 2014: 355.

${ }^{210}$ Lacruz, 2000: 384-385; Serrano Acitores, 2012: 16, 25.

${ }^{211}$ Cf. Viguri, 1994: 70.

${ }^{212}$ Gámez, 2003: 17; Marín Narros, 2012: 305; Ragel, 2000: 241; Aznar Giner, 2010: 99.

${ }^{213}$ Son contadas las ocasiones en que una de la partes negociadoras queda obligar a resarcir el daño de la confianza (Díez-Picazo, 2007: 322; Cuadrado, 2003: 56; Aznar Giner, 2010: 80; Garía Rubio \& Otero, 41-42).

${ }^{214}$ Díez-Picazo, 2007: 325; Oviedo, 2008: 108; Bercovitz Álvarez, 2009: 1491-1492; LlodráGrimalt, Com.: 4; Marín Narros: 8; García Rubio \& Otero, 2010: 5; Serrano Acitores, 2012: pp. 9-10; Sánchez Lorenzo, 2012: 47.

${ }^{215}$ Alpa, 2005: 69; Díez-Picazo, 2007: 392; Marín Narros, 2012: 284.

${ }^{216}$ Calvo Caravaca \& Carrascosa, Curso, 2006: 157.

${ }^{217}$ Díez-Picazo, 2007: 326, 392; Echarri, 2002: 261; VicentChuliá, 2006: 231; Aznar Giner, 2010: 78; García Rubio \& Otero, 2010: 30-31; Gaspar, 2010: 134; Marín Narros: 15; Marín Narros, 2012: 300; Parra Lucán, 2013: 431; Fernández Rozas, 2013: 266.

${ }^{218}$ Díez-Picazo, 2007: 326; Sánchez Lorenzo, 2012: 48; Mascareñas, 2011: 131; Marín Narros, 2012: 301; Fernández Rozas, 2013: 266.

${ }^{219}$ Marín Narros, 2012: 301. 
que se habrá depositado con anterioridad ${ }^{220}$.

Es también común fijar una hoja de ruta (term sheet) donde se señalan hitos comerciales y jurídicos ${ }^{221}$ estableciendo un calendario de plazos para su consecución. Durante la ejecución del programa, se expone el estado actual de la negociación ${ }^{222}$, se apuntan las cuestiones básicas consensuadas ${ }^{223}$ y va dejando constancia documental del avance de las diversas reuniones ${ }^{224}$ (memorialize)- ${ }^{225}$, recogiendo acuerdos parciales $^{226}$ que, en teoría, habrían de operar como seguro anti-renegociación ${ }^{227}$.

\section{B. Objetivos y metodología}

\section{Breve estudio jurisprudencial}

Cuando estos instrumentos foráneos, típicos del comercio internacional ${ }^{228}$, como la letter of intent, llegan a los Tribunales españoles resulta harto complicado realizar su encaje dentro del sistema. Lo más común es calificar la carta de intenciones siguiendo el elenco de categorías jurídicas españolas, dado que esta labor compete al tribunal (iura novit curia) y no a las partes, distinguiendo en la nomenclatura clásica si se trata de: a-. una oferta ${ }^{229}$, cuya aceptación genera un contrato, luego

\footnotetext{
${ }^{220}$ Díez-Picazo, 2007: 326.

${ }^{221}$ Calvo Caravaca, 2006: 156; Miquel, 1998: 151; Echarri, 2002: 28.

${ }^{222}$ Así, Calvo Caravaca \& Carrascosa, Curso, 2006: 156.

${ }^{223}$ Fernández Rozas, 2011: 258; Gaspar, 2010: 132; Fernández Rozas, 2013: 264.

${ }^{224}$ Guardiola, 2001: 50.

${ }^{225} \mathrm{MoU}$ : Acuerdos precontractuales destinados a contemplar acuerdos parciales que se han ido alcanzando durante las negociaciones sobre el contrato proyectado; documento escrito que proporcionará un registro de las negociaciones que han tenido lugar hasta la fecha (aunque ningún contrato se haya alcanzado) (así, Marín Narros, 2012: 306).

226 Carrasco \& Álvarez Arjona, 2004: 88.

227 "El acuerdo de intenciones al que han llegado las partes sería demostrativo de un acuerdo entre ellas sobre determinados extremos, que les impediría retractarse, pero han de seguir negociando los restantes hasta su configuración" (STS 3 junio 1998 [RJ 1998, 3715]). Esta misión, propia de la letter of intent, en el CommonLaw, resulta, sin embargo, bastante dudosa en un sistema civilista (Carrasco, A. Arjona, 2004: 116),

228 Gámez Jiménez, 2003: 1 (consultado a través de Westlaw).

229 "Declaración de voluntad de naturaleza recepticia (...) dirigida al otro sujeto y emitida con el definitivo propósito de obligarse si la aceptación se produce" (así, STS 10 octubre de 1980 [RJ 1980, 3623]); entre la doctrina, vid. sobre la oferta, Lobato, 1976: 572; Llodrà, 2003: 16 .
} 
vinculante-230, a veces sometidos a condición suspensiva ${ }^{231}$, otras a la integración de un elemento esencial por parte de un tercero, p. ej. el precio ${ }^{232}$; pues sin él no puede, en principio, haber oferta ${ }^{233}$; b-. un precontrato ${ }^{234}$ o pactum de contrahendo ${ }^{235}$, especialmente en la constitución de sociedades ${ }^{236} \mathbf{c}$-. o simples tratos preliminares ${ }^{237}$, donde caben también acuerdos parciales, que no implican la obligación final de concluir el negocio ${ }^{238}$. Para realizar esta operación jurídica se combinan dos parámetros, similares a los requisitos para la formación del contrato en el país origen de la figura: la intención ${ }^{239}$ o elemento subjetivo (intention) y el grado de concreción del acuerdo alcanzado $^{240}$ o elemento objetivo (certainty).

En la mayoría de ocasiones, el TS ha interpretado el término "acuerdo de intenciones" como indicativo de la ausencia de una verdadera voluntad de las partes de quedar obligado por el contenido de lo rubricado. A título de ejemplo, se manifiesta que tal convenio "no llega a la categoría jurídica de precontrato ni, desde luego, de contrato"241; que la suscripción de este documento "seguiría dentro de la zona de los tratos preliminares, que no obligan a la celebración del contrato por su propia naturaleza" 242 o que "no pueden tener otra consideración que la de actos preparatorios del contrato, de los cuales no surge acción para la otra parte por la que pueda exigir su

\footnotetext{
${ }^{230}$ STS 2 diciembre 1995 [RJ 1995, 9156]; STS 30 enero 1998 [RJ 1998, 353]; SAP Gerona 12 julio 2004 [AC 2004, 1748].

${ }^{231}$ STS 24 julio 1998 [RJ 1998, 6393].

232 STS 29 noviembre 2000 [RJ 2000, 9245].

233 STS 31 diciembre 1998 [RJ 1998, 9772].

${ }^{234}$ STS 1 julio 1950 [RJ 1950, 1187]; STS 5 octubre 1961 [RJ 1961, 3284]; STS 4 julio 1991 [RJ 1991, 5325]; STS 14 octubre 1996 [RJ 1996, 7107]; STS 8 febrero 2010 [RJ 2010, 395]; SAP Coruña 9 diciembre 1994 [AC 1994, 2103].

235 STS 2 febrero 1960 [RJ 1960, 456].

${ }^{236}$ STS 19 julio 1994 [RJ 1994, 6698]; STS 5 julio 1940 [RJ 1940, 684]; STS 9 julio 1940 [RJ 1940, 691].

${ }^{237}$ STS 3 junio 1998 [RJ 1998, 3715]; STS 14 junio 1999 [RJ 1999, 4105]; STS 11 abril 2000 [RJ 2000, 2434]; STS 28 abril 2000 [RJ 2000, 2677]; SAP Valladolid 9 noviembre 1998 [AC 1998, 8974]; SAP Barcelona 26 julio 2004 [RJ 2004, 283215] y, últimamente, SAP Barcelona 15 marzo 2013 [JUR 2013, 214748]).

${ }^{238}$ STS, Sala 4 ${ }^{\text {a }}, 9$ marzo 1998 [RJ 1998, 2372]; STS 3 junio 1998 [RJ 1998, 3715]; SAP Vizcaya 13 octubre 2000 [AC 2000, 2441]; SAP Madrid 13 septiembre 2000 [JUR 2000, 279377]; SAP León 8 febrero 2002 [JUR 2002, 113725]; STSJ Cataluña 5 enero 2012 [RJ 2012, 4201]).

${ }^{239}$ Llodrà, 2003: 18; Parra, 2013: 425.

${ }^{240}$ Llodrà, 2003: 17; Marín Narros, 2012: 284, 304; Parra Lucán, 2013: 426.

${ }^{241}$ STS 11 abril 2000 [RJ 2000, 2434].

${ }^{242}$ STS 3 junio 1998 [RJ 1998, 3715].
} 
cumplimiento" 243 . Este significado suele coincidir, en general, con la pretensión de la parte que quiere desvincularse aduciendo que no se está ante una verdadera oferta, sino de una simple declaración de intenciones ${ }^{244}$. Esta última, adopte o no forma epistolar, son sinónimo de invitación ya no a contratar, sino meramente a negociar, o plasmación de los tratos preliminares, es decir, la constancia escrita, a efectos probatorios, de que existe una negociación en curso sin prejuzgar su posible resultado.

\section{Análisis De La Doctrina Científica}

En vista de que bajo expresión "carta de intenciones" se cobijan diversas figuras $^{245}, \mathrm{y}$ declaraciones de muy diversa índole ${ }^{246}$, incluso disgregadas dentro de un propio instrumento, la comunidad científica evitasentar una regla general acerca de su naturaleza jurídica ${ }^{247} \mathrm{e}$ indica que no existe efecto típico o propio ${ }^{248}$. Al contrario, esta rica y complicada casuística fuerza a que su eficacia deba inferirse escudriñando su concreto contenido; a pesar de ser soporte documental ${ }^{249}$ de un cúmulo de realidades heterogéneas con efectos jurídicos diversos ${ }^{250}$, se es proclive a interpretar que la carta no genera obligaciones entre las partes, más allá de los pactos concretos rectores de la negociación ${ }^{251}$ y a situarla en la fase precontractual ${ }^{252}$

Ante la multiplicidad de efectos e imprevisibilidad de sus consecuencias, la letter of intent ha sido bautizada en el mundo anglo-americano como "un invento del diablo"253; razón por la que los prácticos desaconsejan su uso salvo en procesos

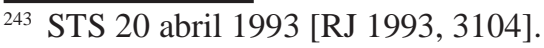

${ }^{244}$ Así sucedió en las STS 19 julio 1994 [RJ 1994, 6698]; STS 28 abril 2000 [RJ 2000, 2677]; STS 8 febrero 2010 [RJ 2010, 395] o en la reciente SAP Barcelona 15 marzo 2013 [JUR 2013, 214748].

${ }^{245}$ Llodrá, 2002: 129-130; Llodrà, 2003: 14-15; Carrasco, 2004: 88; Simó, 2005: 336

246 Gaspar, 2010: 131; Marín Narros, 2012: 282.

${ }^{247}$ Gaspar, 2010: 131-132.

${ }^{248}$ Egusquiza, 1998: 212; Valés, 2012: 84.

${ }^{249}$ Así, Carrasco, Álvarez Arjona, 2004: 89, 111; Gaspar, 2010: 131; Quesada Sánchez, 2011: 83.

${ }^{250}$ Carrasco \& Álvarez Arjona, 2004: 89, 111.

${ }^{251}$ Carrasco \& M. Arjona, 2004: 111; Díez-Picazo, 2007: 392; Gaspar, 2010: 133; Parra Lucán, 2013: 431; Aragón, 2000: 102; Mascareñas, 2011: 132; BernadMainar, 2014: 356, 362.

252 Díez-Picazo, 2007: 392.

${ }^{253}$ Parece que las partes pueden, por un lado, decidir si un pacto de intenciones es un contrato y, por otro lado, no pueden evitar, a pesar del principio de autonomía de la voluntad, que un pacto de intenciones completo, aunque no conste intención de obligarse, sea obligatorio si eso es lo razonable (así, Llodrà, 2003: 18; cfr. también Marín Narros, 2012: 284).
} 
negociación complejos y prolongados ${ }^{254}$. En nuestro sistema continental, parte la doctrina niega que quepa establecer una presunción general de no vinculación ${ }^{255} \mathrm{y}$, por este motivo, está muy extendida la recomendación de introducir como cierre del escrito una cláusula de no vinculación" 256 ("sin compromiso"257, "sujeto a contrato" ${ }^{258}$, etc.) para huir del vínculo contractual ${ }^{259}$ al igual que sucede fuera de nuestras fronteras ("without obligation", "subject to contract"...).

\section{Conclusiones}

La letter of intent contribuye a crear un marco propicio para que fructifiquen contratos de perfección sucesiva cuya negociación se augura compleja, larga y costosa desde un principio. En ella se establecen unas pautas de comportamiento (exclusividad, confidencialidad...) para conducirse durante el iter negociador que son elevadas a nivel de responsabilidad contractual mediante pactos que unas desplazan y otras refuerzan, por vía convencional, la culpa in contrahendo; y previenen la aparición de costes hundidos (sunk costs) repartiendo anticipadamente entre los intervinientes el coste económico del fracaso de la operación proyectada frente al resarcimiento ocasional del interés negativo (reliance damages) que conlleva la aplicación del régimen habitual de los tratos. También deja el instrumento constancia escrita de las conversaciones preliminares e intercambio de información sensible como prueba de que se existe una negociación en curso si uno de los intervinientes en el proceso pretendiera negarlo más adelante.

La carta de intenciones no es así más que el soporte documental que sirve de vehículo de expresión a la autonomía privada con la que las partes pretender corregir las deficiencias de la legislación estatal; y en tanto que manifestación de la autonomía de la voluntad, conoce sus límites habituales, p. ej. no cabría la exoneración por actos contrarios a la buena fe (art. $1102 \mathrm{Cc}$ ), y el pacto por el que se obligan a conducirse conforme a sus exigencias, si bien conocido extramuros (good faith and fair dealing), resultaría superfluo en nuestro sistema. Tiene la virtud de aportar certidumbre ex ante a transacciones de gran envergadura que sin ella probablemente nunca se concertarían. No obstante y pese a su utilidad, debe ser redactada con sumo cuidado, insertando cláusulas que evidencien de manera inequívoca la verdadera intención de los firmantes para evitar que, frustrada la celebración del contrato y sobrevenido el conflicto, pueda depararles un resultado jurídico inesperado.

\footnotetext{
${ }^{254}$ Carrasco \& Álvarez Arjona, 2004: 98; Mascareñas, 2011: 132.

255 Carrasco \& Álvarez Arjona, 2004: 106.

${ }^{256}$ Dávalos, 1993: 61; Echarri, 2002: 261; Gámez, 2003: 7; Carrasco \& Álvarez Arjona, 2004: 96, 103; Llodrá, p. 134; Quesada Sánchez, 2011: 82-83; Fernández Rozas, 2013: 265.

${ }^{257}$ Carrasco, ibíd.; Viguri, 1994: 20; Puig Brutau, 1978: 186; Puig Brutau, 1997: 218.

258 Llodrà, 2003: 14; Calvo Caravaca \& Carrascosa, Curso, 2006: 156.

${ }^{259}$ Carrasco \& Álvarez Arjona, 2004: 92.
} 


\section{Bibliografía}

ALONSO PÉREZ, M. (1971). La responsabilidad precontractual, RCDI, 485, 859922.

AZNAR GINER, E. (2010). Las negociaciones o tratos preliminares al contrato. Doctrina y jurisprudencia, Tirant lo Blanch, Valencia.

BERNADMAINAR, R. (2014). En torno a la naturaleza jurídica del precontrato, $R C D I, 742,353-381$.

CABANILLAS SÁNCHEZ, A. (1995). El ámbito de la responsabilidad precontractual o culpa in contrahendo, RCDI, 628, 747-788.

CALVO CARAVACA, A. \& Carrascosa González, J. (2006). Curso de contratación internacional, Colex, Madrid.

CARRASCO PERERA, A. (2004). Las cartas de intenciones, Fusiones y Adquisiciones de Empresas (dir. A. Carrasco \& J. M. Álvarez Arjona), Aranzadi, Cizur Menor (Navarra), 87-143.

CARRASCO PERERA, A. (2005). Cartas de intenciones, precontratos, responsabilidad in contrahendo y obligatoriedad de los tratos en la Jurisprudencia española, ArC, 21(3), 2369-2392.

DÁVALOS FERNÁNDEZ, R. (1995). Las empresas mixtas: regulación jurídica, CJI, Madrid.

DÍEZ-PICAZO, Luis (2007). La formación del contrato, Fundamentos del Derecho civil patrimonial, Civitas, Madrid, 1, 309-419.

ECHARRI ARDANAZ, A. (2002). Joint Venture, Confemetal, Madrid.

EGUSQUIZABALMASEDA, M. A. (1998). El gentleman'sagreement: aspectos teóricos y prácticos en Derecho español, RJNot, 27, 173-232.

FERNÁNDEZ DE LA GÁNDARA, L. \& Calvo Caravaca, A. L. (1995). Derecho mercantil internacional, Tecnos, Madrid.

FERNÁNDEZ ROZAS, J. C., Arenas García, R. \& Miguel Asensio, P. A (2013). Derecho de los Negocios Internacionales, Iustel, Madrid.

GÁMEZ JIMÉNEZ, J.M. (2002). Las cartas de intención en el Comercio Internacional. Una aproximación a su régimen Jurídico desde el Derecho privado español, $B A C M, 52$, (consultado a través de Westlaw).

GARCÍA CANTERO, Gabriel (1992). La vida del contrato, Derecho civil español, común y foral, Madrid, Reus, 3, 700-723. 
MARÍA PAZ GARCÍA RUBIO, M. P. \& Otero Crespo, M. (2010). La responsabilidad precontractual en el Derecho contractual europeo, Indret, 2, 1-62.

GASPAR LERA, S. (2010). Negociaciones, garantías y responsabilidades en la transmisión de empresas, Transmisiones de Empresas y Modificaciones Estructuralesde Sociedades, Bosch, Barcelona, 127-155.

GÓMEZ POMAR, F. \& Gili Saldaña, M. A. (2010), Cuestiones de formación del contrato en la Propuesta de Anteproyecto de Ley de contratos de distribución", InDret, 1, 37.

GUARDIOLA SACARRERA, E. (2001).La compraventa internacional. Importaciones y exportaciones, Barcelona, Bosch.

ILLESCAS, R. \& Perales Viscasillas, P. (2003). Derecho mercantil internacional. El Derecho uniforme, Centro de Estudios Ramón Areces-Universidad Carlos III, Madrid.

JARNE MUÑOZ, P. (2013). La responsabilidad precontractual en el sector de la distribución comercial, $R D C D, 13,51-80$.

LUTTER, M. (1982). Der Letter of Intent. Zur rechtlichen Bedeutung von Absichtserklärungen, Köln, Heymanns.

LLODRàGRIMALT, F. (2002). "Letter of intent", carta de intenciones, precontrato", $R D P a, 8,129-148$.

LLODRàGRIMALT, F. (2003). "Letter of intent", carta de intenciones, precontrato", Derecho de los negocios, 151, 14-30.

MARÍN NARROS, H. D. (2012). Concepto y eficacia de los principales acuerdos precontracturales en Derecho estadounidense, Revista Crítica de Derecho Inmobiliario, 729, 281-317.

MARTíneZ DE AGUIRRE, C., De Pablo Contreras, P., Pérez Álvarez, M. A. \&Parra Lucán, M. A (2011).Curso de Derecho Civil. II. Derecho de Obligaciones, Madrid, Colex.

MASCAREÑAS PÉREZ-ÍNIIGO, J. (2011). Fusiones, adquisiciones y valoraciones de empresas, Ecobook, Madrid.

MIQUEL RODRÍGUEZ, J. (1998). La sociedad conjunta (jointventurecorporation), Civitas, Madrid.

MORENO QUESADA, B. (1963). La oferta de contrato, Nereo, Barcelona.

OVIEDO ALBÁN, J. (2012). Negociación y documentos preliminares en la contratación internacional, Revista de Derecho Privado, 22, 73-106.

PARRA LUCÁN, M.A. (2013). "Promesa de compraventa, precontrato y cartas de 
intenciones en la jurisprudencia", Homenaje a Rodrigo Bercovitz. Aranzadi, Navarra, 1, 423-434.

PARRA LUCÁN, M. A. (2014). Negociación y perfección de los contratos, Thomson Reuters-Aranzadi, Navarra.

PASQUAU LIAÑO, M. (2009). Jurisprudencia civil comentada. Código civil, II, Comares, Granada.

PUIG BRUTAU, J. (1978). Fundamentos de Derecho civil. Bosch, Barcelona, 2(1).

QUESADA SÁNCHEZ, A. J. (2011). "Las negociaciones dirigidas a la formación del contrato", Derecho privado europeo y modernización del derecho contractual en España (Eds. K. J. AlbiezDohrmannet al.), Barcelona, Atelier, 55-107.

SÁNCHEZ LORENZO, S. (2012). Cláusulas en los contratos internacionales. Redacción y análisis, Atelier, Barcelona.

VALÉS DUQUE, P. (2012). La responsabilidad precontractual, Madrid, Reus.

VICENTCHULIÁ, F. (2006). Introducción al Derecho Mercantil, Tirant lo Blanch, Valencia.

VIGURI PEREA, A. (1994). Los tratos preliminares: Las Cartas de Intenciones y Otros Documentos Legales Precontractuales, PPU, Barcelona.

WOLF, R. C (1995). A Guide to International Joint Venture withSampleClauses, London, KluwerLaw International. 

El DESISTIMIENTO UNILATERAL EN LOS CONTRATOS DE TRACTO SUCESIVO: CIVIL VS COMMON LAW EN LOS CONTRATOS DE DISTRIBUCIÓN

Unilateral withdrawal on successive contracts: civil vs common law on distribution contracts

\section{Maria Cruz lascorz Collada}

\section{RESUMEN}

El desistimiento -como causa de extinción del contrato- viene por tanto reconocido en los ordenamientos jurídicos y sanciona con la nulidad las vinculaciones perpetuas osine die. Es una de las causas de terminación de los contratos de tracto sucesivo, y uno de los principales aspectos problemáticos en la extinción de los contratos de distribución. Este resumen extenso de la comunicación examina la normativa relativa al derecho de desistimiento, y sus principales manifestaciones en los contratos de carácter mercantil: distribución y franquicia. Por último, se finalizará en un análisis comparativo del desistimiento entre el Civil Law y el Common Law. En especial, teniendo en cuenta las diferencias que presentan los ordenamientos jurídicos del Derecho de Estados Unidos e inglés.

Palabras clave: Derecho de contratos. Desistimiento contractual. Contratos distribución. LaW of contract. Termination of contracts. Distribution agreeMENTS.

\section{Abstract}

The cause of extinction, such as withdrawal of the Contract is therefore recognized in the laws and punishable by perpetual invalid links osine die. It is one of the causes of termination of successive contracts , and a major problem in the termination of contracts of distribution aspects . This extensive summary of the paper examines the legislation on the right of withdrawal, and its main manifestations in mercantile contracts : distribution and franchising . Finally, it will end in a comparative analysis of withdrawal from the Civil Law and Common Law . In particular, given the differences in the legal systems of the US law and English. 
Keywords: Contract law. Contractual withdrawal. Distribution contracts. LAW of CONTRACT. Termination of CONTRACts. AgreEments Distribution.

SumARIO: Desistimiento como causa de extinción del contrato: concepto y fundamento jurídico. 1. Manifestaciones del desistimiento o denuncia unilateral en los contratos de distribución y franquicia. 2. Análisis comparado del desistimiento en el civil y common law (derecho de EEUU e inglés). Conclusiones. Bibliografía.

\section{DESISTIMIENTO COMO CAUSA DE EXTINCIÓN DEL CONTRATO: CONCEPTO Y FUNDA- MENTO JURÍDICO}

El desistimiento como causa de extinción de las obligaciones se admite por todos los ordenamientos jurídicos europeos. Sin embargo, no ha existido unanimidad ni terminológica ni legal en el tratamiento de la figura del derecho de desistimiento $^{260}$.

La denuncia unilateral o desistimiento implica, en algunos casos, la posibilidad de extinguir el contrato por la voluntad de cualquiera de las partes mediante un acto completamente libre y voluntario que no tiene que fundarse en ninguna causa especial $^{261}$.

El fundamento jurídico del desistimiento parte de aplicación del principio general del derecho por el que ninguna de las partes puede quedar vinculada por una relación jurídica eterna o sine die y se pone de manifiesto en la extinción del contrato. A lo largo del presente estudio, se abordará el análisis del desistimiento como causa de extinción contractual no sólo en nuestro ordenamiento jurídico, sino desde una perspectiva comparativa del Common Law.

La posibilidad de que una de las partes ejerza este derecho es a priori una excepción a la irrevocabilidad y conservación del contrato, tal y como se entiende en nuestro Código Civil (véanse artículos 1091 CC, 1256 y 1258 CC). Esto es, la prohibición de que una de las partes se desligue arbitrariamente por su sola voluntad de la relación contractual ${ }^{262}$. Esta posibilidad suele ser más frecuente en los contratos

${ }^{260}$ Véase, DIÉGUEZ OLIVA, Rocío. "El Derecho de desistimiento en el marco común de referencia", InDret, 2/2009, Revista para el análisis del Derecho, Barcelona, p. 4. Ahora bien, la mayoría de la doctrina reconoce y utilizar indistintamente el término desistimiento o denuncia unilateral.

${ }^{261}$ Por todos, DIEZ-PICAZO, L., Fundamentos de Derecho Civil Patrimonial II, Las relaciones obligatorias, Editorial Thompson Civitas, $6^{\mathrm{a}}$ ed. Pamplona, pp.1086 y ss.

262 Para la mayoría de la doctrina, el desistimiento ad nutum constituye una excepción a la 
de tracto sucesivo. De hecho, una gran parte de la doctrina estudia este derecho en relación con los contratos de larga duración, y se sostiene incluso que es su principal forma de extinción ${ }^{263}$.

En el caso de los contratos de distribución -entendidos en sus múltiples modalidades- se permite ejercer la facultad unilateral de extinguir del contrato mediante el desistimiento. De un lado, el tradicional campo de aplicación de facultades unilaterales para la extinción del contrato se sitúa en el ámbito de los contratos de carácter duradero ${ }^{264}$. De otro, los contratos de distribución son contratos de colaboración intuitu personae y la pérdida de confianza entre las partes permite a cualquiera de ellas la posibilidad poner fin al contrato a través de una denuncia unilateral. Con todo, esta facultad de las partes de denunciar el contrato posee sus límites pues debe realizarse de buena fe, sin que pueda ser, por tanto, abusiva ${ }^{265}$.

\section{Manifestaciones del desistimiento o denuncia unilateral en los Con- TRATOS DE DISTRIBUCIÓN Y FRANQUICIA}

Convertidos en el instrumento jurídico preferido por las marcas para comercializar sus bienes y servicios, los contratos de distribución generan una asimetría inter partes que coloca al distribuidor - a excepción de la cadena alimentaria ${ }^{266}$ en una posición vulnerable especialmente en el momento final del contrato.

El desistimiento facultativo por una de las partes supone en un elevado porcentaje la causa más representativa de los problemas que se suscitan en el momento de la extinción de los contratos de distribución. La libertad del proveedor

obligatoriedad e irrevocabilidad del contrato. Otros van más allá y consideran que la consecuencia fundamental del desistimiento supone una admisión del arbitrio o una condición potestativa. Véase KLEIN, M., EL desistimiento unilateral del contrato, Editorial Civitas, Madrid, 1997, pp. 20 y ss.

263 Ídem n 33

${ }^{264}$ Así lo explica ÁLVAREZ MORENO, M.T., El desistimiento unilateral en los contratos con condiciones generales, Editorial EDERSA, Madrid, 2000, pp. 382 y ss.

${ }^{265}$ Véase VÁZQUEZ ALBERT, D., "La terminación de los contratos de distribución: causas y efectos patrimoniales", en Los Contratos de Distribución Comercial: Novedades legislativas y jurisprudenciales, Tirant lo Blanch, Valencia, 2010, pp.152-96.

${ }^{266} \mathrm{Si}$ bien la denuncia unilateral o desistimiento faculta a ambas partes para finalizar la relación contractual, en la práctica, el desistimiento por parte del concesionario no se produce, o cuanto menos, tiene un índice de litigios dad muy escaso. Como excepción, el distribuidor únicamente ha resuelto el contrato en aquellos casos en los que se procedía a la distribución de productos de pequeños proveedores por parte de grandes marcas de distribución alimentaria. A diferencia de los contratos de distribución, el legislador español sí que ha intervenido activamente para corregir las prácticas comerciales abusivas mediante la Ley 12/2013, de 2 de agosto, de medidas para mejorar el funcionamiento de la cadena alimenticia. 
-fabricante o franquiciador- de poner fin a la relación comercial y reorganizar la red, choca a menudo con el interés del distribuidor de mantenerse en el sistema, que le sitúa frente a otros revendedores en una posición privilegiada ${ }^{267}$. Especialmente, por la reputación de la marca, la calidad de sus productos o bien, por las cláusulas que le otorgan una protección territorial.

Las principales manifestaciones de la denuncia unilateral en los contratos vienen influenciados por uno de los aspectos más conflictivos del contrato: su duración $^{268}$. La delimitación del tiempo en los contratos y su impacto en el derecho de desistimiento es una de las cuestiones que mayor litigios dad plantea en la actualidad. De hecho, no cabe el desistimiento en los contratos de duración determinada. En el caso de que una de las partes quisiera poner fin al contrato se estaría ante un incumplimiento contractual. Por el contrario, en los contratos cuya duración no ha sido prefijada - esto es, en los contratos de duración indeterminada- se permite la facultad de denuncia unilateral.

Aunque en la mayoría de los contratos no se regule expresamente el desistimiento, sí que acontece su reconocimiento en algunas de sus disposiciones. La posibilidad de denunciar ad nutum -sin causa- este tipo de relación obligatoria está contemplada expresamente en la comisión mercantil, artículo 302 del Código de Comercio, que reconoce esta facultad en los "casos en que el empeño no tuviere tiempo señalado, cualquiera de las partes podrá darlo por fenecido, avisando a la otra con un mes de antelación". Aunque la regulación más completa de la facultad de desistimiento por tiempo indeterminada es la establecida en la Ley 12/1992, de 27 de mayo, sobre Contrato de Agencia, (en adelante, LCA) que dedica un capítulo a la extinción del contrato ${ }^{269}$. El artículo 25 LCA prevé expresamente que "el contrato de agencia de duración indefinida se extinguirá por la denuncia unilateral de cualquiera de las partes mediantes el preaviso por escrito", además de fijar también los plazos de preaviso en función de la duración que haya tendido el contrato ${ }^{270}$. Asimismo, el artículo 25 LCA en su apartado segundo, fija legalmente un mes por año de vigencia del contrato, con un máximo de seis meses.

Ahora bien, ante la atipicidad de los contratos de distribución, cabe preguntarse si tanto doctrina como jurisprudencia admiten la aplicación analógica de la Ley del contrato de agencia en el derecho de desistimiento y en las posibles indemnizaciones derivadas del mismo. De admitirse la analogía, el distribuidor dispondría de poderosas armas para reclamar indemnizaciones en caso de ruptura contractual,

\footnotetext{
${ }^{267}$ Así lo apunta GARCIA HERRERA, A., El impacto del tiempo en los contratos de franquicia y distribución exclusiva, Editorial Tirant lo Blanch, Valencia, 2008, p.27.

268 Ídem no 8.

269 Véase KLEIN, M., El desistimiento unilateral del contrato, Editorial Civitas, Madrid, 1997, p. 101-102.

${ }^{270}$ Por todos, LLOBREGAT HURTADO, M.L., El contrato de agencia mercantil, Barcelona, 1994, pp. 195 y ss.
} 
mientras que si rechaza tal analogía el derecho a obtener dichas indemnizaciones resultaría más improbable ${ }^{271}$. De este modo, la aplicación analógica determinaría de forma decisiva el desenlace de los numerosos conflictos que se plantean en la práctica.

La doctrina española no ha mantenido una posición unánime frente a esta cuestión. De un lado, ambos contratos presentan ciertas similitudes -en especial, ambos son contratos de colaboración basados en la confianza- pero al mismo tiempo tienen diferencias importantes en lo que respecta al riesgo que debe asumir el distribuidor-franquiciador frente al agente que actúa como intermediario comercial por cuenta ajena ${ }^{272}$.

No es este el caso de la doctrina de los ordenamientos jurídicos del Common Law -en especial, el Derecho inglés- que se ha mostrado firme y partidaria de no aplicar analógicamente las disposiciones del Agency Act para suplir la atipicidad de los contratos de distribución y tratar así de resolver las posibles controversias que puedan surgir entre las partes.

Por otra parte, de conformidad con la jurisprudencia española, lo que singularizaría al contrato de distribución con respecto al de agencia es que el agente actúa en nombre y por cuenta propia, adquiriendo los productos del proveedor para su reventa ${ }^{273}$. No obstante, la línea divisoria entre el contrato de agencia y distribución es difusa, pero la jurisprudencia ${ }^{274}$ admite con normalidad la terminación de los contratos de distribución en los que no se ha fijado un plazo mediante la denuncia unilateral a voluntad de cualquiera de las partes. En ocasiones, el Tribunal Supremo ha apelado a la identidad de razón para hacer efectiva la aplicación analógica de la LCA para determinar el plazo de preaviso razonable si una de las partes hubiera puesto fin al contrato de distribución desistiendo unilateralmente. Con todo, la Sala

${ }^{271}$ Señala, VAZQUEZ ALBERT, D. "Los terminación de los contratos de distribución", en Los contratos de distribución comercial: novedades legislativas y jurisprudenciales, Editorial Tirant lo Blanch, Valencia, 2010, pp. 160 y ss.

${ }^{272}$ Un sector relevante de la doctrina rechaza la aplicación analógica de la LCA a los contratos de distribución. Especialmente en la aplicación analógica de los plazos previstos impuestos para el contrato de agencia, aunque sí atribuyen el carácter mínimo modulador del plazo de preaviso razonable. Por todos, ECHEBARRÍA SÁENZ, J.A., El contrato de franquicia. Definición y conflictos en las relaciones internas, McGraw-Hill, Madrid, 1995, pp. 465.

${ }^{273}$ Por todos, CORDERO LOBATO, E., "La jurisprudencia relativa al contrato de distribución: exclusividad, inhibición de la competencia, desistimiento y otras cuestiones", Revista Doctrinal Aranzadi Civil-Mercantil, núm. 13/2008, de 26 de marzo de 2008, pp. 2/22. (BIB 2008\2444).

${ }^{274}$ Véanse las siguientes SSTS de 21 de noviembre de 2005 (RJ $2005 \backslash 7677$ ), de 20 de marzo de 2007 (RJ $\backslash 2007 \backslash 2622$ ), de 26 de marzo de 2008 (RJ $2008 \backslash 4128$ ), de 26 de junio de 2008 (RJ $\backslash 2008 \backslash 3305)$, de 30 de diciembre de 2010 (RJ $2010 \backslash 7563)$ y de 12 de marzo de 2013 (RJ $\backslash 2012 \backslash 1583$ ). 
Primera del Tribunal Supremo sostiene que la LCA no es automáticamente aplicable a los contratos de distribución ${ }^{275}$.

Son muchos los interrogantes que establecen por qué se rigen los contratos de distribución en España. La jurisprudencia ha tratado de suplir la atipicidad de estos contratos delimitando el régimen jurídico de los contratos de distribución y el alcance de la LCA sobre los mismos. No obstante, las resoluciones del Tribunal Supremo tampoco han seguido siempre una doctrina coincidente provocando una cierta inseguridad jurídica ${ }^{276}$ que ha precisado de resoluciones de Pleno de la Sala Primera.

Como se ha apuntado anteriormente, el desistimiento es la principal causa de extinción de los contratos de distribución y la duración, uno de los aspectos más conflictivos del contrato ${ }^{277}$. El tratamiento inadecuado de la duración del contrato conlleva el ejercicio del desistimiento o denuncia unilateral, especialmente por motivos estructurales o jurídicos y coyunturales o económicos. A continuación, se va a analizar el tratamiento jurídico del desistimiento y de la duración del contrato en el Derecho comparado.

\section{ANÁLISIS COMPARAdo DEL DESISTIMIENTO EN EL CIVIL Y COMMON LAW (DERE- CHO DE EEUU E INGLÉS)}

El desistimiento -como causa de extinción del contrato- viene reconocido en los ordenamientos jurídicos y sanciona con la nulidad las relaciones perpetuas o sine die. En cuanto a los ordenamientos propios del Civil Law destaca el "Kündigung" en Alemania ${ }^{278}$ y el recesso unilaterale en Italia, desarrollado más ampliamente que en cualquier otro Derecho y regulado en el artículo 1373 del Codice Civile como causa de extinción contractual en los contratos de duración indefinida ${ }^{279}$. Esto

${ }^{275}$ Véase la STS de Pleno 243/2008, de 26 de marzo de 2008 (RJ $\backslash 2008 \backslash 4128$ ), que establece lo siguiente: "Los plazos de preaviso establecidos en los contratos de agencia del artículo 25.2 LCA no son trasladables a la distribución en exclusiva". Asimismo, esta resolución apunta que según la doctrina de dicha Sala los artículos 25 y ss. LCA tampoco son automáticamente aplicables.

276 Es en estos casos cuando el Tribunal Supremo ha acudido a uno de los remedios que permite enmendar la carencia de una jurisprudencia uniforme: la resolución por el Pleno de la Sala Primera. En especial, véanse las SSTS de Pleno de 15 de enero y de 26 de marzo de 2008.

277 Véase GARCIA HERRERA, A., El impacto del tiempo en los contratos de franquicia y distribución exclusiva, Editorial Tirant lo Blanch, Valencia, 2008, p.31 y ss.

${ }^{278}$ El alcance del "Kundigung” es más amplio que el del desistimiento. Véase, KLEIN, M., "El desistimiento...", ob. cit. 26, es la figura que más se acerca a nuestro concepto de desistimiento. El término desistimiento ha encontrado su homónimo más próximo en el Derecho italiano (véase 1373 Codice Civile).

279 Por todos, LIPARI, N. y RESCIGNO, P., Diritto Civile, Obbligazioni e contratti, Vol. II, 
es, se permite pactar una cláusula contractual que atribuya a cualquiera de las partes, o a ambas, la facultad de desistir unilateralmente el contrato discrecionalmente en cualquier estado de ejecución del mismo pero sin efectos retroactivos.

En el caso del Derecho español, se reconoce expresamente el desistimiento en el artículo 1583 del Código Civil relativo al arrendamiento de obras y serviciosque declara la nulidad del arrendamiento hecho por toda la vida. Asimismo, se regula el desistimiento expresamente en el Código Civil en los contratos de mandato, sociedad civil, comodato y depósito. En realidad, se está estudiando si puede generalizarse esta regla y aplicarla a contratos diferentes para los que no está expresamente prevista. Tiene especial interés confrontar la solución española con la trascendencia jurídica que tiene el desistimiento en otros ordenamientos. En especial, estudiar las diferencias entre el Civil y el Common Law.

Además del Código Civil, la legislación especial española sobre competencia desleal también recoge la casuística del desistimiento con preaviso. En particular, el artículo 16.3 de la Ley 3/1991, de 10 de enero, de competencia desleal, considera desleal la ruptura de una relación comercial sin que haya existido preaviso por escrito y preciso con una mínima antelación de seis meses, salvo incumplimiento grave de las condiciones pactadas o fuerza mayor.

En los contratos de distribución, es el titular de la red empresarial -sea fabricante o proveedor- la parte que en la mayoría de los casos decide poner fin al contrato aludiendo un hipotético incumplimiento del distribuidor sobre los objetivos propuestos o el nivel de servicio o calidad exigido. Sin embargo, esa resolución por incumplimiento es una ficción jurídica cuya finalidad consiste en enmascarar un desistimiento o denuncia unilateral que conllevaría la indemnización al distribuidor por daños y perjuicios, inversiones no amortizadas, etc. Con todo, el principal objetivo del proveedor o franquiciador es apropiarse de las rentas e invadir el territorio contractual para acceder a su cuota de mercado (encroachment). Todo ello nos podría llevar a pensar que estamos ante una práctica abusiva.

Es abusivo el desistimiento cuando el distribuidor cuenta con un copioso stock y muy especialmente, estaba obligado a ello por contrato. Igualmente es abusiva la conducta del proveedor que poco a poco va reduciendo el ámbito territorial de la distribución exclusiva alegando unos incumplimientos infundados con el fin de resolver indemnización ${ }^{280}$.

Si el comportamiento detallado es muy frecuente entre los proveedores

Giuffrè Editore, Milano, 2009. Con todo, el derecho del receso fue previamente introducido como concepto en la ley italiana de sociedades anónimas. El derecho de receso italiano aparece entonces como la respuesta normativa al desarrollo francés y alemán del principio mayoritario en la reforma de los estatutos de las sociedades anónimas. Véase: http://revistaderecho.um.edu.uy/wp-content/uploads/2012/12/Olivera-Garcia-El-derecho-de-receso-Cinco-lustros-despues.pdf

${ }^{280}$ Por todos, CORDERO LOBATO, E., p. 17/22. 
-a excepción de aquellos que suministran productos a la cadena alimentaria- el tratamiento del desistimiento es diferente en países tradicionales de Common Law y Civil Law. De hecho, el desistimiento -como causa de extinción del contrato de distribución- es una excepción a la obligatoriedad y conservación de los contratos. En especial, la duración del plazo de preaviso en los ordenamientos de Civil Law puede derivarse como una obligación derivada del deber de buena fe contractual recogida en el artículo 1258 de nuestro Código Civil. Por el contrario, en el Derecho inglés el principio de buena fe como tal no está expresamente regulado -si lo hace expresamente el Restatement Second of Contracts estadounidense ${ }^{281}$ - y las reglas de interpretación restringen la operatividad de los deberes implícitos ${ }^{282}$.

Sin embargo, no pueden tratarse los ordenamientos jurídicos que forman parte del Common Law como compartimentos estancos. De hecho, en Estados Unidos, cuna del contrato de distribución y franquicia durante la etapa de expansión de la business format franchise, el periodo de codificación se remonta a la década de los setenta $^{283}$. Con todo la normativa federal sobre la institucionalización de la franquicia constituida por la Federal Trade Comission Disclosure Requeriments and Prohibitions Concerning Franchising and Business Opportunity Ventures (FTC Rule), aún no ha resuelto todos los conflictos de interés relacionados con su terminación, y en particular, el derecho de desistimiento unilateral por cualquiera de las partes. Pero a diferencia del primer movimiento codificador, el espíritu que anima en la actualidad las nuevas propuestas no se dirige tanto a buscar mecanismos correctores de una situación de abuso como a elevar a rango de ley los principios de buena fe y equidad en el desarrollo de la relación jurídica, generando, de paso, una legislación uniforme en materia de distribución y franquicia, capaz de acabar con la miscelánea legislativa que supone la disparidad de normas estatales, poco homogéneas, al no seguir un patrón común en la regulación del contrato ${ }^{284}$. Todo ello viene completado por la legislación estatal. En realidad más de la tercera parte de los Estados disponen de Franchise Relationship Laws que regulan la distribución de productos petrolíferos,

${ }^{281}$ El Restatement Second of Contracts aplica la cláusula implícita de Buena fe y equidad a todo tipo de contratos.

${ }^{282}$ SÁNCHEZ LORENZO, S.A., El Derecho inglés y los contratos internacionales, Editorial Tirant lo Blanch. Monografías, Valencia, 2013.

${ }^{283}$ Todo ello en parte a los frecuentes abusos de los franquiciadores y a los supuestos escándalos que durante los años cincuenta provocan la crisis del sistema. Véase, GARCIA HERRERA, A., El impacto del tiempo en los contratos de franquicia y distribución exclusiva, Editorial Tirant lo Blanch, Valencia, 2008, p.31 y ss.

${ }^{284}$ Véase GARCÍA HERRERA...p.45.Además de BELL, J. "The effect of changes in Circumstances on Long-term contracts", Contract Law Today, Oxford University Press, p.207; O'SULLIVAN, J., in Chapter 9, Term of the Contract II: exemption clauses and unfair terms", The Law of Contract, 6th ed., Oxford University Press, 2014, p.200; CARNEGIE, "Terminability of contracts of Unspecific Duration", 1969, 85 LQR 392. 
farmacéuticos, vinos y otras bebidas alcohólicas además de la tradicional industria del automóvil.

En los Estados carentes de regulación específica sobre distribución y franquicia, se aplicarán además de la normativa federal, los principios generales del Derecho derivados del Common Law, que también son los que rigen los contratos de distribución y franquicia en el Derecho inglés.

En el Derecho inglés los contratos de distribución son atípicos. De este modo, los franquiciados y distribuidores han resuelto los conflictos de interés que ocasiona la terminación por denuncia unilateral acudiendo a las diversas instituciones del Common Law. En el caso de acuerdos de duración indefinida, el Common Law reconoce la posibilidad de desistir del contrato, sin necesidad de invocar justa causa, a falta de normativa escrita (Statutory Law) y cuando el contrato prevea una cláusula de terminación at will. Ahora bien, deberá de respetarse un plazo de preaviso suficiente. He aquí cuando se nos plantea la pregunta de qué plazo de preaviso será el suficiente. Por el contrario, en el caso de que el contrato no prevea expresamente una cláusula de terminación -en la actualidad es poco frecuente- muchos tribunales han sujetado el contrato de distribución y franquicia al implied covenant of goodfaith and fair dealing. O sea, se considera que la buena fe es una condición que queda implícita en el contrato y que las partes deben respetar. La principal duda que aquí se plantea es si en estos casos el implied covenant u obligación implícita de buena fe prevalece sobre el derecho escrito.

La respuesta al planteamiento de si prevalece la obligación implícita de buena fe (implied covenant) sobre el derecho escrito se cita expresamente en algunas de las resoluciones falladas por los tribunales británicos. En realidad, la sentencia Baird Textile Holdings vs Marks and Spencer ${ }^{285}$ pone de manifiesto la prevalencia de los contratos escritos (express contracts) frente a los implied terms en razón del comportamiento de las partes y no en virtud de sus declaraciones. Es más, esta resolución no reconoce la buena fe en el Derecho inglés como una cláusula contractual implícita, tal y como se deduce de las palabras siguientes: "The presence in the suggested contractual formulation of implied duties of good faith is an additional barrier in the way of the conclusion for which Baird contends, in view of English law's general refusal to recognise any duty of this nature as an implied contractual term ${ }^{286}$ ".

El derecho de desistimiento goza de una mayor regulación en el Derecho de EEUU frente al tradicional Derecho inglés. De hecho, la norma general en EEUU ha sido la exigencia de una justa causa (good cause), así como el cumplimiento de requisitos formales en la terminación de los contratos, y la indicación de un plazo de preaviso que permita al distribuidor o franquiciado modificar la conducta atribuida

${ }^{285}$ Baird Textile Holdings Ltd v Marks \& Spencer plc [2001] EWCA Civ 274; [2001] All E.R. (Comm) 737; [2001] C.L.C. 999

${ }^{286}$ Véase la conclusión $n^{\circ} 68$, (Contract) de Baird Textile Holdings Ltd. v Marks \& Spencer plc [2001]. 
(cure period). Este plazo será inmediato al periodo de preaviso razonable que ponga fin a la relación contractual de no solventar las diferencias entre las partes.

La determinación de la causa justa de terminación y el preaviso supondrán en múltiples ocasiones la aparición de cláusulas abusivas en el contenido del contrato. Esta es otra de las cuestiones problemáticas que afectan al desistimiento unilateral de los contratos de distribución. Tomando como ejemplo las disposiciones establecidas para consumidores y usuarios cabe la posibilidad de estudiar -a modo de paralelismo- cuál será el resultado de equiparse el consumidor con el empresario débil en la celebración de los contratos de distribución con el objetivo de eliminarla asimetría inter partes considerando la amplia casuística de supuestos.

En España, la facultad de denuncia unilateral -como se ha citado anteriormente- también posee sus límites: debe realizarse de buena fe, con previo aviso y sin que pueda resultar abusiva. Para que el ejercicio de esta facultad no sea abusivo, debe realizarse en los términos legal y contractualmente establecidos. Al tratarse de contratos atípicos, en los contratos de distribución y franquicia rige el principio de libertad de forma en lo relativo a la voluntad de desistimiento. De este modo, las partes podrán acordarlo expresamente en el contrato con la finalidad de evitar futuros litigios $^{287}$.

\section{Conclusiones}

Con posterioridad al estudio del derecho de desistimiento unilateral por cualquiera de las partes en los contratos duraderos, cabe plantearse en Derecho comparado las cuestiones siguientes: ¿Debe existir una justa causa para denunciar unilateralmente el contrato -o, cabe la denuncia contractual ad nutum?, ¿cuál debe de ser el plazo de preaviso para los contratos de distribución?, y ¿se extingue el contrato cuando la denuncia es efectiva? Se abordarán estas cuestiones teniendo en cuenta un análisis doctrinal y estudio de la jurisprudencia española. Además de tener en cuenta las diferencias existentes entre los ordenamientos jurídicos del Common Law: Derecho de EEUU e inglés, considerando la teoría de los deberes implícitos de la buena fe (implied covenant of good faith and fair dealing).

Se tratará de delimitar las bases sobre las que debe de construirse el desistimiento en los contratos de distribución y franquicia, partiendo de las aportaciones de las respuestas a dichos interrogantes, de ambas perspectivas contractuales -pro-

${ }^{287}$ Aunque la jurisprudencia del Tribunal Supremo español ya reconoció a finales de los ochenta la denuncia unilateral de los contratos de colaboración siempre y cuando se realizaran de buena fe, mediante preaviso y por escrito, la STS de 22 de marzo de 1988 supuso el la consolidación de una amplia jurisprudencia en un momento en que ambos contratos de colaboración, distribución y agencia, eran atípicos. Asimismo, dicha sentencia establece los dos grandes tipos de resarcimientos a los que deberá hacer frente el empresario que decida poner fin a la relación sin justa causa y con abuso de derecho: una indemnización por daños y perjuicios, y una compensación por clientela. 
veedor y distribuidor- así como de sus posibles puntos de convergencia.

Aunque todos los ordenamientos jurídicos han reconocido el desistimiento unilateral ad nutum, no es tan evidente que deba admitirse la previsión contractual de un desistimiento sin preaviso y sin indemnización alguna para la parte que resulta perjudicada. Es aconsejable para las partes que realicen una redacción precisa de las cláusulas contractuales que prevean el desistimiento unilateral conforme al principio de libertad contractual del 1255 Código Civil. Sin embargo, no creemos que sea conforme al Derecho español el desistimiento sin plazo de preaviso. No sólo por la proclividad de los tribunales de recurrir al modelo del contrato de agencia ${ }^{288}$, sino porque todo ello sería contrario al artículo 1256 Código Civil.

Sin embargo, la jurisprudencia de la Sala Primera del Tribunal Supremo ha admitido que las partes pacten el derecho de desistimiento o de denuncia unilateral sin justa causa, sin indemnización alguna y con un plazo de preaviso simbólico, si ambas partes están de acuerdo. Este es el caso de la STS de 9 de julio de 2008 cuya asimetría empresarial entre proveedor y distribuidor es evidente, siendo el primero COCA COLA, S.A. y su distribuidor Envasados del Sur, S.A ${ }^{289}$. En la práctica, algunos distribuidores -a excepción de los anteriormente mencionados productos relativos a la cadena alimenticia- desean acceder a un nicho de mercado y ceden a las imposiciones de proveedores y franquiciadores titulares de redes de distribución. Con todo, cada vez es más frecuente que los contratos de distribución de duración indefinida establezcan un periodo de preaviso -no siempre razonable- que permita a los proveedores ejercer el derecho de desistimiento o denuncia unilateral.

A diferencia de este último supuesto cuyo plazo de preaviso resulta poco razonable, también surgen otros casos en los que la duración del plazo de preaviso se ajusta a la legalidad impuesta por el Reglamente 1475/95, de la Comisión Europea, de 28 de junio, relativo al sector de vehículos y automóviles. Concretamente, la STS de 22 de mayo de 2009 resuelve el conflicto existente en un contrato de concesión mercantil de duración indefinida entre la concedente BMW Ibérica S.A. y un concesionario de coches que permitía a cualquiera de las partes ejercer el derecho el desistimiento unilateral ad nutum si se respetaba el plazo de preaviso de dos años. Por tanto, no existía ni mala fe ni abuso de Derecho.

${ }^{288}$ Todo ello, a pesar de las STS de Pleno de la Sala Primera de 15 de enero y 26 de marzo de 2008.

${ }^{289}$ El Tribunal Supremo en la STS de 9 de julio de 2008 estimó oportuno que las partes hubieran convenido un plazo de preaviso de tan sólo siete días en base al entendimiento y confianza mutua. Sin embargo, no consideró relevante la asimetría entre las partes y las cláusulas de adhesión a las que hacía referencia la sentencia de la Audiencia Provincial de Sevilla, al resolver el asunto número 3400/00. El fundamento de la STS recaía sobre la plena capacidad de las partes para contractar las cláusulas que estimaran por conveniente. La STS de 9 de julio de 2008 hace referencia a numerosas resoluciones, entre ellas, las SSTS de Pleno de 15 de enero y de 26 de marzo de 1008, que sostienen las mismas argumentaciones. 
Por otra parte, en el Common Law la identificación de una justa causa (good cause) no es una tarea desdeñable. Si se atiende al Derecho de EEUU, se observa que en la legislación estatal relativa al contrato de franquicia ${ }^{290}$ queda pendiente la institucionalización de ciertos aspectos relacionados con la extinción del contrato, en especial, la terminación sin causa. Además de la legislación federal, más de la tercera parte de los Estados disponen en EEUU una legislación sobre el contrato de franquicia, concretamente, Franchise Relationship Laws, cuyas disposiciones se centran mayoritariamente en la terminación del contrato y en la transmisión de la franquicia ${ }^{291}$. El punto de encuentro entre todas ellas ha sido la justa causa (good cause), así como el cumplimiento de ciertos requisitos formales relativos a la terminación de la relación jurídica con la necesaria mención de un plazo de preaviso para el que el franquiciado -y por ende, distribuidor- modifique la conducta atribuida (cure period). No obstante, la dificultad radica en identificar que se entiende por justa causa, puesto que en las legislaciones estatales relativas al contrato de franquicia no hay un concepto uniforme de good cause. De hecho, en algunas Franchise Acts como las leyes de Minnesota, New Jersey o Nebrasca se define la justa causa como el incumplimiento de las obligaciones contractuales razonables impuestas por el franquiciador. De ahí que este supuesto jurídico no sea un desistimiento unilateral ad nutum, sino a la facultad que tiene el franquiciador exigir el cumplimiento del contrato al franquiciado, o bien proceder a la resolución por incumplimiento. Con todo, resulta interesante confrontar el Civil versus el Common Law, especialmente en el Derecho de EEUU, porque a diferencia de éste último, los distintos ordenamientos jurídicos de la esfera del Civil Law si reconocen el desistimiento unilateral ad nutum, o sin causa.

Por otra parte, tanto en el Derecho inglés como el Derecho de EEUU se prevé la presunción de revocar los contratos de tracto sucesivo para evitar las relaciones jurídicas perpetuas. Sin embargo, el Derecho de EEUU es más explícito que el Derecho inglés ${ }^{292}$ y el Uniform Commercial Code establece esta posibilidad siempre que se respete necesariamente el plazo de preaviso ${ }^{293}$ razonable. Ahora bien,

${ }^{290}$ Véase la Federal Trade Comission Rule, de 21 de noviembre de 1978, en vigor desde el 21 de octubre de 1979. No obstante, los cambios acontecidos en la franquicia desde su entrada en vigor, propiciaron la revisión formal de la norma ya en 1995, y en 1997, se adopta la Advance Notice of Proposed Rulemaking (ANPR) y en 2004 se realizó el informe (FTC Staff Report) en el que se recomendaban varios cambios. Con todo, a día de hoy, no se ha prosperado la proposición de una normativa reguladora de la relación interna que determine los aspectos relativos de la terminación del contrato.

291 Véase GARCIA HERRERA, A., El impacto del tiempo en los contratos de franquicia y distribución exclusiva, Editorial Tirant lo Blanch, Valencia, 2008, pp.51 y ss.

${ }^{292}$ Resulta interesante para el Derecho inglés, CANERGIE, XX, 'Terminability of Contracts of Unspecified Duration', (1969), 85 LQR pp. 392 y ss.

${ }^{293}$ Véase BELL, J. "The effect of changes in Circumstances on Long-term contracts", Con- 
¿cuál es el plazo de preaviso razonable? De un lado, una posibilidad sería dar por bueno aquel que las partes pacten, independientemente de los desequilibrios en la capacidad de negociación de las partes. Póngase por caso, el ejemplo de la STS de 9 de julio de 2008, que enfrentó a COCA COLA con Envasados del Sur S.A. De otro, la intervención legislativa de cada uno de los Estados para corregir los desequilibrios del mercado preservando los intereses de los distribuidores independientes. En el sector del automóvil, tanto en el Common como en el Civil Law se encuentran algunos ejemplos. En EEUU, desde 1956 la Federal Automobile Deale Franchise Act (en adelante, FADFA) se ha venido sujetando a los fabricantes de vehículos de motor al principio de la buena fe en el desarrollo de las relaciones con sus franquiciados. Asimismo, se agradece la labor realizada por el legislador europeo en el Reglamento $1475 / 95$ para el complejo sector industrial del automóvil principalmente por el amplio número de problemas que se suscitan en el momento de la extinción de los contratos de distribución. Con todo, tanto en el Civil como en el Common Law no es tarea fácil determinar cuál debe ser el plazo de preaviso razonable en los contratos de distribución indefinidos.

La respuesta para ambos ordenamientos pasa por estudiar individualmente cada sector económico del mercado. De hecho, resulta menos complejo resolver los conflictos en aquellos sectores en los que el legislador - sea de la UE o de EEUU- ha intervenido. Sin embargo, la atipicidad contractual de los contratos de distribución en algunos ordenamientos conlleva la aparición de diversos debates internos que implican diferentes formas de afrontar la litigios dad. Quizás la respuesta a este planteamiento pueda resolverse teniendo en cuenta no sólo la estructura jurídica de los sectores económicos de cada uno de sus Estados sino también su tejido empresarial con independencia de su pertenencia a las esferas del Civil o el Common Law.

\section{Bibliografía}

ALONSO SOTO, R., "Bases para una regulación de los contratos de distribución", Capítulo I, en La reforma de los contratos de distribución comercial, Editorial La Ley, Madrid, 2012.

ALVAREZ MORENO, M.T., El desistimiento unilateral en los contratos con condiciones generales, Editorial Edersa, Madrid, 2000.

BELL, J., in Contract Law Today, Anglo-French comparisons, Harris and Tallon, Oxford University Press, Clarendon Press, Oxford, 1989 (Edited by Donald Harris and Denis Tallon).

BIRDS, J., BRADGATE, R. and VILLIERS, C., Termination of Contracts, Institute for Commercial Law Studies, University of Sheffield, Wiley Chancery, Contract

tract Law Today, Oxford University Press, p.207. 
Law Series, 1995.

CALAVIA MOLINERO, J.M., "El Contrato de distribución en exclusiva", Capítulo IV, en Los contratos de distribución comercial: Novedades legislativas y jurisprudenciales, Editorial Tirant lo Blanch, Valencia, 2010.

CANERGIE, XX, 'Terminability of Contracts of Unspecified Duration', $85 L Q R$, 1969.

CORDERO LOBATO, E., "La jurisprudencia relativa al contrato de distribución: exclusividad, inhibición de la competencia, desistimiento y otras cuestiones", Revista Doctrinal Aranzadi Civil-Mercantil, núm. 13/2008, Pamplona, 2008.

DIÉGUEZ OLIVA, Rocío. "E1 Derecho de desistimiento en el marco común de referencia”, InDret, 2/2009, Revista para el análisis del Derecho, Barcelona, 2009.

DÍEZ-PICAZO, L., Fundamentos de Derecho Patrimonial I, Thompson Reuters, Cizur Menor (Navarra), 6 ${ }^{\text {a }}$ edición, 2007.

ECHEBARRÍA SÁENZ, J.A., El contrato de franquicia. Definición y conflictos en las relaciones internas, McGraw-Hill, Madrid, 1995.

GARCIA HERRERA, A., El impacto del tiempo en los contratos de franquicia y distribución exclusiva, Editorial Tirant lo Blanch, Valencia, 2008.

KLEIN, M., El desistimiento unilateral del contrato, Editorial Civitas, Madrid, 1997.

LIPARI, N. y RESCIGNO, P., Diritto Civile, Obbligazioni e contratti, Vol. II, Giuffrè Editore, Milano, 2009.

LLOBREGAT HURTADO, M.L., El contrato de agencia mercantil, Barcelona, 1994.

MARTÍ MIRAVALLS, J., "Desistimiento unilateral e indemnización por daños en los contratos de Distribución: estudio de la naturaleza jurídica de la indemnización por inversiones no amortizadas", en Revista de Derecho Mercantil 285, Julio-Septiembre 2012.

Mc KENDRICK, E., "The Regulation of Long-Term Contracts in English Law", in J. Beatson and D. Friedmann (eds.) Good faith and fault in Contract Law, Oxford, 1995.

MUNDAY, R., Agency, Law and Principles. Second Edition, Oxford University Press, Oxford, 2013.

O'SUlLIVAN, J. and HILLIARD, J., The Law of Contract, 5th edition, Core Text Series, Oxford University Press, 2012.

RODRIGUEZ MARÍN, C., El desistimiento unilateral (como causa de extinción del contrato), Editorial Montecorvo, Madrid, 1991. 
RUIZ PERIS, J.I., Hacia un Derecho para las redes empresariales, Tirant Monografías 679, Editorial Tirant lo Blanch, Valencia, 2009.

SÁNCHEZ LORENZO, S.A., El Derecho inglés y los contratos internacionales, Tirant lo Blanch, Valencia, 2013.

VAZQUEZ ALBERT, D., "Los terminación de los contratos de distribución”, en Los contratos de distribución comercial: novedades legislativas y jurisprudenciales, Editorial Tirant lo Blanch, Valencia, 2010. 



\section{9}

Deben las leyes españolas Regular el CONTRato de aloJamiento?

The spanish law should regulate the contract of accommodation?

Paula Castaños Castro

Profesora. Derecho Civil I da Universidad de Malaga.

E-mail: paulacc@uma.es

\section{Luisa Moreno-Torres Herrera}

Profesora. Derecho Civil I da Universidad de Malaga.

E-mail:mlmt@uma.es

\section{RESUMEN}

Las autoras reflexionan sobre la conveniencia y oportunidad de regular el contrato de alojamiento u hospedaje en el Derecho español, y toman postura sobre la cuestión. Esta reflexión es muy necesaria debido a la relevancia del sector del turismo en la economía del país, y es hoy especialmente oportuna a la vista del cambio de criterio producido recientemente sobre su inclusión en el futuro Código Mercantil. Mientras que la Propuesta de Código Mercantil elaborada por la Comisión General de Codificación del Ministerio de Justicia español, publicada en 2013, incluía dentro de su articulado normas sobre distintos contratos de servicios turísticos $\mathrm{y}$, dentro de ellos, del contrato de alojamiento, el Proyecto de Ley de Código Mercantil aprobado por el Consejo de Ministros el 30 de mayo de 2014, ha decidido prescindir de la totalidad de los preceptos que aquella dedicaba a los contratos turísticos.El objetivo de este trabajo es promover el debate científico y aportar ideas a la necesaria discusión sobre cuál debe ser la postura del legislador estatal ante el contrato de hospedaje.Aunque el análisis está referido estrictamente al contrato de hospedaje, algunas de las ideas que se exponen y parte de las conclusiones que se defienden son trasladables a otros contratos turísticos.

Palabras clave: Hospedaje. Custodia. Responsabilidad. Hostelero. Turista. 


\begin{abstract}
The authors reflect on the desirability and possibility to adjust the accommodation contract in Spanish law, and take position on the issue. This consideration is quite necessary due to the importance of the tourism sector in the economy, and it is especially timely today, in view of the recent position change with regards to its inclusion in the future Commerce Code. While the proposed Commerce Code prepared by the Law Commission of the Spanish Ministry of Justice, published in 2013, outlined the different standards and practices for tourist service contacts, and, within them, the accommodation contract, the Project Law of the Commerce Code approved by the Cabinet on May 30, 2014, has decided to completely dispense with all the precepts that engaged specifically in tourist contracts. The objective of this work is to promote scientific discussion and contribute ideas to the necessary discussion on what the position of the state legislature should be regarding the accommodation contract. Although the analysis is strictly based on the aforementioned accommodation contract, some of the ideas exposed and some of the conclusions that are reached, are also applicable to other tourist contracts.
\end{abstract}

Keywords: Accommodation. Agreement. Custody. Liability. Host. Tourist.

SumARIO: Normativa actualmente aplicable al contrato de alojamiento u hospedaje en derecho español. 1. El estado de la cuestión en otros ordenamientos jurídicos y el planteamiento adoptado por distintos textos de derecho europeo y nacional. 2. Las razones en las que debe descansar la decisión del legislador sobre la regulación del contrato de alojamiento. 3. La necesidad de regular explícitamente la responsabilidad del hostelero por la pérdida de los objetos de los clientes. 4. Conclusión sobre la postura que debe adoptar el legislador español. 5. ¿cuál es el texto legal idóneo para regular la responsabilidad del hostelero? Conclusiones. Bibliografía.

\title{
Normativa ACTUALMENTE APLiCABle Al CONTRATO de AlOJAMIENTO U hOSPE- DAJE EN DERECHO ESPAÑOL
}

El contrato de hospedaje es aquel en el que una de las partes se obliga a prestar a la otra una serie de servicios de distinta naturaleza que giran en torno a una prestación principal que sería el alojamiento; mientras que la otra se obliga a pagar un precio global por el conjunto de prestaciones (REPRESA POLO, 2004, p. 
$36)^{294}$. También se puede definir como aquel contrato por virtud del cual el titular de un establecimiento de alojamiento se obliga frente a su cliente a cederle el uso de una o varias habitaciones o dependencias, así como a la custodia de su equipaje, y a prestarle otros servicios, a cambio de una contraprestación en dinero" (art. 534-12 de Propuesta de Anteproyecto de Código Mercantil elaborada por la Comisión General de Codificación y publicada en 2013).

En el ordenamiento jurídico español, el contrato de hospedaje es un contrato atípico, es decir, un contrato carente de una normativa específica que regule de modo sistematizado las relaciones contractuales entre el empresario hotelero y el sujeto que hace uso de un servicio de alojamiento ofrecido por aquél. No hay una regulación de Derecho privado para este tipo contractual; cuestión distinta es que existan normas de naturaleza administrativa, muchas de ellas autonómicas, que se ocupan de establecer cuestiones tales como los requisitos de los establecimientos hoteleros, categorías y otras cuestiones similares.

Sin embargo, pese a su atipicidad, existen ciertos preceptos del Código civil encargados de regular determinados aspectos concretos del hospedaje. Estos preceptos son los siguientes: en primer lugar, los artículos 1783 y 1784 del Código civil contemplan la responsabilidad del hostelero por los efectos introducidos en el establecimiento por los clientes; por su parte, el art. 1922hace referencia al crédito preferente del hostelero para el cobro de las deudas derivadas del contrato de hospedaje; finalmente, el art. 1967se refiere a la prescripción especial de la acción para el cobro de las deudas que provienen de este contrato, que será de tres años.

Dejando al margen la abundante legislación administrativa que afecta de modo directo al ejercicio de la actividad (BADENAS CARPIO, 2000, p. 622), y teniendo en cuenta que España no ratificó la Convención europea sobre responsabilidad de los hosteleros, celebrada en París en 1962, y cuya entrada en vigor se produjo el 15 de febrero de 1967, la cualconstituye un referente en el ámbito comunitario, son muy escasas las referencias al hospedaje en textos distintos del Código civil. De forma muy tímida se refiere al contrato de alojamiento el Real Decreto Legislativo $1 / 2007$, de 16 de noviembre, por el que se aprueba el texto refundido de la Ley General para la Defensa de los Consumidores y Usuarios y otras leyes complementarias,

\footnotetext{
${ }^{294}$ También la jurisprudencia seadhiere a definir el contrato de forma semejante. Así, la Sentencia de la Audiencia Provincial de Cádiz de 19 de julio de 2004 (JUR 2004\293531)lo define como la relación que une a las partes según la cual se presta alojamiento a cambio de precio; por su parte, la Sentencia de la Audiencia Provincial de Madrid de 30 de noviembre del mismo año (JUR 2005\35373)es más específica, y con el fin de diferenciarlo de un subarriendo de vivienda, señala que en el hospedaje, además de cederse el uso y disfrute de la habitación, se le presta al huésped algún servicio más, como son los servicios de limpieza y arreglo de la habitación, lavado y planchado de ropa, manutención total o desayuno, etc. Todo ello unido a otra característica: el cliente busca la prestación de los servicios de forma puramente temporal y transitoria, sin que exista en él un ánimo de constituir el alojamiento como su residencia habitual.
} 
al excluir en su artículo 103 1) las normas referentes al derecho de desistimiento de la contratación a distancia cuando estamos en presencia de un contrato de suministro de servicio de alojamiento para fines distintos del de servir de vivienda, es decir, frente a un contrato de hospedaje.

Quizá la explicación de dicha atipicidad se encuentre en el hecho de que las prestaciones integrantes de este contrato pueden encontrar acomodo en las distintas figuras que lo conforman, esencialmente en el contrato de servicios (REPRESA POLO, 2004, p. 34), entendido éste, según el artículo 1:101 PEL SC (Principles of European Law Service Contracts) como aquel en el que una parte, "el profesional" o "prestador del servicio", realiza un servicio a favor de la otra parte, "el cliente", a cambio de una remuneración.

\section{El ESTAdo de La CUESTIÓN EN OTROS ORDENAMIENTOS JURÍdiCOS Y EL PLAN- TEAMIENTO ADOPTADO POR DISTINTOS TEXTOS DE DERECHO EUROPEO Y NACIONAL}

En la mayor parte de los países de nuestro entorno el contrato de hospedaje es asimismo un contrato atípico, regulándose únicamente, como ocurre en España a través de los artículos 1783 y 1784 del Código civil295, la responsabilidad del hostelero por los equipajes y objetos que los clientes introducen en los establecimientos ${ }^{296}$. Sin embargo, mientras que tanto el Code civil francés como el Código civil español y el Código civil brasileño, -estos dos últimos por influencia del Código Napoleónico de 1804-, regulan la responsabilidad del hostelero dentro de las normas del depósito

${ }^{295}$ El artículo 1783 del Código español establece lo siguiente: «Se reputa también depósito necesario el de los efectos introducidos por los viajeros en las fondas y mesones. Los fondistas o mesoneros responden de ellos como tales depositarios, con tal que se hubiese dado conocimiento a los mismos, o a sus dependientes, de los efectos introducidos en su casa, y que los viajeros por su parte observen las prevenciones que dichos posaderos o sus sustitutos les hubiesen hecho sobre cuidado y vigilancia de los efectos». Por su parte, el artículo 1784 señala que «La responsabilidad a que se refiere el artículo anterior comprende los daños hechos en los efectos de los viajeros, tanto por los criados o dependientes de los fondistas o mesoneros, como por los extraños; pero no los que provengan de robo a mano armada, o sean ocasionados por otro suceso de fuerza mayor».

${ }^{296}$ Establecen parámetros semejantes a los artículos 1783 y 1784 del Código civil español los parágrafos §701-\$704 BGB, los artículos 1783-1786 del Codice Civile, los artículos 19521954 del Code francés y los artículos 647-650 del Código civil brasileño. Aunque con algunas variaciones, -la mayor parte de ellas relativas a la limitación de la responsabilidad del hostelero-, los distintos Códigos europeos poseen una regulación similar a la ofrecida por el Código civil español. Si bien es cierto que algunos de estos Códigos contienen una normativa más detallada, como ocurre por ejemplo en el Código civil alemán, no menos cierto es que la esencia del contenido de sus preceptos guarda gran similitud con lo establecido por los arts. 1783 y 1784 del texto español. 
necesario ${ }^{297}$, la mayor parte de los Códigos han sufrido una evolución que conlleva la supresión de tal ubicación. Consecuentemente, hoy en día, calificar esta clase de depósito como necesario es un residuo histórico del que se han desprendido tanto el Código civil italiano de 1942, en el que desaparece la figura del depósito necesario, como el Código civil alemán, que dedica un título propio a la responsabilidad del hostelero. También el Código suizo de las obligaciones de 1980 o el Código neerlandés de 1992 suprimen la categoría del depósito necesario.

No obstante, pese a la escasa regulación del contrato objeto de análisis en los ordenamientos de nuestro entorno, siendo el único problema que precisa de una regulación detallada el que concierne a la responsabilidad del hostelero por los efectos introducidos en el hotel, existen asimismo ordenamientos jurídicos en los que el hospedaje se presenta como un contrato típico. Es el caso del Código civil de Perú de 1984, el cual dedica los artículos 1713-1727 a regular el contrato que nos ocupa en su conjunto, y no solamente la responsabilidad del hostelero como depositario. Así, tras definir el contrato, al que considera una figura totalmente autónoma respecto del depósito, se refiere a cuestiones tales como los derechos del huésped, el deber de exhibición de tarifas por parte de los establecimientos destinados al hospedaje o el derecho de retención del hospedante. Mas también en este texto legal la cuestión objeto de una regulación más detallada es la de la "responsabilidad del hospedante como depositario".

En cuanto al planteamiento adoptado por los distintos textos de Derecho europeo, tampoco éstos dedican al hospedaje regulación alguna. Así, por ejemplo, el DCFR (Draft Common Frame of Reference), pese a que regula ciertos contratos típicos, como el contrato de servicios y el de obra, no dedica ningún precepto al hospedaje. Por su parte, los PEL SC (Principles of European Law Service Contracts) tampoco establecen ninguna previsión específica para el contrato de alojamiento, aunque regulan contratos como el de depósito y contienen preceptos que, en principio, son aplicables a cualquier contrato de servicios, incluido el alojamiento.

Entre nosotros, como era de prever, la Propuesta de Anteproyecto de Ley de Modernización del Derecho de obligaciones y contratos elaborada por la Comisión General de Codificación no incluye tampoco la regulación de este contrato turístico. Si lo hizo, en cambio, la Propuesta de Código Mercantil elaborada por la Comisión General de Codificación y publicada en 2013, si bien su criterio no ha sido mantenido en el Proyecto de Ley de Código Mercantil aprobado por el Consejo de Ministros el 30 de mayo de 2014, que ha decidido prescindir de los preceptos referi-

${ }^{297}$ La razón por la cual el Código Napoleónico situaba este tipo de depósito dentro de las normas del depósito necesario es bien sencilla: se incluye la responsabilidad dentro de la disciplina del depósito necesario con el fin de permitir a los viajeros beneficiarse del régimen probatorio reconocido al depositante en el depósito miserable; sin embargo, actualmente han desaparecido los beneficios probatorios, por lo que resulta incoherente seguir considerando depósito necesario el de los efectos introducidos por los viajeros en las fondas y mesones. 
dos a los contratos turísticos.

Así las cosas, el panorama que presenta este contrato en los distintos ordenamientos jurídicos no ofrece consenso alguno sobre la conveniencia de regular de modo sistematizado e independiente los aspectos jurídico-privados del contrato de alojamiento, lo que aconseja reflexionar con detenimiento sobre la necesidad o no de regular el contrato objeto de estudio.

\section{LAS RAZONES EN LAS QUE DEBE DESCANSAR LA DECISIÓN DEL LEGISLADOR SO- BRE LA REGULACIÓN DEL CONTRATO DE ALOJAMIENTO}

Como venimos diciendo, aunque casi todos los ordenamientos jurídicos, incluido el español y el brasileño, dan respuesta al problema de la responsabilidad del hotelero por la pérdida o deterioro de los efectos de los huéspedes, el contrato de hospedaje es un contrato atípico en la mayor parte de aquéllos. Por tanto, conviene preguntarse qué es lo que lleva al legisladora no regular el contrato en su conjunto y si dicha postura está justificada.

En este sentido, debemos advertir que el Derecho positivo español cuenta con un marco normativo apropiado al que las partes -hostelero y cliente- pueden acudir en caso de controversia. Así, el Real Decreto Legislativo 1/2007 da respuesta a los conflictos que puedan surgir con respecto a los deberes precontractuales, haciendo especial hincapié en el derecho a la información. De este modo, para conseguir la finalidad pretendida por el ordenamiento, la información que el consumidor recibe debe reunir una serie de características propias, que hagan efectiva la protección; para determinar dichos requisitos, bastaría con acudir al principio de buena fe, sin embargo, igualmente la ley detalla cuales deben ser sus atributos distintivos. A tal fin, el art. $60 \mathrm{RD} 1 / 2007$, entre otros preceptos, señala que ha de tratarse de una información clara, comprensible, adaptada a las circunstancias, relevante, veraz y suficiente. Por su parte, las cuestiones que se puedan plantear debido al ejercicio de la facultad de desistimiento del cliente encuentran respuesta en los usos, siendo una práctica habitual que el establecimiento hotelero permita al cliente desistir del contrato en cualquier momento anterior a su comienzo sin imponerle indemnización, salvo que otra cosa distinta se disponga en la información precontractual. Por último, los casos de incumplimiento se solventan por los Tribunales acudiendo al régimen del incumplimiento contractual contemplado en el Código civil, en su interpretación jurisprudencial, que resulta más acorde con las previsiones más actualizadas, de textos sin rango de ley como los ya citados DCFR (DraftCommonFrame of Reference), los PECL (Principles of European Contract Law) o la Propuesta de Modernización del Código civil.

Así las cosas, la decisión del legislador de no regular el contrato de hospedaje en su conjunto parece estar justificada, y descansa principalmente en que las normas del contrato se servicios (que es la categoría general a la que pertenece), las 
normas generales de las obligaciones y contratos, y las normas sobre protección de los consumidores, en concreto el Real Decreto Legislativo 1/2007, resultan suficientes y adecuadas para resolver las distintas cuestiones que suscita esta relación contractual, y ello a pesar de que, como es bien sabido, el contrato de servicios precise de una normativa adaptada a los tiempos actuales ${ }^{298}$. (JIMÉNEZ HORWITZ, 2012, p.554).

Otro argumento que se puede invocar a favor de la no necesidad de regular el contrato de hospedaje es la casi inexistente conflictividad en las relaciones entre hotel y huésped, lo cual se pone de manifiesto a través del estudio de la jurisprudencia de nuestros tribunales, y lo cual revela que la mayoría de los conflictos entre el cliente y el establecimiento se solucionan por otras vías. Así, en la mayor parte de los casos, las pretensiones no se ejercitan judicialmente, constituyendo una vía mucho más práctica, dadas las características del contrato de hospedaje, ejercitar los remedios de forma extrajudicial.

\section{LA NECESIDAD DE REGULAR EXPLÍCITAMENTE LA RESPONSABILIDAD DEL HOSTE- LERO POR LA PÉRDIDA DE LOS OBJETOS DE LOS CLIENTES.}

A pesar de que por la razones antes aludidas creemos innecesario convertir el contrato de hospedaje en un contrato típico, no menos cierto es que existe una cuestión específica, cual es la responsabilidad del hostelero por la pérdida o deterioro de los objetos de los clientes, que sí aparece regulada en la mayor parte de los ordenamientos jurídicos, aunque en lugares distintos ${ }^{299}$.

No cabe duda de que se trata ésta de una de las cuestiones que mayor número de litigios ha ocasionado entre el establecimiento y el cliente y que, habida cuenta de las singularidades que presenta, precisa de una respuesta concreta por parte del legislador. Dichas particularidades se centran principalmente en las dificultades probatorias que para el cliente presenta el hecho que desencadena la responsabilidad y, en concreto, la excesiva dificultad de acreditar la preexistencia de sus objetos en el establecimiento hotelero, siempre que no hayan sido depositados para su custodia directa. Estas dificultades probatorias presentan un dilema no fácil de resolver para el legislador: por un lado, la norma no puede hacer recaer sobre el hotel indiscriminadamente una responsabilidad objetiva por la pérdida de los efectos de los viajeros, sin ofrecerle al menos una cierta garantía de que la pérdida o dete-

\footnotetext{
${ }^{298}$ El Código civil desarrolla la regulación del arrendamiento de obras y servicios en dos secciones. La sección primera, bajo el título del servicio de criados y trabajadores asalariados, establece una regulación del arrendamiento de servicios que se refiere a la despedida de los criados, menestrales, artesanos y demás trabajadores asalariados. Fácilmente se puede comprender que una regulación de estas características no puede ordenar de forma adecuada las relaciones modernas entre un profesional y el cliente.
}

${ }^{299}$ Vid. Nota 3 
rioro de los efectos tuvo lugar en el establecimiento; por otra parte, también resulta ilógico que el huésped deba hacer un inventario completo de los objetos que porta consigo, puesto que si bien es cierto que tal requisito constituiría un medio de prueba irrefutable, no menos cierto es que se trata de una exigencia que resultaría excesiva e irracional en la práctica.

Así las cosas, aunque abordaremos la postura que creemos que debe adoptar el legislador español en el siguiente apartado, no debemos concluir este epígrafe sin hacer una crítica a la respuesta que actualmente da la ley española al problema de la responsabilidad del hotelero por la pérdida o deterioro de los efectos de los huéspedes. Los arts. 1783y 1784 del Código civil, redactados en 1889, son claramente obsoletos y se muestran del todo insuficientes para dar solución a los problemas que se originan en la práctica, que pueden ir desde la desaparición de un efecto introducido por el cliente en el hotel, hasta el deterioro de un objeto depositado por aquél en la caja fuerte de la habitación. De ahí que los tribunales vengan realizando una tarea de verdadera creación del Derecho, lo que provoca una inseguridad jurídica que podría evitarse dando una nueva redacción a los preceptos señalados.

Así, no es inusual encontrar pronunciamientos en uno y otro sentido aleatoriamente. Muestra de ello es que mientras que la Sentencia de la Audiencia Provincial de Málaga de 30 de julio de 2001 (AC 2002\328) establece, en su Segundo Fundamento de Derecho, que la puesta a disposición de los clientes de una caja de seguridad en la que depositar los efectos releva a los mismos de la necesidad de poner en conocimiento de la empresa hotelera los efectos depositados, haciendo responsable en todo caso a esta última de los daños causados a los efectos, por sus empleados o por terceras personas, la Sentencia de la Audiencia Provincial de Málaga de 5 de diciembre de 2006 (AC 2007\882) afirma, siguiendo distinto criterio, que «la mera solicitud por los clientes de una caja de seguridad individual en la que depositar los efectos en ningún caso puede equivaler a la comunicación al establecimiento de los efectos que se están introduciendo en el mismo, sin que ni siquiera ello presuponga la introducción de objetos de valor, y ello porque esa equivalencia vulnera lo dispuesto en el artículo 1783, inciso $2^{\circ}$ del Código civil, en cuanto que la solicitud de una caja de seguridad individual por el cliente de un hotel no supone la introducción de objeto alguno en el mismo».

Por tanto, la inseguridad jurídica que crea la actual redacción de los artículos 1783 y 1784 del Código civil español hace necesaria una urgente reforma de los mismos, que posibilite mantener un criterio unánime en caso de conflicto entre las partes, y cuyo propósito debe ser dar una respuesta lo más equilibrada posible al problema que genera la pérdida o deterioro de los efectos introducidos por los clientes en el establecimiento hotelero. 


\section{CONClusión SObRe la POSTURA QUE DEBE ADOPTAR EL LEgISLAdOR ESPAÑol}

Para cumplir el objetivo de este trabajo y responder a la pregunta de si las leyes españolas deben o no regular el contrato de alojamiento, es preciso en primer lugar establecer el marco normativo de este contrato en la actualidad, y en segundo lugar, valorar su suficiencia y adecuación. Porque en nuestra opinión, la decisión del legislador de regular un determinado tipo contractual sólo está justificada si las normas (generales o especiales) por las que se rige en un momento dado son, bien insuficientes, bien inadecuadas, para resolver de modo satisfactorio las distintas cuestiones que suscita en la práctica la relación contractual de que se trate. Dicho en otras palabras, las intervenciones legislativas en el ámbito contractual deben reducirse lo más posible, pues si no son estrictamente necesarias, pueden traer consigo más inconvenientes que ventajas.

En lo que se refiere al hospedaje, el marco legislativo actual está formado por: el régimen general de las obligaciones y contratos del libro IV del Código civil, los artículos 1783 y 1784 del mismo texto legal, sobre responsabilidad del hostelero, la Ley 7/1998, sobre condiciones generales de la contratación, y el Real Decreto Legislativo 1/2007, mediante el que se aprueba el Texto Refundido de la Ley de consumidores. Todo ello sin perjuicio de que en algún caso concreto pudiera resultar de aplicación, alguna ley especial, como la Ley 16/2011, de contratos de crédito al consumo.

Es claro que la Ley de condiciones generales de la contratación sólo será aplicable en aquellos casos en los que se hayan utilizado en la contratación cláusulas predispuestas que hayan sido redactadas con la finalidad de ser incorporadas a una finalidad de contratos y cuya incorporación al contrato sea impuesta por una de las partes (art. 1 de la citada ley). Por su parte, el Texto Refundido de la Ley de consumidores es de aplicación sólo a las relaciones entre consumidores o usuarios y empresarios (art. 2), términos que poseen el significado preciso que les atribuye este texto legal. Con muchísima frecuencia, aunque no siempre, el contrato de hospedaje se habrá celebrado con un consumidor, esto es con un sujeto que actúa "en un ámbito ajeno a una actividad empresarial o profesional". En este caso el sujeto que disfruta del servicio de alojamiento, que es siempre una persona física, será generalmente un "turista", esto alguien que se encuentra fuera del lugar de su residencia habitual con una finalidad no profesional.

Pasando a la segunda cuestión, ¿Qué valoración nos merece este régimen jurídico? ¿Resulta adecuado para el contrato de hospedaje?

La respuesta es que en términos generales, sí, aunque con una importante excepción: el régimen de la responsabilidad del hotelero por la pérdida de los objetos de los huéspedes en el propio establecimiento.

Mientras que aspectos tales como el contenido del contrato, los deberes de información del empresario, el desistimiento o el incumplimiento encuentran res- 
puestas razonables, bien en el Derecho codificado, bien en la normativa protectora de los consumidores, no puede decirse lo mismo del problema que se le plantea al huésped ante la "desaparición" durante su estancia en el hotel de objetos que portaba consigo. Son muchas las dudas e incertidumbres que en relación con estos supuestos se le plantean al aplicador del Derecho: ¿la responsabilidad del hostelero alcanza a todos los objetos que el viajero lleve consigo o únicamente a aquellos que haya puesto en conocimiento del empresario?, ¿es responsable el establecimiento de los daños o de la sustracción de los vehículos de los clientes aparcados en el recinto del hotel?, ¿y de los daños sufridos por los objetos guardados en la caja fuerte de la habitación?, ¿corresponde al cliente que exige una indemnización al hotelero probar que introdujo en el hotel los objetos cuyo valor reclama?, ¿cómo puede probar este hecho?, ¿con qué criterios deberá fijar el juez la cuantía de la indemnización?, ¿la indemnización debe consistir únicamente en el valor del objeto o debe también comprender el daño moral u otros daños patrimoniales que en su caso se hayan producido?...

Aunque los tribunales han ido respondiendo a estas preguntas al resolver los casos que se les han ido planteando, lo cierto es que no hay una doctrina consolidada y estable sobre la mayor parte de ellas. Muy por el contrario, el análisis jurisprudencial revela discrepancias notorias. Además de ello, las soluciones de los tribunales no son siempre convincentes desde el punto de vista jurídico, aunque en ocasiones puedan estimarse acertadas en términos de justicia material.

En conclusión, si bien no estimamos necesaria una regulación específica del contrato de hospedaje, sí consideramos necesario modificar el régimen sobre responsabilidad de los hosteleros de los artículos 1783 y 1784 del Código civil. En lo que se refiere al alojamiento en establecimientos hoteleros, no hay una laguna normativa, pese a no existir una regulación ad hoc; lo que hay es, tan sólo, una inadecuación a la realidad actual de la disciplina (especial) sobre la responsabilidad de los establecimientos por la pérdida de los objetos de los clientes durante la vigencia del contrato de hospedaje.

Esta inadecuación es totalmente lógica, dado que las normas que dentro del Código español se ocupan de este problema fueron tomadas del Código francés de 1804 , lo que significa que están referidas a una realidad social y económica muy diferente a la actual. La solución establecida en los preceptos citados tiene dos siglos de vida, por lo que difícilmente puede resolver de modo convincente la más variada y rica problemática que la pérdida o deterioro de los objetos de los clientes de los hoteles suscita en la actualidad.

\section{5. ¿CuÁl ES EL TEXTO LEgAl IDÓNEO PARA REgUlaR LA RESPONSABILIDAD DEL HOSTELERO?}

Para terminar, conviene preguntarse, y no es un asunto menor, cuál es el texto legal adecuado para regular la responsabilidad de los establecimientos hotele- 
ros por la pérdida y por los daños sufridos en los equipajes y objetos de los viajeros.

Es claro que no tendría sentido dictar una ley especial, pues el único objetivo a alcanzar es dar respuesta a un problema muy puntual, que exigirá un número reducido de previsiones normativas. Un texto legal independiente no estaría justificado.

Podría pensarse que el lugar adecuado es el Texto Refundido de la Ley General para la defensa de los consumidores y usuarios, por cuanto que es nuestra ley "general" (que no "código") reguladora de las relaciones entre empresarios y consumidores. Sin embargo, esta opción debe descartarse por dos motivos:

En primer lugar, porque el problema que nos ocupa merece idéntica respuesta en los casos en que el huésped es un consumidor y en los casos en que no lo es. En esta ocasión no hay razón alguna que justifique una diferencia de trato. No tiene sentido atribuir un trato más favorable a quien se hospeda en el hotel por razones que nada tienen que ver con su actividad profesional o empresarial cuando el problema que se plantea es la pérdida de objetos que llevaba consigo. Este huésped no está más desprotegido frente al hotelero de lo que lo está el que ha perdido los objetos durante la utilización de los servicios de hospedaje con ocasión de una actividad empresarial o profesional.

En segundo lugar, porque el problema planteado no requiere una solución que proteja al huésped frente al empresario, sino algo bien distinto, una solución equilibrada, que tenga en cuenta y concilie de modo equitativo los dos intereses en conflicto: el del cliente, desde luego, pero también el del establecimiento, que no debe verse expuesto a reclamaciones de este tipo sin una prueba suficiente de la preexistencia de los objetos y de su valor, salvo que se limite de algún modo su responsabilidad, como de hecho hacen algunos ordenamientos (caso del art. 1953 del Código civil francés y del art. 1783 del Código civil italiano) y como ocurre también en el caso de pérdida de equipajes de los viajeros en el transporte aéreo (art. 22 del Convenio de Montreal para la unificación de ciertas reglas para el transporte aéreo internacional, ratificado por España en 2004).

Otra posibilidad a considerar es la inclusión de las normas sobre responsabilidad de los hosteleros en el Código mercantil. Es claro que en los últimos tiempos se constata una notoria tendencia a incrementar el ámbito de lo mercantil, siendo una clarísima muestra de ello el Proyecto de Ley de Código Mercantil. Sin embargo, y sin profundizar en las críticas -que compartimos- de las que ha sido objeto el código proyectado por parte del Grupo para la reforma y actualización del Derecho privado en España, y sin entrar tampoco en la sinrazón de la distinción entre contratos civiles y contratos mercantiles (GARCÍA RUBIO, 2013, pp.4-5), es claro que el Código Mercantil, que debe quedar para aquellas normas especiales que se aparten del Derecho privado general por necesidades del tráfico, no es el lugar adecuado para regular la responsabilidad de los hosteleros por los daños sufridos en los objetos de los huéspedes. Este problema no requiere una solución especial, es decir una solución contraria a las reglas generales de la responsabilidad contractual, sino una solución 
especifica, que no es lo mismo.

Tal solución no debe venir determinada por la lógica del mercado, que es la que inspira a los códigos mercantiles. No se trata de que el "mercado" de la hostelería funcione de modo satisfactorio para el sector empresarial, sino, como ya se ha dicho, de conciliar los intereses en juego y de diseñar un sistema de responsabilidad que sortee del mejor modo posible las dificultades probatorias que se le plantean al perjudicado, siendo al mismo tiempo equitativo para el prestador del servicio.

A nuestro modo de ver, lo relativo a la prueba de la desaparición de los objetos, y de su valor, posee una importancia crucial en el tema, algo que ya se percibió por los redactores del Código de Napoleón. Conscientes éstos de las dificultades a las que se habría de enfrentar el viajero que sufriese daños en sus bienes durante su estancia en el hotel, para probar tanto la introducción del equipaje, como su pérdida, admitió a tal fin todo tipo de prueba, incluyendo la prueba de testigos. La misma solución se estableció para el llamado depósito necesario, que es aquél que "tiene lugar con ocasión de alguna calamidad, como incendio, ruina, saqueo, naufragio u otras semejantes" (art. 1781 del Código civil español). De ahí que también el depósito de los efectos de los viajeros fuera legalmente conceptuado como un caso de depósito necesario.

La importancia de los aspectos probatorios en el supuesto que nos ocupa no significa, desde luego, que el problema al que se enfrenta el legislador sea un problema procesal, ni que deba ser resuelto en las leyes procesales. Significa, simplemente, que la regulación sustantiva de la responsabilidad del hotelero ha de tomar muy en cuenta las dificultades de prueba a las que se habrá de enfrentar el perjudicado; unas dificultades que tampoco sería sensato que se convirtiesen en una ventaja para él y en un perjuicio para el otro contratante. Es aquí donde se encuentra la mayor dificultad.

Nuestra opinión es que las reglas sobre la responsabilidad de los establecimientos hoteleros deben permanecer en el Código civil. Es el criterio unánime en Derecho comparado y aunque pueda pensarse que ello se debe a razones históricas, lo cierto es que continúa siendo el texto adecuado, pues se trata de una responsabilidad derivada de un contrato entre el prestador de un servicio concreto (el hospedaje) y el sujeto acreedor del servicio.

Lo que no convence, ciertamente, es la actual ubicación de la norma o, más exactamente, su consideración como depósito necesario, algo que, como ya se ha explicado, responde a razones históricas, pero que hoy carece de sentido.

No es menos cierto que al ser el fundamento de la responsabilidad del hostelero su deber de custodia de los objetos de los clientes, hay una clara conexión entre este asunto y el contrato de depósito, por virtud del cual un sujeto se obliga a custodiar las cosas que a tal fin le han sido entregadas por el otro contratante.

Por esta razón, y a fin de no alterar excesivamente la sistemática del Código, la solución que propugnamos es la de crear, dentro del capítulo dedicado al depósito, una nueva sección sobre el depósito (o quizás mejor sobre la custodia) en los establecimientos hoteleros, sección que estaría integrada por los arts. $1783 \mathrm{y}$ 
1784, a los que habría que dar nueva redacción. Todo ello, claro está, para el caso de aprobarse únicamente una reforma puntual referida a esta materia. Cuestión distinta sería que se acometiese una reforma en profundidad del Libro IV del Código civil, en cuyo caso, deberían considerarse otras soluciones más innovadoras.

\section{Conclusiones}

El contrato de alojamiento carece de regulación en el Derecho positivo español. El único aspecto de Derecho privado directamente tratado en las leyes es el de la responsabilidad de los hoteleros por los daños sufridos en los efectos de los viajeros, del que se ocupan los arts. 1783 y 1784 del Código civil, dentro de las normas dedicadas al contrato de depósito, en concreto al llamado depósito necesario.

Éste es el planteamiento más frecuente en los Códigos civiles analizados. Lo adoptan el Código francés, italiano, suizo de obligaciones, chileno, brasileño y argentino.

En algunos ordenamientos jurídicos, en cambio, el hospedaje es un contrato típico. Es el caso del Código civil de Perú. En España, la Sección Mercantil de la Comisión General de Codificación del Ministerio de Justicia acogió este planteamiento. En su Propuesta de Código Mercantil de 2013 incluyó los contratos turísticos y, dentro de ellos, el contrato de alojamiento. No obstante, la redacción final suprimió cualquier referencia a los mismos.

Así pues, no hay coincidencia entre los distintos ordenamientos, lo que quiere decir que no hay consenso acerca de la conveniencia de regular de modo sistematizado e independiente los aspectos jurídico-privados del contrato de hospedaje o alojamiento.

La decisión del legislador de regular el contrato de hospedaje sólo estaría justificada si las normas del contrato se servicios (que es la categoría general a la que pertenece), las normas generales de las obligaciones y contratos, y las normas sobre protección de los consumidores, resultan insuficientes e inadecuadas para resolver las distintas cuestiones que suscita esta relación contractual. No cabe, pues, tomar una postura general y abstracta sobre este asunto, sino que es preciso hacerlo en referencia a cada ordenamiento jurídico.

El Derecho español cuenta con un marco normativo idóneo al que acudir para dar respuesta a la mayor parte de las cuestiones que se plantean en el ámbito de las relaciones entre empresario hotelero y cliente: la fase precontractual y en particular los deberes de información del empresario están hoy suficientemente tratados en el Texto Refundido de la Ley de consumidores, las dudas que pueda plantear la facultad de desistimiento del cliente encuentran respuesta en los usos, mientras que los casos de incumplimiento se solventan por los Tribunales acudiendo al régimen del incumplimiento contractual del Código civil.

El hecho de que actualmente el contrato de servicios sea, de facto, un con- 
trato carente de regulación, no altera la conclusión anterior de que la Teoría general de las obligaciones y contratos del Libro IV del Código civil y las normas sobre protección de los consumidores del Real Decreto Legislativo $1 / 2007$, por el que se aprueba el Texto Refundido de la Ley General para la Defensa de los Consumidores y Usuarios, ofrecen base suficiente al aplicador del Derecho para dar respuesta a las cuestiones que suscita el contrato de hospedaje entre el empresario hotelero y el cliente. Cuestión distinta es que resulte deseable contar con una normativa sobre contrato de servicios, adaptada a los tiempos.

El estudio de la jurisprudencia del Tribunal Supremo y de las Audiencias provinciales, así como la comprobación de la tarea realizada por las Juntas Arbitrales de Consumo, evidencia, en términos generales, una escasa conflictividad en las relaciones entre hotel y cliente.

El problema que origina mayor número de litigios es el de la "pérdida" de objetos de los huéspedes durante su estancia en el establecimiento hotelero.

La respuesta de la ley española al problema de la responsabilidad del hotelero por la pérdida o deterioro de los efectos de los huéspedes es inadecuada. Los arts. 1783 y 1784 del Código civil, redactados hace casi dos siglos, son claramente obsoletos y se muestran insuficientes para resolver de modo satisfactorio la variada y cambiante problemática que se origina en la práctica. De ahí que los tribunales vengan realizando una tarea de verdadera creación del Derecho, lo que provoca altas dosis de inseguridad jurídica, lo que no es nunca deseable.

La responsabilidad del hotelero por la pérdida de los objetos de los huéspedes no puede dejarse en manos de las normas generales. Habida cuenta de las particularidades que presenta, precisa de una particular respuesta por parte del legislador. Prueba de ello es que todos los ordenamientos contienen previsiones específicas sobre este asunto, aunque lo hagan en lugares distintos.

La respuesta legislativa al problema de la responsabilidad del hotelero por la pérdida o deterioro de los objetos de los viajeros debe construirse teniendo muy presentes las dificultades probatorias que para el cliente presenta el hecho que desencadena la responsabilidad y, en concreto, la dificultad de acreditar la preexistencia de sus objetos en el establecimiento hotelero. Pero no es menos cierto que las leyes no puede hacer recaer sobre el empresario, indiscriminadamente, una responsabilidad objetiva por la pérdida de los efectos de los viajeros, sin ofrecerle al menos una cierta seguridad de que la pérdida o deterioro se produjo en su establecimiento.

La respuesta legislativa al problema de la responsabilidad del establecimiento hotelero exige conciliar adecuadamente los intereses en juego, lo que en este caso en particular no es una tarea en absoluto fácil. Por una parte, hay que contemplar el interés del huésped de ser razonablemente protegido durante su estancia en el hotel. Es claro que el sistema debe darle confianza. La protección del huésped exige imponer al hotelero un deber de custodia que alcance a los objetos que llevan consigo los viajeros. Por otra parte, los intereses del empresario exigen concretar los 
casos y circunstancias en las que le es exigible ese deber de custodia, que no debe ser ilimitado.

El objetivo que debe perseguir el legislador cuando conceda derechos a los huéspedes por la pérdida de los objetos que porten consigo, no debe ser, sólo y exclusivamente, proteger a los clientes. Debe aspirar a ofrecer una solución lo más equitativa y equilibrada pese a las dificultades del supuesto a resolver.

Dado que la finalidad única o preponderante de la intervención legislativa no ha de ser tuitiva, y dado que, además, el destinatario de la norma debe ser el huésped (persona física), con independencia de que el alojamiento se realice con un propósito privado o profesional, la legislación de consumo no es el lugar idóneo para regular la responsabilidad de los establecimientos hoteleros.

Tampoco es el lugar idóneo el Código mercantil. Aunque la tendencia es otra, no creemos que deban ser considerados mercantiles todos aquellos contratos realizados por un empresario u operador económico en el ejercicio de su actividad empresarial. La lógica que inspira el Código mercantil es la lógica del mercado y esta lógica no es adecuada para resolver el problema de la responsabilidad del hotelero por los objetos que los huéspedes "pierdan" en sus establecimientos, como tampoco es adecuada a tal fin la lógica pura y dura del Derecho del consumo.

Las reglas sobre responsabilidad de los hoteleros deben permanecer en el Código civil, lo que no significa que se deba mantener como un caso de depósito necesario. A fin de respetar, no obstante, la estructura del Código, la solución más factible sería la de crear, dentro del capítulo dedicado al depósito, una nueva sección sobre el depósito en los establecimientos hoteleros, sección que estaría formada por los artículos 1.783 y 1.784 , a los que habría que dar nueva redacción.

La sistemática que se propone es la seguida por el Código civil de Quebec, la cual resulta muy convincente, por cuanto que supone regular sólo aquel aspecto del contrato de hospedaje que precisa de una respuesta particular. Y no debe resultar extraño que ello se haga dentro de las normas que se dedican al depósito, dado que el fundamento jurídico de la responsabilidad del hostelero por la pérdida o daños acaecidos en los efectos de los viajeros, no es otro que su deber de custodia, un deber de custodia que, con toda lógica, se considera contenido inderogable del contrato de hospedaje.

\section{Bibliografía}

BADENAS CARPIO, J.M.: "Sobre la posible publificación del contrato de hospedaje", Actualidad Civil, n.16, 2000.

GARCÍA GÓMEZ, R.: "Hospedaje y turismo. Breve excursus sobre la responsabilidad de los profesionales de la hostelería".II Jornadas de Derecho y Turismo. Ávila, Noviembre, 1995, pp. 79-86. 
GARCÍA RUBIO, M. P.: "Una propuesta de Código mercantil sin modelo comparado", Cuaderno Electrónico de Estudios Jurídicos (www.ceej.es), n.1. 2013, pp.1-11. GONZÁLEZ CABRERA, I.: "La seguridad del turista en la ejecución del contrato de hospedaje: breves consideraciones", Derecho de los negocios, n. 208. 2008.

JIMÉNEZ HORWITZ, M.: "La distinción entre los contratos de obras y servicios en el Derecho español (estudio comparado con el Derecho alemán)", Anuario de Derecho Civil, Abril-Junio 2012, pp. 551- 584.

MARLASCA MARTÍNEZ, O.: Los establecimientos de hospedaje: Estudio histórico. Responsabilidades que derivan para los titulares de los mismos: De Roma al Derecho actual. Bilbao, 2006.

PÉREZ MARTELL, R. y GONZÁLEZ CABRERA, I.: El alojamiento turístico: problemática y soluciones en la ejecución del contrato de hospedaje. La Ley, Madrid, 2008.

REPRESA POLO, M.P.: Responsabilidad de los establecimientos hoteleros por los efectos introducidos por los clientes. Madrid, 2004.

RODRÍGUEZ MARTÍNEZ, M.E.: "La responsabilidad de los hoteleros por los efectos introducidos por los viajeros: los artículos 1783 y 1784 del Código Civil", Anuario de Derecho Civil, $n$. LXI-2, Abril, 2008, pp. 721-834.

SÁNCHEZ HERNÁNDEZ, A.: "El depósito derivado del hospedaje y la responsabilidad del hospedero", Boletín de la Facultad de Derecho de la UNED, n. 7, 1994. 


\title{
El fenómeno de la subcontratación en Brasil y España. Principales diferencias y CUeSTiOnes Controvertidas de ambos Países
}

The phenomenon of outsourcing in Brazil and Spain. Main differences and controversial issues in both countries

\section{Pepa Burriel Rodríguez-Diosdado}

Profesora Lectora de la Universidad de Barcelona. Abogada.

E-mail pepaburriel@ub.edu

\section{RESUMEN}

El trabajo realizado en subcontratación constituye un régimen jurídico excepcional, altamente utilizado en la práctica brasileña y española. El problema reside en las peores condiciones de trabajo a las que pueden estar expuestos los trabajadores de las empresas de servicios, su mayor inestabilidad y la dificultad encontrar responsables, por ejemplo, en casos de conflictos en materia de salud laboral. Mientras que en España hay un importante desarrollo legal del fenómeno, logrando una equiparación de derechos y beneficios de los trabajadores de empresas prestadoras de servicios, en Brasil no existe un desarrollo legal, completo del tema por el momento, solucionándose los conflictos a través de la jurisprudencia consolidada del Tribunal Superior de Trabajo. El presente escrito tiene como finalidad poner de manifiesto las debilidades del sistema brasileño actual tomando como parámetro el desarrollo del sistema español.

Palabras Clave: Subcontratación. Precarización. Empresas de servicios.

\begin{abstract}
Thelabor in outsourcingisanexceptional legal regime, highlyused in Brazilian and Spanishpractice. Theproblemistheworstworkingconditions to whichworkersmay be exposed to servicecompanies, mostinstability and difficultyfindingresponsible, forexample, in cases of conflicts in occupationalhealth. While in Spainthereisanimportant legal development of thephenomenon, achievingequalrights and benefits of employees of servicecompanies in Brazilthereis no legal, full development of thesubjectforthemoment, solucionándose conflictsthroughestab-
\end{abstract}


lishedjurisprudence of the Superior LabourCourt. Thisletterisintended to highlighttheweaknesses of thecurrentBraziliansystemtaking as parameterthedevelopment of theSpanishsystem.

\section{Keywords: Outsourcing. InSeCurity. Service companies.}

SumARIO: Planteamiento. El origen y los problemas del fenómeno. 1. La regulación del fenómeno del trabajo en régimen de subcontratación: una asignatura pendiente de la OIT. 2. La evolución de la regulación de la subcontratación en ambos países. 3. El concepto de subcontratación en Brasil y España. Los elementos característicos. 4. El proyecto de ley brasileño 4330/94 bajo el prisma de la legislación española. Conclusiones. Bibliografía.

\section{Planteamiento. El origen y los Problemas del fenómeno}

Con las expresiones de contratas y subcontratas nos referimos a un fenómeno más de externalización o descentralización de los servicios de la empresa, outsourcing en terminología anglosajona, figuras en las que con carácter general una parte de la actividad económica es realizada por empresas auxiliares a través de sus propios trabajadores. De tal manera que una empresa, a la que denominamos principal, comitente o contratante, encarga a otra empresa, auxiliar, denominada contratista, subcontratista o de servicios, la realización de una obra o la prestación de un servicio con sus propios trabajadores, asumiendo la principal la obligación de pagar un precio cierto a esta auxiliar.

La mencionada descentralización productiva puede llevarse a cabo a través de diferentes títulos jurídicos: contrato de empresa, contrato de ejecución de obra, contrato de arrendamiento de servicios o incluso concesión administrativa para la gestión indirecta de servicios públicos. Sn embargo la importancia cuantitativa y los numerosos problemas que suscita la subcontratación-tercerización merecen un análisis diferenciado.

El incremento en el uso de estas formas de descentralización responde básicamente a la mejor eficiencia económica ique se consigue a través de ellas, son un instrumento adecuado para la adaptación a la realidad económica, esto es, para lograr la flexibilidad o flexibilización productiva, su mejor competitividad. Permite, en muchos casos, un mayor grado de especialización, de cualificación de los trabajadores y una más frecuente utilización de los medios técnicos que se emplean, lo que influye positivamente en la inversión en nueva tecnología. Pero veremos que en la afectación a las relaciones laborales los efectos no serán ni mucho menos tan beneficiosos como los efectos económicos descritos, de ahí el interés que presenta este fenómeno. 
La "tercerización" de los servicios y actividades industriales nace y evoluciona como una consecuencia del desarrollo de la lógica del funcionamiento del sistema capitalista, por una necesidad básica: mantenerse competitivo frente a sus rivales; por ello, surgen en todo el mundo nuevas empresas y nuevas formas de vincularse jurídicamente con el trabajador, sin perder de vista esa finalidad de mejora de la competitividad.

Los trabajadores inmersos en fenómenos de contratación y subcontratación están expuestos como cualquier trabajador a los riesgos típicos de la relación laboral, pero junto a éstos, por el hecho de estar inmerso en una estructura empresarial compleja de contrataciones y subcontrataciones se produce un efecto multiplicador cuantitativo y cualitativo de los riesgos para con su salud laboral ${ }^{300}$, a saber, al concurrir en un mismo espacio los trabajadores estará expuestos a un doble riesgo: los de su propia empresa y los de las restantes empresas intervinientes en el fenómeno productivo. Cuantas más empresas intervengan en el proceso productivo mayores serán los riesgos potenciales.

Pero la mayor vulnerabilidad de los trabajadores de las empresas auxiliares también deriva, entre otros, de los siguientes factores concretos:

- $\quad$ Desconocimiento del centro de trabajo, sí existe concurrencia física de diversas empresas con sus respectivos trabajadores en un mismo lugar de trabajo. Los trabajadores de contratistas y subcontratistas desarrollan su actividad en un centro de trabajo ajeno, desconocido en principio para ellos, de manera que la exigencia en el cumplimiento de los deberes de información y formación en materia preventiva debía ser mayor, situación que no es habitual en la práctica, llegando en ocasiones a un incumplimiento manifiesto en el nivel de formación otorgado ${ }^{301}$.

- $\quad$ La desvinculación en la relación laboral del empresario principal o contratista con los trabajadores de las restantes empresas, considerándolos como ajenos, a pesar de que en ocasiones la parte de la producción que se descentraliza es la que más riesgo comporta ${ }^{302}$. En otras palabras, nos referimos a la ausencia de una relación laboral con la empresa principal, que

${ }^{300}$ GARCIA NINET, J.I. Obligaciones y responsabilidades en materia de seguridad y salud en los supuestos de contratas y subcontratas. Consideraciones en torno al art. 24 (coordinación de actividades empresariales) de la LPRL. En: AAVV, Descentralización productiva y protección del trabajo en contratas, Valencia, 2000. P. 278.

${ }^{301}$ MOLTÓ GARCÍA, J.L. MOLTÓ GARCÍA, J.I. La prevención de riesgos laborales de los trabajadores de las empresas de trabajo temporal en las empresas usuarias. Ministerio de Trabajo y Asuntos Sociales. Edita Instituto Nacional de Seguridad e Higiene en el Trabajo. Madrid, 2009. P. 15.

${ }^{302}$ MIÑARRO YANINI, M. La prevención de riesgos laborales en la contratación temporal, empresas de trabajo temporal, y contratas y subcontratas. Ministerio de Trabajo y Asuntos Sociales. Edita Instituto Nacional de Seguridad e Higiene en el Trabajo. Madrid, 2002. P. 511. 
sin embargo es la que se beneficia del producto de su trabajo, que puede dar lugar a la desatención de los trabajadores externos por parte de la empresa principal, dando lugar a diversos niveles de seguridad en un mismo centro de trabajo.

- $\quad$ Disminución de las condiciones de trabajo y disminución del gasto en prevención. En relación con la dualidad en la protección del trabajador, afirmamos que dada la finalidad principal de la subcontratación (reducción de costes empresariales y obtención de mayor beneficio a través de la descentralización productiva) a medida que se reproduce la subcontratación las condiciones de trabajo y seguridad en las que los trabajadores de las empresas auxiliares realizan su tarea sean cada vez peores.

- $\quad$ Precariedad en las relaciones laborales, esto así porque el mecanismo contractual mayormente utilizado por las empresas contratistas y subcontratistas utilizan para la incorporación de sus trabajadores es la contratación temporal, dado que la finalidad de la actividad es limitada en el tiempo. Los riesgos que se derivan de las modalidades temporales de contratación se sumarán a los propios de las contratas y subcontratas.

En definitiva, factores de la relación laboral tales como la reducción de la seguridad, la estabilidad, la igualdad y la debilidad sindical que inciden significativamente en un nivel menor de protección de la seguridad y salud de los trabajadores afectados por procesos de descentralización productiva como éste ${ }^{303}$, lo cual se refleja en el mayor número de accidentes de trabajo.

Esta modalidad de contratación -nacida en el boom del modelo neoliberal, en la década de los 90- fue vendida como la panacea para la recomposición salarial y para tener la posibilidad de elegir la empresa que más convenía a "los intereses de los trabajadores". Pero, en realidad, la subcontratación y otras nuevas formas de relación entre nuevas empresas y trabajadores han logrado imponer, tanto en la Unión Europea como más allá, un modelo de la desigualdad, de fraude laboral.

\section{LA REGULACIÓN DEL FENÓMENO DEL TRABAJO EN RÉGIMEN DE SUBCONTRATA- CIÓN: UNA ASIGNATURA PENDIENTE DE LA OIT}

Destacamos la carencia de una norma internacional de la OIT en esta materia, pues, como se profundizará más adelante en este apartado, tras diversas discusiones de la Conferencia Internacional del Trabajo a finales de la década de los 90 fue imposible lograr un acuerdo en diversos frentes tanto para la aprobación de una Recomendación como de un Convenio. Pero eso no significa que la OIT no haya dictado normas o recomendaciones que pudieran ser aplicables a fenómenos de

${ }^{303}$ CRUZ VILLALÓN, J. Outsourcing. Contratas y subcontratas. En: ponencia temática del X Congreso de Derecho del Trabajo y la Seguridad Social. Zaragoza, 1999. P. 33. 
subcontratación o tercerización y a la protección de los trabajadores en este ámbito. Vayamos por orden cronológico.

En primer lugar, apareció el Convenio $\mathrm{n}^{\mathrm{o}} 155$ de la OIT de 22 de junio de $1981^{304}$ sobre seguridad y salud de los trabajadores y medio ambiente de trabajo, ubicado dentro del objetivo principal de la OIT de búsqueda del bienestar integral del trabajador, en todos sus ámbitos. Se reconoce en este Convenio la incidencia en la seguridad y salud de los trabajadores implicados en una de estas formas de organización de la actividad empresarial, constituyendo un importante riesgo a proteger para el cumplimiento del objetivo principal mencionado.

Así, el art. 17 establecía como medida preventiva, que "siempre que dos o más empresas desarrollen simultáneamente actividades en un mismo lugar de trabajo, tendrán el deber de colaborar en la aplicación de las medidas previstas en el presente convenio".

Se trata de un planteamiento muy amplio de la concurrencia empresarial física, con independencia de la relación que pueda existir entre ellas, abarcando todos los supuestos en los que se dé la simultánea presencia en un mismo medio de trabajadores de una pluralidad de empresas. No se refería expresamente a la contratación y subcontratación pero, dada la extensión del precepto, estos fenómenos quedarían incluidos.

Asimismo, es un planteamiento poco concreto, ya que no se especifica esa obligación empresarial de colaboración, sino simplemente se establece como un deber esencial, básico, de garantizar la protección de los trabajadores en los supuestos de concurrencia locacional, debiendo encargarse de su desarrollo las legislaciones nacionales.

En este mismo Convenio se ofrece la definición de "lugar de trabajo" a los efectos de comprensión del texto, así el art. 3.c) en conexión con su propio apartado d) afirmaba que lugar de trabajo son "todos los sitios donde los trabajadores deben permanecer o adonde tienen que acudir por razón de su trabajo y que se hallan bajo el control directo o indirecto del empleador", alcanzando cualquier lugar en el que, por razón de trabajo, se solicite la presencia del trabajador, independientemente del tiempo de permanencia en el mismo pero, eso sí, siempre que el empresario pueda controlar el desarrollo de su actividad directa o indirectamente.

Algún autor ha destacado que en el Convenio no se especifica lo que debe entenderse por control inmediato o mediato del empresario sobre estos lugares dónde el trabajador es desplazado, generando un problema en orden a los límites de la responsabilidad empresarial y, por tanto de las obligaciones del empresario ${ }^{305}$.

En segundo lugar, la Recomendación $\mathrm{n}^{\mathrm{o}} 164$ sobre seguridad y salud de los trabajadores complementa el Convenio $\mathrm{n}^{\circ} 155$, estableciendo una regulación más detallada en cuanto al deber de colaboración empresarial.

${ }^{304}$ Ratificado por Brasil el 19 de mayo de 1992 y por España el 11 de septiembre de 1985.

${ }^{305}$ MiñarroYanini, M. Op. cit, p. 522. 
En primer término, el art. 11, especifica el art. 17 del Convenio en los siguientes términos: "cuando dos o más empresas desarrollen simultáneamente actividades en un mismo lugar de trabajo, deberían colaborar en la aplicación de las medidas relativas a la seguridad y salud de los trabajadores y el medio ambiente de trabajo, sin perjuicio de la responsabilidad de cada empresa por la salud y la seguridad de sus propios trabajadores. En casos apropiados, la autoridad o autoridades competentes deberian prescribir las modalidades generales de tal colaboración".

Este artículo sigue siendo un precepto demasiado amplio al tomar en consideración, al igual que el Convenio, la pluralidad de empresas en un mismo lugar de trabajo como factor determinación del deber de colaboración, sin atender al tipo de vínculo entre ellas, lo que vuelve a dar lugar a las inclusión de las contratas y subcontratas en el reconocimiento de dicha obligación.

Sin embargo, debemos destacar que con carácter diferenciador respecto al Convenio se añade que la colaboración que debiera existir no debe afectar a la responsabilidad, de hecho se mantiene que, en materia de prevención de riesgos laborales, recae sobre cada una de las empresas respecto de sus propios trabajadores.

$\mathrm{Y}$, asimismo, la referencia a la intervención de las autoridades competentes tampoco aparecía en el Convenio, aunque dada la amplitud de este art. 11 no se especifica cuando debe proceder esta actuación, esto es, cuando es apropiado o no la intervención y en qué consistirán las "modalidades generales" de tal colaboración prescritas por la autoridad.

En segundo término, el art. 16 de la Recomendación se ocupa de este deber de colaboración interempresarial en casos de concurrencia física, y establece reglas generales para su cumplimiento. Reza así: "el objetivo de las disposiciones adoptadas en virtud del artículo 17 del Convenio debería ser garantizar que los trabajadores:

a) Velen, dentro de límites razonables, por su propia seguridad y por la de otras personas

a quienes puedan afectar sus actos $u$ omisiones en el trabajo;

b) Cumplan las instrucciones dadas para garantizar su propia seguridad y salud, así

como las de otras personas, y observen los procedimientos de seguridad e higiene;

c) Utilicen correctamente los dispositivos de seguridad y el equipo de protección y no los hagan inoperantes;

d) Informen inmediatamente a su superior jerárquico directo de cualquier situación que, a su juicio, pueda entrañar un riesgo que ellos mismos no puedan remediar;

e) Informen acerca de todo accidente o daño para la salud que sobrevenga durante el trabajo o en relación a éste". 
Una de los cambios significativos con respecto al Convenio es que las medidas establecidas en el anterior artículo de la Recomendación van dirigidas a los propios trabajadores, alusión que hasta el momento no había aparecido en la normativa de la OIT. Pese al todavía carácter genérico del deber u obligación de colaboración interempresarial, con este último precepto se dibujan ya los perfiles del mismo, dando pautas relativas a la información y formación global, que deben conocer todos los trabajadores que coinciden en el mismo lugar de trabajo, de lo que se deduce el conocimiento de los riesgos del mismo y de las medidas de protección aplicables.

Pero al margen de estas dos disposiciones no ha sido posible el tratamiento unitario del fenómeno de la subcontratación por la OIT. La primera discusión sobre el asunto del trabajo en régimen de subcontratación tuvo lugar en la 85. ${ }^{a}$ reunión (1997) de la Conferencia Internacional del Trabajo. A raíz de dicha discusión, y de conformidad con el artículo 39 del Reglamento de la Conferencia, la Oficina Internacional del Trabajo preparó y envió a los gobiernos de los Estados Miembros un informe en el que figuraban un proyecto de convenio y un proyecto de recomendación sobre el trabajo en régimen de subcontratación, basados en las conclusiones que la Conferencia adoptó en su 85. ${ }^{a}$ reunión.

En realidad, el proyecto de Convenio contemplaba tres formas de trabajo en régimen de subcontratación: 1) una relación bilateral directa entre una empresa usuaria y un trabajador, sin que existiera un contrato de trabajo; 2) una relación trilateral entre una empresa usuaria y un trabajador puesto a disposición por un subcontratista no especificándose si éste es el empleador o si hay un contrato de trabajo entre ellos; y 3) una relación trilateral en la que el subcontratista es sustituido por un intermediario con el que el trabajador no está vinculado por un contrato de trabajo. En los tres casos, el trabajador presta sus servicios en condiciones de dependencia o subordinación efectivas respecto a la empresa usuaria.

Se invitó a los gobiernos a que enviaran las enmiendas u observaciones que desearan formular o a que comunicaran a la Oficina, si consideraban que los textos propuestos constituían una base apropiada de discusión para la 86. ${ }^{a}$ reunión (1998), con fecha límite el 30 de noviembre de 1997. E igualmente, de conformidad con el párrafo 6 del artículo 39 del Reglamento de la Conferencia, se pidió a los gobiernos que, antes de dar forma definitiva a sus respuestas, consultaran a las organizaciones más representativas de empleadores y de trabajadores y que indicasen cuáles eran las organizaciones consultadas.

El Gobierno de Brasil emitió respuesta, elaborada en consulta con las organizaciones de empleadores y trabajadores, tal y como había sugerido la OIT $^{306}$.

${ }^{306}$ Los gobiernos de los 16 Estados Miembros que se citan a continuación señalaron que sus respuestas habían sido elaboradas en consulta con las organizaciones de empleadores y de trabajadores: Brasil, Canadá, República Checa, Chipre, Dinamarca, Finlandia, Hungría, Kenya, Mauricio, Noruega, Seychelles, Singapur, Suecia, Suiza, Trinidad y Tabago y Zambia. 
A nivel general, se destacaba la conveniencia de adoptar una recomendación que regulara el trabajo en régimen de subcontratación en lugar de un convenio, dada la complejidad del tema, que incluía situaciones muy divergentes y diferencias desde el punto de vista técnico y jurídico entre los diversos Estados Miembros. Consideraba el Estado brasileño que una recomendación aportaría mayor claridad y proporcionaría directrices generales respecto de las diversas repercusiones que entraña el trabajo en régimen de subcontratación, señalándose que el texto propuesto, una vez enmendado -por ejemplo en cuanto a la controvertida definición del trabajo en régimen de subcontratación-, constituiría una base válida para su discusión en la próxima reunión de la Conferencia. En general, las definiciones propuestas, concluía el Gobierno, eran sustancialmente ambiguas y traducían la dificultad de establecer inequívocamente una definición del concepto de acuerdo de trabajo contractual, que revistiera formas diferentes de un Estado Miembro a otro.

Por su parte, laConfederación Nacional de la Industria en Brasil (CNI), de una manera más rotunda manifestaba que la adopción de un convenio para regular la subcontratación a nivel internacional era totalmente improcedente al imponer rigideces a los mercados de trabajo, poner en peligro los niveles de empleo y, por consiguiente, consecuencias socioeconómicas negativas, en especial en los países en desarrollo. Para esta asociación empresarial, dada la complejidad y diversidad del trabajo en régimen de subcontratación, sólo sería posible adoptar conclusiones y directrices generales, concluyendo que el texto de Convenio propuesto invadía el ámbito de las relaciones comerciales legítimas, que no entraban dentro del mandato de la OIT.

La Confederación Nacional del Comercio de Brasil (CNC), indicaba que los instrumentos que tenían por objetivo regular las condiciones de trabajo en situaciones específicas como esta no deberían revestir la forma de normas internacionales, reiterando la inflexibilidad y falta de realidad de la propuesta, que en sí representaría en su opinión un obstáculo para el recurso al trabajo en régimen de subcontratación.

En último lugar, la Central Única de Trabajadores (CUT) consideraba que el sistema de trabajo en subcontratación debería ser aceptado en calidad de régimen jurídico de excepción, y su práctica debería aceptarse únicamente a personas jurídicas. Según este sindicato no era aceptable incluir en la definición de «empresa usuaria» e «intermediario» a las personas físicas, insistiendo en que las normas del trabajo deberían favorecer el establecimiento de relaciones directas entre el trabajador y la empresa usuaria y permitir, sólo en forma excepcional, la actuación de intermediarios o de agentes jurídicos secundarios.

El Gobierno de España, por su parte, comenzaba sus consideraciones sobre el proyecto de convenio remitiéndose a la normativa interna, en la que el contratista responde de la realización de una obra o de la prestación de un servicio; el objeto del contrato es el resultado del trabajo, por lo que en él no se hace referencia a los trabajadores a título individual. Destacando que la definición del texto propuesto por 
la OIT, en lugar de centrarse en la dependencia y la subordinación, debería definir el trabajo en régimen de subcontratación como aquel que se realiza con intervención de uno o varios de los elementos que caracterizan la relación laboral; esto así, porque según el Estado español el problema radicaba en que el proyecto de convenio y el proyecto de recomendación crean de hecho una tercera categoría de trabajadores, independientemente de que figuren o no las palabras «análogas a las». En relación con otro problema terminológico que se planteaba se inclinaba por referirse sea en forma directa, sea en forma indirecta a los contratos de empleo únicamente utilizándose el término «contrato de trabajo». Sin perjuicio de las observaciones sobre algunas disposiciones específicas, la orientación general de los proyectos de instrumentos sobre trabajo en régimen de subcontratación no planteaba problemas internos para el sistema español de trabajo y seguridad social dado que, en España, a los trabajadores en régimen de subcontratación no sólo se les trata conforme a su situación particular, sino que también disfrutan de un nivel de protección similar al de los demás trabajadores.

La Oficina Internacional del Trabajo resumía su punto de vista, tras la recepción de todos los documentos, indicando que mientras que las organizaciones de empleadores consideran que en la primera discusión no se habían producido resultados satisfactorios, y que no era posible lograr instrumentos aceptables, las organizaciones de trabajadores mantenían la importancia de que se adoptara un convenio completado por una recomendación; es decir fuerte tendencia ideológica en las conclusiones de ambos interlocutores sociales. Y, por su parte, varios gobiernos habían indicado en sus observaciones generales que los textos adoptados en 1997 constituían una base adecuada para la discusión en 1998. Si bien es cierto, ponía de manifiesto cómo de los diversos trabajos y discusiones en el seno de las reuniones en el seno de la OIT se había revelado que los mandantes de la OIT, a través de sus Estados miembros, interpretaban y entendían de diferente manera varias e importantes cuestiones de naturaleza sustantiva tales como la definición del «trabajo en régimen de subcontratación», el alcance de los instrumentos propuestos y la terminología que había de utilizarse; por ello abogaba por seguir trabajando y armonizar los diversos conceptos y resolver las controversias relativas a la definición del trabajo en régimen de subcontratación.

No hubo después de este serio intento de convenio, salvo error u omisión por mi parte, una propuesta sincera de reglamentar la subcontratación del trabajo. Quizás las fuertes críticas de distintos países intervinientes hicieron desistir al organismo internacional.

\section{LA EVOLUCIÓN DE LA REgULACIÓN DE LA SUBCONTRATACIÓN EN AMBOS PAÍSES}

La carencia de una regulación normativa detallada, exhaustiva y sin ambigüedades ha generado en la realidad del trabajo en Brasil durante los siglos XX y 
XXI situaciones conflictivas que detallaremos más adelante. En España, la situación también ha sido definida a través de diferentes golpes de efecto que desarrollaremos en el mismo hilo cronológico.

Para entender el panorama actual debemos recurrir a cuáles son los parámetros legales y jurisprudenciales existentes en la actualidad en Brasil para la configuración de la figura de la subcontratación o tercerización, así como en un epígrafe posterior, el análisis del Proyecto de Ley que se encuentra encima de la mesa desde el año 2004 y que cambiaría el panorama actual, PL 4330/2004, no exento de polémica.

En primer lugar, el arte. 4 de la Ley de Introducción al Código Civil ${ }^{307}$ establece que cuando la ley no diga nada, el juez decidirá el litigio de conformidad con la analogía, las costumbres y los principios generales del derecho. Dada la falta de una legislación de tutela del tema en cuestión, es necesario buscar la solución en la interpretación sistemática del ordenamiento jurídico, en particular en los principios contenidos en la Constitución y en la Compilación de las Leyes de Trabajo brasileñas (en adelante, CLT).

Los principios son considerados como el marco legal, cuyo objetivo es facilitar la aplicación de las normas en casos concretos. Ellos tienen una gran relevancia en el sistema jurídico de Brasil, ya que son considerados como una guía y, en este sentido, no difiere en exceso del sistema jurídico español. El artículo 8 del CLT establece una función de los principios esenciales ante un vacío legal, disponiendo que las autoridades administrativas y los Tribunales de Trabajo, en ausencia de disposiciones legales o contractuales decidirán en base a la analogía, la equidad y otros principios y normas del derecho, sobre todo de derecho de acuerdo con los usos y derecho comparado, pero siempre sin ningún interés de clase en particular o prevalencia del interés público. Se establece asimismo, el derecho consuetudinario como fuente subsidiaria del derecho del trabajo, en el mismo sentido que el art. 3.1. d) del Real Decreto Legislativo 1/1995, de 24 de marzo, por el que se aprueba el Texto refundido de la Ley del Estatuto de los Trabajadores español (en adelante, ET).

Los principios propiamente laborales, y fundamentales, en ambos sistemas de derecho son los denominados principios protectores, esto es, pro operario, norma más favorable y condición más beneficiosa, los tres con el objeto de equilibrar las relaciones entre capital y trabajo, que por origen son desiguales. Con respecto al último de los principios enunciados, el de condición más favorable destacamos el art. 10 CLT que especifica que: "cualquier cambio en la estructura legal de la empresa no afectará a los derechos adquiridos por los trabajadores"; y, este mismo razonamiento, se reitera en el 468 del mismo CLT que dispone que en los contratos individuales de trabajo, sólo se permite cambiar las condiciones inicialmente pactadas de mutuo acuerdo, siempre y cuando no se produzcan, directa o indirectamente, daño al empleado, bajo pena de nulidad de la variación adoptada.

${ }^{307}$ Ley n$^{\mathrm{o}} 10.406$, de 10 enero 2002. 
Pero también es necesario destacar, en el sistema brasileño, el principio de la primacía de la realidad que prevé, en el caso de discordancia entre la realidad y los documentos de hecho o de los contratos existentes, la prevalencia de la realidad sobre la forma, con base en la verdad real, porque la realidad de los hechos no es objeto de ninguna manipulación por la voluntad humana y los documentos no pueden expresar con precisión la voluntad de las partes. Y, este principio ha sido inspirador en la solución de conflictos en la subcontratación.

La externalización de las estructuras empresariales en Brasil no se hace patente hasta los años 70, por eso cuando se redacta el CLT en 1943, el fenómeno no mereció una atención especial.

Las primeras normas en torno a la subcontratación se producen en el ámbito público, eso es lo que sucedió con el Decreto-Ley n ${ }^{\circ}$ 200/67 (art. 10) y la Ley $\mathrm{n}^{0} 5.645 / 70^{308}$, especifica qué servicios públicos podrían ser subcontratados, refiriéndose a las actividades relacionadas con el transporte, conservación, custodia, funcionamiento de ascensores, limpieza y otros similares.

Estas normas respondieron a un cambio en el escenario público, puesto que el propio Estado había adoptado la subcontratación como parte de la descentralización administrativa y fueron seguidas de otras, así se crearon reglas específicas adicionales para la contratación externa, en el marco de empresas de trabajo temporales (Ley 6.019/74) y en los servicios de monitoreo de banco (Ley 7.102/83).

El 9 de diciembre 1985 se publicó la Doctrina del Tribunal Superior de Trabajo ${ }^{\circ} 239$ quién declaraba la ilegalidad de la cesión de trabajadores en el sector bancario, concretamente referida al traspaso de trabajadores entre empresas pertenecientes al mismo grupo de empresas bancario. La recopilación o Suma fue editada porque era necesario frenar el fraude que se estaba produciendo en el sector ${ }^{309}$.

$\mathrm{Y}$ en este contexto de desorden y la inseguridad jurídica causada por las distintas normas, el Tribunal Superior del Trabajo vuelve a editar la doctrina consolidada a través de la Suma ${ }^{\circ} 256$ en 1986, para guiar las decisiones sobre el asunto, destacándose que, salvo en los casos de trabajo temporal y el servicio de vigilancia previstos en las Leyes $\mathrm{n}^{\circ} 6019$ y n $^{\circ} 7102$, era ilegal contratar a trabajadores a través de una empresa intermediaria, que realizan el trabajo directamente con el prestatario de los servicios.

La Ley $n^{0} 8.863 / 94$ prorrogó la hipótesis de la externalización para los sectores de la vigilancia pública o privada, no sólo referido a empresas sino también a personas físicas.

De tal manera, que con la legislación brasileña en la mano en el ámbito privado, sólo estos dos tipos de externalización -a través de empresas de trabajo tem-

${ }^{308}$ DELGADO, M. Curso de Derecho del trabajo del curso. Sao Paulo: LTr, 2002. p. 418419.

${ }^{309}$ En este sentido, MARTINS Sergio Pinto. La subcontratación y la legislación laboral . $3^{\text {a }}$ ed. Sao Paulo:Malheiros, 1997. p. 14. 
poral y el sector de la vigilancia o seguridad, se encontraban permitidos por la ley.

En España, Ley 8/1980, de 10 de marzo, del Estatuto de los Trabajadores mantenía casi la misma configuración que el actual ET de 1995 permitiendo la subcontratación en su art. 42, ya derogado, entre empresas, para todo tipo de sectores y relativa a la denominada actividad inherente de la empresa contratante. Sin embargo, en el art. 43 ET prohibía e ilegalizaba toda cesión de trabajadores o intermediación laboral que no fuera pública, esto es a través de los servicios de empleo públicos. Las Empresas de Trabajo Temporal (ETT) se encontraban prohibidas en nuestra legislación laboral hasta 1993, pero con la Ley 14/1994 de 1 de junio obtienen una regulación completa y se autoriza la intermediación laboral -la cesión de mano de obra- a través de ellas; es importante tener en cuenta que esta norma, todavía vigente, establece unos estrictos requisitos para la constitución de $\mathrm{ETTs}^{310}$, y la responsabilidad de ésta en materia de salario y seguridad social de los trabajadores a su cargo y formativas -la ETT está obligada a destinar anualmente al menos un $1 \%$ de la masa salarial de los trabajadores contratados para ser cedidos y, por tanto, a ella le corresponde formar al trabajado-. La empresa contratante, denominada en este caso, empresa usuaria, tendrá una responsabilidad subsidiaria en materia de salario y seguridad social, y sólo solidaria si se han incumplido los límites de la cesión.

En Brasil, la ley 8.949/94, de 9 diciembre de 1994 introdujo el párrafo único del art. 442 CLT, fomentando la externalización a través de cooperativas, al afirmar que independientemente de la rama de actividad de la sociedad cooperativa, no existe una relación laboral entre ella y sus miembros, o entre éstos y los tomadores de ese servicio.

Esta modificación legal abrió posibilidades de fraude, al permitir la cesión de mano de obra sin el marco legal de la empresa temporal constituida para ello, reflejándose en el aumento de las demandas laborales, con pronunciamientos judiciales contradictorios, generando una singular inseguridad jurídica.

La doctrina consolidada del Tribunal Superior de Trabajo brasileño de 1994, a través de la Suma n 331 trató de aclarar el contrapunto entre ofertas lícitas e ilícitas y de externalización con cuatro casos, excepcionales, en los que era posible y legal la externalización, así, el trabajo temporal para cubrir necesidades transitorias - para reemplazo de trabajadores regulares y permanentes de la empresa o para una necesidad extraordinaria y secundaria de la empresa-, vigilancia, servicios de mantenimiento y limpieza, y servicios especializados relacionados con las actividades accesorias o secundarias del servicio del prestatario.

\footnotetext{
${ }^{310}$ En la actualidad, deben cumplir los siguientes requisitos: una autorización administrativa para su constitución; la dedicación exclusiva de la empresa a tal actividad; la carencia de obligaciones pendientes de carácter fiscal o de Seguridad social por parte de la empresa (o sociedad o socios); el establecimiento de una garantía financiera a disposición de la autoridad laboral a la que corresponda conceder la autorización administrativa (para asegurarse el cumplimiento de las obligaciones salariales y de seguridad social de la futura ETT).
} 
La empresa que realiza servicios especializados, a saber, la vigilancia, mantenimiento y limpieza y relacionados con la actividad a través de debe realmente se especializa en ese tipo de servicio, y debe tener una formación específica. Esto significa que no puede ser una simple contratación de mano de obra calificada, debe ser especializado.

La ausencia de subordinación jurídica (directa) con el servicio asegurado era una de las condiciones para la legalidad de la contratación externa. Los trabajadores tercerizados debían mantener esos vínculos con el proveedor de servicios, y no con el prestatario. Si se queda caracterizada la subordinación legal se establecía la relación de trabajo y con ello el cumplimiento de todas las normas laborales.

Según Paulo Moraes la Suma 331 incidía en la necesidad de que los servicios $-\mathrm{y}$ los trabajadores- fueran especializados precisamente para evitar el simple suministro de mano de obra calificada, afirmando que de ello se deduce que el prestador de servicios debe ser una empresa que se especializa en ese tipo de servicio, que tenga una capacitación y organización para llevar a cabo el servicio que se le propone y que ese es precisamente el objeto de la concesión ${ }^{311}$.

La legalización de la externalización en los servicios de telefonía vino en Brasil de la mano de la Ley 9.472/97, de 16 julio 1997 y en las empresas de prestación de servicios públicos, en la forma definida en la Ley 8.987/95.

El Ministerio de Trabajo y Empleo brasileño, teniendo en cuenta la necesidad de estandarizar el procedimiento de control del trabajo en el ámbito de la tercerización, máxime después de la Sentencia $n^{0} 331$, emitió la Instrucción normativa $\mathrm{n}^{\mathrm{o}} 3$ agosto de 1997, que prevé la supervisión del trabajo en las empresas con el fin de prevenir el fraude en la contratación externa. En dicha instrucción se hacía hincapié en que para la prestación de servicios a terceros era necesaria la válida constitución de la empresa y la especialización de la misma, pues la finalidad de la externalización era lograr una especialización y eficiencia en ese servicio, que no se correspondía con la actividad básica de la empresa que externaliza pero sí era actividad habitual de la empresa de servicios.

Se determinó además que el prestatario y el contratista debían desarrollar diferentes actividades y tener diferentes efectos en el mercado, así como diferenciar a sus empleados quienes debían depender técnica y disciplinariamente de la empresa para la que fueron contratados.

Dada la inseguridad jurídica creada por la carencia de una norma omnicomprensiva del fenómeno de la subcontratación tanto en el ámbito público como en el privado se sucedieron los proyectos de Ley, con objeto de modificar la Ley 8.666/93, para regular la subcontratación de servicios en el sector público, tales

\footnotetext{
${ }^{311}$ Moraes, Paulo Almeida de Douglas. Contratación indirecta y servicios de outsourcing en la actividad principal de las personas jurídicas: la capacidad jurídica y la conveniencia social. . 2003 Disponible en:<www.mte.gov.br / policía / ms / ms_monografia.pdf > . Consultado el 16 de julio de 2014. P. 101.
} 
como los proyectos 1.292/1995, 1.587/2003, 6.420/2005 y 6.894/2006.

En el caso del sector privado, se destaca el diseño del Proyecto de Ley $5.439 / 2005$, que prohíbe el uso de mano de obra interpuesta. Este proyecto fue presentado por la Sra. Ann Bridges, con la intención de añadir al Código de Trabajo brasileño un nuevo art. 442, que manifestara que "Salvo en los casos de trabajo temporal -a través de empresas de trabajo temporal-, la vigilancia, los servicios de mantenimiento y la limpieza, se prohibe la contratación de trabajadores a través de una empresa intermediaria", añadiéndose además que en las obligaciones laborales y de seguridad social para con el trabajador regiría la responsabilidad solidaria entre la empresa prestataria y la prestadora, siempre que haya sido así declarado por un procedimiento judicial de ejecución.

Según la propuesta, la prohibición podría contribuir eficazmente a reducir la precariedad laboral y el fraude ahora regulada únicamente por la Sentencia nº331 del Tribunal Superior del Trabajo.

Sin embargo, en junio de 2005, el proyecto se adjuntó a un Proyecto previo, el PL 4.330/2004, cuyo autor es el Sr. Sandro Mabel, que establece a, grandes rasgos, la ausencia total de relación laboral entre el contratista y los empleados del contratista y la aplicación de las normas de derecho civil para determinación de las relaciones entre las sociedades. Su contenido y las polémicas en torno a él serán analizados en otro epígrafe.

\section{El concepto de subcontratación en Brasil y España. Los elementos CARACTERÍSTICOS}

La contratación y subcontratación de obras o servicios son expresión de la libertad de empresa que reconoce la Constitución Española en su artículo 38 y la Constitución brasileña en su art. 170 .

La subcontratación en Brasil, denominada tercerización, no encuentra desarrollo legal completo y exhaustivo, pero sí se sienta el siguiente principio básico: la contratación de trabajadores a través de una empresa intermediaria es ilegal, dando lugar a un vínculo jurídico laboral entre el trabajador y el receptor o beneficiario de los servicios, esto es la empresa principal; esta regla general admite excepción, esto es, que se trate de trabajo temporal, conforme todo ello a la Ley $\mathrm{n}^{\circ} 6019$, de 3 de enero de 1974 y los casos que, a continuación, veremos. En este postulado o fundamento jurídico, se está prohibiendo directamente la denominada "cesión ilegal de trabajadores" que se realice fuera de un trabajo típicamente temporal, en el mismo sentido que en España el art. 43 del ET prohíbe la cesión de trabajadores al margen del marco de las denominadas Empresas de Trabajo Temporal.

La Suma o Recopilatorio de la doctrina consolidada brasileña $\mathrm{n}^{\circ} 331$, del Tribunal Superior de Trabajo (TST) del 4 de enero de 1994, resume en los siguientes postulados la única forma de legalidad de esta descentralización productiva en el 
sector privado, a saber ${ }^{312}$ :

En primer lugar, debe existir una relación entre dos empresas, ambas con capacidad económica, pues es imprescindible que la empresa contratada -la no principal o empresas de servicios- se encuentre en condiciones de asumir los riesgos derivados del negocio jurídico - mercantil- incluyendo las obligaciones para con los trabajadores. Asimismo, la dirección de la actividad que se externaliza debe ser a cargo de la empresa no principal, la empresa de servicios, teniendo por tanto los trabajadores el vínculo jurídico laboral con ella y nunca al contario, con la empresa contratante.

En segundo lugar, una limitación en cuanto al tipo de prestación de servicios, esto es, que los servicios que son contratados por la empresa principal sean servicios especializados, tales como la vigilancia o seguridad (Ley $\mathrm{N}^{\circ} 7.102$, de 20.06.1983.), la higiene o limpieza, el mantenimiento, servicios de alimentación o restauración, y la asistencia técnica, entre otros. En este sentido, al tratarse de actividades especializadas el personal que los preste debe ser también especializado, ya que la utilización de personal no especializado es un claro indicio de ilicitud o ilegalidad de la tercerización. Tal y como hemos visto éste ha sido el resultado de la evolución normativa y jurisprudencial del país.

En tercer lugar, y en conexión con el anterior, con carácter general, los servicios que sean externalizados o descentralizados por parte de la empresa principal no deben consistir en la colaboración con la actividad principal de la empresa sino, al contrario, tratarse de las denominadas actividades-medio o actividades secundarias que no contribuyen al objeto social de la empresa principal. Detengámonos aquí, ya la elaboración de esta nota característica es fundamental para entender la conceptualización de la subcontratación en Brasil.

El problema más común en la caracterización de la licitud o ilicitud de la subcontratación es la distinción entre actividad-medio (legal) y actividad-final (ilegal).

La denominada actividad fin está conectada con la finalidad de la empresa, el objetivo de la producción empresarial o prestación de servicios. Es una actividad indispensable, sin la cual la propia empresa pierde su utilidad. Podemos recurrir al art. 581.§.2 de la CLT que nos trae una buena definición de la actividad fin: "(...) se entiende por la actividad principal que caracteriza a la unidad de producto, operación o meta final, cuyo logro para todas las demás actividades convergen exclusivamente bajo la conexión funcional'. Por tanto, la actividad fin viene generalmente descrita en el objeto del contrato social de la empresa; sin embargo, debido a la diversificación de los negocios y la relevancia del mercado es posible que el contrato social esté reñida con la actividad principal de hecho, por lo que algún autor

${ }^{312}$ Un resumen o esquematización de las notas características puede encontrarse en VARGAS, Luiz Alberto de; SILVEIRA, AlmirGoulart da. Terceirização e o enunciado 331 DO TST. Breves considerações. Disponible en: http://lavargas.sites.uol.com.br/terceira.html. 
ha considerado que si en el contrato social existen una multitud de objetos sociales, nos encontramos ante una clara evidencia de mera intermediación ilícita o tráfico de mano de obra calificada ${ }^{313}$. Y es ahí cuando para el análisis de la actividad fin, se debe utilizar el principio de la primacía de la realidad, impidiendo fraudes en el marco normativo de protección, de conformidad con el art. 9 de la CLT ${ }^{314}$.

En la práctica, por tanto, la verificación de la actividad principal de la empresa se realiza a través del análisis de su contrato social; de tal manera que si el trabajador lleva a cabo alguna actividad que contribuye a la producción de objetos sociales, no está proporcionando un servicio externalizado y puede derivarse una relación de trabajo directamente con el contratante y no con la empresa de servicios, según lo determinado por los Precedentes-Suma- no 331 del Tribunal Superior del Trabajo. Cuando se trata de la actividad principal, la subcontratación es ilegal.

Por su parte, la actividad-medio puede ser definida, por contraposición a la actividad fin como aquella que no coincide con los principales propósitos de la empresa, añadiéndole por ejemplo las notas de actividad secundaria, de apoyo o complementaria ${ }^{315}$.

El trabajo del fiscal, Maurice Correia de $\mathrm{Melo}^{316}$ explica que las actividades intermedias y finales pueden ser comparadas con el cuerpo humano. Algunas partes de nuestro cuerpo son más esenciales que otras. El cerebro, por ejemplo, es esencial, no se puede "subcontratar", pero una persona puede sobrevivir perfectamente sin un dedo o un pedazo de la mano. Para el fiscal, las empresas también tienen actividades que son esenciales, las que definen la empresa y otras actividades que son de apoyo, a continuación, que pueden ser externalizados.

La carencia de una definición legal ha generado cierta inseguridad jurídica, habiendo sido los Tribunales los encargados, en cada caso concreto de señalar sí la actividad era principal o no. Algunos pronunciamientos interesantes se han ofrecido, por ejemplo, en el sector bancario para deslindar ambos conceptos y declarar la cesión legal o ilegal ${ }^{317}$; téngase en cuenta que en caso de cesión ilegal se dará "la

${ }^{313}$ En este sentido, De Oliveirea Ramos, M. citada por Moraes, Paulo Almeida de Douglas. Contratación indirecta y servicios de outsourcing en la actividad principal de las personas jurídicas: la capacidad jurídica y la conveniencia social. 2003 Disponible en: www. mte.gov.br / policía / ms / ms_monografia.pdf. Consultado el 16 julio 2014. P. 100.

${ }^{314} \mathrm{El}$ art. 9 CLT establece que automáticamente se anularán los actos realizados con el fin de distorsionar, evitar o eludir la aplicación de los preceptos contenidos en esta consolidación.

${ }^{315}$ En un sentido similar, se expresa, MARTINS, Sergio Pinto. La Ley de Subcontratación y Trabajo. $9^{a}$ ed. rev. y ampl. Sao Paulo: Atlas 2009. P.128, dando ejemplos en el sector de la limpieza, la automoción o la banca.

${ }^{316}$ Correia de Melo, Maurice. Programa Entrevista Foro, Court TV, salió al aire el 22 de marzo 2010 Disponible en: http://www.youtube.com/watch?v=6eNf09c-Y9w. Consultado 19 julio 2014.

${ }^{317}$ Sobre la cesión ilegal por la externalización de la actividad principal y no de la activi- 
solidaridad entre las empresas demandadas, que se basa en la realización de un acto encaminado a obstaculizar y estafar la aplicación de los preceptos laborales (art. 9 CLT)" "318, y se impone el reconocimiento del contrato de trabajo directamente con el receptor de los servicios -la empresa contratante- ${ }^{319}$. Los Tribunales también se han encargado de manifestar que la tercerización de la mano de obra implica salarios significativamente más bajos para los trabajadores de las empresas de servicios que para los trabajadores de la empresa contratante o receptora de los servicios, señalándose que la "(...) externalización de la mano de obra tiene por objeto unas relaciones sociales flexibles si se utilizan para de manera legal, pero sin embargo, no puede servir como una forma de evadir las normas laborales, lo que agrava la desigualdad social de las categorías profesionales en aras de la contención de costos de mano de obra" $320 \mathrm{y}$, en definitiva, "la contratación de la mano de obra humana a través de una empresa intermediaria no es aceptado en nuestro sistema legal (salvo las disposiciones especiales de la Ley 6.019/74 y 7.102/83)"321.

En el sector de las telecomunicaciones, donde rige la Ley n ${ }^{\circ}$ 9472/97 también han sido frecuentes las discusiones en sede judicial sobre las denominadas "actividades inherentes" y su significado. El art. 94. §. II de la Ley, permite la contratación de empresas de servicios para el desarrollo de actividadesconexas, accesorias o complementarias al servicio". La dudaestablecida se refiere a la tendencia interpretativa que considera "actividadinherente " como actividadfin. La interpretación de la jurisprudencia laboral es que "las actividadesinherentes, accesorias o complementarias" se refiere a actividad-medio ${ }^{322}$.

En último lugar, la responsabilidad subsidiaria de la contratante en caso de incumplimiento de la empresa prestadora de servicios, de las obligaciones con

dad-medio en el sector bancario se alzan estos pronunciamientos: en el año 2002, ROAR -. 804604-93.2001.5.05.5555, Ministro Ponente: IvesGandraMartinsFilho, fecha de la sentencia: 20/08/2002, Subsección II Especializada en la negociación individual, Fecha de publicación: 27/09/2002; y en el 2009, TRT tercera Región -0068200-49.2009.5.03.0062 RO - RO Cuarto Panel -. Relator Des LuizOtávioLinhares Renault - 30/11/2009 p.

${ }^{318}$ TRT tercera Región - Séptima Clase - 02309-2006-136-03-00-0 RO - Relator convocó WilméiaBenevides da Costa - 12/04/2007 p.

${ }^{319}$ TRT $6{ }^{\text {a }}$ Región - Primera Clase - RO - 00.746 hasta 2.009 - 005-06-00-9 - Relator Bartolomé Alves Bezerra - 13/05/2010 $p$.

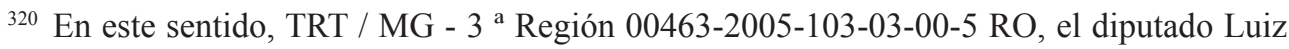
Felipe Vieira de Mello Filho, quinta clase, Publicado 09/07/2005.

${ }^{321}$ Así se expresa, la TRT / MG - $3{ }^{\text {a }}$ Región 00176-2004-088-03-00-6 RO, el representante Paul Costa Roberto Sifuentes, tercera clase, publicado 18/12/2004.

${ }^{322}$ En este sentido, resolvieron, en Proceso No TST-RR-66800-44.2009.5.03.0112. Tribunal Superior del Trabajo. Órgánojuzgador: $5^{\mathrm{a}}$ turma. Relatora: Ministra KátiaMagalhãesArruda. Publicado en DEJT el 14/10/2011; y el proceso No TST-RR-134200-39.2009.5.04.0018 Órgánojuzgador: $2^{\mathrm{a}}$ Turma, Relator: Min. Caputo Bastos. Publicado no DEJT em 16/09/2011. 
los trabajadores, siempre que hayan participado en la relación procesal y también se incluye en la aplicación judicial. Nos estamos refiriendo a que la subcontratación sea legal pero la empresa de servicios no pague los salarios a los trabajadores o no abone los conceptos de seguridad social correspondientes; en caso que la cesión fuera ilegal, la responsabilidad que se generaría para los dos implicados en la relación mercantil -contratante y prestador- sería subsidiaria.

En España se consideran formas lícitas en base al art. 42 ET mientras no contraríen el ordenamiento jurídico, encontrándose los perfiles con la cesión ilegal de mano de obra muy próximos a estas figuras ${ }^{323}$, teniendo en cuenta además que en nuestra legislación tampoco existe una definición del fenómeno de subcontratación. Por ello, la doctrina judicial española ha recurrido a la aplicación de diversos criterios de valoración que no son excluyentes, sino complementarios, y que tienen un valor indicativo u orientador, tales como: la justificación técnica de la contrata, la autonomía de su objeto, la aportación de medios de producción propios (Sentencia del Tribunal Supremo 7-03-1988), el ejercicio de los poderes empresariales por parte de la empresa que presta el servicio (Sentencias del Tribunal Supremo de 12-09-1988, 16-02-1989, 17-01-1991 y 19-01-1994) y la realidad empresarial del contratista, que se pone de manifiesto en relación con datos de carácter económico (capital, patrimonio, solvencia, estructura productiva).

En definitiva, la Sentencia del Tribunal Supremo de 30 de mayo de 2002, que es doctrina consolidada de la Sala de lo social, afirmaba que la línea divisoria entre los supuestos de subcontratación lícita y de pseudocontrata o cesión ilegal de trabajadores bajo falsa apariencia de contrata de obras o servicios ha de ser trazada de acuerdo con la doctrina del empresario efectivo ${ }^{324}$, debiendo ponderarse el desempeño de la posición empresarial no de manera general sino en relación al trabajador concreto que la solicita ${ }^{325}$.

De tal manera que las empresas contratistas que asuman la posición de empresarios o empleadores respecto de sus trabajadores, ejerciendo su poder de dirección y haciendo frente a las responsabilidades propias de su posición se considerarán subcontratación lícita, regulada por el art. 42 ET; por el contrario, los casos de contratas ficticias de obras o servicios que encubren una "mera provisión de mano de obra" constituirán cesión ilegal de trabajadores, prohibida y regulada por el 43 ET, en los siguientes términos en el apartado 2: “(...) se entiende que se incurre en la cesión ilegal de trabajadores contemplada en el presente artículo cuando se produzca alguna de las siguientes circunstancias: que el objeto de los contratos de servicios

${ }^{323}$ Sentencia del Tribunal Supremo 25-10-1999, Sentencia del Tribunal Superior de Justicia de Catalunya de 1-01-2001, Sentencias del Tribunal Supremo 14-03-2006 y 4-03-2008, entre otras.

${ }^{324}$ Sentencias del Tribunal Supremo de 11-07-1986, 1-07-1993, 11-10-1993, 18-03-1994 y 12-12-1997, entre otras.

${ }^{325}$ Sentencias del Tribunal Supremo 12-09-1988 y 19-01-1994. 
entre las empresas se limite a una mera puesta a disposición de los trabajadores de la empresa cedente a la empresa cesionaria, o que la empresa cedente carezca de una actividad o de una organización propia y estable, o no cuente con los medios necesarios para el desarrollo de su actividad, o no ejerza las funciones inherentes a su condición de empresario".

Asimismo, ha sido labor jurisprudencial la delimitación de los requisitos necesarios para la calificación de una empresa como empresa contratista -prestadora de servicios- ${ }^{326}$. Se pueden resumir en los siguientes:

- $\quad$ Disponer de una organización autónoma e independiente, incluyendo todos los medios materiales y personales necesarios (sede, plantilla y titularidad de los medios materiales utilizados).

- $\quad$ Asunción de la organización, el control y la dirección de la actividad, encontrándose los trabajadores sujetos a sus órdenes e instrucciones. - $\quad$ El objeto ha de ser una actividad específica y delimitada, por lo que se ha de poder diferenciar de la propia actividad de la empresa principal.

- $\quad$ Asunción de las responsabilidades y los riesgos de la actividad empresarial.

El último elemento a destacar del fenómeno de la subcontratación en España es la "propia actividad". El art. 42 ET lo incluye como nota caracterizadora de la subcontratación legal, de tal manera que las actividades descentralizadas por una empresa en el marco de este artículo sólo pueden referirse a su propia actividad, concepto interpretado desde el año 1995 y que ha sido objeto de múltiples pronunciamientos.

Los primeros pronunciamientos del Tribunal Supremo en torno a este concepto partían de un concepto estricto, considerando como tal la actividad inherente o absolutamente indispensable para el objeto de la empresa principal ${ }^{327}$; es decir "la propia actividad" de la empresa principal engloba aquellas operaciones o labores que corresponden a su ciclo productivo, en concreto las que son inherentes a la producción de bienes y servicios específicos que se propone prestar ${ }^{328}$ excluyendo las tareas complementarias o no nucleares. Por tanto, no sería propia actividad aquellos

326 Sentencias del Tribunal Supremo 25-10-1999, 21-03-1997, 18-03-1994, 17-02-1993, 17 marzo 1993, 11-10-1993, 15-11-1993.

${ }^{327}$ Entre otras muchas, vid. Sentencias del Tribunal Supremo 18-1-1995, 24-11-1998, 27-102000, 22-11-2002, 18-1-2010, 3-7-2012.

${ }^{328}$ Algunas de los casos planteados que afirman la existencia de "propia actividad" son: Sentencia del Tribunal Supremo 24-11-1998: un servicio de comedor y cafetería en un Colegio Mayor; Sentencia del Tribunal Supremo 3-7-2012: entre empresa de proyectos basados en el uso intensivo de la tecnologías de la información y constructora; Sentencia del Tribunal Supremo 15-4-2010: entre entidad bancaria y empresa de servicios informáticos. 
servicios y obras desconectados de la finalidad productiva y de las actividades normales de la empresa comitente y las actividades complementarias o auxiliares que no absolutamente esenciales ${ }^{329}$.

En definitiva, será el examen de cada supuesto concreto el que revele la existencia de dicha condición ${ }^{330}$.

Como efecto básico de la denominada cesión ilegal se deriva la responsabilidad solidaria de las empresas participantes, sin posibilidad de exclusión alguna. Sin embargo, en materia de subcontratación válida existe una pequeña variación en materia de responsabilidad: la empresa contratante durante el año siguiente a la terminación del servicio responderá de manera solidaria de las obligaciones de naturaleza salarial contraídas durante el encargo por las empresas de servicios o auxiliares intervinientes en la operación (art. 42.2 ET); sin embargo con respecto a las obligaciones en materia de seguridad social existen variaciones: primero, el empresario contratante o principal deberá comprobar que las empresas de servicios con las que se contrata están al corriente del pago de las cuotas de la seguridad social, librándose de responsabilidad solidaria de las deudas que se contraigan durante la vigencia del servicio, una vez expedida la certificación o transcurridos 30 días sin contestación de la Administración, pero manteniendo una responsabilidad subsidiaria de las cuotas a la seguridad social que el contratista tuviera pendientes de pago -no prescritos- a la hora de suscribir el contrato mercantil -arts. 104 y 127 de la Ley General de la Seguridad social-; segundo, la responsabilidad subsidiaria en materia de cuotas de la seguridad social aparecerá cuando la actividad que se haya externalizado no corresponda a la propia actividad.

Si tenemos que realizar una comparativa de elementos básicos nos encontraríamos con que tanto en Brasil como en España son dos empresas legalmente constituidas y con la suficiente solvencia las que pueden realizar servicios externalizados, tanto activa como pasivamente; asimismo, por el lado de los trabajadores, se destaca en ambos países que el vínculo laboral, si la institución es legal y válida, no se genera con la empresa principal sino con la empresa secundaria realizadora del servicios; pero, en tercer lugar se alza la diferencia fundamental pues si en España la descentralización a través de la subcontratación debe referirse a la actividad esencial

${ }^{329}$ A modo de ejemplo, la Sentencia del Tribunal Supremo 28-10-2010 considera que no es propia actividad la desarrollada entre empresa y contratas de labores de vigilancia de edificios, locales y centros de trabajo; y la Sentencia del Tribunal Superior de Justicia de Cataluña 4-4-2003 afirma que tampoco hay propia actividad entre Renfe y la empresa dedicada a la venta de billetes, información al pasajero, limpieza y mantenimiento. En el mismo sentido negativo se expresa la Sentencia del Tribunal Superior de Justicia de Madrid 30-5-2011 que niega la propia actividad entre la actividad de una aerolínea y la empresa que realiza la limpieza de los aviones.

${ }^{330}$ Sentencias del Tribunal Supremo 20 junio de 2005, 22 noviembre de 2002, 27 marzo de 2001, 10 julio de 2000, entre otras. 
de la empresa -concepto de gran desarrollo jurisprudencial como a continuación veremos-, en Brasil sólo sería válida aquella descentralización referida a actividad no principales, actividades medio de las cuales además constan diversos ejemplos -vigilancia, limpieza, mantenimiento, servicios de restauración o asistencia técnica-.

\section{El PROYECTO dE LEY BRASILEÑO 4330/94 BAJO EL PRISMA DE LA LEGISLACIÓN ESPAÑOLA}

El giro radical en la propuesta de ley de subcontratación ha provocado no pocas manifestaciones en su contra, a continuación desarrollamos las últimas, más significativas.

En primer lugar, las movilizaciones sociales de parte de los sindicatos, destacando las diversas acciones del sindicato IndustriaALL en julio de $2013^{331}$, básicamente por tres motivos: a) porque el proyecto de Ley aboga por un mercado laboral más flexible; b) porque debilitaría la relación laboral; c) porque mermaría la fuerza de acción de los sindicatos. Y, en este último aspecto, se destaca que, a pesar de la falta de regulación de la subcontratación y de las dificultades que tienen los sindicatos sectoriales para organizar a los trabajadores precarios, el sindicato mencionado ha logrado algunos acuerdos para limitar el uso de trabajadores subcontratados a nivel de la empresa; por ejemplo, el sindicato de trabajadores de la química en la región de Rio de Janeiro negoció la firma de un código de conducta con la empresa Bayer para limitar el uso de trabajadores precarios, de tal manera que la empresa no puede recurrir a subcontratistas sin consultar al sindicato; también el sindicato de trabajadores metalúrgicos ha conseguido un acuerdo similar con la empresa Mercedes-Benz en la región de Sao Paulo, la dirección y el comité de empresa negocian la tasa de trabajadores subcontratados que se emplearán en las plantas.

En segundo lugar, los presidentes de las Universidades y de los Fiscales de los Tribunales Regionales del Trabajo fueron llamados a dar su opinión en una audiencia pública sobre el Proyecto de Ley, y de este análisis preliminar se publicó una carta abierta firmada por los miembros de Coleprecor, que entre otras consideraciones alcanzó siguiente conclusión en septiembre de $2013^{332}$ :

"Como sabemos los derechos y garantías de los trabajadores subcontratados son claramente inferiores a los de los empleados permanentes, principalmente por los niveles de remuneración y contratación significativamente más modestos, el resultado del proyecto es la profunda y rápida reducción del valor social del trabajo en la vida social y económica de Brasil involucrando potencialmente a millones de personas".

En tercer lugar, la propuesta provocó una reacción inmediata de los Mi-

${ }^{331}$ Información extraída de http://www.industriall-union.org/es/continua-en-brasil-la-luchacontra-la- subcontratacion, consultado 2 julio 2014.

${ }^{332}$ Disponible en el sitio web de Coleprecor: http://coleprecor.wordpress.com/2013/09. 
nistros de la Corte Superior del Trabajo. Diecinueve de los veintiséis miembros de la Corte enviaron un documento al diputado autor del proyecto afirmando que la propuesta provocará un "grave daño social, los derechos sociales, laborales y de seguridad social" en contra de los trabajadores.

Un breve análisis del Proyecto de Ley 4330 permite inferir que en sólo dos párrafos reside el cambio radical de paradigma en las relaciones de trabajo en régimen de subcontratación, una ruptura con la doctrina del trabajo construida por los tribunales durante décadas en aras el establecimiento de límites a la subcontratación y la creación de derechos y garantías para los trabajadores.

El proyecto es breve en su articulado, sólo 19 artículos, y extenso en su justificación. En ella se pone de manifiesto que el origen del mismo se halla en el Proyecto de Ley n ${ }^{\circ} 4302$ de 1998 y en la necesidad de regular un fenómeno expansivo en las últimas décadas, la tercerización; en este sentido, en la justificación del Proyecto se añade que el contenido del mismo supone una garantía para el trabajador y contribuye a la mejora del medio ambiente laboral, para así evitar los fenómenos no deseables que son con frecuencia achacados a la tercerización: la precarización de las relaciones laborales y los altos índices de accidentes de trabajo.

Pasando al contenido sustantivo más polémico del Proyecto en sí -fundamentalmente los artículos relativos al sector privado-, los arts. 1 y 4.2 imponen ya el primer cambio radical: la liberalización de las actividades que pueden ser externalizadas, sin limitación alguna. De tal manera que se podría subcontratar tanto las actividades inherentes de la empresa como las accesorias o complementarias, pero no entrarían dentro del ámbito de aplicación del Proyecto - exclusiones directas, por tanto- la prestación de servicios de naturaleza doméstica y los servicios realizados por las empresas de seguridad (art. 16. II).

Evidentemente esto supone una vuelta de tuerca del sistema brasileño, en el que salvo las excepciones señaladas -seguridad, limpieza, mantenimiento y asistencia técnica- la tercerización a través de contrato de prestación de servicios sólo podría realizarse cuando se tratara de la actividad-medio y no principal de la empresa.

Pero estos artículos suponen también un cambio en el propio concepto de subcontratación que ahora abarcaría cualquier tipo de contrato de prestación de servicios que se realizara entre una persona física o jurídica y una empresa, prestadora de servicios específicos a terceros. En este sentido y, por lo explicado en epígrafes precedentes, el concepto brasileño de subcontratación, en caso de aprobarse el Proyecto, se aproximaría mucho al español, sin entrar en si eso es una buena o mala idea.

Es interesante destacar que el Proyecto reconoce un segundo eslabón en la cadena $-\mathrm{y}$, en este sentido, cabría también un tercero, un cuarto, etc.- de la subcontratación y fija diferentes responsabilidades entre ellos. Así, el art. 2.1 reconoce que la empresa prestadora de servicios puede realizar el trabajo a través de sus propios 
trabajadores - de los que es responsable en virtud de una relación de dependencia y subordinación- o a través de la propia subcontratación de esa actividad encomendada, -no aclara el Proyecto si en todo o en parte- con otra empresa de servicios, incrementando el número de empresas implicadas y, por tanto, en mi opinión, generando mayor complicación de control de las sucesivas cadenas.

Y esto último se agrava por la fijación de diferentes tipos de obligaciones y responsabilidades entre las empresas implicadas, según consta en los arts. 7, 8, 10 y 11, me explico:

Las condiciones de seguridad y salud de los trabajadores son responsabilidad de la empresa contratante, o principal, siempre y cuando los trabajadores estén a su servicio y en sus dependencias o en las que haya designado, liberando de cualquier responsabilidad a la empresa de servicios que es la que realmente ha contratado a los trabajadores (art. 7).

Esta situación difiere significativamente del caso español, en el que en virtud del art. 24 LPRL impera el deber de coordinación de las empresas implicadas en fenómenos interempresariales, pese a que el titular del centro de trabajo donde se desarrolla la actividad al tener una posición preponderante en las relaciones posee también particulares obligaciones respecto de las restantes empresas que operan en el mismo; en este sentido, el párrafo segundo del art. 24 LPRL que las «medidas necesarias» que debe llevar a acabo consisten en informar a las empresas prestadoras de servicio involucradas de los riesgos existentes, propios y generales del lugar de trabajo que puedan afectarles por el desarrollo de sus actividades e informar e instruir sobre las medidas de protección, prevención y emergencia necesarias, en atención a los riesgos. Esta información y formación que reciben las empresas auxiliares deberá trasladarse por ellas mismas a sus propios trabajadores (art. 9.3 RD 171/2004); pero, asimismo, se le impone a la empresa principal o contratante la obligación de comprobar, tanto de manera previa como periódica, la solvencia técnica de la empresa auxiliar, en cuanto al cumplimiento de las normas laborales, de seguridad social y de prevención (rt. 24.3 LPRL en relación con el art. 10.3RD 171/2004).

En segundo lugar, si fuera necesario que el trabajador poseyera una formación específica para la realización del servicio subcontratado, la empresa contratante puede optar por reclamar esa certificación a la empresa de servicios para comprobar la capacidad o formarle ella misma u vez que se haya iniciado ya en su servicio (art. 8). Las interrogantes que surgen respecto a esta disposición son múltiples, ¿no prevalece ninguna de las dos opciones? ¿Qué sucede ante el incumplimiento de la empresa principal de formar al trabajador? ¿No recae sobre la empresa de servicios ningún tipo de coste añadido? Sin respuesta, salvo error u omisión por mi parte, en el Proyecto de Ley.

No existe previsión similar en la normativa española, donde la formación del trabajador es responsabilidad de la empresa contratante -y un derecho del trabajador- y sólo en el caso de la formación específica en materia de riesgos laborales del 
nuevo lugar donde se desempeña el trabajo debe intervenir la empresa contratante o principal (arts. 19 y 24 LPLR).

La empresa principal o contratante tendría una responsabilidad subsidiaria de las obligaciones salariales y de Seguridad social de los trabajadores de la empresa auxiliar relativas al periodo de prestación del servicio, sin perjuicio de la posibilidad de reclamar posteriormente el desembolso, al estilo del solve et repete(art. 10). Y, sin embargo, en caso que la empresa de servicios haya subcontratado la actividad a realizar para el tomador del servicio, con otra empresa-también de servicios- la responsabilidad de la primera empresa de servicios -la que recibe el encargo inicial- con respecto a las mismas obligaciones salariales que debía cumplir la segunda empresa de servicios es solidaria (art. 11). La interpretación conjunta de estos dos preceptos adolece de una incoherencia manifiesta, pues no es posible que la responsabilidad especificada derivada de un mismo fenómeno de descentralización difiera en función de si la empresa es prestadora de servicios o tomadora de los mismos. No se entiende ni se justifica en el Proyecto el porqué de esta divergencia, insisto, sin ningún tipo de coherencia.

Aunque en este aspecto ya nos hemos pronunciado previamente, en España la responsabilidad está configurada, con carácter general, de modo solidario entre las diferentes empresas que intervengan en la cadena de subcontratación, con los límites ya expresados.

Los arts. $4 . \S 1$ y 5 establecen dos interesantes y, en mi opinión, polémicas disposiciones dignas de mención. En primer lugar, se especifica que está prohibida la utilización de los trabajadores por el contratante en actividades distintas de aquellas que fueron objeto del contrato - mercantil, claro está- con la empresa prestadora del servicio. Y, en segundo lugar, se acepta la legalidad del hecho que el trabajador pueda prestar trabajo a través de contratos sucesivos con distintas empresas de servicios para el mismo contratante, de forma consecutiva.

Tal y como están configurados estos dos artículos - con una malísima técnica jurídica-, bajo el prisma de jurista española, se está reconociendo la posibilidad de tráfico ilegal de mano de obra.

La empresa prestadora de servicios, ¿presta un servicio o un trabajador? El Proyecto parece dar la idea de que lo que presta es un trabajador, pues sí se prohíbe la utilización del trabajador por la contratante en otro fin distinto del establecido en el contrato de servicios, se está reconociendo implícitamente que el poder de dirección sobre el trabajador lo ostenta la contratante, encontrándose aquel dentro del ámbito de organización y dirección de ésta.

$\mathrm{Si}$, asimismo, se permite que un trabajador tenga sucesivos vínculos jurídicos, subordinación legal por tanto, de diferentes empresas de servicios pero preste su actividad para la misma contratante consecutivamente y, a su vez, se establezca que no existe vínculo jurídico entre la empresa contratante y el trabajador (según art. $2^{\circ} \S 2$ ), sumándole el hecho de que la contratante le puede aplicar al trabajador 
algunos de los beneficios que sus trabajadores posean (art. $9^{\circ}$ ), se está creando una extraña situación en la que el trabajador es asimilado a los auténticos trabajadores subordinados de la contratante pero se le impide adquirir una condición estable en la empresa donde efectivamente presta servicios -la contratante-, y legalizando, por tanto, su cesión sin un objeto o necesidad temporal real y no permanente.

\section{Conclusiones}

Buena parte de las conclusiones ya han sido vertidas a lo largo del presente texto, pero se pueden resumir como siguen;

El mundo del trabajo afronta grandes y profundas transformaciones, iniciadas en décadas y que nos distancian cada vez más de obtener un empleo estable y permanente. Prevalece la precarización del trabajo, los contratos temporales, la tercerización de los servicios (subcontratación), la degradación de las condiciones de trabajo y la negación de derechos históricamente conquistados.

El importante crecimiento de la tercerización de la mano de obra tiene un efecto positivo para la economía y la competitividad, pero también tiene efectos dañosos para los trabajadores, ya que pierden su vinculación con el verdadero tomador de servicios, reciben salarios menores que los demás trabajadores y peores condiciones de seguridad laboral.

Brasil y España atraviesan diferentes fases económicas, jurídicas y sociales. Brasil se encuentra en una importante fase de estabilidad económica y democrática, con un aumento de su PIB, la elevación de la esperanza media de vida de sus habitantes e, incluso, con el reconocimiento internacional de ser una potencia emergente y, aunque, es cierto que la Constitución Federal, promulgada el 5 de octubre de 1988, trajo avances significativos para los trabajadores, positivando varios derechos, y además extendiéndolos a categorías de trabajadores antes no incluidas, como los trabajadores rurales o los trabajadores domésticos, es necesario mayor protección en este ámbito. España, por el contrario, se encuentra en una fase de recuperación económica y de empleo, pero afrontó los problemas de la subcontratación hace casi décadas con una profusa legislación y con un concepto básico: la extensión de la responsabilidad de manera solidaria a todas las empresas implicadas en un fenómeno interempresarial como la subcontratación.

Aunque en Brasil está planteado un proyecto de Ley de regulación de la subcontratación, los términos del mismo no aparece adecuados para combatir la precarización laboral y el tráfico ilegal de mano de obra, pareciendo que el modelo español adaptado a las circunstancias brasileñas quizá pudiera ser una buena opción. 


\section{Bibliografía}

CRUZ VILLALÓN, J. Outsourcing. Contratas y subcontratas. En: ponencia temática del X Congreso de Derecho del Trabajo y la Seguridad Social. Zaragoza, 1999.

DELGADO, Mauricio Godinho. Curso de Derecho del Trabajo. Sao Paulo: LTr, 2002.

GARCIA NINET J.I. Obligaciones y responsabilidades en materia de seguridad y salud en los supuestos de contratas y subcontratas. Consideraciones en torno al art. 24 (coordinación de actividades empresariales) de la LPRL. En: AAVV, Descentralización productiva y protección del trabajo en contratas. Valencia, 2000.

MARTINS Sergio Pinto. La subcontratación y la legislación laboral. 3 a ed. Sao Paulo:Malheiros, 1997.

MARTINS, Sergio Pinto. La Ley de Subcontratación y Trabajo. $9^{\text {a }}$ ed. rev. yampl. Sao Paulo: Atlas, 2009.

MIÑARRO YANINI, M. La prevención de riesgos laborales en la contratación temporal, empresas de trabajo temporal, y contratas y subcontratas. Ministerio de Trabajo y Asuntos Sociales. Edita Instituto Nacional de Seguridad e Higiene en el Trabajo. Madrid, 2002.

MOLTÓ GARCÍA, J.I. La prevención de riesgos laborales de los trabajadores de las empresas de trabajo temporal en las empresas usuarias. Ministerio de Trabajo y Asuntos Sociales. Edita Instituto Nacional de Seguridad e Higiene en el Trabajo. Madrid, 2009.

MORAES, Paulo Almeida de Douglas. Contratación indirecta y servicios de outsourcing en la actividad principal de las personas jurídicas: la capacidad jurídica y la conveniencia social. 2003. Disponible en: <www.mte.gov.br / policía / ms / ms_monografia.pdf $>$. Consultado el 16 de julio de 2014.

VARGAS, Luiz Alberto de; SILVEIRA, AlmirGoulart da.Terceirização e o enunciado 331 DO TST. Breves considerações. Disponible en:http://lavargas.sites.uol. com.br/terceira.html. 


\title{
EL DERECHO DE INFORMACIÓN EN LAS SOCIEDADES DE CAPITAL Y LAS CONSECUENCIAS DE SU VULNERACIÓN
}

The right to information on limited liability companies and the consequences of their violation

\section{Silvia Gómez Trinidad}

Profesora del área de Derecho Mercantil Universidad de Barcelona. E-mail: sgomezt@ub.edu

\section{Judith Morales Barceló}

Profesora del área de Derecho Mercantil Universidad de Barcelona. E-mail: jmorales@ub.edu

\section{RESUMEN}

El derecho de información, a pesar de su carácter instrumental, es el que permite el ejercicio del resto de derechos. Ante la vulneración del mismo, el ordenamiento vigente prevé como medio de reacción la impugnación del acuerdo social afectado. A pesar de ello, las modificaciones proyectadas no apuntan hacia esa línea, por tanto, resulta de especial interés determinar cuáles serán las alternativas propuestas.

Palabras clave: Sociedades mercantiles. Derecho de información. Impugnación DE ACUERDOS.

\begin{abstract}
Shareholder's information right is the one that allows the full exercise of other shereholder's rights. Company Law has forseen as a tool to protect its correct exersice bymeans of contesting the Company agreement affected. However the new proposed ammendments to the Spanish regulations do not follow the previous solutions. In consequence, it is of a special interest to determine the new regulation proposals.
\end{abstract}

Keywords: Corporations. Right OF INFORMATION. CONTESTATION AGREEMENT 
SumArio: 1. El derecho de información del socio o accionista. Generalidades. 1.1 Concepto, naturaleza jurídica y características del derecho de información del socio o accionista. 1.2 Contenido del derecho de información y límites en su ejercicio. 2. Vulneración del derecho de información. 2.1 Consecuencias previstas en el régimen actual: la ley de sociedades de capital. 2.2 Consecuencias previstas en el régimen futuro: anteproyecto de ley de código mercantil y proyecto de ley por el que se modifica la ley de sociedades de capital para la mejora del gobierno corporativo. Bibliografía.

\section{El derecho de información del socio o aCCiOnista. Generalidades.}

El derecho de información se encuentra incardinado dentro del conjunto de derechos que forman parte de la condición de socio o accionista en las Sociedades de capital. La comunicación que se presenta permite abordar este derecho analizando su concepto, características y límites. Ello no obstante, consideramos interesante, iniciar el presente análisis con una breve reflexión previa y, que dejamos abierta para debate, sobre el concepto de información en sede societaria si, se puede afirmar que ésta, se encuentra efectivamente conceptualizada. En este sentido, el concepto de información en sede societaria se puede abordar, a nuestro parecer, desde una perspectiva interna o externa atendiendo a sus efectos (ad. ex. para con los órganos de la sociedad, para con los terceros que contraten con la misma) y a los sujetos afectados (socios o accionistas, terceros). El concepto información societaria o corporativa se puede considerar como un gran concepto con distintas vertientes, y desde la perspectiva interna, afirmar que, de la misma, forma parte el derecho de información del socio o accionista.

La información corporativa es un elemento relevante en toda sociedad mercantil. Desde la perspectiva externa, la información societaria se caracteriza por el elemento de publicidad a los que se someten actos ${ }^{333}$ societarios o, incluso, hechos relevantes de carácter económico que afectan a la misma, para con terceros. El ordenamiento jurídico prevé los instrumentos válidos para dar publicidad a esa información social. Así se puede encontrar disponible en la página web corporativa de la sociedad, en sede de Registro Mercanti1 ${ }^{334}$, o en registros de entidades rectoras de los mercados $^{335}$ en su caso. De ahí se deriva la información societaria o corporativa que es conocida por terceros a los efectos de constatar la situación patrimonial de la so-

\footnotetext{
${ }^{333}$ Ad. Ex. de los actos inscribibles en el Registro Mercantil, véase el art. 94 RRM.

${ }^{334}$ Con esta inscripción la información social tendrá publicidad frente a terceros, rigiéndose por los tres principios registrales: publicidad material, legalidad y presunción de validez.

335 Para sociedades cotizadas véase el régimen de publicidad de la información corporativa recogida en la Ley del Mercado de Valores.
} 
ciedad para iniciar las relaciones negociales o procedimientos judiciales oportunos.

Ello no obstante, el concepto información societaria puede ir más allá y analizarse desde la perspectiva interna societaria. Así por ejemplo, en situaciones de conflicto de interés de un socio con la sociedad o, en situaciones de posible infracción de los deberes de los administradores para con la sociedad a consecuencia de un conflicto, la información que éstos aporten al órgano correspondiente será clave para su delimitación. La importancia del contenido de esa información radica en el posible y necesario análisis del conflicto de interés y, permitirá que se valore la existencia del mismo por el órgano societario oportuno, autorizando o no la situación conflictiva mediante la adopción de una decisión societaria.

Por tanto, el concepto de información en sede de sociedades puede alcanzar un amplio espectro que afecta desde las relaciones externas de la sociedad, hasta las relaciones internas de la misma y siempre con efectos sobre el interés social.

Hemos considerado interesante realizar esta mínima reflexión en torno a la relevancia del concepto de información societaria o corporativa, por cuanto está adquiriendo una mayor importancia a propósito de la implantación de los Códigos de Buen Gobierno Corporativo y, en particular, de las modificaciones que se van a acometer en materia de sociedades de capital con el Proyecto de Ley por la que se modifica la ley de sociedades de capital para la mejora del Gobierno corporativo ${ }^{336}$ y que, en suma, puede afectar al derecho de información del socio o accionista.

Así las cosas, no hay duda alguna que el derecho de información del socio forma parte de su condición y afecta a la relación interna del socio con la sociedad. A la par ello tiene un reflejo externo con las decisiones que se adoptan mediante acuerdos de Junta y atendiendo a la información detentada. Veamos a continuación como se configura este derecho en sede de la Ley 1/2010 de Sociedades de Capital ${ }^{337}$.

\subsection{CONCEPTO, NATURALEZa JURídica Y CARACTERíSTICAS DEL DERECHO DE IN- FORMACIÓN DEL SOCIO O ACCIONISTA}

Como es bien sabido, los socios o accionistas en calidad de miembros de una sociedad de capital, detentan toda una serie de derechos para con la sociedad que integran. Los derechos de los socios o accionistas se han clasificado por la doctrina mercantilista española con una doble distinción como derechos económicos y derechos políticos o sociales ${ }^{338}$. Los primeros generan, con carácter general, la obtención de unas ganancias patrimoniales o rendimientos económicos en su caso, bien sea a través de la participación proporcional en dividendos, en cuota de liquidación o

${ }^{336}$ En adelante, Anteproyecto de Ley de reforma del Gobierno corporativo.

337 Texto refundido aprobado por el Real Decreto Legislativo 1/2010, de 2 de julio. En adelante, se hará referencia a la misma como LSC.

338 Véanse ad. Ex. BROSETA PONT, "Manual de Derecho Mercantil", Madrid, 2011; MENENDEZ, A., "Lecciones de Derecho Mercantil”, Pamplona, 2009. 
mediante la tenencia de un derecho de preferencia económico ${ }^{339}$ por citar algunos supuestos. Los derechos de tipo social o político permiten al socio o accionista conocer la situación económico-financiera, participar en la adopción de decisiones sociales, también de alcance patrimonial, como la adopción de acuerdos en el reparto de dividendos o en la aprobación de la gestión social. En suma, los derechos sociales, son derechos que si bien no tienen carácter económico, sí que inciden en decisiones económicas en pro del interés social.

Entre los derechos políticos o sociales del socio o accionista nos hallamos con el derecho de voto, el derecho de asistencia y de representación en Junta, el derecho de impugnación de acuerdos sociales y el derecho de información ${ }^{340}$. Con carácter general, podemos afirmar que no todos los derechos sociales tienen la misma intensidad, algunos son renunciables a favor de rendimientos de tipo económico, como sucede en el supuesto de las acciones o participaciones sin voto y otros, se caracterizan por ser accesorios o instrumentales de otros derechos sociales como el derecho de información respecto del derecho de voto.

El derecho de información del socio o accionista es sin duda un derecho de carácter político-social que permite al socio, en primer lugar, conocer el devenir económico de la sociedad en la que participa. El derecho de información en sede de sociedades de capital podría definirse como un derecho legítimo del socio, que le permite tomar decisiones adecuadas que guiarán la consecución del objeto social, pautar la estrategia de desarrollo de la sociedad en el mercado y examinar la viabilidad económica de la sociedad. De ahí, la relevancia de su correcto ejercicio y las consecuencias previstas en nuestro ordenamiento jurídico ante la vulneración del mismo.

El derecho de información en sede de sociedades de capital vincula al socio o accionista en el devenir social y le habilita para conocer la situación social, y con carácter general, debatir propuestas presentadas por el órgano de administración o, por otros socios o accionistas, en sede de Junta. Así la información entregada al socio le permite debatir las decisiones a adoptar mediante acuerdo en sede de Junta $\mathrm{y}$, votar, en su caso, en un sentido u otro.

Como hemos apuntado en alguna obra anterior ${ }^{341}$, la doctrina mercantilista ha considerado el derecho de información como un derecho esencial a la calidad de socio, por tanto se adquiere con la adquisición de la condición de socio y se transmite con la transmisión de esa condición. Por lo anterior, el derecho de información corresponde tanto a socios o accionistas mayoritarios como a minoritarios, representando para estos últimos un elemento más que garantiza la gestión social y clave

339 Por ejemplo, las acciones o participaciones sin voto.

340 Art. 93 LSC.

${ }^{341}$ En pág. 211, GÓMEZ TRINIDAD, S.:Revisión del derecho de información en las sociedades de capital: Derecho del socio versus deber social, RDM 281 /Julio-Septiembre - 2011 págs. 233 a 270. 
para la defensa de sus intereses ante posibles conflictos entre mayorías y minorías sociales $^{342}$. El derecho de información se presenta como irrenunciable, por tanto, no es modificable en sede de contrato social y, a la par, como hemos afirmado anteriormente, es accesorio o instrumental de otros derechos sociales como el derecho de voto. Esto último no hace que sea un derecho menor, mas al contrario. El defectuoso ejercicio del derecho de información da lugar a un vicio en el voto emitido por el socio o accionista, hecho que puede comportar, en consecuencia, la impugnación del acuerdo social que contenga esa decisión.

Junto a las anteriores características mencionadas y elaboradas por la doctrina mercantilista, la jurisprudencia del Tribunal Supremo ha delimitado y configurado la naturaleza jurídica y el concepto de derecho de información. Jurisprudencialmente, se ha incidido en su carácter irrenunciable, inderogable y accesorio, respecto de otros derechos. A mayor abundamiento, el Alto Tribunal le concede naturaleza pública e imperativa, siendo un derecho "consustancialmente unido al derecho de voto" ${ }^{343}$. A la par define el derecho de información como un derecho de cumplimiento inexcusable para el órgano ejecutivo de una sociedad, es decir, del órgano de administración ${ }^{344}$. Además en STS 197/2006, se considera un derecho inderogable, por cuanto la falta de puesta a disposición de documentos solicitados comporta la infracción del derecho a ser informado. Por considerarse un derecho inderogable e inalienable, el TS reitera que hace que no nos hallemos ante un derecho genérico o abstracto sino que para poder ser considerado lesionado, debe ser ejercitado por el socio o accionista. Por tanto, no existe una lesión del derecho en abstracto, por cuanto es necesario que éste se ejercite para que pueda invocarse su vulneración.

\subsection{CONTENIDO DEL DERECHO DE INFORMACIÓN Y LÍMITES EN SU EJERCICIO}

El derecho de información en sede de sociedades de capital se encuentra reconocido en diversas partes del articulado de la LSC. Uno de los supuestos en los que en sede societaria el derecho de información detenta una mayor relevancia es previamente a la celebración de Junta de socios o accionistas. En este contexto, el derecho se encuentra doblemente y separadamente regulado en sede de Sociedades de Responsabilidad Limitada ${ }^{345}$ y en sede de Sociedades Anónimas ${ }^{346}$ en los arts. 196 y 197 del citado texto legal. Las diferencias entre ambos artículos son mínimas, pero a fecha de hoy, todavía existentes y relevantes. Esta diversa configuración puede

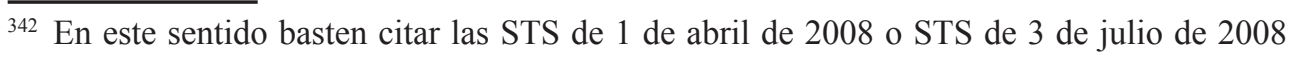
que consideran el adecuado ejercicio del derecho de información como clave para conocer la situación económica de la sociedad por el socio minoritario.

${ }^{343}$ STS 4327/2000.

${ }^{344}$ STS citada en nota al pie anterior.

${ }^{345}$ En adelante, SL.

${ }^{346}$ En adelante, S.A. 
considerarse que no se encuentra claramente justificada, por cuanto, como es bien sabido ambos modelos societarios, si bien pensados para necesidades societarias diferenciadas, su evolución histórica ha hecho que en la praxis societaria se utilicen indistintamente para vehicular grandes, medianas o pequeñas empresas ${ }^{347}$.

Primeramente, cabe mencionar como diferencia existente en la regulación de ambos tipos sociales, el plazo previo a la fecha de celebración de Junta en el que se puede solicitar la información a los administradores respecto de los puntos contenidos en el orden del día. En sede de SL no hay límite temporal alguno de entrega de la información, por cuanto se autoriza que se solicite información o aclaraciones por escrito con anterioridad a la reunión de la Junta. Por el contrario, en sede de SA, el límite para solicitar informaciones o preguntas escritas dirigidas al órgano de administración es de siete días de antelación a la fecha de celebración de la Junta. En este caso, la LSC expresamente prevé que los administradores tendrán la obligación de entrega por escrito de la información requerida hasta el mismo día de celebración de la Junta. Ello no obstante, la legislación mercantil admite en ambos casos, que se puedan solicitar verbalmente aclaraciones a los administradores sobre las cuestiones objeto de debate durante la celebración de la Junta.

La doctrina mercantilista se ha manifestado en torno a la falta de justificación del diferente plazo en sede de SL y SA, y a la par, del mantenimiento de ese plazo de siete días en sede de SA. En este último caso, esa situación puede llevar a una disparidad de información entre accionistas, atendiendo al tipo de información solicitada por un grupo de accionistas y a la asistencia o no a la Junta. A ello se debe añadir el debate referente al momento en que debe ser entregada la información por parte de los administradores a los accionistas solicitantes. La doctrina mercantilista ha debatido esta cuestión, barajando conflictos intra-societarios y el abuso de derecho como elementos que pueden hacer que esa información sea entregada adecuadamente o no. Particularmente, nos posicionamos considerando que la entrega del mayor número de información y con la mayor anterioridad a la celebración de la Junta permitiría que los accionistas o socios puedan tener una idea más clara sobre los puntos del orden del día. Esta cuestión se ha debatido por la doctrina, por cuanto, del articulado de la LSC no hay referencia alguna de cuando se ve debidamente cumplido el deber de entrega de la información solicitada por parte de los administradores y es la jurisprudencia del Tribunal Supremo la que ha puntualizado cuando este deber se ve cumplido, tanto en sede de SA como de SL. Así, mediante STS de 10 de febrero de 2006, núm. 85/2006, y en el mismo sentido, la STS de 8 de noviembre de 2007 anteriormente citada, se considera debidamente cumplido el deber de entrega de la información por parte del órgano de administración, cuando esta se entrega en su totalidad y, ello sirve para cumplir el fin último del derecho de información, cual es permitir la formación de una idea clara y precisa del debate, y

${ }^{347}$ Comentar la inexistencia de una diferenciación real entre sociedades que utilizan un método u otro. 
ello se cumple, tanto de forma oral a lo largo de la Junta como de forma escrita con anterioridad a la misma.

La segunda diferencia entre ambos tipos sociales se encuentra en el órgano que puede denegar la información en sede de Junta de socios o accionistas. La LSC no ha desarrollado una tarea homogeneizadora en este sentido. En sede de SL el órgano de administración es el encargado de decidir si deniega la entrega de información solicitada por el socio, viniendo esa negativa justificada por la defensa del interés social. Por el contrario, en sede de SA, se deja al Presidente de la Junta la decisión de poner esa información a disposición del accionista durante la celebración de la misma si el interés social, se ve perjudicado ${ }^{348}$. En cualquier caso, no se encuentra justificada esta diferenciación de órganos que pueden decidir la entrega o no de información a lo largo de la celebración de la Junta y, ello no tan sólo, por el tipo social, sino también en sede de Anónimas entre órgano de administración o Presidente de la Junta. La doctrina mercantilista ha incidido en que la negativa de entrega de la información solicitada por socios o accionistas, es una excepción al derecho de información y el concepto de interés social se debe interpretar de forma restrictiva. Junto a lo anterior se ha incidido en el hecho de que no siempre el Presidente de la Junta puede conocer si el interés social se vulnera o no, por cuanto, puede carecer de esa información detallada y ser el órgano de administración quien pueda decidir en mayor medida sobre ese extremo.

La tercera diferencia y vinculada a la anterior, es el porcentaje de capital en base al cual, no se puede alegar la excepción del interés social como causa que justifique la negativa de entrega de información solicitada por el socio o accionista. En sede de SL la denegación de información, no podrá tener lugar cuando la solicitud se apoye por al menos socios que representen el veinticinco por ciento del capital social. En SA el porcentaje es el mismo, salvo disposición contraria en estatutos, que puede llevar a fijar un porcentaje menor, pero nunca inferior al cinco por ciento del capital social.

Si bien, hasta el momento, hemos referenciado situaciones en las que el derecho de información se ve ejercitado en sede de Junta de socios o accionistas, ello no obstante, es necesario hacer mención a que el derecho de información también se extiende a otros artículos de la LSC. Así por ejemplo, cuando se regula la información necesaria a entregar al socio o accionista cuando se propone una modificación estatutaria como el aumento o reducción de capital ${ }^{349}$ planteado por el órgano de administración o cuando se plantea la aprobación de la gestión social y de las cuentas

${ }^{348}$ Como veremos el interés social es uno de los límites del derecho de información, salvo ciertas excepciones relacionadas con el porcentaje de participación en el capital social del socio o accionista solicitante

${ }^{349}$ Así los arts. 287 y 290 LSC recogen el modo de confección de la información que contiene la propuesta y la documentación que se debe entregar a los socios o accionistas, el contenido del anuncio de la junta y la publicidad del acuerdo que adopte la modificación de estatutos. 
anuales. En este último supuesto, la aprobación de las cuentas anuales, el contenido del derecho de información también difiere atendiendo a si nos hallamos en sede de Limitadas o de Anónimas. En ambos tipos sociales se reconoce la entrega de forma inmediata y gratuita de los documentos que han de ser sometidos a la aprobación de la Junta desde el momento de su convocatoria ${ }^{350}$. Además este derecho debe constar en el anuncio de convocatoria. Por tanto, se concreta el derecho de información en el conjunto de documentos que se van a debatir en Junta y su puesta a disposición inmediata al socio o accionista. La diferencia entre ambos tipos sociales radica en la admisión en SL que el socio que represente un cinco por ciento del capital social pueda examinar en el domicilio social por sí o mediante experto contable, los documentos que sirvan de soporte y de antecedente de las cuentas anuales ${ }^{351}$. Una disposición en este sentido, no se prevé en sede de SA.

En suma, el contenido del derecho básicamente se configura, como indicado, por ser un derecho de naturaleza pública, imperativa, irrenunciable y connatural a la condición de socio. Ese contenido varía, como hemos visto, atendiendo al tipo de operación societaria de la que se necesite aprobación. En cualquier caso, la información que debe recibir el socio o accionista configura el contenido del derecho de información. De las características del derecho de información deriva un aspecto esencial del mismo cual es, su carácter limitado. Se puede afirmar en consecuencia que el contenido del derecho de información viene configurado por sus límites, que no son otros que el ejercicio del mismo con abuso de derecho y la defensa del interés social.

El socio o accionista puede ejercitar su derecho de información abusando del mismo. Ello puede ocurrir en situaciones en las que a través de la posición en Junta de los socios o accionistas se pretenda bloquear constantemente la gestión del órgano ejecutivo social o bien, a través del bloqueo en Junta de acuerdos sociales que reflejen situaciones de conflicto entre mayorías y minorías en sede de Junta. En este sentido, ello no es más que un abuso del derecho ejercitado por el socio para paralizar el normal funcionamiento de la sociedad. Diversa jurisprudencia del TS se ha manifestado afirmando que el ejercicio del derecho debe ser pacífico y de buena $\mathrm{fe}^{352}$. Destacamos la reciente STS de 19 de Septiembre de 2013, [RJ 4950/2013] en la que se incide en el ejercicio no abusivo del derecho ni de forma objetiva como subjetiva, añadiendo que ello se debe valorar con la revisión de diversos parámetros "como las características de la sociedad y la distribución de su capital, volumen y forma de la información solicitada". Ello no obstante, el abuso del derecho también puede tener lugar cuando el órgano ejecutivo de una sociedad niega la entrega de información reiteradamente o la entrega con carácter defectuoso a los socios o accionistas que la requieren.

${ }^{350}$ Art. 272.2LSC.

${ }^{351}$ Art. 272.3LSC.

${ }^{352}$ STS de 24 de noviembre de 2006, STS de 4 de octubre de 2005 y de 3 de julio de 2008. 
El interés social como excepción a la entrega de información ${ }^{353}$ se encuentra configurado como límite tanto en sede de SL como en sede de SA en los arts. 198 y 199 LSC. El TS se ha manifestado al respecto y vincula el posible abuso de derecho del socio en la solicitud de información, con la defensa del interés social. En este sentido mediante Sentencia de 24 de abril de 2007, 480/2007 [RJ 2007 2394] el Alto Tribunal manifiesta que cuando se presenta información escrita clarificadora y aclaraciones verbales suficientes sobre la información que se ha de discutir en sede de Junta, no se puede esgrimir una infracción del derecho por parte de un accionista, aludiendo a su condición de minoritario, siempre y cuando esa falta de documentación ulterior se mantiene reservada ante una posible vulneración del interés social. En el mismo sentido la STS de 22 de julio de 2005, núm. 658/2005 [RJ 2005\5835] incide en la adecuada negativa de entrega de información por parte del órgano de administración, tanto por hallarse en peligro la protección del interés social -la entrega de documentación podría comportar que un competidor conociera la estrategia financiera de la sociedad - y además, incide en la necesidad del cumplimiento efectivo del porcentaje de capital exigido para poder solicitar información complementaria a la sociedad. En cualquier caso, corresponde al órgano de administración o al Presidente de la Junta valorar la existencia de un riesgo para el interés social y, en su caso, el socio que considere infringido su derecho de información, si detenta el porcentaje exigido por ley, recurrir la decisión del órgano no autorizante.

Es ante el juego de esos límites del derecho de información y el correcto cumplimiento o no de ese derecho que es cuando el ordenamiento jurídico y la jurisprudencia plantean soluciones ante su infracción. Como veremos en los próximos apartados, esas soluciones pasan por la posibilidad de impugnación de los acuerdos sociales adoptados con infracción del derecho.

\section{VULNERACIÓN DEL DERECHO DE INFORMACIÓN}

El ordenamiento jurídico español no prevé ninguna norma específica que establezca las consecuencias de la infracción del derecho de información. Por esta razón se debe acudir a las reglas generales sobre impugnación de acuerdos de la junta general previstas en la LSC. En esta línea, consideramos de especial relevancia realizar un estudio no sólo del régimen actualmente en vigor sino también de las futuras reformas previstas en esta materia, por ello éstas serán las cuestiones que revisaremos en el presente apartado. En concreto, estas propuestas de futuro son el Proyecto de Ley por la que se modifica la Ley de Sociedades de Capital para la mejora del gobierno corporativo y el Anteproyecto de Ley de Código Mercantil. En el primer supuesto, el Proyecto de Ley propone la modificación de los artículos 204 y

${ }^{353}$ Sobre el dilema planteado véase en Gómez Trinidad, S.: "Revisión del derecho de información en las sociedades de capital" págs. 244 y 245 , sobre la excepción a la negativa de entrega de información fundamentada en el interés social. 
206 de la LSC, que regulan los acuerdos impugnables y la legitimación para impugnar, respectivamente. En el segundo supuesto, el Anteproyecto de Código Mercantil, dedica seis apartados del artículo 214 al régimen de la impugnación de los acuerdos sociales. Éste último es de especial importancia, puesto que el régimen previsto dista mucho del régimen de la LSC, con una supresión de la distinción entre los acuerdos nulos y los acuerdos anulables.

A modo de apunte, puesto que será objeto de un extenso desarrollo posterior, querríamos comentar que con la entrada en vigor de la Ley que modificará la LSC, el artículo 204 prevé excluir expresamente, con carácter general, como causa de impugnación de los acuerdos sociales "la incorrección o insuficiencia de la información”, a pesar de que como veremos, contempla alguna excepción.

Con carácter previo consideramos de especial relevancia establecer ante qué situaciones el derecho de información de los socios se puede ver vulnerado. En este sentido, es posible distinguir entre el derecho de información que se ejercita en sede de sociedad anónima y el que se ejercita en sede de sociedad de responsabilidad limitada.

En el primer supuesto, el artículo 197 LSC, prevé que los accionistas de una sociedad anónima pueden solicitar a los administradores aclaraciones, informaciones o plantear alguna pregunta respecto de los asuntos comprendidos en el orden del día hasta el séptimo día antes de la celebración de la junta. El plazo en el que los administradores deben facilitar esa información es el día de la celebración de la junta. No obstante, para aquella información solicitada verbalmente durante la celebración de la junta que no pueda ser facilitada en ese momento, la ley amplía el plazo a los 7 días siguientes contados desde la terminación de la junta. Se debe tener presente que el órgano de administración puede denegar la información solicitada cuando a su juicio considere que su entrega puede perjudicar el interés social, salvo que lo soliciten accionistas que representen al menos un $25 \%$ del capital social, supuesto en el que no será posible la denegación. En este contexto, el derecho de información del accionista puede verse vulnerado en un doble sentido: por un lado, el órgano de administración no facilita la información solicitada o bien no lo hace en el plazo establecido, en ambos casos, la vulneración traería causa en un comportamiento de los administradores.

En el segundo supuesto, el artículo 196 LSC contempla que los socios de una sociedad de responsabilidad limitada pueden solicitar por escrito, antes de la celebración de la junta, sin que, a diferencia de las sociedades anónimas, esté sometido a un límite temporal de 7 días antes de la celebración de la junta, o bien verbalmente, durante la celebración de la misma, las aclaraciones e informes que consideren convenientes sobre los asuntos comprendidos en el orden del día. La información puede ser denegada en el caso en el que a juicio del presidente de la junta, la entrega de la misma perjudique el interés social, salvo que sea solicitada por socios que representen al menos el $25 \%$ del capital social. Del mismo modo 
que para las sociedades anónimas, la vulneración del derecho de información del accionista se puede dar por la falta de entrega de la información solicitada o bien, a nuestro entender, por no entrega en el momento adecuado según el tipo de información solicitada. En este supuesto, la ley no establece límites para el cumplimiento de la obligación de facilitar la información por parte de los administradores, por ello se debe estar a las circunstancias concretas de cada caso. Así como la falta de entrega en el momento adecuado implica una vulneración del derecho de información cuyo origen se encuentra en el comportamiento de los administradores, la falta de entrega de la información puede tener origen en el comportamiento de los administradores o bien en el presidente de la junta, que es quien está legitimado, en las sociedades de responsabilidad limitada, para denegar la información en caso de que considere que su entrega perjudica el interés social.

De todo ello, podemos concluir que el efectivo ejercicio del derecho de información requiere que la información sea suministrada en tiempo, forma y con el contenido adecuado ${ }^{354}$.

\subsection{Consecuencias PREVISTAS en EL RÉgimen aCtual: La Ley de SociedadeS de Capital}

Como hemos señalado, nuestro ordenamiento jurídico no contempla ningún mecanismo específico ante la infracción del derecho de información. Por tanto, ante esta situación, el socio tan sólo tendrá la posibilidad de impugnar el acuerdo social por lesión de su derecho de información, puesto que no se le ha proporcionado la información en los términos que exige la ley.

El régimen de impugnación de los acuerdos sociales está previsto en los artículos 204 a 208 de la LSC. En concreto, el artículo 204 de la LSC contempla dos causas de impugnación de los acuerdos sociales: por un lado, los acuerdos afectados por una causa de nulidad; y por otro, los acuerdos afectados por una causa de anulabilidad. En atención a la previsión de este artículo, los acuerdos contrarios a la ley son acuerdos nulos y aquellos acuerdos que sean contrarios a los estatutos o lesionen el interés social en beneficio de uno o varios socios o terceros son acuerdos anulables.

La LSC contempla una única causa de nulidad de los acuerdos sociales que consiste en que éstos sean contrarios a la ley. A pesar de que no hay mayor precisión, el término ley debe ser interpretado de forma estricta, de tal forma que no todo acuerdo contrario a una ley puede ser declarado nulo. De esta forma, se debe distinguir entre aquellas normas que son imperativas y las que son dispositivas. Tan

${ }^{354}$ En este sentido el TS argumenta en la sentencia de 19 de octubre de 2013, que la discrepancia con las informacions o explicacions facilitades no supone que el derecho de información se haya vulnerado. Sino que es suficiente que se le informe razonablemente sobre los extremos interesados. 
sólo el acuerdo adoptado vulnerando las normas imperativas debe ser sancionado con la nulidad ${ }^{355}$.

En atención a las causas de impugnación citadas, la vulneración del derecho de información da lugar a la nulidad del acuerdo adoptado con infracción de este derecho, puesto que ha provocado un vicio del procedimiento de formación de la voluntad de la junta al adoptar el acuerdo, que podría haber sido diferente si se hubiese proporcionado la información adecuada. La nulidad tan sólo afecta a ese concreto acuerdo y no a toda la junta en la que se haya adoptado el acuerdo.

La acción de nulidad de los acuerdos sociales está sujeta al plazo de caducidad de un año, a excepción de que el acuerdo sea contrario al orden público, en cuyo caso no está sometido a plazo alguno. En el supuesto de infracción del derecho de información, puesto que está previsto en una norma de carácter imperativo pero su infracción no implica que el acuerdo adoptado sea contrario al orden público, caduca al año desde la fecha de adopción del acuerdo o bien desde la fecha de publicación en el BORME, si fuese inscribible (art. 205 LSC).

La legitimación activa para impugnar un acuerdo nulo corresponde a todos los accionistas, a los administradores y a cualquier tercero que acredite un interés legítimo (art. 206 LSC). Como se puede inferir, en nuestro supuesto concreto será el socio quien tendrá interés en ejercitar la acción de nulidad, puesto que ha sido su derecho el que se ha vulnerado. A pesar de que la LSC tan sólo prevé que todos los socios podrán ejercitar la acción de nulidad de un acuerdo, el Tribunal Supremo ha insistido que el socio debe haber actuado de buena fe, conforme a lo previsto en el artículo 7 del Código Civil. En este sentido, diversas son las sentencias en las que se pronuncia sobre en qué supuestos considera que el socio no ha actuado de buena fe y, por tanto, no puede ejercitar la acción de nulidad ${ }^{356}$. En concreto, cuando el socios sea consciente de alguna infracción legal en la convocatoria o constitución de la junta y no lo ponga de manifiesto, está actuado de un modo contrario a la buena fe. En este sentido, el socio, que conociendo que en el anuncio de convocatoria de la junta no se ha hecho mención a este derecho o bien que no se ha entregado toda la información de modo completo, no lo ponga de manifiesto tan pronto como le sea posible para subsanar el error, está actuando de mala fe $\mathrm{e}^{357}$.

Finalmente, querríamos apuntar que la infracción de este derecho puede originar la responsabilidad de quien haya causado la lesión de este derecho, puesto que el origen se encuentra en el incumplimiento de los deberes de proporcionar la información por parte de los administradores o bien en su caso del presidente de la junta.

\footnotetext{
${ }^{355}$ En el mismo sentido debe ser considerado aquel acuerdo que se haya adoptado vulnerando una cláusula estatutaria que recoja una norma imperativa.

356 STS de 19 de octubre de 2013, de 23 de noviembre de 2010 y de 21 de julio de 2010.

357 STS de 19 de octubre de 2013 y de 23 de julio de 2010.
} 


\subsection{Consecuencias previstas en el régimen futuro: Anteproyecto de Ley de Código Mercantil y Proyecto de Ley por el Que se modifica la Ley de Sociedades de CAPITAL PARA LA MEJORA DEL GOBIERNO CORPORATIVO}

El anteproyecto de Ley de Código Mercantil (en adelante, anteproyecto de ley) y el proyecto de ley por el que se modifica la ley de sociedades de capital para la mejora del gobierno corporativo (en adelante, proyecto de ley) prevén unas modificaciones que afectan a la infracción del derecho de información. A pesar de que a simple vista suponen un cambio radical respecto al régimen que actualmente se sigue ante la vulneración de este derecho, un análisis más detallado nos permite afirmar que no hay tal modificación sino una clarificación respecto al régimen de impugnación de los acuerdos sociales como medio de reacción ante la infracción del derecho de información.

Las modificaciones previstas en el proyecto de ley que serán introducidas en la LSC así como el régimen que contempla el anteproyecto en el nuevo Código Mercantil son exactamente las mismas. Por ello, realizaremos un análisis conjunto de las dos propuestas y las compararemos con el régimen actualmente en vigor.

El proyecto de ley introduce en el artículo 197 de la LSC, cuyo título es "derecho de información en la sociedad anónima", un apartado en el que expresamente se pronuncia sobre la infracción de este derecho. En concreto, contempla en el apartado 5 que la vulneración del derecho de información tan sólo facultará al accionista para exigir el cumplimiento de la obligación de información y los daños y perjuicios que se le hayan podido causar. En esta línea, establece una precisión que resulta de interés, puesto que expresamente excluye esta infracción como causa de impugnación de la junta general. A pesar de que, a priori podamos considerar que el único remedio previsto en la ley ante la vulneración de este derecho sea solicitar una indemnización por los daños y perjuicios causados, si acudimos al artículo 204 de la LSC, que trata sobre los acuerdos impugnables y que también resulta modificado por el proyecto, podemos confirmar que se mantiene la infracción de este derecho como causa de impugnación de los acuerdos sociales. Como hemos comentado, el anteproyecto de ley prevé exactamente el mismo régimen que propone el proyecto de ley. En concreto, en el artículo 233-39.2 se recoge el derecho de información del accionista de una SA con un reconocimiento expreso del derecho a solicitar una indemnización por daños y perjuicios ante la vulneración del mismo así como una exclusión de la posibilidad de impugnar la junta general ante esta situación. Y en el artículo 214-11 del anteproyecto de ley, que contempla el régimen de impugnación de los acuerdos sociales,

Un análisis más detallado, nos permite confirmar que el apartado 5 del artículo 197 LSC, como hemos mencionado, niega que la infracción del derecho de información sea una causa de impugnación de la junta general. A pesar de que el actual artículo 197 LSC no se pronuncia sobre ello, tanto la doctrina como jurisprudencia 
habían llegado a la misma conclusión, puesto que tan sólo admitían la impugnación del acuerdo social adoptado con vulneración del derecho de información pero manteniendo la eficacia de la junta en la que se adoptó así como del resto de acuerdos sociales no afectados por esta infracción.

La vulneración del derecho de información como causa de impugnación de los acuerdos sociales se mantiene en el artículo 204 LSC a pesar de la modificación introducida por el proyecto. Esta modificación introduce un apartado 3 en este artículo en el que se prevén cuatro supuestos en los que no procederá la impugnación de los acuerdos sociales. En concreto, el segundo de estos supuestos hace referencia a la vulneración del derecho de información. Según este apartado, no procede la impugnación de un acuerdo cuando esté basada en "la incorrección o insuficiencia de la información facilitada por la sociedad en respuesta al ejercicio del derecho de información, salvo que la información incorrecta o no facilitada hubiera sido esencial para el ejercicio razonable por parte del accionista o socio medio, del derecho de voto o de cualquiera de los demás derechos de participación”.

\section{Bibliografía}

BAENA BAENA, P.J.: Legitimación activa para la impugnación de acuerdos sociales, Madrid, 2006.

BROSETA PONT, M.: Manual de Derecho Mercantil, Madrid, 2007.

CABALLOL I ANGELATS, L.: "Artículo 115. Acuerdos impugnables", en Comentarios a la Ley de Sociedades Anónimas, ARROYO, I. et alt. (coord.), Madrid, 2009, pp. $1171 \mathrm{a}$

ESTEBAN VELASCO, G.: Derecho de información del accionista, en Derecho de sociedades anónimas. II Capital y acciones. Vol. 1., ALONSO, A. et alt. (coord.), Madrid, 1994, pp. 175 a 253.

GINES CASTELLET, N.: "Impugnación de acuerdos sociales y abuso de derecho: algunas reflexiones para el ordenamiento jurídico español a la luz de la experiencia", Revista Derecho de Sociedades, núm. 40/2013, pp. 273 a 315.

GÓMEZ TRINIDAD, S.: "Revisión del derecho de información en las sociedades de capital: derecho del socio versus deber social", Revista de Derecho Mercantil, núm. 281/2011, pp. 213 a 249.

MARTÍ LACALLE, R.: "El derecho de información del accionista en la junta general: últimas aportaciones de la jurisprudencia del Tribunal Supremo", en Cuadernos de Derecho y Comercio, núm. 29/1999, pp. 289 a 322.

MENENDEZ MENENDEZ, A., Lecciones de Derecho Mercantil, Pamplona, 2009 
MUÑOZ PALMA, C. Y TORTUERO ORTIZ, J.: “Algunas cuestiones prácticas sobre la impugnación de acuerdos sociales", Revista Aranzadi Doctrinal, núm. 8/2013, pp. 195 a 210.

QUIJANO GONZÁLEZ, J.: "Bases para una revisión del derecho de impugnación de los acuerdos sociales", en La Modernización del derecho de sociedades de capital en España: cuestiones pendientes de Reforma, ALONSO LEDESMA, C Y ALONSO UREBA, A. (direcc), vol. 1, 2011, pp. 261 a 292.

Idem: "Ideas generales y reforma del sistema de impugnación español de los acuerdos sociales" La Notaría, núm. 2/2013.

ROMERO FERNÁNDEZ, J.A.: El derecho de información del accionista: objeto, límites y forma de ejercicio, Madrid, 2001.

SOTILLO MARTÍ, A.: “Acuerdos impugnables de la Junta General y del Consejo de Administración: análisis de la jurisprudencia del Tribunal Supremo sobre impugnación de acuerdos sociales", Estudios de Derecho judicial, núm. 107/2006.

VICENT CHULIA, V.: Introducción al Derecho mercantil, Valencia, 2007. 



\title{
INSTRUMENTOS JURÍDICOS PARA LA AUTODETERMINACIÓN PERSONAL: RELACIONES DE CONSUMO, COMUNICACIONES COMERCIALES, PRIVACIDAD Y SMART SOCIETY
}

Legal instruments for self-determination personal: consumer relations, advertising, privacy and smart society

\section{María Rosa Llácer Matacás}

Catedrática de Derecho civil. Universidad de Barcelona. E-mail: mrllacer@)ub.edu

\section{RESUMEN}

Para que el principio de autonomía personal no sea una mera apariencia la sociedad actual, caracterizada por profundas asimetrías, son precisas normas imperativas y funcionales. Este artículo analiza la cuestión en la sociedad de consumo y de las TICs. La libertad económica requiere preservar una efectiva autonomía en las relaciones de consumo. Se analizan la contratación de consumo, con especial consideración del consentimiento informado, así como las prácticas comerciales desleales como mecanismo de regulación del mercado. Los instrumentos que garantizan la libertad en la sociedad de la información permiten controlar la esfera personal y el acceso a la persona. Esto es difícil a causa del gap tecnológico entre ciudadanos y responsables de la sociedad de la información. La privacidad en entornos Smart se enfrenta a nuevas formas de contactabilidad y requiere la colaboración de la tecnología.

Palabras clave: Autodeterminación personal. Contratación de consumo. PráctiCas comerciales. Privacidad. Datos Personales.

\begin{abstract}
For the principle of personal autonomy is not a mere appearance in modern society, characterized by deep asymmetries, imperative and functional standards are necessary. This article discusses the issue in the consumer society and ICT. Economic freedom must maintain effective autonomy in consumer relations. Consumer engagement are analyzed, with special consideration of informed consent, and unfair
\end{abstract}


business practices as a market regulation mechanism. The instruments that guarantee freedom in the information society to control the personal sphere and access to the person. This is difficult because of the technological gap between citizens and responsible for the information society. Privacy smart environments are facing new forms of contactability and requires technology collaboration.

Keywords: Personal Self-Determination. Business practices. Consumer contracting. Privacy. Personal data.

SumARIO: 1. Los retos de la autonomía personal en escenarios asimétricos: sociedad de consumo y sociedad de la información. 2. Instrumentos para la libertad económica: las relaciones de consumo. 2.1. La contratación de consumo; especial consideración del consentimiento informado. 2.2. La protección en el mercado: la prohibición de las prácticas comerciales desleales. 3. Instrumentos para la libertad tecnológica: el derecho a la vida privada. 3.1. El derecho a ser dejado en paz: comunicaciones comerciales y régimen de acceso a la persona. 3.2. La privacidad en el escenario de las nuevas tecnologías: el control sobre la esfera personal en la sociedad de la información. 3.3. Protección de datos personales y entornos smart. 3.3.1. Nuevas formas de contactabilidad: ¿nuevos datos personales? 3.3.2. La necesaria colaboración de derecho y técnica. Conclusión. Bibliografía.

\section{LOS RETOS DE LA AUTONOMÍA PERSONAL EN ESCENARIOS ASIMÉTRICOS: SOCIE- DAD DE CONSUMO Y SOCIEDAD DE LA INFORMACIÓN.}

Nuestra sociedad sitúa a las personas entre grandes beneficios tecnológicos y enormes riesgos individuales y colectivos. La falta de conocimientos acerca de los productos y servicios o de técnicas de comercialización incide sobre la autodeterminación del cliente o del usuario, que se convierte en un valor a preservar. El examen se centrará en dos grandes ámbitos, ineludibles a lo largo de lo que podríamos llamar una "vida normal": el mercado de consumo y la sociedad de la información. Todo ciudadano necesita acudir al mercado para proveerse de bienes y servicios, utilizar las nuevas tecnologías y moverse en una realidad virtual tan necesaria y real como la presencial. Corresponde al derecho ordenar la actividad de los prestadores de servicios con el fin de garantizar la autonomía individual, así como la libertad colectiva que caracteriza y sostiene una sociedad democrática.

Proliferan leyes especiales que acometen la regulación de sectores caracterizados por la asimetría entre sus protagonistas: por un lado, quienes organizan y prestan bienes y servicios; por otro, quienes los reciben o necesitan. Los primeros 
disponen del know how y la fuerza negocial de la que carecen los segundos. Por esta razón, son normas que ordenan el sector estableciendo el estatuto del prestador. No son normas neutrales sino sociales cuya finalidad es garantizar el principio de libertad y la autonomía inherente a las personas, comprometidas en dichos escenarios ${ }^{358}$. El derecho se vale de estatutos, es decir, de normas imperativas que protegen los derechos de una parte de la relación generando deberes a cargo de la otra. Reúnen una serie de instrumentos jurídicos que reequilibran la relación en beneficio de quien se halla en una situación de desconocimiento o debilidad por el hecho de pertenecer al colectivo (usuario de TICs, consumidor). En un Estado social, las nuevas formas de sumisión deben tener su corrección jurídica como base un desarrollo armónico ${ }^{359}$. Las Directivas europeas en el ámbito del consumo y de la protección de datos personales han orientado decisivamente este "derecho social" 360 .

La contratación con consumidores presenta un grado de imperatividad impropia de los Códigos civiles que no asumían una función redistributiva, ajena a los principios de igualdad y libertad ${ }^{361}$. Ello no significa que actualmente, en escenarios

${ }^{358}$ El trabajo se enmarca en la ejecución del Proyecto DER2012-32667 del Ministerio de Economía y Competitividad sobre "La nueva contratación privada: diseño y codificación de instrumentos reequilibradores en contextos de asimetría negocial" y en les actividades del Grup de Recerca consolidat en Dret Privat, Consum i Noves Tecnologies de la Universitat de Barcelona (GREDINT) 2014 SGR 688. HESSELINK M. W. CFR \& Social Justice. Munich, Sellier European Law Publishers, 2008, p.13.

${ }^{359}$ GRUNDMANN, S. 'L'autonomia privata nel mercato interno. Le regole d'infomazione come strumento". En: Europa e diritto privato, 2001, pp. 257-304; TEMPLE, H. «Le droit de la consommation est-il subversif?», Mélanges en l'honneur de Jean Calais-Auloy. Paris, Dalloz, 2004, p. 1078: «Si le droit de la consommation permet de corriger ce déséquilibre il est donc a-subsersif, indispensable à l'économie: on pourrait dire 'suprasubversif'».

${ }^{360}$ Básicamente, en cuanto a la protección de los consumidores: Directiva 2011/83/UE del Parlamento Europeo y del Consejo de 25 de octubre de 2011, sobre los derechos de los consumidores; transpuesta en España por la Ley 3/2004, de 27 de marzo que modifica el Real Decreto Legislativo 1/2007, de 16 de noviembre, por el que se aprueba el texto refundido de la Ley General para la Defensa de los Consumidores y Usuarios y otras leyes complementarias. Por lo que respecta a la protección de datos personales: Directiva 95/46/EC del Parlamento Europeo y del Consejo de 24 de octubre de 1995 relativa a la protección de las personas físicas en lo que respecta al tratamiento de datos personales y a la libre circulación de estos datos. Téngase en cuenta la Resolución legislative del Parlamento Europeo de 12 de marzo de 2014, on the proposal for a regulation of the European Parliament and of the Council on the protection of individuals with regard to the processing of personal data and on the free movement of such data (General Data Protection Regulation) ((COM(2012)0011 - C70025/2012 - 2012/0011(COD)). En España: Ley Orgánica 15/1999, de 13 diciembre, de protección de datos de carácter personal y Real Decreto 1720/2007, de 21 de diciembre, por el que se aprueba el Reglamento de desarrollo de la Ley Orgánica 15/1999, de 13 de diciembre, de protección de datos de carácter personal.

${ }^{361}$ Lo realmente revolucionario consistió, entonces, en reconocer la igualdad esencial de las 
mayoritariamente asimétricos, no puedan desempeñarla mediante instrumentos de reequilibrio que recuperan la libertad de elección en toda persona sin especiales conocimientos ${ }^{362}$. Esta función social se manifiesta en la regulación de estándares con finalidad correctora ${ }^{363}$. La norma puede disponerlos en escenarios individuales o colectivos. La unfair exploitation constituye un ejemplo de lo primero ya que permite adaptar o rescindir un contrato sobre la base de la ventaja desleal obtenida con la explotación de una concreta debilidad de la contraparte (cfr. art. II. - 7:207 DCFR). En cambio, el deber de información en los tratos precontractuales tanto puede fundarse en un estándar tuitivo (art. 60 TRLCU $^{364}$, art. II. - 3:102 DCFR) como en el deber general de lealtad y cooperación (art. II.- I:102 (1) DCFR).

La autodeterminación también es el fundamento del derecho a la protección de la información personal. En efecto, la sociedad de la información funciona.... con información; y desde el momento en puede relacionarse con una persona, el responsable de su tratamiento detenta un instrumento de poder. Una sociedad que admite los sistemas de colecta de datos a gran escala, asociados a actos de la vida cotidiana (entre los cuales la obtención de servicios de consumo, con lo cual se redoblarían los motivos de desequilibrio), compromete la capacidad de autodeterminación individual y, finalmente, la libertad colectiva ${ }^{365}$. La protección de datos es pues una garantía de la privacy o vida privada en sentido amplio. El conocimiento acerca de la vida, hábitos y debilidades de una persona confiere capacidad de decisión sobre ella $^{366}$. Los proveedores de servicios tienen gran interés en obtener datos personales

persones y plasmarla en Constituciones y Códigos: MALUQUER DE MOTES, C. J. " $\mathrm{La}$ codificación civil en España (síntesis de un proceso". En: R.D.P., 1981, pp. 1083 ss.

${ }^{362}$ MELI, M. "Social Justice, Constitutional Principles and Protection of the Weaker Contractual Party". En: ERCL, 2006, p. 165: "the concept of justice refers to the weak party relationship, that is, basically, the consumer, in order to assure a good exercise of its power of choice".

${ }^{363}$ HESSELINK, M.W: CFR \& Social Justice, cit., p. 21.

${ }^{364}$ Real Decreto Legislativo $1 / 2007$, de 16 de noviembre, por el que se aprueba el texto refundido de la Ley General para la Defensa de los Consumidores y Usuarios y otras leyes complementarias (BOE» núm. 287, de 30/11/2007).

${ }^{365}$ ROUVROY A. y POULLET, Y: "The right to informational self-determination and the value of self-development. Reassessing the importance of privacy for democracy". En: Reinventing Dara Protection?, S. Gutwirth, Y. Poullet, P. De Hert, C. de Terwange, S. Nouwt (edit.). Munich, Spinger, 2009, p. 260: "the right to privacy is irreducible to the right to data protection (...); the concept of data protection appears in a second step, taking fully into account the new risks threatening the two 'aspects' of the privacy (the right to seclusion and the right of decisional autonomy), ensuing from the development of the Information and communication technologies".

${ }^{366}$ COHEN, J. E.: "Examined Lives: Informational Privacy and the Subject as Object". En: 52 Stan. L. Rev., 1999-2000, pp. 1406 y 1427: "The autonomy fostered by informational 
adicionales y la autorización para utilizarlos en su propio beneficio. Esto explica los sistemas de recogida, organizados por "little brothers" que ya no ejercen una vigilancia manifiestamente represiva porque se participa en ellos voluntariamente al usar los servicios de la sociedad de la información ${ }^{367}$. Internet y objetos smart capturan automáticamente datos del tráfico y de localización, permiten obtener rápidamente perfiles de comportamiento y aplicar decisiones inmediatas a través de los objetos receptores. Internet ya parece un medio «convencional» de tratamiento invisible des datos $^{368}$ frente al nuevo escenario que presenta el ubiquitous networking. El Internet of things y las aplicaciones de inteligencia ambiental (relaciones M2M) permiten capturar información constantemente, actualizar los perfiles en línea y utilizarlos para anticipar decisiones. El gap tecnológico entre los responsables del tratamiento y los ciudadanos que utilizan un servicio plagado de " peajes », pone en evidencia un déficit de información creciente y una proactividad cada vez más difícil.

\section{INSTRUMENTOS PARA LA LIBERTAD ECONÓMICA: LAS RELACIONES DE CONSUMO.}

\subsection{La CONTRATACIÓN DE CONSUMO; ESPECIAL CONSIDERACIÓN DEL CONSENTI- MIENTO INFORMADO.}

En la relación de consumo, que media entre un profesional y un consumidor considerado como la persona que carece de aquella cualificación, el principio de igualdad formal se quiebra a favor de dichas personas "típicamente desaventajadas" atribuyéndoles derechos que se convierten en limitaciones y deberes para la otra parte ${ }^{369}$ con el objeto de reconstruir un equilibrio efectivo en el ejercicio de la libertad contractual. Para ello van a crearse "estándares" jurídicos sobre situaciones típicas $^{370}$. La expresión "tipicidad" indica la adecuación a un colectivo predefinido,

privacy also generates more concrete collective benefits. Development of the capacity for autonomous choice is an indispensable condition for reasoned participation in the governance of the community and its constituent institutions-political, economic, and social. The cornerstone of a democratic society is informed and deliberate self-governance".

${ }^{367} \mathrm{NEHF}, \mathrm{J}$. P. "Recognizing the societal value in Information privacy". En: 78 Wash. L. Rev., 2003, pp. 11 y 14.

${ }^{368}$ Advertido ya por la Recomendación 1/99 on Invisible and Automatic Processing of Personal Data on the Internet Performed by Software and Hardware, de 23 de febrero de1999 (Working Party on the Protection of Individuals with regard to the Processing of Personal data, WP17). http://ec.europa.eu/justice/data-protection/article-29/documentation/opinion-recommendation/files/1999/wp17_en.pdf

${ }^{369}$ EICHENHOFER, E. “'L'utilizzazione del diritto privato per scopi di política sociale”. En: Rivista di Diritto Civile, 1977, pp. 195 y 201.

${ }^{370}$ EICHENHOFER, E. “L'utilizzazione..." cit, p. 209: "Il diritto privato utilizzato a scopi di politica sociales può con il jus cogens formulare uno standard minimo a tuttela della 
con el fin de trasladar un estatuto en bloque a quienes encajan en ella y ponerlo a cargo del profesional.

El estatuto está formado por normas especiales que modifican la norma general contenida en el Código civil. Uno de los aspectos en los que mejor se manifiesta esta alteración es el proceso de celebración del contrato, que contiene normas que protegen tanto la consciencia de la declaración contractual como su contenido. La declaración debe ser cierta, consciente y libre: pero mientras que los arts. 1254 y 1262 CCE presuponen la libertad contractual, el Real Decreto Legislativo 1/2007, que aprueba el texto refundido de la Ley General para la Defensa de los Consumidores y Usuarios, contiene preceptos que precisamente quieren prevenir dicha libertad.

En primer lugar, el empresario debe obtener de forma inequívoca la voluntad del consumidor de contratar (art. 62.1 TRLCU) o de poner fin al contrato (art. 62.3 y 4 TRLCU). Debe disponer los medios para asegurarse de la certeza de la declaración. En particular, en la contratación a distancia, el consumidor debe confirmar la oferta por escrito (o en cualquier soporte de naturaleza duradera a menos que éste se oponga): el art. 98.6 TRLCU sólo considera vinculado al consumidor "una vez que haya aceptado la oferta mediante su firma o mediante el envío de su acuerdo por escrito, que, entre otros medios, podrá llevarse a cabo mediante papel, correo electrónico, fax o sms" ${ }^{\prime 371}$.

En segundo lugar, la declaración debe ser consciente por parte del consumidor. Esto explica la prohibición de predisponer el valor positivo del silencio y de realizar envíos no solicitados que incluyan pretensión de pago (art. 66 quáter TRLCU), disposiciones que contrastan con la perspectiva civil que se limita a negar que el silencio o inacción "por sí solos" puedan valer como aceptación de la oferta ${ }^{372}$. Así, la falta de respuesta del consumidor no se considera una aceptación de la oferta (arts. 66 quáter.1.2 y 101 TRLCU) y no genera obligaciones (devolución o custodia) ni ampara la reclamación de pago (art. 101.2 TRLCU). La conciencia de la declaración se protege, asimismo, a través de opciones opt-in que preservan el consentimiento expreso. El art. 60 bis. 1 TRLCU las prevé para los pagos adicionales sobre la remuneración pactada, que deben comunicarse de manera clara y comprensible, y cuya aceptación se realizará "sobre una base de opción de inclusión". Se descarta el consentimiento deducido de la falta de pronunciamiento frente a opciones por defecto, predispuestas por el empresario y que imponen proactividad al consumidor

parte contrattuale “debole". La ragion d'essere di questa disciplina è sempre trovare tra le parti un equilibrio di interessi in conflitto oppure anche contrapposti”.

${ }^{371}$ La misma finalidad persigue la previsión de solicitud expresa para iniciar la prestación del servicio antes de que expire el plazo de desistimiento (art. 98.8 TRLCU).

372 Véase el art. 1250 Propuesta de Modernización del Código Civil español en materia de Obligaciones y Contratos (PMCCE)file://C:/Users/Maria\%20Rosa/Downloads/720629-Propuesta $\% 20 \mathrm{de} \% 20$ modernizaci $\% \mathrm{C} 3 \% \mathrm{~B} 3 \mathrm{n} \% 20 \mathrm{de} \% 20$ obligaciones $\% 20 \mathrm{y} \% 20$ contratos $\% 20 \mathrm{CC} \% 20(2009)$.pdf 
y la carga de rechazarlas.

Finalmente, la declaración debe ser libre, no entorpecida ni inducida por el empresario. El art. 62.2 TRLCU prohíbe las "cláusulas que impongan obstáculos onerosos o desproporcionados para el ejercicio de los derechos reconocidos al consumidor en el contrato". El art. 62.3.1 TRLCU protege la libertad de poner fin al contrato al vedar las cláusulas que establezcan plazos de duración excesiva o limitaciones que la excluyan u obstaculicen y reconociendo el derecho de poner fin al contrato en la misma forma en que se celebró, sin ningún tipo de sanción o de cargas onerosas o desproporcionadas. Tal derecho tiene su reverso en el deber del empresario prestador de servicios o suministros de tracto sucesivo de "contemplar expresamente el procedimiento a través del cual el consumidor y usuario puede ejercer su derecho a poner fin al contrato".

El consentimiento informado protege la consciencia sobre el contenido de la declaración. En los Códigos civiles, la supervisión de la voluntad sobre el contenido contractual se ordena en torno a los vicios de la voluntad (arts. 1266, 1269 y 1270 CC) y la incorporación del principio de buena fe en la negociación: aunque el art. 1258 CCE sólo menciona la buena fe en la ejecución del contrato, es oportuno recordar la incorporación de la buena fe en los tratos precontractuales tanto en los nuevos códigos (art. 111-7 CCCat, referido a las relaciones jurídicas privadas en general), como en recientes propuestas (art. 1245.2 PMCCE, arts. $2 \mathrm{CESL}^{373}$ ) o textos académicos (art. II 3:101 DCFR $\left.{ }^{374}\right)^{375}$.

Con carácter general el derecho a la información se enuncia en el art. 8.d TRLCU y genera el correlativo deber de informar en el empresario (art. 60 TRLCU). Este deber se contextualiza bien por razón de la técnica de contratación (a distancia y fuera de establecimiento mercantil: art. 97 TRLCU, art. 7.3 Ley 22/2007, de 11 de julio, sobre comercialización a distancia de servicios financieros destinados a los consumidores), bien por la presencia de un intermediario (art. 7.1.1.c Ley 22/2007, art. 15 Directiva 2014/17/UE), bien por razón del bien o servicio contratado (a título de ejemplo, art. 152 TRLCU en relación con los viajes combinados; art. 3 Ley 43/2007, de 13 de diciembre, de protección de los consumidores en la contratación de bienes con oferta de restitución del precio; arts. 9, 10 y 12 Ley 16/2011, de 24 de junio, de contratos de crédito al consumo; arts. 9 y 10 Ley 4/2012, de 6 de julio, de contratos de aprovechamiento por turno de bienes de uso turístico, art. 7.2 y 8.1

\footnotetext{
${ }^{373}$ Propuesta de Reglamento del Parlamento Europeo y del Consejo, relativo a una normativa común de compraventa europea, Bruselas, 11.10.2011, COM(2011) 635 final, 2011/0284 (COD)

374 Principles, Definitions and Model Rules of European Private Law Draft Common Frame of Reference (DCFR),http://ec.europa.eu/justice/policies/civil/docs/dcfr_outline_edition_ en.pdf

${ }^{375}$ Art. 1.5 del Código civil de la República de Lituania, Art. 6:193 y 6:34 del Código civil holandés.
} 
Ley $22 / 2007)^{376}$. Cabe señalar la tendencia a la estandarización de la información a través de fichas (así, Anexos I a IV Ley 4/2012; Anexos II y III Ley 16/2011; Anexo II ficha europea de información normalizada o FEIN en la Directiva 2014/17/UE).

La función del standard de información de consumo es asegurar unas condiciones generales de elección racional. En la norma de consumo subyace o se expresa la idea de que la información habilita "para tomar una decisión fundada sobre la conveniencia de celebrar o no un contrato" (art. 14.1, art. 16.1 Directiva 2014/17/ $\mathrm{UE})^{377}$.

El deber de informar puede configurarse como un deber bilateral o unilateral. Los contratos de servicios constituyen un ejemplo de información bilateral, que tiene dos finalidades: preservar la decisión informada del consumidor, pero también hacer aflorar los datos suficientes para delimitar adecuadamente el objeto del contrato. Así ocurre en la Directiva 2014/17/UE del Parlamento Europeo y del Consejo, de 4 de febrero de 2014, sobre los contratos de crédito celebrados con los consumidores para bienes inmuebles de uso residencial. Mientras que los arts. 14 y 15 Directiva 2014/17/UE se refieren a la información precontractual ligada a la condición de consumidor, sus arts. 7 y 20 apelan a la buena fe en los tratos precontractuales sin fijar imperativamente el contenido o la forma de la información; contemplan el deber de actuar "de manera honesta, imparcial, transparente y profesional, teniendo en cuenta los derechos y los intereses de los consumidores" y el deber del consumidor de informar sobre sus circunstancias y solvencia ${ }^{378}$. Asimismo, la protección del "cliente de

${ }^{376}$ La ley incide también en la manera en que se debe suministrar la información, ya que ello también converge en la toma de decisión. Así, prevé el momento en que se suministrará la información (arts. 60.1, 60 bis, 97.1 TRLCU) y el deber de transparencia: deberes de veracidad, objetividad, accesibilidad, claridad, carácter inequívoco (véanse los arts. art. 60.1, 97.1, 98.1, 2 y 3 TRLCU. El deber de documentar la información también entraña una función protectora (arts. 97.4 y 98.7.a TRLCU) por cuanto integra el contrato (art. 61 TRLCU) y permite consultar y probar este contenido.

${ }^{377}$ Debe diferenciarse del deber de asistencia o que presupone la previa calificación del cliente, con el fin de darle información adaptada a su perfil (art. 11 y 16/2011, de 24 de junio, de contratos de crédito al consumo, referente a la asistencia al consumidor previa al contrato). De nuevo se trata de un deber de asesoramiento personalizado que dependerá de las características del consumidor o bien -más ampliamente- del cliente minorista (art. 73 Real Decreto 217/2008, de 15 de febrero, sobre el régimen jurídico de las empresas de servicios de inversión y art. 79 bis. 7 de la Ley 24/1988, de 28 de julio, del Mercado de Valores, vigente hasta el 24 de Diciembre de 2014).

${ }^{378}$ La Propuesta de Reglamento del Parlamento Europeo y del Consejo, relativo a una normativa común de compraventa europea (CESL), concreta el principio de buena fe en la contratación entre empresarios, fijando el deber de informar de las características principales que tuvieran o pudiera esperarse que tuvieran de los bienes y que fuera contrario a la buena fe contractual no revelar a la otra parte (art. 23 CESL). Véase asimismo el CDO 31 CESL: "El principio de buena fe contractual debe servir de guía a la hora de decidir la forma en que 
servicios bancarios" se propone "garantizar el adecuado nivel de protección de los clientes de entidades de crédito, mediante la implantación de medidas de transparencia en la prestación de servicios financieros bancarios" (art. 1 Orden EHA/2899/2011, de 28 de octubre, de transparencia y protección del cliente de servicios bancarios). A tal efecto, la Orden establece deberes de transparencia (información "clara, oportuna y suficiente, objetiva y no engañosa") y de oportunidad (con la debida antelación y, en todo caso, antes de que el cliente quede vinculado) así como la entrega al cliente de un ejemplar del documento contractual (art. 7) y la documentación en papel, formato electrónico u otro soporte duradero (art. 11) ) $^{379}$. El art. 6 Orden EHA/2899/2011 enfatiza que su finalidad no es otra que "adoptar una decisión informada sobre un servicio bancario y comparar ofertas similares". Se complementa con el deber de cooperación (art. 9): las entidades de crédito deben facilitar explicaciones adecuadas y suficientes "para comprender los términos esenciales de todo servicio bancario ofertado y adoptar una decisión informada, teniendo en cuenta sus necesidades y su situación financiera", todo ello de acuerdo con la diligencia profesional exigible. Por otra parte, el deber de evaluar la solvencia del cliente involucra también al mismo que deberá facilitar la documentación requerida para evaluar la variabilidad de los ingresos (art. 18.1 y 18.2.a) que fundamentará la decisión contractual (art. 18.5 y 6).

\subsection{LA PROTECCIÓN EN EL MERCADO: LA PROHIBICIÓN DE LAS PRÁCTICAS CO- MERCIALES DESLEALES.}

Como consumidor eventual, la persona es destinataria de publicidad y de prácticas comerciales. Ambas actividades se sujetan a regímenes que ordenan sus condiciones de licitud. Nos centraremos brevemente en las normas de protección de los consumidores, considerados como intervinientes en el mercado y objetivo de conductas con fines concurrenciales. Las conductas de los empresarios deben ajustarse a la buena fe que, aplicada a sus relaciones con consumidores, no puede

han de cooperar las partes (...). Los requisitos concretos resultantes del principio de buena fe contractual deben depender, entre otras cosas, del nivel relativo de conocimientos especializados de las partes y, por consiguiente, deben ser diferentes en las transacciones entre empresas y consumidores y en las transacciones entre empresas. En las transacciones entre comerciantes, las buenas prácticas comerciales en la situación especifica de que se trate deben ser un factor pertinente en este contexto". Destacamos en cursiva la especificidad de la información entre comerciantes, que no puede definirse a priori en función de un desconocimiento típico, sino en función del contexto, es decir, considerando "todas las circunstancias", que el art. 23.2 CESL ejemplifica.

${ }^{379}$ Respecto a los préstamos hipotecarios, el deber de información se sujeta a la Ficha de Información Precontractual y a la Ficha de Información Personalizada (arts. 21 y 22), que se integran en el régimen de la oferta vinculante (art. 23). Se añade el deber de informar sobre los instrumentos de cobertura del riesgo de tipo de interés (art. 24) y sobre sobre cláusulas suelo y techo. 
ser susceptible de distorsionar el comportamiento económico del consumidor medio. En definitiva, se pretende la protección del consumidor a través de la regulación del mercado, que tiene en cuenta los legítimos intereses de todos sus participantes ${ }^{380}$ (Exposición de Motivos de la Ley 3/1991, de 10 de enero, de Competencia Desleal-LCD-). Para ello se prohíben determinadas conductas, con el fin de crear unas condiciones de concurrencia que garanticen la subsistencia condiciones para una efectiva la libertad de decisión en los consumidores, garantizando que las prácticas comerciales no mermen de forma apreciable su capacidad de decidir con pleno conocimiento de causa, de forma que tomen una decisión que de otro modo no habrían tomado (art. 2.e Directiva 2005/29/CE del Parlamento Europeo y del Consejo, de 11 de mayo de 2005, relativa a las prácticas comerciales desleales de las empresas en sus relaciones con los consumidores en el mercado interior).

Este régimen se predica de las prácticas comerciales y no de una relación contractual. Así se desprende del art. 19 TRLCU que, por una parte, se refiere a las "prácticas comerciales" consideradas como actos unilaterales del empresario hacia su clientela consumidora y, por otra, a las "relaciones de naturaleza contractual" que se sujetan a los arts. 59 y ss. TRLCU. En efecto, la noción de "práctica comercial" es extraordinariamente amplia ${ }^{381}$ y sólo se contempla desde la perspectiva contractual cuando se celebra o se frustra la celebración del cotnrato (así, la ruptura culpable de los tratos precontractuales). Esta diferenciación justifica la naturaleza mercantil del régimen de las prácticas desleales y la regulación civil del derecho contractual; por citar sólo algunas de las materias jurídicas en que se distribuye el llamado derecho de consumo ${ }^{382}$.

Si es desleal todo comportamiento objetivamente contrario a las exigencias de la buena $\mathrm{fe}^{383}$, en las relaciones con consumidores éste se mide con referencia a la

\begin{abstract}
${ }^{380}$ E.M. II.2 de la Ley 29/2009, de 30 de diciembre, por la que se modifica el régimen legal de la competencia desleal y de la publicidad para la mejora de la protección de los consumidores y usuarios: "Las normas que imponen la protección de la libre competencia o prohíben la competencia desleal protegen a los consumidores de la misma manera que protegen el funcionamiento del mercado y los intereses de los operadores económicos que actúan en el mismo. Es por ello que esta ley articula la protección de los consumidores teniendo en cuenta las exigencias del propio mercado y los legítimos intereses de los operadores económicos que actúan en el mismo".
\end{abstract}

381 Art. 19.2.2 TRLCU: "todo acto, omisión, conducta, manifestación o comunicación comercial, incluida la publicidad y la comercialización, directamente relacionada con la promoción, la venta o el suministro de un bien o servicio a los consumidores y usuarios, con independencia de que sea realizada antes, durante o después de una operación comercial".

${ }^{382}$ Llácer Matacás, M. R.: "El llibre sisè $i$ la proposta de nou 'código mercantil”. En: Materiales de las XVII Jornades de Dret català a Tossa sobre El Llibre sisè del Codi Civil de Catalunya: Anàlisi de l'avantprojecte de llei, Tossa de Mar, 25 y 26 de septiembre de 2014. http://civil.udg.edu/tossa/2014/textos/pon/1/LLACER.pdf

383 Se trata de un modelo de diligencia que toma por referencia "el nivel de competencia y 
infracción del estándar de diligencia profesional (definida como el nivel de competencia y cuidados especiales que cabe esperar de un empresario conforme a las prácticas honestas del mercado) con capacidad para distorsionar o poder distorsionar de manera significativa el comportamiento económico del consumidor medio (art. 4.1 y 2 LCD). Representa una merma apreciable de la capacidad de adoptar una decisión con pleno conocimiento de causa, con incidencia en el comportamiento económico.

El bien directamente protegido mediante la regulación de las conductas concurrenciales es la autodeterminación económica, dificultada o impedida por las conductas que proporcionan $\mathrm{u}$ omiten información necesaria para decidir (actos de engaño por contener información falsa o que induzca o pueda inducir a un error -art. 5.1 LCD- y actos de omisión por ocultar información o proporcionarla sin la transparencia necesaria -art. 7.1 LCD-) o que por su agresividad merman de manera significativa la libertad de elección del destinatario (art. 8.1 LCD). La deslealtad converge pues en un resultado: la alteración del comportamiento económico deseable, que presupone decisiones tomadas "con el debido conocimiento de causa" y sin presión. Plenitud de información y ausencia de influencia indebida son condiciones de conducta leal en el mercado.

Con tal fin el ordenamiento prohíbe los actos de competencia desleal mediante una cláusula general y definiendo y enumerando los actos específicos de engaño y agresividad en relación con los consumidores (art. 19 a 31 LCD). La prohibición de la conducta conlleva la atribución de medios de tutela en caso de contravención. Su finalidad es declarar la deslealtad, reponer el estado de cosas anterior (cesación o prohibición, remoción de los efectos, rectificación) y resarcir los daños y perjuicios si intervino dolo o culpa del agente ${ }^{384}$. La tutela es individual o colectiva. El art. 33.1 LCD legitima activamente a cualquier persona participante en el mercado, si bien es poco probable que las acciones se ejerzan individualmente por un consumidor. Por ello es fundamental la vía colectiva (art. 33.1.4 y 33.2 LCD) ${ }^{385}$.

Una práctica comercial en particular permite abordar la transición hacia el

cuidados especiales que cabe esperar de un empresario conforme a las prácticas honestas del mercado", luego un modelo objetivable como lo es la honradez en los tratos o las reglas propias del mercado (cfr art. 111-7 del Código civil catalán). Para diferenciar los dos principios presentes en el art. 111-7 CCCat, véase BADOSA COLL, F. "Les fonts del Dret civil català". En: Manual de Dret civil català. Madrid-Barcelona, Marcial Pons, 2003, p. 91 y EGEA FERNÁNDEZ, J. “Comentari a l'art. 111-7 CCCat”. En: Comentari al llibre primer del Codi civil de Catalunya. Disposicions preliminars. Prescripció i caducitat (ed. A. Lamarca i Marquès i A. Vaquer Aloy). Barcelona, Atelier, 2012, pp. 239-240.

${ }^{384}$ Art. 32.6. ${ }^{a}$ LCD: “Acción de enriquecimiento injusto, que sólo procederá cuando la conducta desleal lesione una posición jurídica amparada por un derecho de exclusiva u otra de análogo contenido económico".

${ }^{385}$ CORDOBÉS MILLÁN, E. Prácticas comerciales desleales: tutela del consumidor y del mercado, Tesis doctoral inédita, Universitat de Barcelona, 2013. 
próximo apartado dedicado a la protección de la vida privada: son desleales determinadas formas de contactar con el consumidor. El art. 29.2 LCD califica de agresivas por acoso las propuestas no deseadas y reiteradas por teléfono, fax, correo electrónico u otros medios de comunicación a distancia. Mientras que esta norma protege la libertad de decisión como requisito de buen funcionamiento del mercado y criterio de defensa de un interés de los consumidores (art. 19.1 y 2 TRLCU), el régimen de las comunicaciones comerciales protege el acceso a los particulares y, en definitiva, la vida privada y el uso de la información personal (arts. 94 y 96 TRLCU y arts. 19 a 22 Ley 34/2002, de 11 de julio, de servicios de la sociedad de la información y de comercio electrónico -LSSICE-) $)^{386}$.

\section{INSTRUMENTOS PARA LA LIBERTAD TECNOLÓGICA: El DERECHO A LA VIDA PRI- VADA. \\ 3.1. EL DERECHO A SER DEJADO EN PAZ: COMUNICACIONES COMERCIALES Y RÉGI- MEN DE ACCESO A LA PERSONA.}

Cuando un requerimiento comercial se dirige de forma personalizada están en juego tanto el derecho sobre la vida privada como sobre los datos personales utilizados para acceder a la persona. Las normas que enfocan la comunicación comercial como una forma de acceso personalizado se detectan en varios ámbitos normativos: el derecho de consumo (arts. 94 y 96 del Real Decreto Legislativo 1/2007, de 16 noviembre, que aprueba el texto refundido de la ley general para la defensa de los consumidores y usuarios y otras leyes complementarias; art. 14 de la Ley 22/2007, de 11 de julio, de comercialización a distancia de servicios financieros destinados a los consumidores; art. 29 LCD), la regulación de los servicios de la sociedad de la información (arts. 19 a 22 y Anexo a) LSSICE ${ }^{387}$ ), de las telecomunicaciones (art. 46 y 48 LGT y arts. 67 y 69 de su Reglamento) y de la protección de datos personales (art. 6, 11 y 30 Ley Orgánica 15/1999, de 13 de diciembre, de Protección de Datos de Carácter Personal. -LOPD- y art. 45 de su Reglamento).

${ }^{386}$ ARROYO APARICIO, A. "Comentario al art. 8”. En: Comentarios a la ley de Competencia Desleal (dir. A. Bercovitz Rodríguez-Cano). Madrid, Aranzadi Thomson Reuters, 2011, p. 212. Por ejemplo, un solo correo electrónico que infrinja el art. 21 LSSICE puede calificarse de spam desde la perspectiva de la legislación de protección de datos; sin embargo no reúne las condiciones de una práctica agresiva por acoso de conformidad con el art. 29.2 LCD.

387 Aunque el Anexo a) LSSICE incluye el envío de comunicaciones comerciales entre los servicios de la sociedad de la información, cabe notar que no siempre serán un servicio prestado a petición individual del destinatario. Justamente el Título III LSSICE, se refiere tanto a las que se amparan en una solicitud previa como a las pueden remitirse lícitamente, con base en una legitimación legal. En ambos casos son una iniciativa del emisor que, en ejercicio de su libertad de empresa, organiza el envío de mensajes a unos destinatarios que considera adecuados. 
El envío de publicidad personalizada ${ }^{388}$ es una actividad comercial que satisface el interés individual del empresario pero no tiene por qué coincidir con el del destinatario. La recepción del mensaje incide directamente sobre la esfera privada del destinatario, a quien se atribuyen facultades para gestionar la intensidad del acceso por parte de terceros. Correlativamente se imponen distintos regímenes al emisor, en calidad de empresario, de proveedor de SSI o de responsable del tratamiento de datos personales. Con la expresión "régimen" se alude al conjunto de límites legales impuestos al ejercicio de una actividad comercial lícita, con el fin de tutelar otros intereses, personales o económicos, dignos de protección.

El envío de comunicaciones comerciales es una actividad económica y, como tal, sujeta a disciplina ${ }^{389}$ que encierra una restricción en el uso de técnicas de comunicación a distancia ${ }^{390}$. En su momento, el Libro Verde de la Comisión Europea sobre las Comunicaciones comerciales en el mercado interior (8/5/1996) admitió limitaciones a la libre prestación de servicios basados en la protección de trabajadores y consumidores, en la protección de la propiedad intelectual y en la lealtad de las transacciones comerciales y de la competencia. Apuntaba la necesidad de regular la publicidad invasiva que, en aquellos momentos, se centraba en el marketing directo telefónico y por correo postal, aludiendo al entonces proyecto de Directiva de venta a distancia y a la Directiva 95/46/CEE, de protección de datos personales, sin desconocer su potencial incremento mediante nuevas técnicas de comunicación ${ }^{391}$. Basta consultar el Dictamen 2/2010 del Grupo de trabajo del art. 29, sobre publicidad comportamental en línea, para apreciar la facilidad con qué puede confeccionarse publicidad a medida, adaptada al perfil del destinatario, y los múltiples canales para

${ }^{388}$ El art. 2 de la Ley 34/1988, de 11 de noviembre, general de publicidad, utiliza la expresión "comunicación" para definir la publicidad (toda forma de comunicación procedente de una persona en el ejercicio de una actividad comercial, industrial, artesanal o profesional, cuyo fin es promover de forma directa o indirecta la contratación de bienes muebles o inmuebles, servicios, derechos y obligaciones). Una comunicación no es necesariamente personalizada: son destinatarios todos a quienes se dirija o alcance el mensaje publicitario. Tampoco inciden en la personalización la definición del Anexo f) de la Ley 34/2002, de 11 julio de servicios de la sociedad de la información y de comercio electrónico (la comunicación se dirige "a la promoción, directa o indirecta, de la imagen o de los bienes o servicios de una empresa, organización o persona que realice una actividad comercial, industrial, artesanal o profesional"), ni el art. 27 TRLCU que destaca la finalidad promocional pero no precisa en el destino individual o general de la comunicación

${ }^{389}$ CHIAPPETTA, G.: Persona e informazioni aziendali riservate. Napoli, Edizioni Scientifiche italiane, 2010, pp. 116-117.

${ }^{390}$ ARROYO APARICIO, A. Los contratos a distancia en la Ley de ordenación del comercio minorista. Ley 47/2002, de 19 de diciembre, de reforma de la Ley de ordenación del comercio minorista, Cizur Menor, Thomson-Aranzadi, 2003, pp. 169 y 181.

${ }^{391}$ Accesible en: http://europa.eu/documents/comm/green_papers/pdf/com96_192_1_fr.pdf 
hacerla llegar a su esfera personal ${ }^{392}$.

El derecho a no ser molestado o a la tranquilidad individual ${ }^{393}$ es una manifestación del carácter exclusivo de la vida privada (cfr. art. 8.1 del Convenio para la Protección de los Derechos Humanos y de las Libertades Fundamentales). La elección de estar o no accesible constituye pues un acto de disposición o de ejercicio de un derecho de la personalidad ${ }^{394}$, de la misma naturaleza que el consentimiento a las intromisiones a la intimidad (art 2 Ley Orgánica 1/1982, de 5 de mayo, de Protección Civil del Derecho al Honor, a la Intimidad Personal y Familiar y a la Propia Imagen) o al tratamiento de datos personales (art. 6.1 LOPD). Cabe diferenciar los regímenes siguientes, que varían en función del medio de comunicación utilizado, en particular de si se trata de servicios de comunicación electrónica o de otras técnicas de comunicación a distancia con consumidores ${ }^{395}$. La capacidad real de gestionar estos accesos o de hacer valer la exclusividad se ve seriamente comprometida si el emisor de mensajes publicitarios no se somete a un régimen dirigido a facilitar su identificación, su

${ }^{392}$ El Grupo de Trabajo del Artículo 29 en su Dictamen 2/2010, sobre publicidad comportamental en línea, adoptado el 22 de junio de 2010 (00909/10/ES, GT 171), clasifica la publicidad personalizada en comportamental, contextual y seleccionada. Todas ellas representan una selección del mensaje publicitario en función de características conocidas de un individuo, aunque la comportamental se caracteriza por el tratamiento permanentemente actualizado del comportamiento, por ejemplo, el tratamiento de cookies. Indica en su p. 5: "La publicidad comportamental es publicidad basada en la observación continuada del comportamiento de los individuos. La publicidad comportamental busca estudiar las características de dicho comportamiento a través de sus acciones (visitas repetidas a un sitio concreto, interacciones, palabras clave, producción de contenidos en línea, etc.) para desarrollar un perfil específico y proporcionar así a los usuarios anuncios a medida de los intereses inferidos de su comportamiento".

${ }^{393}$ Véanse estas expresiones en ATELLI, M. Il diritto alla tranquilità individuale. Dalla rete Internet al 'door to door', Napoli, Jovene Editore, 2001, p. 63 y ss y en CAVANILLAS MÚGICA, S. «Dos derechos emergentes del consumidor: a no ser molestado y a una interacción informativa". En: Liber amicorum Guido Alpa. Private Law Beyond the National Systems (ed. M. Andenas, S. Díaz Alabart, B. Markesinis, H. Micklitz y N. Pasquini), British Institute of International and Comparative Law, 2007, p. 222.

${ }^{394}$ MEULDERS-KLEIN, M. T. "L'irrésistible ascension de la "vie privée" au sein des droits de l'homme. Synthèse et conclusions". En: Le droit au respect de la vie privée au sens de la Convention européenne des droits de l'homme (dir. F. Sudre), Bruselas, Bruylant-Nemesis, 2005 , p. 305.

${ }^{395}$ ROSSELLO, C. "Gli obblighi informativi del prestatore di servizi”. En: Commercio elettronico, Trattato di Diritto Privato (dir. M. Bessone). Vol. XXXII (a cura di Carlo Rossello, Giusella Finacchiaro e Emilio Tosi, G.), Torino, Giappichelli Editore, 2007, pp. 135 y 145, distinguiendo el régimen aplicable a los destinatarios de comunicaciones comerciales en función de si son un servicio de la sociedad de la información o una relación de consumo. 
recepción efectiva y la oposición a seguir siendo su blanco ${ }^{396}$.

a) El régimen propiamente relacionado con la protección de la vida
privada. Garantiza el control sobre la accesibilidad mediante comunicaciones o mensajes no solicitados. Nos centramos en la persona física y en la tutela de su esfera personal ${ }^{397}$. Desde esta perspectiva, el consentimiento para ser destinatario de mensajes equivale a ejercer un derecho de la personalidad, legitimando la perturbación en la esfera privada. La autorización para ser el blanco de determinadas técnicas de marketing directo se regula sectorialmente. Tanto los arts. 96.3 y 4 TRLCU como el art. 21.1 LSSICE delimitan los medios de contacto que el comunicante no puede acceder sin la autorización expresa del destinatario. Así, queda prohibido el envío de comunicaciones publicitarias o promocionales por correo electrónico $\mathrm{u}$ otro medio de comunicación electrónica equivalente que previamente no hubieran sido solicitadas o expresamente autorizadas por los destinatarios de las mismas (art. 21.1 LSSICE); asimismo se sujeta al consentimiento expreso del consumidor o usuario el uso de sistemas de automatizados de llamadas sin intervención humana (art. 96.3 TRLCU). En cambio, la ley admite el acceso por otros medios considerados menos invasivos o esperables por destinatario pero dispone el derecho de oponerse a recibir ofertas comerciales no deseadas, por teléfono, fax u otros medios de comunicación equivalente (art. 96.5 TRLCU), así como oponerse a recibir comunicaciones comerciales por correo electrónico (o equivalente; se entiende que se trata de comunicaciones relacionadas con los tratos previos entre el comunicante y el cliente, cfr. art. 21.2 LSSICE). Finalmente, también debe consentir el envío de comunicaciones siempre que previamente hubiese decidido no figurar en las guías de comunicaciones electrónicas disponibles al público, se hubiera opuesto al uso promocional de los datos

${ }^{396}$ PODDIGHE, E. “La tutela Della riservatezza dei dati personali nelle comunicación eletttoniche e il diritto di autordeterminazione dell'interessato". En: Il Codice dei dati personali. Temi e problemi (dir. Cardarelli, F., Sica, Salvatore, Zeno-Zencovich), Milano, Giuffrè Editore, 2004, p. 501: "L'abbonato, da parte sua, viene sottoposto ad un vero e proprio "attaco" pubblicitario provinente da più fronti, particolarmente pregiudizievole non solo della propria privacy (...) ma anche della gestione del proprio tempo, della libertà dei luoghi di ricezione delle comunicazioni e del diritoo alla autodeterminazione nella scelta della destinazione delle proprie risorse economiche".

397 Naturalmente las personas jurídicas también son destinatarias de servicios de la sociedad de la información y pueden considerarse "abonados". Aunque la Directiva 95/46/CE, relativa a la protección de las personas físicas en lo que respecta al tratamiento de datos personales y a la libre circulación de estos datos, no concierne a las personas jurídicas (el Cdo. 24), la Directiva 2002/58/CE, sobre la privacidad y las comunicaciones electrónicas, sí protege los intereses legítimos de las personas jurídicas (Cdos. 7, 8, 12, 26, 38 y 45 y art. 1.2). 
que aparecen en ellas, o hubiera solicitado la incorporación a los ficheros comunes de exclusión de envío de comunicaciones comerciales (art. 96.3.2 TRLCU) ${ }^{398} 399$. Evidentemente, el consentimiento prestado a la recepción de comunicaciones comerciales es revocable en cualquier momento (art. 22.1 LSSICE). En todos estos ámbitos se regula el derecho a controlar la recepción de mensajes de marketing directo. Se limita el uso de determinados medios invasivos (requieren un opt-in expreso) y, a contrario, se legitima determinados medios que cabe llamar "convencionales" (correo postal, llamadas de voz; basta la posibilidad de opt-out).

b) El régimen del mensaje o la regulación de la forma interna y externa de las comunicaciones comerciales. Afecta a la exteriorización de la naturaleza comercial del mensaje, de la identidad del emisor e impone límites sobre los contenidos. Su finalidad es doble: proteger la libertad económica del destinatario (a quien se dota de instrumentos para identificar la naturaleza de la comunicación) y facilitar una decisión informada ${ }^{400}$. El art. 96.1 y 2 TRLCU establece que en todas las comunicaciones comerciales a distancia deberá constar inequívocamente su carácter comercial y el régimen específico de las comunicaciones telefónicas, incluidas sus limitaciones horarias. En el ámbito de los servicios de la sociedad de la información y del comercio electrónico, el art. 20.1 LSSICE detalla la información exigida sobre las comunicaciones comerciales, ofertas promocionales y concursos y el art. 20.2. LSSICE establece el deber de claridad en el contenido de las ofertas promocionales y la accesibilidad a juegos y promociones.

\section{c) El régimen de la autorización al tratamiento de los datos de carác-} ter personal necesarios para hacer llegar la comunicación a su destinatario. Se aplica tanto al tratamiento de la información conducente a la creación de perfiles (acumulación y cruce de datos sobre gustos, aficiones, historial de consumo, etc.) como a los datos de contacto (dirección postal, correo electrónico, datos de localización de terminales, etc.). Se sujeta a la Ley Orgánica 15/1999, de 13 de diciembre, de protección de datos de

\footnotetext{
398 Art. 14 de la Llei 22/2007, de 11 julio, de comercialización a distancia de servicios financieros destinados a los consumidores

${ }^{399}$ Art. 22.2.3 LSSICE: "Cuando las comunicaciones hubieran sido remitidas por correo electrónico, dicho medio deberá consistir necesariamente en la inclusión de una dirección de correo electrónico u otra dirección electrónica válida donde pueda ejercitarse este derecho, quedando prohibido el envío de comunicaciones que no incluyan dicha dirección"; art. 96.4.2 in fine TRLCU.

${ }^{400}$ CHIAPPETTA, G. Persona e informazioni aziendali riservate. p. 49 y pp. 86-87; la autora destaca el valor de la información para la "tutela de la persona en el mercado".
} 
carácter personal y al Real Decreto 1720/2007, de 21 de diciembre, que aprueba su Reglamento). Cabe diferenciar entre el régimen de los datos provenientes de ficheros accesibles al público (art. 3.j LOPD), sobre los que cabrá ejercer el derecho de oposición, y de los carecen de esta condición cuyo uso debe consentir previamente el interesado (art. 6.1 LOPD).

d) La idea de exclusividad o seclusion se desprende de la noción norteamericana de privacy formulada por Warren y Brandeis, autores que retomaron el "right to be let alone" para concretar un derecho a la privacy que protegía manifestaciones individuales como el derecho a exteriorizar opiniones o emociones, a no ser molestado y a entablar relaciones con los demás ${ }^{401}$. La formulación "negativa" de la privacy, como intangibilidad de la esfera privada, se ha adaptado a nuevas formas de inmisiones frente a las cuales el aislamiento ya no resulta suficiente. Su vertiente "positiva" va más allá de la prohibición y se manifiesta en la capacidad de decidir la información se proporcionará a terceros y frente a quien permanecer accesible $^{402}$.

\subsection{LA PRIVACIDAD EN EL ESCENARIO DE LAS NUEVAS TECNOLOGÍAS: EL CONTROL SOBRE LA ESFERA PERSONAL EN LA SOCIEDAD DE LA INFORMACIÓN.}

Las nuevas tecnologías son medios que permiten múltiples formas de vulnerar derechos de la personalidad, entre los que cobran un papel destacado el derecho a la intimidad y a la propia imagen y los datos personales. De forma más general diremos que entrañan riesgos para la privacidad, concepto más amplio en que confluyen todas aquellas manifestaciones de la personalidad que habilitan para decidir por sí mismo sobre cualquier aspecto que ataña al libre desarrollo de la personalidad. La autodeterminación personal designa el derecho a tomar decisiones sobre uno mismo sin quedar sujeto a constreñimientos o interferencias de terceros ${ }^{403}$. Está pues ligado a la dignidad personal y comprende todas las facultades que permiten un control sobre la imagen y la proyección de la vida personal, sobre la reputación o sobre los perfiles de la personalidad.

Así pues el derecho a la intimidad limita su objeto a garantizar un ámbito

${ }^{401}$ WARREN, S. Y BRANDEIS, L. «The right to privacy». En: Harvard Law Review, 14, 1890, p. 213; MCCARTHY, J. T. The rights of publicity and privacy, vol. 1, Thomson West, 2008, p. 12 ss.

402 WESTIN, A. F. Privacy and freedom, New York, Atheneum, 1967, p. 7, definiendo la privacy como "claim of individuals, groups or institutions to determine for themselves when, how, and to what extent information about them is communicated to others".

${ }^{403}$ ROUVROY, A. y POULLET, Y., The right to informational self-determination... cit., p. 260 . 
reservado de vida frente a la acción y al conocimiento de terceros y atribuye facultades para resguardar el ámbito de reserva de un conocimiento indeseado o para controlar a quien se confiere el acceso a la esfera personal, diferenciándola de aquella que es pública y expuesta. Por ejemplo, es el caso del derecho a la imagen o a la representación del aspecto físico que permite la identificación de la persona y confiere una determinada proyección de la misma ${ }^{404}$. Por tanto corresponde gestionar la imagen al titular del derecho a quien corresponde decidir si permite o no su captación o difusión. Lo mismo se predica del derecho al honor o a la buena reputación que comprende la facultad de controlar expresiones que desacrediten una persona frente a las demás y puedan condicionar negativamente la opinión de terceros sobre ella.

Mientras que estos tres derechos limitan la libertad de expresión (art. 20.4 $\mathrm{CE}$ ), el derecho a la protección de datos personales limita el acceso y el uso de la información. En la medida que se trata de datos personales se reconoce al titular la facultad de vetar o controlar el acceso sobre su información que no sólo permite conocer aspectos personales, sino también obtener información nueva, no facilitada directamente, que puede utilizarse para tomar decisiones sobre los afectados. Lo relevante no es pues la naturaleza de la información (no necesariamente íntima) sino el acto de tratamiento por quien se identifica como responsable del mismo. Se trata de controlar la formación de perfiles (extraordinariamente fácil en entornos TIC) y su uso (decisiones automatizadas o discriminatorias, envío de publicidad personalizada, invasión de la esfera privada).

Si el acto de disposición (consentimiento a autorización al tratamiento de información) guarda la estructura común del ejercicio de los derechos de la personalidad, lo realmente nuevo es el entorno en que se realiza ya que, retomando la idea general de esta exposición, se caracteriza por unas asimetrías o un gap cognitivo que requiere de un régimen especial con el objeto de reforzar la posición del afectado, atribuyendo un estatuto de deberes al responsable ${ }^{405}$. Este aspecto caracteriza el derecho sobre los datos personales que, como da a entender la expresión usual, es un derecho a su "protección".

Habida cuenta que el ejercicio del derecho está condicionado por medios técnicos, por los conocimientos y por la capacidad del responsable del tratamiento para influir sobre el afectado, la ley establece un régimen destinado a proteger a todo un colectivo: el del afectado por el tratamiento y titular de los datos. El concepto coincide con el de la persona o el ciudadano que actúa en la sociedad actual. La diná-

404 STC de 26 de marzo de 2001 (Aranzadi, RTC 2001, 81): "no debe olvidarse añade el Tribunal Constitucional en otra sentencia la número 99/1994 y la de 2 de julio de 2001 -número 156/200 - que «el aspecto físico, en cuanto instrumento básico de identificación y proyección exterior y factor imprescindible para el propio reconocimiento como individuo constituye el primer elemento configurador de la esfera personal de todo individuo y por ello nuestro ordenamiento constitucional le dispensa esta especial protección»,

${ }^{405}$ LLÁCER MATACÁS, M. R. La autorización al tratamiento de información personal en la contratación de bienes y servicios, Madrid, Dykinson, 2012, p. 125 y ss. 
mica del acto de disposición sobre los derechos de la personalidad es relativamente simple si se compara con el régimen que rodea el tratamiento ${ }^{406}$. Pero la sociedad de la información precisa un control constante porque el tratamiento puede realizarse en cualquier momento, sin interrupción, gran inmediatez y aplicando parámetros diversos. El cruce de datos, la obtención de perfiles de la personalidad y la capacidad de tomar decisiones basadas en esta información confiere un poder insospechado al responsable del tratamiento. Las posibilidades técnicas ponen a los afectados en una situación de desamparo evidente, sobre todo si partimos de la sencillez del esquema jurídico basado en el acto de disposición a través del consentimiento y en la legitimación legal para acceder a la esfera exclusiva del interesado. Es prácticamente imposible mantener el secreto sobre determinadas informaciones, necesarias para el funcionamiento de determinados servicio y en particular de las TIC (así, los datos del tráfico y de localización, tal como evidencia la Directiva «de sector» 2002/58/CE sobre la privacy y las comunicaciones electrónicas). Esta complejidad se refleja en la legislación que construye un estatuto a cargo del responsable del tratamiento, que es el reflejo de un derecho de control difícil de vehicular.

En realidad, es preciso enfocar la "cuestión del consentimiento" como un reto que debe adaptarse constantemente a serias dificultades. El control individual sobre la información personal no es un mero elemento conceptual de legitimación. Debe ser un elemento material y, en este punto, corre el riesgo de ser un espejismo si atendemos a la cantidad ingente de datos que proporcionamos a diario. Se plantea un problema de comprensión de la trascendencia individual y colectiva de la privacidad, de predisposición para leer y comprender la información y de percepción de los riesgos reales para uno mismo ${ }^{407}$.

${ }^{406}$ Recordemos que los derechos de la personalidad son innatos a la persona, intransmisibles, irrenunciables, imprescriptibles y oponibles erga omnes. Sus consecuencias son la irrenunciabilidad (por ser contraria al orden público, art. 6.2 Código civil español), la nulidad de los actos o negocios que los vulneren (art. 6.3 CCE) y su imprescriptibilidad (art. 1.936 CCe a contrario). La esfera privada no accesible a terceros a menos que exista una legitimación, la cual proviene, bien de la ley (determinadas intromisiones son "legítimas": art. 8 de la Ley Orgánica 1/1982, de 5 de mayo, sobre protección civil del derecho al honor, a la intimidad personal y familiar y a la propia imagen -LOHIPI- y art. 6.2 LOPD), bien del consentimiento o autorización que habilita el acceso a su destinatario y eliminando la ilegitimidad (art. 2.2 y 3 LOHIPI, art. 6.1 y 11.1 LOPD). La esfera personal vulnerada se tutela atribuyendo acción para prevenir o poner fin a la intromisión (cese, reposición del estado anterior, prevención) y para obtener indemnización incluidos los daños morales (art. 9.2 LOHIPI). En el caso de los datos personales, la existencia de un régimen sometido a procedimiento sancionador y al control de una Autoridad completa la perspectiva: tutela ante la AEPD o las Agencias Autonómicas), ejercicio de los llamados derechos “ARCO” (acceso, rectificación, cancelación y oposición, arts. 6.4 i 15 a 17 LOPD), impugnación de decisiones automatizadas (art. 13 LOPD) e indemnización (art. 19 LOPD).

407 SOLOVE, D. J. “Introduction: Privacy self-Management and the Consent Dilemma”. En: Harward Law Review, vol. 126, 2013, p. 1880. 
Así, este apartado debe concluir evidenciando la necesidad de vincular los deberes a cargo del responsable y los principios del tratamiento a un empowerment real del ciudadano. En el momento de consentir, el titular de los datos va a sufrir los mismos problemas que un consumidor frente a un clausulado poco accesible o abusivo. Estas dificultades podrían utilizarse para argumentar un cambio de percepción frente a lo inevitable o lo antieconómico (en términos de tiempo empleado por el interesado o de los beneficios de un sistema basado en la industria del dato). Es necesario sopesarlas, habida cuenta la brecha entre perspectiva europea (basada en el reconocimiento y la protección de derechos individuales y sociales) y estadounidense (crítica frente a los llamados paternalismos), con el fin de hallar mecanismos que se adapten a una privacidad construida sobre la titularidad y ejercicio de derechos sobre bienes de la personalidad.

El otro gran reto se relaciona con la tecnificación y la pretendida anonimidad de los comportamientos humanos en entornos virtuales.

\subsection{Protección de datos Personales y entornos SMart}

\subsubsection{Nuevas formas de contactabilidad: ¿nuevos datos personales?}

En los entornos Smart se diversifican los medios para captar, difundir o utilizar información personal. Esta es la razón por la cual gana peso la disciplina de la protección de datos personales: mucha información se convierte en dato personal desde el momento en que se capta, circula y retorna al usuario por medios electrónicos que la someten a tratamiento. Cabe decir que en dicho escenario los particulares se convierten en infractores habituales: personas que no se dedican al negocio de la divulgación de imágenes o noticias y operan a través de medios propios o redes sociales y "little brothers" quienes, junto al "big brother" (asimilado al poder público), tratan información de sus clientes: cualquier empresa prestadora de bienes o servicios con quien contratamos virtualmente, que comercializa servicios asistidos por tecnología smart o simplemente la utiliza durante la prestación.

El ámbito de datos personales se ha ampliado a medida que las comunicaciones proporcionan nuevos datos técnicos útiles para identificar una persona o singularizar el portador de un objeto Smart. Hay medios de identificación evidentes (como el número del Documento Nacional de Identidad, la dirección, número de teléfono), otros cuyo conocimiento se ha popularizado en mayor o menor medida (dirección IP, cookies) y otros aun difícilmente imaginables (información de geolocalización proporcionada por objetos Smart, datos biométricos). Se han multiplicado los servicios a través de objetos Smart: terminales móviles, entornos equipados con lectores de chips per RFID (permiten atender a la clientela sobre la base de su comportamiento o de su geolocalización a través de terminales; poner en marcha 
servicios a partir de objetos inteligentes $-Y_{c a r}{ }^{408}$; Glowcap ${ }^{409}$-). El aumento de las capacidades técnicas permite conocer y rastrear los hábitos de las personas, aplicar decisiones automatizadas a través de las pertenencias $\left(\mathrm{M} 2 \mathrm{M}^{410}\right)$ y asociar persona y objetos a perfiles de comportamiento construidos tanto sobre información real como sobre patrones anónimos que se aplican posteriormente a un sujeto.

La sociedad de la información ha dado paso a la sociedad de la observación, plagada de sistemas de captación de datos, integrados en actividades tan cotidianas como la compra diaria o el cuidado de la salud, y en manos de responsables numerosos y difícilmente identificables. Se completa con una falta de cultura de la privacidad y la ignorancia sobre las capacidades técnicas del entorno que la desaparición de la frontera entre lo real y lo virtual no hace más que agravar. El entorno tecnológico engrandece el gap informativo y los productos Smart se convierten productos de riesgo no sólo individual, sino también colectivo, porque disminuyen el nivel de autonomía de una sociedad. Conduce a planteamientos éticos, en particular, el equilibrio entre seguridad o eficiencia y la libertad. Evidentemente las empresas que proporcionan servicios o productos eficientes y seguros deben obtener beneficios. El mercado subyacente de información personal explica la gratuidad de numerosas prestaciones $^{411}$. ¿Hasta qué punto debe sacrificarse la vida privada per razones de eficiencia y de gratuidad? Este es un tema de libertad personal y colectiva. Al mismo tiempo que se transfiere poder de decisión sobre nuestras vidas a terceros, se normaliza un perfil de ciudadano dispuesto a actuar de la forma "correcta", es decir, de aquella forma que le proporciona mayor comodidad en la sociedad de la información y de la vigilancia ("the righteous citizen"412).

La proliferación de sistemas de inteligencia ambiental muestra una evolución en la noción de datos personales. Ya no es imprescindible identificar a una persona para aplicarle una decisión. Basta con contactar el usuario de un objeto,

\footnotetext{
${ }^{408} \mathrm{http}: / /$ www.mapfre.es/portal/YCAR2-html/html/

${ }^{409} \mathrm{http}: / /$ www.vitality.net/glowcaps.html

$410 \mathrm{https}: / / \mathrm{m} 2 \mathrm{~m}$.telefonica.com/
}

411 “Si c'est gratuit, c'est vous le produit”, http://www.sciencespo.fr/edc/en/blog/si-c-est-gratuit-vous-etes-le-produit.KUNEVA, M.: Roundtable on Online Data Collection, Targeting and profiling: "Internet is an advertisement supported service and the development of marketing based on profiling and personal data is what makes it go round. Personal data is the new oil of the internet and the new currency of the digital world". "We accept this reality because it is one chosen by users. Internet users have massively opted for free services offered in exchange for acceptance of advertisement. Today, advertisement online is individually targeted and increasingly based on the user's profile and behavior (...) no one in the digital space cares about our actual names or exact physical addresses. What traders want is a description of who we are and a way to reach us". (Bruselas 31.03.2009). http://europa.eu/ $\mathrm{rapid} /$ pressReleasesAction.do?reference=SPEECH/09/156

${ }^{412}$ SIMITIS, S. “Reviewing privacy in an information society”. En: 135 U. Pa. L. Rev, 19861987. 
con singularizarlo sin necesidad de conocer su identidad, simplemente a través de identificadores o de objetos que revelan sus hábitos. Se ha pasado de datos predicados de personas identificadas o identificables por medios razonables a datos que singularizan el destinatario de una decisión $\mathrm{n}^{413}$. La misma incertidumbre se predica de la anonimización que teóricamente privaría el "dato" de su carácter "personal"... hasta el momento indefinido en que la desanonimización sea factible con medios razonables ${ }^{414}$.

Frente a ello, la respuesta jurídica es perfectible y requiere una adaptación constante $^{415}$ que depende de la colaboración entre tecnología y derecho. La Propuesta de un nuevo Reglamento sobre protección de personas físicas y del tratamiento de datos de carácter personal intenta dar respuesta a los nuevos retos ${ }^{416}$. El texto inicial de la Propuesta se centraba en la idea de identificación, es decir, la asociación del dato con una persona. El Cdo. 24 PRGPD consideró que los identificadores online generados por los terminales, las aplicaciones y los protocolos no deben considerarse necesariamente datos personales en cualquier circunstancia, entendiendo que las huellas que proporcionan sólo pueden usarse si los identificadores únicos se combinan con otra información. No obstante, el Draft Report on the Proposal by the Committee on Civil Liberties, Justice and Home Affairs (Parlamento europeo, 17.12.2012) consideró que la Regulación también debía aplicarse a los identificadores por la imposibilidad de saber si en el futuro algunos identificadores iban a permitir la singularización de personas. En estos momentos, el texto votado en el Parlamento Europeo ${ }^{417}$ admite un giro en el concepto de "dato personal", si bien ha minimizado las menciones a la mera singularización de personas. El Cdo. 23 indica: "To determine whether a person is identifiable, account should be taken of all the means reasonably likely to be used either by the controller or by any other person

\footnotetext{
${ }^{413}$ Pero la identificación no es necesaria para contactar un terminal, tal como hacen notar algunos documentos: Grupo de Trabajo del Art. 29, Opinión 4/2007, sobre el concepto de dato de carácter personal (20-062007, WP 136); Grupo de Trabajo del Art. 29, Opinión 01/2012, sobre las propuestas de reforma de la protección de datos (23-03-2012, WP 191).

414 Art. 29 Working Party Opinion 05/2014 on Anonymisation Techniques (0829/14/EN WP216). Véase también OHM, P. "Broken Promises of Privacy: Responding to the Surprising Failure of Anonymization”. En: 57 UCLA L. Rev, 2009-2010, p. 731.

415 Ponderando críticamente la relación, véase SCHWARTZ, P. M. \& SOLOVE, D. J. "The PII Problem: Privacy and a New Concept of Personally Identifiable Information". En: 86 N.Y.U. L. Rev, 2011, p. 1846; SCHWARTZ, P. M. "The EU-U.S. Privacy Collision: a Turn to Institutions and Procedures”. En: 126 Harv. L. Rev., 2012-2013, p. 1966.

416 Bruselas 25.01.2012 COM(2012) 11 final.

417 European Parliament legislative resolution of 12 March 2014 on the proposal for a regulation of the European Parliament and of the Council on the protection of individuals with regard to the processing of personal data and on the free movement of such data (General Data Protection Regulation) (COM(2012)0011 - C7-0025/2012 - 2012/0011(COD))
} 
to identify or single out the individual directly or indirectly. To ascertain whether means are reasonably likely to be used to identify the individual, account should be taken of all objective factors, such as the costs of and the amount of time required for identification, taking into consideration both available technology at the time of the processing and technological development" 418 .

Asimismo, el tratamiento de perfiles anónimos también puede utilizarse para predecir el comportamiento o aptitudes de una persona y tomar decisiones concretas por el mero hecho de encajar en el perfil. La calificación referida a un perfil (positivo o negativo) se convierte en un factor de discriminación. La Propuesta modificada de Reglamento general de protección de datos también contiene una definición de "profiling" (art. 4.3.a) como "any form of automated processing of personal data intended to evaluate certain personal aspects relating to a natural person or to analyse or predict in particular that natural person's performance at work, economic situation, location, health, personal preferences, reliability or behavior". De nuevo, el responsable debe informar sobre la existencia del profiling y de sus consecuencias. Su uso debe ser legítimo, es decir, consentido, autorizado por la ley, o necesario para el cumplimiento de un contrato. El profilaje no debe generar datos especiales (por ejemplo, reveladores de la raza u origen étnico, de opiniones políticas, religión o creencias, datos genéticos o relativos a la salud o a la vida sexual ${ }^{419}$ ) ni puede ser la única base de una decisión con efectos jurídicos (art. 20.5 Propuesta).

\subsubsection{La necesaria colaboración de derecho y técnica.}

Todo gap, en este caso tecnológico, requiere instrumentos jurídicos de redistribución de poder entre la persona afectada y los «señores de la información» ${ }^{420}$. Transferir instrumentos jurídicos característicos de escenarios asimétricos (así, el consentimiento informado) resulta insuficiente cuando los medios técnicos dificultan su utilización o incluso la mera percepción de una captación y tratamiento.

Por esta razón, el Internet of things y las aplicaciones de inteligencia ambiental requiere medios que habiliten al portador del objeto Smart para controlar su

${ }^{418}$ Las cursivas son nuestras. El Cdo. 24) añade: "This Regulation should be applicable to processing involving identifiers provided by devices, applications, tools and protocols, such as Internet Protocol addresses, cookie identifiers and Radio Frequency Identification tags, unless those identifiers do not relate to an identified or identifiable natural person".

${ }^{419}$ Art. 20 (3a) Propuesta: “ sprofiling' means any form of automated processing of personal data intended to evaluate certain personal aspects relating to a natural person or to analyse or predict in particular that natural person's performance at work, economic situation, location, health, personal preferences, reliability or behaviour; resulting from profiling. Profiling shall not be based solely on the special categories of personal data referred to in Article 9" (categorías especiales de datos).

${ }^{420}$ RODOTÀ, S. Tecnologie e diritti, Bologna, Il Mulino, 1995, pp. 55 y 72. 
interacción con el sistema (relaciones M2M): la persona no debe "cosificarse" sino conservar su poder de decisión sobre el dispositivo. En este sentido la Propuesta pone las bases para la colaboración entre ingenieros y juristas, acuñando la expresión "privacy by design" 421 y difundiendo la necesidad de implementar el empowerment a través de la tecnología: Privacy Enhancing Technologies (PETs), Impact Privacy Assessment (PIA) y mecanismos de certificación, sellos y marcas (arts. 23, 33 and 39). Un tratamiento seguro y legal depende de un buen diseño.

Estas implicaciones técnicas amplían la perspectiva jurídica sobre los objetos Smart: son productos de riesgo en lo que se refiere a la privacidad y su fabricación debe incorporar la tecnología adecuada para que el responsable del tratamiento pueda cumplir con el régimen legal. Se trata de producir dispositivos privacy frien$d l y \mathrm{y}$, sin duda, el diseño puede implementar reglas por defecto y medios de gestión transparente ${ }^{422}$. Ello implica necesidad de cooperación entre los agentes del proceso de fabricación y un reparto de responsabilidades al que naturalmente se suma el responsable del tratamiento. Los estándares técnicos se convierten en instrumentos para el cumplimiento de la ley y los diseñadores y los fabricantes juegan un papel acti$\mathrm{vo}^{423}$, diferenciando capacidad técnica y legalidad, evitando el tratamiento por defecto e implementando medios para el consentimiento "táctil". La Directiva 2006/42/ EC de 17 de mayo de 2006, sobre maquinaria, sienta las bases para la armonización de los requisitos esenciales europeos de salud y seguridad. La Directiva 2001/95/ EC de 3 de diciembre de 2001, sobre seguridad general de los productos, establece el deber de poner en el mercado productos seguros y que no presenten riesgos (o los mínimos compatibles con el uso del producto) con el fin de mantener un alto nivel de protección de la salud y la seguridad de los usuarios. En España, el RD 1801/2003

${ }^{421}$ See Microsoft GS1 EPC/RFID Privacy Impact Assessment (PIA) Tool, http: //www.gs1. org/epcglobal/pia/

422 REIDENBERG, J. R. "Lex informatica: the formulation of information policy rules through technology". En: Tex. L. Rev. 76, 1997-1998, p. 553; Yang, Y. T. y Borg, K.: “Regulatory Privacy Protection for Biomedical Cloud Computing". En: Beijing Law Review, 20123, pp. 146 y 148. Es destacable que la propuesta de Reglamento imponga al responsable el principio de transparencia (art. 11 PRGPD), el deber de conservación de la documentación de las operaciones de tratamiento (art. 28 PRGPD), de implementar requisitos en materia de seguridad (art. 30 PRGPD), la evaluación de impacto sobre la privacidad (art. 33 PRGPD) y el deber de alerta o comunicar las violaciones a la Autoridad de control y al interesado (arts. 31 y 32 PRGPD).

${ }^{423}$ TRUDEL, P. "Privacy protection on the Internet: risk management and networked normativity”. En: Reinventing Dara Protection?, Gutwirth, S., Poullet, Y., De Hert, P., De Terwange, C., Nouwt, S. (edit.). Heidelberg, Spinger, 2009. Así lo pone de relieve el Grupo de Trabajo del Art. 29 en su Opinion 02/2013, on apps on smart devices, de 27 de febrero de 2013 (WP 202), al advertir del riesgo de la fragmentación de responsables en el desarrollo de apps; http://ec.europa.eu/justice/data-protection/article-29/documentation/opinion-recommendation/files/2013/wp202_en.pdf 
sobre seguridad general de los productos impone a los productores el deber de poner en circulación productos seguros y el deber de vigilancia, información y actuación y crea un sistema a cargo de la Administración de advertencia, retirada, prohibición del producto y alertas. En el futuro, la privacidad debe convertirse en un factor de seguridad de los productos y un aspecto a certificar de conformidad con la normativa europea. Un producto se presume seguro cuando se ajusta a estándares de seguridad y los productores deben además proporcionar información relevante para evaluar sus riesgos inherentes e informar a las autoridades cuando se detecta un riesgo para la privacidad ${ }^{424}$.

Si un tratamiento seguro depende de un diseño y una fabricación adecuados, que devuelvan el control al usuario ${ }^{425}$, es importante determinar aspectos como el lugar dónde se almacenarán los datos (en los terminales, en los sistemas del proveedor, en la nube), cómo se transferirán en un entorno seguro que evite accesos no autorizados y con qué seguridad va a contar la identificación y autenticación del usuario. Éste debe poder optar por el tratamiento (opt-in), comprobar qué datos se tratan y habilitar o deshabilitar los permisos o consentimientos que ha emitido con anterioridad ${ }^{426}$. Los terminales deben facilitar esta relación proactiva y, por tanto las certificaciones de calidad y seguridad industrial deberían establecer un Privacy mode que evitara las opciones por defecto, evidenciara iconos relativos a la privacidad y permitieran una revocación sencilla, la desconexión temporal, kill switchs, la disminución de la distancia de lectura y la encriptación.

\section{Conclusión}

La realidad no suele reflejar la igualdad que el principio de autonomía de la voluntad presupone entre sujetos de derecho. Las decisiones no son autónomas si no pueden tomarse en verdadera libertad, es decir, cuando media una asimetría de poder y de conocimientos entre partes. Nos hemos referido a desigualdades que condicionan comportamientos económicos o en la esfera personal. Cuando una persona puede influir sobre las decisiones de otra en su propio beneficio, debe admitirse que esta última necesita instrumentos jurídicos para detectarlo y reaccionar, que actúan como un factor de reequilibrio. El reconocimiento de derechos al consumidor se traduce en deberes a cargo del profesional. Nos hemos centrado básicamente en la autonomía en la formación del contrato para evidenciar la función social de los instrumentos

${ }^{424}$ Tales fallos técnicos serían una información a difundir a través de una Red europea. La Propuesta de Reglamento sobre protección de datos personales contempla una "notification of a personal data breach to the supervisory authority" (art. 31). Respecto a la seguridad de los productos, téngase en cuenta la red RAPEX: http://ec.europa.eu/consumers/safety/rapex/ alerts/main/index.cfm?event=main.listNotifications

${ }^{425}$ YANG, Y. T. y BORG, K.: “Regulatory Privacy Protection for Biomedical Cloud Computing", cit., p. 150.

${ }^{426}$ Art. 29 WP Opinion 02/2013 on apps on smart devices, p. 18. 
que devuelven al consumidor el control sobre sus propios intereses.

Lo mismo ocurre en el ejercicio de determinados derechos de la personalidad, que son además derechos fundamentales. Cuando la tecnología convierte a las personas en fuentes de información, permanentemente captada y analizada, la autodeterminación informativa es casi ilusoria. Se ha expuesto cómo la legislación sobre protección de datos personales necesita una profunda renovación para adaptarse a los riesgos de localización e identificación que plantean los entornos Smart y el ubiquitous computing. La tecnología es un instrumento que ofrece nuevos servicios o incrementa su eficacia de los servicios; pero la privacidad es también un valor en sí mismo y su respeto garantiza la confianza de los ciudadanos, así como en último término, la libertad personal y colectiva.

\section{Bibliografía}

ARROYO APARICIO, A. "Comentario al art. 8". En: Comentarios a la ley de Competencia Desleal (dir. A. Bercovitz Rodríguez-Cano). Madrid, Aranzadi Thomson Reuters, 2011.

ARROYO APARICIO, A. Los contratos a distancia en la Ley de ordenación del comercio minorista. Ley 47/2002, de 19 de diciembre, de reforma de la Ley de ordenación del comercio minorista, Cizur Menor, Thomson-Aranzadi, 2003.

ATELLI, M. Il diritto alla tranquilità individuale. Dalla rete Internet al 'door to door', Napoli, Jovene Editore, 2001.

BADOSA COLL, F. "Les fonts del Dret civil català". En: Manual de Dret civil català. Madrid-Barcelona, Marcial Pons, 2003.

CAVANILLAS MÚGICA, S. «Dos derechos emergentes del consumidor: a no ser molestado y a una interacción informativa". En: Liber amicorum Guido Alpa. Private Law Beyond the National Systems (ed. M. Andenas, S. Díaz Alabart, B. Markesinis, H. Micklitz y N. Pasquini), British Institute of International and Comparative Law, 2007.

CHIAPPETTA, G.: Persona e informazioni aziendali riservate. Napoli, Edizioni Scientifiche italiane, 2010.

COHEN, J. E.: "Examined Lives: Informational Privacy and the Subject as Object". En: 52 Stan. L. Rev., 1999-2000.

CORDOBÉS MILLÁN, E. Prácticas comerciales desleales: tutela del consumidor y del mercado, Tesis doctoral inédita, Universitat de Barcelona, 2013.

EGEA FERNÁNDEZ, J. “Comentari a l'art. 111-7 CCCat”. En: Comentari al llibre primer del Codi civil de Catalunya. Disposicions preliminars. Prescripció i caducitat (edit. A. Lamarca i Marquès i A. Vaquer Aloy). Barcelona, Atelier, 2012. 
EICHENHOFER, E. 'L'utilizzazione del diritto privato per scopi di política sociale”. En: Rivista di Diritto Civile, 1977.

GRUNDMANN, S. "L'autonomia privata nel mercato interno. Le regole d'infomazione come strumento". En: Europa e diritto privato, 2001.

Grupo de Trabajo del Art. 29. Opinion 02/2013, on apps on smart devices, de 27 de febrero de 2013 (WP 202),

Grupo de Trabajo del Art. 29. Dictamen 2/2010, sobre publicidad comportamental en línea, de 22 de junio de 2010 (00909/10/ES, GT 171).

Grupo de Trabajo del Art. 29. Opinión 4/2007, sobre el concepto de dato de carácter personal (20-062007, WP 136).

Grupo de Trabajo del Art. 29. Opinión 01/2012, sobre las propuestas de reforma de la protección de datos (23-03-2012, WP 191).

Grupo de Trabajo del Art. 29. Opinion 05/2014 on Anonymisation Techniques (0829/14/EN WP216).

HESSELINK M. W. CFR \& Social Justice. Munich, Sellier European Law Publishers, 2008.

KUNEVA, M.: Roundtable on Online Data Collection, Targeting and profiling (Bruselas 31.03.2009)

http://europa.eu/rapid/pressReleasesAction.do?reference=SPEECH/09/156

LLÁCER MATACÁS, M. R. La autorización al tratamiento de información personal en la contratación de bienes y servicios, Madrid, Dykinson, 2012.

Llácer Matacás, M. R.: "El llibre sisè i la proposta de nou 'código mercantil”". En: Materiales de las XVII Jornades de Dret català a Tossa sobre El Llibre sisè del Codi Civil de Catalunya: Anàlisi de l'avantprojecte de llei, Tossa de Mar, 25 y 26 de septiembre de 2014. http://civil.udg.edu/tossa/2014/textos/pon/1/LLACER.pdf

MALUQUER DE MOTES, C. J. "La codificación civil en España (síntesis de un proceso". En: R.D.P., 1981.

Mc CARTHY, J. T. The rights of publicity and privacy, vol. 1, Thomson West, 2008. MELI, M. "Social Justice, Constitutional Principles and Protection of the Weaker Contractual Party". En: ERCL, 2006.

MEULDERS-KLEIN, M. T. "L'irrésistible ascension de la "vie privée" au sein des droits de l'homme. Synthèse et conclusions". En : Le droit au respect de la vie privée au sens de la Convention européenne des droits de l'homme (dir. F. Sudre), Bruselas, Bruylant-Nemesis, 2005.

NEHF, J. P. "Recognizing the societal value in Information privacy". En: 78 Wash. 
L. Rev., 2003.

OHM, P. "Broken Promises of Privacy: Responding to the Surprising Failure of Anonymization". En: 57 UCLA L. Rev, 2009-2010.

PODDIGHE, E. "La tutela Della riservatezza dei dati personali nelle comunicación eletttoniche e il diritto di autordeterminazione dell'interessato". En: Il Codice dei dati personali. Temi e problemi (dir. Cardarelli, F., Sica, Salvatore, Zeno-Zencovich), Milano, Giuffrè Editore, 2004.

REIDENBERG, J. R. "Lex informatica: the formulation of information policy rules through technology". En: Tex. L. Rev. 76, 1997-1998.

RODOTÀ, S. Tecnologie e diritti, Bologna, Il Mulino, 1995.

ROSSELLO, C. "Gli obblighi informativi del prestatore di servizi”. En: Commercio elettronico, Trattato di Diritto Privato (dir. M. Bessone). Vol. XXXII (a cura di Carlo Rossello, Giusella Finacchiaro e Emilio Tosi, G.), Torino, Giappichelli Editore, 2007.

ROUVROY A. y POULLET, Y: "The right to informational self-determination and the value of self-development. Reassessing the importance of privacy for democracy". En: Reinventing Dara Protection?, S. Gutwirth, Y. Poullet, P. De Hert, C. de Terwange, S. Nouwt (edit.). Munich, Spinger, 2009.

SIMITIS, S. "Reviewing privacy in an information society". En: 135 U. Pa. L. Rev, 1986-1987.

SCHWARTZ, P. M. \& SOLOVE, D. J. "The PII Problem: Privacy and a New Concept of Personally Identifiable Information”. En: 86 N.Y.U. L. Rev, 2011.

SCHWARTZ, P. M. "The EU-U.S. Privacy Collision: a Turn to Institutions and Procedures". En: 126 Harv. L. Rev., 2012-2013.

SOLOVE, D. J. "Introduction: Privacy self-Management and the Consent Dilem$m a "$. En: Harward Law Review, vol. 126, 2013.

TEMPLE, H. «Le droit de la consommation est-il subversif?», Mélanges en l'honneur de Jean Calais-Auloy. Paris, Dalloz, 2004.

TRUDEL, P. "Privacy protection on the Internet: risk management and networked normativity". En: Reinventing Dara Protection?, Gutwirth, S., Poullet, Y., De Hert, P., De Terwange, C., Nouwt, S. (edit.). Heidelberg, Spinger, 2009.

WARREN, S. Y BRANDEIS, L. «The right to privacy». En: Harvard Law Review, 14, 1890,

WESTIN, A. F. Privacy and freedom, New York, Atheneum, 1967.

Yang, Y. T. y Borg, K.: “Regulatory Privacy Protection for Biomedical Cloud Computing". En: Beijing Law Review, 2012- 3. 


\title{
LA REGULACIÓN DE LA INCAPACIDAD TEMPORAL COMO FACTOR DINAMI- ZADOR DE LAS RELACIONES LABORALES: LA EXPERIENCIA ESPAÑOLA ${ }^{427}$
}

\author{
The regulation of temporary disability as a dynamic factor of labor \\ relations: the spanish experience
}

\section{Juan Carlos García Quiñones}

Profesor Contratado Doctor (Acreditado a Profesor Titular) de Derecho del Trabajo y de la Seguridad Social. Facultad de Derecho. Universidad Complutense de Madrid. E-mail: juancarlosgarciaquinones@der.ucm.es

\section{Francisca Moreno Romero}

Profesora Asociada de Derecho del Trabajo y de la Seguridad Social. Facultad de Derecho. Universidad Complutense de Madrid. E-mail: francamoro2@gmail.com

\section{RESUMEN}

La incapacidad temporal constituye una institución jurídica relevante y con una importancia singular como factor dinamizador de las relaciones laborales. Además, si se toma como base la experiencia acaecida en el ordenamiento jurídico español, su complejidad intrínseca se ha visto acrecentada con ocasión de las sucesivas reformas que se han implementado sobre la misma, con mayor virulencia si cabe durante los últimos veinte años, ausente muchas veces un planteamiento claro y permanente que garantice unos mínimos estándares de uniformidad y coherencia cada vez que ha tenido lugar un cambio legislativo de cierta significación. Un análisis que, necesariamente, debe completarse con el estudio de las técnicas de control dispuestas dentro de su propia ordenación jurídica, bien que a veces en clave de contradicción con los criterios de racionalidad, latente siempre esa apelación repetida a la construcción de un nuevo modelo de gestión y control. Del mismo modo que resulta necesario reflexionar mínimamente sobre la necesaria interacción entre la incapacidad temporal y el contrato de trabajo. Aspectos todos que pueden servir de base para una aproximación científica a la regulación de la incapacidad temporal como factor dinamizador de las relaciones laborales, a partir de la experiencia que ofrece

${ }^{427}$ La presente Comunicación se inserta en las actividades del Proyecto de Investigación "La Incapacidad Temporal en el trabajo de hombres y mujeres" (Subprograma de Proyectos de Investigación Fundamenta no orientada, convocatoria 2011 (DER2011-29448-C03-01). 
el ordenamiento español. Y elementos que deben analizarse también, en clave de actualidad, a la luz de lo dispuesto en la última manifestación legal, el Real Decreto $625 / 2014$, de 18 de julio, por el que se regulan determinados aspectos de la gestión y control de los procesos por incapacidad temporal en los primeros trescientos sesenta y cinco días de su duración.

Palabras clave: Incapacidad temporal. Técnicas de control. Contrato de trabaJO.

\section{Abstract}

Temporarily unable for work is a relevant legal institution and a factor singular importance in the dynamics of labor relations. Also, if you take on the experience occurred in the Spanish legal system, its inherent complexity has been increased during the successive reforms that have been implemented on same, more virulent if possible during the last twenty years, many missing sometimes a clear and ongoing approach to ensure minimum standards of uniformity and consistency every time has been a major legislative change. An analysis must necessarily be supplemented by the study of control techniques provided within its own legal order, albeit sometimes in contradiction with the key criteria of rationality. In addition to appealing to the construction of a new model of management and control. And conclude with a reflection on the necessary interaction between temporary disability and the employment contract. All aspects that can be the basis for the scientific approach to the regulation of temporary disability as a dynamic factor in industrial relations from the experience offered by the Spanish system.

KeYWords: TEMPORARILY UNABLE FOR WORK. CONTROL TECHNIQUES. EMPLOYMENT CONTRACT.

SUMARIO: 1. Retrospectiva histórica del tratamiento legislativo dado a la incapacidad temporal. 2. Problemática inherente a la regulación de la incapacidad temporal. 3. Técnicas de control versus racionalidad en la ordenación jurídica: la construcción de un nuevo modelo de gestión y control. 4. Una última manifestación legal relevante: El Real Decreto 625/2014, de 18 de julio, por el que se regulan determinados aspectos de la gestión y control de los procesos por incapacidad temporal en los primeros trescientos sesenta y cinco días de su duración. 4.1. Un tópico en la incapacidad temporal: gasto y fraude como justificativos del control. 4.2. La ubicación y los espacios del RD 625/2014 de 18 de Julio. 4.3. La fragmentación temporal de los procesos y la hegemonía de los protocolos. 4.3.1. Instrumentos de control sobre la actuación de los facultativos y centralización de la información. 4.3.2. La fragmentación temporal de los procesos como mecanismo control-presión. Conclusión. Bibliografía 


\section{INTRODUCCIÓN}

La incapacidad temporal constituye una institución jurídica relevante y con una importancia singular como factor dinamizador de las relaciones laborales. Además, si se toma como base la experiencia acaecida en el ordenamiento jurídico español, su complejidad intrínseca se ha visto acrecentada con ocasión de las sucesivas reformas que se han implementado sobre la misma, con mayor virulencia si cabe durante los últimos veinte años, ausente muchas veces un planteamiento claro y permanente que garantice unos mínimos estándares de uniformidad y coherencia cada vez que ha tenido lugar un cambio legislativo de cierta significación. Un análisis que, necesariamente, debe completarse con el estudio de las técnicas de control dispuestas dentro de su propia ordenación jurídica, bien que a veces en clave de contradicción con los criterios de racionalidad, latente siempre esa apelación repetida a la construcción de un nuevo modelo de gestión y control.

Del mismo modo que resulta necesario reflexionar mínimamente sobre la necesaria interacción entre la incapacidad temporal y el contrato de trabajo. Aspectos todos que pueden servir de base para una aproximación científica a la regulación de la incapacidad temporal como factor dinamizador de las relaciones laborales, a partir de la experiencia que ofrece el ordenamiento español. Y elementos que deben analizarse también, en clave de actualidad, a la luz de lo dispuesto en la última manifestación legal, el Real Decreto 625/2014, de 18 de julio, por el que se regulan determinados aspectos de la gestión y control de los procesos por incapacidad temporal en los primeros trescientos sesenta y cinco días de su duración.

En definitiva, aspectos todos cuyo análisis en clave integradora puede servir de base para esa aproximación científica a la regulación de la incapacidad temporal como factor dinamizador de las relaciones laborales, desde la experiencia que ofrece el ordenamiento español. Y examen donde no puede faltar una referencia concreta a la última manifestación legal de relevancia, por alusión al Real Decreto $625 / 2014$, de 18 de julio, por el que se regulan determinados aspectos de la gestión y control de los procesos por incapacidad temporal en los primeros trescientos sesenta y cinco días de su duración

\section{RETROSPECTIVA HISTÓRICA DEL TRATAMIENTO LEGISLATIVO DADO A LA INCA- PACIDAD TEMPORAL}

Las viejas y nunca pacíficas contingencias de incapacidad laboral transitoria e invalidez provisional, fueron reformadas por la Ley 42/1994, de 27 de diciembre, de Medidas fiscales, administrativas y del orden social, que procedió a la redenominación de la contingencia -incapacidad temporal- y a reformar parcialmente su régimen jurídico, suprimiendo formalmente la invalidez provisional. A la referida reforma habría que añadir otras anteriores (por ejemplo, la efectuada en materia de cuantía de la prestación y responsables del pago por la Ley 42/1992, 
de 24 de noviembre, cuya constitucionalidad fue declarada por STCO 34/1994, de 10 de febrero) y posteriores ,por ejemplo, la efectuada en materia de extinción de la prestación económica por las Leyes 66/1997, de 30 de diciembre y 24/2001, de 27 de diciembre, así como por el Real Decreto-Ley 6/2000, de 23 de junio. Junto a ellas, las más recientes incorporadas por la Ley 30/2005, de 29 de diciembre de Presupuestos Generales del Estado para el año 2006, la Ley 40/2007, de 4 de diciembre, de Medidas en Materia de Seguridad Social que rectifica parcialmente las reformas del 2006, las recogidas en la disposición final tercera de la Ley 26/2009, de 24 de diciembre, de Presupuestos Generales del Estado para el año 2010 y, finalmente, las incorporadas a la Ley 35/2010, de 17 de septiembre, de medidas urgentes para la reforma del mercado de trabajo.

Las reformas referidas, aunque importantes, no son las únicas, todavía habría que añadir otras múltiples reformas directas de alcance reglamentario y otras indirectas que proceden de la reforma de otras contingencias, de materias e instituciones que son comunes al Sistema, o finalmente, de normas procedentes de otras parcelas del ordenamiento, singularmente del Estatuto de los Trabajadores. De igual modo que merece significarse también cómo, en el conjunto de la normativa referida, la "ausencia del empresario es absoluta", a pesar de soportar una parte importante del gasto directo e indirecto. Normativa reguladora de las facultades del empresario que sigue invariable desde la incorporación del artículo 20.4 en la primera versión del Estatuto de los Trabajadores.

Por lo demás, toda la complejidad normativa referida se ha producido manteniéndose la ordenación reglamentaria procedente del desarrollo de la Ley de Seguridad Social de 1966 (singularmente el Decreto 3158/1966, de 23 de diciembre y la Orden de 13 de octubre de 1967, que han encajado múltiples reformas) que convive con todo un elenco de normas reglamentarias posteriores de distinta procedencia y alcance (desde el Decreto 1646/1972, de 23 de junio, pasando por el Real Decreto 53/1980, de 11 de enero, hasta los más recientes sobre gestión y control, el Real Decreto 575/1997, de 18 de abril, modificado por el Real Decreto 1117/1998, de 5 de junio y el Real Decreto 430/2009, de 1 de septiembre, de desarrollo reglamentario de la Ley 40/2007), incluida la aplicación de las modernas tecnologías para la presentación en soporte informático de los partes médicos (O Tas/399/2004, de 12 de febrero). Sobre esta anacrónica y compleja estructura normativa, han impactado reformas procedentes de la incapacidad permanente, la maternidad, el riesgo durante el embarazo, la jubilación parcial, el desempleo..., lo que dificulta su comprensión. Finalmente, algunas de las reformas producidas, singularmente las que han afectado a la Ley General de Seguridad Social, no han tenido desarrollo reglamentario, dejando vacíos normativos que se resuelven por criterios internos de las entidades gestoras o por decisiones jurisprudenciales no siempre afortunadas. 


\section{Problemática inherente a la Regulación de la INCAPACIDAd temporal}

La evolución desordenada, en cierto modo asistemática, de la que ha sido objeto la incapacidad temporal explica también el interés mostrado por la doctrina científica sobre determinadas materias centrales relacionadas con la misma, como sucede de manera específica con las vacaciones y la incapacidad temporal en la Administración General del Estado ${ }^{428}$; o desde una proyección más amplia, con el estudio de la incapacidad temporal de los funcionarios públicos ${ }^{429}$; el derecho al disfrute efectivo de las vacaciones, a partir de las referencias básicas que suponen la jurisprudencia comunitaria y la regulación estatutaria ${ }^{430}$; apelación a las vacaciones desde variantes distintas que dan cuenta de la compleja relación existente entre la prestación por incapacidad temporal y el derecho de vacaciones, considerando también los nuevos criterios judiciales y legales ${ }^{431}$; la incapacidad temporal como causa de despido ${ }^{432}$; y, en directa conexión con lo anterior, con el referente de la tutela del trabajador enfermo dentro del Estatuto de los Trabajadores ${ }^{433}$; desde el examen omnicomprensivo de la protección de la incapacidad temporal en el régimen general de la Seguridad Social ${ }^{434}$; también a la luz de la evolución de la normativa sobre

${ }^{428}$ ARRIBAS LÓPEZ, E., El tan traído y llevado tema de las vacaciones y la incapacidad temporal en la Administración General del Estado, Actualidad Administrativa, núm. 4, 2014, Págs. 403 y ss.

${ }^{429}$ ARETA MARTÍNEZ, Ma ${ }^{\text {. }}$, La incapacidad temporal de los funcionarios públicos, AA. VV.: Cuestiones en torno a la incapacidad temporal de los funcionarios públicos, Cinca, Madrid, 2011, págs.. 198 y ss.

${ }^{430}$ En este sentido, GORELLI HERNÁNDEZ, J., El derecho al disfrute efectivo de las vacaciones: de la jurisprudencia comunitaria a la regulación estatutaria, Relaciones Laborales, núm. 1, 2014, págs. 1 y ss.; LÓPEZ INSUA, B. M., La incapacidad temporal en el Sistema de la Seguridad Social, Comares, Granada, 2014; Vacaciones e Incapacidad Temporal: perspectiva comunitaria y española, Aranzadi Social Revista Doctrinal, núm. 10, 2013, págs.. 243 y ss.; RODRÍGUEZ-PIÑERO, M., Derecho a vacaciones y baja del trabajador en la reciente jurisprudencia del TJCE, Relaciones Laborales, núms. 13/14, 2012, págs. 1 y ss.

${ }^{431}$ GALA DURÁN, C., La compleja relación entre la prestación por incapacidad temporal y el derecho a vacaciones: nuevos criterios judiciales y legales, La administración pública, núm. 10, 2012, págs. 916 y ss.

${ }^{432}$ ARENAS VIRUEZ, M., La incapacidad temporal como causa de despido: nulidad o improcedencia, Relaciones Laborales, núm. 1, 2011, págs. 21 y ss.;AZAGRA SOLANO, M., Reflexiones sobre el despido del trabajador enfermo, Revista Aranzadi Doctrinal, núm. 4, 2011, págs. 57 y ss.; SAN MARTÍN MAZZUCONI, C., El despido del trabajador en situación de incapacidad temporal, AA. VV.: Cuestiones en torno a la Incapacidad Temporal (Dir. SEMPERE NAVARRO, A. V.), Cinca, Madrid, 2011, págs. 49 y ss.

${ }^{433}$ CARRIZOSA PRIETO, E., La tutela del trabajador enfermo en el Estatuto de los Trabajadores, Revista Española de Derecho del Trabajo, núm. 157, 2013, págs. 135 y ss.

${ }^{434}$ FERNÁNDEZ PRATS, C., La protección de la incapacidad temporal en el régimen ge- 
la incapacidad para el trabajo, siempre con la referencia del ordenamiento jurídico español ${ }^{435}$; o, de manera más acotada en el tiempo, considerando la incidencia de la reforma laboral de 2012 en el sistema público de la Seguridad Social ${ }^{436}$; desde la interdependencia entre la incapacidad temporal y el presente y futuro de las mutuas de accidentes de trabajo y enfermedad profesional ${ }^{437}$; a partir de una triple problemática proyectada sobre la incapacidad temporal, con una dimensión legal, jurisprudencial y propiamente médica ${ }^{438}$; analizando la evolución de la jurisprudencia del Tribunal Supremo respecto de la compatibilidad entre el trabajo y la pensión de incapaci$\operatorname{dad}^{439}$; o por la proyección de la incapacidad temporal vinculada con determinados colectivos específicos de trabajadores, como sucede significativamente respecto de los trabajadores autónomos ${ }^{440}$; o por su juego en relación con determinadas modalidades de contratos, en alusión al trabajador a tiempo parcial y los trabajadores fijos discontinuos ${ }^{441}$.

Problemática acrecentada cuando se constata que, tanto en la vieja normativa como en la nueva, el impacto y las relaciones reciprocas entre la incapacidad temporal y el contrato de trabajo, son permanentemente ignorados, lo que provoca importantes problemas aplicativos. La importancia del tema y la interrelación de

neral de la Seguridad Social, Tirant lo Blanch, Valencia, 2011; LÓPEZ INSUA, B. M., La incapacidad temporal en el Sistema de la Seguridad Social, Comares, Granada, 2014; Vacaciones e Incapacidad Temporal: perspectiva comunitaria y española, Aranzadi Social Revista Doctrinal, núm. 10, 2013, págs. 45 y ss.

${ }^{435}$ RODRÍGUEZ ÁLVAREZ, V., Evolución de la normativa sobre la incapacidad para el trabajo en el ordenamiento jurídico español, Revista del Ministerio de Trabajo e Inmigración, núm. 94, 2011, págs. 173 y ss.

${ }^{436}$ BLASCO LAHOZ, J. F., La incidencia de la reforma laboral en el sistema público de la Seguridad Social, AA. VV.: Tres años de cambio laboral, Lex Nova, Valladolid, 2013; Págs. 20121 y ss.

${ }^{437}$ BLÁZQUEZ AGUDO, E. Ma ., Presente y futuro de las mutuas de accidentes de trabajo y enfermedad profesional, Aranzadi Social Revista Doctrinal, núm. 2, 2012, págs.. 373 y ss.

${ }^{438}$ BRUNA REVERTER, J., La incapacidad laboral: problemática legal, jurisprudencial y médica, Comares, Granada, 2012, págs. 1 y ss.

${ }^{439}$ FERNÁNDEZ LOMANA, M., Compatibilidad trabajo-pensión de incapacidad: evolución de la jurisprudencia del Tribunal Supremo, Actualidad Laboral, núm. 2, 2013, págs. 181 y ss.

${ }^{440}$ CASTRO CONTE, M., Evolución de la Seguridad Social de los trabajadores autónomos o por cuenta propia, AA. VV.: Cuestiones en torno a la Incapacidad Temporal (Dir. SEMPERE NAVARRO, A. V.), Cinca, Madrid, 2011; GARCÍA QUIÑONES, J. C., Ampliación de la prestación por incapacidad temporal para los trabajadores por cuenta propia, Documentación Laboral, núm. 70, 2004, págs. 59 y ss.

${ }^{441}$ MEDINA MAILHO, R., Trabajo a tiempo parcial y fijos discontinuos, AA. VV.: Cuestiones en torno a la Incapacidad Temporal (Dir. SEMPERE NAVARRO, A. V.), Cinca, Madrid, 2011, págs. 151 y ss. 
ambos institutos es clara, ya que el efecto incapacitante temporal que constituye el elemento de protección es, a su vez, la causa que motiva la suspensión del contrato de trabajo. De ello deriva que las reformas que actúan sobre la incapacidad temporal (prorrogas, suspensión cautelar, procedimiento de impugnación del alta médica, extinción...) provocan sus efectos sobre el contrato de trabajo.

\section{TÉCNICAS DE CONTROL VERSUS RACIONALIDAd EN LA ORDENACIÓN JURÍDI- CA: LA CONSTRUCCIÓN DE UN NUEVO MODELO DE GESTIÓN Y CONTROL}

El análisis de la incapacidad temporal debe completarse, necesariamente, con el estudio de las técnicas de control dispuestas dentro de su propia ordenación jurídica, bien que a veces en clave de contradicción con los criterios de racionalidad. Materia que constituye, de igual modo, un referente continuo de atención por parte de la doctrina científica, cuando analiza la conexión de la incapacidad temporal con el control público del absentismo laboral ${ }^{442}$; con la atención puesta en el control médico de la incapacidad temporal desde la reordenación de las competencias de las entidades que intervienen en la prestación citada, a partir de la regulación que establece el artículo 128 de la Ley General de Seguridad Social ${ }^{443}$; constatando la relevancia del control de las bajas médicas como objetivo permanente de las sucesivas reformas acaecidas en materia de incapacidad temporal ${ }^{444}$; con atención sobre el control y la gestión de la incapacidad temporal a partir de un análisis crítico del marco jurídico positivo vigente, conscientes en cualquier caso del equilibrio complejo que exige la preservación de elementos necesarios a considerar como son la eficiencia y el garantismo ${ }^{445}$; atendiendo a la incidencia que reviste el control de la incapacidad temporal sobre la contención del gasto público y el aumento de la productividad

${ }^{442}$ PURCALLA BONILLA, M. A., Incapacidad temporal y control del absentismo, AA. VV.: Régimen jurídico y gestión racional del tiempo en la empresa (Dirs. ROMERO BURILLO, A. Ma y ARGÜELLES BLANCO, A. R.), Aranzadi, Cizur Menor, 2013, págs. 227 y ss.

${ }^{443}$ CASTILLA CASTILLA, Á., Control médico de la Incapacidad Temporal: la reordenación de las competencias de las entidades que intervienen en la prestación de la Incapacidad Temporal: artículo 128 de la LGSS, Revista de Información Laboral, núm. 3, 2012, págs. 17 y ss. ${ }^{444}$ GONZÁLEZ ORTEGA, S., El control de las bajas médicas como objetivo permanente de las reformas de la incapacidad temporal (I) (El control durante la primera fase de la incapacidad temporal, Relaciones Laborales, núm. 12, 2011, págs. 11 y ss.; El control de las bajas médicas como objetivo permanente de las reformas de la incapacidad temporal (y II) (Prórrogas y recaídas. El tránsito hacia la incapacidad permanente), Relaciones Laborales, núm. 13, 2011, págs. 19 y ss.

${ }^{445}$ OLARTE ENCABO, S., Control y gestión de la incapacidad temporal: análisis crítico del marco jurídico-positivo vigente, el complejo equilibrio entre eficiencia y garantismo, Aranzadi Social Revista Doctrinal, núm. 20, 2011, págs.. 63 y ss. 
empresarial ${ }^{446}$; o para corroborar la opción preferencial por el control público frente al poder de dirección del empresario, dentro de los mecanismos de control de la incapacidad temporal ${ }^{447}$. Elementos todos que están en la base de una llamada, repetida y recurrente, a la construcción de un nuevo modelo de gestión y control.

Como es notorio, la problemática que afecta a la ordenación, gestión y control de la incapacidad temporal, es compleja en sí misma y exige clarificar los condicionamientos sociales y jurídicos sobre los que opera, con la finalidad de fijar el rumbo de las posibles reformas futuras o, al menos, evidenciar algunos de los elementos que proporcionan la complejidad anunciada. Con todo, se trata de una cuestión nuclear en la ordenación de la incapacidad temporal, que afecta a todos los intervinientes, a saber: Servicio Público de Salud, Mutua de accidentes de trabajo y enfermedades profesionales, Instituto Nacional de la Seguridad Social, Instituto Social de la Marina, empresario y trabajador, así como, en ocasiones, al Servicio Público de Empleo Estatal. Singularidad ésta que al ser exclusiva de la incapacidad temporal, anuncia por sí misma su complejidad.

En definitiva, el conjunto de cuestiones enumeradas evidencia a las claras cómo la incapacidad temporal, al igual que otras contingencias de la Seguridad Social, tiene una ordenación sumamente compleja, caótica y desordenada, que dificulta su comprensión y aplicación, situándonos en un espacio de inseguridad jurídica difícilmente justificable.

Situación que no se ha visto favorecida por el hecho de que en los últimos veinte años, desde 1992, la incapacidad temporal ha sido el centro de atención del legislador, realizando reformas continuas -y no siempre debidamente maduradas- con la finalidad de construir un nuevo modelo de gestión y control, que permita recomponer el papel que deben asumir las entidades intervinientes en el proceso, reconducir su utilización -no siempre ortodoxa- y situar el gasto en parámetros de racionalidad. Un entramado normativo que ha tenido como objetivo principal la creación de un modelo de gestión y control bajo la pretensión de centralizar los espacios de competencia. Y materia en la que incide, de manera directa, la aprobación por el Gobierno del Real Decreto 625/2014, de 18 de julio, por el que se regulan determinados aspectos de la gestión y control de los procesos por incapacidad temporal en los primeros trescientos sesenta y cinco días de su duración, bajo esa pretensión declarada de afianzar el modelo en construcción y singularmente incorporar a la gestión los procesos telemáticos, con la finalidad de que todos los "agentes" intervinientes operen y

${ }^{446}$ RODRÍGUEZ ESCANCIANO, S., El control de la incapacidad temporal: su incidencia sobre la contención del gasto público y el aumento de la productividad empresarial, Temas Laborales, núm. 118, 2013, págs. 113 y ss.

447 TORTUERO PLAZA, J. L., La incapacidad temporal, contingencia y situaciones protegidas: un análisis teórico, Tribuna Social, núms. 44/45, 1994; El control público de las Mutuas en materia de incapacidad temporal, AA. VV.: Accidentes de trabajo y Mutuas, La Ley, Madrid, 2008, págs. 217 y ss. 
dispongan de toda la información clínica del trabajador. Texto legal que analizamos, de manera específica, en el epígrafe que sigue a continuación.

\section{Una Última manifestación legal ReleVante: El Real Decreto 625/2014, DE 18 DE JULIO, POR EL QUE SE REGULAN DETERMINADOS ASPECTOS DE LA GES- TIÓN Y CONTROL DE LOS PROCESOS POR INCAPACIDAD TEMPORAL EN LOS PRIME- ROS TRESCIENTOS SESENTA Y CINCO DÍAS DE SU DURACIÓN}

\subsection{UN TÓPICO EN LA INCAPACIDAD TEMPORAL: GASTO Y FRAUDE COMO JUSTIFI- CATIVOS DEL CONTROL}

Tradicionalmente, el incremento del gasto en incapacidad temporal ha propiciado que las principales reformas de los últimos años se hayan centrado casi en exclusividad sobre la ordenación de los mecanismos de control, bajo la hipótesis de que un mayor control conducirá a una reducción del gasto. No obstante, las reformas no se plantearon la problemática existente en forma sosegada y reflexiva, sino más bien conducidas por la obsesión razonable del gasto y la idea de que el fin justifica cualquier medio. En este orden, el aluvión normativo producido entre el año 1997 y el año 2014, ha buscado la reordenación de los mecanismos de control con la finalidad de alcanzar el resultado económico deseado.

Junto a las razones económicas y/o vinculado a ellas, el espacio competencial ha constituido el eje direccional de las reformas, sin que se haya logrado el equilibrio necesario. En esta línea, todas las reformas, con mayor o menor fortuna, se han dirigido a convertir al Instituto Nacional de la Seguridad Social -y en su espacio competencial al Instituto Social de la Marina- en parte, juez, fiscal instructor... con una centralización de competencias que, como ha afirmado la doctrina ${ }^{448}$, plantean dudas razonables en la construcción de un modelo de gestión equilibrado.

En un diálogo entre competencias y nivel de gasto, podríamos decir que las últimas reformas ha primado el elemento competencial ${ }^{449}$. La crisis económica se ha encargado por sÍ sola de reducir el gasto, tanto por la pérdida de afiliados, como por la reducción de salarios y cotizaciones -factores externos que condicionan el gasto en incapacidad temporal- e, incluso, por el temor razonable del trabajador a perder el empleo, temor que ha primado sobre su derecho a la salud.

Es frecuente imputar a los trabajadores el uso incorrecto de la incapacidad

448 AA. VV.: Cuestiones en torno a la Incapacidad Temporal (Dir. SEMPERE NAVARRO, A. V.), Cinca, Madrid, 2011; TORTUERO PLAZA, J. L El control público de las Mutuas en materia de incapacidad temporal, AA. VV.: Accidentes de trabajo y Mutuas, La Ley, Madrid, 2008, págs. 137 y ss.

449 PANIZO ROBLES, J. A., Un nuevo paso en el control de la prestación de la seguridad social por incapacidad temporal: el RD 1430/2009, de 4 de diciembre, Revista de Trabajo y Seguridad Social, CEF, núm. 320, 2009, pág. 3. 
temporal, en el sentido de que es utilizada o mantenida temporalmente, al margen del efecto incapacitante que la caracteriza. Igualmente lo es, imputar a los facultativos del servicio público de salud de falta de rigor en la apertura y mantenimiento de los procesos de incapacidad temporal. Las imputaciones no son nuevas, más bien son consustanciales a la contingencia misma y de ellas hemos hecho un tópico que incluso constituye guía y razón de las reformas legislativas. Es cierto que no sólo debemos valorar el importante impacto económico que tiene sobre el sistema público de protección social y sobre las empresas, sino también los importantes impactos colaterales. Así, el absentismo causado por la incapacidad temporal, tiene importantes repercusiones que afectan a la productividad y competitividad de las empresas, a los espacios organizativos, a la gestión de personal... ${ }^{450}$. Las soluciones sobrepasan los espacios de control, sobre todo cuando se rompe el necesario equilibrio entre derecho a la salud, protección y control. Múltiples son las valoraciones y análisis realizados por la doctrina, al plantearse la incapacidad, como un "refugio protegido", como un instrumento del "compensar las irregularidades del mercado laboral", su "impacto de determinadas actividades económicas", sobre la "función social impropia que cumple". Sin embargo, el legislador lejos de profundizar en estos espacios para buscar soluciones equilibradas, ha optado por la creación de múltiples mecanismos de control ejercitables desde todas las instituciones intervinientes, los inspectores médicos del Instituto Nacional de la Seguridad Social, los facultativos y la Inspección del servicio público de salud, los facultativos de las mutuas y el empresario. Controles y actuaciones seguidos -en ocasiones- de un abanico de procedimientos de impugnación, revisión, determinación de la contingencia, etc. Todo ello completado con un sinfín de convenios de colaboración entre todas las entidades intervinientes, con las correspondientes dotaciones económicas. Las dudas sobre el equilibrio final son más que razonables.

\subsection{La ubiCaCión y LOS ESPACIOS DEL RD 625/2014 de 18 DE JULIO}

Las normas sobre gestión y control de la incapacidad temporal contempladas en el Real Decreto 575/1997, de 18 de abril y sus normas de desarrollo habían quedado obsoletas. Desde aquellos años las reformas operadas en la Ley General de la Seguridad Social han sido múltiples y han ido poco a poco cambiando el modelo de gestión de la incapacidad temporal. Era necesario por tanto proceder a su actualización e incluso a la armonización de toda la normativa reglamentaria referida a la contingencia.

En este espacio se sitúa el RD 625/2014, que deroga el viejo RD 575/1997. La sustitución significa actualización /modernización con respecto a las reformas de la LGSS, pero como veremos no significa armonización de la normas reglamen-

${ }^{450}$ MERCADER UGUINA, J. El control de la incapacidad temporal (historia de una sospecha), Revista de Relaciones Laborales, Tomo I, 2002, pág. 413. 
tarias. Lamentablemente se ha perdido la oportunidad de afrontar la ordenación de todas las materias vinculadas a la gestión y control, tanto durante los primeros trescientos sesenta y cinco días - periodo éste en el que se sitúa el RD- como de los tiempos posteriores hasta alcanzar su duración máxima de setecientos treinta días.

Las materias objeto de reforma son múltiples y de distinto alcance. A modo de resumen afectan a las siguientes materias:

- La nueva ordenación es aplicable a los primeros 365 día, cualquiera que sea la contingencia determinante - accidente de trabajo, enfermedad profesional, enfermedad común y accidente no laboral- y cualquiera que sea en régimen - general o especiales-, reflejando su vocación universal.

- Deja fuera como suele ser habitual a los denominados los regímenes especiales de las Fuerzas Armadas, de los Funcionarios Civiles de la Administración del Estado y del personal al servicio de la Administración de Justicia.

- Se moderniza la gestión formal (partes de baja, confirmación y alta) diferenciando los procesos según su duración estimada - inferior a cinco día, entre 5 y 30 días naturales; entre 31 y 60 y entre 61 y más días- en base a protocolos técnico-sanitarios, con identificación de los sujetos responsables en función de la contingencia y de los contenidos de los nuevos partes. - Se apuesta por la gestión telemática en todas las fases y respecto de todos los intervinientes.

- Se reconoce y facilita el acceso a la información clínica del trabajador incapacitado en una ordenación extendida a "los trabajadores del sistema de seguridad social, que posiblemente vulnera por su amplitud los límites legales establecidos en la Ley Orgánica 1/1982, de 5 de mayo, sobre protección civil del derecho al honor, a la intimidad personal y familiar y a la propia imagen, dictada en desarrollo del artículo 18.1 CE.

- Ordena el procedimiento para las propuestas de alta médica formuladas por las mutuas en los procesos derivados de contingencias comunes.

- Ordena, en desarrollo del artículo 132.2 de la LGSS, los requerimientos para reconocimientos médicos de control y la suspensión cautelar de la prestación ante la falta de comparecencia del trabajador.

- Incorpora un nuevo artículo 6 al RD 1430/2009, donde se regula el procedimiento administrativo de determinación de la contingencia causante en los procesos de incapacidad temporal.

- Igualmente, incorpora un nuevo artículo 7 al RD 1430/2009, donde se regula la prolongación de efectos de la incapacidad temporal y agotamiento de la misma. 


\subsection{LA FRAGMENTACIÓN TEMPORAL DE LOS PROCESOS Y LA HEGEMONÍA DE LOS PROTOCOLOS}

\subsubsection{INSTRUMENTOS DE CONTROL SOBRE LA ACTUACIÓN DE LOS FACULTATIVOS Y CENTRALIZACIÓN DE LA INFORMACIÓN}

La nueva ordenación realizada por el RD 625/2014 de los elementos formales vinculados al nacimiento, duración y extinción de la incapacidad temporal - baja médica, confirmación y alta-, son estructurados de forma que en sí mismos constituyen mecanismos de control que pretenden actuar contra la utilización inadecuada de la contingencia, tanto en lo que refiere a su nacimiento, como en su duración. Los instrumentos son múltiples - imposición de protocolos clínicos, fragmentación temporal de los procesos, códigos de diagnostico, código nacional de ocupación, informes complementarios...- y pretenden controlar la acción médica y centralizar la información, cualquiera que sea la entidad gestora, a través de medios telemáticos en el Instituto Nacional de la Seguridad Social.

El parte médico de baja es el acto constitutivo de la incapacidad temporal que, por un lado provoca la suspensión del contrato de trabajo y, por otro, determina el nacimiento de la incapacidad temporal. De esta forma, el parte médico de baja irá precedido de un reconocimiento médico del trabajador que permita la determinación objetiva de la incapacidad para el trabajo habitual, a cuyo efecto el médico requerirá al trabajador los datos necesarios que contribuyan tanto a precisar la patología objeto de diagnóstico, como su posible incapacidad para realizar su trabajo. Lo que impone el precepto, según el artículo 2 del RD, es que el facultativo tenga toda la información, tanto en los aspectos clínicos, como en los vinculados a la actividad laboral del trabajador - tipo de actividad, contenido obligacional, forma de prestar la actividad, condicionantes...-, con la finalidad de poder realizar la correspondiente evaluación que determine o no el efecto incapacitante de la patología.

Con el fin de que las actuaciones médicas cuenten con el mayor respaldo técnico se pondrá a disposición de los médicos a los que competan dichas actuaciones, tablas de duración óptima tipificadas por los distintos procesos patológicos susceptibles de generar incapacidades, así como tablas sobre el grado de incidencia de aquellos procesos en las distintas actividades laborales.

Los partes médicos de incapacidad temporal se confeccionarán con arreglo a un modelo que permita su gestión informatizada, en el que figurará un código identificativo del centro de salud emisor de aquellos.

Desde el momento inicial, el Instituto Nacional de la Seguridad Social centraliza toda la información. Así, el servicio público de salud o la mutua, según cuál sea la entidad facultada para emitir el parte de baja, remitirá por vía telemática- al INSS- de manera inmediata y en todo caso, en el primer día hábil : los datos personales del trabajador y, además, los datos obligatorios del parte de baja relativos a la 
fecha de la baja, a la contingencia causante, al código de diagnóstico, al código nacional de ocupación del trabajador, a la duración estimada del proceso y, en su caso, la aclaración de que el proceso es recaída de uno anterior, así como, en este caso, la fecha de la baja del proceso que lo origina. Asimismo, hará constar la fecha en que se realizará el siguiente reconocimiento médico.

\subsubsection{La fragmentación temporal de los procesos como mecanismo control -presión}

Otro de los mecanismos de control novedosos se centra en la fragmentación de los procesos de incapacidad en función de su posible duración, lógicamente según los protocolos aplicables. A pesar del revestimiento de buenas intenciones y justificaciones tecnológicas contenidas en la Exposición de Motivos se hace patente expresamente -se cuela en el discurso- la clara intencionalidad del "control".

Como veremos, tras la apariencia de facilitar la expedición y tramitación de los partes médicos, se ejercita un drástico mecanismo de control y de presión sobre el facultativo y sobre el trabajador, al predeterminarse la fecha de alta médica en cada proceso. La propia Exposición de Motivos del RD, ofrece como justificación que “... es importante modificar el modelo actual dando la oportunidad al médico de atención primaria de que determine cuándo tiene que hacer un seguimiento de la enfermedad de su paciente sin condicionarlo, como actualmente, a que semanalmente deba expedir un parte médico de confirmación de la baja".

Los partes de baja y de confirmación de la baja se extenderán en función del periodo de duración que estime el médico que los emite. A estos efectos se establecen cuatro grupos de procesos:

a) En los procesos de duración estimada inferior a cinco días naturales, el facultativo del servicio público de salud, o de la mutua, emitirá el parte de baja y el parte de alta en el mismo acto médico.

El facultativo, en función de cuando prevea que el trabajador va a recuperar su capacidad laboral -los protocolos-, consignará en el parte la fecha del alta, que podrá ser la misma que la de la baja o cualquiera de los tres días naturales siguientes a ésta.

No obstante el trabajador podrá solicitar que se le realice un reconocimiento médico el día que se haya fijado como fecha de alta y el facultativo podrá emitir el parte de confirmación de la baja, si considerase que el trabajador no ha recuperado su capacidad laboral.

b) En los procesos de duración estimada de entre 5 y 30 días naturales, el facultativo del servicio público de salud, o de la mutua, emitirá el parte de baja consignando en el mismo la fecha de la revisión médica prevista que, en ningún caso, excederá en más de siete días naturales a la fecha de baja 
inicial. En la fecha de revisión se extenderá el parte de alta o, en caso de permanecer la incapacidad, el parte de confirmación de la baja. Después de este primer parte de confirmación, los sucesivos, cuando sean necesarios, no podrán emitirse con una diferencia de más de catorce días naturales entre sí.

c) En los procesos de duración estimada de entre 31 y 60 días naturales, el facultativo del servicio público de salud, o de la mutua, emitirá el parte de baja consignando en el mismo la fecha de la revisión médica prevista que, en ningún caso, excederá en más de siete días naturales a la fecha de baja inicial, expidiéndose entonces el parte de alta o, en su caso, el correspondiente parte de confirmación de la baja. Después de este primer parte de confirmación, los sucesivos, cuando sean necesarios, no podrán emitirse con una diferencia de más de veintiocho días naturales entre sí.

d) En los procesos de duración estimada de 61 o más días naturales, el facultativo del servicio público de salud, o de la mutua, emitirá el parte de baja en el que fijará la fecha de la revisión médica prevista, la cual en ningún caso excederá en más de catorce días naturales a la fecha de baja inicial, expidiéndose entonces el parte de alta o, en su caso, el correspondiente parte de confirmación de la baja. Después de este primer parte de confirmación, los sucesivos, cuando sean necesarios, no podrán emitirse con una diferencia de más de treinta y cinco días naturales entre sí.

Siempre que se produzca una modificación o actualización del diagnóstico, se emitirá un parte de confirmación que recogerá la duración estimada por el médico que lo emite. Los siguientes partes de confirmación se expedirán en función de la nueva duración estimada.

El elemento de presión-control consistente en la predeterminación temporal del parte de alta médica y, por tanto, de la extinción de la incapacidad temporal tiene posiblemente un efecto adicional. Cuando el alta predeterminada no se consolide, bien por la modificación del diagnóstico, bien por la evolución del propio proceso, actuará como señal de alarma para la actuación puntual de los inspectores médicos del Instituto Nacional de la Seguridad Social, en la medida en que tienen competencias para expedir el alta médica. Actuación que, como hemos visto, viene facilitada por la información recibida por el INSS desde el mismo momento en que se expide la baja médica, como por el acceso telemático a toda la información clínica del trabajador, como reiteradamente recoge el RD.

Ciertamente se respeta el derecho del trabajador, pero a través de un acto expreso, lo que evidentemente constituye un condicionante, sobre todo si, como presumimos, queda vinculado a la acción inspectora de los facultativos del INSS o en su caso del servicio público de salud. Actuación de unos y otros inspectores, que tiene como efecto adicional en caso de expedir el alta médica, la asunción de la 
competencia sobre el control futuro de la patología -con la correspondiente perdida de competencias del facultativo que trata al trabajador-, al establecerse que durante los ciento ochenta días naturales siguientes a la fecha en que se expidió el alta, serán estas entidades las únicas competentes, a través de sus propios médicos, para emitir una nueva baja médica por la misma o similar patología.

Finalmente repárese en que es constante en el RD la determinación de reconocer a los inspectores médicos el acceso a la información clínica del trabajador. Determinación que se extiende hasta llegar a la vulneración del artículo 18.1 CE, al establecer en su artículo 8.1 que "en todo caso, los inspectores médicos del Instituto Nacional de la Seguridad Social o, en su caso, del Instituto Social de la Marina, para el ejercicio de sus competencias, tendrán acceso, preferentemente por vía telemática, a la documentación clínica de atención primaria y especializada de los trabajadores del sistema de la Seguridad Social, incluida la documentación clínica de los trabajadores protegidos frente a las contingencias profesionales con las mutuas...".

\section{Conclusión}

El modelo de gestión de la incapacidad temporal se ha transformado en los últimos 20 años, pero las múltiples reformas efectuadas no han encontrado el punto de equilibrio donde se armonicen debidamente los mecanismos de control, los derechos del trabajador, las relaciones con el contrato de trabajo, la participación del empresario. La causa posiblemente esté en una desproporcionada preocupación por el control, no siempre paralela a un desproporcionado gasto.

\section{Bibliografía}

AA.VV.: La incapacidad temporal (Coord. OJEDA AVILES, A.), Tecnos, Madrid, 1996

AA. VV.: Cuestiones en torno a la Incapacidad Temporal (Dir. SEMPERE NAVARRO, A. V.), Cinca, Madrid, 2011;

ALONSO OLEA, M. y TORTUERO PLAZA, J. L., Instituciones de Seguridad Social, Civitas, $18^{\mathrm{a}}$ edic., Madrid, 2006;

ARENAS VIRUEZ, M., "La incapacidad temporal como causa de despido: nulidad o improcedencia”, Relaciones Laborales, núm. 1, 2011;

ARETA MARTÍNEZ, M., "La incapacidad temporal de los funcionarios públicos", AA. VV.: Cuestiones en torno a la incapacidad temporal de los funcionarios públicos, Cinca, Madrid, 2011;

ARRIBAS LÓPEZ, E., "El tan traído y llevado tema de las vacaciones y la incapaci- 
dad temporal en la Administración General del Estado", Actualidad Administrativa, núm. 4, 2014;

AZAGRA SOLANO, M., "Reflexiones sobre el despido del trabajador enfermo", Revista Aranzadi Doctrinal, núm. 4, 2011;

BARBA MORA, A., Incapacidad temporal, Tirant Lo Blanch, Valencia, 2000;

BLASCO LAHOZ, J. F., "La incidencia de la reforma laboral en el sistema público de la Seguridad Social", AA. VV.: Tres años de cambio laboral, Lex Nova, Valladolid, 2013;

BLÁZQUEZ AGUDO, E. Ma., "Presente y futuro de las mutuas de accidentes de trabajo y enfermedad profesional", Aranzadi Social Revista Doctrinal, núm. 2, 2012;

BRUNA REVERTER, J., La incapacidad laboral: problemática legal, jurisprudencial y médica, Comares, Granada, 2012;

CARRIZOSA PRIETO, E., "La tutela del trabajador enfermo en el Estatuto de los Trabajadores", Revista Española de Derecho del Trabajo, núm. 157, 2013;

CASTILLA CASTILLA, Á., "Control médico de la Incapacidad Temporal: la reordenación de las competencias de las entidades que intervienen en la prestación de la Incapacidad Temporal: artículo 128 de la LGSS", Revista de Información Laboral, núm. 3, 2012;

CASTRO CONTE, M., "Evolución de la Seguridad Social de los trabajadores autónomos o por cuenta propia", AA. VV.: Cuestiones en torno a la Incapacidad Temporal (Dir. SEMPERE NAVARRO, A. V.), Cinca, Madrid, 2011;

DUEÑAS HERRERO, L. F., "La contingencia de incapacidad (laboral) temporal en el régimen general de Seguridad Social", Relaciones Laborales, núm. 4, 1996;

FERNÁNDEZ LOMANA, M., "Compatibilidad trabajo-pensión de incapacidad: evolución de la jurisprudencia del Tribunal Supremo", Actualidad Laboral, núm. 2, 2013;

FERNÁNDEZ PRATS, C., La protección de la incapacidad temporal en el régimen general de la Seguridad Social, Tirant lo Blanch, Valencia, 2011;

GALA DURÁN, C., "La compleja relación entre la prestación por incapacidad temporal y el derecho a vacaciones: nuevos criterios judiciales y legales", La administración pública, núm. 10, 2012;

GARCÍA MURCIA J. y ROMÁN VACA, E., "Nuevas pautas de la regulación de la incapacidad temporal", Aranzadi Social, num. 2, 1996;

GARCÍA NINET, J. I., "La incapacidad temporal”, AA.VV.: La incapacidad temporal, (Coord. OJEDA AVILES, A.), Tecnos, Madrid, 1996; 
GARCÍA QUIÑONES, J. C., “Ampliación de la prestación por incapacidad temporal para los trabajadores por cuenta propia”, Documentación Laboral, núm. 70, 2004;

GONZÁLEZ ORTEGA, S., "El control de las bajas médicas como objetivo permanente de las reformas de la incapacidad temporal (I) (El control durante la primera fase de la incapacidad temporal, Relaciones Laborales, núm. 12, 2011; "El control de las bajas médicas como objetivo permanente de las reformas de la incapacidad temporal (y II) (Prórrogas y recaídas. El tránsito hacia la incapacidad permanente), Relaciones Laborales, núm. 13, 2011;

GORELLI HERNÁNDEZ, J., "El derecho al disfrute efectivo de las vacaciones: de la jurisprudencia comunitaria a la regulación estatutaria", Relaciones Laborales, núm. 1, 2014;

JOVER RAMÍREZ, C., La incapacidad temporal para el trabajo. Aspectos laborales y de seguridad social, Tirant lo Blanch, Valencia, 2006;

LÓPEZ INSUA, B. M., La incapacidad temporal en el Sistema de la Seguridad Social, Comares, Granada, 2014; "Vacaciones e Incapacidad Temporal: perspectiva comunitaria y española", Aranzadi Social Revista Doctrinal, núm. 10, 2013;

MARTÍN VALVERDE, A., "Incapacidad laboral transitoria e Invalidez Provisional: legislación y jurisprudencia”, Actualidad Laboral, núm. 39, 1994;

MEDINA MAILHO, R., "Trabajo a tiempo parcial y fijos discontinuos", AA. VV.: Cuestiones en torno a la Incapacidad Temporal (Dir. SEMPERE NAVARRO, A. V.), Cinca, Madrid, 2011;

MUÑOZ MOLINA, J., La incapacidad temporal como contingencia protegida por la Seguridad Social, Aranzadi, Pamplona, 2005;

OLARTE ENCABO, S., "Control y gestión de la incapacidad temporal: análisis crítico del marco jurídico-positivo vigente, el complejo equilibrio entre eficiencia y garantismo", Aranzadi Social Revista Doctrinal, núm. 20, 2011;

PANIZO ROBLES, J. A., "Un nuevo paso en el control de la prestación de la seguridad social por incapacidad temporal: el RD 1430/2009, de 4 de diciembre", Revista de Trabajo y Seguridad Social, CEF, núm. 320, 2009;

PÉREZ ALONSO, M. A., La incapacidad temporal, Tirant lo Blanch, Valencia, 1995;

PURCALLA BONILLA, M. A., "Incapacidad temporal y control del absentismo", AA. VV.: Régimen jurídico y gestión racional del tiempo en la empresa (Dirs. ROMERO BURILLO, A. M y ARGÜELLES BLANCO, A. R.), Aranzadi, Cizur Menor, 2013;

RODRÍGUEZ ÁLVAREZ, V., "Evolución de la normativa sobre la incapacidad para 
el trabajo en el ordenamiento jurídico español", Revista del Ministerio de Trabajo e Inmigración, núm. 94, 2011;

RODRÍGUEZ ESCANCIANO, S., "El control de la incapacidad temporal: su incidencia sobre la contención del gasto público y el aumento de la productividad empresarial", Temas Laborales, núm. 118, 2013;

RODRÍGUEZ-PIÑERO, M., "Derecho a vacaciones y baja del trabajador en la reciente jurisprudencia del TJCE”, Relaciones Laborales, núms. 13/14, 2012;

SALA FRANCO, T., La incapacidad temporal para trabajar derivada de enfermedad o accidente, Tirant Lo Blanch, Valencia, 2005;

SAN MARTÍN MAZZUCONI, C., "El despido del trabajador en situación de incapacidad temporal", AA. VV.: Cuestiones en torno a la Incapacidad Temporal (Dir. SEMPERE NAVARRO, A. V.), Cinca, Madrid, 2011;

TORTUERO PLAZA, J. L., "La incapacidad temporal, contingencia y situaciones protegidas: un análisis teórico", Tribuna Social, núms. 44/45, 1994; "El control público de las Mutuas en materia de incapacidad temporal", AA. VV.: Accidentes de trabajo y Mutuas, La Ley, Madrid, 2008;

TORTUERO PLAZA, J. L. y MORENO ROMERO, F., "Poder de dirección del empresario y los mecanismos de control de la incapacidad temporal: la opción por el control público", AA. VV.: Libertad de empresa y poder de dirección del empresario en las relaciones laborales: estudios ofrecidos al profesor Alfredo Montoya Melgar, Aranzadi, Cizur Menor, 2011;

TORTUERO PLAZA J. L. y SÁNCHEZ-URÁN AZAÑA, Y., "La incapacidad temporal. Régimen jurídico y negociación colectiva", Fundación MAPFRE, Madrid, 1996;

VICENTE PALACIO, M. A., "El control de la Incapacidad Temporal: el control en el ámbito de la relación laboral individual y en el ámbito de la Seguridad Social", Tribuna Social, núm. 168, 2004. 


\title{
DATOS ABIERTOS, TRANSPARENCIA Y FILOSOFÍA DEL DERECHO
}

\author{
Open data, transparence and philosophy of law
}

\section{Fernando Galindo}

Doctor en Derecho por la Universidad de Zaragoza. Catedrático de Filosofía del Derecho del Departamento de Derecho Penal, Filosofía del Derecho e Historia del Derecho de la Universidad de Zaragoza. Zaragoza, Aragón, España. E-mail: cfa@unizar.es.

\section{RESUMEN}

El trabajo muestra, mediante la consideración de la problemática que comportan la expansión en Internet de los "datos abiertos" y la puesta en práctica de la transparencia de las actividades de las instituciones financiadas públicamente, la conveniencia de que se produzca un cambio de orientación de la Filosofía del Derecho, y subsiguientemente de los contenidos y aproximaciones de las Ciencias del Derecho, las diferentes Dogmáticas, que son explicadas en las Facultades de Derecho, atendiendo a los requisitos característicos del Derecho del siglo XXI. El cambio es exigido en cuanto que el Derecho hoy ha de ser tenido en cuenta en forma interdisciplinar a partir de su dependencia de las actividades propias de los "actores del desarrollo económico, político y social" y no únicamente "en abstracto" como norma aprobada por el Parlamento, los representantes de los ciudadanos, interpretada y aplicada por los jueces en el proceso, atendiendo al contenido de la misma norma y los valores a los que ella apela cuando se quiere hacer valer en relación a actividades sociales concretas.

Palabras clave: Datos abiertos. Transparencia. Concepto comunicativo del DereCHO.

\section{Abstract}

Thepaper shows, throughtheconsideration of theproblemsthattheexpansion of "open data" in Internet, and the use of the clearnessof theactivities of public institutionsinvolve, thedesirability of a change in theorientation of the way of thinkingthe Law, and thecontent and approaches of theScience of Lawwhich are 
explainedbythe professors of Law, goingtotheattributes of theLaw of the XXI century. Thechangeisrequired as theLawnow has to be takenintoaccount in interdisciplinary form, fromitsdependenceontheactivities of the "money-based, political and social developmentactors" and notjust "abstract"policyadoptedbyParliament, representatives of citizens, interpreted and appliedbyjudges in theprocess, accordingtothecontent of thesamestandards and thevaluestowhichit appeals whenitwantstoapply in relationtospecific social activities.

Keywords: Open data. Transparence. Communicative concept of Law.

Sumario: Introducción. 1. Datos abiertos. 1.1. Caracterización. 1.2. La regulación. 2. Transparencia. 2.1. Exigencias. 2.2. Normativa. 3. Filosofía del Derecho. 3.1. Positivismo y iusnaturalismo. 3.2. La teoría comunicacional del Derecho. 3.3. Concepto comunicativo del Derecho. Conclusión. Bibliografía.

\section{INTRODUCCIÓN}

El título de la reunión: “Actores del desarrollo económico, político y social frente al Derecho del siglo XXI", expresa justamente, desde la Filosofía del Derecho, aquello de lo que se ocupa el presente trabajo. El trabajo muestra, en concreto, mediante la consideración de dos ejemplos, la conveniencia de que se produzca un cambio de orientación de la Filosofía del Derecho, y subsiguientemente de los contenidos y aproximaciones de las Ciencias del Derecho, las diferentes Dogmáticas, que son explicadas en las Facultades, atendiendo a las características del Derecho del siglo XXI, en cuanto que éste, como el títulode la reunión menciona, ha de ser tenido en cuenta a partir desu dependencia de las actividades propias de los "actores del desarrollo económico, político y social" y no únicamente "en abstracto" como norma aprobada por el Parlamento, los representantes de los ciudadanos,e interpretada y aplicada por los jueces en el proceso, atendiendo al contenido de la misma norma y a los valores a los que ellaapela cuando se quiere hacer valer en relación a actividades sociales concretas, en definitiva el que es el considerado paradigma de funcionamiento del Estado de Derecho desde su implantación por la Revolución francesa.

Ello se va a mostrar aquí expresando el papel que se requiere cumpla la Filosofía del Derecho si quiere resolver dos problemas que, como otros, se producen en sociedades democráticas diariamente. Los problemas tomados como referencia son: la implantación y usoen Internet de los "datos abiertos" y la puesta en acción de la normativa sobre transparencia y acceso a la información de la gestión administrativa de carácter público.

El problemade los datos abiertos se remite al hecho de que son numero- 
sas las indicaciones que se hacen en la actualidad por distintos agentes sociales, especialmente los desarrolladores de programas de ordenadory también numerosas autoridades públicas, referidas a que es precisa la publicación en Internet de todo tipo de información existente (de carácter científico, personal, estadística...) sobre la realidad,con independencia de los derechos que sus titulares tengan sobre la misma.

El segundo problema hace referencia a la circunstancia de que por exigencias democráticas los procedimientos que justifican la realización de actividades administrativaspor las instituciones públicas han de ser accesibles a los ciudadanos, lo que ha sido objeto de regulaciónpor leyes destinadas al efecto. Esto hace que tenga interés para los juristas losprocedimientos de creación de los actos administrativos y los reglamentos y las técnicas que se utilizan en su elaboración (jurídicas y no jurídicas), y no sólo las leyes y su interpretación lógica, como se propugnaba desde que se estableció su papel (el de los juristas) por Napoleón Bonaparte en la nueva Facultad de Derecho que creó tras la promulgación de su Código y que sólo debía explicar el "Código Civil" "451.

Es por lo anterior que en el presente trabajo presentamosresumidamenteambos problemas (capítulos II y III) y, tras ello, indicamos (capítulo IV) las características propias de una Filosofía del Derecho, y subsidiariamente una Dogmática,distante de considerar que la ejercitación de los juristas en las propuestas del positivismo jurídico o del iusnaturalismo son las aproximaciones más adecuadaspara resolver cualquierproblema jurídico. Finalmente se concluye (capítulo V).

\section{Datos abiertos}

\subsection{Caracterización}

Se habla de datos abiertos pese a que no existen definiciones claras acerca de qué son. Acaso, como vemos a continuación, lo más correcto sea expresar que es un "movimiento de opinión" dirigido a promover y expandir la oferta de información que está en Internet en régimen de libre uso. ${ }^{452}$

${ }^{451}$ Es conocida y reiteradamente citada la frase del profesor francés Jean-JosephBugnet del siglo XIX “Je neconnaispas le droit civil, jen'enseigne que le Code civil”. Ver al respecto: http://www.universalis.fr/encyclopedie/droit-civil/ (2014-06-28).

${ }^{452} \mathrm{El}$ "movimiento de opinión" es fuerte como lo indica la existencia del "Instituto de Datos Abiertos “ (Open Data Institute, ODI), promovido y financiado por el Gobierno del Reino Unido, cuyos fines se reducen a catalizar "theevolution of open data culture tocreateeconomic, environmental, and social value. It helps unlock supply, generates demand, creates and disseminates knowledge to address local and global issues." A estosefectos el ODI pone de acuerdo a: "world-class experts to collaborate, incubate, nurture and mentor new ideas, and promote innovation. We enable anyone to learn and engage with open data, and empower our teams to help others through professional coaching and mentoring." Ver: http://theodi.org/ about-us(2014-06-18). 
La siguientedefinición resume la filosofía del movimiento: "A piece of data or content is open if anyone is free to use, reuse, and redistribute it - subject only, at most, to the requirement to attribute and/or sharealike" ${ }^{453}$.

Tambiénestáargumentadacomo "idea" la definición de Open Data en la Wikipedia, versióninglesa: "Open data is the idea that certain data should be freely available to everyone to use and republish as they wish, without restrictions from copyright, patents or other mechanisms of control" 454 .

Estas declaraciones muestran sus límites, y que no pueden superar el terreno de las ideas, intenciones o movimientos de opinión, ni, por lo tanto, convertirse en realidad. Esto es así porque preconizan algo imposible: el "libre acceso a los datos", al margen de los derechos existentes sobre ellos, una vez que los datos, como los programas de ordenador, no son libres: siempre están referidos a personas y a sus derechos. En otras palabras: forman parte de aplicaciones, servicios o programas. Es decir, en su uso, como en el de los programas de ordenador, hay que atender a los derechos de sus propietarios, sin poder ser éstos obviados como las definiciones presentadas proponen.

Esto es coherente, además, con la circunstancia de que en la primera de las definiciones mencionadas se excluye de la expresión datos, que se hace equivalente a conocimiento, a los programas de ordenador: "Software isexcludeddespiteitsob-

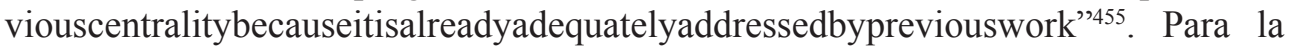
definición, por tanto, los datos/el conocimiento son de libre uso mientras que los programas no... Como indica esta excepción la misma ha de tomarse como regla general porque tanto los programas como los datos tienen fines y propietarios: han sido trabajados previamente por quienes los publican o se refieren a personas. Es decir no existen, en puridad, los "datos abiertos" o de libre uso: siempre es preciso respetar los derechos de sus titulares, sean ellos empresas o personas físicas.

Pese a la contradicciones e implicaciones jurídicas que presentan estas propuestas lo cierto es que cada día están más extendidas: es mayor la información de todo tipo, expresada en toda clase de formatos, que está accesible en Internet. Esto no tanto porque las empresas en las que se integran los técnicos que constituyen el movimiento "open data" lo hagan, una vez que por lo general sus datos no son de libre uso, y si lo son ello es o bien durante un breve periodo de tiempo que está destinado a la captación de posibles usuarios de los programas que los utilizan, o bien porque forman parte de un todo con el que las empresas persiguen que la publicidad adjunta les reporte beneficios. La paradoja reside en que otra cosa sucede, en cambio, con las informaciones o datos que proceden de individuos o de las Administra-

${ }^{453} \mathrm{http}$ ://opendefinition.org/ (2014-06-18).Esta página web ilustra sobre el contenido y filosofía del movimiento protagonizada por los diseñadores de Internet.

${ }^{454}$ http://en.wikipedia.org/wiki/Open_data (2014-06-18). La definición está basada en la expuesta por Auer y otros (2007)

${ }^{455} \mathrm{http}$ ://opendefinition.org/ (2014-06-18). 
ciones como consideramos a continuación.

Si existen datos abiertos ello es, especialmente, o bien porque los publican los mismos usuarios de la red: es el caso de las comunicaciones hechas a través de redes sociales como Twitter o los Blogs, o bien porque, en lo referido a información pública, los Gobiernos la están colocando en forma respetuosa (más o menos) con la legislación vigente, haciéndola accesible a todos aquellos que los quieren utilizar ${ }^{456}$. Esto último se ha visto incrementado por algo diferente/coadyuvante de lo que nos ocupamos en el siguiente capítulo de este trabajo: la expansión de la aceptación del principio político de transparencia y acceso ciudadano a las actividades de las Administraciones Públicas, prescrito, por ejemplo, por la Ley española 19/2013 de 9 de diciembre de transparencia, acceso a información y buen gobierno, y la obligación consiguiente que las mismas tienen de dar acceso a información públicaincluso en el formato de "portales de la Administración", es decir mediante Internet, que almacenan y tratan en su vida diaria, en forma respetuosa con el carácter y contenido, los derechos, de la información publicitada.

En la expansión de la idea de datos abiertos influye también la existencia de programas en funcionamiento que permiten la recuperación en forma rápida y eficaz de la información que está accesible en Internet. Si nos fijamos en el buscador Google, por ejemplo, éste cada vez más proporciona respuestas más atinadas a aquellos usuarios de los que aprende, contando con su aceptación, cuáles son sus perfiles en forma de hábitos, usos y gustos. Virtualidades que proporcionan a la empresa ingresos por la explotación del acceso a los datos de las empresas que los publican y $\operatorname{tratan}^{457}$.

Ahora cabe preguntarnos: ¿cuál es la última razón de la existencia de expresiones de interés, financiación e incluso movimientos de opinión a favor de los “open data"? Como vamos a ver a continuación ella es una razón económica. Es ilustrativa al respecto la reseña de algunas aplicaciones o servicios ${ }^{458}$ que los utilizan o que pueden utilizarlos.

La exigencia de publicación de los datos abiertos depende del hecho de que cabe desarrollar servicios que detecten, en función de cuál sea la temperatura

${ }^{456}$ Con respecto a datos abiertos de las instituciones de la Unión Europea trata la página http://open-data.europa.eu/en/data/ (2014-06-18). Un resumen de lo que sucede en distintos países en relación a datos estadísticos, con los links correspondientes, se encuentra en la siguiente página de Naciones Unidas: http://data.un.org/ (2014-06-18).

${ }^{457}$ Ver algunas novedades sobre el desarrollo de algoritmos de búsqueda de Google en, por ejemplo: http://insidesearch.blogspot.com.es/2013/09/fifteen-years-onand-were-just-getting. html\#uds-search-results(2014-06-18).

${ }^{458}$ Se les denomina "servicios inteligentes". Ver al respecto el documento titulado Iniciativas de Linked Data para Smart Cities que se encuentra en http://www.innprontaciudad2020. es/index.php/es/documentacion-ficheros-relativos-al-proyecto/white-papers/90-iniciativasde-linked-data-para-smart-cities(2014-06-28). 
interior y exterior de una vivienda, por ejemplo, el momento en el que la calefacción o la refrigeración deban ser apagadas automáticamente. La temperatura interior se averigua por la información sobre el ambiente recogida por termómetro, la exterior por otro termómetro $\mathrm{y}$, si se quiere programar el servicio para un periodo de tiempo determinado, por las previsiones hechas por un Servicio Meteorológico. Lo mismo ocurre con la iluminación de casas y vías públicas o calles. Así se entiende que sería deseable tecnológicamente, por ello, que los datos que permiten realizar las predicciones y las nuevas aplicaciones sean abiertos o de libre uso.

Se puede desarrollar, igualmente, servicios que proveen por medio del uso de semáforos y otras señales de tráfico o sensores adecuados, gestionados por instituciones públicas, rutas abiertas para el movimiento de servicios de urgencia o el transporte de vehículos que hacen la distribución de mercancía. En consecuencia, sería deseable que los datos o la información que permiten crear estas rutas estuvieran abiertos para poderse desarrollar nuevos sistemas.

Existen/existirán programas de ordenador capaces de indicar si hay o no plazas libres en un aparcamiento de automóviles a la vez que hacen previsiones de ocupación para el futuro, permitiendo reservarlas para un determinado momento. Los datos en este caso pueden ser proporcionados por instituciones públicas o por empresas que gestionan los aparcamientos.

Estos ejemplos dan cuenta de que efectivamente se están construyendo servicios o programas, contando con datos, que pueden auxiliar a los ciudadanos.

La construcción de los servicios o programas cuenta con la información captada de la naturaleza y la vida diaria por sensores cuyo funcionamiento está regido por las reglas y técnicas de la Física, Meteorología o Mecánica, por ejemplo. También la de los ciudadanos anonimizada capturada, acumulada y tratada atendiendo a pautas de comportamiento individuales, de usuarios de los servicios, que se ponen a disposición de quien las ha generado o a la de otros usuarios/ciudadanos que los adquieran. En todo caso, de ello nos ocupamos a continuación, no son datos abiertos como propugnan los movimientos de opinión sobre "open data" porque siempre existe algún derecho sobre ellos.

\subsection{LA REGULACIÓN}

Hemos dicho que una importante fuente de información "abierta" está constituida por los datos de carácter público, que cada vez más son accesibles en formatos estándar en Internet, siendo puestos a disposición de ciudadanos o empresas por las Administraciones a través de los correspondientes reglamentos.

Es por ello que la regulación sobre datos abiertos está referida a datos de carácter público. Así lo permiten y regulan las directivas europeas y leyes estatales referidas a reutilización de datos públicos, acceso a la información y transparencia.

Sumariamente, desde una perspectiva española, la regulación vigente es la siguiente. 
Regulación española: Ley 37/2007, de 16 de noviembre, sobre el reúso de información del sector público, Real Decreto 1495/2011, de 24 de octubre, que desarrolla la ley 37/2007, y Ley19/2013, del 13 de diciembre sobre Transparencia, Acceso a la información pública y Buen Gobierno.

Regulación europea: el 13 de abril de 2013, el Consejo de la Unión Europea revisó la Directiva 2003/98/EC ontheReuse of Public Sector Information; el 13 de junio de 2013 el Parlamento europeo adoptó una resolución legislativa “ ontheproposalfor a directive of theEuropeanParliament and of the Council amendingDirective 2003/98/EC onreuse of public sector information (COM(2011)0877 - C70502/2011 - 2011/0430(COD)).

En esta normativa se regula, como sus enunciados dicen, la forma de "reutilizar" por servicios, aplicaciones, sistemas o programas concretos los datos que reciben en el ejercicio de sus funciones las Administraciones mediante su publicación en Internet, respetando siempre las garantías que se da en su recopilación a la preservación de la propiedad intelectual e industrial y la protección de datos personales. También se prescribe que cada información suministrada por las correspondientes Administraciones de ámbito estatal, autonómico y local, establezca las notas o avisos legales referidos al uso de dicha información (art. 7 Real Decreto 1495/2011).

En la actualidad los avisos legales establecen en muchas ocasiones la no obligación de las Administraciones en relación a la continuación de la publicación de datos abiertos, circunstancia que ha de ser tenida en cuenta por los proveedores de servicios que utilizan los datos públicos a efectos de que establezcan los oportunos acuerdos con las Administraciones con el fin de garantizar la continuación de la publicación de los mismos y la subsistencia de la oferta de sus servicios.

Con lo hasta aquí señalado observamos que la puesta en acción de la regulación sobre datos abiertos apela, una vez bien conocidas y estudiadas las características de la discusión y puesta en acción de los datos abiertos, mediante la prescripción de la elaboración de notas o avisos legales por quienes suministran la información, a establecer una guía para el acceso a los datos. Es decir hay que acudir a la regulación existente sobre programas y servicios mediante los cuales se "atesoró" inicialmente los datos y contrapesar, expresándolo en forma de avisos legales, los distintos valores a los que la información reutilizada responde. Para realizar estas funciones es preciso entre en funcionamiento la Filosofía del Derecho a la que hacemos referencia en el capítulo IV.

\section{Transparencia}

\subsection{ExigenCIAS}

No quedan suficientemente satisfechos los principios jurídicos cuando las instituciones se limitan a expandir las posibilidades de crecimiento que tiene la 
construcción de "servicios/programas" en cuanto se considera que este desarrollo es capaz de crear riqueza o empleo. Sin duda que esta es "una" obligación de su función, pero ahí no acaban "todas" sus obligaciones para con los ciudadanos. Nos referimos a que las instituciones públicas en el Estado de Derecho han de ocuparse de promover todo tipo de actividades democráticas, es decir, si tenemos en cuenta el uso de "datos abiertos", la realización de nuevos diseños o programas en razón a garantizar con ello el cumplimiento de todos los fines del Estado de Derecho, como a continuación exponemos, y no sólo en razón a la satisfacción del referido a la generación de empleo.

Esto es así porque ha de recordarse que un sistema político democrático, y las instituciones que lo integran, no sólo está justificado por la creación de empleo sino que lo está porque atiende: (1) a la garantía e impulso de tres mecanismos, hoy principios jurídicos fundamentales, a los que nos referimos a continuación, reconocidos en las constituciones y hechos realidad en la vida diaria de los países donde las mismas funcionan, (2) a la satisfacción de un requisito previo para el ejercicio de mecanismos y principios: el acceso a información y (3) a la adopción como política de acción de la gobernanza, el buen gobierno, en cuanto, como veremos, ella es una de las principales filosofías o políticas que cabe seguir para la puesta en realidad de los principios democráticos y el diseño de servicios/programas, lo último en forma especial cuando no existen normas que regulan directamente su funcionamiento al no haberse hecho realidad el fenómeno, una vez que los principios de gobernanza/ prudencia han de respetarse en la construcción y puesta en funcionamiento de servicios porque éstos no pueden atender por si mismos a resolver toda la complejidad que sucede en la realidad en el campo de aplicación de dichos servicios ${ }^{459}$.

Los tres principios/mecanismos jurídicos fundamentales son los referidos a: 1) la libre elección de los gobernantes por los ciudadanos, 2) la efectiva puesta en práctica de la división del ejercicio del poder político por las instancias de gobierno competentes, y 3) la salvaguarda de la protección y promoción ${ }^{460}$ de los derechos humanos por los poderes públicos con respecto a las actividades que tienen lugar en el desarrollo de la vida propia de los ciudadanos.

Los tres mecanismos son considerados propios del funcionamiento del Estado de Derecho. Su contenido y función característicos son resumidos a continuación.

1) El primer mecanismo es el de la libertad, concretada como libre elección de los gobernantes por los ciudadanos, que se pone en práctica mediante la realización de procesos electorales que permiten a todos los ciudadanos

\footnotetext{
${ }^{459}$ Se dan detalles sobre la concreción de los principios indicados en varios países en las investigaciones de la Academia de Derecho Internacional de La Haya recogidas en Foblets y Yassari (2013).

${ }^{460}$ Sobre el papel activo del Estado en la promoción de derechos más que en la simple protección, véase, por ejemplo, Carbonell (2008).
} 
participar en el gobierno nombrando periódicamente a sus representantes en distintos ámbitos políticos de decisión. Este procedimiento participativo, democrático, se ve completado por la posibilidad que tienen los ciudadanos de intervenir en las actividades gubernamentales mediante la puesta en realidad de otros medios como el referéndum con relación a cuestiones concretas sometidas a opinión de la ciudadanía por los representantes políticos, la coparticipación en actividades de carácter gubernamental mediante la intervención de ciudadanos cuya actuación está prevista en la regulación de procedimientos administrativos, y la participación de los ciudadanos en la solución de conflictos por los tribunales de justicia mediante su intervención como jurados.

2) El segundo mecanismo democrático es la división de poderes, es decir la aceptación de que el ejercicio de los recursos, instrumentos y medios que han de poner en práctica los gobernantes elegidos, tiene que atender a la separación de dicho ejercicio en el de tres "poderes" o funciones: legislativo, ejecutivo y judicial. Ello implica que la actividad propia de cada poder ha de ser realizada respetando la distribución de las competencias funcionales establecida mediante la satisfacción de los procedimientos reconocidos y articulados por la constitución y el resto del ordenamiento. Estos procedimientos permiten garantizar tanto la independencia de acción de cada uno de los poderes, cuanto que la coordinación y el equilibrio del ejercicio de las funciones o competencias propias de los mismos.

3) El tercer mecanismo es el del reconocimiento, respeto, preservación y promoción de las declaraciones de derechos humanos contenidas en la constitución y el ordenamiento jurídico en su conjunto, realizados por la práctica del ejercicio de las competencias y funciones propias de los poderes con respecto a actividades ocurridas en sociedades concretas.

Completa lo hasta aquí expresado la consideración de que, obviamente, la democracia o la participación política no puede ser puesta en práctica efectivamente en ninguna de las facetas reseñadas sin la satisfacción de un requisito previo: que los ciudadanos estén informados o, lo que es lo mismo, tengan suficiente conocimiento sobre el objeto de su participación.

Es por ello que en la actualidad cabe decir, sintéticamente, que un sistema político democrático es aquel cuyo funcionamiento está basado en la participación consciente e informada de los ciudadanos en el ejercicio del poder político o bien indirectamente mediante la elección de sus representantes o bien directamente colaborando en la toma de decisiones políticas utilizando otros mecanismos. Esto implica reconocer que los ciudadanos pueden participar en prácticamente todas las actividades de los poderes públicos, atendiendo, además, al hecho de que el Estado 
de Derecho actual no es el Estado liberal del siglo XIX que limitaba la acción de los organismos públicos a actuar políticamente como policía elaborando las correspondientes leyes básicas y aplicándolas mediante penas o sanciones a los infractores del orden jurídico: salvaguardando el funcionamiento del mercado, sus posibles violaciones, sino que el Estado es, a la vez, Estado social, democrático, del bienestar, de la gobernanza y, hoy, el Estado propio de la denominada sociedad del conocimiento, que tiene potestad para participar en prácticamente todas las actividades diarias, especialmente las propias de las instituciones públicas una vez están financiadas con fondos públicos.

Lo anterior implica que se satisface este requisito democrático cuando los servicios son transparentes en su estructura, diseño y funcionamiento para con todos los ciudadanos.

A lo dicho hasta aquí no le impide el reconocimiento que de un tiempo a esta parte se está aceptando como práctica política propia común de las competencias propias de los poderes públicos la del ejercicio de la democracia y de la función de los poderes públicos a través de lo que se denomina gobernanza. La gobernanza está definida por el Diccionario como "Arte o manera de gobernar que se propone como objetivo el logro de un desarrollo económico, social e institucional duradero, promoviendo un sano equilibrio entre el Estado, la sociedad civil y el mercado de la economía".

Esto significa reconocer la expansión en el ámbito público, como prácticas o usos propios de los gobernantes (incluyendo en la expresión a todos los funcionarios públicos que ponen en acción a los tres poderes), de los principios, técnicas o usos de gobierno propios del ámbito empresarial junto a los de carácter público. Esto es lo mismo que decir: la puesta en acción de la eficiencia y las reglas del mercado como criterio de acción preferente o concomitantes con las de la administración pública.

Este estilo de acción o política no impide decir que el respectivo poder ha de ser ejercido en forma compatible con la puesta en práctica de los principios propios del Estado de Derecho, que resumen la acción de la democracia que, por mandato legal, gobierna la acción de los poderes públicos, es decir todos aquellos asuntos sobre los que éstos son competentes según el ordenamiento propio de los Estados de Derecho en cuanto son agentes activos en la vida social y política de la sociedad del conocimiento.

\subsection{NORMATIVA}

En coherencia con lo hasta aquí dicho se están promulgando regulaciones sobre transparencia a la vez que sobre participación y buen gobierno, no lo que es el caso de la normativa española aprobada en diciembre de 2013. El contenido de la Ley consiste, sucintamente, en establecer principios y mecanismos dirigidos a hacer 
públicas las razones, argumentos y documentos que están presentes en la realización de una actividad administrativa entendida en sentido amplio: financiada por fondos públicos (arts. 2 a 11). La Ley también establece fórmulas para conocer por parte de los ciudadanos dicha información mediante, entre otras, la previsión de la publicación en Internet de un portal de la administración en el que se coloque todo tipo de información que esté en la base de sus decisiones (arts. 12 a 24). Finalmente la Ley da indicaciones referidas a la satisfacción de los principios del buen gobierno/la gobernanza, centradas, especialmente, en reclamar de funcionarios y políticos mecanismos para establecer su responsabilidad en el caso de actividades de "mal" gobierno realizadas, por ejemplo, sin contar con recursos para llevarlas adelante (arts. 25 a 32$)$.

\section{Filosofía del Derecho}

\subsection{Positivismo y iUSnaturalismo}

Con lo hasta aquí dicho cabe plantear la pregunta ¿qué teorías son las más adecuadas para presentar ordenadamente, y profundizar en las mismas, las competencias profesionales ${ }^{461}$ que se requieren al abogado -tomado como prototipo de jurista- para el ejercicio de su función a través de las actividades que la sociedad le demanda en casos como los hasta aquí reseñados en forma ejemplar?

La respuesta inicial puede ser: las teorías básicas que han sido y son propuestas a los juristas desde el Renacimiento hasta nuestros días. Sustancialmente dos: el iusnaturalismo y el positivismo jurídico ${ }^{462}$.

La primera teoría pone énfasis en proponer al jurista considerar el origen y legitimación natural/racional o teológica del Derecho como teoría justificadora del mismo y por lo mismo ser su mecanismo idóneo para su amplificación y desarrollo, capaz de articular, expandir y dar consistencia a los textos jurídicos a efectos de poder resolver los problemas aparecidos en la práctica diaria y que se le plantean para

${ }^{461}$ En este apartado nos referimos a competencias teniendo en cuenta las que se establece en la Ley 34/2006, de 30 de octubre, sobre el acceso a las profesiones de Abogado y Procurador de los Tribunales, y el Reglamento que la desarrolla: Real Decreto 775/2011, de 3 de junio, por el que se aprueba el Reglamento de la Ley 34/2006, de 30 de octubre, sobre el acceso a las profesiones de Abogado y Procurador de los Tribunales.

${ }^{462}$ Aquí se hace uso de estas denominaciones porque son las que se extienden frecuentemente en manuales y discusiones. Hace tiempo que no son suficientes para denominar a la discusión filosófico jurídica. EnMarmor(2012), por ejemplo, se hace un resumen actual de las denominaciones de posiciones filosófico jurídicas actuales utilizando las siguientes expresiones: naturaleza del Derecho, razonamiento jurídico e interpretación, teorías sobre áreas particulares del Derecho, Derecho como orden coactiva, obligaciones morales hacia el Derecho y Derechos e igualdad. Estas son las denominaciones de los capítulos de la obra. Una interesante crítica al positivismo anglosajón se encuentra en Martin (2014). 
resolverlos.

La segunda teoría: el positivismo jurídico, propone como solución admitir las reglas y principios establecidos por el contenido de las Constituciones y el funcionamiento del esquema básico del Estado del Derecho, integrado por el principio de separación de poderes, y que se concreta en el reconocimiento de que el Derecho está integrado por las leyes aprobadas por el Parlamento. El positivismo jurídico centra sus indicaciones en proponer al jurista el texto de las leyes y el resto de las normas promulgadas por las instituciones públicas (que integran los poderes legislativo, ejecutivo y judicial) como prácticamente único elemento articulador de sus actividades, aplicando en éstas simplemente las composiciones hechas a partir de las normas por la Dogmática o la Ciencia del Derecho como soluciones adecuadas para los problemas aparecidos en la práctica diaria.

Esta breve reseña, significativa del contenido básico de ambas teorías, nos muestra claramente su insuficiencia para servirnos como elemento de articulación y desarrollo del contenido de todas las competencias profesionales requeridas al abogado, y al jurista en general, en la actualidad si tomamos como referencia los dos ejemplos tomados en consideración en este trabajo. En el caso de los datos abiertos el jurista ha de conocer un ámbito de acción, el desarrollo tecnológico, que no está recogido ni en los principios ni en los textos jurídicos, en cuanto que es radicalmente nuevo, no ha sucedido hasta el momento en el que se produce la presentación y manejo instantáneos de información abierta en cualquier lugar del mundo utilizando Internet. En el caso de la transparencia el jurista ha de conocer la organización y el funcionamiento de las instituciones públicas en el momento en el que toman decisiones utilizando uno u otro tipo de herramientas propio de nuestra época: el ordenamiento jurídico, pero también datos económicos, presupuestarios, expresados en forma de números, proyectos, programas, datos abiertos, portales de Internet o estadísticas.

Todo lo anterior nos hace concluir que ni el iusnaturalismo ni el positivismo jurídico, es decir las teorías que se fijan en los textos de las leyes y en las fundamentaciones utilizadas supuestamente por sus promulgadores, son suficientes teorías para que los abogados con su ayuda sean competentes en la resolución de problemas sociales. En la actualidad hemos observado gracias a nuestros ejemplos que, considerando simplemente la propuesta de ambas teorías (positivismo-iusnaturalismo) de atender a dichos textos, el ordenamiento o la legislación, éstos han de ser entendidos en sentido amplio, es decir tener en cuenta que incluyen en muchas ocasiones algo que no está recogido explícitamente por los mismos: los códigos de práctica existentes, por ejemplo, las reglas aplicadas de la programación funcional para la resolución de servicios concretos, las reglas de la gobernanza o los estándares técnicos.

Estos recursos son generados por el mismo desarrollo social e incluso tecnológico, una vez que originan situaciones que no están contempladas por los órganos legislativos en las leyes, siendo las reglas de uso de las mismas: las reglas 
propuestas por los creadores de servicios a sus usuarios, por ejemplo, las que han de ser tenidas en cuenta como regulación efectiva en caso de aparición de conflictos, siendo ello coherente con la circunstancia de que el pacto entre las partes, que no vaya contra la Ley, es considerado regla válida en el Estado de Derecho.

Todo lo cual hace reconocer que hacen falta teorías del Derecho más precisas y concretas que las señaladas hasta ahora (positivismo y iusnaturalismo) que tomen como referencia las necesidades sociales o todas las actividades y el conjunto de competencias académicas/científico jurídicas necesario para ser abogado, como ejemplo de jurista, en lo referido a: "Poseer, comprender y desarrollar habilidades que posibiliten aplicar los conocimientos académicos especializados adquiridos en el grado a la realidad cambiante a la que se enfrentan los abogados para evitar situaciones de lesión, riesgo o conflicto en relación a los intereses encomendados o su ejercicio profesional ante tribunales o autoridades públicas y en las funciones de asesoramiento." ${ }^{463}$ Estas competencias son las que están referidas directamente al estudio de los textos jurídicos tratados por los conocimientos académicos especializados: la Dogmática o Ciencia del Derecho. Frente a ellolas competencias requeridas a los abogados, sujetos fundamentales de la vida jurídica, son más amplias, hacen referencia a actividades jurídicas propiamente dichas (incluyendo dominio de conceptos jurídicos, interpretación y aplicación del Derecho), actividades profesionales conformes con reglas éticas, de gestión y de comercialización, actividades propias de la "sociedad del conocimiento", actividades comunicativas y actividades guiadas por la consecución del valor justicia o su plasmación en la regulación sobre derechos humanos.

Estas circunstancias hacen que en muchas ocasiones se organicen las teorías jurídicas como mal menor, teniendo en cuenta que ante los conflictos son los jueces y los integrantes de los tribunales de arbitraje quienes tienen que tomar resoluciones que atiendan a normas, intereses y al logro del consenso/justicia/seguridad al que el ordenamiento democrático está avocado, como el resto de las competencias antes indicadas expresan en parte. A ello se refiere la teoría comunicacional del Derecho a la que nos referimos a continuación.

\subsection{La teoría comunicacional del Derecho}

Los ejemplos dados son una muestra significativa de que se hace preciso contar, al menos, con una teoría comunicacional del Derecho (TCD) que, más allá de versiones positivistas o iusnaturalistas, centradas en la exclusiva consideración de los textos regulativos aprobados por los órganos responsables, o las reglas y principios de carácter social comúnmente aceptados o revelados, se fije, sin perder como referencia básica el principio de legalidad propio del Estado de Derecho, en el con-

${ }^{463}$ Art. 10, número 3 del Reglamento (Real Decreto 775/2011, de 3 de junio citado) que concreta las "Competencias de los cursos de formación para el acceso a la profesión de abogado" 
texto o el ámbito comunicativo concreto que permitan tener en cuenta todos aquellos elementos que son precisos en la solución de problemas jurídicos concretos.

Lo anterior concreta prácticamente la propuesta de TCD de Gregorio Robles (ROBLES, 2010): "Mi propuesta concreta de Teoría del Derecho se basa en contemplar este último como un conjunto de procesos de comunicación entre los hombres cuya misión inmanente es dirigir la acción humana. Como tal conjunto de procesos de comunicación, es analizable como lenguaje, como una pluralidad de mensajes y de signos. Esta es la idea básica de lo que he denominado Teoría comunicacional del Derecho".

Teoría que Robles concreta más al expresar su conexión con la teoría de los juegos: el Derecho es un juego en cuanto que en él se dan como en todo juego "los siguientes elementos necesarios ('necesarios' quiere decir aquí que no es posible el juego sin ellos): el reglamento del juego (llámese así o de cualquier otra manera), el espacio, el tiempo, los sujetos (jugadores), las competencias de éstos, los procedimientos para jugar, así como los poderes y los deberes de los jugadores al realizar las acciones de juego".

Estas concreciones satisfacen, igualmente, las exigencias que se hacen a toda teoría científica para considerarla como tal.

A partir de la misma Robles elabora su obra titulada Teoría del Derecho. Fundamentos de Teoría Comunicacional del Derecho, Volumen 1, en la que construye un detallado y preciso sistema comunicativo que ofrece soluciones jurídicas mediante la aplicación de la teoría de los juegos de alcance mayor que el mero estudio de los textos legales o los principios subyacentes a los mismos.

El autor realiza en su obra un acto de comunicación con el lector, del que presume es un estudiante de Derecho, exponiendo en 23 capítulos, explicados en 121 lecciones, los elementos básicos de su Teoría. Elementos que están integrados por propuestas de contenido jurídico conformadas por los textos de las leyes y reflexiones hechas sobre ellos por la teoría o la Filosofía del Derecho y la Dogmática jurídica en relación a un problema jurídico hipotético, el objetivo del capítulo correspondiente, precisamente definido en sus características fácticas, comprendiendo las institucionales. Los problemas se dan o pueden darse en la realidad.

Todo ello hace que el conjunto de los elementos de la Teoría sean un instrumento de indudable valor director para satisfacer las competencias básicas requeridas al abogado. El problema es que no se ocupa del resto de competencias y actividades que son precisas como necesarias socialmente para resolver problemas como los aquí presentados sucintamente.

Lo último hace preciso que nos sigamos preguntando: ¿basta una teoría comunicacional o son necesarias más teorías?

Hemos expresado que las actividades en las que han de ser competentes los juristas tienen características de plural carácter: no sólo hacen relación a los textos jurídicos. Recuérdese que hemos hablado de actividades conformes con reglas éti- 
cas, de gestión y de comercialización, actividades propias de la "sociedad del conocimiento" 464 , actividades comunicativas y actividades guiadas por la consecución del valor justicia o su plasmación en la regulación sobre derechos humanos. Lo cual nos hace decir que no son sólo teorías jurídicas las precisas sino también aportes de otras teorías que estudian y dan propuestas a otras actividades: las necesarias para hacer competentes a los profesionales del Derecho. La TCD de Robles se fija en los signos objeto de comunicación: los textos jurídicos y las reflexiones e incluso instituciones que con los mismos se crean, pero ello no es suficiente: es preciso prestar atención, igualmente, a las características de la misma comunicación y a las de las actividades que la realizan. También a otros instrumentos que se utilizan en dichas actividades. Por lo anterior cabe concluir que en Derecho es preciso utilizar otras teorías explicativas y articuladoras de actividades, conocimientos y valores distintos a los presentes explícita o implícitamente en textos jurídicos.

Ello es lo que ha realizado la denominada Metodología jurídica que, desde el siglo XIX, ha utilizado las propuestas de distintas teorías procedentes del terreno de la discusión filosófica y científica, especialmente, a las que luego nos referimos, para aportar fundamentaciones a las actividades o competencias propias de los profesionales del Derecho y no sólo a los textos jurídicos, los signos, considerados objeto de las mismas.

¿Hace falta, por ello, instruir a los juristas en todas las teorías que explican sus competencias profesionales? Aquí no vamos a centrarnos en exponer el contenido de esas otras materias o teorías ${ }^{465}$. En verdad cada especialista o experto en ellas ha de proponer lo que entienda sea pertinente para la formación y el ejercicio profesional en forma de competencias. Aquí vamos a optar por proponer algo más limitado aun cuando tenga potencialmente los mismos efectos. Lo que vamos a hacer es proponer una teoría del Derecho escasamente explícita: un concepto comunicativo de Derecho, coherente con las teorías que fundamenten la instrucción en competencias, que sirva como apoyo teórico a los juristas que tienen que aprender y practicar todo tipo de habilidades y actividades, y no tan sólo el estudio ordenado o sistematizado de los textos de derecho positivo o los valores que amparan.

La utilización de un concepto como marco teórico es un recurso de uso extendido en el ámbito jurídico: la precisión de un concepto de Derecho que pueda ser utilizado como referencia por los juristas como criterio orientador práctico para

${ }^{464}$ Se hacen propuestas a este respecto en relación al ámbito local en Estados Unidos en $\operatorname{Katz}(2010)$. Visiones críticas sobre la relación entre Derecho y Gobernanza global véase Búrca, Kilpatrick y Scott (2014).

465 Están expresadas en los Masters aprobados conducentes al ejercicio profesional de abogado y procurador de los Tribunales. Un ejemplo es el Máster Universitario en Abogacía por la Universidad de Zaragoza ya aprobado y cuyo expediente de aprobación y contenido puede leerse en: http://derecho.unizar.es/v_calidad/documents/MemoriaRegistrada.pdf (2014-0628) 
el ejercicio de las competencias que se le requieran como jurista, superando con ello las debilidades que tiene el uso de una red de conceptos, instituciones o textos que expresen un contenido concreto, siempre caduco por efecto de los factores tiempo y espacio, elaborado a partir de la aceptación de que el Derecho es norma o justicia.

En este sentido en varios trabajos hemos propuesto considerar al Derecho como actividad justa de juristas con relación a textos jurídicos ${ }^{466}$. Este es un concepto comunicativo. A continuación resumimos sucintamente el contenido de la definición.

Actividad significa atender a que el Derecho, plasmado en signos escritos y no escritos: imágenes por ejemplo, siempre se pone en acción por profesionales del Derecho mediante la realización de actividades o actos concretos analizables y escrutables a través del uso de los recursos que permiten las ciencias sociales para estudiar los comportamientos humanos y no sólo el estudio de los textos jurídicos.

El concepto también atiende a que los profesionales del Derecho están siempre guiados por la consecución de una u otra apreciación del valor justicia, que está presente heterogéneamente, sin poder obviarse, como creencia, prejuicio, convicción o sentimiento, en cualquier resolución, profesional o no (por medios judiciales o extrajudiciales), de conflictos jurídicos.

El concepto, más allá de iusnaturalismo y positivismo jurídico, tiene la propiedad de que en cuanto apela a actividades, textos y valores, permite fundamentar el aprendizaje jurídico en todo el ámbito de comunicación al que es preciso apelar en el ejercicio de las distintas competencias jurídicas. Con él el aprendiz, futuro profesional, que lo utilice estará precavido y preparado para resolver cualquier problema jurídico con consciencia de su complejidad, estando dispuesto a admitir la necesidad y relevancia de la intervención y participación de otros agentes sociales en la resolución de conflictos junto a las suyas propias.

A esto lo llamamos utilizar el concepto comunicativo de Derecho como teoría.

\subsection{Concepto comunicativo del Derecho}

Esta perspectiva es más satisfactoria/enriquecedora que la que se fija únicamente en que el Derecho es el imperativo externo descubierto histórica y filosóficamente que protege y promueve el ejercicio de la libertad al que Friedrich Karl von Savigny se refería a finales del siglo XVIII en tiempos en los que el Derecho y su aplicación debían ser coherentes con las exigencias del desarrollo industrial y su realización por la puesta en práctica de los principios propios del libre mercado. También lo es con respecto a conceptos normativos del derecho más recientes como los de RalfDreier y Robert Alexy que exponemos a continuación.

El primero de ellos, formulado por Dreier a comienzos de los años ochenta

${ }^{466}$ F.Galindo y otros (1993). F.Galindo(1998).Un manual de introducción elaborado a partir del concepto comunicativo es: F. Galindo(1993). 
del pasado siglo XX, dice lo siguiente : "Derecho es la totalidad de las normas que pertenecen a la Constitución de un sistema normativo organizado estatal o cuasiestatalmente, una vez que este sistema de normas es socialmente real, en general y en su totalidad, y satisface mínimamente la justificación ética o la justificación en general, y las normas que son creadas en desarrollo de esta Constitución, una vez que éstas incorporan en sí mismas una mínima referencia a la realidad social o a la posibilidad de realidad social y a la justificación ética o a la posibilidad general de justificación" (DREIER,1980).

El concepto de Alexy, propuesto en mil novecientos noventa y dos, dice : "El Derecho es un sistema normativo, (1) llamado a la justicia, (2) integrado por la totalidad de las normas que pertenecen a una Constitución reconocida socialmente, y no son absolutamente injustas, así como por la totalidad de las normas que han sido dictadas en virtud de esa Constitución, muestran un mínimo de realidad social o posibilidad de realidad social y no son absolutamente injustas, y por (3) los principios y los argumentos normativos especiales en los que se fundamenta y/o debe fundamentarse el procedimiento de aplicación jurídica para satisfacer las exigencias de justicia" (ALEXY, 1992).

El concepto comunicativo, a diferencia de los anteriores centrados de una $\mathrm{u}$ otra forma exclusivamente en la norma, se fija en lo que es más relevante del Derecho en la actual compleja sociedad: su actuación en actividades concretas por los profesionales del Derecho en forma respetuosa con la idea de justicia que queda recogida, especialmente, en textos jurídicos aprobados por los organismos responsables de su aprobación, a la vez que en otras reglas de práctica o convicciones que sin haber sido aprobadas por el Parlamento no van en contra de los textos legales.

Este estilo de acción o política jurídica profesional es coherente con la exigencia de que el Derecho ha de ser ejercido por los poderes en forma compatible con la puesta en práctica de los principios propios del Estado de Derecho, principios que resumen la acción de la democracia que, por mandato legal, gobierna la acción de los poderes públicos, es decir todos aquellos asuntos sobre los que éstos son competentes en cuanto son agentes activos en la vida social y política de la sociedad del conocimiento. Ello se predica especialmente de la regulación sobre transparencia y de la misma aplicación del Derecho, realizada por los juristas, según se reconoce, en el proceso judicial de forma compleja: atendiendo al mecanismo de la ponderación, propio de la gobernanza, más que al de la aplicación "automática" de la subsunción, modelo liberal.

Es conveniente resumir a estos efectos la guía de acción básica propuesta como Metodología jurídica a juristas por algunos de los estudiosos, filósofos del Derecho, que fundamentan la propuesta de un concepto comunicativo del Derecho, para con las decisiones judiciales desde un tiempo ya lejano como el constituido por los comienzos del siglo XX cuando se iniciaba la puesta en cuestión de la realización capitalista de la revolución industrial mediante la reducción del Derecho a normas y 
su puesta en acción por el positivismo jurídico ${ }^{467}$.

Desde aquella época, justamente desde el comienzo de la obligación de los jueces de poner en ejecución el Código Civil alemán bajo su responsabilidad ante todos los casos que los ciudadanos les plantearan, surgieron consideraciones críticas con respecto a la idea de que la aplicación del Derecho por los jueces estaba reducida a la realización de la subsunción del caso concreto en la Ley, como planteaban y presumían los Códigos liberales y la Metodología jurídica positivista. Ehrlich, junto a los tratadistas y jueces que se integraron en el Movimiento de Derecho Libre, puso de manifiesto que el proceso de aplicación del Derecho no podía estar reducido a la subsunción una vez que la irremediable existencias de lagunas jurídicas hace que la mayor parte de las resoluciones judiciales sean creaciones "libres", de los mismos jueces, a efectos de no incurrir en la responsabilidad correspondiente por no tomar decisiones en casos, sometidos a su decisión por imperativo legal, cuyos supuestos y soluciones no coincidieran con los previstos por la Ley (EHRLICH, 1903).

A partir de estas consideraciones surgieron a lo largo del siglo XX hasta la actualidad reflexiones dirigidas a completar el proceso de aplicación judicial del Derecho con otras explicaciones. Algunas de las soluciones propuestas han sido las siguientes: el conocimiento de las concepciones y convicciones sociales (propuesta hecha por Ehrlich a través de la Sociología: el derecho vivo), la consideración de que el proceso judicial y el razonamiento jurídico están integrados por tópicos o lugares comunes que auxilian a la aplicación (VIEHWEG, 1974), el establecimiento de sistemas normativos auxiliares a la aplicación elaborados mediante el uso de la lógica contando con la construcción de la pirámide normativa que amplía racionalmente el ámbito legal (KELSEN, 1979), la propuesta del estudio de las leyes atendiendo a que se interpretan a partir de la "precomprensión" de su contenido (ESSER 1961; ENGISCH, 1968; GADAMER, 1977), el estudio de la aplicación judicial del Derecho atendiendo al amplio ámbito y contenido de las argumentaciones que en la misma se produce (PERELMAN, 1979; ALEXY, 1992), la consideración del acuerdo de legitimación social: el consenso, al que están dirigidas las leyes y la organización estatal en su totalidad (los tres poderes) en las sociedades democráticas (HABERMAS, 1993), la consideración de que todas las actividades humanas son realizadas atendiendo a un conocimiento de la realidad producido en el contacto mantenido con la misma realidad: "autopoiéticamente" (MATURANA, 1988), y no por la mera elucubración o desarrollo intelectual de las propuestas científicas... ${ }^{468}$

\footnotetext{
${ }^{467}$ Informa sobre el estado de la cuestión de la discusión filosófico jurídica sobre estas cuestiones: Robles (2010). Desde la perspectiva anglosajona puede verse: Coyle (2014).

468 Trabajos consecuentes con la puesta en acción de estas teorías son los expresados en forma resumida en Galindo (2013).
} 


\section{Conclusión}

Mediante las herramientas que proporciona el concepto comunicativo del Derecho ya podemos resolver los ejemplos aquí presentados ${ }^{469}$. La problemática expresada en relación a la implantación de los "datos abiertos" porque el uso de dicho concepto nos permite discutir con los agentes sociales que preconizan su implantación utilizando las características totales de dichos datos: su formulación en lenguaje máquina o lenguaje de programación, en discusión con los técnicos. La problemática referida a la transparencia porque el jurista está abierto a la utilización de todo tipo de herramientas, en conversación en muchas ocasiones con los respectivos expertos en las herramientas, que permita su puesta en práctica: sean ellas normas jurídicas, teoría de sistemas o conocimientos estadísticos.En definitiva la reflexión jurídica ha de ser interdisciplinar.

\section{Bibliografía}

ALEXY, R. Begriff und Geltung des Rechts.Alber: Freiburg, 1992.

AUER, S. R.; BIZER, C.; KOBILAROV, G.; LEHMANN, J.; CYGANIAK, R.; IVES, Z. DBpedia: ANucleusfor a Web of Open Data. TheSemantic Web. Lecture Notes in ComputerScience, v. 4825. p. 722, 2007.

BÚRCA, G.; KILPATRICK, C.; SCOTT, J. (Eds.) Critical Legal Perspectives on Global Governance: Liber Amicorum David M. Trubek. Oxford: Hart Publishing, 2014.

CARBONELL, M. Constitution's functionality and social rights: outline of some problems. EstudiosConstitucionales, Santiago, v. 6, n. 2, p. 43-71, 2008.

COYLE, S. Modern Jurisprudence.A Philosophical Guide.Oxford: Hart Publishing, 2014.

DREIER, R. Der Begriff des Rechts.NeuejuristischeWochenschrift, p.896, 1980.

EHRLICH, E. FreieRechtsfindung und freieRechtswissenschaft.Aalen: ScientiaVerlag, 1903.

ENGISCH, K. La idea de concreción en el derecho y en la ciencia jurídica actuales. Pamplona: EUNSA, 1968.

\footnotetext{
${ }^{469}$ Y otros muchos más: el ejercicio de la Administración de Justicia no se entiende hoy sin el auxilio consciente de las tecnologías de la información y la comunicación, el Derecho a la vida sólo puede ser discutido junto a los conocimientos científicos y técnicos de la biología, la actividad bancaria ha de contar con legislación y códigos de prácticas, lo mismo que sucede con la vida empresarial...
} 
ESPAÑA. Ley 34/2006, de 30 de octubre, sobre el acceso a las profesiones de Abogado y Procurador de los Tribunales.BOE núm. 260, de 31 de octubre de 2006, pp. 37743 a 37747

ESPAÑA. Ley 37/2007, de 16 de noviembre, sobre reutilización de la información del sector público. BOE núm. 276, de 17 de noviembre de 2007, pp. 47160-47165.

ESPAÑA. Real Decreto 775/2011, de 3 de junio, por el que se aprueba el Reglamento de la Ley 34/2006, de 30 de octubre, sobre el acceso a las profesiones de Abogado y Procurador de los Tribunales.BOE núm. 143, de 16 de junio de 2011, pp. 61762 a 61774.

ESPAÑA. Real Decreto 1495/2011, de 24 de octubre, por el que se desarrolla la Ley 37/2007, de 16 de noviembre, sobre reutilización de la información del sector público, para el ámbito del sector público estatal. BOE núm. 269, de 8/11/2011, pp. 116296-116307.

ESPAÑA. Ley 19/2013, de 9 de diciembre, de transparencia, acceso a la información pública y buen gobierno. BOE núm. 295, de 10 de diciembre de 2013, pp. 9792297952.

ESSER, J. Principio y norma en la elaboración jurisprudencial del derecho privado. Barcelona: Bosch, 1961.

FOBLETS, M.C.; YASSARI, N. Legal Approachesto Cultural Diversity. Leiden: MartinusNijhoff, 2013

GADAMER, H. G. Verdad y método: fundamentos de una hermenéutica filosófica. Salamanca: Sígueme, 1977.

GALINDO, F. El acceso a textos jurídicos. Introducción práctica a la Filosofía del Derecho. Zaragoza: Mira, 1993.

. The communicative concept of Law. Journal of legal Pluralism and Unofficial Law, pp. 111-129, 1998.

. Soluciones jurídicas para las ciudades inteligentes: una perspectiva. Revista Democracia Digital e GovernoEletrônico.v. 10, pp. 26-58,2013

GALINDO, F.y otros.El concepto de Derecho. De la argumentación a la comunicación.Anuario de Filosofía del Derecho, pp. 223-254, 1993.

HABERMAS, J. Faktizität und Geltung.BeiträgezurDiskurstheorie des Rechts und der demokratischenRechtsstaats.Frankfurt: Suhrkamp, 1993

KATZ, E.D. Engineering the Endgame. Michigan Law Review, Ann Arbor, v. 109, n. 3, p. 349-386, 2010.

KELSEN, H. Teoría general del Estado. México: UNAM, 1979. 
MARMOR, A.TheRoutledgeCompaniontoPhilosophy of Law New York: Routledge, 2012.

MARTIN, M. JudgingPositivism. Oxford: Hart Publishing, 2014.

MATURANA, H. El árbol del conocimiento: las bases biológicas del conocimiento humano. Santiago de Chile: Editorial Universitaria, 1988.

PERELMAN, C. La lógica jurídica y la nueva retórica. Madrid: Civitas, 1979.

ROBLES, G. Teoría del Derecho. Madrid: Thomson Civitas, 2010.

UNION EUROPEA. Directive 2003/98/EC of the European Parliament and of the Council of 17 November 2003 on the re-use of public sector information.Official Journal of the European Communities L 345, 31/12/2003, pp. 90-96.

UNION EUROPEA. Directive 2013/37/EU of the European Parliament and of the council of 26 June 2013 amending Directive 2003/98/EC on the re-use of public sector information. Official Journal of the European Communities L 175, 27/06/2013, pp. 1-8.

VIEHWEG, T. Topik und Jurisprudenz.München: Beck, 1974. 



\title{
LOS RETOS DE LA SEGURIDAD SOCIAL ESPAÑOLA EN EL SIGLO XXI: DE LAS PEN- SIONES A LA INCAPACIDAD TEMPORAL ${ }^{470}$
}

The challenges of the spanish social security in the XXI century: pensions for temporary disability

\section{José Luis Tortuero Plaza}

Catedrático de Derecho del Trabajo y de la Seguridad Social y Director del Titulo de Experto en Seguridad Social de la Universidad Complutense de Madrid. E-mail: jltortuero@gmail.com

\section{RESUMEN}

El trabajo pretende realizar un análisis de los principales retos del Sistema español de Seguridad Social, utilizando como hilo conductor dos prestaciones hegemónicas. Por un lado la jubilación, que constituye el centro neurálgico de cualquier sistema de pensiones, tanto por su importancia cuantitativa, como cualitativa. Por otro, los instrumentos de protección temporal que cubre las alteraciones de la salud con efecto incapacitante y de carácter transitorio.

Palabras Claves : Seguridad social española. Incapacidad temporal .

\begin{abstract}
This work aims to conduct an analysis of the main challenges of the Spanish Social Security System, using thread two benefits hegemonic. For one retirement, which constitutes the hub of any pension system , both by their quantitative importance, such as qualitative. Furthermore, temporary protective covering health with disabling effect alterations and instruments of a transitory nature.
\end{abstract}

Keywords Spanish Social Security system. Temporary disability.

${ }_{470}$ La presente Ponencia se inserta en las actividades del Proyecto de Investigación "La Incapacidad Temporal en el trabajo de hombres y mujeres" (Subprograma de Proyectos de Investigación Fundamental no orientada, convocatoria 2011 (DER2011-29448-C03-01). 
Sumario: I. La jubilación como centro neuralgico del sistema de pensiones.1. Demografia, sistema de pensiones y costes: una aproximación en clave europea. 2. Rreflexiones sobre la edad de jubilacion y su reforma.3. Tiempos de crisis versus tiempos de reformas. 3.1. La reforma de la jubilación en la Ley 27/2011, sobre actualización, adecuación y modernización del Sistema de la Seguridad Social: la clave del dialogo social. 3.2. La implantación del factor de sostenibilidad. 3.2.1. Antecedentes: La creación del Comité de Expertos.3.2.2. El proyecto de Ley y la Ley 23/2013, de 23 de diciembre, reguladora del Factor de Sostenibilidad y del Índice de Revalorización del Sistema de Pensiones de la Seguridad Social 3.2.3. La reforma y la ruptura del consenso político y social. II. La función de las prestaciones temporales: la incapacidad temporal. 1. El modelo de gestión y control de la incapacidad temporal: un proceso de reforma interminable. 2. Nuevas reglas de gestión y control: el real decreto 625/2014.2.1 Ubicación y alcance de la reforma. 2.2. Elementos destacables de la reforma y sus puntos críticos.2.2.1. Instrumentos de control sobre la actuación de los facultativos y centralización de la información. 2.2.2. La fragmentación temporal de los procesos como mecanismo control-presión.2.2.3. Facultades de control y la posible vulneración del derecho a la intimidad.

\section{LA JUbILACIÓN COMO CENTRO NEURALGICO DEL SISTEMA DE PENSIONES}

De todos los riesgos cubiertos por la Seguridad Social consistentes en defectos de rentas, el más importante, con mucho, es el de vejez. Y ello, porque se trata de una contingencia caracterizada por la frecuencia de su cristalización, al constituir el término previsible y normal de la vida profesional del individuo, tan sólo alterada por situaciones cuantitativamente irrelevantes de invalidez y muerte. Podemos decir, por tanto, que la jubilación es receptora, en términos generales, del conjunto de ciudadanos que se incorporan a la población activa, de ahí la importante dependencia de las estructuras demográficas de cada país y de los fenómenos que inciden sobre aquéllas. La característica referida viene agravada por el progresivo aumento de la esperanza de vida de la población lo que deriva en el creciente disfrute temporal de la pensión y su añadida necesidad de su revalorización periódica, de forma que las pensiones mantengan, al menos, su poder adquisitivo.

Conforme lo anterior, podemos afirmar que la jubilación constituye la médula espinal de cualquier sistema de protección social. Igualmente lo es, que su ordenación jurídica gira en torno al establecimiento de una edad fija o variable que articula el tránsito de la situación de activo a la situación de pensionista de jubila- 
ción. La edad se convierte así, en la llave maestra del sistema y adquiere por tanto connotaciones de especial relevancia. Precisamente por ello, hay que ser especialmente cuidadoso a la hora de redefinir la edad de jubilación, no sólo por la complejidad de la tarea en sí misma, sino por el entramado de condicionantes propios y ajenos o colaterales, presentes y futuros que actúan en un espacio múltiple de difícil y necesario equilibrio. La singularidad de los tiempos actuales está en que múltiples piezas del entramado global se han desencajado afectando al equilibrio del sistema y, por tanto, a su viabilidad. A todos estos temas me referiré a lo largo de las reflexiones que siguen.

\section{Demografia, Sistema de PENSIONES y COSTES: UnA APROXimaCión EN ClaVe EUROPEA}

Junto a los elementos descritos, debemos añadir otro de singular importancia, a saber, la ruptura del equilibrio o de la proporcionalidad entre el conjunto de ciudadanos que entran en la población activa y los que salen de la misma para acceder a la jubilación. Esta ruptura viene provocada por la disminución progresiva y notable de la tasa de natalidad (si bien en la parte baja de la pirámide de población es donde más diferencias existen entre los países de la UE, se da como promedio del número de hijos por mujer la cifra de 1,5 - siendo el umbral de la rotación generacional el 2,1- y se prevé una tasa de 1,6 para el 2030; en España, los datos más recientes, fijan el índice de fecundidad en 1,39 en el 2007, con una previsión para el 2017 de 1,46). No obstante, la disminución de la población nacional puede ser parcialmente compensada, como ha ocurrido en España en los años anteriores a la crisis, con el incremento de la población emigrante. Si bien los datos son muy desiguales en los países de la UE, en el periodo 1995-2007, España, Italia y el Reino Unido han recibido las tres cuartas partes de la migración europea ${ }^{471}$.

El incremento de la esperanza de vida fue tremendamente importante en los últimos cincuenta años (desde 1960, el incremento medio de la UE ha sido de 8 años, con una importante brecha entre Oriente y Occidente en la UE.27, y que en particular se refiere al hombre, que puede esperar vivir sólo hasta los 65-70 años en ocho de los Estados miembros de Europa central y oriental, en comparación con un promedio de más de 76 años en la UE-15) y lo seguirá siendo, aunque con menor intensidad, en el futuro (las previsiones en la UE, son de 5 años de aumento sobre el

${ }^{471}$ Commission of the European communities. Demography Report 2008, Brussels, SEC (2008)2911. La Comisión ha vuelto a realizar un Informe sobre el envejecimiento demográfico en el año 2009 (“Abordar los efectos del envejecimiento de la población de la UE”), basado en las previsiones presentadas por Eurostat 2008 donde de nuevo vuelve a replantear la transición demográfica que está viviendo Europa y los costes sociales de dicha realidad. Ver la Comunicación de la Comisión al Parlamento Europeo, al Consejo, al Comité Económico y Social Europeo y al Comité de Regiones de 29 de abril de 2009 (COM (2009) 180 FINAL- no publicado en el Diario Oficial 
dato actual hasta 2.050). Igualmente relevante es la esperanza de vida a los 65 años que se sitúa como media (UE.27) en 16,8 años para los hombres y 20,4 años para las mujeres, si bien la media es superada en los Estados del UE. $15^{472}$ De ello deriva una desconexión creciente entre las edades jubilatorias fijadas, en términos generales, durante la primera mitad del siglo XX, y la actual esperanza de vida a los 65 años, lo que exige medidas de reordenación que pueden tener, como veremos, distinto alcance y contenido. La importancia de la esperanza de vida ha provocado que en varios Estados de la UE, [ y en breve (posiblemente a partir del 2014) también en España] quede integrado en el cálculo de las pensiones iniciales de jubilación mediante la aplicación del denominado factor de equidad intergeneracional (factor de primera generación) ${ }^{473}$

Conviene también hacer referencia a los cambios en la intensidad de los flujos jubilatorios. Una característica notable con fecha en los calendarios europeos es la llegada a la jubilación de las generaciones del baby boom, esto es, de generaciones singularmente numerosas nacidas en Europa occidental y Estados Unidos después de la Segunda Guerra Mundial, en el periodo de 1946 a 1964. En España el fenómeno se retrasó hasta avanzados los años cincuenta, esto es, hasta el periodo comprendido entre 1957 y 1977. La mayor intensidad en el flujo jubilatorio ha encendido las luces de alarma, tanto por el impacto que en sí mismo provocará el fenómeno, como por la confluencia de una reducción de la población activa motivada por la bajada de las tasas de natalidad. Singularmente, cuando se anuncia que la ratio activos-pasivos fijada hoy es de aproximadamente cuatro personas en edad de trabajar por cada persona mayor de 65 años, en el futuro (2060), la ratio será sólo de dos activos ${ }^{474}$. Con todo, adviértase que si bien los problemas de los sistemas de pensiones son en gran medida de origen demográfico, las soluciones están lejos de ser "sólo" de carácter demográfico.

\footnotetext{
472 FUENTE: Europe in figures. Eurostat yearbook 2010.

${ }^{473}$ Sobre este factor puede verse el trabajo de MENEU GAYA, R.; DEVESA CARPIO, J. E.;; DEVESA CARPIO, M.; NAGORE GARCIA, A.; DOMINGUEZ FABIAN, I.; y ENCINAS GOENECHEA, B.:“El factor de sostenibilidad: diseños alternativos y valoración financiero-actuarial de sus efectos sobre los parámetros del sistema”. Revista Economía Española y Protección Social, 2013.

${ }^{474}$ Comisión Europea, Libro verde en pos de unos sistemas de pensiones adecuados, sostenibles y seguros, SEC (2010) 830.
} 


\section{Evolución de la relación de dependencia demográfica entre 2010 y 2060}

\section{España/Unión Europea}

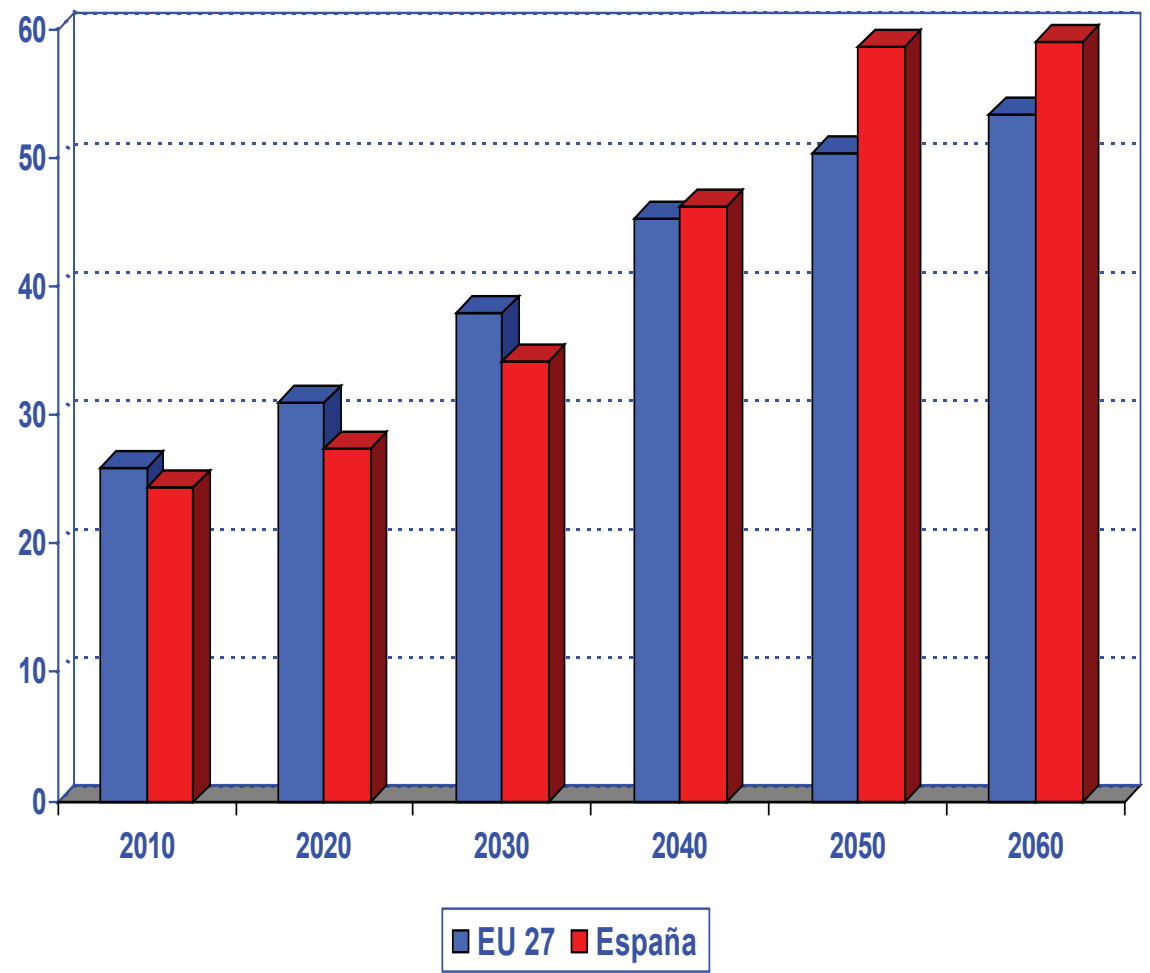

Todo lo dicho hasta aquí se deduce fácilmente del análisis de los cohortes de población en la UE, cuando se examinan comparativamente en la actualidad y en el futuro. Así, en la siguiente figura se puede observar como se incrementará el número de ciudadanos en las edades en que se accederá a la jubilación desde 2008 hasta 2060, con las consecuencias propias del incremento del número de pensiones, que ya se han señalado. 


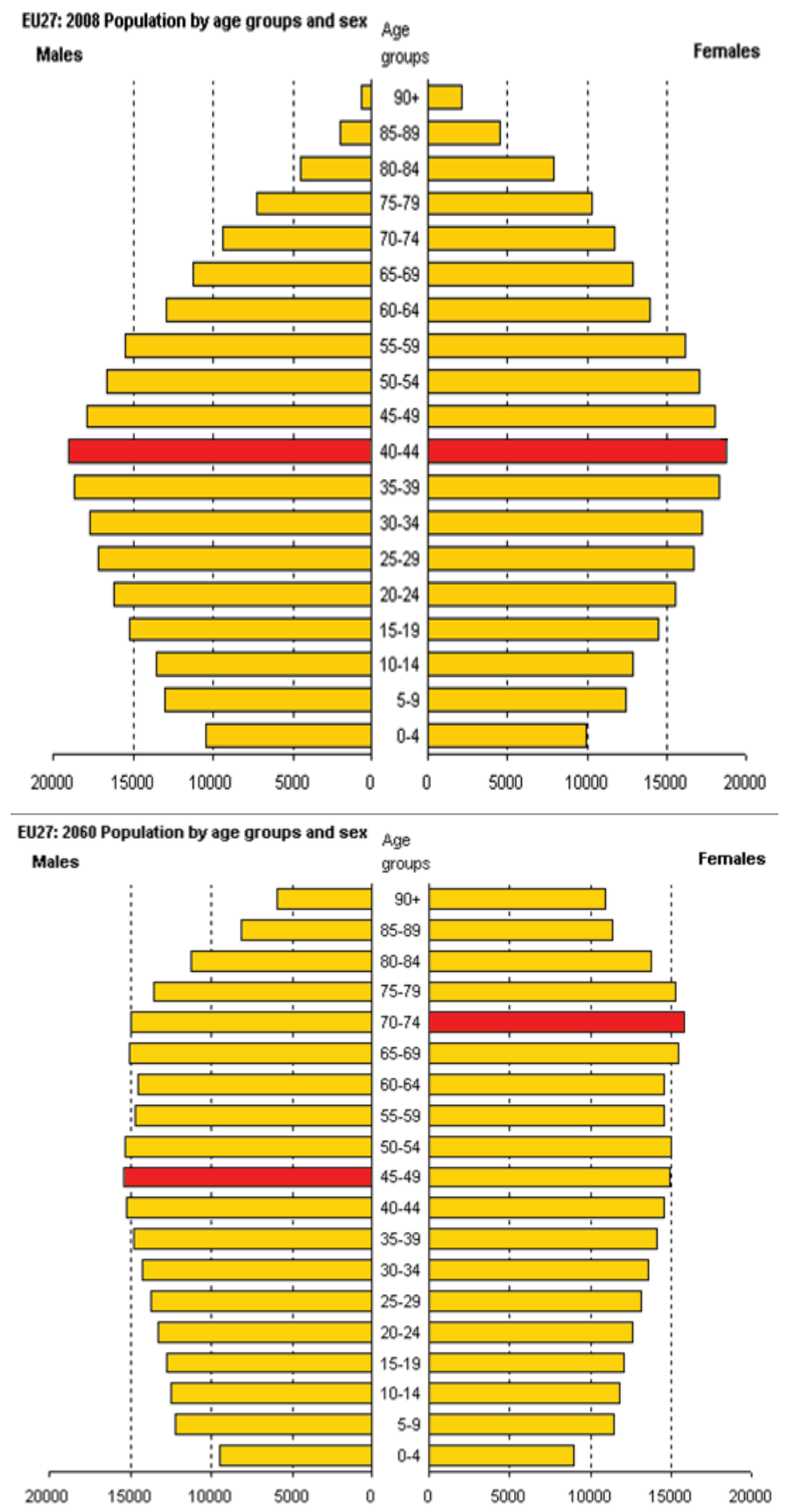

Fuente: European Comisión, Anexes to the Interim EPC-SPC Joint Report Pensions, Bruse- 
las, 2010.

Aunque parezca una obviedad, que lo es, debemos constatar que las generaciones que accedan a la jubilación, no llegan y se van, sino que se instalan con carácter definitivo, lo que implica que las pensiones deben ser revalorizadas - cualquiera que sea la formula, - con la finalidad de mantener su poder adquisitivo, de tal forma que provoca un efecto multiplicador sobre el gasto en pensiones de vital importancia. Posiblemente, la reordenación de sistema de revalorización de las pensiones está siendo el principal reto en la búsqueda de una mayor conexión con los parámetros de referencia que afectan a la situación económica del sistema y que impactan sobre su viabilidad futura. Constituye uno de los elementos del denominado "factor de sostenibilidad", que comienza a generalizarse en los países de la UE (factor de segunda generación) y también en España, a partir del 2014. Se trata con este factor (distinto del de longevidad) de asegurar los potenciales riesgos demográficos asociados a la tasa de dependencia ( $\mathrm{o}$, visto de otro modo, la ratio entre pensionistas y cotizantes), y los riesgos económicos de carácter estructural, a ésta materia me referiré más adelante.

El conjunto de datos y las reflexiones planteadas tiene su reflejo económico en términos de impacto sobre el PIB, lo que constituye un elemento de preocupación de la UE - y de los mercados financieros- que de forma reiterada (recientemente, 2006,2009 y 2012) advierte sobre los incrementos de gastos.

En los último informes (2009- 2012) ${ }^{475}$ se reconoce que, en términos generales, se producirá una disminución del número de ciudadanos en condiciones de trabajar ${ }^{476}$, que reducirá las cotizantes $\mathrm{y}$, consecuentemente, provocará la necesidad de soportar desde el sector público parte del coste del mantenimiento de la población con edades más avanzadas (pensiones, asistencia sanitaria y cuidados a los dependientes, entre otros).

Como consecuencia del envejecimiento de la población ${ }^{477}$, aumentará la necesidad de que el sector público proporcione transferencias y servicios relaciona-

${ }^{475}$ Todos los ratos referidos se encuentran cuantificados en los Anexos de la Comunicación de la Comisión al Parlamento Europeo, al Consejo, al Comité Económico y Social Europeo y al Comité de Regiones de 29 de abril de 2009 (COM (2009) 180 FINAL- no publicado en el Diario Oficial. Igualmente en el Libro Blanco, Agenda para unas pensiones adecuadas, seguras y sostenibles. COM (2012) 55 final, 16.2.2012

${ }^{476}$ No obstante, una primera conclusión consiste en la estimación de que en 2060 la población europea total será la misma, debido principalmente a los flujos migratorios y a la tasa de natalidad más alta de algunos de los países miembros respecto a otros. No obstante, dicha población tendrá una media de edad más avanzada.

477 A este respecto y motivado por la preocupación creciente del impacto demográfico en los sistemas de protección social, pueden verse el informe "Cambios demográficos y seguridad social: desafíos y oportunidades", elaborado por la Asociación Internacional de la Seguridad Social (AISS) en diciembre de 2010 y "Empleo y protección social en el nuevo contexto demográfico" elaborado por la OIT en el 2010. 
dos con la edad. Por consiguiente, se prevé que los efectos del envejecimiento de la población sobre el presupuesto serán substanciales en casi todos los Estados miembros, y se dejarán sentir ya en el transcurso de la próxima década.

Globalmente, sobre la base de las políticas actuales ${ }^{478}$, se prevé que el gasto público derivado del envejecimiento de la población aumente por término medio en aproximadamente 4,75 puntos porcentuales del PIB de aquí a 2060 en la UE, y en más de cinco puntos porcentuales en la zona euro, debido principalmente a los gastos en pensiones, asistencia sanitaria y en cuidados de larga duración. En todo caso, se advierte que el aumento del gasto público probablemente será muy significativo (igual o superior a siete puntos porcentuales del PIB) en nueve Estados miembros de la UE (Luxemburgo, Grecia, Eslovenia, Chipre, Malta, Países Bajos, Rumanía, España e Irlanda), aunque para algunos países este gran aumento se producirá a partir de un nivel relativamente bajo.

Si bien las previsiones realizadas por las instituciones de la UE se han visto alteradas por la crisis económica, son útiles como elemento de reflexión y de previsión de futuro. Con estos matices debe analizarse el cuadro que sigue.

\footnotetext{
${ }^{478}$ En el referido informe se cuantifican a la baja las previsiones respeto de Estados que han iniciado políticas de reformas de distinto alcance. Las reformas efectuadas por los países miembros de la Unión Europea sobre sus sistemas de pensiones han sido analizadas en el Informe "Avances y retos en la prestación de pensiones adecuadas y sostenibles en Europa", elaborado conjuntamente por las Comisiones de Política Económica y de Protección Social, de 7 de junio de 2010. Dicho Informe fue tomado en consideración por el Consejo en su reunión de 8 de noviembre de 2010 y constituye la base sobre la que se sustentan las consideraciones que en esa materia hacen el Libro Verde y el Libro Blanco.
} 


\section{Proyección del gasto público destinado a pensiones, expresado en porcentaje del PIB en los Estados miembros de la UE27 (2007-2060)}

\begin{tabular}{|c|c|c|c|c|c|c|c|c|}
\hline Pais & 2007 & 2010 & 2020 & 2030 & 2040 & 2050 & 2060 & $\begin{array}{c}\text { Variación } \\
2007 \cdot 2060 \\
\text { (en p.p.) }\end{array}$ \\
\hline Luxemburgo & 8.7 & 86 & 9.9 & 142 & 18,4 & 22.1 & 23,9 & 15.2 \\
\hline Alemania & 11.7 & 116 & 132 & 17.1 & 21.4 & 24 & 24.1 & 124 \\
\hline Chipre & 63 & 69 & 8.9 & 10.8 & 12.8 & 15.5 & 17.7 & 11.4 \\
\hline Rumania & 66 & 84 & 8,8 & 10,4 & 12.6 & 14.8 & 15,8 & 9.2 \\
\hline Eslovenia & 9.9 & 10.1 & 11.1 & 13,3 & 16.1 & 18.2 & 18,6 & 88 \\
\hline España & 8,4 & 8,9 & 9,5 & 10,8 & 13,2 & 15,5 & 15,1 & 6.7 \\
\hline Malla & 72 & 83 & 9,3 & 9.3 & 10.5 & 12 & 13.4 & 6.2 \\
\hline Belgica & 10 & 10,3 & 11.8 & 13,9 & 14,6 & 14.7 & 14,7 & 48 \\
\hline Noruega & 8.84 & 9.57 & 11.46 & 12.7 & 13.39 & 13.33 & 13.58 & 4.7 \\
\hline Irlanda & 4 & 4.1 & 4.6 & 5.4 & 6.4 & 8 & 86 & 46 \\
\hline Lituania & 68 & 6.5 & 6,9 & 8.2 & 9.1 & 10,4 & 11,4 & 46 \\
\hline Paises bajos & 66 & 65 & 7,8 & 9.3 & 10.3 & 10.3 & 10,5 & 4 \\
\hline Eslovaquia & 68 & 6.6 & 6.3 & 7.3 & 8.3 & 9.4 & 10.2 & 3.4 \\
\hline epública Che & 78 & 7.1 & 6,9 & 7.1 & 8.4 & 10,2 & 11 & 3,3 \\
\hline Finlandia & 10 & 10,7 & 12.6 & 13,9 & 13,6 & 13,3 & 13,4 & 3,3 \\
\hline Bubaria & 83 & 9,1 & 8,4 & 8.6 & 9.5 & 10,8 & 11,3 & 3 \\
\hline Hungria & 10.8 & 11,3 & $\pi$ & 11 & 122 & 13.2 & 13.8 & 3 \\
\hline Reino Unido & 66 & 67 & 6.9 & 7.6 & 8 & 8,1 & 93 & 2.7 \\
\hline Dinamarca & 10,4 & 10,2 & 10.5 & 11,5 & 12,1 & 12,3 & 12,8 & 2,3 \\
\hline Potugal & 11.4 & 119 & 124 & 126 & 125 & 13.3 & 13,4 & 21 \\
\hline Francia & 13 & 13.5 & 13.6 & 14.2 & 14.4 & 14.2 & 14 & 1 \\
\hline Austria & 12,8 & 12.7 & 13 & 13,8 & 13,9 & 14 & 13,6 & 0.9 \\
\hline Dinamaica & 9.1 & 94 & 10,6 & 10,6 & 10.4 & 96 & 92 & 0,1 \\
\hline Suecia & 95 & 96 & 9.4 & 9.5 & 9.4 & 9 & 94 & -0.1 \\
\hline Italia & 14 & 14 & 14.1 & 148 & 15.6 & 14.7 & 13.6 & .0 .4 \\
\hline Lelonia & 54 & 5,1 & 5,2 & 5,9 & 6,1 & 5,8 & 5,1 & $.0,4$ \\
\hline Estonia & 56 & 6.4 & 5,9 & 5.6 & 5,4 & 5,3 & 49 & .0 .7 \\
\hline Polonia & 11,6 & 10,8 & 9.7 & 9.4 & 9.2 & 9.1 & 88 & 2.8 \\
\hline
\end{tabular}

Fuente: Pacto de Toledo que recoge como fuente ;Comisión Europea, “Ageing report 2009”, tomado del informe elaborado por la Asociación de Instituciones de Inversión Colectiva y Fondos de Pensiones (inverco), diciembre de 2010.

Datos más recientes publicados por la Comisión Europea en 2012, reflejan que el gasto bruto en pensiones públicas en el 2010 en relación con el PIB (últimos datos disponibles en Eurostat),son los siguientes: para España se situó en el 10,7\%, quedando por debajo de la media de la zona euro (13,4\% del PIB) y de la UE-27 $(12,9 \%)$. Por países, oscila entre el 7,2\% del PIB en Irlanda y el 16\% de Italia. 


\section{GASTO EN PENSIONES (\% PIB)}

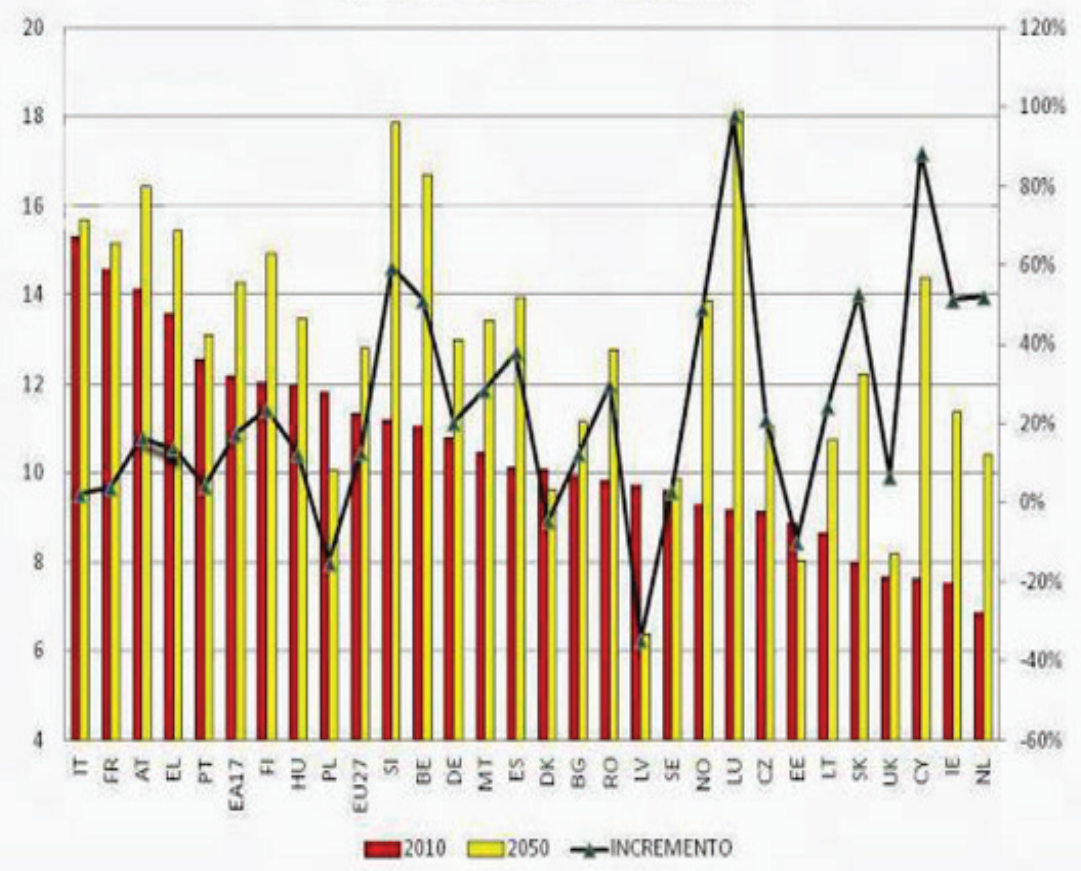

Fuente: EUROPEAN COMMISSION 2012 AGEING REPORT . Gasto en pensiones como porcentaje del PIB año 2010 y previsiones para el año 2050 (escala izquierda). Incremento esperado en el gasto en pensiones entre los años 2010 y 2050 como porcentaje del PIB (línea -escala derecha).

Con la idea de utilizar elementos diferenciales, conviene tener presente el gasto y las proyecciones para la UE.15, según el siguiente grafico 


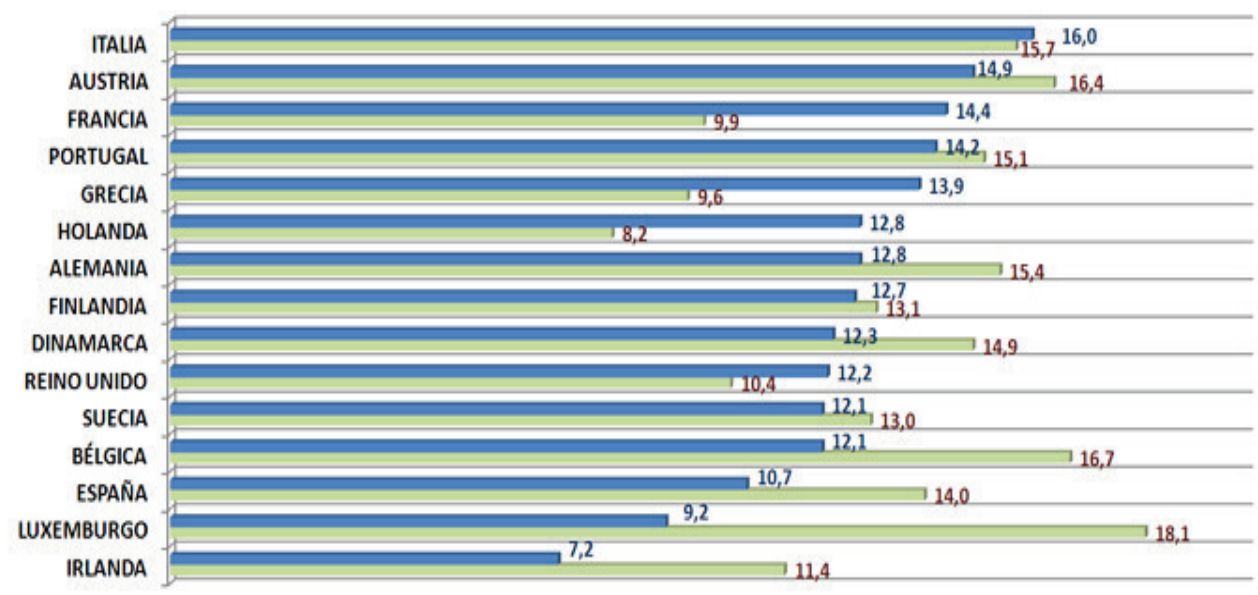

Fuente: Gasto bruto en pensiones públicas UE15 (\%PIB). 2010-2050. European commission 2012 ageing report

\section{REFLEXIONES SOBRE LA EDAD DE JUBILACION Y SU REFORMA}

La importancia del tema exige la revisión cautelosa y, a la vez, rigurosa de los parámetros que rodean la jubilación, entre ellos, todos los que confluyen en el entorno de la edad de jubilación ${ }^{479}$.

La edad de jubilación se ha convertido en los últimos treinta años en un concepto cíclicamente revisado ${ }^{480}$ y en continua experimentación, sobre el que inciden una multiplicidad de variantes ${ }^{481}$. Por un lado, los efectos de las sucesivas crisis

\footnotetext{
${ }^{479}$ Partiendo de la escasa atención que la propia Constitución española presta a la vejez, como así lo afirma con razón CARRIL VÁZQUEZ, JM, "El papel atribuido a la edad en la legislación laboral y de seguridad social española", en La relevancia de la edad en la relación laboral y de seguridad social, AAVV, CABEZA PEREIRO, J, BALLESTER PASTOR, Ma A., FERNÁNDEZ PRIETO, M., (dirs.), Thomson Reuters Aranzadi, Navarra, 2.009, pág. 364.

${ }^{480}$ ALONSO OLEA, M y TORTUERO PLAZA, JL. Instituciones de la Seguridad Social, Decimoctava edición, año 2.002, págs. 332 a 338.

${ }^{481}$ Como describe MALDONADO MOLINA, JUAN ANTONIO en "La edad de jubilación, retiro y vejez" en AAVV, MONEREO PÉREZ, JL y MALDONADO MOLINA, JUAN ANTONIO (Dirección y coordinación) La edad de jubilación, Editorial Comares, Granada, 2.011, pág. 85. "Clarificar qué es la vejez es una tarea compleja, ya que su definición adolece necesariamente de un fuerte relativismo: está en función de muy diversos factores (biológicos, socio-económicos, culturales, ideológicos, psicológicos, médicos, antropológicos), y condicionada por la perspectiva con que cada uno afronte la cuestión, tanto desde un punto de vista profesional como personal: según su propia actitud vital y los valores sociales, éticos y religiosos imperantes en su entorno"
} 
económicas, de las transformaciones en los modos de producción, de la composición y estructura del mercado de trabajo, de la globalización de las economías y de los mercados, del paro creciente o sostenido ${ }^{482}$... Por otro, las ya apuntadas y referidas al envejecimiento de la población, en sus distintas dimensiones ${ }^{483}$. Y finalmente, el impacto de todas ellas sobre los problemas actuales y futuros de financiación de los sistemas de pensiones ${ }^{484}$. Todas estas variantes hacen oscilar la relación dominante entre política de empleo y política de pensiones, sin que se haya llegado a un punto de equilibrio ${ }^{485}$, lo que impacta sobre las relación necesaria entre los ciclos vitales y la proyección protectora de los sistemas de pensiones ${ }^{486}$.

No cabe duda, que en los tiempos actuales la fijación de la edad de jubilación debe efectuarse teniendo en cuenta la esperanza de vida de los ciudadanos.

${ }^{482}$ A este respecto, GARCÍA VIÑA, JORDI. “¿Cómo afecta la crisis económica a los modelos actuales europeos de Seguridad Social?" en AAVV, El futuro europeo de la protección social, Laborum, Murcia, 2.010.

483 La propia Exposición de Motivos de la Ley 27/2011, afirma que "la disminución prolongada de las tasas de natalidad y el simultáneo incremento de la esperanza de vida de las personas mayores está provocando una inversión de la estructura de la pirámide de población, aumentando el número de pensionistas en relación con la población activa, esto es, variando la tasa de dependencia de los pensionistas. De no modificarse, aún parcialmente, esta tendencia mediante el incremento de las tasas de natalidad y de los flujos migratorios, la misma se acentuará en las próximas décadas, por la propia evolución demográfica. Esta tendencia demográfica afecta a todas las generaciones, pero sobre todo a las más jóvenes, por el hecho de que serán estas generaciones jóvenes las que serán mayores de sesenta y cinco años durante más tiempo.

${ }^{484}$ Sobre este aspecto, MALDONADO MOLINA, J A. "La edad de jubilación, retiro y vejez", Op. Cit., Pág. 85-120.

${ }^{485}$ El desequilibrio y las contradicciones son gráficamente dibujadas por OLARTE, al afirmar que "Por un lado, nos encontramos con unas medidas de fomento del empleo que pretenden contrarrestar la situación desventajosa en el mercado de trabajo de los trabajadores de edad avanzada...con otras, que presuntamente, pretenden proceder a un mas equitativo reparto generacional del empleo (prejubilaciones, jubilaciones anticipadas incentivadas o forzosas) ..y por otro lado, en sentido contrario las políticas y el derecho de la seguridad social empeñados en fomentar el alargamiento de la vida activa" OLARTE ENCABO, S, Edad y empleo. Colectivos desfavorecidos, en AAVV (Dir, CABEZA PEREIRO,J, BALLESTER PASTOR, $\mathrm{M}^{\mathrm{a}}$ A. FERNANDEZ PRIETO, M), La relevancia de la edad...cit. Pag.94

${ }^{486}$ Por todos, MONEREO PEREZ JL. Ciclos vitales y Seguridad Social: trabajo y protección social en una realidad cambiante, Revista Ministerio de Trabajo e Inmigración, núm. Extraordinario 74, 2008, pags. 49-134 y MONEREO PÉREZ, JL. "La política de pensiones tras el acuerdo social y económico de 2.011: La fase actual de la construcción de un "nuevo" sistema de pensiones" en AAVV, MONEREO PÉREZ, JL y MALDONADO MOLINA, JUAN ANTONIO (Dirección y coordinación) La edad de jubilación, Editorial Comares, Granada, 2.011, pág. 27 
Y ello, porque con la financiación actual y con la futura ${ }^{487}$, hoy planteada, cabe el peligro de que los Sistemas de Seguridad Social - que son y han sido parte esencial de nuestra cultura y del progreso económico ${ }^{488}$ - tengan dificultades para soportar el pago creciente de pensiones de jubilación, suficientes y revalorizadas, durante largos períodos de tiempo ${ }^{489}$. En este orden de cosas es necesario redefinir los espacios de imputación de la protección social, distinguiendo claramente los que responden a las cotizaciones sociales en un sistema financiero de reparto. Claridad que permitirá ponderar adecuadamente los medios de financiación desde una concepción autónoma de la seguridad social y dar un contenido real al término "contributividad". Clarificación que, en modo alguno, impide la fijación de fuentes complementarias de financiación ${ }^{490}$, o mejor y además una nueva redistribución de las mismas aligerando los impuestos sobre la nómina para aumentar la productividad e incorporar fuentes procedentes del capita ${ }^{491}$.

487 Por las razones anunciadas en el texto, el Artículo 8 de la Ley 27/2011, cuyo análisis realizo en el incorpora a la LGS una Disposición adicional quincuagésima novena, bajo la rúbrica "Factor de sostenibilidad del sistema de la Seguridad Social". Con el objetivo de mantener la proporcionalidad entre las contribuciones al sistema y las prestaciones esperadas del mismo y garantizar su sostenibilidad, a partir de 2027 los parámetros fundamentales del sistema se revisarán por las diferencias entre la evolución de la esperanza de vida a los 67 años de la población en el año en que se efectúe la revisión y la esperanza de vida a los 67 años en 2027. Dichas revisiones se efectuarán cada 5 años, utilizando a este fin las previsiones realizadas por los organismos oficiales competentes.

${ }^{488}$ Con frecuencia olvidamos el significado e impacto económico de la seguridad social en todas sus dimensiones, en este sentido, ver ZUBIRI ORIA, I. "Un análisis económico de la Seguridad Social”. AAVV (Dir. TORTUERO PLAZA,JL). Cien años de protección social en España. Libro conmemorativo del I centenario del Instituto Nacional de Previsión. Ministerio de Trabajo y Asuntos Sociales. Madrid, 2.007.

${ }^{489}$ La dinámica de estos dos factores, viabilidad financiera y evolución demográfica, condicionan el diseño de la estructura del sistema y su objetivo de ofrecer una protección suficiente a los trabajadores en situación de necesidad. En este sentido, MONEREO PÉREZ, J.L. "Reestructuraciones de empresas y edad de jubilación: Una reforma necesaria", en AAVV, MONEREO PÉREZ, J.L. (Dir.). La política de pensiones en el Estado social en transformación. Aspectos crítcicos. Granada, Comares, 2.010, pág. 146.

${ }^{490}$ La disposición adicional undécima de la Ley 27/2011, refiere expresamente a las alternativas de financiación complementaria, disponiendo que "Los Ministerios de Trabajo e Inmigración y de Economía y Hacienda y los agentes económicos y sociales, examinarán, en el marco de las recomendaciones del Pacto de Toledo, la conveniencia de establecer posibles escenarios de financiación complementaria de nuestro sistema de Seguridad Social en el medio y largo plazo".

491 "El mantenimiento de las fuentes de financiación y la falta de iniciativas alternativas previstas ha venido siendo una de las limitaciones más significativas del proceso de reforma que se viene acometiendo desde el Pacto de Toledo y sus revisiones sucesivas. Tan sólo el 
Si bien el punto de partida en los distintos Estados de la Unión Europea es diferente, lo cierto es que, desde hace algunos años, se ha consolidado, entre otras, una serie de tendencias agrupadas en los siguientes bloques: a) elevación ponderada de la edad de jubilación con criterios igualitarios para hombres y mujeres; b) desincentivación o penalización de las jubilaciones anticipadas; c) fomento o incentivación del retraso en el acceso a la jubilación; d) endurecimiento de las exigencias contributivas mediante reformas paramétricas; e) reformas sistémicas que pretenden, de forma voluntaria u obligatoria, redistribuir riegos entre lo público y lo privado, esto es, entre el mercado y la sociedad; f) incorporación de factores de sostenibilidad, bien referidos a la esperanza de vida, bien a la revalorización de las pensiones.

Aunque todas las tendencias forman parte de un "todo", cada una tiene su propia problemática y ofrece márgenes de actuación distintos. Con todo, las reformas deben ser de protección larga donde se conviven, en un sistema de prestación definida, el ayer, el hoy y singularmente el mañana ${ }^{492}$.

Si nos referimos a la edad de jubilación y nos situamos en la edad emblemática de los 65 años, nos damos cuenta de que el margen de actuación de cada Estado es distinto condicionando el impacto más o menos traumático de las medidas. Cierto es, que se ha producido una evolución paulatina de las edades de jubilación en la generalidad de los Estados, sin embargo también lo es, que el punto de partida era diferente. No es lo mismo moverse entre los 60 y los 65 años que superar la edad "talismán" de los 65 años. Con todo, el margen de actuación hacia el futuro es cada vez menor, en la medida en que durante los últimos quince años se ha recortado el espacio hacia la edad de 65 años. De esta forma, si el resto de las medidas no producen efecto, tendremos - y así lo ha hecho España con la Ley 27/2011- que cambiar la "edad emblemática", lo que ya han comenzado a diseñar distintos Estados de la Unión Europea (Alemania, Reino Unido, Dinamarca, Irlanda, Suecia, entre otros) que con fórmulas distintas y de aplicación progresiva elevan el umbral jubilatorio hacia los 67 años, asociando generalmente su impacto con la llegada de las generaciones del baby boom.

En este orden España cuenta con una posición privilegiada en términos tem-

Acuerdo de 2.011 parece recoger alguna mención a propósito de las posibles alternativas de financiación complementaria de nuestro sistema de Seguridad Social en el corto y medio plazo" MONEREO PÉREZ, JL. "La política de pensiones tras el acuerdo social y económico de 2.011: La fase actual de la construcción de un "nuevo" sistema de pensiones". Op. Cit. Pág. 7 .

492 Esta claridad de ideas en MONEREO PÉREZ, JL. "El ciclo largo de la reforma de la seguridad social: significación técnica y político jurídica del proceso de reforma legislativa actual" La reforma de la Seguridad Social. Estudio sistemático de la Ley 40/2007 de 4 de diciembre, de medidas en materia de Seguridad Social. Editorial La Ley. Madrid, 2.008, asi como en GARCÍA MURCÍA, J. "La política contemporánea de jubilación: algunos dilemas y algún contrasentido" Tratado de jubilación. Homenaje al Profesor Luis Enrique de la Villa Gil. Iustel, Madrid, 2.007. 
porales, en la medida en que la presión demográfica ejercida por las generaciones del baby boom se producirá con efectos retardados, lo que nos debería permitir afrontar las reformas necesarias desde una posición más sosegada y teniendo en cuenta las experiencias de los Estados europeos donde el impacto de las referidas generaciones está próximo.

Sin embargo las teorías han dado paso a las realidades impuestas por la presión de los mercados financieros ${ }^{493}$, que buscan o imponen su llamada "confianza" en reformas inmediatas que podríamos llamar de "impacto escénico o mediático", que no siempre producen los efectos reales anunciados y necesarios, como veremos más adelante ${ }^{494}$.

Sin duda los sistemas de pensiones deben enfrentarse a dos retos importantes, la elevada esperanza de vida de los ciudadanos y la llegada de las masivas generaciones del baby boom. No obstante, los retos referidos no son ajenos a un sin fin de variantes, que van desde los niveles de crecimiento económico y productividad ${ }^{495}$, hasta alcanzar unas tasas de ocupación razonable de hombres y mujeres a partir de los 55 años, lo que viene siendo un objetivo constante de la UE.

${ }^{493}$ En el mismo sentido, LOPEZ CUMBRE, afirma que "La Ley $27 / 11 \ldots$ constituye un ejemplo más de esa legislación negociada, condicionada, impuesta o "exigida" por la Unión Europea a la que se hacía referencia, entre otras razones, con el fin de evitar consecuencias económicas y financieras desfavorables para España semejantes a las que, antes o después, sufrirían Grecia, Portugal e Italia, por este orden" LOPEZ CUMPRE, L. La reforma de la jubilación, Revista General de Derecho del Trabajo y Seguridad Social, núm 29-30 (extraordinario) junio/2012 http://www.iustel.com/v2/revistas/detalle_revista.asp?id_noticia $=412140$ ${ }^{494}$ En esta línea son sumamente ilustrativas las consideraciones previas que realiza MOLINA NAVARRETE, sobre la reforma de la negociación colectiva, MOLINA NAVARRETE, CRISTOBAL, La decretada reforma de la negociación colectiva: ¿el último botín" de los mercaderes del templo, en Revista de Trabajo y Seguridad Social, CEF, núm. 340, julio 2011, pags.8-9.

${ }^{495}$ El sistema de seguridad social no es un sistema cerrado donde únicamente el juego de determinados factores conduzca a un resultado positivo o negativo de sus cuentas. Por el contrario, se trata de un sistema dinámico donde elementos como la evolución de la productividad tienen una importancia significativa en la consecución de equilibrio presupuestario. En este sentido, DE LA FUENTE LAVÍN, MIKEL, en "La flexibilidad en la jubilación", AAVV, MONEREO PÉREZ, JL y MALDONADO MOLINA, JUAN ANTONIO (Dirección y coordinación) La edad de jubilación, Editorial Comares, Granada, 2.011, pág. 447-448, expone que "La recuperación de los incrementos de la productividad a favor de los asalariados permite financiar el aumento del gasto en pensiones $\mathrm{y}$, además, queda margen disponible para el necesario incremento en otras partidas del gasto social, el aumento de los salarios y la reducción del tiempo de trabajo". 


\section{TIEMPOS DE CRISIS VERSUS TIEMPOS DE REFORMAS ${ }^{496}$}

Afirmar que el sistema de pensiones tiene problemas, no es nada nuevo. Los tuvo en el pasado, los tiene en el presente y los tendrá en el futuro. Las crisis económicas y sus efectos han sido y son un permanente "compañero de viaje". No obstante, ahora damos especial relevancia y la tiene, a otros factores. Por un lado, se está produciendo un envejecimiento de la población española, que como es conocido se incrementará con la llegada a la edad de jubilación de las cohortes del baby boom, derivando en un desequilibrio de la relación entre pensionistas y cotizantes. Por otro, se está produciendo un incremento constante de la esperanza de vida, lo que supone una extensión del tiempo en que se percibe la pensión y, por tanto, un incremento del gasto en pensiones.

Nótese que ninguno de los problemas apuntados es nuevo. Desde hace décadas sabemos y así se ha venido advirtiendo hasta la saciedad, que los factores demográficos producirían sus efectos. El rosario de factores determinantes es sobradamente conocido, bajísima tasa de natalidad, incremento constante de la esperanza de vida, existencia de generaciones especialmente numerosas, las del baby boom, etc. Sus efectos, como hemos apuntado, también eran y son sobradamente conocidos. A todos ellos se unen los propios de la crisis económica, destrucción masiva de empleo, reducción de salarios y cotizaciones, precipitación de jubilaciones anticipadas, aumento de gasto en desempleo... en definitiva, menos ingresos y mayores gastos. La crisis no solo ha puesto de manifiesto sus propios efectos, sino que ha despejado el bosque para que los factores demográficos renazcan con su mayor nitidez y dureza.

Los tiempos más duros de la crisis, con una destrucción de empleo sin precedentes, no son los más adecuados para afrontar reformas superpuestas, o reducciones de las pensiones sobre pensiones ya reducidas o endurecimiento de requisitos configuradores (edad, tiempo de cotización, cálculo de la pensión, jubilaciones anticipadas...) sobre requisitos ya endurecidos.

El sistema de protección social está demostrando que constituye un factor social de primer orden para atemperar los gravísimos efectos de la crisis, donde cada parcela de protección está cumpliendo adecuadamente su función social, desde la protección por desempleo, hasta las pensiones que dan cobertura no sólo a sus titulares, sino a los núcleos familiares dependientes; sin estos espacios estrictos y amplios de protección la situación social sería insostenible.

Igualmente, la crisis ha demostrado que el carácter dinámico de nuestro sistema le confiere una capacidad de adaptación a las situaciones de crisis (la actual

${ }^{496}$ Una primera versión de las reflexiones de los apartado de este epígrafe la efectué en TORTUERO PLAZA, J.L, La construcción de la reforma de la jubilación y el factor de sostenibilidad: imperfecciones y trampas. Ponencia a las XVII Xornadas de Outono de Vigo (11/2013), ACTUM SOCIAL núm. 83/2014 (, Ed.Francis Lefebvre). 
y las pretéritas) sin parangón con respecto a otros sistemas. No hay duda por tanto y lejos de catastrofismos, que el sistema sabrá y podrá adaptarse a los nuevos retos demográficos.

A lo anterior debemos añadir el impacto económico del sistema de protección, siempre importante y ahora vital, en la medida en que la situación propicia que la práctica totalidad de las prestaciones recibidas se dedique al consumo propio y ampliado.

Con la idea de fijar el escenario, conjuntamente con la destrucción de tejido productivo y de empleo (que parece no cesar en el corto plazo y no recuperarse sustancialmente en el medio plazo, según las previsiones del Gobierno), habría que hacer referencia a la reducción salarial producida en los últimos años, a los retrasos constantes ( y con frecuencia irrecuperables) en el percibo del salario, la congelación (plena o parcial) de las pensiones y los efectos reductores de las pensiones propiciados por las reformas, la elevación generalizada de impuestos, el encarecimiento ( $\mathrm{y}$ las restricciones) en el acceso a servicios públicos ... etc.

No parece que el escenario actual sea el más propicio para afrontar reformas que precipiten y/o endurezcan (reducción adicional) las pensiones. Todo ello, sin perjuicio del "efecto expulsión", (desprotección) que habitualmente no se tiene en cuenta.

Con la finalidad de ofrecer un marco global de las reformas presentes y futuras anunciadas, conviene aproximarnos a sus planteamientos generales abordando las sucesivas fases y su valoración.

\subsection{LA REFORMA DE LA JUBILACIÓN EN LA LEY 27/2011, SOBRE ACTUALIZACIÓN, adecuación y Modernización del Sistema de la Seguridad Social}

La Ley 27/2011, sobre actualización, adecuación y modernización del sistema de seguridad social, inicio su andadura legislativa en un claro escenario de consenso político y social. En efecto, el proyecto de reforma estuvo precedido por la renovación del Pacto de Toledo ${ }^{497}$ y la firma del Acuerdo Social y Económico para el crecimiento, el empleo y la garantía de las pensiones ${ }^{498}$, suscrito por el Gobierno, la CEOE, CEPYME, CCOO y la UGT, retomando así el escenario de consenso que propicio la reforma del 2007 en materia de seguridad social ${ }^{499}$.

${ }^{497}$ En este sentido, MONEREO PÉREZ, J L, "El sistema de pensiones en el marco de la nueva revisión y actualización del Pacto de Toledo", Aranzadi Social: Revista Doctrinal, $\mathrm{n}^{\circ}$ 15 , diciembre, 2.010 , pág. 58 y ss.

${ }^{498}$ Un análisis del Acuerdo en CAVAS MARTÍNEZ, F. Y el dialogo social dio sus frutos, en Aranzadi Social, núm. 22/2011, págs. 11-24 y MONEREO PÉREZ,JL. La reforma concertada de las pensiones. el Acuerdo Social y Económico de 2011 y su desarrollo legislativo, Rev. De Derecho del Trabajo y Seguridad Social,(Iustel) núm. 25, mayo 2011

499 Una visión general de la evolución de nuestra seguridad social al hilo de la historia de los 
Conviene resaltar que han quedado fuera de la Ley partes importantes del Acuerdo Social y Económico, básicamente y por lo que aquí interesa, las referidas a las políticas de empleo de trabajadores de mayor edad, que constituyen la otra cara de la moneda y condicionan la efectividad de la misma reforma ${ }^{500}$. A esta materia refería el Acuerdo bajo el titulo "Estrategia global para el empleo de los trabajadores de más edad",

Agotándose la legislatura y, por tanto, con impacto más bien testimonial, se aprobó el marco de las políticas de empleo mediante Acuerdo del Consejo de Ministros de 28 de octubre de 2011 sobre la Estrategia Global para el Empleo de los Trabajadores y las Trabajadores de Más Edad 2012-2015 (en adelante, Estrategia 55 y más) . La Estrategia 55 y más constituye el marco general de la intervención de los poderes públicos en materia de empleo de trabajadores de edad, y extenderá su vigencia a lo largo del trienio 2012-2014, coincidiendo con la vigencia de la Estrategia Española de Empleo.

Siguiendo la línea de reformas paramétricas iniciadas en otros Estados de la UE, la Ley española proyecta los cambios más significativos en las siguientes materias: la edad de jubilación, los elementos que integran el contenido económico de la prestación y las jubilaciones anticipadas, tanto plenas, como parciales. La jubilación, es por tanto y con toda lógica, la estrella o el núcleo duro de cualquier sistema de pensiones ${ }^{501}$. El alcance de la reforma afecta en forma gráfica a los siguientes

Pactos de Toledo, puede verse en el ejemplar e ilustrativo trabajo de PANIZO ROBLES, J A. "Dos décadas de reformas de la Seguridad Social: del Pacto de Toledo de 1.995 al Acuerdo Social y Económico de 2.011", Revista de Trabajo y Seguridad Social, Centro de Estudios Financieros, $n^{\circ} 336,2.011$, pág. 77.

${ }^{500}$ En esta línea, ESTEBAN LEGARRETA,R. Jubilación y políticas de empleo. Un análisis de la reforma de la jubilación en clave de empleo (http://www.iuslabor.org/jornades-i-seminaris/ponencies/)

501 Sobre la reforma ver, AA. VV. (García-Perrote, I., Mercader Uguina, J. R., Directores). La reforma de la Seguridad Social 2011. Valladolid (Lex Nova), 2011; AA. VV. (Monereo Pérez, J. L y Maldonado Molina, J. A., Dirección y Coordinación). La edad de jubilación. Granada (Comares), 2011.GETE CASTRILLO, P.: - La reforma de pensiones de 2011: procedimiento y contenidos (I y II) Relaciones Laborales núm. 20, 2011, pág. 12 ; LÓPEZ GANDÍA, J. y TOSCANI GIMÉNEZ, D.: La reforma de la jubilación. Comentarios a la Ley 27/2011 de 1 de agosto, Valencia, Tirant lo Blanch, 2011; PÉREZ ALONSO, M ${ }^{\text {a }}$ A.: - La nueva pensión de jubilación y otras reformas en el sistema de Seguridad Sociall Aranzadi Social, núm. 9/2012, (BIB 2011/1761); ESTEBAN LEGARRETA,R. Jubilación y políticas de empleo. Un análisis de la reforma de la jubilación en clave de empleo (http://www.iuslabor.org/jornades-i-seminaris/ponencies/); SEMPERE NAVARRO, A.V.: Actualización del sistema de Seguridad Social. Una visión sinóptica y global de la Ley 27/2011 (I), (II), en AS $n^{\circ}$ 6/2011 y n 7/2011; TORTUERO PLAZA, J.L.:" La pensión de jubilación en el Proyecto de Ley sobre actualización, adecuación y de modernización ( I y II)", en Revista de Aranzadi social $\mathrm{n}^{\mathrm{o}} 3$ y 5/ /2011, pp. 4 y ss.; SEMPERE NAVARRO, A.V y FERNANDEZ ORICO, 
parámetros:

$>\quad$ La edad de jubilación que evoluciona desde los 65 años a los 67 en una progresión paulatina entre el año 2013 y el año 2027.

$>\quad$ La edad de las jubilaciones anticipadas y de la jubilación parcial, que evolucionan (tras la reforma operada por el RDL 5/2013) con la misma secuencia que la edad general.

$>\quad$ Se reduce la tasa de sustitución de la pensión (reducción de la pensión), al endurecerse los siguientes parámetros:

- Elevación del número de años exigibles para obtener el 100 por 100 de la pensión, que evoluciona desde los 35 años a los 37 años.

○ $\quad$ El sistema de cálculo de la pensión de jubilación, ampliándose el número de años computables para la determinación de la base reguladora de la pensión desde los 15 a los 25 años.

○ Igualmente se aminora el "valor" de cada año de cotización, a efectos de fijar la cuantía de la pensión.

- Se endurece respecto a la situación anterior el sistema de integración de lagunas en la base reguladora.

Característica de la reforma, consustancial a la seguridad social, es su aplicación lenta y progresiva, que se inicia en el año 2013 y se proyecta, según las materias, hasta el año 2022 o 2027. La reforma pretende, siguiendo el criterio de otros Estados de la EU, que su proyección temporal esté concluida para recibir a las generaciones del baby boom, esto es, las nacidas a partir de 1957, que cumplirán los 65 años en el año 2022, aunque el mayor impacto se producirá con la llegada de los nacidos a mediados de los años 60, cuando la Ley este plena aplicación.

F.J.: Reforma y modernización de la Seguridad Social. Aranzadi, 2012; TOSCANI: La reforma de la jubilación a edad ordinaria por la Ley 27/2011, en Aranzadi social $\mathrm{n}^{\circ}$ 7/2011; GONZÁLEZ ORTEGA, J.: "Las nuevas edades de jubilación y sus efectos en la cotización y en la cobertura", en Revista General de Derecho del Trabajo y Seguridad Social n' 29-30 (2012);TORTUERO PLAZA, JL, La reforma de la Jubilación, Pamplona, edit. Aranzadi, 2012; VILLA GIL, LE. La reforma de la composición del Sistema de Seguridad Social y del modelo de protección social, Revista General de Derecho del Trabajo y Seguridad Social, núm 29-30 (extraordinario) junio/2012; LOPEZ CUMPRE, L. La reforma de la jubilación , Revista General de Derecho del Trabajo y Seguridad Social, núm 29-30 (extraordinario) junio/2012; MONEREO PEREZ,JL y MALDONADO MOLINA,JA, La reforma de la jubilación, Revista General de Derecho del Trabajo y Seguridad Social, núm 29-30 (extraordinario) junio/2012 


\subsection{LA IMPLANTACIÓN DEL FACTOR DE SOSTENIBILIDAD}

\subsubsection{Antecedentes: La creación del Comité de Expertos}

El Gobierno anunció que para el mes de septiembre llevaría al Parlamento la Ley que creara el factor de sostenibilidad, posiblemente con la idea de implantarlo a partir del 1 de enero de 2014. La aceleración viene impuesta por las instancias Europeas. En efecto, el día 28 de Junio de 2013, el Consejo Europeo aprobó las Recomendaciones por países y, concretamente para España, una especialmente importante en materia de pensiones cuyo tenor es el siguiente: "culminar al final de 2013 a más tardar la regulación del factor de sostenibilidad, a fin de garantizar la estabilidad financiera a largo plazo del sistema de pensiones, aumentando, entre otras cosas, la edad efectiva de jubilación, ajustando la edad de jubilación o el pago de las pensiones de jubilación a las modificaciones de la esperanza de vida".

De esta forma, por Acuerdo de Consejo de Ministros de 12 de abril de 2013, se crea un Comité de Expertos ${ }^{502}$ para que realice un informe donde se defina el factor de sostenibilidad del sistema de la Seguridad Social, en el marco legal referido.

El 7 de junio de 2013 el Comité aprobó ${ }^{503}$ y presento el Informe. Sin entrar en el entramado de las formulas, el Informe expone la finalidad del factor de sostenibiliadad y su contenido en los siguientes términos:

"El factor de sostenibilidad está diseñado para que los desequilibrios del sistema de pensiones se puedan anticipar cada año de manera transparente y se neutralicen de una forma distribuida en el tiempo. Los principales tributos que el factor de sostenibilidad puede rendir a la sociedad española son, por una parte, la transparencia y la predictibilidad de las pensiones; por otra, un mecanismo de corrección automático de errores distribuido en el tiempo, y por tanto, aceptable en sus consecuencias.

El factor se compone, en primer lugar, de un Factor de Equidad Intergeneracional (FEI) que busca que las condiciones de las pensiones sean iguales para todos los jubilados, con independencia de la cohorte demográfica a la que pertenezcan, algo que no ocurre en la actualidad. En segundo lugar, consta de un Factor de Revalorización Anual (FRA) que al proceso, digamos, natural de evolución de la

${ }^{502}$ Integrantes del Comité: Víctor Pérez-Díaz (Presidente), Manuel Lagares Calvo, José María Marín Vigueras, Santos Ruesga Benito, Miguel Ángel Vázquez Burgos, Ignacio Conde Ruiz, Rafael Doménech Vilariño, José Enrique Devesa Carpio, Mercedes Ayuso, Miguel Ángel García Díez, Francisco Castellano Real, José Luis Tortuero Plaza.

${ }^{503}$ El Informe se aprueba con 10 votos a favor, 1 voto en contra (Santos Ruesga) 1 abstención (Tortuero) y se presentaron 3 votos particulares ( Ruesga, Tortuero -http://estaticos. elmundo.es/documentos/2013/06/07/voto_tortuero.pdf y García Díaz) 
pensión media, une una corrección basada en la relación entre ingresos y gastos del sistema de pensiones. Sucintamente, cuando los gastos crecen más que los ingresos, el FRA frena el crecimiento natural de la pensión; en las situaciones contrarias, lo expande. Para evitar que la revalorización de las pensiones aboque a los pensionistas a sacrificios poco tolerables en las fases bajas de la economía, el FRA no se calcula con cifras de un solo año, sino de un conjunto de años que abarquen, en la medida de lo posible, la totalidad del ciclo económico, y, en caso de desequilibrio, permite la corrección, no de golpe, sino a lo largo de varios años" ${ }^{204}$.

Defendido el Informe y los votos particulares en la Comisión del Pacto de Toledo del Congreso de los Diputados y remitido a los Interlocutores Sociales, solo quedaba esperar al Proyecto de Ley del Gobierno presente en el Congreso de los Diputados.

3.2.2. El proyecto de Ley y la Ley 23/2013, de 23 de diciembre, reguladora del Factor de Sostenibilidad y del Índice de Revalorización del Sistema de Pensiones de la Seguridad Social

En este orden, el Gobierno presento el Proyecto de Ley sobre el factor de sostenibilidad, iniciando los trámites correspondientes. El Proyecto, como era de esperar y advertí continuamente en la Comisión de Expertos ha levantado el rechazo generalizado de los ciudadanos, por entender, entre otras cosas, que estamos rompiendo el pacto intergeneracional que constituye la esencia de nuestro sistema de pensiones. Una vez más, el Proyecto propiciara la precipitación de jubilaciones, como ya lo hicieron las reformas precedentes, y fomentara un efecto "huida". Deterioro que se une a la disminución de ingresos, propiciada por la destrucción de empleo y la reducción generalizada de salarios.

Finalizado el trámite parlamentario, con algunas variaciones que apuntaré más adelante, el proyecto se convirtió en la Ley 23/2013, de 23 de diciembre, publicada en el Boletin Oficial del Estado el 26 de diciembre, entrando en vigor al dia siguiente de su publicación, a excepción del factor de sostenibilidad que se aplicara a las pensiones de jubilación del Sistema de la Seguridad Social que se causen a partir del 1 de enero de 2019 (Disp. Final $5^{\mathrm{a}}$ ). ${ }^{505}$

La Ley sigue en lo fundamental las consideraciones del Informe de los Expertos, y diseña un Factor de sostenibilidad vinculado a la esperanza de vida (en el Informe denominado Factor de Equidad Intergeneracional.FEI), que se tendrá en

504 Puede consultarse : http://www1.seg-social.es/ActivaInternet/groups/public/documents/ rev_anexo/rev_032187.pdf

505 Un análisis de la Ley en TORTUERO PLAZA,JL. Ley 23/2013, de 23 de diciembre, reguladora del factor de sostenibilidad y del índice de revalorización del sistema de pensiones de la Seguridad Social: régimen jurídico, Rev. Relaciones Laborales núm. Monográfico dedicado a la reforma de las pensiones, 2014, págs.. 109-130. 
cuenta en el cálculo de la pensión de jubilación, una vez aplicada la formula general. Igualmente, fija un denominado Índice de revalorización de las pensiones (en el Informe denominado, Factor de Revalorización Anual, FRA) que rompe con la tradicional vinculación al IPC, fijando un porcentaje "suelo" y "techo", de forma que la revalorización de las pensiones se mueva en un margen determinado.

Por lo que refiere al Factor de Sostenibilidad, se aplicará, en los términos establecidos en esta ley, por una sola vez para la determinación del importe inicial de las nuevas pensiones de jubilación del sistema de la Seguridad Social, para lo cual se modifica el apartado 1 del artículo 163 de la LGS. Esto quiere decir que su impacto alcanza exclusivamente a los trabajadores por cuenta propia, ajena y asimilados incorporados a la LGS, por tanto, no es aplicable a Clases Pasivas del Estado y al resto de las pensiones con cargo a fondos públicos

Por el contrario, el Índice de Revalorización será aplicable tanto a los incorporados a la LGSS, como a Clases Pasivas del Estado, para lo cual se modifican las normas reguladoras para los referidos colectivos, esto es, el apartado 1 del artículo 27 del texto refundido de la Ley de Clases Pasivas del Estado, aprobado por el Real Decreto Legislativo 670/1987, de 30 de abril y el artículo 48 del texto refundido de la Ley General de la Seguridad Social, aprobado por el Real Decreto Legislativo 1/1994, de 20 de junio.

En ambos preceptos, la revalorización de las pensiones (a partir del 1/I/2014) se vincula "al índice de revalorización previsto en la correspondiente Ley de Presupuestos Generales del Estado".

Por lo que refiere a la determinación del "suelo "y el "techo" aplicable a la revalorización anual de las pensiones, se establece que "en ningún caso el resultado obtenido podrá dar lugar a un incremento anual de las pensiones inferior al 0,25 por ciento ni superior a la variación porcentual del Índice de Precios al Consumo en el periodo anual anterior a diciembre del año t, más 0,50 por ciento". En el Proyecto de Ley, el techo se incrementaba en el 0,25.

En efecto, en su aplicación, los arts. 37 y 41 de la LPGE 2014, establecen que "Las pensiones contributivas de Seguridad Social, así como las de Clases Pasivas del Estado, experimentarán en el año 2014 un incremento del 0,25\%, sin perjuicio de algunas excepciones...".

Los límites fijados significan, que las pensiones nunca se congelan en términos absolutos (si entendemos que subir 2 euros al mes, no constituye congelación), pero el poder adquisitivo perdido, tampoco se recupera, pues lo impide el límite o "techo" de revalorización fijado para los años de bonanza económica.

\subsubsection{La reforma y la ruptura del consenso político y social}

No debemos olvidar que la Ley 27/2011 constituyó el fruto de un gran consenso entre las fuerzas políticas (a través de la Comisión del Pacto de Toledo) 
y de las organizaciones sociales, a través del Pacto Social que sustenta la reforma.

Recuérdese, basta con hacer algo de historia, que el consenso referido no ha sido fácil de alcanzar, buena prueba de ello es el análisis de las principales reformas realizadas desde el año 1997, donde el consenso nunca fue global.

Sin perjuicio de la decisión legítima tomada por el Gobierno de nombrar un Comité de Expertos, lo cierto es que la decisión no ha sido consensuada ni en el marco del Pacto de Toledo, ni con los interlocutores sociales, lo que anunciaba una posición "poco receptiva" al informe del Comité, como asé fue. A ello, debemos añadir el impacto social de las medidas, que sin duda tendrán su respuesta social, tanto por las medidas en sí mismas de gran sensibilidad social, como por el efecto acumulativo respecto de otras medidas tomadas. En definitiva, la ruptura del consenso constituira una provocación innecesaria e injustificada.

Por último y a pesar de la importantísima problemática existente, no debemos olvidar que el sistema español cuenta con un Fondo de Reserva para equilibrar en el corto plazo los efectos negativos del ciclo y que las cohortes del baby boom (1957-1977) anuncian su llegada, pero en un plazo (2022-2042) que nos permite actuar con un margen razonable, alejado de la urgencia inmediata. Ésta es una de las diferencias con nuestro socios europeos donde sus generaciones del baby boom (1946-1964) ya comenzaron su llegada a la jubilación a partir del 2011 (si tomamos la edad de 65 años, no compartida en todos los Estados), de ahí que las reformas y ajustes de sus sistemas se realizaran en un tiempo anterior.

\section{LA FUNCIÓN DE LAS PRESTACIONES TEMPORALES: LA INCAPACIDAD TEMPORAL}

Los sistemas de protección social incorporan mecanismos de protección de carácter temporal, que tienen como función cubrir las vicisitudes que se producen durante la vida laboral. Dependiendo de cada sistema o modelo el abanico prestacional cubre la incapacidad temporal, la maternidad y los riesgo a ella vinculados, la paternidad y el desempleo. Si bien cada situación tiene su propia configuración, justificación y ordenación, un elemento común es la naturaleza temporal del estado de necesidad que cubren.

Del conjunto prestacional descrito, nos ocuparemos singularmente de la incapacidad temporal para el trabajo.

La incapacidad temporal es una situación de incapacidad para trabajar causada por accidente o enfermedad, que requiere asistencia y que se supone transitoria o de corta duración. Es una de las contingencias que concede a tal efecto dos tipos de prestaciones: una prestación en especie, en forma de asistencia sanitaria, y una prestación económica, que lógicamente tiene la finalidad de sustituir la pérdida de los ingresos propios del trabajo durante ese período. La situación que en este caso protege la seguridad social no es sólo la alteración de la salud, sino también la pérdida temporal de ingresos (del salario, si se trata de trabajador asalariado) que como 
consecuencia de la misma puede sufrir quien vive de su trabajo.

La contingencia de incapacidad temporal puede surgir de riesgos profesionales o de riesgos comunes, esto es, de accidente de trabajo o accidente no laboral, y de enfermedad profesional o enfermedad común. En el fondo de todo ello existe un proceso patológico de intensidad suficiente como para imposibilitar la realización del trabajo por lo que inevitablemente requiere una decisión no sólo de carácter administrativo o burocrático, sino también de carácter médico, lo cual plantea un problema básico en la determinación y calificación de esta contingencia: la necesaria concurrencia de criterios técnico-administrativos (que residen en las instituciones de seguridad social) y criterios médicos (que pertenecen a las instituciones sanitarias).

\section{EL MODELO DE GESTIÓN Y CONTROL DE LA INCAPACIDAD TEMPORAL: UN PRO- CESO DE REFORMA INTERMINABLE}

En un largo proceso de reformas que ya dura más de veinte años - desde 1992- la incapacidad temporal ha sido el centro de atención del legislador- y de la doctrina científica ${ }^{506}$ - realizando reformas continuas -y no siempre debidamente

506 Una incompleta pero grafica reseña de la preocupación doctrinal por la materia es la siguiente: AA.VV.: La incapacidad temporal (Coord. OJEDA AVILES, A.), Tecnos, Madrid, 1996; AA. VV.: Cuestiones en torno a la Incapacidad Temporal (Dir. SEMPERE NAVARRO, A. V.), Cinca, Madrid, 2011; ALONSO OLEA, M. y TORTUERO PLAZA, J. L., Instituciones de Seguridad Social, Civitas, 18 edic., Madrid, 2006; ALVAREZ DE LA ROSA. M. Incapacidad temporal y maternidad, en "Tribuna Social" n 53; ARETA MARTÍNEZ, M"., "La incapacidad temporal de los funcionarios públicos", AA. VV.: Cuestiones en torno a la incapacidad temporal de los funcionarios públicos, Cinca, Madrid, 2011; BARBA MORA, A., Incapacidad temporal, Tirant Lo Blanch, Valencia, 2000; BLÁZQUEZ AGUDO, E. Mª., "Presente y futuro de las mutuas de accidentes de trabajo y enfermedad profesional", Aranzadi Social Revista Doctrinal, núm. 2, 2012; BRUNA REVERTER, J., La incapacidad laboral: problemática legal, jurisprudencial y médica, Comares, Granada, 2012; CARRIZOSA PRIETO, E., "La tutela del trabajador enfermo en el Estatuto de los Trabajadores", Revista Española de Derecho del Trabajo, núm. 157, 2013; CASTILLA CASTILLA, Á., "Control médico de la Incapacidad Temporal: la reordenación de las competencias de las entidades que intervienen en la prestación de la Incapacidad Temporal: artículo 128 de la LGSS", Revista de Información Laboral, núm. 3, 2012; CASTRO CONTE, M., "Evolución de la Seguridad Social de los trabajadores autónomos o por cuenta propia", AA. VV.: Cuestiones en torno a la Incapacidad Temporal (Dir. SEMPERE NAVARRO, A. V.), Cinca, Madrid, 2011; DESDENTADO BONETE, A. y TEJERINA ALONSO, J. I. El subsidio de la incapacidad temporal. Cuantía, nacimiento, duración y extinción en "Tribuna Social", núm. 44-45, 1.994; DESDENTADO BONETE, A “Mutuas de accidentes de trabajo y Seguridad Social: puntos críticos desde la perspectiva de la gestión de la incapacidad temporal". Actualidad Laboral. No 6. 2008; DUEÑAS HERRERO, L. F., "La contingencia de incapacidad (laboral) temporal en el régimen general de Seguridad Social”, Relaciones Laborales, núm. 4, 1996; FERNANDEZ LOMANA GARCÍA, M., «El control por las Mutuas de Accidentes de Trabajo de las 
bajas médicas por contingencias comunes: situación actual y perspectiva», Actualidad Laboral nº 8, 2008;FERNANDEZ ORRICO, F J “Medidas encaminadas a racionalizar el subsidio de incapacidad temporal por Ley30/2005, de 29 de diciembre, AA VV "La economía de la Seguridad Socia. Sostenibilidad y viabilidad del sistema”. Laborum. 2006; FERNÁNDEZ PRATS, C., La protección de la incapacidad temporal en el régimen general de la Seguridad Social, Tirant lo Blanch, Valencia, 2011; GARCÍA MURCIA J. y ROMÁN VACA, E., "Nuevas pautas de la regulación de la incapacidad temporal", Aranzadi Social, núm. 2, 1996; GARCÍA NINET, J. I., "La incapacidad temporal", AA.VV.: La incapacidad temporal, (Coord. OJEDA AVILES, A.), Tecnos, Madrid, 1996; GARCÍA QUIÑONES, J. C., “Ampliación de la prestación por incapacidad temporal para los trabajadores por cuenta propia”, Documentación Laboral, núm. 70, 2004; GARCÍA VIÑA, J. El deber recíproco de buena fe en la incapacidad temporal, en AA.VV.(COOR. A. OJEDA AVILES), La incapacidad temporal, 1996 ; GIL PLANA, J y GONZALEZ DEL RIO, J M “Aspectos polémicos en la colaboración de las Mutuas en la gestión de la Seguridad Social”. Revista Española de Derecho del Trabajo GOERLICH PESET, J M "La reforma de la incapacidad temporal” en VV.AA "La reforma de la Seguridad Social”. Ed. Tirant lo Blanch. 2008; GONZÁLEZ ORTEGA, S., "El control de las bajas médicas como objetivo permanente de las reformas de la incapacidad temporal (I) (El control durante la primera fase de la incapacidad temporal, Relaciones Laborales, núm. 12, 2011; "Prórrogas y recaídas. El tránsito hacia la incapacidad permanente", Relaciones Laborales, núm. 13, 2011 ; GRANADO MARTINEZ, O "El control de la incapacidad temporal en el Instituto Nacional de la Seguridad Social en AA VV "La economía de la Seguridad Social. Sostenibilidad y viabilidad del sistema”. Laborum. 2006I); JOVER RAMÍREZ, C., La incapacidad temporal para el trabajo. Aspectos laborales y de seguridad social, Tirant lo Blanch, Valencia, 2006; LÓPEZ INSUA, B. M., La incapacidad temporal en el Sistema de la Seguridad Social, Comares, Granada, 2014; MARTÍN VALVERDE, A., "Incapacidad laboral transitoria e Invalidez Provisional: legislación y jurisprudencia", Actualidad Laboral, núm. 39, 1994; MARTINEZ-GIJON MACHUCA, M A "Sobre la incapacidad laboral: tránsito entre prestaciones y duración de la temporal (al hilo de la reforma operada por la Ley 30/2005). Relaciones Laborales. N²1. 2006; MARTINEZ-GIJON MACHUCA, M A "Sobre la incapacidad laboral: tránsito entre prestaciones y duración de la temporal (al hilo de la reforma operada por la Ley 30/2005). Relaciones Laborales. No 21. 2006; MERCADER UGUIA, JR., El control de la incapacidad temporal (historia de una sospecha), en Revista de Relaciones Laborales, Tomo I/2004; MONEREO PEREZ, JL y FERNANDEZ AVILES, JA. Determinación de la contingencia, en AAVV (Dir. BORRAJO DACRUZ) Accidentes de Trabajo y Mutuas, edit. Lay y Fremap, Madrid, 2009; MONERO ROMERO, F "La responsabilidad empresarial en materia de prestaciones a la luz de la incapacidad temporal". AA.VV, "La responsabilidad del empresario". Ediciones Laborum. 2012. y "El papel de las mutuas en la gestión de la incapacidad temporal: Previsiones sobre la nueva ordenación". en AAVV, Público y Privado en el Sistema de Seguridad Social. AESSS. Ediciones Laborum, Murcia, 2013; MUÑOZ MOLINA, J., La incapacidad temporal como contingencia protegida por la Seguridad Social, Aranzadi, Pamplona, 2005; OLARTE ENCABO, S., "Control y gestión de la incapacidad temporal: análisis crítico del marco jurídico-positivo vigente, el complejo equilibrio entre eficiencia y garantismo", Aranzadi Social Revista Doctrinal, núm. 20, 2011; 2006; PANIZO ROBLES, J El control de la incapacidad temporal: A 
propósito del Real Decreto 575/11997, de 18 de abril”. Revista del Ministerio de Trabajo y Asuntos Sociales. No 4/ 1997; "De nuevo sobre el control de la IT (A propósito del Real Decreto 1117/1998)”. En Revista de Trabajo y Seguridad Social. CEF. No 187. Septiembre.1998; "La Seguridad Social en los comienzos de 2006 (comentario a las novedades incorporadas a la Ley 30/2005, de 29 de diciembre, de Presupuestos Generales del Estado para 2006 y en otras disposiciones legales y reglamentarias de reciente promulgación).” Revista de Trabajo y Seguridad Social. CEF. No 275. Enero 2006; , "Un nuevo paso en el control de la prestación de la seguridad social por incapacidad temporal: el RD 1430/2009, de 4 de diciembre", Revista de Trabajo y Seguridad Social, CEF, núm. 320, 2009; PÉREZ ALONSO, M. A., La incapacidad temporal, Tirant lo Blanch, Valencia, 1995; PUEBLA PINILLA, A “El alta médica: efectos laborales e impugnación por el trabajador. Examen especial de la posición de las Mutuas de accidentes de trabajo". Actualidad Laboral. N 11. Junio 2008; PURCALLA BONILLA, M. A., "Incapacidad temporal y control del absentismo", AA. VV.: Régimen jurídico y gestión racional del tiempo en la empresa (Dirs. ROMERO BURILLO, A. M ${ }^{\mathrm{a}}$ y ARGÜELLES BLANCO, A. R.), Aranzadi, Cizur Menor, 2013; RIOS SALMERON, B y FERRANDO GARCIA, F “La prestación por incapacidad temporal: equilibrio entre la protección y control del fraude” FORO DE SEGURIDAD SOCIAL. Mayo 2007; RODRÍGUEZ ÁLVAREZ, V., "Evolución de la normativa sobre la incapacidad para el trabajo en el ordenamiento jurídico español", Revista del Ministerio de Trabajo e Inmigración, núm. 94, 2011; RODRÍGUEZ ESCANCIANO, S., "El control de la incapacidad temporal: su incidencia sobre la contención del gasto público y el aumento de la productividad empresarial", Temas Laborales, núm. 118, 2013; SALA FRANCO, T., La incapacidad temporal para trabajar derivada de enfermedad o accidente, Tirant Lo Blanch, Valencia, 2005; SALA FRANCO, T y SALAS BAENA, A “La incapacidad temporal: aspectos laborales, sanitarios y de Seguridad Social”. Ed. Tirant Lo Blanch. Valencia, 2007 SANTAMARIA RUIZ, M D “Gestión y control de la prestación económica por incapacidad temporal: una gestión compleja”. Foro de Seguridad Social. No 13-14, 2005; SIRVENT HERNANDEZ,N, "Nuevas medidas de control en la gestión de los procesos de incapacidad temporal introducidas a raíz de la Ley 35/2010, de 17 de septiembre", Actualidad Laboral núm. 16, 2011 ; TOROLLO GONZÁLEZ, F. "Las mutuas y su lugar de conflictos jurídicos derivados de la incapacidad temporal", en AAVV. Público y Privado en el Sistema de Seguridad Social. AESSS. Ediciones Laborum, Murcia, 2013; TORTUERO PLAZA, J.L. "la incapacidad temporal para el trabajo en la seguridad social", Madrid, Tesis Doctoral, 1.987; "La incapacidad temporal, contingencia y situaciones protegidas: un análisis teórico", Tribuna Social, núms. 44/45, 1994; "Régimen jurídico de la incapacidad temporal: una perspectiva general". Foro de Seguridad Social. No 12-13. 2005; "Apuntes sobre la reforma de la incapacidad temporal”. En AA VV. "La economía de la Seguridad Social. Sostenibilidad y viabilidad del sistema”. Laborum. 2006; "El control público de las Mutuas en materia de incapacidad temporal", AA. VV.: Accidentes de trabajo y Mutuas, La Ley, Madrid, 2008; TORTUERO PLAZA, J. L. y MORENO ROMERO, F., "Poder de dirección del empresario y los mecanismos de control de la incapacidad temporal: la opción por el control público", AA. VV.: Libertad de empresa y poder de dirección del empresario en las relaciones laborales: estudios ofrecidos al profesor Alfredo Montoya Melgar, Aranzadi, Cizur Menor, 2011; TORTUERO PLAZA,JL. Y MORENO ROMERO,F. La reforma de la Incapacidad Temporal en la Ley 35/2010 y materias conexas, en 
maduradas- con la finalidad de construir un nuevo modelo de gestión y control, que permita recomponer el papel que deben asumir las entidades intervinientes en el proceso, reconducir su utilización -no siempre ortodoxa- y situar el gasto en parámetros de racionalidad.

Cierto es que en la incapacidad temporal intervienen todo un conjunto de sujetos e instituciones - Servicio Público de Salud, Mutua de accidentes de trabajo y enfermedades profesionales, Instituto Nacional de la Seguridad Social, Instituto Social de la Marina, empresario y trabajador, así como, en ocasiones, al Servicio Público de Empleo Estatal- que dificultan su ordenación, singularmente desde la esfera competencial. No obstante y como veremos, el equilibrio, la ponderación y la racionalidad no se han conseguido, ¡después de más de 20 años de reformas!, ¿tan difícil es?

Cierto es también, que en su momento asistimos a un constante y alarmante incremento del gasto en incapacidad temporal, que justifico en parte que las principales reformas de los últimos años se hayan centrado casi en exclusividad sobre la ordenación de los mecanismos de control, bajo la hipótesis de que un mayor control conducirá a una reducción del gasto. No obstante, las reformas no se plantearon la problemática existente en forma sosegada y reflexiva, sino más bien conducidas por la obsesión razonable del gasto y la idea de que el fin justifica cualquier medio. En este orden, el aluvión normativo, producido entre el año 1997 y el año 2007, buscó la reordenación de los mecanismos de control con la finalidad de alcanzar el resultado económico deseado. No obstante, desde hace años el gasto en incapacidad temporal alcanzo el espacio normalidad y, aun más, la crisis económica se ha encargado de reducirlo considerablemente, tanto por razones técnicas - menos afiliados, menos salarios...-, como humanas, el miedo a perder el empleo ha hecho que el trabajador -salvo en situaciones extremas- acuda a trabajar estando incapacitado.

Por último, otra asignatura pendiente, es el frecuente desencuentro entre el contrato de trabajo y la incapacidad temporal. Como sabemos, a tenor de lo estable-

AA.VV (Dir. ANTONIO V. SEMPERE NAVARRO) "La reforma Laboral de 2010. Estudio de la Ley 35/2010, de 17 de septiembre, de Medidas Urgentes para la Reforma del Mercado de Trabajo" Editorial: Thomson Reuters. Aranzadi. Pamplona, 2010; TORTUERO PLAZA J. L. y SÁNCHEZ-URÁN AZAÑA, Y., "La incapacidad temporal. Régimen jurídico y negociación colectiva", Fundación MAPFRE, Madrid, 1996;TOSCANI GIMENÉZ, D., "La impugnación judicial de las altas médicas emitidas por las entidades gestoras de la seguridad social", Revista capital Humano, núm. 257/21011; Laborum. 2006; VALLE JOZ, J y TRILLO GARCIA, A "Las Mutuas de accidentes de trabajo y enfermedades profesionales como gestoras de la incapacidad temporal derivada de contingencias comunes". en VV.AA "Mutuas de accidentes de trabajo y enfermedades profesionales". La Ley, 2007; VALLE MUÑOZ A., "La facultad de control por las Mutuas Patronales de los procesos de incapacidad temporal mediante reconocimientos médicos, Aranzadi Social 22/2011; VICENTE PALACIO, M. A., "El control de la Incapacidad Temporal: el control en el ámbito de la relación laboral individual y en el ámbito de la Seguridad Social”, Tribuna Social, núm. 168, 2004. 
cido en el artículo 45. 1.c) del Estatuto de los Trabajadores, la incapacidad temporal es causa de suspensión del contrato de trabajo, quedando vinculado el espacio suspensivo a las reglas sobre nacimiento, duración y extinción de la incapacidad temporal establecidas en la normativa de la seguridad social, singularmente en la LGSS. Esto que parece elemental, no lo debe ser, ya que el legislador suele olvidarse con cierta frecuencia de los efectos que las normas de seguridad social tienen sobre el contrato de trabajo, olvido que adquiere especial relevancia, cuando la norma laboral delega tácitamente su ordenación en las de seguridad social, como es el caso de la incapacidad temporal.

\section{Nuevas Reglas de gestión y CONTROL: el Real Decreto 625/2014}

\subsection{UBICACIÓN Y ALCANCE DE LA REFORMA}

Después de un largo periodo en incubación y siempre al rebufo del denominado Proyecto de Ley de Mutuas, el Boletín Oficial del Estado publico el día 21 de julio, el Real Decreto 625/2014, de 18 de julio, por el que se regulan determinados aspectos de la gestión y control de los procesos por incapacidad temporal en los primeros trescientos sesenta y cinco días de su duración.

El RD 625/2014 viene a sustituir a su precedente, -que es derogado expresamente por la disposición derogatoria única- el Real Decreto 575/1997, de 18 de abril, por el que se regulan determinados aspectos de la gestión y control de la prestación económica de la Seguridad Social por incapacidad temporal.

Ciertamente el RD 575/1997, de 18 de abril, había quedado desfasado en muchos de sus contenidos, lo que es habitual en materia de seguridad social, donde rara vez la reforma de la LGSS va acompañada del correspondiente texto reglamentario, bien para sustituir al viejo ,bien para adaptarle.

Como indica el titulo del RD -regulación de "determinados aspectos..."no se pretende proceder a dar una regulación completa, unitaria y acabada de la gestión y control de la incapacidad temporal, sino abordar aspectos parciales, de suma importancia, pero parciales. Nuevamente y una vez más, perdemos la oportunidad de proceder -después de un largo periodo de gestación de la norma- a abordar una regulación completa, optando de forma incomprensible por la ordenación parcelada. La parcelación, provoca ausencia de globalidad y por tanto de visión y ordenación de conjunto, más aun cuando las normas reguladoras tienen infinidad de conexiones.

Las materias objeto de reforma son múltiples y de distinto alcance. A modo de resumen afectan a las siguientes materias:

$>\quad$ La nueva ordenación es aplicable a los primeros 365 día, cualquiera que sea la contingencia determinante - accidente de trabajo, enfermedad profesional, enfermedad común y accidente no laboral- y cualquiera que sea el régimen - general o especiales-, reflejando su vocación universal. 
$>\quad$ Deja fuera como suele ser habitual a los denominados los regímenes especiales de las Fuerzas Armadas, de los Funcionarios Civiles de la Administración del Estado y del personal al servicio de la Administración de Justicia.

D Se moderniza la gestión formal (partes de baja, confirmación y alta) diferenciando los procesos según su duración estimada - inferior a cinco día, entre 5 y 30 días naturales; entre 31 y 60 y entre 61 y más días- en base a protocolos técnico-sanitarios, con identificación de los sujetos responsables en función de la contingencia y de los contenidos de los nuevos partes. $>\quad$ Se apuesta por la gestión telemática en todas las fases y respecto de todos los intervinientes.

$>\quad$ Se reconoce y facilita el acceso a la información clínica del trabajador incapacitado en una ordenación extendida a "los trabajadores del sistema de seguridad social.

$>\quad$ Ordena el procedimiento para las propuestas de alta médica formuladas por las mutuas en los procesos derivados de contingencias comunes. $>\quad$ Ordena en desarrollo del artículo 132.2 de la LGSS los requerimientos para reconocimientos médicos de control y la suspensión cautelar de la prestación ante la falta de comparecencia del trabajador.

> Incorpora un nuevo artículo 6 al RD 1430/2009, donde se regula el procedimiento administrativo de determinación de la contingencia causante en los procesos de incapacidad temporal.

$>\quad$ Igualmente, incorpora un nuevo artículo 7 al RD 1430/2009, donde se regula la prolongación de efectos de la incapacidad temporal y agotamiento de la misma.

\subsection{Elementos DESTACABLES DE LA REFORMA Y SUS PUNTOS CRÍTICOS}

\subsubsection{Instrumentos de control sobre la actuación de los facultativos y centra-} lización de la información

La nueva ordenación realizada por el RD 625/2014 de los elementos formales vinculados al nacimiento, duración y extinción de la incapacidad temporal - baja médica, confirmación y alta-, son estructurados de forma que en sí mismos constituyen mecanismos de control que pretenden actuar contra la utilización inadecuada de la contingencia, tanto en lo que refiere a su nacimiento, como en su duración. Los instrumentos son múltiples - imposición de protocolos clínicos, fragmentación temporal de los procesos, códigos de diagnostico, código nacional de ocupación, informes complementarios...- y pretenden controlar la acción médica y centralizar la información, cualquiera que sea la entidad gestora, a través de medios telemáticos en el Instituto Nacional de la Seguridad Social. 


\subsubsection{La fragmentación temporal de los procesos como mecanismo control -presión}

Otro de los mecanismos de control novedosos se centra en la fragmentación de los procesos de incapacidad en función de su posible duración (inferior a cinco días naturales, entre 5 y 30 días, entre 31 y 60 días y de 61 o más días), lógicamente según los protocolos aplicables. A pesar del revestimiento de buenas intenciones y justificaciones tecnológicas contenidas en la Exposición de Motivo se hace patente expresamente -se cuela en el discurso- la clara intencionalidad del "control".

Es claro que tras la apariencia de facilitar la expedición y tramitación de los partes médicos, se ejercita y drástico mecanismo de control y de presión sobre el facultativo y sobre el trabajador, al predeterminarse la fecha de alta médica en cada proceso.

El elemento de presión-control consistente en la predeterminación temporal del parte de alta médica y, por tanto, de la extinción de la incapacidad temporal, tiene posiblemente un efecto adicional. Cuando el alta predeterminada no se consolide, bien por la modificación del diagnostico, bien por la evolución del propio proceso, actuará como señal de alarma para la actuación puntual de los inspectores médicos del Instituto Nacional de la Seguridad Social, en la medida en que tienen competencias para expedir el alta médica. Actuación que, como hemos visto, viene facilitada por la información recibida por el INSS desde el mismo momento en que se expide la baja médica, como por el acceso telemático a toda la información clínica del trabajador, como reiteradamente recoge el RD.

Ciertamente se respeta el derecho del trabajador, pero a través de un acto expreso, lo que evidentemente constituye un condicionante, sobre todo sí como presumimos, queda vinculado a la acción inspectora de los facultativos del INSS o en su caso del servicio público de salud. Actuación de unos y otros inspectores, que tiene como efecto adicional en caso de expedir el alta médica, la asunción de la competencia sobre el control futuro de la patología - con la correspondiente perdida de competencias del facultativo que trata al trabajador-, al establecerse que durante los ciento ochenta días naturales siguientes a la fecha en que se expidió el alta, serán estas entidades las únicas competentes, a través de sus propios médicos, para emitir una nueva baja médica por la misma o similar patología.

\subsubsection{Facultades de control y la posible vulneración del derecho a la intimi- dad}

La gestión sanitaria vinculada a la incapacidad temporal se moderniza, apostando por la utilización de procedimientos telemáticos, tanto en la gestión de los elementos formales - que se ordenan en función del previsible tiempo de baja - , en la utilización de protocolos, que pretenden dotar al facultativo de herramientas de 
respaldo técnico, y en el acceso a la documentación clínica del trabajador por parte de las instituciones con competencias en materia de gestión y control. Parece que la apuesta por los protocolos es excesiva, olvidándose que más que enfermedades existen enfermas.

En este orden y con insuficiente rango legal, el artículo 8 del RD, incorpora una competencia abusiva, a saber, que "los inspectores médicos del Instituto Nacional de la Seguridad Social o, en su caso, del Instituto Social de la Marina, para el ejercicio de sus competencias, tendrán acceso, preferentemente por vía telemática, a la documentación clínica de atención primaria y especializada de los trabajadores del sistema de la Seguridad Social". La carencia de rango legal y el carácter abusivo de la competencia no se soluciona con la coletilla habitual que advierte que "el tratamiento de los datos de los trabajadores afectados así como el acceso a los mismos quedará sujeto a lo dispuesto en la Ley Orgánica 15/1999, de 13 de diciembre, de Protección de Datos de Carácter Personal y en sus disposiciones de desarrollo" (art.8.3). Repárese en que los apartados 1 y 2 del artículo 2 de la Ley Orgánica 1/1982, de 5 de mayo, sobre protección civil del derecho al honor, a la intimidad personal y familiar y a la propia imagen, dictada en desarrollo del artículo $18.1 \mathrm{CE}$, establecen que " la protección civil de la intimidad y de la propia imagen quedará delimitada por las leyes...", " no se apreciará la existencia de intromisión ilegítima en el ámbito protegido cuando estuviere expresamente autorizada por Ley ...”. El RD busca apoyo en la disposición adicional cuadragésima de la LGSS, sin embargo, ésta refiere a “...datos médicos estrictamente relacionados con las lesiones y dolencias padecidas por el interesado que resulten relevantes para la resolución del procedimiento...". El diferente ámbito es notable y, por tanto, la autorización legal resulta insuficiente. 

LA ORDENACIÓN DE LA CARTERA DE SERVICIOS DEL SISTEMA NACIONAL

DE SALUD Y EL DERECHO A LA PRESTACIÓN POR INCAPACIDAD TEMPORAL

\author{
Portfolio management service national health system and the \\ right to temporary disability benefit
}

\title{
Olimpia del Águila Cazorla
}

Profesora TitularInterina de Derecho del Trabajo y de la Seguridad Social de la

Universidad Complutense de Madrid. E-mail: olimpiadelaguila@der.ucm.es

\section{RESUMEN}

El artículo 128 de la Ley General de Seguridad Social establece los requisitos para el reconocimiento del derecho a la prestación por Incapacidad Temporal. Entre éstos, el ser atendido por los servicios públicos de salud es el que plantea una mayor indefinición. La ordenación del ámbito objetivo de la asistencia sanitaria actúa como elemento determinante del hecho causante de la prestación por Incapacidad Temporal. La aplicación de este criterio objetivo desplaza el criterio de voluntariedad, de manera que se causará derecho a la prestación por Incapacidad Temporal una vez comprobada la inclusión de la patología en la cartera de servicios del Sistema Nacional de Salud. El requisito objetivo para declarar el derecho a una prestación por incapacidad temporal de ser atendido por la asistencia sanitaria pública genera un problema de desigualdad cuando la prestación sanitaria está incluida en la cartera de servicios complementaria de las Comunidades Autónomas. Article 128 of Ley General de la Seguridad Social establishes requirements for the recognition of the right to temporary disability benefit. Among these, be treated by the public health services is the one that posed greater uncertainty. The objective rules of the health care field acts as a determinant of the fact causing the temporary disability benefit. Applying this objective standard shifts the test of voluntariness, so as to be eligible for Temporary Disability Benefit after verifying the inclusion of pathology in the portfolio of services of the National Health System. The requirement for declaring the right to temporary disability benefits requires to be served by the public health care, creates a problem of inequality when health provision is included in the portfolio of complementary services of the Comunidades Autónomas. 
Palabras Clave: Seguridad Social. Asistencia sanitaria. Incapacidad temporal. Seguro Social. Saúde. Incapacidade temporária.

\section{Abstract}

Article 128 of the General Social Security Act establishes requirements for the recognition of the right to temporary disability benefit. Among these, to be attended by public health services is posed by greater uncertainty. The management objective of the healthcare field acts as a key element of the event causing temporary disability allowance. Applying this objective standard shifts the criterion of voluntariness, so as to be eligible for temporary disability benefit after verifying the inclusion of pathology in the service portfolio of the National Health System. The aim to declare the right to temporary disability benefits being attended by public health care creates a problem of inequality as health provision is included in the portfolio of complementary services of the Autonomous Communities requirement. Article 128 of the General Law on Social Security Establishes requirements for the recognition of the right to temporary disability benefit. Among these, You be Treated by the public health services is The One That posed Greater uncertainty. The objective rules of the health care field acts as a determinant of the fact Causing the temporary disability benefit. Applying esta objective standard shifts the test of voluntariness, so as to be eligible for Temporary Disability Benefit after verifying the inclusion of pathology in the portfolio of services of the National Health System. The requirement for declaring the right to temporary disability benefits requires to be served by the public health care, a problem of inequality Creates When health provision is included in the portfolio of complementary services of the Autonomous Communities

Keywords: Social Security. Health care. Temporary disability

SumARIO: 1. La asistencia sanitaria pública como requisito configurador de la incapacidad temporal. 2. Ámbito objetivo de la asistencia sanitaria. 3. La reforma de la asistencia sanitaria: el real Decreto-Ley 16/2012, de 20 de Abril. 4. El requisito objetivo de la inclusión en la cartera común de servicios versus el requisito subjetivo de la involuntariedad. 5. El principio de igualdad en el acceso a las prestaciones sanitarias y su repercusión en la protección por incapacidad temporal. 6. La suspensión del contrato de trabajo por incapacidad temporal. Conclusión. Bibliografía. 


\section{LA ASISTENCIA SANITARIA PÚblica COMO REQUiSito CONFIGURAdOR DE LA INCAPACIDAD TEMPORAL}

El derecho a la protección por incapacidad temporal requiere para su reconocimiento, según establece el artículo 128 LGSS, una alteración de la salud que precise asistencia sanitaria por los Servicios Públicos Sanitarios y que por su gravedad o naturaleza impida al trabajador continuar prestando sus servicios profesionales durante un periodo de tiempo determinado, sin perjuicio de los periodos de observación por enfermedad profesional.

De entre todos los elementos que configuran el derecho a la prestación por incapacidad temporal, el derivado de la necesidad de un reconocimiento previo del derecho a la asistencia sanitaria pública, es el que plantea una mayor indefinición. Del tenor literal de la norma, que continúa remitiéndose a la asistencia sanitaria de la Seguridad Social, junto a las profundas modificaciones legislativas que han venido operando sobre el derecho a la protección de la salud y la propia evolución jurisprudencial en esta materia, se desprende la necesidad de una valoración analítica de dicho requisito.

El derecho a la protección a la salud aparece recogido en el artículo 43 de la Constitución. El diseño constitucional en materia sanitaria parte de la reserva al Estado de dos importantes títulos competenciales: las bases y la coordinación general de la Sanidad (artículo 149.1.16 de la Constitución). A través de esta reserva competencial el sistema público de salud garantiza la equidad territorial, al partir de la facultad que se brinda al Estado para, a través de la legislación básica, establecer el modelo sanitario, garantizar un sistema público de asistencia sanitaria y, significativamente, fijar el ámbito objetivo del derecho a la asistencia sanitaria mediante el establecimiento de un contenido mínimo e igual de las prestaciones para todo el territorio nacional. Por su parte, las Comunidades Autónomas en base a las competencias de ejecución y desarrollo legislativo en materia de asistencia sanitaria reconocidas en el artículo 148.1.21 desarrollaron su propia normativa autonómica en materia de organización, gestión y prestación de la asistencia sanitaria, (con la única excepción de Ceuta y Melilla donde la Administración central del Estado gestiona directamente la asistencia sanitaria a través del Instituto Nacional de Gestión Sanitaria, (INGESA)). La Ley 14/1.986, de 25 de abril, General de Sanidad, regula la estructura y organización del sistema sanitario de las Comunidades Autónomas.

En el desarrollo de la estructura y organización de la gestión de la asistencia sanitaria jugó un papel fundamental la Ley 16/2003, de 28 de mayo, de Cohesión y Calidad del Sistema Nacional de Salud. Esta disposición, de carácter básico, tiene como objeto, según dispone el artículo 1 de dicha Ley, establecer el marco legal para las acciones de coordinación y cooperación de las Administraciones públicas sanitarias en el ejercicio de sus respectivas competencias. La coordinación y cohe- 
sión del sistema se ordena a través de los mecanismos contemplados en esta ley: el Consejo Interterritorial del Sistema Nacional de Salud, la regulación del catálogo de prestaciones sanitarias y el establecimiento del ámbito subjetivo del derecho a la asistencia sanitaria.

\section{2. ÁMbito OBJETIVo DE LA ASISTENCIA SANITARIA}

El marco normativo que regula las prestaciones ofrecidas por el sistema público de salud se establece a partir de las reglas sobre prestaciones sanitarias contenidas en la Ley 16/2003, de 28 de mayo, de Cohesión y Calidad del SNS y el Real Decreto 1030/2006, de 15 de septiembre, por el que se establece la Cartera de Servicios Comunes del SNS y el Procedimiento para su Actualización. La Ley 16/2003 fija la estructura básica y los contenidos fundamentales de la atención sanitaria que dispensa nuestro sistema público de salud. Según el artículo 7 de la Ley 16/2003, las prestaciones sanitarias comprendidas en el Catálogo son las de salud pública, atención primaria, atención especializada, atención socio-sanitaria, atención de urgencias, la prestación farmacéutica, la ortoprotésica, de productos dietéticos y de transporte sanitario. Esta cobertura había que interpretarla en relación con lo establecido por el Real Decreto 1.030/2.006, de 15 de septiembre, por el que se establece la Cartera de Servicios Comunes del Sistema Nacional de Salud y del procedimiento para su actualización, de manera que las prestaciones sanitarias no desarrolladas en el Real Decreto 130/2006 quedaban fuera del ámbito objetivo de protección del Sistema Nacional de Salud. En todo caso, y dado el carácter básico del catálogo de prestaciones las CCAA no pueden excluir ninguna prestación incluida en el mismo.

\section{La Reforma de la asistencia sanitaria: el Real Decreto-ley 16/2012, DE 20 DE ABRIL}

La crisis financiera y económica internacional ha servido de justificación a toda una batería de políticas basadas en la reducción del gasto público y la asistencia sanitaria no ha sido excepción. El Real Decreto-Ley 16/2012, de 20 de abril, de Medidas Urgentes para Garantizar la Sostenibilidad del Sistema Nacional de Salud y Mejorar la Calidad y Seguridad de sus Prestaciones plantea una reforma radical del sistema, hasta el punto de poder interpretar la reforma como el establecimiento de un nuevo modelo de asistencia sanitaria pública que recupera el Seguro de Enfermedad, que se entendía absolutamente superado en aras de la consecución de un derecho universal a la asistencia sanitaria.

El eje más radical de la reforma y que fundamenta el cambio de modelo es la modificación del ámbito subjetivo del derecho a la asistencia sanitaria. Con esta nueva normativa se abandona definitivamente la aspiración universalista del derecho a la sanidad. A partir del Real Decreto-Ley 16/2012, se recuperan los antiguos con- 
ceptos de asegurado y beneficiario del asegurado, de forma que va a ser la inclusión en el sistema de seguridad social el requisito determinante para el nacimiento del derecho a la asistencia sanitaria. Recuerda esta nueva estructura a la Ley de 14 de diciembre de 1.942 por la que se constituyó el Seguro Obligatorio de Enfermedad, (SOE), y en el que quedaba asociada la prestación sanitaria a los riesgos derivados del trabajo y por tanto, se integraban en el sistema de salud únicamente los trabajadores, sus familiares (beneficiarios) y los pensionistas.

La Constitución produce una disrupción en la evolución del sistema preexistente. Tanto el artículo 43 como el artículo 49 de la Constitución reconocen el derecho a la protección de la salud a todos los ciudadanos, y así lo interpreta la Ley General de Sanidad de 1.986, que asume los principios constitucionales reconociendo el derecho a la protección de la salud a todos los ciudadanos y a los extranjeros residentes en España. Aún sin plena efectividad, este principio fue reiterado por la Ley 16/2003, de 28 de mayo. Acorde con este principio de universalidad, la Ley 24/1997, de 15 de julio, configuró la asistencia sanitaria como una prestación no contributiva de la seguridad social, y se estableció que su financiación corriera a cargo de los presupuestos generales del Estado. Posteriormente, la Ley 21/2001, de 27 de diciembre, continúa esta línea excluyendo las cotizaciones como fuente de financiación del sistema sanitario.

El último peldaño legislativo en la construcción del derecho a la asistencia sanitaria como un derecho universal lo constituyó la ley 33/2.011, de 4 de octubre, general de salud pública. Trató esta norma de terminar de cubrir las lagunas de protección en la cobertura sanitaria que todavía afectaban a algunos colectivos, fundamentalmente dos, los parados de larga duración que agoten la prestación o el subsidio de desempleo y algunos grupos de trabajadores por cuenta propia que contaban con mutualidades propias y no tenían la obligación de afiliarse en el Régimen Especial de Trabajadores Autónomos. La Disposición Adicional Sexta de esta Ley integra a estos dos colectivos, y de manera automática a los parados de larga duración y con una ampliación paulatina para el resto de sectores de acuerdo con la evolución presupuestaria que permitiera la extensión del derecho al resto de colectivos.

Esta construcción de una sistema sanitario de carácter público, vocación universal, y financiada a cargo de los presupuestos generales fue interrumpida bruscamente con la publicación del Real Decreto-Ley 16/2012, de medidas urgentes para garantizar la sostenibilidad del sistema nacional de salud. El eje básico de esta disposición consiste en la vinculación del derecho a la asistencia sanitaria pública a la afiliación al sistema de seguridad social.

Con la entrada en vigor del Real Decreto Ley 16/2012, la titularidad del derecho a la asistencia sanitaria deja de recaer en el ciudadano para pasar al trabajador. Se recupera así, el concepto de asegurado, que parecía ya definitivamente superado, desandando así el camino emprendido hacia la universalización del derecho a la sanidad, que en última instancia no es otra cosa que el derecho a la salud. 
El Real Decreto-Ley 16/2012 también modifica la ordenación de la cartera de servicios del Sistema Nacional de Salud e incorpora una serie de medidas en relación con la prestación farmacéutica, como la prescripción por principio activo en patologías agudas y primeras prescripciones de enfermedades crónicas, la ampliación de los supuestos de exclusión de la lista de medicamentos mediante resolución del Ministerio de Sanidad y la introducción del copago farmacéutico según el nivel de renta del asegurado.

El ámbito objetivo de protección en materia de asistencia sanitaria viene determinado por el catálogo de servicios y prestaciones que contemple el Sistema Nacional de Salud y viene establecido por lo dispuesto en el Capítulo I de la Ley 16/2003, de 28 de mayo, de cohesión y calidad del Sistema Nacional de Salud, en la redacción dada por el Real Decreto-ley n ${ }^{\circ}$ 16/2012, de 20 de abril.

El Real Decreto-Ley 16/2012 clasifica la Cartera de Servicios del Sistema Nacional de Salud en tres modalidades, esto es, la Cartera común básica de servicios asistenciales del Sistema Nacional de Salud (servicios de prevención, diagnóstico, tratamiento y rehabilitación que se dispensan en centros sanitarios o socio sanitarios, así como el transporte sanitario urgente), la Cartera común suplementaria del Sistema Nacional de Salud (prestaciones cuya provisión se realiza mediante prestación ambulatoria incluyendo prestación farmacéutica, prestación ortoprotésica, prestación con productos dietéticos y transporte sanitario no urgente prescrito por un facultativo por razones clínicas y Cartera común de servicios accesorios del Sistema Nacional de Salud, (actividades, servicios o técnicas, sin carácter de prestación, que no se consideran esenciales y/o que son coadyuvantes o de apoyo para la mejora de una patología de carácter crónico). La cartera común de servicios del Sistema Nacional de Salud (básica, suplementaria y accesoria) se acuerda en el seno del Consejo Interterritorial del Sistema Nacional de Salud para cada ejercicio, se aprobará mediante Real Decreto y se actualizará por Orden ministerial. Las CCAA, en el ámbito de sus competencias, aprobaran sus respectivas carteras de servicios complementaria, que incluirán como mínimo la cartera común de servicios del Sistema Nacional de Salud, (artículo 8 quinquies de la Ley 16/2003, de 28 de mayo).

\section{El requisito objetivo de la inclusión en la Cartera Común de Servi- CIOS VERSUS EL REQUISITO SUBJETIVO DE LA INVOLUNTARIEDAD}

El derecho de seguros nos exige que, para que un riesgo pueda ser asegurado, debe tratarse de un hecho incierto, futuro y, por tanto, no cabe el aseguramiento de acontecimientos en cuyo origen se encuentre el comportamiento voluntario del asegurado. Consecuentemente con el criterio de involuntariedad en la actualización del riesgo, se ha venido interpretando restrictivamente el acceso a la prestación por Incapacidad Temporal derivado situaciones muy diversas tales como de la práctica de deportes de riesgo, drogodependencia y alcoholismo, la cirugía estética, el 
tratamiento de infertilidad para mujeres sin pareja o lesbianas. Cada una de estas situaciones ha tenido una evolución y una respuesta jurisprudencial diferente que requieren de un análisis valorativo singular.

El artículo 128 de la LGSS vincula la protección por incapacidad temporal a aquellas situaciones derivadas de enfermedad común o profesional, así como a los accidentes sean o no de trabajo, en las que el trabajador reciba asistencia sanitaria de la Seguridad Social y durante el periodo que el trabajador esté impedido para el trabajo.

La interpretación que otorguemos al requisito relativo a la asistencia sanitaria condicionará la amplitud del ámbito objetivo de la prestación por incapacidad temporal. En sentido estricto, esto es, entendiendo que la mención a la asistencia sanitaria de la Seguridad Social limita la protección por Incapacidad Temporal a aquellas situaciones que son objeto de atención por el sistema público de sanidad, excluye de su espacio de aplicación cualquier patología que, independientemente de que origine o no una limitación en la capacidad laboral del trabajador, no vea autorizado su tratamiento por los servicios públicos de salud.

En cualquier caso habría que considerar que la mención a los servicios sanitarios de la seguridad social se entiende realizada al Sistema Nacional de Salud, y por tanto, será su propia normativa reguladora la que determine el acceso a la protección por incapacidad temporal. No cabe suponer con esto que se produce una merma de la libertad de elección del trabajador para optar entre el sistema sanitario público o privado como pareció entender alguna resolución judicial, como la sentencia 3253/2007, de 18 de diciembre del TSJ del País Vasco (Sala de lo Social, Sección $1^{\text {a }}$ ) que entre otras argumentaciones señala que "el trabajador bien puede preferir ser tratado por una instancia privada, a su coste, sin que esta decisión haya de condicionar su derecho al subsidio cuando consta acreditada su incapacidad para la actividad". No es el hecho de la incapacidad para el trabajo el fundamento del subsidio de incapacidad temporal que, así entendido, hiciera irrelevante quien es el sujeto que soporta el coste de la asistencia sanitaria sino que es la posibilidad de tratamiento por el sistema sanitario público de una patología que da origen a esa incapacidad real para trabajar lo que determina el nacimiento del derecho a la incapacidad temporal. Este derecho de elección entre el sistema sanitario público y el privado se mantiene en todo caso pero respetando la inclusión del tratamiento en la cartera común de servicios como requisito configurador del acceso a la prestación por incapacidad temporal.

La cirugía por motivos meramente estéticos no está incluida en la protección otorgada por el Sistema Nacional de Salud. El sistema de sanidad público excluye la posibilidad de que este tipo de intervenciones puedan formar parte de la cartera de servicios comunes. En este sentido, el Real Decreto 1030/2006, de 15 de septiembre, por el que se establece la cartera de servicios comunes del Sistema Nacional de Salud y el procedimiento para su actualización indica, en su artículo 
4.a) $3^{\circ}$, que no podrán ser incluidos aquellas técnicas, tecnologías o procedimientos que no tengan su origen en accidentes, enfermedades o malformaciones congénitas, como es el caso de la cirugía puramente estética y no con finalidad reparadora. Más elocuente es el apartado $4^{\circ}$ del mismo artículo que rechaza explícitamente la inclusión, entre otros, de aquellos procedimientos que tengan como finalidad la mera mejora estética o cosmética.

En consecuencia, hemos de considerar que la LGSS contiene una remisión explícita a la normativa sanitaria de carácter público, y por tanto, únicamente será posible causar derecho a una incapacidad temporal si el trabajador supera el filtro de la normativa sanitaria porque su tratamiento esté contemplado en la cartera de servicios del sistema público sanitario.

Esta cuestión ha sido definitivamente resuelta por el Tribunal Supremo en sentencia de 21 de febrero de 2.012. En esta sentencia, el Tribunal Supremo rechaza considerar la cirugía realizada por motivos puramente estéticos como causa del reconocimiento a la incapacidad temporal, de manera que la cirugía estética a la que el paciente se somete de manera voluntaria y sin vinculación alguna con un accidente, enfermedad o malformación congénita no genera derecho a una declaración del derecho a disfrutar de un subsidio económico que supla los salarios dejados de percibir a causa de dicha intervención quirúrgica. La fundamentación de esta exclusión no gira tanto en la vinculación del derecho a la incapacidad temporal con las prestaciones sanitarias incluidas en la cartera de servicios sino que su principal argumentación se basa en la voluntariedad del trabajador a la hora de enfrentar una intervención de este tipo. La incertidumbre actuará como elemento de exclusión de la protección incluso en el caso hipotético de que el sistema de salud pública decidiera integrar la cirugía estética en su catálogo de prestaciones.

El rechazo del Tribunal Supremo a la inclusión de las operaciones de cirugía estética por carecer del requisito de involuntariedad se desarrolla a partir de la consideración de que el artículo 128. 1 a) de la Ley General de Seguridad Social estipula como elemento constitutivo del derecho al reconocimiento de la prestación por incapacidad temporal que ésta tenga su origen en una enfermedad común o profesional, o un accidente. En los supuestos de cirugía estética no puede apreciarse que el origen esté amparado en una de estas contingencias determinantes de la situación de incapacidad temporal, ya en estos casos no existe una patología previa a la cirugía. A salvo quedan, por supuesto, las intervenciones quirúrgicas que deriven directamente de un accidente o de una enfermedad, o como tratamiento de una malformación congénita. Asimismo hay que considerar incluidas aquellos tratamientos quirúrgicos que, aún cuando tienen una finalidad estética, pretenden remediar patologías de carácter psiquiátrico, toda vez que dentro del concepto de enfermedad quedan integradas tanto las alteraciones de la salud de carácter físico como psíquico.

Íntimamente conectado con lo anterior, el Tribunal Supremo considera la involuntariedad en el acceso a la situación de incapacidad del trabajador para 
prestar sus servicios profesionales como requisito constitutivo de la protección económica por incapacidad temporal. La libertad del trabajador para someterse a este tipo de cirugías no puede entenderse incluidas dentro del concepto de situaciones de necesidad que, según el artículo 41 de la Constitución, integra el ámbito de protección de nuestro sistema público de seguridad social. Las contingencias protegidas en el artículo 128 de la Ley General de Seguridad Social son aquellas enfermedades o accidentes que se han producido de manera involuntaria, esto es, el riesgo origen de la contingencia protegida debe ser una situación o hecho futuro e incierto y no una decisión individual del trabajador. Por este mismo motivo, sí se reconoce la protección por incapacidad temporal a aquellos sujetos que, habiéndose sometido a una cirugía estética y por tanto excluida de protección, sufren complicaciones en el postoperatorio o en el periodo de recuperación de la cirugía, ya que nos encontraríamos con el elemento de involuntariedad necesario para originar el reconocimiento a la prestación por incapacidad temporal.

Por último, el Tribunal Supremo no olvida la necesaria adecuación de la acción protectora del sistema de seguridad social a los condicionantes económicos y por las opciones de política legislativa. La financiación de prestaciones de incapacidad temporal que cubran los procesos derivados de esta clase de intervenciones quirúrgicas desborda los límites del concepto de situación de necesidad que conforman nuestro sistema.

\section{El PRINCIPIO DE IGUALDAD EN EL ACCESO A LAS PRESTACIONES SANITARIAS Y SU REPERCUSIÓN EN LA PROTECCIÓN POR INCAPACIDAD TEMPORAL}

La configuración de la estructura del Sistema Nacional de Salud en una organización descentralizada exigió el establecimiento de mecanismos que garantizasen la igualdad efectiva de los ciudadanos en el acceso a la protección de la salud y a la asistencia sanitaria, independientemente del lugar de residencia del beneficiario. Desde el inicio del diseño de nuestro sistema de salud, este principio de igualdad se ha venido reconociendo en las sucesivas disposiciones reguladoras de esta materia. Así, la Ley General de Sanidad, en su artículo 3.2 señala que "La asistencia sanitaria pública se extenderá a toda la población española. El acceso y las prestaciones sanitarias se realizarán en condiciones de igualdad efectiva" y las posteriores normativas básicas en materia sanitaria han venido reiterando esta garantía de acceso en condiciones de igualdad con diferentes redacciones, hasta el Real Decreto-ley 16/2012, de 20 de abril, de medidas urgentes para garantizar la sostenibilidad del Sistema Nacional de Salud y mejorar la calidad y seguridad de sus prestaciones, que en su Exposición de Motivos destaca como objetivo de la reforma operada con dicha norma garantizar la igualdad de trato en todo el territorio nacional con una cartera básica de servicios.

Este derecho a la igualdad efectiva de acceso a las prestaciones sanitarias 
se ve alterado por la posibilidad de que las CCAA, en el ámbito de sus competencias, aprueben sus respectivas carteras de servicios complementarias a las ofrecidas por la cartera común de servicios, (artículo 8 quinquies de la Ley 16/2003, de 28 de mayo). Las Comunidades Autónomas son libres, con la única limitación de dotar de la suficiente financiación, para asumir los procedimientos sanitarios que consideren necesario ofrecer a su población.

En la medida en que esta cartera complementaria de las Comunidades Autónomas está integrada en la cartera de servicios del sistema nacional de salud, hay que entender que la remisión hecha a la asistencia sanitaria de la seguridad social, incluye los procedimientos y técnicas o tecnologías incluidas en la cartera complementaria de las comunidades autónomas.

Las consecuencias en el ámbito de la seguridad social de esta estructura normativa son cuestionables, toda vez que implican una brecha en el principio de igualdad. El artículo 128 de la Ley General de Seguridad Social exige como requisito para acceder a la prestación por incapacidad temporal que el trabajador reciba asistencia sanitaria pública, y es incuestionable que la financiada por las Comunidades Autónomas tiene esa condición. Estarían por tanto comprendidas en el ámbito de dicho artículo las prestaciones sanitarias ofrecidas en el ámbito de sus competencias por las Comunidades Autónomas.

Los resultados son inasumibles, en cuanto a que producen una quiebra de la igualdad de los trabajadores en relación con la seguridad social. En el caso de que una Comunidad Autónoma llegado el caso, financiara un tratamiento quirúrgico, y no fuera así contemplado por las restantes Comunidades Autónomas, sólo los trabajadores residentes en la primera tendrán acceso a la prestación por incapacidad temporal.

La falta de definición de la redacción de este artículo, producto de la evolución histórica legislativa, ha dado origen a un posible tratamiento desigual de la protección por incapacidad temporal, y que en última instancia va a depender del nivel de cobertura objetiva de la asistencia sanitaria de las Comunidades Autónomas.

\section{LA SUSPENSIÓN DEL CONTRATO DE TRABAJO POR INCAPACIDAD TEMPORAL}

Una dimensión relevante en esta materia es la repercusión en el ámbito laboral de los tratamientos que sin estar incluidos en la cartera de servicios del Sistema Nacional de Salud producen en el trabajador que voluntariamente se somete a ellos, una situación de incapacidad para su actividad profesional.

En primer lugar hay que conocer el alcance de la libertad del trabajador para determinar el momento adecuado para someterse a una intervención quirúrgica o a un procedimiento médico que le merme su capacidad para trabajar y que no está cubierto por el sistema público de salud. En este sentido, hay que tener en cuenta que no se trata únicamente de situaciones fútiles o frívolas como pudiera llegar a 
pensarse de alguna intervención de cirugía estética, sino que pueden entrar en juego derechos esenciales de la persona como la maternidad en las técnicas de reproducción asistida.

La cuestión de fondo es la valoración del grado de libertad del trabajador que de manera voluntaria y unilateral se somete a una intervención médica que le ocasiona una limitación transitoria de su capacidad para el trabajo, esto es, en definitiva, qué posibilidades existen para que el trabajador pueda imponer al empresario la suspensión del contrato de trabajo. Obviamente la problemática surgirá cuando exista discrepancias al respecto entre el trabajador y el empresario, ya que sería de aplicación el artículo 45.1.a) del Estatuto de los Trabajadores por el que se permite la suspensión del contrato de trabajo por mutuo acuerdo de las partes.

En los supuestos en los que es el trabajador el que decide, sin contar con la autorización empresarial, someterse a un procedimiento médico que le vaya a impedir la prestación ordinaria de su trabajo, debemos analizarlo desde la perspectiva laboral y desde su anclaje normativo.

El contrato de trabajo como instrumento regulador de la relación jurídica existente entre el empresario y el trabajador y, por tanto, su ámbito efectivo de aplicación será la propia prestación de servicios. En estos supuestos, aunque es claro que las consecuencias de la decisión que tome el trabajador sobre el procedimiento o técnica sanitaria a la que se someta, tendrán repercusiones importantes sobre la prestación laboral, también es cierto que el ejercicio de la libertad individual en el ámbito de lo privado no puede quedar condicionado por el contrato hasta el punto de impedir el acceso a los tratamientos médicos que considere adecuados. Entender lo contrario sería tanto como condenar al trabajador a destinar el periodo de vacaciones a estos procesos, o lo que es lo mismo, a suprimir su derecho a vacaciones. Por tanto, y en el espacio de las relaciones laborales, el empresario vendrá obligado a soportar la suspensión del contrato de trabajo, previo parte facultativo que certifique la necesidad de reposo o de periodo de recuperación para el trabajador, teniendo, eso sí, las facultades que le concede el ordenamiento jurídico para prevenir y reaccionar frente a hipotéticas situaciones de abuso por parte del trabajador.

Uno de los problemas principales que suscita esta materia es la situación en la que se encuentra el trabajador que tras ser intervenido de una cirugía estética no se puede incorporar a su puesto de trabajo. La convalecencia posterior a esta cirugía no da origen a causar derecho a un subsidio por incapacidad temporal a no ser que surgieran complicaciones en el curso de su recuperación que sí fueran objeto de atención por los servicios públicos de salud, en cuyo caso daría origen a una situación ordinaria de incapacidad temporal por contingencias comunes.

Para que el contrato pueda suspenderse válidamente en base a lo dispuesto en el artículo 45.1.c) del Estatuto de los Trabajadores, es requisito imprescindible el previo reconocimiento de la situación de incapacidad temporal por parte de los servicios públicos de salud o entidades colaboradoras. En este supuesto, y para in- 
terpretar el tenor literal del artículo 45.1.c), que se limita a reconocer la "incapacidad temporal de los trabajadores" como causa de suspensión hay que valorar la situación del trabajador recuperándose de una intervención no incluida en la cartera de servicios del sistema nacional de salud. A este respecto hay que tener en cuenta que el artículo 128 de la Ley General de Seguridad Social no hace discriminación alguna entre las causas que pueden general una situación de incapacidad temporal, por lo que hay que entender que la incapacidad temporal nacerá, independientemente de la causa que la genere, toda vez que exista una enfermedad o accidente que impida al trabajador mantener su actividad laboral. Por tanto, los periodos de recuperación o de descanso pautado por el médico podrán fundamentar una suspensión del contrato de trabajo, aún cuando no provengan de intervenciones médicas contempladas en la cartera de servicios del sistema nacional de salud, siempre y cuando claro está, los facultativos de los servicios públicos de salud emitan el parte de baja correspondiente, que no tendrá efectos económicos, que lo justifique.

\section{Conclusión}

El ámbito objetivo establecido por la cartera de servicios del Sistema Nacional de Salud actúa como límite objetivo de la protección ofrecida por la prestación de Incapacidad Temporal.

La aplicación del requisito de ser acreedor del derecho a la asistencia sanitaria pública ha contribuido a la superación del criterio de involuntariedad propio del derecho de seguros como criterio único, sino que tiene que ser conjugado con el relativo al preceptivo tratamiento prestado por la asistencia sanitaria pública. Así, independientemente del grado de participación que el beneficiario de la prestación por Incapacidad Temporal haya tenido en la generación de la contingencia, causará derecho a la protección por Incapacidad Temporal si su patología está recogida en el catálogo de la cartera común de servicios del Sistema Nacional de Salud. Ahora bien, para que nazca una situación de incapacidad temporal se requiere que ésta tenga origen en una enfermedad o accidente, común o profesional, pero, en todo caso, que se presente una alteración del estado de la salud que impida la realización ordinaria de prestación de servicios por el trabajador, esto es, que haga surgir la situación de necesidad por la que se justifique la sustitución de salarios por parte de la seguridad social.

La objetivación del acceso a las prestaciones ofrecidas por el sistema de seguridad social constituye un elemento positivo en la evolución de la técnica y la eficiencia de la protección, pero en esta construcción legislativa se pueden encontrar diferentes distorsiones.

La propia estructura de estructura de organización descentralizada del sistema nacional de salud, junto con la ordenación de su ámbito prestacional ha originado que existan desigualdades en la asistencia sanitaria derivada de la autonomía 
competencial de las Comunidades Autónomas. La dependencia de la Ley General de Seguridad Social a la cobertura ofrecida por el sistema nacional de salud en el acceso a la prestación por incapacidad temporal hace que esta prestación se vea contagiada de esa posibilidad de tratamiento diferenciado según el territorio donde el trabajador tenga fijada su residencia. Bien es verdad que este efecto únicamente se producirá en los prestaciones sanitarias que queden integradas en la cartera complementaria de servicios de las Comunidades Autónomas, pero su sola eventualidad es suficiente para perjudicar el principio de igualdad, que resulta aún menos asumible en lo concerniente al acceso en condiciones de igualdad a las prestaciones del sistema de seguridad social.

Sería deseable una reforma legislativa que paliase tanto el riesgo de "turismo sanitario" entre Comunidades Autónomas, con la consiguiente constitución de la prestación de incapacidad temporal correspondiente, como el de permitir un tratamiento diferente en el acceso a las prestaciones.

La propuesta de reforma pasaría por delimitar el ámbito de los tratamientos médicos que pueden dar lugar a una incapacidad temporal, y actualizando de esta forma la remisión a la asistencia sanitaria de la seguridad social.

\section{Bibliografía}

MARGARITA ARENAS VIRUEZ. "El componente físico o psíquico de las operaciones de cirugía estética y su repercusión en la determinación de la incapacidad temporal: Sentencia del Tribunal Supremo, de 21 de febrero de 2.012" Aranzadi Social: Revista Doctrinal, Vol. 6, No1 (Abr), 2.013, págs. 259-270.

JOSÉ FRANCISCO BLASCO LAHOZ. "Modificaciones en materia de asistencia sanitaria consecuencia del RD-L 26/2.012, DE 20 de abril". Revista de Información Laboral, $\mathrm{N}^{\mathrm{o}} 11,2.012$, págs. 21-40.

SARA MEDINA GONZALEZ. "El sistema sanitario español” Editorial Civitas, Enero de 2.014.

GONZALO MOLINER TAMBORERO. "Seguridad Social, prestación económica por incapacidad temporal: no tiene derecho a percibir el subsidio por incapacidad temporal quien se somete voluntariamente a una intervención de cirugía estética" Diario La Ley, № 7939, 2.012.

AMANDA MORENO SOLANA. "Las intervenciones de cirugía estética: voluntad para encontrarse inmerso en una situación de incapacidad temporal" Aranzadi Social: Revista Doctrinal, Vol. 4, No 9 (ene), 2.012, págs. 1.486-1.488.

SARA RUANO ALBERTOS "El subsidio de incapacidad temporal ante un supuesto de baja médica motivada por intervención de cirugía puramente estética”. Revista de Aranzadi Social, no 17/2.011, paraf. 61/2.011. 
JOSE LUIS TORTUERO PLAZA, FRANCISCA MORENO ROMERO. "Un nuevo y definitivo giro en la reforma de la Incapacidad Temporal" Revista Aranzadi Doctrinal, $\mathrm{N}^{\mathrm{o}} 8,2.010$, págs. 211-222.

JOSE LUIS TORTUERO PLAZA. "Reflexiones acerca de la incapacidad temporal". Revista General de Derecho del Trabajo y de la Seguridad Social, No 10. 2.006.

ANDRÉS RAMÓN TRILLO GARCÍA. "La asistencia sanitaria de los deportistas en el marco de la protección de la salud en la actividad deportiva" Revista del Ministerio de Empleo y Seguridad Social, No 109, 2.004, págs. 229-262.

JAVIER VÁZQUEZ GARRANZO. La protección de la salud. Editorial Aranzadi. 2.012 . 


\section{LA CONTRIBUCIÓN A LOS GASTOS PÚBLICOS, UN DEBER MÁS ALLÁ DE LA RECAUDACIÓN}

Contribution to public expenditure: beyond duty to contribute

\section{Miguel Ángel Sánchez Huete}

Profesor de Derecho Financiero y Tributario de la Universitat Autónoma de Barcelona, con anterioridad y durante más de quince años se ha de dedicado al ejercicio profesional de la abogacía. Es Licenciado en Derecho por la Universitat de Barcelona y Doctor por la Universitat Internacional de Catalunya. Dentro de sus líneas principales de investigación y publicación destacan: las infracciones y sanciones tributarias, el uso de sociedades como instrumento de elusión y el análisis de la responsabilidad social desde la perspectiva tributaria. E-mail: miguelangel.sanchez@uab.es

\section{RESUMEN}

En la presente artículo se pretende reflexionar sobre la naturaleza jurídica y el valor ético del deber de contribuir. De una parte, se analiza y defiende el carácter fundamental del deber de contribuir, pues se haya vinculado al valor de solidaridad. Por otra parte, el deber de contribuir se exige de acuerdo a principios jurídicos. A tal efecto se estudia la exigencia ética de tal derecho y en concreto los riesgos de las medias preventivas del fraude.

Con ello deseamos mostrar el carácter, además de jurídico, intrínsecamente valorativo y ético, tanto del deber de contribuir, como de su exigencia. Ambos aspectos -deber y exigencia- son parte de una misma dimensión, pero de diversa perspectiva. Con el deber se afirma su vinculación y con la exigencia se estudia el papel del legislador y de la Administración, pero también de sus límites

Palabras clave: Deber de contribuir. Solidaridad. Dignidad. Derechos fundamentales. Prevención del fraude. Buena fé. 


\begin{abstract}
In the present article aims to reflect on the legal nature and ethical duty to contribute value. On one hand, discusses and defends the fundamental nature of the duty to contribute, as has been linked to the value of solidarity. Moreover, the duty to contribute is required according to legal principles. Ethics requiring such a right is studied and, in particular, the risks of fraud preventative measures.

With this we want to show the character, plus legal inherently evaluative and ethical duty to contribute both as your requirement. Both aspects-duty and requirement-are part of the same dimension, but different perspective. With the duty states and its links with the requirement of the legislature and the role of government, but its limits are studied.
\end{abstract}

Keywords: Duty to contribute. Solidarity. Dignity. Fundamental Rights. Fraud PREVENTION. GOOD FAITH.

SumARIO: 1. Introducción y objeto de estudio. 2. El carácter fundamental del deber de contribuir. 2.1. Deber de contribuir y derechos fundamentales. 2.2. El valor del deber de contribuir. 3. La exigencia del deber y sus riesgos. 3.1. La aceptación y exigencia ética de la deuda tributaria. 3.2. La prevención del fraude y sus riesgos. Conclusiones.

\title{
1. INTRODUCCIÓN Y OBJETO DE ESTUDIO
}

En el contexto de crisis actual resulta más necesario que nunca recordar que la tributación es instrumento de redistribución y elemento esencial para el funcionamiento de los servicios y prestaciones del Estado social. Pocas normas como las tributarias evidencian más claramente el compromiso ético de una sociedad. Son normas éticas porque son instrumento de solidaridad y redistribución. Lejos quedan concepciones que las ideaban únicamente como normas negativas, de carácter limitativo e interpretación restrictiva, también son disposiciones que comportan una perspectiva positiva, de solidaridad y redistribución de los recursos de una comunidad.

La solidaridad resulta un valor que evidencia una ética laica cuya principal manifestación resulta un deber: el deber de contribuir. El carácter fundamental de dicho deber no acostumbra a ponerse de manifiesto, a pesar de tener por base uno de los valores que junto a la libertad, seguridad e igualdad, cimentan los derechos así considerados. Afirmar dicho carácter fundamental tiene como correlato el estableci- 
miento de las medidas necesarias para su garantía y para protegerlo de los peligros que encierran las conductas insolidarias. Para tal finalidad se han de utilizar normas preventivas ante la situación de riesgo potencial que suponen algunos comportamientos. Ahora bien la adopción de tal función normativa supone una especial injerencia en la esfera patrimonial y personal de los obligados, de ahí que su regulación ha de ser adecuada y proporcional al fin perseguido.

Guiándonos por tales orientaciones pretendemos tanto enfatizar el carácter fundamental del deber de contribuir como analizar -sobre la base de las normas tributarias del Estado español- las disfunciones que puede suponer el abuso de las normas preventivas del fraude.

El anterior objetivo nos exige plantear, en primer lugar, la relación existente entre el deber de contribuir y los derechos humanos para mostrar su carácter fundamental. En segundo lugar, procederemos a abordar la problemática de la exigibilidad de tal deber. Para ello tendremos en consideración su carácter ético, la necesidad de instrumentos adecuados para prevenir el fraude, y la proporcionalidad de las medidas para tal fin. Con ello intentaremos evidenciar el carácter, además de jurídico, intrínsecamente valorativo y ético tanto del deber de contribuir, como de la necesidad de establecer límites ante determinadas visiones preventivas del fraude. Ambos aspectos -deber y exigencia- son parte de una misma dimensión, pero de diversa perspectiva; en tanto que deber, se afirma su vinculación y; en tanto que exigencia, se alude al poder del legislador y de la Administración, pero también a sus límites.

Dicho análisis supone un abordaje jurídico centrado en la legislación y doctrina española en donde tendrá especial relevancia la regulación tributaria establecida en la Constitución de 1978. También, y para el estudio de dicha temática, se adopta un enfoque que conjuga diversas disciplinas jurídicas, el Derecho Tributario y el Financiero en que se inserta, principalmente, pero también la Filosofía del Derecho y el Derecho Constitucional. Todo ello teniendo presente tanto las aportaciones de la doctrina como de la jurisprudencia de nuestro Tribunal Constitucional.

\section{El CARÁCTER FUNDAMENTAL DEL DEBER DE CONTRIBUIR}

Determinar el carácter de fundamental del deber de contribuir ha de partir de su concreción en los derechos de los cuales se predica. O sea, ¿cuál es el elemento que permite calificar a unos derechos como fundamentales? Y a renglón seguido, ¿puede predicarse también de un deber jurídico?, ¿existe alguna correlación entre la afirmación de unos y otros?

Los derechos tienen que ver con los valores sobre los que se basan, pero también con las necesidades sentidas como esenciales. Dichas necesidades son mutables en el tiempo y aparecen vinculadas a un contexto histórico. Así se afirma que el catálogo de derechos humanos se apoya en un sistema de valores dinámico que 
está conectado con necesidades básicas generalizables ${ }^{507}$. Tal dinamismo, junto a la ampliación de su concepto y la fuerte carga ideológica que los acompañan, ha llevado a hablar de una cierta indeterminación y ambigüedad de su sentido ${ }^{508}$. De ahí que a efectos terminológicos, y también en aras de concretar su contenido, se ha preferido denominar a los derechos humanos como fundamentales. Así PECES-BARBA MARTINEZ considera que la utilización del término de derechos fundamentales resulta mejor que el de derechos humanos pues posee una menor ambigüedad y aparece desprovisto de bagajes ideológicos -se desconecta de las pretensiones morales asociadas al derecho natural-. Dicha designación también se vincula a un reconocimiento constitucional o legal y refuerza su dimensión ética ${ }^{509}$. La idea básica que anima a tales derechos es entenderlos como fundamentadores del sistema jurídico -político del Estado de Derecho. En tanto que derechos subjetivos resultan posiciones jurídicas de atribución, ya sea como poder, o ya sea como esfera de libertad, que tiene todo individuo por razón de su humanidad.

Los derechos fundamentales aparecen, en un primer momento histórico, configurados como posiciones jurídicas individuales frente al Estado, como esferas de libertad que garantizan la no injerencia de éste en espacios de libertad. Será más tarde cuando se conciban como derechos a la prestación, derechos que comportan un hacer positivo de los poderes públicos.

En origen los derechos considerados como fundamentales poseen una función tuitiva que pretende garantizar la autonomía personal y la independencia moral. Por ello una de las funciones básicas de los derechos es la de garantizar unos espacios exentos en donde sus titulares puedan actuar libremente ${ }^{510}$. Dicha perspectiva garan-

${ }^{507}$ RODRIGUEZ PALOP, María Eugenia. Claves para entender los nuevos derechos humanos. Madrid: Catarata. 2011, p. 37.

${ }^{508}$ MARTINEZ MORÁN, Narciso y DE CASTRO CID, Benito (Coordinadores). Diecisiete lecciones de Teoría del Derecho. $2^{\text {a }}$ edición, Madrid: Uned Editorial Universitas, 2011, p. 211.

509 PECES-BARBA MARTINEZ, Gregorio. Lecciones de Derecho Fundamentales. Madrid: Dykinson. 2004, p. 28. PEREZ LUÑO remarca también que el término de derechos humanos posee unos contornos más amplios e imprecisos al aludir a derechos y libertades reconocidos en declaraciones y convenios internacionales que, debiendo ser objeto de positivación, no lo han sido. Por el contrario los derechos fundamentales poseen un concepto más estricto y preciso se trata siempre de "derechos delimitados espacial y temporalmente, cuya denominación responde a su carácter básico o fundamentador del sistema jurídico político del Estado de Derecho". (PEREZ LUÑO, Antonio Enrique. Los derechos fundamentales. $8^{\text {a }}$ edición, Madrid: Tecnos. 2004, p. 46-47.)

510 Ver PECES BARBA que señala que son cuatro las dimensiones de los derechos: la garantizadora o protectora, la participativa, la promocional y la de disenso (PECES-BARBA MARTINEZ, Gregorio. Lecciones de Derecho Fundamentales. Madrid: Dykinson. 2004, p. 278). DIÉZ PICAZO habla de la función de protección -que salvaguarda al individuo- y de legitimación -como criterio de diferenciación de lo justo e injusto-. (DIÉZ PICAZO, Luís 
tista comporta configurarlos como un límite al poder que garantizan la autonomía, o sea, un deber de abstención de los poderes públicos. Esta idea de libertad, asociada a la no injerencia de un poder público, se ha de entender en su sentido primigenio: como límites a un poder público autoritario no democrático. Resulta indicativo, para apreciar de donde venimos conceptualmente y denotar algunas rémoras que persisten, el confrontar el sentido de las libertados con el sentido primero de la tributación.

El tributo nace como manifestación del poder del Estado, concretamente del poder militar, en tanto que se imponía a los pueblos vencidos. Era así concebido como un mero ejercicio del poder autoritario y de la fuerza y que, por consiguiente, no precisa fundamentación o principio regulador para su exigencia ${ }^{511}$. La obligada contribución se manifiesta como un deber derivado del ejercicio de la fuerza unilateral, en donde quien paga la carga tributaria es un vencido, sin más derechos que los concedidos graciablemente. Tal concepción contrasta con la idea actual de tributo vinculada a la autoimposición, al reconocimiento del estatus de ciudadano, y a su ordenación en base a principios jurídicos.

El tributo es fruto de la autoimposición a través de normas dictadas en parlamentos democráticos por ciudadanos. Ciudadanos, con posiciones jurídicas de atribución y vinculación preestablecidas normativamente. $\mathrm{Y}$ en donde la carga tributaria se establece en base a principios constitucionalizados que fundamentan una imposición justa.

\subsection{DERECHOS FUNDAMENTALES Y DEBER DE CONTRIBUIR}

La libertad, asociada a los derechos fundamentales, ha de entenderse conformada de acuerdo con la convivencia social, de ahí que no resulta absoluta. No perjudica o contraría su existencia las modulaciones derivadas de la propia decisión manifestada formalmente a través de la ley, expresión de los representantes libre y democráticamente elegidos.

El paso de una situación de sujeción, propia de súbditos, a una posición jurídica de atribución y vinculación, propia de ciudadanos, tiene que ver con el principio de legalidad como manifestación de autoimposición. En tal escenario, el fundamento de la tributación y su régimen a través de principios resulta básico, pues no hay lugar en el Estado de Derecho para un poder sustraído de toda regla ${ }^{512}$. En

María. Sistema de derechos fundamentales. $4^{\mathrm{a}}$ edición. Madrid: Civitas Thonsom-Reuters, 2013, p. 37).

${ }^{511}$ MARTIN QUERALT, Juan, LOZANO SERRANO, Carmelo, TEJERIZO LOPEZ, José Manuel y CASADO OLLERO, Gabriel. Curso de Derecho Financiero y Tributario. Madrid: Tecnos. 2007, p. 214.

${ }^{512}$ MARTIN QUERALT, Juan, LOZANO SERRANO, Carmelo, TEJERIZO LOPEZ, José Manuel y CASADO OLLERO, Gabriel. Curso de Derecho Financiero y Tributario. Madrid: Tecnos. 2007, p. 214. 
palabras de BAYONA DE PEROGORDO y SOLER ROCH lo más característico del poder soberano en el Estado constitucional es que se trata de un poder sometido a la Constitución, pues ésta es al mismo tiempo fundamento y límite de la actuación del órgano que detenta la supremacía financiera ${ }^{513}$.

La doctrina de nuestro Tribunal Constitucional -Sentencia del Tribunal Constitucional (en adelante STC) 3/2003, de 16 de enero- señala que como consecuencia directa del principio de autoimposición surge el derecho del ciudadano, no sólo a consentir los tributos, sino también a conocer su justificación y el destino a que se afectaba. Tal derecho se recogió tempranamente en la Bill of Rights de 1969, se expresó claramente la Declaración de los Derechos del Hombre y del Ciudadano de 1789 (art. 14), y se estableció nuestra Constitución de Cádiz de 1812 (art. 131) (14 $^{514}$ El principio de autoimposición implica, en palabras del Tribunal Constitucional, que "[...] cuando un ente público impone coactivamente una prestación patrimonial a los ciudadanos, cuente para ello con la voluntaria aceptación de sus representantes" (STC 185/1995, de 14 de diciembre, FJ 3).

El principio de legalidad vinculado a su legitimidad democrática, a la idea de autoimposición y de control, evidencian la existencia de un deber de contribuir fuera de los parámetros de la sujeción y subordinación tradicionales. Es un deber

${ }^{513}$ BAYONA DE PEROGORDO, Juan José y SOLER ROCH, María Teresa. Compendio de Derecho Financiero. Alicante: Librería Compas, 1991, p. 136.

${ }^{514}$ Mas extensamente dicha resolución en su Fundamento Jurídico $3^{\circ}$ analiza el entronque histórico e imbrica tales comentarios en el análisis de la institución presupuestaria "Los primeros presupuestos, así pues, constituían la autorización del Parlamento al Monarca respecto de los ingresos que podía recaudar de los ciudadanos y los gastos máximos que podía realizar y, en este sentido, cumplían la función de control de toda la actividad financiera del Estado. En la segunda mitad del siglo XIX, sin embargo, cuando los tributos se convierten en la principal fuente de financiación de los Estados, se produce un desdoblamiento del principio de legalidad financiera, fenómeno que en nuestro Estado tiene lugar con la Constitución de 1869. La Ley de presupuestos, en efecto, pasa de establecer una autorización respecto de los ingresos a recoger una mera previsión de los mismos, en la medida en que su establecimiento y regulación se produce mediante otras normas de vigencia indefinida (principio de legalidad tributaria). Sin embargo, respecto de los gastos la Ley de presupuestos mantiene su carácter de autorización por el Parlamento, autorización que es indispensable para su efectiva realización (principio de legalidad presupuestaria). Este principio de legalidad presupuestaria dio lugar a la Ley provisional de administración y contabilidad de la hacienda pública de 25 de junio de 1870. Así, la conexión esencial entre presupuesto y democracia parlamentaria debe ser destacada como clave para la resolución de este recurso de inconstitucionalidad. El presupuesto es, como hemos visto, la clave del parlamentarismo ya que constituye la institución en que históricamente se han plasmado las luchas políticas de las representaciones del pueblo (Cortes, Parlamentos o Asambleas) para conquistar el derecho a fiscalizar y controlar el ejercicio del poder financiero: primero, respecto de la potestad de aprobar los tributos e impuestos; después, para controlar la administración de los ingresos y la distribución de los gastos públicos". 
consentido cuya necesidad se evidencia en establecer las condiciones materiales para que la persona se desarrolle como tal.

En definitiva, las decisiones sobre la propia libertad no cuestionan o niegan su esencia, pues el individuo la conforma en relación a las necesidades de la vida en comunidad. De la misma manera, la obligación que se autoimpone el individuo en la forma del deber de contribuir no resulta privación de la libertad. Es más, la contribución conlleva también una perspectiva positiva de solidaridad ${ }^{515}$. Solidaridad, como valor básico del individuo y de su coexistencia en una comunidad. En tal contexto se ha de tener presente que la concepción y la dimensión de tal deber fundamental determina la propia significación del poder público. Pues existe una íntima relación entre el papel de los derechos y el modo de organizar y ejercer las funciones estata1 es ${ }^{516}$.

Desde la perspectiva del obligado, la tributación es contemplada tradicionalmente como un mero costo. En ocasiones, con la afirmación de que el tributo es un límite a la propiedad se pretende enfatizar no una mera visión negativa del mismo, sino su necesidad. Los tributos son la contrapartida más evidente al disfrute de determinados estándares de derechos individuales y sociales. Normalmente una mayor contribución garantiza a la colectividad, y no necesariamente a su pagador, un mayor nivel de prestaciones y derechos. Es así recurrente la expresión de que el tributo resulta el precio de la libertad ${ }^{517}$, aun cuando el tributo ni jurídicamente es precio, ni la libertad el único de los derechos asociados a su pago. El tributo hace posible la existencia material de las estructuras de organización básicas que permiten hablar de lo público, por compartido y colectivo. De ahí su necesidad en los Estados contemporáneos.

La deuda fiscal no es sólo costo o límite patrimonial también es contribución que expresa y vehicula el valor de solidaridad ciudadana. Solidaridad que, configurada como deber, resulta el correlato a los derechos cívicos que nos corresponden por vivir en una concreta comunidad política, en un concreto Estado social. Ambas posiciones, de atribución -derechos cívicos- y vinculación -deber de solidaridad-, resultan genéricas e inespecíficas ya que ex ante no se concretan las prestaciones que las integran, hasta que no se configuran en posiciones jurídicas definidas de presente. Dicha dicotomía y correlación permiten visualizar que la solidaridad no es un mero altruismo voluntarista, y explica su necesidad y exigencia racional, en clave jurídica, como valor, principio y deber ${ }^{518}$. Con ello se pone de relieve que el tributo, además

${ }^{515}$ Ver PEREZ ROYO, Fernando. Derechos Financiero y tributario. Parte General. Madrid: Thonson-Civitas. 2005, p. 104.

516 PEREZ LUÑO, Antonio Enrique. Los derechos fundamentales. $8^{\text {a }}$ edición, Madrid: Tecnos. 2004, p. 20.

517 Ver TIPKE, Klaus. Moral tributaria del Estado y de los contribuyentes. Madrid: Marcial Pons, 2002, p. 56-57.

${ }^{518}$ Ver a este respecto ROZAS VALDÉS, José Andrés. "Nota preliminar", en Franco GALLO. 
de su función instrumental, al procurar la realización de otros derechos, posee una función propia y autónoma a través de la solidaridad ${ }^{519}$.

Es tradicional contemplar a la contribución como un límite a otros derechos básicos como la propiedad ${ }^{520}$. Limite que aparece asociado al ejercicio de poder por el Estado, al que los derechos fundamentales -en origen- están llamados a poner coto. Pero el deber de contribuir no es un mero ejercicio de poder del Estado, como reiteramos, es la plasmación de un valor fundamental para vida colectiva y el ejercicio de los demás derechos: la solidaridad. El ejercicio de tal deber se disciplina en un fundamento y régimen de principios normalmente positivados en normas constitucionales, en nuestro caso en el art. 31 de la Constitución Española (en adelante CE).

Los principios de derecho tributario consagran valores y postulados fundamentales; desde la perspectiva formal, el principio de legalidad, y desde la material; los principios de reparto de la carga tributaria orientados en función de la capacidad económica, de la igualdad, la generalidad, la progresividad y la no confiscatoriedad. Tanto en los derechos como en los deberes públicos se imbrican valores básicos y compartidos por la sociedad que permean todas las expresiones normativas, también en el ámbito tributario. En tal sentido la STC 53/1981, 11 de abril señala al referirse a los derechos fundamentales que "son los componentes estructurales básicos tanto del conjunto del ordenamiento jurídico objetivo como de cada una de las ramas que lo integran, en razón de que son expresiones jurídicas de un sistema de valores que, por decisión del constituyente, han de informar la organización jurídica y política".

La solidaridad se ha configurado como un valor que encuadra una cierta ética laica y cuyo punto de partida es el reconocimiento de la realidad del otro y la

Las razones del Fisco. Ética y justicia en los tributos. Madrid: Marcial Pons, 2012, p. 16.

519 Se ha de tener presente que en el tributo convergen diversas finalidades; la que podríamos denominar intrínseca, que supone obtener recursos dinerarios para financiar gastos públicos y; la asociada a la anterior, en tanto que pretende, además de la recaudación, determinadas finalidades sociales, como la redistribución de la riqueza o la solidaridad. Ver VARONA ALABERN, Juan Enrique. Extrafiscalidad y dogmática tributaria. Madrid: Marcial Pons, 2009, p. 157-158 y CAZORLA PRIETO, Luís María. Derecho Financiero y Tributario. Parte General. Pamplona: Aranzadi, 2002, p. 41.

520 Al hablar de derechos humanos y tributación resulta recurrente enfatizar los espacios de no injerencia que poseen la ciudadanía y que el poder tributario no puede vulnerar. En tal sentido se defiende derechos a las personas jurídicas, asegurar un estatuto jurídico del contribuyente, también se declaran límites al poder del Estado sometido al principio de legalidad o regido por el de igualdad, de manera que la misma capacidad tribute de manera semejante. En tal sentido se afirma que la tributación ha de asegurar la libre circulación y un mínimo existencial y no puede perjudicar otras libertades (Ver Conclusiones de XX Jornadas Latinoamericanas de Derecho Tributario, Salvador (Bahía) - Brasil, 2000, [consultado 5 junio 2014]. Disponible en: http://www.iladt.org/frontend/ResolutionPage.aspx. 
consideración de sus problemas como propios, susceptibles de resolución con intervención de los poderes públicos y de los demás ${ }^{521}$. El deber de contribuir se basa en el valor de la solidaridad, ínsito y connatural de las sociedades en que se reconocen derechos fundamentales. En tal sentido, el ordenamiento español declara la solidaridad como valor superior del ordenamiento jurídico - art. 1 de la CE- base de derechos fundamentales y criterio de interpretación de los mismos. La solidaridad participa de los rasgos generales de la cultura jurídica y política en que surgen tales derechos. Si bien, y a diferencia de los demás valores, la solidaridad legitima la creación de deberes, y no directamente la creación de derechos. Llegados a este punto cabe interrogarse sobre la posibilidad de considerar a tal deber como fundamental.

\subsection{El VALOR DEL DEBER De CONTRIBUiR}

Somos del parecer - e intentaremos argumentarlo seguidamente- que el carácter fundamental del deber de contribuir puede predicarse en la medida que aparezca integrado como contenido propio de la dignidad de la persona ${ }^{522}$. Pues la dignidad resulta consustancial a los derechos fundamentales por su relación con la propia esencia de la persona. De ahí, que si puede incluirse el deber de contribuir como contenido de la dignidad de la persona podrá ser considerado como fundamental. Junto a la anterior consideración también se han de tener presente las exigencias que supone la existencia, dentro de los derechos fundamentales, de los derechos con contenido prestacional. Pues su realización demandan recursos materiales que sin la solidaridad, vehiculada a través de la tributación, no son posibles en nuestros contextos.

Las anteriores perspectivas manifiestan las diversas funciones atribuidas al deber de contribuir; una función autónoma - escasamente puesta de relieve- en tanto que lo vincula con el valor de solidaridad y lo imbrica en la dignidad de la persona; y otra función instrumental en la medida que resulta un medio para allegar recursos que han de hacer posible la realización material de los derechos reconocidos ${ }^{523}$.

${ }^{521}$ En tal sentido PECES-BARBA MARTINEZ, Gregorio. Lecciones de Derecho Fundamentales. Madrid: Dykinson. 2004, p. 178.

${ }_{522}$ Por el contrario DIÉZ PICAZO es de la opinión que los deberes constitucionales no son correlativos de los derechos fundamentales. Su enunciación posee un valor simbólico que sugiere que los beneficios de los ciudadanos no son gratuitos y se limitan a dar cobertura constitucional a la intervención del el legislador en algunos ámbitos de libertad (DIÉZ PICAZO, Luís María. Sistema de derechos fundamentales. $4^{\mathrm{a}}$ edición. Madrid: Civitas Thonsom-Reuters, 2013, p. 54). Sin duda tal perspectiva contempla al deber más como límite a la propiedad y a otros derechos y libertades que como vinculo con sustantividad propia.

${ }^{523}$ Los deberes acostumbran a aparecer en relación con los derechos fundamentales, como un reflejo de los mismos, como límites a la acción pública, pero no con una configuración autónoma. No obstante también existen deberes independientes, sobre la base de derechos, es el caso de bienes que se corresponden con derechos positivos que exigen la intervención del Estado -salud, educación, trabajo, vivienda...- (En tal sentido PALOMBELLA, Gianluigi. 
La idea de dignidad singulariza a la persona como algo diferente y distinto a cualquier otra realidad, dicha consideración le confiere una protección primaria e incluso superior a la propia de la comunidad en que se organiza. La dignidad, como concepto jurídico, aparece con fuerza en el derecho nacional e internacional vinculado a la defensa de los derechos humanos en el siglo pasado, y adquiere un fuerte protagonismo a partir de la Segunda Guerra Mundial ${ }^{524}$. En tal sentido el Tribunal Constitucional afirma que la Constitución Española salvaguarda aquellos derechos "que pertenecen a la persona en cuanto a tal y no como ciudadano o, dicho de otro modo aquellos que son imprescindibles para la garantía de la dignidad humana[...]" (STC 91/2000 de 20 de marzo). El ser humano no es, no puede ser, instrumento para otra finalidad, ni sus derechos ceden ante los intereses del Estado o de la sociedad.

En tal sentido los derechos humanos son derechos subjetivos originarios -pre sociales- ligados a la propia esencia de la persona ${ }^{525}$. Así se puede deducir de la dicción del art. 10.1 de la Constitución Española al afirmar que "La dignidad de la persona, los derechos inviolables que le son inherentes, el libre desarrollo de la personalidad, el respeto a la ley y a los derechos de los demás son fundamento del orden político y de la paz social." En tal configuración prima tanto su visión como límite a la actuación de los poderes públicos, espacio de libertad en donde no pueden intervenir, como evidencia un reconocimiento previo y superior al efectuado por un concreto ordenamiento positivo. La regla establecida implica un "valor espiritual y moral inherente a la persona ha de permanecer inalterada en cualquier situación en que la persona se encuentre" (STC 53/1985, 11 de abril F.J. 8) $)^{526}$.

El sentido de dignidad se relaciona con un ámbito de inmunidad al poder del Estado, pero también se asocia con garantizar condiciones de existencia física para la vida humana. Es así que tal cualidad se esgrime contra las violaciones de

"De los derechos y de su relación con los deberes y los fines comunes". Derechos y libertades, $\mathrm{n}^{\mathrm{o}}$ 17, época II, junio 2007, p. 130).

${ }^{524}$ Ver GOMEZ SANCHEZ, Yolanda. "Dignidad y ordenamiento comunitario" en Revista de Derecho Constitucional Europeo, ${ }^{\circ}$ 4, 2005, [consultado: 4 junio 2014] Disponible en internet en http://www.ugr.es/ redce/REDCE4/articulos/09yolanda.htm.

${ }^{525}$ Existen dos concepciones de derechos humanos no necesariamente incompatibles, las material que pone el acento en el contenido de los mismos, lo crucial no es cómo se regulan sino su carácter universal, y la formal que prima la fortaleza de tales derechos al recogerse en una norma supralegal como es la constitución (DIÉZ PICAZO, Luís María. Sistema de derechos fundamentales. $4^{\mathrm{a}}$ edición. Madrid: Civitas Thonsom-Reuters, 2013, p. 31).

${ }^{526}$ También la STC 120/1990, 27 de junio -FJ. 4- afirma que "[...] la dignidad ha de permanecer inalterada cualquiera que sea la situación en que la persona se encuentre, también, qué duda cabe, durante el cumplimiento de una pena privativa de libertad, como repetidamente se cuida de señalar la legislación penitenciaria, constituyendo, en consecuencia, un minimun invulnerable que todo estatuto jurídico debe asegurar, de modo que, sean unas u otras las limitaciones que se impongan en el disfrute de derechos individuales, no conlleven menosprecio para la estima que, en cuanto ser humano, merece la persona $[\ldots]$ ". 
derechos personales relacionados con la vida y condiciones físicas de la persona ${ }^{527}$. Ahora bien también cabría plantear si dentro de la idea de dignidad caben las condiciones de vida material, aquellas condiciones que puedan considerarse inherentes a la propia existencia del ser humano. Este interrogante plantea si los derechos sociales, económicos y culturales son inherentes al ser humano, y en qué medida caben incluirlos en el concepto de la dignidad. No obstante, y al margen de tal planteamiento -que excede de nuestro objeto-, queda patente que en la medida que se requieran medios materiales para garantizar los derechos vinculados a la existencia física -el derecho a la vida o a la integridad- se hace necesaria la existencia de un deber de solidaridad. Solidaridad, no como mero altruismo, sino como conditio sine qua non de la existencia y reconocimiento de derechos fundamentales.

La realización de muchos derechos fundamentales tal y como se conciben precisan de la solidaridad. Sin ella no pueden existir aquellos. Pero también a la inversa, sin tales derechos no puedan darse las condiciones para que el deber de contribuir sea posible. Tal faceta configura a la solidaridad en que se imbrica el deber de contribuir como un aspecto básico, más allá de su reconocimiento instrumental de procurar medios materiales. Pues entre los derechos también existe una interdependencia en donde difícilmente pueden ser pensados unos sin la coexistencia de los otros

Por consiguiente para garantizar tanto la dignidad existencial, como la dignidad en las condiciones materiales de vida, se precisa de la solidaridad de los miembros de una comunidad. Solidaridad cuya manifestación más importante en las sociedades contemporáneas se arbitra a través del deber de contribuir a los gastos públicos. Resulta así que dicho deber deviene fundamental, no tan sólo para garantizar la eficacia y el reconocimiento material de los derechos de las personas, sino como aspecto ínsito a su propia existencia.

Pero, además y como venimos afirmando, los derechos fundamentales no se agotan en libertades o espacios de no injerencia de los poderes públicos, también pueden adoptar la técnica de los derechos de prestación -derecho a la tutela judicial efectiva, derecho a la enseñanza pública obligatoria...-. A este respecto se ha de tener presente la existencia de tres generaciones de derechos; la primera, la de los derechos civiles y políticos; la segunda, la de los derechos económicos y culturales; y la tercera, la de los derechos económicos, al desarrollo y a la solidaridad ${ }^{528}$. Estas

${ }^{527}$ Ver doctrina citada en GOMEZ SANCHEZ, Yolanda. "Dignidad y ordenamiento comunitario" en Revista de Derecho Constitucional Europeo, no 4, 2005. [consultado: 4 junio 2014] Disponible en internet en http://www.ugr.es/ redce/REDCE4/articulos/09yolanda.htm.

${ }^{528}$ A decir de PEREZ LUÑO dentro de la Constitución económica se ubican el deber de tributar, los derechos y deberes que delimitan el régimen de la propiedad, la libertad de empresa, las relaciones laborales y de seguridad en tanto que resultan el soporte material del ejercicio y actuación de los derechos fundamentales. (PEREZ LUÑO, Antonio Enrique. Los derechos fundamentales. $8^{\text {a }}$ edición, Madrid: Tecnos. 2004, p. 20. Existen diversas clasificaciones de 
últimas generaciones -segunda y tercera- se hayan integradas derechos que no tienen como objeto un deber de abstención de los poderes públicos, sino que comportan un deber positivo de hacer.

De lo anterior se evidencia que los derechos fundamentales en la actualidad no son meros derechos negativos o de no injerencia frente al Estado, son derechos subjetivos que tienen como correlato deberes de actuación del éste. Así afirma la STC 53/1981, 11 de abril que "los derechos fundamentales no incluyen solamente derechos subjetivos de defensa de los individuos frente al Estado, y garantías institucionales, sino también deberes positivos por parte de éste [...]". Las diversas generaciones de derechos han supuesto una ampliación de las necesidades económicas para poder ser materialmente sustentados y, consecuentemente, una ampliación del deber de contribuir. En tal tesitura la necesidad de la solidaridad para allegar recursos resulta clara, solidaridad que se arbitra a través de un concreto deber jurídico. Desde tal perspectiva nuevamente se hace necesario concebir al deber de contribuir como deber básico, si bien con un carácter más instrumental, para la garantía de los derechos prestacionales reconocidos.

El deber de contribuir constituye el presupuesto, material y lógico, para el reconocimiento y eficacia de unos estándares de derechos y libertades que se consideran fundamentales en nuestras sociedades contemporáneas. Existe una estrecha imbricación entre la proclamación de dicho deber, su eficacia y adecuación a principios que garanticen su justicia, con los derechos que se reconocen. De ahí que las conductas que perjudican el deber de contribuir indirectamente perjudican el sustrato material que garantiza una adecuada aplicación de los derechos reconocidos. Se trata de vasos comunicantes: los derechos precisan de medios públicos para su aplicación, y éstos, se obtienen mediante el deber de contribuir. Atendiendo a tal relación la transgresión de tal deber, anclado en la solidaridad ciudadana, supone también erosionar los derechos fundamentales reconocidos. Dicho deber evidencia una importante función instrumental -en la medida que salvaguarda los derechospero ello no puede llevarnos a ignorarse el valor intrínseco y propio que vehicula -la solidaridad-. Tal interrelación no hace menor o inferioriza su reconocimiento, pues al igual que en muchos derechos el reconocimiento de unos necesita de la existencia de otros.

En otro orden de consideraciones, no se puede confundir la eficacia y garantía económica de tales derechos y libertades con sus garantías jurídicas. Las con-

los derechos DIÉZ PICAZO clasifica los derechos según su evolución histórica y atendiendo a su estructura. Vinculados a su evolución histórica, habla de derechos civiles (garantizan ámbitos de autonomía), políticos (garantizan la gestión democrática de los asuntos públicos) y sociales (garantizan las condiciones de vida digna). En relación a su estructura, habla de derechos de defensa en tanto que pueden exigir la no interferencia de los poderes públicos, de participación, ya que facultan realizar actos con relevancia pública, y de prestación al facultar reclamar un beneficio. (DIÉZ PICAZO, Luís María. Sistema de derechos fundamentales. $4^{\mathrm{a}}$ edición. Madrid: Civitas Thonsom-Reuters, 2013, p. 35). 
diciones económicas y las decisiones de gasto no determinan el reconocimiento y garantía jurídica de los derechos fundamentales. Éstos no son contingentes, ni dependen de decisiones presupuestarias. Tal reflexión adquiere una gran importancia en los contextos actuales, pues vivimos tiempos de crisis y mudanza, y los recortes presupuestarios hacen peligrar la eficacia de algunos derechos. En tal tesitura cabria plantear si los derechos reconocidos y las garantías de su aplicación dependen de un presupuesto silente en nuestras Cartas magnas: los derechos se reconocen en la medida que existen recursos económicos que los garanticen.

La respuesta negativa del anterior planteamiento es clara, pues el reconocimiento y las garantías jurídicas no dependen de las medidas económicas. Tal interrogante se resuelve en clave estrictamente jurídica: los derechos fundamentales son derechos subjetivos que vinculan a todos los poderes públicos y son exigibles ante los tribunales -art. 53 de la CE-, de ahí que no es posible subordinar su aplicación a través del gasto. Y si los poderes públicos no garantizan su eficacia, la ciudadanía podrá reclamarlos y exigirlos ante la jurisdicción debiendo, en caso de condena, autorizar las partidas presupuestarias para su satisfacción. No obstante, también es cierto, que la falta de medios hace más frágil su reconocimiento y más frecuentes las reclamaciones para demandar su restauración. Son así, los actuales, momentos de fragilidad para los derechos reconocidos.

\section{LA EXIGENCIA DEL DEBER Y SUS RIESGOS}

A través de los principios contenidos en nuestras constituciones se establecen criterios básicos que conforman la tributación y también su exigencia. En el ámbito español el art. 31 de la Constitución reconoce los principios que rigen y fundamentan el deber de contribuir. También la Ley 58/2003, 17 de diciembre, General Tributaria (en adelante LGT) de en su art. 3 alude a principios de ordenación y aplicación, reiterando algunos de los reconocidos Constitucionalmente.

Los principios de ordenación del sistema tributario suponen mandatos al legislador para el establecimiento de los tributos de acuerdo, básicamente, a los principios constitucionalizados de carácter material y formal. Los primeros, atienden al reparto de la carga tributaria: justicia, capacidad económica, generalidad, igualdad, progresividad y no confiscatoriedad. Y, como principio formal, se reconoce el de legalidad, que procura garantías y control.

Los principios de aplicación suponen directrices a la Administración para que actúe con proporcionalidad, eficacia, limitando los costes indirectos, y asegurando el respeto de los derechos y garantías de los obligados tributarios.

Los principios hacen referencia a valores esenciales o presupuestos lógicos sobre los que se asienta el ordenamiento jurídico ${ }^{529}$. Son elementos básicos

${ }^{529}$ GARCIA DE ENTERRIA, Enrique. y FERNANDEZ, Tomás Ramón. Curso de Derecho Administrativo. Vol I. Madrid: Civitas, 1995, p. 75-76. Estos autores se refieren a ellos como 
referidos a todo el sistema tributario y su contenido resulta exigible jurídicamente respecto del conjunto de impuestos, tasas y contribuciones especiales que conforman el sistema tributario en su globalidad, y no necesariamente de cada uno de sus tributos. En tal sentido ZAGREBELSKY afirma que los principios desempeñan un papel constitutivo del orden jurídico al poseer una eficacia más allá de su significado, evidenciando ideas o pensamientos básicos ${ }^{530}$. Pero también manifiestan una dimensión normativa en su reconocimiento Constitucional. A este respecto se ha de tener presente la cogencia del texto constitucional ${ }^{531}$, pues como afirma el Tribunal Constitucional: "[...] la Constitución, lejos de ser un mero catálogo de principios de no inmediata vinculación y de no inmediato cumplimiento hasta que no sean objeto de desarrollo legal, es una norma jurídica, la norma suprema de nuestro ordenamiento [...]" (STC 16/1981, FJ $\left.1^{\circ}\right)$.

Tales principios resultan limites a la actuación de los poderes públicos y también configuran una esfera positiva que demandan su actuación. Así, por ejemplo, cabe demandar que todos tributen de manera igualitaria, de acuerdo con su capacidad económica, de forma que no exista discriminación por las oportunidades que origina la deslocalización de determinadas rentas -de los capitales principalmenteatendiendo a nuestro contexto globalizado de libre circulación.

Si bien es necesario que los tributos integren los valores que evidencian los anteriores principios, pero también son precisas medidas normativas que favorezcan la percepción ciudadana del fenómeno tributario.

Por un lado, se hace necesaria una mejor regulación y una mayor estabilidad de las disposiciones tributarias. La estabilidad de la normativa ha de hacer posible la seguridad jurídica y la previsibilidad de los cambios, de manera que se eviten modificaciones sorpresivas mediante normas de urgencia. También es preciso una técnica jurídica adecuada que haga inteligible y clara las normas tributarias que, en la gran mayoría de ocasiones, ha de ser aplicada por la ciudadanía y no por avezados técnicos en Derecho ${ }^{532}$.

valores materiales básicos de un ordenamiento jurídico, no son meras tendencia morales sino principios técnicos, fruto de la experiencia jurídica.

${ }^{530}$ ZAGREBELSKY, Gustavo. El derecho dúctil. Ley, derechos, justicia. Madrid: Editorial Trotta. 2009, p. 110.

${ }^{531}$ Ver en tal sentido el art.5 de la Ley Orgánica 6/1985, de 1 de julio, del Poder judicial.

${ }^{532}$ Del art. 4 al 7 de la Ley 2/2011, de 4 de marzo, de Economía Sostenible se evidencia una preocupación por la calidad de la regulación estableciendo en su art. 4 los principios de buena regulación. Así el párrafo 1 del art. 4 señala que "En el ejercicio de la iniciativa normativa, el conjunto de las Administraciones Públicas actuará de acuerdo con los principios de necesidad, proporcionalidad, seguridad jurídica, transparencia, accesibilidad, simplicidad y eficacia. En la iniciativa normativa quedará suficientemente justificada la adecuación a dichos principios." Si bien son normas de eficacia imprecisa por sus consecuencias, al no establecerse sanción concreta al incumplimiento de sus dictados. 
Por otro lado, es necesario visibilizar que el tratamiento tributario -el pago de los tributos y las obligaciones que conlleva- no es una mera carga o dificultad. Para ello, respecto del pago de los tributos, se ha de valorar y mostrar la calidad de los servicios prestados y su vinculación con el ingreso público. Respecto de la carga que suponen las numerosas obligaciones formales de colaboración e información impuestas, se ha de apreciar su lógica y proporcionalidad.

Junto a las anteriores consideraciones se ha de tener en cuenta la exigencia ética que supone el deber de contribuir o, en otros términos, que llevar a cabo su cumplimiento demanda unos condicionantes de valor. No basta el mero poder de realización, es necesario actuar de acuerdo a los fines y principios que legitiman su ejercicio. El prescindir de tal orientación hace que el cumplimiento del deber de contribuir resida más en el efecto - la recaudación- que en la fuerza moral y jurídica que supone su vinculación. Al centrarse en la recaudación se dota de una cierta asepsia moral a la problemática y plantea la cuestión en términos técnicos y de eficiencia. Así no se reprocha tanto el incumplimiento del deber de contribuir como la perdida de recaudación.

En tal línea se muestran dos manifestaciones a tratar en el próximo epígrafe: la denominación y tratamiento como competencia fiscal -como un aspecto mercantil más de concurrencia- que se otorga a los esfuerzos y prácticas de los Estados para captar contribuyentes, y el empleo de mecanismos de cobro disimulados o poco visibles, como si la exigencia del tributo fuera algo vergonzante.

\subsection{LA ACEPTACIÓN Y EXIGENCIA ÉTICA DE LA DEUDA}

En actuales contextos económicos globalizados las rentas de capital -no así las rentas de trabajo- poseen un gran margen de decisión para ubicarse en un territorio u otro. Es por ello que los Estados compiten a la baja en la tributación de tales rentas, con la finalidad de atraer, en esta lógica, a los clientes-contribuyentes. En tal situación los Estados actúan como unos agentes más en un hipotético mercado competitivo de la recaudación.

En tal sentido existen prácticas competenciales que son calificadas por organismos internacionales (OCDE) como competencia fiscal perjudicial -respecto de la existencia de paraísos fiscales-, o "competencia fiscal perniciosa" (Unión Europea), una suerte de competencia desleal. Define el Código de conducta sobre la fiscalidad de las empresas la competencia fiscal perniciosa como aquella que influye o puede influir de forma significativa en la radicación de la actividad empresarial dentro de la Comunidad y que establecen un nivel impositivo notablemente inferior al que se suele aplicar en el Estado miembro afectado ${ }^{533}$. Hemos de reiterar que la

${ }^{533}$ Comunicación de la Comisión al Consejo, al Parlamento Europeo y al Comité Económico y Social Europeo - Fomento de la Buena Gobernanza en el Ámbito Fiscal COM(2009) 201 final. A este respecto se ha de tener presente la preocupación de velar por una competencia 
contribución no solamente se significa por los recursos que allega, sino por el valor que en sí posee. Por ello cabe enfatizar la transgresión ética y jurídica que supone -la causa- más que su efecto, la recaudación.

Relacionado con la anterior reflexión se ha de tener presente que el cumplimiento del deber de contribuir no acostumbra a resultar popular, ni a gozar de prestigio social por lo que el legislador se plantea sortear tales resistencias a través de diversas estrategias, bien vinculando la contribución a fines concretos para buscar una mayor aceptación social, o bien camuflando la contribución como parte de un precio o de la percepción disminuida de un salario o renta.

En primer lugar, las medidas que relacionan la contribución con concretos fines sociales genéricamente aceptados se llevan acabo mediante dos instituciones: la afectación de ingresos a gastos específicos, y el reconocimiento de la extrafiscalidad en el seno del tributo. Por un lado, se establece la afectación de los recursos que se obtienen en la recaudación para aplicarse a concretas finalidades, por ejemplo, a gastos sanitarios, a necesidades escolares o a la investigación médica. Y, por otro lado, se establecen tributos sobre la base de consideraciones extrafiscales. Con ellos se buscan otros fines diversos a la contribución a los gastos generales; el ejemplo más común acostumbra a ser la tributación medioambiental. Tales gravámenes buscan disuadir las conductas más nocivas medioambientalmente -el mayor consumo de productos contaminantes- o incentivar comportamientos más beneficiosos para el medio ambiente -uso de recursos energéticos menos contaminante-.

En segundo lugar, y en ocasiones de manera paralela, existen esfuerzos para que la carga tributaria aparezca camuflada o menos visible. Esta es una suerte de "función camaleónica" que se produce tanto en la tributación directa como indirecta. Dicha función tiene que ver con la confusión del tributo con el precio que se paga por un producto -en el caso de la tributación que grava el consumo, así el IVA-. Pero también con el menor salario o renta que se recibe, es el caso de las retenciones que se efectúan con la finalidad de efectuar pagos anticipados en el Impuesto de la Renta de las Personas Físicas.

Los anteriores son mecanismos que evidencian la existencia de resistencias ante la tributación y lo impopular que supone su exigencia. El deber de contribuir es un deber devaluado éticamente. Tradicionalmente, su cumplimiento no ha comportado el reconocimiento y la estima social asociados a otros, como podría ser cumplir los deberes militares. Obsérvese que mientras que al deber de contribuir se asocia a la idea de gravamen y sometimiento - de manera concordante a su origen histórico-, al deber militar se relaciona con valentía y honor. Tal situación precisa de ser recon-

fiscal de los Estado, tanto eliminando los paraísos fiscales - preocupación sobre todo de la OCDE- como de los regímenes fiscales que pueden considerarse perniciosos -aspecto desarrollados en el contexto de la Unión Europea-. (Ver VALLEJO CHAMORRO, José Ma "La competencia fiscal perniciosa en el seno de la OCDE y la Unión Europea". Revista de economía. $\left.\mathrm{n}^{\circ} 825,2005\right)$. 
ducida y en tal función la educación juega un gran papel

Es preciso fomentar y mejorar la educación tributaria ${ }^{534}$ introduciendo una formación específica no sólo en el sistema educativo formal, en los planes de estudio, sino también incidir en los ámbitos de la educación no formal e informal. Para ello habrá que ofrecer e impulsar una educación que no se limite al saber, a tener unos conocimientos acerca de la tributación, junto a ello, será necesario favorecer los aprendizajes éticos relativos al principio de solidaridad que comporta el pago de los tributos. Especial atención deberá ponerse en la educación informal, la no planificada de forma intencional y explícita pero que permea las relaciones con la Administración.

\subsection{LA PREVENCIÓN DEL FRAUDE Y SUS RIESGOS}

Existen una pluralidad de instrumentos normativos que buscan erradicar el fraude tributario; desde mecanismos punitivos -sanciones administrativas o delitos- de carácter eminentemente represivo, a los preventivos que buscan disuadir al contribuyente de incumplir el deber de contribuir.

Ante la existencia de comportamientos insolidarios se hacen necesarias normas tributarias preventivas o disuasorias que eviten la lesión que supone la falta de ingreso. Ahora bien, al aparece fundamentado el deber de contribuir por principios que lo ordenan, la configuración de las normas preventivas del fraude no es libérrima. Han de ser ponderadas y adecuadas en sus efectos, pues no pueden transmutar el deber jurídico creando una presunción generalizada de mala fe, ni suponer un estado de sujeción propio de súbditos o vencidos. No obstante, antes de desarrollar tales reflexiones y de poner de relieve la importancia de los mecanismos normativos de carácter preventivo existentes, se ha de explicitar algunas estrategias del legislador que buscan luchar contra el fraude a través de medidas que podemos considerar como extravagantes a los fines y valores éticos que han de inspirar su exigibilidad.

\section{A. Los otros instrumentos para combatir al fraude}

En la actualidad apelar al cumplimiento del deber jurídico y cívico de contribuir parece no ser suficiente. En tal sentido la Hacienda Pública se plantea combatir el fraude con mecanismos en donde la exigencia ética de la contribución no parece estar presente -al menos de una manera directa-. Nos referimos a instrumentos como el pago a confidentes para que delaten a los sujetos evasores a cambio de una cuantía dineraria, la adquisición de datos fiscales de las personas consideradas como

${ }^{534}$ Ver al respecto DELGADO LOBO, María Luisa, FERNÁNDEZ-CUARTERO PARAMIO, Marta, MALDONADO GARCÍA-VERDUGO, Ascensión, ROLDAN MUÑIO, Concepción y VALDENEBRO GARCÍA, María Luisa. La educción fiscal en España. Doc. $\mathrm{n}^{\circ}$ 29/05. Madrid: Instituto de Estudios Fiscales, 2005. 
evasores, la organización de loterías fiscales...En el caso de las loterías fiscales se introduce el elemento del azar como estímulo positivo -por el premio que puede obtenerse- para aquellos sujetos que participen aportando facturas de prestaciones de servicios en ámbitos en donde existen normalmente dificultades de control -pequeño comercio, profesionales...-.

La admisibilidad ética de algunas de las anteriores medidas resulta cuestionable. Pues si las normas tributarias evidencian un compromiso ético de la sociedad, los instrumentos y formas de exigencias han de ser coherentes $\mathrm{y}$, en todo caso, respetar los principios que las justifican. En tales parámetros, discutibles y de extravagancia con su contenido ético, se mueven las amnistías fiscales. A este respecto cabe efectuar una breve referencia a la amnistía fiscal de 2012 efectuada por el Estado Español.

El Real Decreto-ley 12/2012, de 30 de marzo, regula en la Disposición adicional primera la declaración tributaria especial, e introduce la que popularmente se ha denominado amnistía fiscal. Amnistía, en tanto que supone dejar de perseguir punitivamente un conjunto genérico de conductas. Y fiscal, derivado del efecto regularizador y ámbito de aplicación. La amnistía fiscal es una medida tributaria, pero también punitiva, mediante la cual las personas que habían ocultado bienes pueden regularizar su situación tributaria pagando el 10\% del valor de los no declarados, sin más intereses, recargos, ni multas.

Tal institución aúna dos aspectos: la valoración de un cierto arrepentimiento espontáneo ante la conducta ilícita realizada, y la tributación específica que supone. Es una regularización que pretende incrementar los ingresos públicos en un momento de crisis, en donde resulta necesario allegar fondos para cumplir con los criterios de estabilidad presupuestaria y reducción del déficit ${ }^{535}$. Se plantea así como una medida extrafiscal vinculada a la crisis económica. Con ella se busca que afloren bienes y derechos no declarados por los obligados, en definitiva, ocultados -la Disposición Adicional $1^{\circ}$ habla eufemísticamente de bienes o derechos que no se correspondan con la renta declarada-. Son bienes o derechos ubicados normalmente en paraísos fiscales, lugares en donde -al margen de una mejor tributación- resultan opacos a la Administración. Pero también posee una finalidad estrictamente fiscal, pues existe una tributación, aunque menor a la ordinaria, y permite mejorar el control futuro de los bienes declarados.

Dicha amnistía, ni es la primera ni, sin duda, será la última. Su admisión genera controversias sobre la eventual lesión al principio de igualdad ya que admite una menor tributación de quienes se acojan a la misma respecto a los sujetos que

${ }^{535}$ Así la Exposición de Motivos del Decreto Ley 12/2012 afirma que "También con el fin de reducir el déficit público, se establece una declaración tributaria especial para determinadas rentas y se adoptan medidas de carácter administrativo que contribuyan a generar ahorros en la gestión del patrimonio inmobiliario del sector público." 
habían cumplido sus obligaciones ${ }^{536}$. En la amnistía fiscal existe el peligro de premiar la ilicitud y desincentivar el cumplimiento legal y puntual. Su presupuesto de aplicación es una conducta ilícita: el haber ocultado bienes, ser titular de bienes y derechos que no se correspondan con los declarados. El régimen efectuado -pago del 10\% del valor de los mismos- supone un tratamiento más beneficioso que el otorgado a los contribuyentes cumplidores. En definitiva, resulta una regulación que trata de manera singularizada y beneficiosa a los sujetos incumplidores de sus obligaciones tributarias. Se evidencia una desigualdad de trato amparada jurídicamente en la posibilidad legal de condonar deudas (art. 75 de la LGT). Ahora bien, dicha justificación formal no es suficiente para evitar la discriminación que origina y que lesiona el principio de igualdad constitucionalizado en el art 31.1 de la CE. En tal sentido trata de manera diversa, y de forma más favorable, a los sujetos incumplidores de las normas tributarias y eventual infractores de las mismas.

La justificación material de tal medida -la extrafiscal de mejorar la recaudación- no resulta suficiente ni proporcionada para la consecuencia establecida. Es por ello que también cabe plantearse si la fiscalidad, y los principios que la informan, han de ceder ante exigencias no fiscales, o cual es el grado de instrumentalidad de la norma tributaria y la virtud de sus principios como límite al legislador.

\section{B. Las medidas preventivas y sus riesgos}

En los contextos actuales de gran movilidad e intercambio económico el Derecho ha de prever con antelación las conductas que le son lesivas. Así, existe una función preventiva en las normas que pretende anticipar y evitar determinadas situa-

\footnotetext{
536 Síntesis de la doctrina sobre el principio de igualdad ante la ley resulta la Sentencia del Tribunal Constitucional 76/1990, de 26 de abril [RTC 1990, 76], y establece: a) no toda desigualdad de trato en la ley supone una infracción del art. 14 de la Constitución, sino que dicha infracción la produce sólo aquella desigualdad que introduce una diferencia entre situaciones que pueden considerarse iguales y que carece de una justificación objetiva y razonable; b) el principio de igualdad exige que a iguales supuestos de hecho se apliquen iguales consecuencias jurídicas, debiendo considerarse iguales dos supuestos de hecho cuando la utilización o introducción de elementos diferenciadores sea arbitraria o carezca de fundamento racional; c) el principio de igualdad no prohíbe al legislador cualquier desigualdad de trato, sino sólo aquellas desigualdades que resulten artificiosas, o injustificadas por no venir fundadas en criterios objetivos y suficientemente razonables de acuerdo con criterios o juicios de valor generalmente aceptados; d) por último, para que la diferenciación resulte constitucionalmente lícita no basta con que lo sea el fin que con ella se persigue, sino que es indispensable además que las consecuencias jurídicas que resultan de tal distinción sean adecuadas y proporcionadas a dicho fin, de manera que la relación entre la medida adoptada, el resultado que se produce y el fin pretendido por el legislador superen un juicio de proporcionalidad en sede constitucional, evitando resultados especialmente gravosos o desmedidos.
} 
ciones que se consideran indeseables. Se regula expresamente, previniendo, situaciones que se consideran peligrosas por la proximidad a la lesión de un valor social. Por ello, respecto de conductas que se consideran de riesgo para el orden establecido y antes de la represión causante de la lesión al orden social, se arbitran medidas jurídicas para ser evitada. Son normas con una función de control cuya existencia conlleva una ampliación de los espacios del Estado para efectuar funciones de vigilancia e injerencia en la vida de los particulares.

El Derecho Tributario puede efectuar diversas funciones: de fomento, de carácter correctivo, y de prevención o disuasión. Desde la vertiente correctiva se pretende reequilibrar el incumplimiento de la obligación material o formal ocasionada. Y desde la faceta preventiva se pretende disuadir algunos comportamientos mediante el uso de diversas instituciones que, por sus efectos tributarios o consecuencias, sean adecuadas para tal fin. Atendiendo a esta última función podríamos hablar de un Derecho tributario preventivo integrado por un conjunto de normas que buscan que los incumplimientos tributarios no se produzcan, estableciendo medidas de control y desanimo para comportamientos que pueden resultar en abstracto peligrosos, sin que constituyan la imposición de una sanción.

Ahora bien, se ha de diferenciar nítidamente entre la prevención del incumplimiento tributario, de la que deriva la imposición de una sanción. La prevención del incumplimiento tributario es una cuestión propia de las normas de tal naturaleza, mientras que la prevención de la infracción es una cuestión netamente punitiva; se disuade del comportamiento infractor, y no del incumplimiento tributario.

La idea de prevención utilizada por el legislador tributario posee normalmente dos perspectivas: la que busca que los incumplimientos no se produzcan, estableciendo medidas de control administrativo basadas generalmente en nuevas fuentes de información; y el establecimiento de medidas jurídicas que, por sus consecuencias, disuadan del comportamiento a evitar. Dentro de las conductas disuasorias se integran un gran número de instituciones en donde se manifiestan diversos grados de ejercicio de la coacción, desde efectos subjetivos no deseados -que comportan mayores cargas materiales o gravámenes formales-, hasta medidas tendentes a reprimir la actuación indeseada, que suponen una lesión patrimonial y aproximan dicha medida a una sanción.

Las instituciones características de este Derecho tributario preventivo son, o bien cláusulas generales, o bien instituciones ad hoc. Las cláusulas pueden ser generales o específicas, y pretenden sobre todo evitar el fraude de ley. También se prevén instituciones tributarias específicas que pueden comportar diversas consecuencias: a) imponer un mayor gravamen, por ser conductas consideradas como no deseadas o peligrosas, valga como ejemplo los recargos tributarios o las ganancias no justificadas, b)poseer algunas consecuencias no deseadas, en particular, las valoraciones administrativas correctivas con efectos tributarios, c)gravar situaciones que no lo estarían a través de instituciones como la transparencia fiscal o las regulaciones 
asociadas a los paraísos fiscales, d)determinar una realidad jurídica diversa a la fáctica mediante las ficciones, o facilitar su determinación con las presunciones.

Las instituciones que conforman el Derecho tributario preventivo parten de un pronóstico de probabilidad que efectúa el legislador sobre el acaecimiento de una conducta lesiva. Ello comporta tener presente dos consideraciones generales. La primera, que el carácter de obligado tributario no comporte una presunción de peligrosidad. La segunda, que la medida a imponer sea proporcionada y no constituya sanción encubierta de la conducta considerada peligrosa.

La primera consideración parte de que la evaluación de dicha peligrosidad no puede efectuarse en juicios abstractos y genéricos, en donde la condición del obligado tributario sea determinante de la medida. El carácter de obligado tributario no puede cualificar al ciudadano de manera que resulte sospechoso, o presunto transgresor de la legalidad tributaria. En el ordenamiento rige el principio de buena fe, y de ahí que no quepa ignorar tal criterio como vector básico de la relación tributaria.

Respecto de la segunda consideración, la que alude a que la medida a imponer no ha de suponer una sanción o mal jurídico. La medida preventiva y la sanción obedecen a miradas y a juicios diversos. La culpabilidad supone un diagnostico con proyección al pasado y la peligrosidad un pronóstico con proyección al futuro. En tal sentido la culpabilidad supone un reproche, un juicio de valor, y la peligrosidad resulta un juicio de probabilidad de contenido fáctico vinculado a la realidad de las $\operatorname{cosas}^{537}$.

Las instituciones preventivas han de respetar la legalidad, preservando el principio de buena fe, pero también la proporcionalidad de sus efectos. Su regulación ha de suponer una evaluación realista del riesgo concurrente y ha de comportar una respuesta adecuada. Es necesario, en primer lugar, un pronóstico de la evasión tributaria que se proyecta hacia el futuro de una determinada situación fáctica. Es un juicio de probabilidad de que se concrete en lesión la situación peligrosa. En segundo lugar, es necesario que la medida empleada sea eficaz por su carácter disuasorio, sin que suponga la imposición de un mal.

Ahora bien, la exacerbación de una visión preventiva puede abocar a algunos riegos y distorsiones en la relación ciudadano-Administración a evitar.

$1^{\circ}$.La existencia de un deber de contribuir "más allá" de los derechos y libertades reconocidos, ¿sumisión ante la Administración?

La doctrina del Tribunal Constitucional ha puesto de relieve tal idea al afirmar que el deber de contribuir al sostenimiento de los gastos públicos establecido

${ }^{537}$ Traemos las palabras empleadas para diferenciar la peligrosidad penal que comporta la adopción de medidas de seguridad, de la culpabilidad que corresponde a la pena, así en ROMEO CASABONA, Carlos María. Peligrosidad y Derecho Penal preventivo. Barcelona: Bosch, 1986, p. 21. 
el artículo 31.1 CE, implica, "más allá del genérico sometimiento de la Constitución y al resto del ordenamiento jurídico que el artículo 9.1 de la norma constitucional impone, una situación de sujeción y de colaboración de los gastos públicos cuyo indiscutible y esencial interés público justifica la imposición de limitaciones legales al ejercicio de los derechos individuales" ${ }^{338}$. Tal afirmación corrobora, por un lado, el carácter fundamental del deber de contribuir. Así al hablar de su vinculación, más allá de las normas positivadas por el legislador, lo entronca con la dignidad de las personas -art. 10.1 de la CE-. Más, por otro lado, genera algunos interrogantes inquietantes ¿se busca una obediencia incondicional a los dictados normativos y a los requerimientos administrativos?, ¿la inconcreción y desmesura no puede llevarnos a un estado de sujeción más propio de súbditos que de ciudadanos? En todo caso, al amparo de tales afirmaciones no pueden crearse situaciones de sospecha generalizadas o la vigencia de principios denostados como el in dubio pro fiscum.

En el contexto tributario persisten manifestaciones impropias que aproximan al ciudadano a un estado de sujeción específico frente la Administración. Tal orientación se evidencia en diversas formulaciones, tanto de resoluciones de tribunales, como normativas ${ }^{539}$. En la relación jurídica tributaria el ciudadano no resulta súbdito, ni funcionario integrado en el orden interno administrativo. En la misma línea, no resulta adecuado la consideración y designación legal del administrado como obligado en el ámbito tributario (art. 35 de la LGT), pues también posee derechos. En tal denominación prevalece una visión de sujeción y vinculación que le inferioriza, pues denota la ausencia de una posición activa o de atribución.

\section{$2^{\circ}$.El peligro de la creación de realidades paralelas}

Las presunciones legales son medios de determinación de los hechos profusamente utilizados por el legislador tributario para prevenir el fraude. Es una institución que fija determinados hechos a partir de la prueba de otros entre los que existe un juicio lógico. Las presunciones legales han de ponderar sus efectos, de manera que no contribuya a crear una "para-realidad" jurídica que poco tenga que ver con la fáctica, e incluso, con la realidad jurídica concretada por otras ramas del Derecho.

Dichas presunciones han de ponderar el peligro que pretenden conjurar con los beneficios que reporta su actuación. Así, si el peligro es muy abstracto, más difícil será la justificación de su injerencia al alterar la normal conformación de los hechos en el ámbito probatorio. Se ha de tener presente que la presunción determina

\footnotetext{
${ }^{538}$ Así el FJ 13 de la Sentencia de 26 de abril de 1990 (RTC 1990, 76).

${ }^{539}$ Existen algunas resoluciones administrativas que afirman la existencia de tal vinculación, sobre todo en el seno de la infracción de resistencia, excusa u obstrucción a la actividad de la Administración. La Res. del TEAC de 26 de febrero de 1999 señala que "el incumplimiento del requerimiento hecho por la Administración es un acto [...]encuadrable en la desobediencia, un acto de policía tributaria, potestad de supremacía especial, no general[...]”.
} 
una realidad probable que sustituye la certeza otorgada por la prueba. De ahí que conformar tal probabilidad, sobre la base de sospechas de evasión o elusión, genere un clima de recelo poco propicio para la vigencia del principio de buena fe en las relaciones tributarias.

En tal sentido la existencia de medidas de prevención han de conjugarse con la exigencia de seguridad jurídica. Tanto en la idea de previsibilidad del gravamen, que toda institución jurídica conlleva, como en desterrar ámbitos de arbitrariedad de los poderes públicos. La ordenación que suponen tales medidas han de compatibilizar la seguridad de los individuos -las garantías de los derechos reconocidos- con la seguridad de la sociedad - los riesgos a la lesión de los deberes que genera la convivencia, en nuestro caso el de contribuir-.

Así las medidas preventivas establecidas han de suponer unas consecuencias previsibles, tanto por su establecimiento previo y claridad de su expresión, como por eliminar o sortear espacios de arbitrariedad de los poderes públicos. Desterrar arbitrariedad supone garantizar el reconocimiento de derechos, pero también la eficacia de las medidas establecidas, al evitar impugnaciones y favorecer su mejor aceptación.

\section{$3^{\circ}$.Presunción de mala fe y el in dubio pro fiscum}

La lucha contra el fraude no puede ignorar la vigencia de este ámbito, como en toda relación jurídica, del principio de buena fe. El principio de buena fe constituye un principio general del Derecho y en él se han de inspirar tanto los actos de la Administración como los de los administrados ${ }^{540}$. Aparece reconocido en el ordenamiento jurídico español en diversas manifestaciones, tanto del ámbito civil ${ }^{541}$ como del administrativo.

La buena fe es un principio general del Derecho que opera tanto desde la perspectiva del ejercicio de los derechos y potestades, como en el cumplimiento de deberes, ya sea por la Administración, ya por los administrados. Dicha afirmación "conlleva la necesidad de una conducta leal, honesta, aquella conducta que, según la

\footnotetext{
${ }^{540}$ Ver PONT MESTRES, Magín. "En torno a la ausencia de presunción de buena fe del contribuyente en la Ley General Tributaria”, Quincena Fiscal, n 19, 2004 [consultado en el servicio westlaw el 15 de julio de 2013]. Dicho autor define a la buena fe como "una actitud de honradez, confianza y fiabilidad dentro y fuera del Derecho, si bien en el seno de éste tal actitud lo es en su proyección en las relaciones jurídicas en que interviene, que es cuando se manifiesta, por lo que ha de valorarse en cada caso concreto."

${ }^{541}$ El Código civil señala que los derechos han de ejercitarse de acuerdo con la buena fe, estableciendo dicho criterio de manera imperativa. No cumplir tal exigencia, sobrepasando manifiestamente los límites normales del ejercicio de un derecho con daño a terceros, es abusar de la posición jurídica. Su consecuencia es la adopción de medidas que impidan la persistencia del abuso y el establecimiento de las correspondientes indemnizaciones -art. 7 del Cc-.
} 
estimación de la gente, puede esperarse de una persona"542. La existencia de la vinculación de la Administración al derecho (principio de legalidad) no resulta óbice para su reconocimiento, pues el principio de legalidad es sólo uno de los elementos del Estado de Derecho, y el principio de la buena fe supone el reconocimiento jurídico del valor ético social de la confianza, es elemento esencial para la paz y la seguridad jurídica ${ }^{543}$.

La buena fe tiene una honda tradición jurídica que aporta seguridad y claridad a la hora de explicar las posiciones subjetivas en las relaciones jurídicas. Dicho criterio cohonesta y aquilata una interpretación equilibrada de los intereses que han de protegerse, los de la Administración y los del administrado. De aquí se deriva que no cabe partir de apriorismos respecto de la prevalencia de unos u otros intereses a la hora de efectuar la exegesis normativa: ni presumir la mala fe, ni preferir los intereses de una de las partes.

\section{por el contribuyente}

$4^{o}$. La privatización de tareas y la internalización de responsabilidades

La privatización ${ }^{544}$ de la gestión tributaria ha conllevado la proliferación de obligaciones formales a cargo del obligado y la ubicación de las tareas administrativas en una fase posterior, de control. Dicha privatización se pone en evidencia con el establecimiento de un conjunto de vinculaciones que concurren en la obligación de autoliquidar. La autoliquidación implica una obligación de declarar -de comunicar unos hechos a la Administración-, de calificar jurídicamente tales acontecimientos facticos, de cuantificar el importe del tributo y de efectuar, eventualmente, el ingreso ${ }^{545}$. El sistema de autoliquidación se fundamenta en el protagonismo del

${ }^{542}$ GONZÁLEZ PÉREZ, Jesús. El principio general de la buena fe en el Derecho administrativo. $4^{\mathrm{a}}$ edición. Madrid: Civitas, 2004, p. 91.

543 PONT MESTRES, Magín. "En torno a la ausencia de presunción de buena fe del contribuyente en la Ley General Tributaria”, Quincena Fiscal, n 19, 2004 [consultado en el servicio westlaw el 15 de julio de 2013].

${ }^{544}$ Expresión acuñada por FERREIRO LAPATZA, José Juan. ’La privatización de la gestión tributaria y las nuevas competencias de los Tribunales Económico- Administrativos", Revista Española de Derecho Financiero, no 37, 1983, p. 84 y 85.

545 SAINZ DE BUJANDA señalaba que el esquema del procedimiento de liquidación tradicional estaba basado en declaración/ liquidación provisional/ comprobación/ liquidación definitiva y es el "propio de un sistema tributario en el que el número de contribuyentes no es excesivamente elevado y que permite una cierta complejidad en las actuaciones administrativas, resulta excesivamente lento y costoso cuando el sistema se convierte en un sistema "masivo" en el que aumenta de forma muy importante tanto el número de los contribuyentes como, en su consecuencia, las declaraciones que han de ser controladas y liquidadas". (SAINZ DE BUJANDA, Fernando. Lecciones de Derecho Financiero. 10 a Edición, Madrid: 
contribuyente, ya que la Administración ha desplazado hacia los contribuyentes el cumplimiento de las tareas que tradicionalmente tenía encomendadas en los procedimientos de aplicación de los tributos. El contribuyente no solamente declara los hechos realizados, sino además liquida el tributo. Correlativo a dicha asunción de tareas gestoras por el particular la actividad de la Administración tributaria pasa, de centrarse en tareas de liquidación, a tareas de comprobación y control de la actividad del contribuyente. En tal esquema la aplicación del sistema tributario descansa, en buena medida, en la actividad del sujeto pasivo, reservándose la Administración el control de lo efectuado mediante la comprobación e investigación ${ }^{546}$.

Tal fenómeno conlleva también una internalización de la responsabilidad en la aplicación de los tributos. La misma para de que es el propio contribuyente el que ha de aplicar normas cuyo conocimiento resulta difícil, dado su dinamismo y volumen masivo de producción.

A nadie sorprende el afirmar y proclamar lo cambiantes, confusas y complicadas que resultan las leyes tributarias, ni tan siquiera los expertos están seguros de conocerlas todas y bien. Con tal panorama la pregunta inmediata que se origina es ¿cómo se logra tan compleja aplicación?, ¿mediante una Administración con conocimientos superlativos sobre la materia? No parece ser esta la respuesta, pues buena parte de sus tareas se han privatizado encomendándose a la ciudadanía. Por ello, de una parte, es ésta quien debe calificar jurídicamente las rentas, cuantificar, e ingresar la mayoría de los tributos. Pero también, de otra parte, respecto de las tareas que todavía desempeña la Administración, se llevan a cabo por funcionarios cuya formación de base resulta ajena a ciencias jurídicas (físicos, economistas, ingenieros...). Pero, entonces, ¿cómo pueden dichos funcionarios aplicar tales normas que tildamos de complejas? Dicha aplicación descansa en la existencia de catálogos de practicas simplificados que unifican actuaciones administrativas, que son dictados a través de circulares y resoluciones administrativas. O sea, el criterio directamente aplicable no son las fuentes del Derecho, sino mandatos jerárquicos. Ello lleva a que más que resolver sobre la base de la norma se resuelva sobre catálogos de soluciones de casos concretos. Con ello la ley y el reglamento sufren un proceso de posposición.

Tal deterioro aplicativo se ve retroalimentado por un legislador especialmente sensible a los concretos problemas administrativos de ahí que, en demasiadas ocasiones, sus leyes pretendan más solucionar prácticas concretas que efectuar regu-

Universidad Complutense, 1993, p. 312).

${ }^{546}$ A este respecto CASADO OLLERO apunta una cierta tendencia a la "“"subsidiariedad" de la actividad administrativa tributaria, en cuanto resulta relegada a una actividad de control y sólo se materializa formalmente para "suplir" la actuación del contribuyente, para "integrarla" cuando parezca insuficiente o para "rectificarla" y "sancionarla", cuando aquélla resulte irregular." (CASADO OLLERO, Gabriel. "La colaboración con la Administración tributaria. Notas para un nuevo modelo de relaciones con el fisco", Hacienda Pública Español, n 68, 1981, p. 170). 
laciones con perspectivas genéricas y sistémicas.

También, al encomendar buena parte de dicha aplicación a los particulares, puede llevarnos a pensar: cuán instruidos que son nuestros ciudadanos que conocen y aplican leyes tan complejas. Pero ello tampoco es así, o no es totalmente de esta manera, la ciudadanía asume la responsabilidad de su aplicación, pero quien realmente aplica la norma son los asesores fiscales. Ahora bien, éstos se encuentran tan perdidos en el marasmo normativo y en las dificultades de su entendimiento que acuden a los funcionarios y a las prácticas de la Administración para encontrar seguridad. Las personas que no poseen los suficientes recursos para acudir a tales asesores técnicos, siempre podrán acudir a la Administración a pedir información y asistencia -art. 85 de la LGT- y ésta les indicará.

Con ello, como puede apreciarse, se cierra un circulo en el que la norma tributaria acaba por ser aplicada, directa o indirectamente, por la Administración. Y en todo este itinerario, ¿qué ha variado de la tradicional aplicación y liquidación del tributo por la Administración, pues ésta continúa teniendo un papel básico en la calificación jurídica? La variación ha sido sustancial, pues ha comportado un proceso de internalización de la responsabilidad de la aplicación del tributo por la ciudadanía. No es la Administración quien asume las consecuencias de su aplicación, pero sí decide sustancialmente los criterios aplicativos.

En tal esquema existe una variación a tener presente que afecta a la justicia del sistema, pues los sujetos que tienen mayores recursos pueden acudir a asesores jurídicos, a buenos conocedores de la normativa para que diseñen operaciones que aprovechen los resquicios de tales leyes imperfectas. Para éstos los defectos de las leyes y la diversidad de tratamientos internacionales en contextos de globalización son espacios de oportunidad. Tal situación conforma un contexto en donde la tradicional desigualdad, de base económica, se reitera y amplifica. A mayor capacidad económica se constatan las mayores capacidades para eludir la aplicación de la carga tributaria justa.

\section{Conclusiones}

De lo expuesto, y aras de sintetizar las principales ideas sustentadas cabe concluir:

$1^{\circ}$.El deber de contribuir resulta una vinculación normativa de carácter valorativo y contenido ético. Si bien la tributación es contemplada habitualmente como un mero costo, la deuda fiscal también expresa y vehicula el valor de solidaridad ciudadana. El deber de contribuir no sólo es límite, también se basa en el valor de solidaridad ínsito y connatural de las sociedades en que se reconocen derechos fundamentales. Solidaridad que, como valor y deber, posee una estrecha relación con los derechos reconocidos. 
$2^{\circ}$.La afirmación del carácter fundamental del deber de contribuir, al igual que los derechos así considerados, se basa en su imbricación con la dignidad de la persona. Dignidad como garantía de condiciones físicas y materiales de la persona sin cuyo reconocimiento no puede ser considerada como tal. Para garantizar tanto la dignidad existencial como la dignidad en las condiciones materiales de vida se precisa de la solidaridad de los miembros de una comunidad. Solidaridad cuya manifestación más importante en las sociedades contemporáneas se arbitra a través del deber de contribuir a los gastos públicos. Resulta así que dicho deber deviene fundamental para garantizar la eficacia y el reconocimiento material de los derechos de las personas.

$3^{\circ}$. La tributación justa resulta presupuesto material para el reconocimiento de unos estándares de derechos individuales y sociales. Existe una clara correlación entre el deber de contribuir y los derechos fundamentales, sobre todo los de carácter prestacional, por lo que dejar de cumplir tal deber erosiona la eficacia de tales derechos. El deber de contribuir resulta el presupuesto material para la garantizar el ejercicio de derechos humanos y sociales, no tan sólo propios, sino de los conciudadanos, lo cual le confiere una especial dimensión solidaria.

$4^{\circ}$.La exigencia de tal deber, como correlato a su reconocimiento, ha de obedecer a criterios éticos y de valor acordes, recogidos normalmente a través de principios constitucionales. Atendiendo a tal consideración de valor resultan criticables las medidas que puedan originar discriminaciones como las amnistías. En concreto, la justificación material de tal medida -la extrafiscal de mejorar la recaudación- no resulta suficiente ni proporcionada para la consecuencia establecida. Es por ello que también cabe plantearse si la fiscalidad, y los principios que la informan, han de ceder ante exigencias no fiscales, o cual es el grado de instrumentalidad de la norma tributaria y la virtud de sus principios como límite al legislador.

$5^{\circ}$.Los contextos actuales demandan el establecimiento de medidas preventivas del fraude que, con carácter previo a la lesión del deber, anticipen soluciones adecuadas. Las instituciones preventivas han de suponer una evaluación realista del riesgo concurrente y han de comportar una respuesta adecuada. De ahí que sea necesario, en primer lugar, un pronóstico de la evasión tributaria que se proyecta hacia el futuro de una determinada situación fáctica. Es un juicio de probabilidad de que se concrete en lesión la situación peligrosa. En segundo lugar, es necesario que la medida empleada sea eficaz por su carácter disuasorio, sin que suponga la imposición de un mal. 
Ahora bien, tales medidas no han de suponer:

a) La afirmación de estados de sujeción más propios de súbditos que de ciudadanos.

b) La creación de realidades paralelas lesivas.

c) La presunción de mala fe en la conducta del ciudadano.

d) El sometimiento cargas de gestión exorbitantes y desproporcionadas.

\section{Bibliografía}

CAZORLA PRIETO, Luís María. Derecho Financiero y Tributario. Parte General. Pamplona: Aranzadi, 2002.

CASADO OLLERO, Gabriel. "La colaboración con la Administración tributaria. Notas para un nuevo modelo de relaciones con el fisco", Hacienda Pública Español, $\mathrm{n}^{\mathrm{o}} 68,1981$.

BAYONA DE PEROGORDO, Juan José y SOLER ROCH, María Teresa. Compendio de Derecho Financiero. Alicante: Librería Compas, 1991.

DELGADO LOBO, María Luisa, FERNÁNDEZ-CUARTERO PARAMIO, Marta, MALDONADO GARCÍA-VERDUGO, Ascensión, ROLDAN MUÑIO, Concepción y VALDENEBRO GARCÍA, María Luisa. La educción fiscal en España. Doc. $n^{\circ}$ 29/05. Madrid: Instituto de Estudios Fiscales, 2005.

DIÉZ PICAZO, Luís María. Sistema de derechos fundamentales. $4^{a}$ edición. Madrid: Civitas Thonsom-Reuters, 2013.

FERREIRO LAPATZA, José Juan. "La privatización de la gestión tributaria y las nuevas competencias de los Tribunales Económico- Administrativos", Revista Española de Derecho Financiero, n 37, 1983.

GARCIA DE ENTERRIA, Enrique. y FERNANDEZ, Tomás Ramón. Curso de Derecho Administrativo. Vol I. Madrid: Civitas, 1995.

GOMEZ SANCHEZ, Yolanda. "Dignidad y ordenamiento comunitario" en Revista de Derecho Constitucional Europeo, ${ }^{\circ}$ 4, 2005, [consultado: 4 junio 2014] Disponible en internet en http://www.ugr.es/ redce/REDCE4/articulos/09yolanda.htm.

GONZÁLEZ PÉREZ, Jesús. El principio general de la buena fe en el Derecho administrativo. $4^{\text {a }}$ edición. Madrid: Civitas, 2004.

Jornadas XX Jornadas Latinoamericanas de Derecho Tributario, Salvador (Bahía) - Brasil, 2000, [consultado 5 junio 2014]. Disponible en: http://www.iladt.org/frontend/ResolutionPage.aspx.

MARTINEZ MORÁN, Narciso y DE CASTRO CID, Benito (Coordinadores). Die- 
cisiete lecciones de Teoría del Derecho. 2a edición, Madrid: Uned Editorial Universitas, 2011.

MARTIN QUERALT, Juan, LOZANO SERRANO, Carmelo, TEJERIZO LOPEZ, José Manuel y CASADO OLLERO, Gabriel. Curso de Derecho Financiero y Tributario. Madrid: Tecnos. 2007.

PALOMBELLA, Gianluigi. "De los derechos y de su relación con los deberes y los fines comunes". Derechos y libertades, n 17, época II, junio 2007.

PECES-BARBA MARTINEZ, Gregorio. Lecciones de Derecho Fundamentales. Madrid: Dykinson. 2004.

PEREZ LUÑO, Antonio Enrique. Los derechos fundamentales. $8^{\text {a }}$ edición, Madrid: Tecnos. 2004.

PEREZ ROYO, Fernando. Derechos Financiero y tributario. Parte General. Madrid: Thonson-Civitas. 2005.

PONT MESTRES, Magín. "En torno a la ausencia de presunción de buena fe del contribuyente en la Ley General Tributaria", Quincena Fiscal, n 19, 2004 [consultado en el servicio westlaw el 15 de julio de 2013].

RODRIGUEZ PALOP, María Eugenia. Claves para entender los nuevos derechos humanos. Madrid: Catarata. 2011.

ROMEO CASABONA, Carlos María. Peligrosidad y Derecho Penal preventivo. Barcelona: Bosch, 1986.

ROZAS VALDÉS, José Andrés. "Nota preliminar", en Franco GALLO. Las razones del Fisco. Ética y justicia en los tributos. Madrid: Marcial Pons, 2012.

SAINZ DE BUJANDA, Fernando. Lecciones de Derecho Financiero. 10 ${ }^{\text {a }}$ Edición, Madrid: Universidad Complutense, 1993.

TIPKE, Klaus. Moral tributaria del Estado y de los contribuyentes. Madrid: Marcial Pons, 2002.

VALLEJO CHAMORRO, José $\mathrm{M}^{\mathrm{a}}$. "La competencia fiscal perniciosa en el seno de la OCDE y la Unión Europea”. Revista de economía. nº 825, 2005.

VARONA ALABERN, Juan Enrique. Extrafiscalidad y dogmática tributaria. Madrid: Marcial Pons, 2009.

ZAGREBELSKY, Gustavo. El derecho dúctil. Ley, derechos, justicia. Madrid: Editorial Trotta. 2009. 
